\title{
Economía aplicada
}

Ensayos de investigación económica 2017

Sol Acuña Flores

Renzo Gabriele Arfinengo Roda Diana Cáceres Atencio Diego Camacho Valencia Dongo Naara Cancino Díaz Luis Cruz Cóndor Mariano Fuster de Bracamonte Alejandra Guardia Muguruza Sandra Huaitalla Rosado Karen Huaringa Aliaga Cynthia Laura Eulogio Renzo Muñoz-Nájar Deza Rodrigo Ojeda del Arco Bautista Nicolle Pegot-Ogier Rodrigo Alonso Takamure Guibu Cristina Meykin Wong Tsang

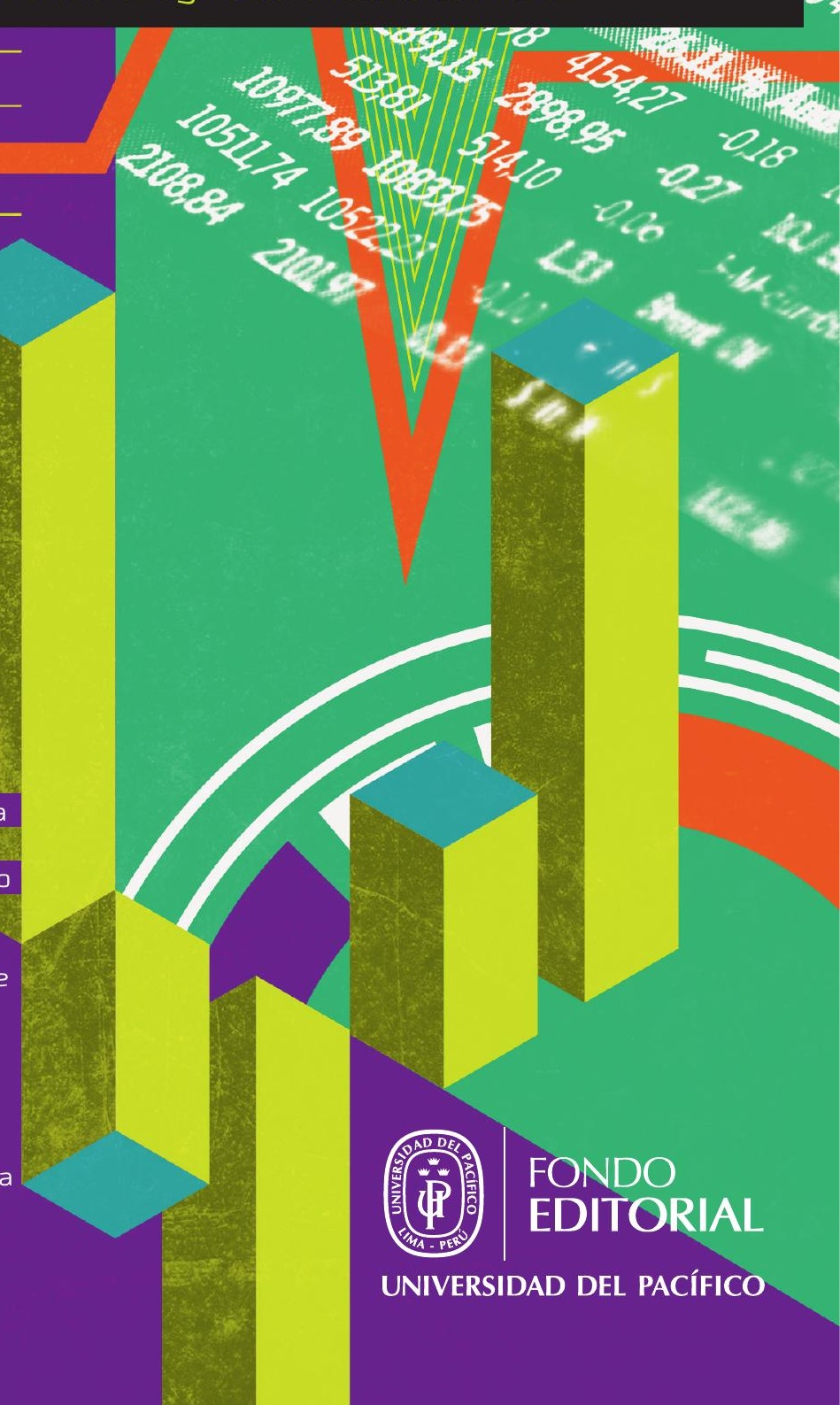






\section{Economía aplicada}

Ensayos de investigación económica 2017

Sol Acuña Flores

Renzo Gabriele Arfinengo Roda

Diana Cáceres Atencio

Diego Camacho Valencia Dongo

Naara Cancino Díaz

Luis Cruz Cóndor

Mariano Fuster de Bracamonte

Alejandra Guardia Muguruza

Sandra Huaitalla Rosado

Karen Huaringa Aliaga

Cynthia Laura Eulogio

Renzo Muñoz-Nájar Deza

Rodrigo Ojeda del Arco Bautista

Nicolle Pegot-Ogier Rodrigo

Alonso Takamure Guibu

Cristina Meykin Wong Tsang 
Economía aplicada. Ensayos de investigación económica 2017

(C) Fernando González Vigil y Pilar Obando Hirano, editores, 2020

De esta edición:

(C) Universidad del Pacífico

Jr. Gral. Luis Sánchez Cerro 2141

Lima 15072, Perú

Economía aplicada. Ensayos de investigación económica 2017

Fernando González Vigil y Pilar Obando Hirano (editores)

1. a edición: noviembre de 2020

Diseño de la carátula: Ícono Comunicadores

ISBN ebook: 978-9972-57-457-3

doi: http://dx.doi.org/10.21678/978-9972-57-457-3

\section{BUP}

Economía aplicada: ensayos de investigación económica 2017 / Fernando González Vigil y Pilar Obando Hirano (editores). -- 1a edición. -- Lima: Universidad del Pacífico, 2020. 341 p. -- (Documento de investigación ; 15)

1. Estudios económicos -- Perú

2. Economía aplicada -- Perú

3. Economía -- Investigación

I. González Vigil, Fernando, editor.

II. Obando Hirano, Pilar Hitomi, editor.

III. Universidad del Pacífico (Lima)

330.07 (SCDD)

La Universidad del Pacífico no se solidariza necesariamente con el contenido de los trabajos que publica. Prohibida la reproducción total o parcial de este texto por cualquier medio sin permiso de la Universidad del Pacífico.

Derechos reservados conforme a ley. 


\section{Índice}

Prólogo

Estimación de la contribución del uso de lluvias sobre el nivel

de bienestar del hogar: el caso de Ccatcca, Cusco

Sol Acuña Flores y Cynthia Laura Eulogio

El efecto de las fluctuaciones climáticas en el ingreso de los hogares

agropecuarios: un análisis para el caso peruano

Sandra Huaitalla Rosado y Karen Huaringa Aliaga

Asimetría en la transmisión de precios agrícolas: el caso del arroz

en el norte del Perú para el 2001-2016

Renzo Muñoz-Nájar Deza y Cristina Meykin Wong Tsang

La infraestructura económica (no urbana) como política win-win en el Perú: hacia el crecimiento económico y la lucha contra la desigualdad

Diana Cáceres Atencio y Luis Cruz Cóndor

Determinantes del rechazo de ofertas de compensación por

expropiación en cinco distritos de Lima Metropolitana

Alejandra Guardia Muguruza y Nicolle Pegot-Ogier Rodrigo

Análisis experimental sobre sobornos e informalidad en la pequeña y mediana empresa: eficiencia de políticas antisoborno Renzo Gabriele Arfinengo Roda

Interpolación del área distorsionada por el cambio de impuesto marginal entre el Régimen General y el Régimen Especial en la distribución conjunta de contribuyentes 
Determinantes del retiro de fondos del Sistema Privado de Pensiones: un análisis de los destinatarios Rodrigo Ojeda del Arco Bautista

El valor de los profesores: un análisis del efecto del conocimiento docente sobre el rendimiento de los estudiantes en el Perú 305 Diego Camacho Valencia Dongo y Naara Cancino Díaz 


\section{Prólogo}

En la Universidad del Pacífico (UP), se busca formar economistas con sólida base académica y la capacidad de aplicarla al análisis riguroso de casos reales, mediante metodologías idóneas para entender el desempeño de individuos e instituciones públicas y privadas, e identificar sus problemas concretos y las soluciones congruentes con el bienestar general. Con tal fin, además de promover que los alumnos se entrenen participando en proyectos del Centro de Investigación (CIUP) y en diversos aprendizajes prácticos durante los años de la carrera, la UP solamente otorga el grado de Bachiller en Economía al estudiante que haya completado el respectivo Plan de Estudios realizando satisfactoriamente un Trabajo de Investigación Económica (TIE).

Los alumnos de Economía deben elaborar su TIE -usualmente en grupos de dos y algunos de manera individual- durante los dos últimos semestres académicos de la carrera. En el primero, eligen el tema que investigarán y formulan su Plan de Trabajo (PT), en el que justifican la pregunta que define el objetivo de su investigación, la correspondiente respuesta tentativa o hipótesis, así como el marco analítico y metodológico que orientará el procesamiento de los datos necesarios para verificarla empíricamente. Y, en el segundo semestre, desarrollan su investigación ciñéndose al PT aprobado, analizan los resultados y, con base en estos, extraen las conclusiones y proponen las soluciones relevantes. La propiedad intelectual de cada TIE (y del PT que lo precede) pertenece exclusivamente a los alumnos autores de este.

La calidad de esa labor es supervisada por profesores - a tiempo completo o parcial- de la UP, quienes participan activamente como asesores y/o jurados. Cada TIE cuenta con un asesor escogido entre dichos profesores por los respectivos alumnos autores, con quienes mantiene una relación ad honorem consistente en orientar la definición de todos los contenidos de la investigación (teniendo en cuenta, cuando es pertinente, las expectativas de la entidad que 
facilite el acceso a información clave, de darse este caso), así como en validar cada entregable que, a su juicio, amerite ser evaluado por el jurado. Para cada TIE, se designa un jurado compuesto por otros dos profesores de la UP, quienes califican los entregables escritos y sustentaciones orales de los alumnos a lo largo del año, por lo que también cumplen una función de asesoría puntual al expresar observaciones dirigidas a mejorar la investigación en curso.

Algunos profesores también realizan aportes adicionales, conduciendo talleres sobre métodos cuantitativos y cualitativos de investigación académica y sobre redacción, que, junto con otros talleres a cargo de especialistas de la UP, en recursos bibliotecarios y para presentaciones orales, refuerzan el conocimiento de los alumnos sobre los estándares de fondo y forma para la elaboración de un TIE, así como sus habilidades para la presentación y sustentación de los avances al respecto. Y todo este proceso es organizado por un equipo de coordinación conformado por un profesor de la UP (cuya función arbitral le impide desempeñarse como asesor o jurado) y su asistente; el cual formula el proceso según las pautas establecidas por el Departamento Académico de Economía con la Facultad de Economía y Finanzas, designa a los jurados, programa las actividades y vela por su cabal cumplimiento.

Entre las pautas del proceso que buscan incentivar la realización de investigaciones de alta calidad, hay una referida a la posibilidad de que la UP publique las que reúnan los dos requisitos siguientes: haber obtenido una nota final de 17 o más y, adicionalmente, que ambos miembros del respectivo jurado recomienden su publicación.

El presente volumen de la serie Ensayos de Economía Aplicada contiene nueve ensayos, los cuales son versiones resumidas y editadas de cinco TIE culminados en junio de 2017 y cuatro culminados en noviembre del mismo año. Además de reunir los dos requisitos antes mencionados, a sus respectivos autores les fue posible resumirlos y presentarlos en una versión ensayo dentro de los límites de extensión y plazos de entrega fijados para la preparación de este volumen.

En el siguiente cuadro, se listan los títulos de esos nueve excelentes TIE de 2017, publicados aquí en forma de ensayos, con los nombres de sus respectivos autores (ordenados alfabéticamente) y asesores, a quienes felicitamos los editores de este volumen. 
Asesor

Concluidos en el semestre académico 2017-I

Acuña Flores, Sol María; y

Laura Eulogio, Cynthia Marlee

Arfinengo Roda, Renzo

Gabriele

Cáceres Atencio, Diana Sofía; y Cruz Cóndor, Luis Enrique

Camacho Valencia Dongo,

Diego José; y

Cancino Díaz, Naara Judith

Guardia Muguruza, Alejandra; y Pegot-Ogier Rodrigo, Nicolle
Estimación de la contribución del uso de lluvias sobre el nivel de bienestar del hogar: el caso de Ccatcca, Cusco

Análisis experimental sobre sobornos e informalidad en la pequeńa y mediana empresa: eficiencia de políticas antisoborno

La infraestructura económica (no urbana) como política win-win en el Perú: hacia el crecimiento económico y la lucha contra la desigualdad

El valor de los profesores: un análisis del efecto del conocimiento docente sobre el rendimiento de los estudiantes en el Perú

Determinantes del rechazo de ofertas de compensación por expropiación en cinco distritos de Lima Metropolitana
Pedro Mateu

Álvaro Cano

Gustavo

Guerra García

Juan Francisco

Castro

Carlos Parodi

Diego

Bohórquez el cambio de impuesto marginal entre el Régimen General y el Régimen Especial en la distribución de conjunta de contribuyentes

El efecto de las fluctuaciones climáticas en

Manuel el ingreso de los hogares agropecuarios: un

Barrón análisis para el caso peruano

Asimetría en la transmisión de precios

Daniel de la

Muñoz-Nájar Deza, Renzo; y agrícolas: el caso del arroz en el norte del Perú para el 2001-2016

Determinantes del retiro de fondos del

Elio Sánchez los destinatarios

Mientras que el orden alfabético adoptado en el cuadro facilita la ubicación de los autores según el semestre académico de 2017 en el que completaron con honores la tarea del TIE, el orden mostrado en el índice de este volumen para la presentación de los respectivos ensayos refleja un intento de agruparlos según afinidades temáticas. Este orden es adoptado para lo que sigue de este 
prólogo, porque facilita la comprensión de la relevancia de los aportes académicos que realizan estas investigaciones, tanto cada una por separado, como en virtud de su interés común por proponer soluciones prácticas a importantes problemas en áreas clave para el bienestar de la economía peruana y de su población vulnerable en particular.

El índice de este volumen empieza con tres investigaciones que tienen en común su preocupación centrada en contribuir a que mejore el bienestar de pequeńos productores agropecuarios, en especial de zonas rurales en condición de pobreza. Con tal motivación, se analiza la medida en que dicho bienestar es impactado por micropresas que almacenan agua de lluvia, en el caso de la primera investigación; por fluctuaciones climáticas, en el caso de la segunda investigación; y por estructuras de mercado, en el caso de la tercera investigación.

En tal sentido, la investigación de Acuńa y Laura (asesorada por el profesor Mateu) evalúa la contribución al bienestar de hogares agropecuarios del distrito de Ccatcca (Cusco) de micropresas para almacenar agua de lluvia con fines de riego en meses de estiaje, construidas mediante el Programa de Siembra y Cosecha (PSC) impulsado por la Asociación Jesús Obrero (Ccaijo) durante el período 1999-2014. Para ello, las autoras formulan un modelo econométrico de bienestar desglosado en tres variables dependientes: ingresos monetarios, educación superior y nutrición; cada una puesta en función de sendas variables explicativas seleccionadas a la luz de la literatura especializada. Los datos al respecto fueron recogidos aplicando (con el apoyo de Ccaijo) una encuesta a una muestra de dichos hogares cusqueños el año 2016, diseñada incluyendo a participantes en el PSC (grupo de tratamiento) y a no participantes (grupo de control), cuyos resultados fueron validados por un método de emparejamiento probabilístico. Acuña y Laura logran así comprobar que las micropresas del PSC tienen un significativo efecto positivo en los ingresos de los hogares participantes, en el porcentaje de sus hijos con educación superior y en su consumo de carnes rojas y verduras (proxy de nutrición). Por esta razón, las autoras proponen que el Programa Nacional de Siembra y Cosecha de Lluvias promovido por el Minagri permita generalizar la experiencia del PSC.

Huaitalla y Huaringa, por su parte (y contando con la asesoría del profesor Barrón), comprueban que el efecto de las fluctuaciones climáticas (temperatura y lluvias) en los ingresos y condición de pobreza de hogares agropecuarios peruanos es significativo pero heterogéneo. A esta conclusión arriban a partir de datos del Tyndall Center for Climate Change Research y de la Enaho para el período 2004-2014, que analizan econométricamente con 
un modelo inspirado en la teoría de Ricardo y desglosado en tres ecuaciones de ingresos agropecuarios - totales, de producción para el autoconsumo y para ventas- considerando sus interacciones; y una ecuación con pobreza como variable dependiente. Con ello, estiman el impacto de oscilaciones y shocks climáticos respecto a rangos óptimos de temperatura (TO) y precipitación pluvial (PO) sugeridos por la literatura especializada. Las autoras hallan así efectos heterogéneos como los siguientes: que la producción agropecuaria total es impactada de manera negativa por las fluctuaciones de temperatura y de manera positiva por las pluviales (alrededor del PO) en regiones con clima debajo del TO; que ambos tipos de fluctuaciones impactan de manera positiva la producción agrícola en climas algo por encima del TO; y que la concavidad de estos impactos es más marcada para la producción de autoconsumo en todos los casos. Así, la probabilidad de que las fluctuaciones climáticas aumenten la pobreza es mayor en la sierra sur del país, donde hay más agricultura de secano para subsistencia y más carencias de infraestructura y acceso al crédito. Por ello, las autoras recomiendan medidas para reducir esta vulnerabilidad y apoyan el plan de gestión de riego y adaptación al cambio climático que implementa el Minagri.

Mientras tanto, la investigación de Muñoz-Nájar y Wong (asesorada por el profesor De la Torre) comprueba que la transmisión de precios internacionales del arroz a los precios en chacra del arroz cáscara es asimétrica, en el sentido de ser mayor cuando los precios bajan que cuando suben. Ello se debe a la estructura del mercado de arroz imperante en las cuatro regiones del norte peruano que concentran la producción nacional de arroz cáscara (San Martín, Piura, Lambayeque y La Libertad), donde la gran mayoría de sus productores agrícolas son pequeños y atomizados y tomadores de precios fijados por intermediarios (molineros y acopiadores) que les financian la cosecha para asegurarse el aprovisionamiento. Estos autores plantean un modelo que estiliza esa estructura de mercado e indagan sobre dicha asimetría aplicando las metodologías de corrección de errores y de vectores autorregresivos, ambas con thresholds, para analizar los datos mensuales -durante el período 2001-2016- de precios internacionales del arroz cáscara (Bloomberg) y en chacra en dichas regiones peruanas (INEI). Ello les permite verificar la existencia de transmisión asimétrica, en especial en las dos regiones donde hay más producción de arroz cáscara -San Martín y Piura- y también en La Libertad, donde la producción nacional es menor pero su fácil sustitución por importaciones favorece la fijación de precios por parte de intermediarios ligados a la poderosa industria molinera de Lambayeque. En consecuencia, los 
autores concluyen enfatizando la necesidad, para el caso de un alimento tan básico en el Perú como es el arroz, de políticas agroindustriales que fomenten la competencia a lo largo de la cadena arrocera y su industria molinera en particular, complementadas con medidas financieras que faciliten el acceso de sus pequeńos productores agrícolas al crédito formal.

Las consecuencias negativas de la inequidad también motivan el par de investigaciones enfocadas en el importante tema de infraestructura. La de Cáceres y Cruz (asesorada por el profesor Guerra García) comprueba que la provisión de infraestructura básica no urbana (IBNU) reduce la desigualdad y aumenta el crecimiento a nivel de departamentos/regiones del país, en especial en los más carentes de infraestructura. Estos autores construyen un índice de IBNU con cuatro componentes (agua, saneamiento, energía, telefonía) y lo relacionan con variables como ingreso per cápita, ruralidad (porcentaje de población en zona rural) y tasa de analfabetismo. Con este modelo econométrico, realizan un análisis de panel con datos de la Enaho y del INEI para el período 2005-2015 (complementado con datos de Osiptel, Minem y MEF), cubriendo 24 departamentos agrupados en cinco macrorregiones del Perú (norte, centro, sur, Amazonía y Lima-Callao). Sus estimaciones verifican la existencia de una relación inversa entre (aumento de) IBNU y (menos) desigualdad (en gasto e ingresos), cuya elasticidad es significativamente mayor tanto en las dos macrorregiones con menos dotación de IBNU (centro y sur), como en los componentes de este índice donde la dotación desigual es más pronunciada. Por ello, dichos autores recomiendan que la sensibilidad de la desigualdad al acceso a IBNU sea el criterio que rija la priorización de la inversión en IBNU por departamentos/regiones y por tipo de IBNU.

Por su parte, Guardia y Pegot-Ogier examinan (con la asesoría del profesor Parodi) los factores explicativos del rechazo a la compensación ofrecida por el Estado para expropiar predios, que demora la realización de proyectos de infraestructura urbana de necesidad pública. Estos autores formulan un modelo en el que la probabilidad de que dicha oferta sea rechazada o aceptada depende de un conjunto de variables, sugeridas por estudios especializados y conformantes del cuestionario que aplicaron a una muestra representativa de jefes de hogares habitantes de predios por expropiar, en los cinco distritos de Lima Metropolitana más afectados por proyectos viales durante el período 2005-2016 (Cercado de Lima, Independencia, San Juan de Lurigancho, Villa El Salvador y Villa María del Triunfo). Así, hallan que la probabilidad de rechazo aumenta cuando: la compensación monetaria es percibida como insuficiente (más aún si el uso del predio incluye algún negocio y si hay expec- 
tativas alcistas respecto a su valor); el predio tiene buen acceso a áreas verdes o recreacionales; y no hay paliativos a la incomodidad de mudarse. Mientras que la probabilidad de aceptación aumenta cuando: el Estado brinda información completa sobre los beneficios del proyecto vial y opciones de mudanza a zonas de tráfico menos congestionado; y los potenciales expropiados tienen un nivel educativo que les permite asimilar esa información respetando el bien común y la ley. Al reforzamiento de estos factores positivos apuntan, por tanto, las recomendaciones de los autores, además de a establecer el valor de mercado del predio como base del cálculo de la compensación monetaria, así como una vía arbitral que zanje de manera expeditiva las controversias al respecto.

Otras conductas socioeconómicamente irresponsables motivan las dos investigaciones que elucidan la relación entre los altos niveles de informalidad y evasión tributaria existentes en el Perú y las deficientes políticas antisoborno y tributaria, respectivamente.

En tal sentido, la investigación de Arfinengo (asesorada por el profesor Cano) estima los efectos de la política antisoborno (medida por la detección del soborno, el sistema legal para sancionarlo y el salario del funcionario público fiscalizador) en las prácticas de sobornos e informalidad. Dicho autor recurre a dos experimentos: uno enfocado en el comportamiento del empresario (formal o informal) y el otro en el del funcionario público, quienes alternativamente pueden asumir los roles de emisores o de receptores de una propuesta de soborno. Así, encuentra que: una mayor probabilidad de detección reduce los sobornos en ambos sectores (formal e informal) e incrementa el costo de ser informal; tanto los sobornos como la informalidad son reducidos por un sistema legal que incentive las denuncias y castigue solo a quien recibe el soborno; un salario alto del funcionario también reduce los sobornos en ambos sectores, pero tiene un efecto neutro en la elección del sector. A la luz de todo ello, este autor propone que el Perú refuerce su capacidad fiscalizadora de sobornos para mejorar los actuales bajos niveles de detección y sanción, y que además modifique su sistema legal a fin de incentivar las denuncias mediante una reducción de las sanciones a la parte denunciante.

Por su parte, la investigación de Fuster y Takamure (asesorada por el profesor Bohórquez) devela los distorsionantes efectos de evasión tributaria que puede ocasionar la convivencia de regímenes tributarios con diferentes bases y umbrales muy discrecionales. En específico, estos autores contrastan -a sugerencia de la Sunat- dos regímenes peruanos de impuesto a la renta empresarial: el especial (RER), con base en las ventas netas, y el general (RG), con base en la utilidad imponible; pero el RER rige hasta un umbral de ventas netas alto 
(equivalente a 25 veces el PIB per cápita, versus el promedio latinoamericano de 16 veces), gravándolas con una tasa fija y baja respecto a la comparable de aplicarse el RG. Para esta contrastación, utilizan la metodología de bunching en su análisis econométrico de los detallados datos para el trienio 2014-2016 que les facilitó la Sunat. Así, demuestran que hay aglomeración de empresas en dicho umbral para evadir el RG, y que la migración del RER al RG no es incentivada debido a la diferencia entre los respectivos impuestos efectivos. Lo cual, unido a otras evasiones incentivadas por un RER que no estimula la solicitud de comprobantes de pago ni el empleo formal en planilla porque no son descontables del tributo en función de las ventas, explica que dichos autores concluyan abogando por la simplificación de los regímenes tributarios peruanos hacia una misma base y tasas solo marginalmente diferentes.

Adicionalmente, las implicancias de la política pensionaria en el bienestar de adultos mayores jubilados (y de sus familiares) motivan la investigación de Ojeda (asesorada por el profesor Sánchez). Este autor realiza, con base en completos datos sobre fondos privados de pensiones facilitados por una AFP local, un análisis econométrico de las características (individuales y sociodemográficas) de los respectivos titulares, explicativas de su decisión de acogerse o no a la ley (de 2016) que les permitió retirar hasta casi la totalidad (95,5\%) de su fondo. Así, encuentra que la probabilidad de retiro es mayor cuando: el fondo es de menor tamaño y menos beneficiarios tiene; y el titular es de nivel socioeconómico bajo, de edad no tan avanzada, de género masculino y poco adverso al riesgo. En vista de lo anterior, el autor concluye afirmando que una reforma pensionaria cabal debe: tener adecuadamente en cuenta esas características, informar bien a los titulares de que con el retiro su dinero deja de ser inembargable y sus beneficiarios pierden el seguro de salud, e incluir medidas que aumenten la rentabilidad -y, por ende, el monto- de los fondos privados de pensiones; todo ello en pro de una vida digna en la vejez y de preservar la macrorrelación ahorro-inversión-crecimiento.

Por ańadidura, este volumen de ensayos testimonia la prominencia del capital humano como factor de desarrollo, no solo mediante las evidencias encontradas por las investigaciones arriba mencionadas sobre la importante relación entre los problemas que analizan y el nivel educativo y/o la calidad deficiente de políticas públicas (y prácticas privadas), sino también en virtud de la investigación de Camacho y Cancino (asesorada por el profesor Castro), cuya motivación es la necesidad de una política educativa que valorice bien el rol del docente en el aprendizaje estudiantil y la reducción de brechas educativas. 
Con tal fin, dichos autores distinguen (a la luz de obras especializadas) dos tipos de conocimiento docente (CD): de los contenidos de la asignatura, y de la pedagogía para su asimilación por los alumnos. Y plantean un modelo econométrico en el que el aprendizaje de alumnos depende de ambos tipos de CD y de factores de valor agregado, como el aprendizaje previamente acumulado por el alumno y otros insumos educativos facilitados por el nivel socioeconómico de su hogar; el cual aplican a una muestra (de datos censales del Minedu) de estudiantes de distintas regiones del país, cuyo aprendizaje de matemáticas en su sexto grado de primaria (en 2013) es comparado con el de su segundo grado (en 2009). De este modo, verifican que el efecto de ambos tipos de CD en el aprendizaje estudiantil (de matemáticas) es siempre positivo pero heterogéneo, porque es mayor cuando es mejor el stock de aprendizajes acumulados del alumno y/o de insumos educativos provenientes de su hogar. Por ello, estos autores proponen que la política educativa debe reforzar ambos tipos de CD, en especial de los docentes en sectores desfavorecidos, a fin de reducir la brecha detectada.

En suma, las investigaciones aquí publicadas son excelentes muestras de creatividad, tanto en el enfoque preciso con que abordan problemas relevantes para el crecimiento y bienestar del Perú, como en su análisis riguroso basado en la correcta aplicación de conocimientos teóricos y metodológicos sólidos e idóneos para poder proponer soluciones prácticas. Sus autores y asesores son, por tanto, ejemplos destacados del economista de calidad que la UP forma y/o alberga en su plana docente.

Y no cabe culminar este prólogo sin resaltar y agradecer el aporte de quienes hicieron posible el éxito de Investigación Económica (IE) 2017. Este reconocimiento se extiende a todos los alumnos de esa asignatura, profesores que actuaron como asesores y/o jurados, y especialistas de otras entidades (como la Sunat y Ccaijo, entre otras) que brindaron información y experiencia. También, a los colegas y profesionales de la UP que se hicieron cargo de talleres metodológicos o de orientación, como fue el caso de los profesores (en orden alfabético) Bonifaz, José Luis; Castro, Juan Francisco; Malca, Óscar; Gómez, Rosario; Parodi, Carlos; Wiesse, Jorge; Winkelried, Diego; y Yamada, Gustavo (representado por Daniel Velásquez), así como de Eva Flores (de Biblioteca) y Magaly Rubina (de Formación Extraacadémica). Asimismo, al decano de la Facultad de Economía y Finanzas y al jefe del Departamento Académico de Economía en el año 2017 (los profesores Roberto Urrunaga y Carlos Parodi, respectivamente), por su supervisión comprometida con el correcto desarrollo de IE y su carácter de requisito indispensable para la obtención del grado de 
Bachiller en Economía; así como al Fondo Editorial de la UP, por acoger esta publicación y realizarla prolijamente bajo la esmerada conducción de su presidenta ejecutiva, María Elena Romero.

Finalmente, merece un agradecimiento muy especial Pilar Obando Hirano, asistenta de IE 2017, por su invalorable labor durante dicho año y para la edición de este volumen.

Fernando González Vigil

Coordinador de la asignatura Investigación Económica 2017 


\title{
Estimación de la contribución del uso de lluvias sobre el nivel de bienestar del hogar: el caso de Ccatcca, Cusco ${ }^{1}$
}

\author{
Sol Acuña Flores \\ Cynthia Laura Eulogio
}

\section{Introducción}

En el Perú, casi la mitad $(45,18 \%)$ de la población rural vive en situación de pobreza (INEI, 2016). La mayor parte de ella depende de la actividad agropecuaria y se caracteriza por una producción de autoconsumo, mínimas ventas de excedentes a los mercados locales y bajos ingresos relativos en mano de obra (Minagri, 2015). Asimismo, más del $90 \%$ de las unidades agropecuarias ${ }^{2}$ se caracterizan principalmente por el uso predominante de fuerza de trabajo familiar y acceso limitado a recursos de tierra, agua y capital (Minagri, 2015). El problema se agudiza debido a que, en el sector agrario, el riesgo de sequías ocupa el primer lugar en comparación con otros riesgos climáticos como heladas, friaje, inundaciones, etc. (Minagri, 2012).

Lo antes mencionado refleja una situación de vulnerabilidad de las zonas rurales. En este contexto, el Estado ha realizado esfuerzos para combatir la pobreza por medio de diversos programas sociales de alcance nacional en beneficio de zonas menos favorecidas, como Juntos, Vaso de Leche y Cuna

\footnotetext{
${ }^{1}$ Este ensayo es una versión resumida y editada del Trabajo de Investigación Económica que, con el mismo título, fue concluido en junio de 2017. Las autoras agradecen al profesor Pedro Mateu por su asesoría durante la realización de la investigación; así como el apoyo brindado por la Asociación Jesús Obrero (Ccaijo) con información y asistencia técnica para la ejecución de las encuestas.

${ }^{2}$ Según el Censo Nacional Agropecuario 2012, la unidad agropecuaria se define como el terreno o conjunto de terrenos dentro de un distrito utilizados total o parcialmente para la producción agropecuaria, conocidos como una unidad económica por el productor agropecuario, sin considerar su extensión, régimen de tenencia y condición jurídica.
} 
Más. Asimismo, existen programas nacionales agrícolas para mejorar la economía del poblador agrario; tal es el caso del Programa Nacional de Innovación Agraria en Agroforestería y del Programa Nacional de Innovación Agraria en Cultivos Andinos que conduce el Instituto Nacional de Innovación Agraria (INIA). Siguiendo esta línea, también existen iniciativas propias de cada región que buscan mejorar las condiciones locales de vida. Un ejemplo de ello es el Programa de Siembra y Cosecha, en adelante PSC, implementado por la Asociación Jesús Obrero (Ccaijo) ${ }^{3}$ en Ccatcca, Cusco.

La implementación del PSC consiste en la construcción de micropresas, que son infraestructuras en la depresión del suelo que permiten almacenar agua de lluvias de manera natural, para su utilización en períodos de estiaje. Ccaijo impulsó el PSC durante el período 1999-2014 en cuatro distritos de la provincia de Quispicanchi: Andahuaylillas, Ccatcca, Urcos y Ocongate. La intervención del PSC se realiza cada ańo: (i) entre los meses de enero y marzo, se realiza la recolección de agua de lluvia; y (ii) durante abril y diciembre, períodos de sequía, se lleva a cabo la utilización de agua de lluvia recolectada, lo que impulsa la producción agropecuaria.

El objetivo principal de esta investigación es determinar la contribución del PSC, mediante el uso de las micropresas, al nivel de bienestar de las familias de Ccatcca; de manera específica, en sus niveles de ingresos monetarios, educación superior y nutrición.

Sobre la base de la revisión de la literatura y entrevistas con la institución Ccaijo, se establecieron las siguientes hipótesis:

- El bienestar de las familias, medido en términos de ingresos monetarios, se incrementa como consecuencia de su participación en el PSC.

- La participación de ingresos agropecuarios en el total de ingresos es mayor en familias que participan del PSC en comparación con las que no.

- El porcentaje de hijos con educación superior es mayor en familias que participan del PSC respecto a otras que no.

- Las familias que participan del PSC logran acceder a alimentos de mejor calidad en comparación con las que no.

La importancia de esta investigación radica en aportar evidencia empírica a la literatura sobre la contribución del uso de micropresas al bienestar

\footnotetext{
${ }^{3}$ Institución de la Compañía de Jesús que lleva más de 30 años trabajando en la provincia de Quispicanchi con la misión de contribuir al desarrollo humano en la zona, en especial en las comunidades más empobrecidas.
} 
de las familias, la cual, según la literatura revisada, aún no ha sido evaluada para el caso peruano. Además, la consistencia de la contribución del PSC al bienestar de la población es evaluada aquí con un enfoque similar a la matriz multirrasgo-multimétodo (Schmitt \& Stults, 1986).

La presentación de esta investigación está estructurada en cinco secciones. En la primera sección, se examina la literatura teórica y empírica en la materia, así como los principales hallazgos sobre programas similares al PSC. En la segunda sección, se plantea el marco analítico que sirve como base para la investigación. La tercera sección aborda la metodología utilizada, junto con el diseño muestral ${ }^{4}$. Luego, en la cuarta sección, se analizan la estadística descriptiva, los resultados y las limitaciones de la investigación. Por último, en la quinta sección, se resumen las conclusiones y algunas recomendaciones de políticas y para futuras investigaciones.

\section{Revisión de la literatura especializada}

El bienestar de las personas depende de sus funciones de producción, en especial de sus funciones de ingresos, educación y nutrición. De hecho, el bienestar es un concepto abstracto (constructo o variable latente), pero abordable operacionalmente mediante un conjunto de variables observadas, como las mencionadas. A continuación, se revisa brevemente la literatura teórica y empírica acerca de cada variable, así como la evidencia empírica del impacto de programas sociales sobre las respectivas funciones.

\section{Función de ingresos}

Rodríguez y Abler (1998) presentan un modelo, basado en el modelo de Becker (1991), en el que la función de ingresos generados en la etapa adulta depende de remuneraciones, conocimiento tecnológico, ratio capital humano / otro capital y stock de capital humano. Al analizar los ingresos rurales, el panorama tiene ciertos contrastes. El perfil de la pobreza en zonas rurales es explicado por la asignación regional de activos humanos, físicos, financieros, organizacionales y públicos (Gonzales de Olarte, 1996; Escobal, Saavedra, \& Torero, 1998). Algunos estudios concluyen que los ingresos no provenientes de actividades agrícolas representan el 40\% aproximadamente (Figueroa, 1989; Gonzales de Olarte, 1996). En un estudio más profundo sobre ingresos rurales en el Perú, Escobal (2001) diseña un modelo en el que los ingresos

\footnotetext{
${ }^{4}$ El modelamiento de muestreo es necesario porque se requerirá realizar encuestas para fines de la investigación. En páginas posteriores, se explica detalladamente el proceso de muestreo.
} 
totales (tanto los provenientes de actividades agropecuarias como los que no) dependen de precios, activos agropecuarios, activos no agropecuarios, activos que facilitan el crédito, activos de capital humano (incluyendo tamaño de la familia, su composición y nivel educativo), activos públicos y activos del área regional. En esta misma línea, De Janvry \& Saudolet (2000) concluyen que los activos de las familias y el contexto social, institucional y geográfico son determinantes claves de los ingresos rurales.

\section{Función de educación}

La literatura especializada muestra que, a mayor nivel de capital humano, específicamente de educación, mayores son los niveles de productividad, salud, vida y desarrollo económico (Schultz, 1961; Becker, 1975). Según la teoría microeconómica, el rendimiento del alumno depende de factores familiares, de características de la escuela y de los profesores, y de aquellas propias del estudiante (Serván \& Tantaleán, 2009). Más específicamente, Heckman, Stixrud \& Urzúa (2006), así como Heckman \& Rubinstein (2001), encuentran que las habilidades no cognitivas son cuantitativamente importantes para la educación superior en los Estados Unidos. Ello es citado por Castro, Yamada $\&$ Arias (2016), quienes encuentran que los estudiantes de secundaria no logran culminar sus estudios, y, por ende, no prosiguen estudios superiores, por falta de habilidades no cognitivas, tales como autodisciplina y perseverancia.

Bassi \& Galiani (2010) demuestran, para el caso de Chile, que la calidad educativa de los colegios cumple un papel importante en la decisión de seguir estudiando, así como también el nivel socioeconómico y la educación de los padres. Para el Perú, Castro et al. (2016) encuentran que el entorno cultural y familiar influyen en el apego a la educación ("taste for education») y el asociado costo marginal de educarse.

\section{Función de nutrición}

Akin et al. (1992) establecen que la función nutricional de un niño es determinada por factores individuales, domésticos y comunitarios. Para el caso peruano, Alderman, Hentschel \& Sabates (2003) encuentran que el estado nutricional de un niño depende de la combinación de nutrientes, salud, cuidado del nińo, potencial genético y condiciones de su hogar y vecindario. Blakely et al. (2005) analizan datos para 53 países y hallan evidencia de que el 37\% de la desnutrición se atribuye al bajo nivel de ingresos, en familias con menos de 1 dólar por día. Para el caso de los Estados Unidos, Furness, Simon, Wold \& Asarian-Anderson (2004) encuentran que las personas con ingresos muy por debajo del nivel de pobreza federal tienen un riesgo alto 
de inseguridad alimentaria; y que la relación entre ingresos familiares y consumo de calorías no mejora la nutrición si es que existen deficiencias en el saneamiento. Adicionalmente, Reyes et al. (2004) reportaron que los padres recién empleados, comparados con padres que tienen trabajo por más de dos ańos, tienen mayor riesgo de tener nińos desnutridos, y que esta probabilidad aumenta si los padres son agricultores.

\section{Programas sociales}

Los programas sociales tienen un rol importante en la mejora del bienestar de las personas. En el Perú, es el caso del programa Juntos, desarrollado por el Ministerio de Desarrollo e Inclusión Social (Midis) con el objetivo de contribuir a la reducción de la pobreza y quebrar el ciclo de su transmisión intergeneracional, mediante la promoción de capital humano (Sánchez \& Jaramillo, 2012). También existen proyectos que apoyan el desarrollo productivo de pequeńos productores rurales, como los implementados por Technoserve, Agroideas, el Proyecto de Reducción y Alivio a la Pobreza (PRA) y el Proyecto Sierra Norte (Fuentes, Medina, Rojas, \& Silva, 2015).

Respecto a la captación y uso gradual del agua de lluvias, esta práctica agrícola ha sido promovida por proyectos en Kenia; en el Perú, mediante el PSC; y en otros países latinoamericanos como México, Chile y Bolivia. Al respecto, la FAO (2000) señala:

El aumento de rendimientos que pueden generar estas prácticas, debe considerarse no sólo como un medio realista y práctico para obtener el aumento de producción, sino también para lograr el alivio de la pobreza de los productores rurales de esas zonas. (p. 1)

La evidencia empírica sobre esos proyectos similares al PSC muestra que:

i. Kenia: generaron un gran ahorro de agua a un costo razonable, flexibilidad en la disponibilidad de agua, creación de puestos de trabajo y beneficios ambientales (Amos, Rahman, \& Gathenya, 2016).

ii. Latinoamérica: fomentaron prácticas eficientes para el uso del agua, con beneficios económicos y sociales. En México, con el uso del agua captada como única fuente de agua potable, se logró una relación lineal igual a 1 entre el tamaño del área de captación de agua y el nivel del servicio (Sámano, Mautner, Chávez, \& Jiménez, 2016). En Chile, se lograron economías de escala, reduciendo gastos incurridos al suministrar agua mediante camiones, e incrementando el 
ingreso familiar, el empleo y la introducción de nuevos productos en el mercado (Carrasco \& Felmer, 2011). En Bolivia, se redujo el peligro de merma o pérdida completa de la cosecha y se diversificó e intensificó la producción agrícola (Goetter \& Pichit, 2011).

\section{Marco analítico}

A la luz de la literatura revisada, el bienestar de las familias será estimado mediante un modelo basado en una función de producción expresada en ingresos, educación y nutrición. Las variables operacionales son ingresos monetarios, porcentaje de hijos con presencia de educación superior y gasto en carnes rojas y vegetales. Para evaluar la contribución del PSC al bienestar, se analiza la medida en que esas variables están en función de otras variables indicativas de la incidencia del PSC, tales como la participación en el PSC, las características del hogar y las características del área geográfica.

La participación en el PSC permite que las familias de la comunidad, dedicadas en su mayoría a la actividad agropecuaria, dispongan de agua para riego durante todo el ańo, lo que les permite optimizar el uso del suelo, y pasar de una cosecha anual a dos o tres cosechas por año, además de transitar de cultivos anuales a cultivos permanentes. Además, el PSC implica que las familias reciban capacitaciones respecto a técnicas de cultivo y de crianza de animales.

Con estas nuevas condiciones de productividad mayor y más sostenida a lo largo del tiempo, las familias incrementan su producción agrícola y logran excedentes, que se traducen en mayores ingresos como resultado de mayores ventas de animales (principalmente cuyes) y productos agrícolas. Las familias venden sus excedentes después de utilizar un porcentaje de su producción para el autoconsumo, con lo que ahorran gastos de comida. Adicionalmente, las familias de Ccatcca no incurren en costos de transporte para vender sus productos, debido a que los interesados en comprarlos van directamente al distrito donde viven ${ }^{5}$.

En cuanto a las condiciones del hogar, el número de sus miembros, sus tipos de actividad económica (principalmente agropecuaria) y el tiempo que le dedican, las migraciones de miembros de la familia, la educación de los padres y el acceso a servicios básicos, son factores que influyen en los niveles de producción e ingresos familiares.

\footnotetext{
${ }^{5}$ La información sobre las familias beneficiadas por el PSC ha sido obtenida de entrevistas directas y con la ayuda del equipo de la Asociación Jesús Obrero (Ccaijo).
} 
Respecto a las condiciones del área geográfica, se consideran tres factores. Primero, la cercanía de la Carretera Interoceánica significa para los productores de Ccatcca un ahorro de tiempo y reducción de gastos en transporte. Segundo, la presencia en Ccatcca de dos programas nacionales: Juntos, un programa de transferencias de dinero sujeto a certificado de matrícula escolar y cartilla de salud, y Vaso de Leche, que ofrece desayunos a niños en educación básica. Ambos aumentan el ingreso monetario de las familias mediante el ahorro en gastos en educación, salud y nutrición. Tercero, la gran afluencia de turistas a la región Cusco hace que algunos de sus productos agropecuarios (como el cuy) sean muy demandados para la preparación de platos típicos.

El objetivo de la investigación incluye estimar la contribución del PSC al bienestar expresada en variables no monetarias, como educación y nutrición. Sobre educación, cabe precisar que un requisito del programa Juntos es la asistencia escolar de los hijos de las familias beneficiadas, por lo que no se prevén diferencias significativas en educación básica. No obstante, sí podría haber diferencias en educación superior, pues los padres de las familias beneficiadas por el PSC matriculan a sus hijos en instituciones privadas. Respecto a nutrición, se plantea que las familias pueden incrementar su consumo de productos más nutritivos (como carnes rojas y vegetales), debido tanto a sus mayores ingresos como al hecho de que algunos son producidos por las propias familias.

\section{Metodología}

\subsection{Diseño de evaluación}

Con base en lo explicado previamente, y recordando que el objetivo principal del trabajo de investigación es la estimación de la contribución del PSC a la mejora del bienestar, se formuló un diseño cuasiexperimental de posintervención con grupo de control ${ }^{6}$. Esta elección se debe a que en la implementación del PSC no existió asignación aleatoria, y a la ausencia de una línea de base.

La intervención evaluada fue con base en las lluvias del año 2016. Durante los meses de enero y marzo, se recolectó agua de lluvia en las micropresas, y los beneficios captados por la intervención son los que se registraron entre los meses de abril y diciembre.

\footnotetext{
${ }^{6} \mathrm{El}$ término «grupo de control» usualmente se refiere a un grupo que no recibe el tratamiento.
} 


\subsection{Descripción del área de intervención y del marco muestral, y determinación del tamańo de la muestra}

El PSC atiende a la población de la provincia de Quispicanchi, Cusco, beneficiando a un total de 910 familias en cinco distritos por medio de 16 micropresas. Nuestra evaluación está centrada en el distrito de Ccatcca. Su elección se debió a que es uno de los distritos más pobres del Perú ${ }^{7}$, y el más pobre entre los distritos donde opera el proyecto. La presente investigación se enfocó en evaluar la contribución del PSC con base en tres micropresas ${ }^{8}$ representativas en Ccatcca: Izqaycocha II, Umuto I y Machaca; el número de familias beneficiadas es de 385 .

Debido a la ausencia de una línea de base, se tuvo que realizar encuestas en el área de intervención. Considerando la teoría estadística y los criterios de representatividad necesarios, se obtuvo que el tamaño de muestra óptimo es de 78 familias?.

La literatura especializada recomienda que el tamaño del grupo de control sea el doble que el de la muestra del grupo tratado ${ }^{10}$. Sin embargo, debido a la complejidad de realizar encuestas, se decidió que el grupo de control fuera 1,5 veces el tamańo de la muestra antes mencionado; es decir, 117 familias ${ }^{11}$. En la tabla 1, se listan las variables consideradas para la determinación del grupo de control:

\footnotetext{
${ }^{7}$ Ccatcca es el décimo distrito más pobre del Perú, como se observa en el «Mapa de pobreza del Perú» en 2013 (INEI, 2016).

${ }^{8}$ Las micropresas comparten el mismo año de creación y cercanía entre ellas.

${ }^{9}$ Cabe indicar que se requirió realizar un ajuste debido a la condición de muestra con reemplazo.

${ }^{10}$ Hace referencia a la muestra que recibe el tratamiento. En esta investigación, se refiere a las familias que participan en el PSC.

${ }^{11}$ Además, se incorporaron 48 observaciones adicionales a fin de mitigar el riesgo en el método de emparejamiento probabilístico, el cual será explicado en páginas posteriores.
} 
Tabla 1

Variables de control

\begin{tabular}{ll}
\hline \multicolumn{1}{c}{ Variable } & \multicolumn{1}{c}{ Valor } \\
\hline Edad & Variable numérica \\
$\begin{array}{l}\text { Número de hijos que no se encuentren } \\
\text { en edad de trabajar }\end{array}$ & Variable numérica \\
Nivel educativo & 7 niveles, desde sin instrucción hasta universitario \\
Ocupación agropecuaria & Variable dummy (0-1) \\
Altitud & Variable numérica \\
Latitud & Variable numérica \\
Longitud & Variable numérica \\
\hline
\end{tabular}

\subsection{Planteamiento del modelo por estimar}

Considerando a los constructos como el eslabón clave para identificar las variables que componen el modelo por estimar, el constructo de intervención es representado por la recolección de agua de lluvia con tres niveles distintos, según el volumen de agua almacenada con las micropresas en cada comunidad tratada, más un grupo de control (figura 1); mientras que el constructo de resultados es bienestar y cuenta con tres variables operacionales: ingresos, educación y nutrición.

Con el propósito de estimar la contribución del PSC al bienestar de las familias, se debe escoger un modelo econométrico bien elaborado. Para ello, se debe realizar adecuadamente la elección de variables dependientes (asociadas al constructo de resultado) e independientes (asociadas al constructo de intervención).

\section{Modelo de bienestar}

La investigación cuantifica el bienestar modelando de la siguiente manera a las respectivas variables dependientes (ingresos monetarios, educación superior y gasto en carnes rojas y verduras):

\section{Ingresos familiares:}

$$
\begin{gathered}
Y=\beta_{0}+\delta_{1} D+\beta_{1} \text { Sem }_{\text {prom }_{\text {trab }}+}+\beta_{2} \text { edad }+\beta_{3} \text { edad }^{2}+\beta_{4} \text { inst }_{\text {sec }}+\beta_{5} \text { Cred }+ \\
\beta_{6} T_{\text {Inter }}+\epsilon
\end{gathered}
$$




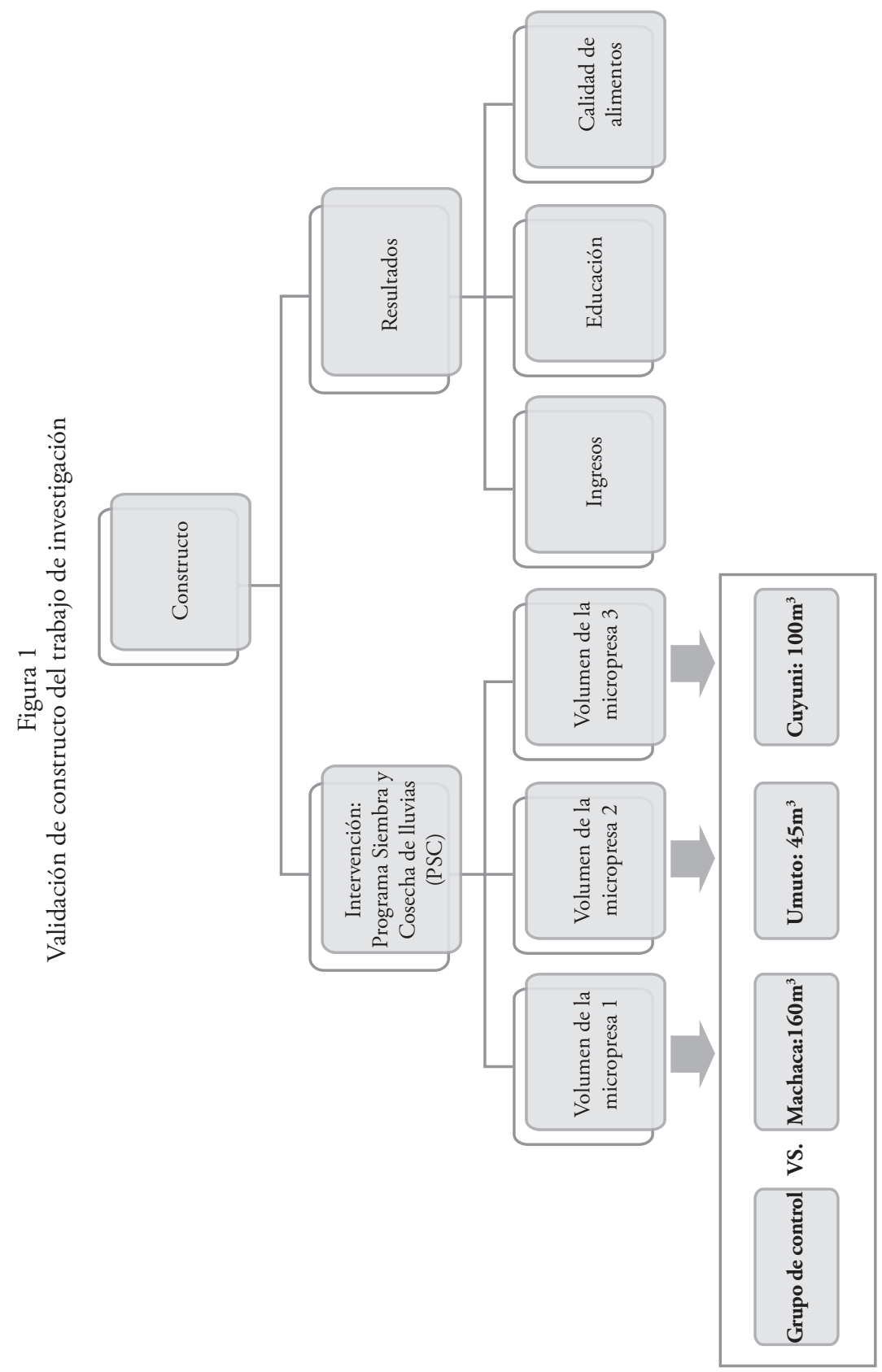


Tabla 2

Variables relacionadas con el ingreso familiar

\begin{tabular}{|c|c|c|c|}
\hline Variable & $\begin{array}{c}\text { Nombre de la } \\
\text { variable }\end{array}$ & Medición & Descripción \\
\hline$Y$ & Ingreso & $\begin{array}{l}\text { Número de } \\
\text { unidades } \\
\text { producidas } \\
\text { multiplicado por } \\
\text { precio de mercado }\end{array}$ & $\begin{array}{l}\text { Se espera que los ingresos aumenten } \\
\text { debido a la participación en el PSC. }\end{array}$ \\
\hline$D$ & $\begin{array}{l}\text { Participación en } \\
\text { el PSC }\end{array}$ & $\begin{array}{c}1=\text { participa } \\
0=\text { no participa }\end{array}$ & $\begin{array}{l}\text { Se espera que participar en el PDC } \\
\text { aumente la producción agropecuaria } \\
\text { debido a una mayor disponibilidad } \\
\text { de agua, lo cual se traduciría en } \\
\text { mayor ingreso familiar. }\end{array}$ \\
\hline Sem $_{\text {Prom }_{\text {Traba }}}$ & Horas trabajadas & Variable numérica & $\begin{array}{l}\text { El número de horas semanales de } \\
\text { trabajo tiene un impacto positivo en } \\
\text { la producción. }\end{array}$ \\
\hline edad & $\begin{array}{l}\text { Edad del jefe del } \\
\text { hogar }\end{array}$ & Variable numérica & $\begin{array}{l}\text { La edad del jefe del hogar influye } \\
\text { positivamente en la generación de } \\
\text { ingresos. }\end{array}$ \\
\hline inst $_{\text {sec }}$ & $\begin{array}{l}\text { Instrucción } \\
\text { secundaria completa } \\
\text { del jefe del hogar }\end{array}$ & $\begin{array}{l}1 \text { = cuenta con } \\
\text { instrucción } \\
\text { superior } \\
0=\text { no cuenta } \\
\text { con instrucción } \\
\text { superior }\end{array}$ & $\begin{array}{l}\text { Se espera que, si el jefe del hogar } \\
\text { cuenta con instrucción superior, la } \\
\text { generación de ingresos será mayor. }\end{array}$ \\
\hline Cred & Acceso a crédito & $\begin{array}{l}1=\text { accede } \mathrm{a} \\
\quad \text { crédito } \\
0= \\
\text { no accede a } \\
\text { crédito }\end{array}$ & $\begin{array}{l}\text { Se espera que el acceso a crédito } \\
\text { tenga una relación positiva con } \\
\text { los ingresos, debido a que ayuda a } \\
\text { financiar cosechas, abonos, inversión } \\
\text { en galpones, etc. }\end{array}$ \\
\hline$T_{\text {inter }}$ & $\begin{array}{c}\text { Tiempo de } \\
\text { demora en llegar } \\
\text { a la Carretera } \\
\text { Interoceánica desde } \\
\text { la casa del jefe del } \\
\text { hogar }\end{array}$ & Variable numérica & $\begin{array}{l}\text { La variable tiempo de demora } \\
\text { está asociada a la conectividad y } \\
\text { el desarrollo de la familia. Estas } \\
\text { características inciden en mayores } \\
\text { oportunidades para potenciar el } \\
\text { ingreso. }\end{array}$ \\
\hline
\end{tabular}

\section{Porcentaje de hijos en educación superior:}

$$
\begin{gathered}
\text { Porc }_{\text {educ }}=\beta_{\text {sup }}=\beta_{0} D+\beta_{1} \text { Sexo }+\beta_{2} \text { edad }+\beta_{3} \text { edad }^{2}+\beta_{4} \text { hijos }+ \\
\beta_{5} \text { Juntos }+\beta_{6} \text { Migra }+\epsilon
\end{gathered}
$$


Tabla 3

Variables relacionadas con educación superior

\begin{tabular}{|c|c|c|c|}
\hline Variable & $\begin{array}{c}\text { Nombre de la } \\
\text { variable }\end{array}$ & Medición & Descripción \\
\hline Porc $_{\text {educ_sup }}$ & $\begin{array}{c}\text { Porcentaje de } \\
\text { hijos en educación } \\
\text { superior }\end{array}$ & $\begin{array}{l}\text { De } 0 \text { a } 1: 0 \text { indica } \\
\text { que no posee hijos en } \\
\text { educación superior; } \\
1 \text { indica que tiene } \\
\text { a todos sus hijos en } \\
\text { educación superior }\end{array}$ & $\begin{array}{l}\text { Se espera que el porcentaje } \\
\text { de hijos en educación } \\
\text { superior aumente debido a } \\
\text { la participación en el PSC. }\end{array}$ \\
\hline$D$ & $\begin{array}{l}\text { Participación en } \\
\text { el PSC }\end{array}$ & $\begin{array}{c}1=\text { participa } \\
0=\text { no participa }\end{array}$ & $\begin{array}{l}\text { Se espera que participar en } \\
\text { el PSC aumente el nivel } \\
\text { educativo, mediante un } \\
\text { aumento en los ingresos. }\end{array}$ \\
\hline Sexo & $\begin{array}{l}\text { Sexo del jefe del } \\
\text { hogar }\end{array}$ & $\begin{array}{c}1=\text { hombre } \\
0=\text { mujer }\end{array}$ & $\begin{array}{l}\text { Se espera que, si el jefe del } \\
\text { hogar es hombre, los hijos } \\
\text { podrán ausentarse para } \\
\text { cursar estudios superiores. }\end{array}$ \\
\hline Hijos & $\begin{array}{l}\text { Número de hijos } \\
\text { en el hogar que no } \\
\text { se encuentren en } \\
\text { edad de trabajar }\end{array}$ & Variable numérica & $\begin{array}{l}\text { Se espera una relación } \\
\text { inversa: a mayor número } \\
\text { de hijos en edad de no } \\
\text { trabajar, menor será el } \\
\text { acceso a la educación } \\
\text { superior de los hijos del } \\
\text { hogar. }\end{array}$ \\
\hline Juntos & $\begin{array}{c}\text { Participación en el } \\
\text { programa Juntos }\end{array}$ & $\begin{array}{c}1=\text { participa } \\
0=\text { no participa }\end{array}$ & $\begin{array}{l}\text { Se espera una relación } \\
\text { positiva entre la } \\
\text { participación del hogar y } \\
\text { el acceso de los hijos a la } \\
\text { educación superior. }\end{array}$ \\
\hline Migr & $\begin{array}{l}\text { Número de } \\
\text { migraciones del } \\
\text { jefe del hogar a } \\
\text { otra provincia }\end{array}$ & Variable numérica & $\begin{array}{l}\text { Se espera una relación } \\
\text { inversa: mientras más } \\
\text { veces migre el jefe del } \\
\text { hogar, menor será el } \\
\text { acceso de los hijos a la } \\
\text { educación superior. }\end{array}$ \\
\hline
\end{tabular}

\section{Gasto en carnes rojas y verduras:}

$$
\begin{gathered}
\text { Gasto }_{\text {carnesrojas_vverduras }}=\beta_{0}+\delta_{1} D+\beta_{1} \text { Capacitaciones agro }_{+} \\
\beta_{2} \text { Porc_hijo }_{\text {educsup }}+\beta_{4} \text { Estado }_{\text {civil }} \text { casado } \\
+\epsilon
\end{gathered}
$$


Tabla 4

Variables relacionadas con gastos en carnes rojas y verduras

\begin{tabular}{|c|c|c|c|}
\hline Variable & $\begin{array}{c}\text { Nombre de la } \\
\text { variable }\end{array}$ & Medición & Descripción \\
\hline Gasto $_{\text {carnesrojas_verduras }}$ & $\begin{array}{l}\text { Gasto en carnes } \\
\text { rojas y verduras }\end{array}$ & Numérica & $\begin{array}{l}\text { Se espera que el gasto } \\
\text { en alimentos aumente } \\
\text { mediante un mayor ingreso } \\
\text { resultante de participar en } \\
\text { el PSC. }\end{array}$ \\
\hline$D$ & $\begin{array}{l}\text { Participación en } \\
\text { el PSC }\end{array}$ & $\begin{array}{c}1=\text { participa } \\
0=\text { no participa }\end{array}$ & $\begin{array}{l}\text { Se espera que la } \\
\text { participación en el PSC } \\
\text { aumente el gasto en carnes } \\
\text { rojas y verduras. }\end{array}$ \\
\hline Porc_hijo $_{\text {educsup }}$ & $\begin{array}{l}\text { Porcentaje } \\
\text { de hijos con } \\
\text { estudios } \\
\text { superiores }\end{array}$ & $\begin{array}{l}\text { Variable } \\
\text { numérica }\end{array}$ & $\begin{array}{l}\text { Se espera una relación } \\
\text { positiva entre la proporción } \\
\text { de hijos que siguen estudios } \\
\text { superiores y el consumo de } \\
\text { los productos mencionados. }\end{array}$ \\
\hline Estado $_{\text {civil }}$ casado $_{\text {os }}$ & $\begin{array}{l}\text { Estado civil } \\
\text { casado }\end{array}$ & $\begin{array}{c}1=\text { casado } \\
0=\text { no casado }\end{array}$ & $\begin{array}{l}\text { Se espera que en hogares } \\
\text { establecidos por matrimonio } \\
\text { sea mayor el gasto en carnes } \\
\text { rojas y verduras. }\end{array}$ \\
\hline
\end{tabular}

\subsection{Descripción de fuentes de información}

Los datos fueron recogidos de la aplicación de la encuesta a 241 hogares $^{12}$ en el distrito de Ccatcca. Para la elaboración de la encuesta, se tomaron en consideración la Encuesta Nacional de Hogares y la Herramienta de Medición de la Pobreza (Poverty Assessment Tool) elaboradas por el INEI y la Agencia de los Estados Unidos para el Desarrollo Internacional (Usaid por sus siglas en inglés), respectivamente.

\subsection{Método de estimación}

La elección del método de estimación se explica por las siguientes circunstancias al inicio de nuestra investigación:

- La implementación del PSC no fue aleatoria: existieron factores observables que determinaron al grupo beneficiario. Estos fueron la re-

\footnotetext{
${ }^{12}$ Se incorporaron 46 observaciones adicionales a fin de mitigar el riesgo en el método de emparejamiento probabilístico, el cual será explicado más adelante.
} 
lación existente con capacitaciones a los beneficiarios y, hasta cierto período, el costo de mantenimiento de la micropresa por parte de Ccaijo.

- No había ninguna investigación previa, realizada en la región o por Ccaijo, que sirviese de referencia para un mejor análisis. En particular, no existía una línea de base acerca de variables relevantes para poder realizar una estimación contrastando un tiempo pretratamiento y uno postratamiento.

Ante lo cual, considerando que la técnica de emparejamiento probabilístico puede ser aplicada para casos con información de un solo corte en el tiempo, siempre y cuando se cuente con observaciones de grupo tratado y de control (Bernal \& Peña, 2011), se procedió a utilizar esta técnica para estimar la contribución del PSC en las siguientes variables de bienestar: ingresos agropecuarios, porcentaje de hijos con educación superior y gasto en carnes rojas y verduras.

¿Qué se necesita, en cuanto a los datos, para tener la seguridad de que esta técnica funcione? Dado que no se podía determinar si se cumplen los supuestos, porque no se podía verificar si lo no observado afecta o no la decisión de participación en el PSC, se optó por calcular las diferencias en las variables observadas mediante la prueba de diferencias de medias (Heinrich, Maffioli, \& Vásquez, 2010), la cual permite inferir que, si los dos grupos (tratado y de control) son demasiado diferentes en las características observadas, es probable que también sean diferentes en características no observadas.

Después de haber realizado exitosamente la prueba correspondiente, se procedió a emplear el método de emparejamiento probabilístico (o PSM, por propensity score matching) propuesto por Rosenbaum \& Rubin (1983), mediante el cual se estimó el efecto del PSC «emparejando» una observación tratada con una no tratada, donde la única diferencia relevante entre ambas era la participación en el PSC. La metodología PSM fue aplicada en cuatro etapas (figura 2). A continuación, se detalla cada etapa, contextualizándola para la investigación.

\section{Figura 2}

Etapas de la estimación a través de la técnica del emparejamiento probabilístico

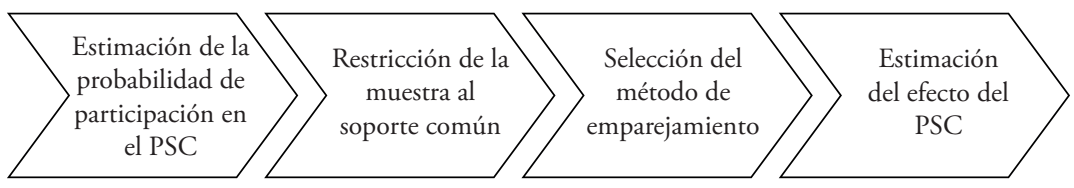




\section{a. Estimación de la probabilidad de participación en el PSC}

Para garantizar el emparejamiento entre observaciones del grupo tratado y el de control, se debe caracterizar cada observación según su probabilidad de participación en el PSC. Para ello, debe considerarse que el PSM se basa en el supuesto de independencia condicional, el cual establece que los resultados potenciales son independientes del tratamiento. Para que ello se cumpla, la probabilidad de participación debe explicarse únicamente por regresores que afecten en simultáneo tanto la decisión de participación en el PSC como a la variable resultado.

Con tal fin, se utilizó un modelo de variable dependiente limitada de tipo probit binomial, mediante el cual se especificó la probabilidad de participación como una función no lineal de las características observables del PSC. De esta manera, el modelo de probabilidad quedó definido así:

$$
\begin{gathered}
\operatorname{Pr}\left(D_{i}=1 / X\right)=F\left(\beta_{0}+\beta_{1} \text { edad }_{\text {ajus }_{j e f e}}+\beta_{2} \text { edad }_{\text {ajus } \text { sefe }_{2} 2}+\right. \\
\left.\beta_{3} \text { Ccaijo }_{\text {bajo }}+\beta_{4} \text { númhijos_educprim }\right)
\end{gathered}
$$

Donde $D_{i}$ es una dummy que toma el valor de 1 si la familia $i$ es una familia tratada, es decir, si es beneficiaria del PSC, y 0 de otro modo; $\operatorname{Pr}\left(D_{i}=1 / X\right)$ representa la probabilidad de que la familia $i$ se considere como tratada, dadas las características observables del programa; edadajus toma el valor numérico de la edad del jefe del hogar cuando se inició el programa; edad $_{\text {ajus } 2}$ toma valores numéricos; Ccaijo $_{\text {bajo }}$ es una dummy que toma el valor de 1 si la familia tiene o tuvo algún tipo de relación con la institución Ccaijo; númhijos_educprim es una variable numérica; y $\beta_{0}$ es la constante de la regresión.

\section{b. Restricción de la muestra al soporte común}

Para asegurar que los grupos tratado y de control sean muy parecidos, el método PSM fue aplicado solo a la región de soporte común, en la cual las familias con las mismas características observables tienen probabilidad similar y positiva de ser participantes del PSC o de no serlo.

A fin de evaluar la robustez de la metodología, se emplearon dos métodos de restricción de muestra al soporte común: (i) por mínimo-máximo, que consiste en eliminar de la muestra las observaciones cuyas probabilidades de participación sean inferiores a la probabilidad mínima del grupo tratado y mayores a la máxima del grupo de control; y (ii) por recorte (trimming), el cual elimina de la muestra un porcentaje determinado de observaciones que correspondan a rangos de la probabilidad de participación que tengan la más baja densidad (Bernal \& Peña, 2011). 


\section{c. Selección del grupo de control según método de emparejamiento}

Se evaluaron tres estimadores de emparejamiento (tabla 5), los cuales plantean distintas maneras de identificar el grupo de control más parecido al de tratamiento (Smith \& Todd, 2005).

Tabla 5

Métodos de emparejamiento probabilístico

\begin{tabular}{cl}
\hline Método de emparejamiento & \multicolumn{1}{c}{ Explicación } \\
\hline Por vecino más cercano & $\begin{array}{l}\text { Escoge como control a la familia cuya probabilidad de } \\
\text { participación en el programa tiene la menor distancia respecto a } \\
\text { la probabilidad de participación del individuo del grupo tratado. }\end{array}$ \\
& $\begin{array}{l}\text { Define un límite a las distancias entre probabilidades de } \\
\text { participación, con lo cual se emparejan familias cuya distancia } \\
\text { entre sus probabilidades de tratamiento es menor o igual a un } \\
\text { número determinado. }\end{array}$ \\
& $\begin{array}{l}\text { Vincula cada familia del grupo tratado con un promedio de } \\
\text { todos los individuos del grupo de control, ponderados según la } \\
\text { distancia entre las probabilidades de participación de la familia } \\
\text { Porima Kernel }\end{array}$ \\
&
\end{tabular}

\section{d. Estimación del efecto del programa PSC}

Por último, se obtiene la diferencia entre las variables de resultado de las familias del grupo de control y del grupo tratado (Bernal \& Peña, 2011).

\section{Análisis de resultados}

Antes de analizar los resultados obtenidos, se examinan las estadísticas descriptivas de las variables relevantes relacionadas con las hipótesis planteadas.

\subsection{Estadística descriptiva}

El ingreso total y el ingreso agropecuario - sin autoconsumo- de las familias que han participado del PSC son, en promedio, superiores a los de las familias que no han participado en S/ 812 y S/ 859, respectivamente. Cuando se considera el autoconsumo, la diferencia asciende a $S / 1.066$ y S/ 1.114, respectivamente. Además, se encontró que, en las familias tratadas, la participación del ingreso agropecuario respecto del total es del $51 \%$, y en las familias del grupo control es del $33 \%$. Cuando se incluye el autoconsumo, 
esas participaciones aumentan en las familias tratadas y de control en un $50 \%$ y un $70 \%$.

Adicionalmente, se encontró que, en su mayoría, el grupo tratado destinaba para la venta una proporción de su producción agropecuaria mucho mayor $(90 \%)$ que la destinada al autoconsumo (10\%). En contraste, el grupo de control destinaba un $29 \%$ para la venta y el $71 \%$ restante para el autoconsumo. $\mathrm{Y}$ respecto al cuy y el pasto, que destacan entre los productos agropecuarios del grupo tratado, la encuesta reportó que el precio al que se comercializan es superior al registrado para el grupo de control en un $45 \%$ en promedio.

En relación con las principales causas de migración, resalta que, en el grupo tratado, los estudios son la principal causa por la que un integrante deja su comunidad. En contraste, en el grupo de control, la principal causa es por trabajo. En cuanto al porcentaje de hijos con educación superior, se halló que, en promedio, en el grupo control, el 3\% de los hijos están siguiendo estudios superiores, mientras que en el grupo tratado el porcentaje asciende al 11\%. Esto influye en que el grupo control registre ingresos inferiores a los del grupo tratado, pese a tener más hijos en promedio. Además, los hombres del grupo tratado tienen mayor participación en la continuidad de estudios superiores que las mujeres ( $88 \%$ vs. $12 \%$ ). Las principales carreras que siguen los jóvenes son: Ingeniería (45\%), Educación (32\%) y Enfermería (10\%).

En el grupo tratado, el gasto en carnes rojas y vegetales registró, en promedio, un monto muy superior (S/ 117,7) al del grupo de control $(S / 21,6)$. También es superior la frecuencia del consumo de dichos productos en el grupo tratado (interdiaria) frente a la del grupo de control (semanal o quincenal).

Por último, se encontró que la satisfacción con el PSC en el grupo tratado es alta, pues un $41 \%$ se declaró muy satisfecho con la implementación del PSC y el 59\% restante está satisfecho con dicho programa.

\subsection{Estimación de resultados}

Antes de aplicar el método de emparejamiento probabilístico, se procedió a hacer una regresión simple, a través de mínimos cuadrados ordinarios (MCO), tomando como variables independientes aquellas teóricamente válidas. Se obtuvieron los siguientes resultados:

\section{Modelo ingresos familiares totales}

$$
\begin{aligned}
Y=\beta_{0}+\delta_{1} D & +\beta_{1} \text { Sem }_{\text {prom }}+\beta_{2} \text { edad }+\beta_{3} \text { edad }^{2}+\beta_{4} \text { inst }_{\text {sec }} \\
& +\beta_{5} \text { Cred }+\beta_{6} T_{\text {Inter }}+\beta_{7} \text { Juntos }+\epsilon
\end{aligned}
$$


Tabla 6

Resultado de la estimación MCO para la variable ingresos familiares

\begin{tabular}{cc}
\hline Variables & Modelo ingresos \\
\hline Constante & $4,4419^{*}$ \\
Semanas promedio de trabajo & $0,4584^{* *}$ \\
Edad & $0,0552^{* *}$ \\
Edad & $-0,0005^{*}$ \\
Instrucción secundaria & $0,6202^{* *}$ \\
Participación en el PSC & $0,5332^{* *}$ \\
Acceso al crédito & $-0,4148^{*}$ \\
Tiempo a la Carretera & $-0,0014$ \\
Participación en Juntos & 0,1946 \\
\hline
\end{tabular}

La tabla 6 muestra que, si un individuo del hogar trabaja una semana más, el crecimiento de los ingresos familiares totales aumenta en 0,45 puntos porcentuales. En el contexto de Ccatcca, el efecto positivo de esta variable en los ingresos familiares ocurre a través de la comercialización de sus productos agropecuarios. Asimismo, si la edad del jefe del hogar aumenta en un año, el crecimiento de los ingresos del hogar sube en 0,05 puntos porcentuales; sin embargo, a medida que sigue aumentando la edad, el crecimiento es cada vez menor. Además, se observa que el rol de la educación del jefe del hogar es relevante para los ingresos del hogar, debido a que, si cuenta con educación secundaria completa, aumenta el crecimiento de los ingresos en 0,62 puntos porcentuales. Se verifica así que las horas trabajadas, la edad del jefe del hogar y su nivel de educación son variables relacionadas positivamente con los ingresos totales, en línea con lo hallado por De Janvry \& Saudolet (2000), Escobal (2001) y Escobal et al. (1998).

También se observa que, si la familia participa en el PSC, los ingresos totales del hogar aumentan considerablemente: en 0,53 puntos porcentuales. Por lo tanto, la disponibilidad de agua en las familias que participan del proyecto marca una diferencia importante en los ingresos totales. Respecto al acceso a crédito, si una familia lo tiene, disminuye el crecimiento de sus ingresos agropecuarios en $0,41 \%$, en línea con lo encontrado en investigaciones sobre familias rurales agrarias (Escobal, 2001; Escobal et al., 1998). Al respecto, la institución Ccaijo nos informó que la mayoría de las familias piden crédito para obtener capital para negocios pequeños de bodegas o venta ambulante en la plaza del distrito. Pero cabe mencionar 
que ese efecto del acceso al crédito es estadísticamente relevante al 10\%, mas no al 5\%.

Por último, el programa Juntos aumenta en 0,19 puntos porcentuales el crecimiento en los ingresos familiares. Pero este efecto no resultó significativo, probablemente porque la mayoría de las familias en el distrito recibe el programa Juntos desde hace varios ańos y, así, este no genera efectos diferenciados.

\section{Modelo porcentaje de hijos en educación superior}

$$
\begin{gathered}
\text { Porc }_{\text {educ }}=\beta_{\text {sup }}= \\
\beta_{1} D+\beta_{1} \text { Sexo }+\beta_{2} \text { edad }+\beta_{3} \text { edad }^{2}+\beta_{4} \text { hijos } \\
+\beta_{5} \text { Juntos }+\beta_{6} \text { Migra }+\epsilon
\end{gathered}
$$

La tabla 7 muestra que, si el jefe del hogar es mujer, disminuye en 0,64 el porcentaje de hijos cursando estudios superiores, en comparación con el caso en el que el jefe del hogar es hombre. Asimismo, la variable «edad del padre» es significativa y tiene rendimientos decrecientes: un año más de edad aumenta en 0,18 puntos porcentuales la proporción de hijos en educación superior. Y, como era de esperarse, a mayor número de hijos, disminuye su proporción en educación superior, en 0,19 puntos porcentuales. Estos resultados para sexo y edad del jefe del hogar y número de hijos en la familia son consistentes con los encontrados por Heckman et al. (2006), Castro et al. (2016) y Bassi \& Galiani (2010).

\section{Tabla 7}

Resultado de la estimación del modelo lineal generalizado para la variable porcentaje de hijos en educación superior

\begin{tabular}{cc}
\hline Variables & Modelo educación superior \\
\hline Constante & $-5,9771^{* *}$ \\
Sexo & $-0,6447^{* *}$ \\
Edad & $0,1891^{* *}$ \\
Edad & $-0,0019^{* *}$ \\
Hijos & $-0,0628$ \\
Participación en el PSC & $0,7338^{* *}$ \\
Programa Juntos & $-0,2225$ \\
Migración & $0,7952^{* *}$ \\
\hline
\end{tabular}

Por otro lado, el efecto de pertenecer al programa Juntos no es significativo, mientras que sí lo es el efecto de las migraciones, positivo en 0,72 puntos 
porcentuales. Lo cual indica que un mayor contacto con ámbitos urbanos impulsa a cursar estudios superiores.

\section{Modelo gasto en alimentos: carnes rojas y verduras}

$$
\begin{gathered}
\text { Gasto }_{\text {carnesrojas_vverduras }}=\beta_{0}+\delta_{1} D+\beta_{1} \text { Capacitaciones agro } \\
+\beta_{2} \text { Porc_hijo }_{\text {educsup }}+\beta_{4} \text { Estado }_{\text {civil }} \text { casado } \\
+\epsilon
\end{gathered}
$$

Tabla 8

Resultado de la estimación MCO para la variable calidad de alimentos

\begin{tabular}{lc}
\hline \multicolumn{1}{c}{ Variables } & Modelo calidad de alimentos \\
\hline Constante & $3,2009^{* *}$ \\
Capacitaciones agropecuarias & $0,13071^{* *}$ \\
Porcentaje educación superior & 0,5054 \\
Participación en el PSC & $1,1963^{* *}$ \\
Casado & $-0,2869$ \\
\hline
\end{tabular}

El gasto en alimentos más nutritivos es explicado básicamente por la participación en el PSC y las relacionadas capacitaciones agropecuarias. Así, la tabla 8 muestra que las familias tratadas, en promedio, ven crecer en 1,19 puntos porcentuales su gasto en carnes y verduras con respecto a las del grupo de control. Esto se debería a que, a mayor disponibilidad de agua, las familias pueden diversificar más sus cultivos y obtener más alimento para sus vacas, cerdos y, en especial, cuyes.

Las capacitaciones agropecuarias están relacionadas positivamente con el gasto en carnes rojas y verduras, porque permiten que las familias conozcan y apliquen mejores prácticas que aumentan la productividad de sus tierras y la obtención de alimento para sus animales. Estas variables surgen como factores familiares y comunitarios relevantes para la nutrición (Akin et al., 1992; Alderman, Hentschel, \& Sabates, 2003).

\section{Prueba de diferencias de medias}

A continuación, se comparan los promedios de los regresores considerados en aquellos tres modelos. Dada la ausencia de asignación aleatoria entre los beneficiarios, se esperaría que los promedios de las variables no sean estadísticamente iguales entre el grupo tratado y de control; lo que se comprobó mediante la prueba de diferencias de medias. 
Tabla 9

Prueba de diferencia de medias entre grupo de control y grupo de tratamiento

\begin{tabular}{|c|c|}
\hline Variables & Grupo de control vs. grupo tratado \\
\hline \multirow{2}{*}{ Semanas promedio de trabajo } & $-0,1617$ \\
\hline & $(-0,1207)$ \\
\hline \multirow{2}{*}{ Edad } & $-1,0216$ \\
\hline & $(-1,8477)$ \\
\hline \multirow{2}{*}{ Instrucción secundaria } & 0,0135 \\
\hline & $(-0,0287)$ \\
\hline \multirow{2}{*}{ Acceso al crédito } & $-0,1218$ \\
\hline & $(-0,0356)^{* *}$ \\
\hline \multirow{2}{*}{ Tiempo a la Carretera Interoceánica } & 44,9611 \\
\hline & $(4,8188)^{* *}$ \\
\hline \multirow{2}{*}{ Juntos } & $-0,1323$ \\
\hline & $(0,0642)^{* *}$ \\
\hline \multirow{2}{*}{ Sexo } & 0,0423 \\
\hline & $(-0,0644)$ \\
\hline \multirow{2}{*}{ Hijos } & $-0,6302$ \\
\hline & $(0,3004)^{* *}$ \\
\hline \multirow{2}{*}{ Capacitaciones agropecuarias } & $-0,4792$ \\
\hline & $(0,0417)^{* *}$ \\
\hline \multirow{2}{*}{ Porcentaje de hijos educación superior } & $-0,0809$ \\
\hline & $(0,00244)^{* *}$ \\
\hline \multirow{2}{*}{ Casado } & $-0,2333$ \\
\hline & $(0,0591)^{* *}$ \\
\hline
\end{tabular}

Notas. Los errores estándar se encuentran entre paréntesis. La hipótesis nula de dicha prueba es que las diferencias de medias de cada variable son iguales. ${ }^{* *} \mathrm{p}<0,05,{ }^{*} \mathrm{p}<0,1$.

Como se observa en la tabla 9, la prueba aceptó las siguientes variables como diferentes estadísticamente entre los grupos tratado y de control: acceso al crédito, tiempo hasta/desde la Carretera Interoceánica, programa Juntos, número de hijos, capacitaciones agropecuarias, porcentaje de hijos en educación superior, y si el jefe del hogar es casado. Se concluye así que los grupos no son homogéneos. Por lo tanto, es relevante la aplicación del emparejamiento probabilístico a fin de estimar la contribución del PSC. 


\section{Método de emparejamiento probabilístico}

La elección de las variables para la ecuación de participación en el PSC que se formula a continuación está sustentada en la información recibida por la institución Ccaijo y en la significancia estadística de cada variable en el modelo probit ${ }^{13}$.

\section{Probparticipación $=\left(\right.$ edad ajustada, edad ajustada ${ }^{2}$, Ccaijo_bajo, numhijos_educprim)}

La distribución de las probabilidades de participación es viable, ya que los integrantes del grupo tratado tienen mayor probabilidad de participación en el PSC que aquellos del grupo de control, tal como se puede observar en la figura 3 .

\section{Figura 3}

Densidad de la probabilidad de participación en el PSC para el grupo de control y el grupo de tratamiento.

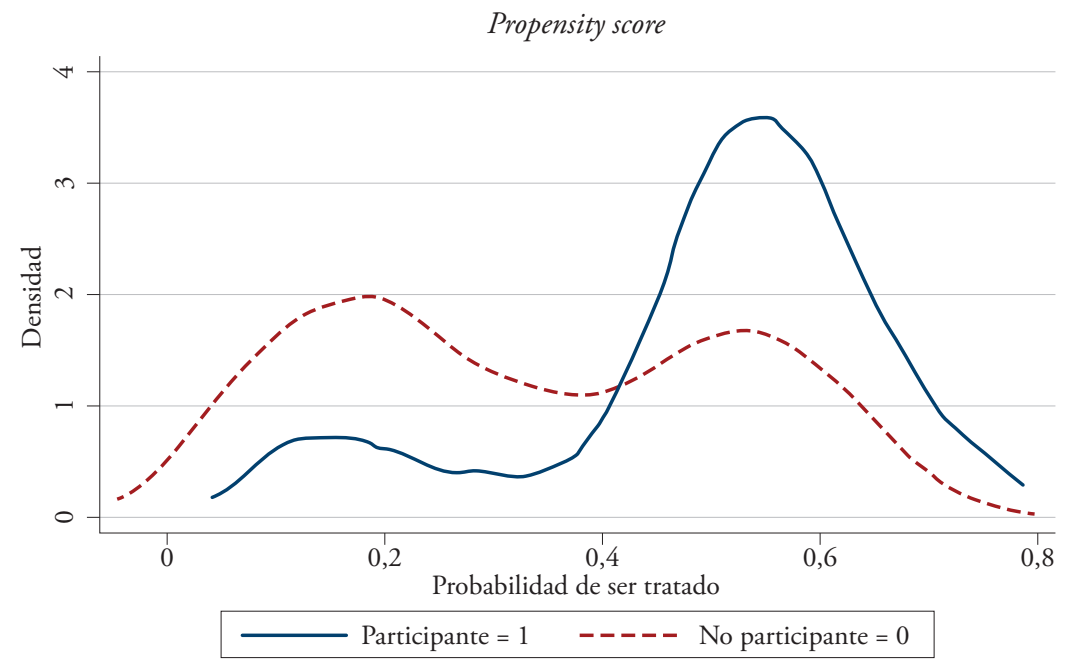

Luego, se procedió a determinar la región de soporte común, eliminando aquellas probabilidades del grupo tratado que resultaron inferiores a la mínima

\footnotetext{
${ }^{13}$ Se realizó la prueba de significancia al modelo probit a fin de asegurar que las variables que se toman en consideración en la implementación del PSC no son homogéneas entre grupo de control y grupo tratado.
} 
probabilidad del grupo tratado. También se eliminaron aquellas probabilidades del grupo tratado que resultaron superiores al máximo de la probabilidad del grupo tratado ${ }^{14}$. Como se puede observar en la figura 4, la región del soporte común es bastante amplia, por lo que solo se eliminan 10 probabilidades de las 241 .

\section{Figura 4}

Densidad de la región de soporte común para la probabilidad de participación en el PSC del grupo de control y del grupo tratado.

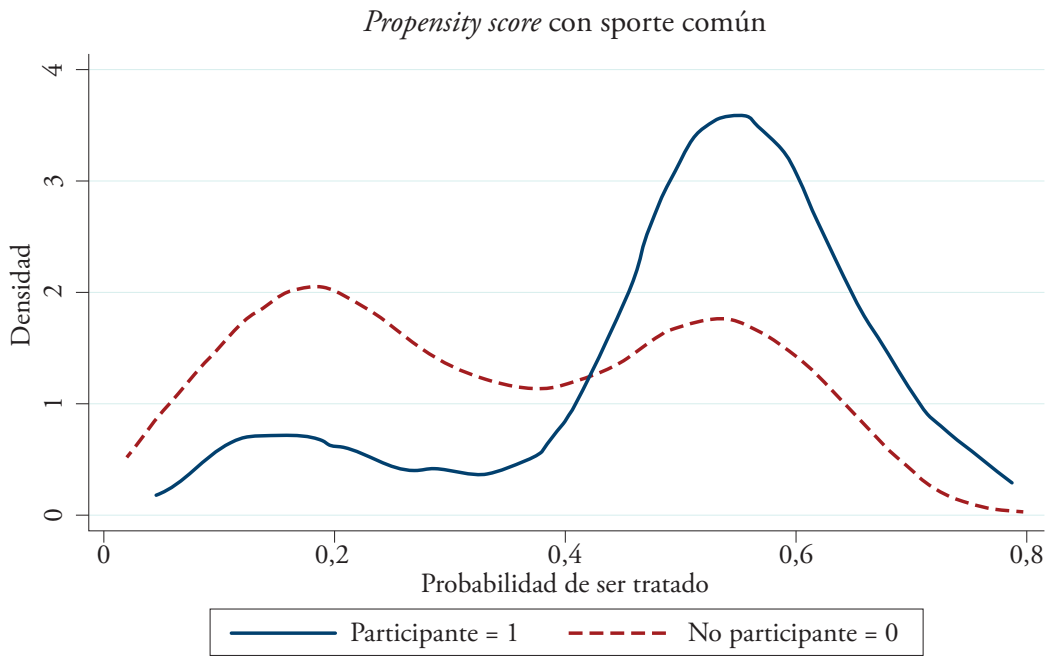

\section{Evaluación de la robustez de los resultados}

Obtenidas así las probabilidades de participación en el PSC, se procedió a estimar el impacto del PSC sobre cada una de las variables de interés mediante diferentes técnicas de estimación, a fin de evaluar la robustez de los resultados.

\section{Modelo ingresos}

Como muestra la tabla 10, el PSC tiene un efecto positivo y significativo en el ingreso total de las familias. Este efecto es, en general, superior al 50\% ${ }^{15}$ en todas las técnicas realizadas, y no pierde significación en ninguna de ellas.

\footnotetext{
${ }^{14}$ Estos dos procedimientos se realizaron con el objetivo de eliminar las observaciones en las que no existía un área común para ambos grupos.

${ }^{15}$ Como la variable ingreso fue transformada a $\mathrm{Ln}$, la interpretación es en porcentaje.
} 


\section{Modelo educación superior}

La tabla 11 muestra una contribución educativa positiva, aunque los resultados pierden significación estadística con dos técnicas: 5 vecinos más cercanos y distancia máxima ( 0,001 y 0,005). La contribución del PSC al porcentaje de hijos que continúan sus estudios superiores es, en promedio, de 0,05 puntos porcentuales.

\section{Modelo calidad de alimentos}

Los resultados en la tabla 12 indican que el PSC tiene un impacto positivo y significativo sobre el gasto en carnes rojas y vegetales. Considerando todas las estimaciones según las distintas técnicas, en general, el efecto del PSC es superior al $70 \%{ }^{16}$.

Tabla 10

Resultados de la estimación del impacto del PSC para la variable ingresos

\begin{tabular}{lccc}
\hline & Método de emparejamiento & $\begin{array}{c}\text { Mínimo-máximo } \\
\text { (preestablecido) }\end{array}$ & Recorte (trimming) \\
\hline & Vecino más cercano & \\
\hline & 1 vecino más cercano & $0,684491019^{*}$ & $0,713815528^{*}$ \\
& 5 vecinos más cercanos & $0,667151509^{*}$ & $0,68330947^{*}$ \\
& 10 vecinos más cercanos & $0,659762672^{*}$ & $0,625182689^{*}$ \\
\hline 0,001 & Distancia máxima & $0,557250994^{*}$ & $0,566096808^{*}$ \\
0,005 & $0,718676182^{*}$ & $0,7349108^{*}$ \\
\hline Local lineal & & $0,608947444^{*}$ & $0,647271795^{*}$ \\
\hline Kernel & $0,631851801^{*}$ & $0,659813376^{*}$ \\
\hline
\end{tabular}

Notas. Los errores estándar se encuentran entre paréntesis. La hipótesis nula de dicha prueba es que las medias de cada variable son iguales. ${ }^{* * *} \mathrm{p}<0,01,{ }^{* *} \mathrm{p}<0,05 \mathrm{y}^{*} \mathrm{p}<0,1$.

\footnotetext{
${ }^{16}$ Como la variable gasto de alimentos en carnes rojas y vegetales fue transformada a Ln, se interpreta en porcentaje.
} 


\section{Tabla 11}

Resultados de la estimación del impacto del PSC para la variable porcentaje de hijos con estudios superiores

\begin{tabular}{lccc}
\hline & Método de emparejamiento & $\begin{array}{c}\text { Mínimo-máximo } \\
\text { (preestablecido) }\end{array}$ & Recorte (trimming) \\
\hline & \multicolumn{1}{c}{ Vecinos más cercanos } \\
\hline & 1 vecino más cercano & $0,078627452^{* *}$ & $0,06409523^{*}$ \\
& 5 vecinos más cercanos & 0,054509805 & 0,03794709 \\
& 10 vecinos más cercanos & $0,062194212^{* *}$ & $0,047333334^{*}$ \\
\hline 0,001 & Distancia máxima & \\
\hline 0,005 & 0,017218351 & 0,009315476 \\
\hline Local lineal & 0,046125364 & 0,055863697 \\
\hline Kernel & $0,064606568 *$ & $0,064606568 *$ \\
\hline
\end{tabular}

Notas. Los errores estándar se encuentran entre paréntesis. La hipótesis nula de dicha prueba es que las medias de cada variable son iguales. ${ }^{* * *} \mathrm{p}<0,01,{ }^{* *} \mathrm{p}<0,05 \mathrm{y}{ }^{*} \mathrm{p}<0,1$.

Tabla 12

Resultados de estimación del impacto del PSC para la variable gasto de carnes rojas y verduras

\begin{tabular}{lcc}
\hline \multicolumn{1}{c}{ Método de emparejamiento } & $\begin{array}{c}\text { Mínimo-máximo } \\
\text { (preestablecido) }\end{array}$ & Recorte (trimming) \\
\hline 1 vecino más cercano & Vecino más cercano & \\
5 vecinos más cercanos & $0,881871416^{*}$ & $0,870995324^{* *}$ \\
10 vecinos más cercanos & $1,09975972^{* *}$ & $1,0942862^{*}$ \\
\hline & $1,02340484^{* *}$ & $0,994901993^{* *}$ \\
\hline 0,001 & Distancia máxima & \\
0,005 & $0,826234187^{*}$ & $0,782389256^{* *}$ \\
\hline Local lineal & $0,968735648^{*}$ & $0,983804949^{* *}$ \\
\hline Kernel & $1,08892515^{* *}$ & 1,08439815 \\
\hline
\end{tabular}

Notas. Los errores estándar se encuentran entre paréntesis. La hipótesis nula de dicha prueba es que las medias de cada variable son iguales. ${ }^{* * *} \mathrm{p}<0,01,{ }^{* *} \mathrm{p}<0,05$ y ${ }^{*} \mathrm{p}<0,1$. 


\section{Análisis de consistencia: matriz multirrasgo-multimétodo}

Por último, se utilizó un enfoque similar a la matriz multirrasgo-multimétodo (Schmitt \& Stults, 1986), a fin de evaluar la consistencia de la contribución del PSC al bienestar de la población analizada, a través de distintos niveles de la intervención según volúmenes recolectados de agua de lluvia por micropresa $\left(\mathrm{en}^{3}\right)$. Si son consistentes los efectos de la intervención en cada variable observada de bienestar (ingresos, educación y alimentación), se valida el constructo de intervención y resultado (figura 1) y se puede concluir que, efectivamente, existe un efecto de la intervención en el bienestar.

Lo anterior permite comprobar si las hipótesis sobre la contribución del PSC al bienestar del grupo tratado (en comparación con el grupo de control) se verifican para distintos niveles de intervención (recolección de agua de lluvia por micropresa). Con tal fin, se procedió a estimar el impacto del PSC mediante tres niveles de intervención $\left(\mathrm{en}^{3}\right)$ sobre las tres variables de bienestar analizadas: ingresos, educación superior y gasto en carnes rojas y verduras. Los tres niveles son $80 \mathrm{~m}^{3}, 75 \mathrm{~m}^{3}$ y $45 \mathrm{~m}^{3}$, presentes en las micropresas para las comunidades de Umuto, Machaca y Cuyuni, respectivamente.

En la tabla 13, se presenta la matriz con los resultados de la mencionada estimación, realizada mediante tres métodos alternativos: 1 vecino más cercano (M1), distancia máxima 0,01 (M2) y lineal (M3).

Los resultados en la matriz validan el constructo y verifican las hipótesis investigadas para cada nivel de volumen de $\mathrm{m}^{3}$. En concreto, se observa que la contribución del PSC al bienestar, en sus tres variables analizadas, es mayor con la micropresa de más volumen de captación de agua de lluvia, $80 \mathrm{~m}^{3}$, que con las micropresas de $75 \mathrm{~m}^{3}$ y $45 \mathrm{~m}^{3}$. Y esta última, al ser la más pequeña, registra una contribución inferior a las otras dos.

Es preciso indicar que, si bien no todos los resultados son significativos al 5\%, debe recordarse que para esta evaluación se determinó el número de muestreo considerando un 10\% de error muestral (sustentado en que la realización de encuestas aconseja un error muestral adicional). Sin embargo, cuando se realiza la validación del constructo en los diferentes niveles de metros cúbicos de cada micropresa, se debe ajustar el nivel de significancia a un 5\%/3. Tomando ello en consideración, la mayoría de los resultados son estadísticamente significativos. 


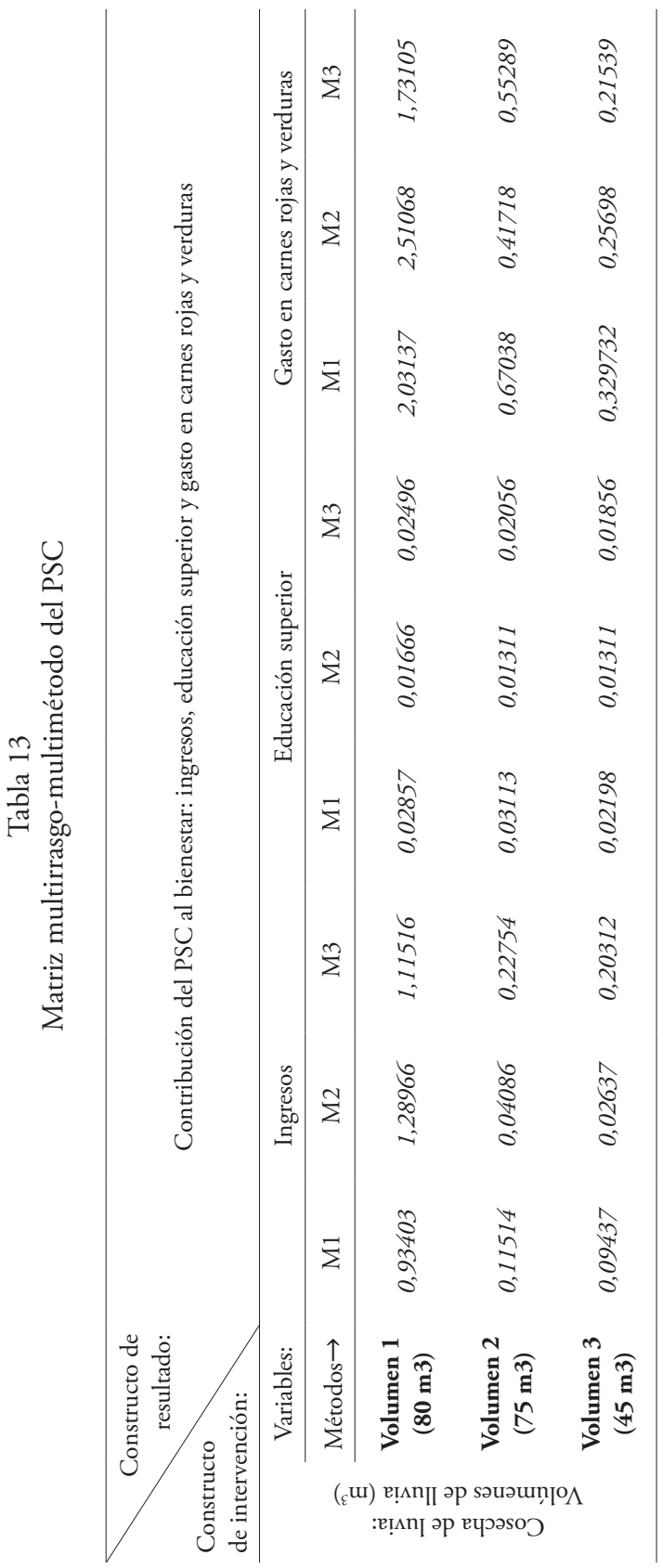




\subsection{Limitaciones de la investigación}

Las principales limitaciones encontradas para esta investigación son: (i) carencia de una línea de base que permitiese utilizar el método de diferencias en diferencias y (ii) carencia de información sobre variables importantes ex ante que permitiesen comparaciones con características previas al proceso de tratamiento. Si bien fue posible rescatar algunas variables importantes, tales como edad del jefe del hogar y número de hijos con educación primaria, no se contó con información para incluir en la ecuación de participación otras variables relevantes, como, por ejemplo, la ocupación del jefe del hogar antes de la construcción de la micropresa.

\section{Conclusiones y recomendaciones}

Esta investigación responde al objetivo -compartido por sus autoras y la asociación Ccaijo- de estimar la contribución del PSC al bienestar de los hogares beneficiarios, medida en términos de ingresos monetarios, educación y nutrición, durante el año 2016, en el distrito de Ccatcca, Cusco.

Los resultados, obtenidos mediante la metodología del emparejamiento probabilístico, guardan relación con la literatura especializada, comprueban las hipótesis planteadas y son estimaciones robustas bajo diferentes métodos de emparejamiento.

En cuanto a los ingresos monetarios, se encontró que las micropresas promovidas por el PSC tienen un efecto positivo importante, atribuible a una mayor disponibilidad de agua por mejor gestión del agua de lluvia. Los productos que destacan al respecto son el pasto y el cuy, cuya producción y venta resultan muy incrementadas. Respecto al efecto del PSC en el nivel educativo de los hijos del hogar, se ha verificado que este es positivo. Los resultados de la encuesta aplicada sugieren que los hijos que continúan estudios superiores son hombres, en su mayoría. Sin embargo, la participación de hijas mujeres que cursan estudios superiores en las familias participantes del PSC es mayor que en las familias del grupo control. Además, casi la mitad de los hijos que siguen estudios superiores lo hacen en una institución privada. Con relación al gasto en alimentos de carnes rojas y verduras, se concluye que el PSC contribuye de manera positiva. Al respecto, destaca la mayor frecuencia del consumo de esos alimentos en familias participantes.

Cabe precisar que, si bien los resultados muestran que la contribución del PSC ha sido positiva en las variables estudiadas, no debe olvidarse que estos resultados también reflejan un efecto aprendizaje, adquirido durante 
el tiempo transcurrido desde la implementación del PSC hasta el año 2016, cuando se realizó esta investigación.

Los resultados obtenidos tienen implicancias para el diseño y promoción de este tipo de intervenciones, a fin de apoyar el desarrollo rural y mitigar el riesgo de sequías. Un buen ejemplo es la iniciativa del Minagri de crear el «Programa Nacional de Siembra y Cosecha de Lluvias».

Por último, se sugiere que posteriores investigaciones puedan analizar la contribución del PSC contando con información histórica. Para ello, se propone que las instituciones pertinentes hagan un seguimiento de las variables aquí analizadas, así como de otras que estimen necesarias para una evaluación más completa de la contribución.

\section{Referencias}

Akin, J., Guilkey, D., Popkin, B., Flieger, W., Briscoe, J., Black, R. E., \& Adair, L. S. (1992). A child health production function estimated from longitudinal data. Cebu Study Team. Journal of Development Economics, 38(2), 323-351.

Alcock, P. (1997). Understanding poverty. 2. ${ }^{\mathrm{a}}$ ed. Londres: McMillan Press Ltd.

Alderman, H., Hentschel, J., \& Sabates, R. (2003). With the help of one's neighbors: externalities in the production of nutrition in Peru. Social Sciences and Medicine, 56(10), 2019-2031.

Alkire, S., \& Foster, J. (2008). Counting and multidimensional poverty measurement OPHI. Working Paper Series 38. Oxford Poverty \& Human Development Initiative.

Amos, C., Rahman, A., \& Gathenya, J. (2016). Economic analysis and feasibility of rainwater harvesting systems in urban and peri-urban environments: A review of the global situation with a special focus on Australia and Kenya. Water, 8(4), 149.

Asociación Jesús Obrero. (2012). Programa Marco de Proyectos 2012-2016. Cusco: Ccaijo. Baker, J. L. (2000). Evaluación del impacto de los proyectos de desarrollo en la pobreza: manual para profesionales. Washington D. C.: Banco Mundial.

Bassi, M., \& Galiani, S. (2010). Labor market insertion of young adults in Chile. Documento inédito. Washington D. C.: Inter-American Development Bank.

Becker, G. (1975). Human capital: A theoretical and empirical analysis, with special reference to education. National Bureau of Economic Research. Nueva York: Columbia University Press.

Becker, G. (1991). A treatise on the family. Cambridge, MA: Harvard University Press.

Bernal, R., \& Peña, X. (2011). Guía práctica para la evaluación de impacto. Bogotá: Universidad de los Andes.

Bertranou, E. (2001). Determinantes del avance en los niveles de educación en la Argentina (tesis de maestría). Universidad Nacional de la Plata - Facultad de Ciencias Económicas, Buenos Aires, Argentina. 
Beyer, H. (1998). ¿Desempleo juvenil o un problema de deserción escolar? Estudios Públicos, (71), 89-139.

Blakely, T., Hales, S., Kieft, C., Wilson, N., \& Woodward, A. (2005). The global distribution of risk factors by poverty level. Bulletin of the World Health Organization, 83(2), 118-126.

Carrasco, J., \& Felmer, S. (2011). Cosecha de aguas lluvia, alternativa que permite resolver la escasez de agua en las áreas de secano de la zona central de Chile. Tierra Adentro, 94, 59-62.

Castro, J. F., Yamada, G., \& Arias, O. (2016). Higher education decisions in Peru: On the role of financial constraints, skills, and family background. Higher Education, 72(4), 457-486.

Castro, J., Baca, J., \& Ocampo, J. (2012). (Re)counting the poor in Peru: A multidimensional approach. Latin American Journal of Economics, $49(1), 37-65$.

De Janvry, A., \& Sadoulet, E. (2000). Rural poverty in Latin America: Determinants and exit paths. Food Policy, 25(4), 389-409.

Escobal, J. (2001). The determinants of nonfarm income diversification in rural Peru. World Development, 29(3), 497-508.

Escobal, J., Saavedra, J., \& Torero, M. (1998). Los activos de los pobres en el Perú. Washington D. C.: Inter-American Development Bank Research Network.

FAO (Organización de las Naciones Unidas para la Alimentación y la Agricultura). (2000). Manual de captación y aprovechamiento del agua. Santiago: Oficina Regional para América Latina y el Caribe

Figueroa, A. (1989). La economía campesina de la sierra del Perú. Lima: Fondo Editorial de la Pontificia Universidad Católica del Perú.

Ford, R., \& Aldana, U. (2001). Efectos de la titulación y registro de tierras sobre el grado de capitalización en la agricultura peruana: una estimación basada en el III Censo Agropecuario. Lima: Grupo de Análisis para el Desarrollo (Grade).

Fuentes, C., Medina, C., Rojas, M., \& Silva, N. (2015). Políticas públicas de desarrollo productivo para pequeños productores rurales. Lima: Universidad ESAN.

Furness, B. W., Simon, P. A., Wold, C. M., \& Asarian-Anderson, J. (2004). Prevalence and predictors of food insecurity among low-income households in Los Angeles County. Public Health Nutrition, 7(6), 791-794.

Gertler, P. J., Martínez, S., Premand, P., Rawlings, L. B., \& Vermeersch, C. M. (2011). Impact evaluation in practice. Washington D. C.: The World Bank.

Gertler, P., \& Glewwe, P. (1990). The willingness to pay for education in developing countries: Evidence from rural Peru. Journal of Public Economics, 42(3), 251-275.

Goetter, J., \& Pichit, H. J. (2011). Adaptación al cambio climático: cosecha de agua de lluvia con "atajados» en Bolivia. La Paz: Agencia de Cooperación Alemana - GTZ.

Gonzales de Olarte, E. (1996). El ajuste estructural y los campesinos. Colección Mínima, 33. Lima: Instituto de Estudios Peruanos.

Heckman, J. J., \& Rubinstein, Y. (2001). The importance of noncognitive skills: Lessons from the GED testing program. American Economic Review, 91(2), 145-149. 
Heckman, J., Stixrud, J., \& Urzúa, S. (2006). The effects of cognitive and noncognitive abilities on labor market outcomes and social behavior. Journal of Labor Economics, 24(3), 411-482.

Heinrich, C., Maffioli, A., \& Vásquez, G. (2010). A primer for applying propensity score matching impact - Evaluation guidelines. Washington D. C.: BID - Oficina de Planificación Estratégica y Efectividad en el Desarrollo.

INEI (Instituto Nacional de Estadística e Informática). (2016). Evolución de la pobreza monetaria: 2009-2015: informe técnico. Lima: Instituto Nacional de Estadística e Informática.

INIA (Instituto Nacional de Innovación Agraria). (s. f.). Lima: Instituto Nacional de Innovación Agraria. Recuperado de http://www.inia.gob.pe/

Kanbur, R. (1987). Measurement and alleviation of poverty with an application to the effects of macroeconomic adjustment. IMF Staff Papers, 34(1). Washington D. C.: Fondo Monetario Internacional.

Kelez, D., \& Mancera, D. (2008). ¿Un mundo feliz?: bienestar subjetivo en Lima Metropolitana. Apuntes, 64. Lima: Universidad del Pacífico.

Kolenicov, S. (1998). The methods of quality of life assessment. Moscú: New Economic School.

Mateu, P., \& Vilca, J. (2004). Modelo de medición de impacto sobre el bienestar objetivo y subjetivo. Un análisis de caso del Proyecto de Reducción y Alivio a la Pobreza (PRA), Lima: Universidad del Pacífico - Centro de Investigación, Usaid.

Minagri (Ministerio de Agricultura y Riego). (2012). Plan de Gestión de Riesgos y Adaptación al Cambio Climático en el Sector Agrario: periodo 2012-2021. Plangracc-A. Lima: Ministerio de Agricultura y Riego.

Minagri (Ministerio de Agricultura y Riego). (2015). Rumbo a un Programa Nacional de Siembra y Cosecha de Agua: aportes y reflexiones. Lima: Ministerio de Agricultura y Riego. Recuperado de http://www.paccperu.org.pe/publicaciones/pdf/258.pdf

Minagri (Ministerio de Agricultura y Riego). (26 de julio de 2006). Minagri presenta publicación sobre siembra y cosecha de agua. Lima: Ministerio de Agricultura y Riego - Oficina de Comunicaciones e Imagen Institucional.

Monge, Á. (2003). Pobreza objetiva y subjetiva: opciones de medición complementarias. En E. Vásquez (Ed.), Inversión social: indicadores, bases de datos e iniciativas. Lima: Universidad del Pacífico.

Monge, Á., \& Ravina, R. (2003). Más allá del componente objetivo en la medición de pobreza: análisis geográfico de las dimensiones objetiva y subjetiva de la pobreza en el Perú. En E. Vásquez (Ed.), Buscando el bienestar de los pobres. ¿Cuán lejos estamos? Lima: Universidad del Pacífico - Centro de Investigación.

Naude, A. Y., \& Meléndez-Martínez, Á. (2007). Efectos de los activos familiares en la selección de actividades y en el ingreso de los hogares rurales de México. Investigación Económica, 66(260), 49-80.

Nielsen, H. S. (1998). Child labor and school attendance: Two joint decisions. CLS Working Paper, 98-015. Dinamarca: University of Aarhus. 
Ravina, R., \& Vallejos, J. (1999). Determinantes de la asistencia escolar en las zonas rurales del Perú. Lima: Universidad del Pacífico.

Reyes, H., Pérez-Cuevas, R., Sandoval, A., Castillo, R., Santos, J. I., Doubova, S. V., \& Gutiérrez, G. (2004). The family as a determinant of stunting in children living in conditions of extreme poverty: A case-control study. BMC Public Health, 4(1), 57.

Ricse, D., \& Villegas, P. (2013). Rol de los desastres naturales en la vulnerabilidad de los hogares. Un método aplicado a la zona rural del Perú. Lima: Universidad del Pacífico.

Rodríguez, J., \& Abler, D. (1998). Asistencia a la escuela y participación de los menores en la fuerza de trabajo en el Perú, 1985-1994. Economía, 21(41), 215-253.

Rosenbaum, P., \& Rubin, D. (1983). The central role of the propensity score in observational studies for causal effects, Biometrika, 70, 41-50.

Sámano, G., Mautner, M., Chávez, A., \& Jiménez, B. (2016). Assessing marginalized communities in Mexico for implementation of rainwater catchment systems. Water, 8(4), 140.

Sánchez, A., \& Jaramillo, M. (2012). Impacto del programa Juntos sobre la nutrición temprana. Estudios Económicos, 23(1), 53-66.

Schmitt, N., \& Stults, D. M. (1986). Methodology review: Analysis of multitrait-multimethod matrices. Applied Ppsychological Measurement, 10(1), 1-22.

Schultz, T. (1961). Investment in human capital. American Economic Review, 51(1), 1-17.

Sen, A. (2001). El nivel de vida. Madrid: Universidad Complutense.

Serván, S., \& Tantaleán, E. (2009). ¿Explican las características de los docentes las diferencias en el rendimiento promedio de los alumnos de colegios públicos y privados? Lima: Universidad del Pacífico.

Shadish, W. R., Cook, T. D., \& Campbell, D. T. (2002). Experimental and quasi-experimental designs for generalized causal inference. Boston: Houghton, Mifflin and Company.

Smith, J., \& Todd, P. (2005). Does matching overcome LaLonde's critique of nonexperimental estimators? Journal of Econometrics, 125(1-2), 305-353.

Urrunaga, R., Hiraoka, T., \& Risso, A. (2014). Fundamentos de Economía Pública. Lima: Universidad del Pacífico - Centro de Investigación.

Vásquez, E. (2001). Los desafíos de la lucha contra la pobreza extrema en el Perú. Lima: Universidad del Pacífico - Centro de Investigación, CIID.

Vásquez, E. (2012). El Perú de los pobres no visibles para el Estado: la inclusión social pendiente a julio del 2012. Lima: Universidad del Pacífico - Centro de Investigación. 


\title{
El efecto de las fluctuaciones climáticas en el ingreso de los hogares agropecuarios: un análisis para el caso peruano ${ }^{1}$
}

\author{
Sandra Huaitalla Rosado \\ Karen Huaringa Aliaga
}

\section{Introducción}

A lo largo de la historia de la humanidad, la acción antrópica sobre el medio ambiente ha generado alteraciones climáticas peligrosas para la sociedad (PNUMA, 2015). Esta acción ha tenido un serio impacto sobre la Tierra y los ecosistemas, con África, Asia y América Latina encabezando la lista (García, 2011). Coincidentemente, la mayoría de los países de esos dos primeros continentes son clasificados por el Banco Mundial como economías de bajos ingresos (véase el anexo 1). La razón básica es que su principal actividad económica está en un sector agropecuario poco tecnificado y poco resiliente a fluctuaciones climáticas.

En el Perú, el 5,3\% del PIB proviene del sector agropecuario (véase el anexo 2). Y este sector es la principal actividad económica del 58,4\% de la población peruana en condición de pobreza (véase el anexo 3), abarca el $30,1 \%$ del territorio peruano y es fuente de subsistencia para 1,4 millones de personas (Minam, 2016). Esto coloca al Perú entre los países más vulnerables al calentamiento global y la variabilidad climática ${ }^{2}$, como se observó en el primer trimestre de 2017, cuando el fenómeno de El Niño Costero

\footnotetext{
${ }^{1}$ Este ensayo es una versión resumida y editada del Trabajo de Investigación Económica que, con el mismo título, fue concluido en noviembre de 2017. Las autoras agradecen profundamente a su asesor, el profesor Manuel Barrón, por el gran apoyo brindado en conocimientos y dedicación de tiempo.

${ }^{2}$ Debido a que involucra grandes pérdidas de volúmenes de agua, tierras cultivables y hogares enteros frente a desastres naturales (Minagri, 2013).
} 
afectó drásticamente al sector agrícola y causó impactos negativos al PIB total $(-0,70 \%)$ (véase el anexo 4).

El cambio en temperaturas es la principal causa de perjuicios a las poblaciones agrícolas. Estas fluctuaciones generan el fenómeno de «evapotranspiración ${ }^{3}$, el cual perjudica el desarrollo de los productos agrícolas con pérdidas de hasta un 50\% (Cline, 2007). Y la actividad pecuaria también se ve perjudicada, debido a que las variaciones climáticas afectan el crecimiento y desarrollo de las crías y pasturas (fuente de alimento del ganado).

Adicionalmente, la vulnerabilidad de los agricultores aumenta por el imperfecto mercado de capitales, reflejado tanto en la demanda como en la oferta. Por el lado de la demanda, el 24,1\% del total de la superficie agrícola no puede ser explotada (INEI, 2013) debido a la falta de capital. Por el lado de la oferta, no existen las facilidades necesarias para otorgar créditos (véase el anexo 5) debido al riesgo que enfrentan los bancos ante préstamos sin garantía a los campesinos, lo que incrementa las tasas de interés ofrecidas, desincentiva la inversión y crea un círculo vicioso de mayor vulnerabilidad en los agricultores frente a shocks climatológicos.

Por ello, el objetivo de esta investigación es cuantificar los efectos de las fluctuaciones climáticas -en temperatura y pluviosidad- sobre la actividad agropecuaria en el Perú. Con tal fin, nos planteamos la siguiente hipótesis: «El efecto de las fluctuaciones climáticas sobre los ingresos de los hogares agropecuarios es significativo, heterogéneo y negativo; y es un factor determinante en la condición de pobreza de dichas familias».

El trabajo de investigación consta de cuatro secciones. En la primera, se revisa la literatura especializada y se explica la interacción entre fluctuaciones climáticas y desarrollo de hogares agropecuarios, con la finalidad de identificar variables similares y/o grupos de países comparables que sustenten nuestra hipótesis. La segunda sección presenta el marco analítico, donde se amplían los conocimientos teóricos sobre recursos naturales, fluctuaciones climáticas, ingresos, pobreza y comportamiento de las familias agropecuarias. Asimismo, se introducen los cuatro modelos desarrollados para probar nuestra hipótesis.

La tercera sección expone los resultados de los modelos planteados y su interpretación. Y la cuarta sección contiene las conclusiones y recomendaciones basadas en la investigación. Su aspiración es contribuir a la formulación de

\footnotetext{
${ }^{3}$ Evapotranspiración es un cambio en la evaporación del suelo producto de mayores o menores niveles de humedad relativa en las hojas.
} 
políticas eficientes y rigurosas que mitiguen el riesgo e implementen acciones para mejorar el nivel de respuesta de las poblaciones más vulnerables.

\section{Revisión de literatura especializada}

Existe una amplia discusión sobre los impactos del cambio climático global (CCG) en el bienestar social y económico de las poblaciones. Para comprender mejor dicho fenómeno, es necesario distinguir dos conceptos que pueden prestarse a confusión: calentamiento global y fluctuaciones climáticas. El calentamiento global es una causa del CCG y se define como las interacciones complejas entre procesos naturales y sociales provocados por el incremento de emisiones de gases de efecto invernadero (GEI), que aumentan a largo plazo la temperatura promedio (Torres, 2010). Por su parte, las fluctuaciones climáticas se definen como un impacto de corto plazo proveniente de variabilidades u oscilaciones del clima provocadas por el calentamiento global (Martínez \& Fernández, 2004).

Horowitz (2009) encontró una relación entre la temperatura y los ingresos per cápita al comparar a países miembro de la OCDE con países no miembros. Su regresión de sección cruzada incluyó variables al cubo para identificar la relación encorvada (humped) entre temperatura e ingresos. Esta relación muestra que los territorios más fríos (países de la OCDE) tienen un mayor nivel de desarrollo y, a medida que la temperatura se eleva, se vuelven más ricos. Este incremento ocurre hasta un nivel óptimo de temperatura $\left(18^{\circ} \mathrm{C}\right)$, a partir del cual la relación se vuelve negativa y decreciente. En este rango se ubican los países fuera de la OCDE.

Dicho estudio brinda información sobre los efectos diferenciados de la temperatura en los ingresos, pero no profundiza sobre esos efectos en países en desarrollo. Sánchez, Gay \& Estrada (2011) investigaron el impacto del cambio climático - reflejado en cambios de precipitaciones pluviales, cambios de temperatura y mayor número de días con tormenta- en México, país que comparte características culturales similares a las del Perú. Ese estudio evalúa el impacto del CCG sobre los diferentes distritos de México insertando un programa de resiliencia.

Para el caso peruano, Andersen, Suxo \& Verner (2009) modelan el efecto de la pluviosidad y la temperatura sobre el logaritmo de los ingresos y el nivel esperado de vida. El resultado es similar a los modelos antes mencionados. El calentamiento global beneficia a provincias con clima frío (Puno y Huancavelica), debido a que tienden al nivel óptimo del clima, pero afecta los indicadores de bienestar en provincias más cálidas (Loreto, Lima o Amazonas). Esto mostraría resultados heterogéneos entre las provincias del país. 
Sin embargo, esas investigaciones tienen una perspectiva de largo plazo, ya que miden los efectos del cambio climático en los indicadores de bienestar poblacional. Por ello, destaca otro estudio enfocado en hallar el efecto de las fluctuaciones climáticas (de corto plazo) sobre la actividad agropecuaria. Deschenes \& Greenstone (2007) proponen un modelo hedónico que mide el impacto económico anual de la variación en temperatura y precipitaciones pluviales sobre la actividad agrícola de los Estados Unidos. Su principal hallazgo es un prolongado efecto significativo en pérdidas económicas debido a la acumulación de costos de producción por la inversión necesaria en tecnología para proteger cultivos. De esta forma, las variaciones climáticas también tendrían un papel decisivo en los ingresos a corto plazo. Se debe considerar, entonces, el nivel de adaptabilidad de un agricultor y/o ganadero para poder asimilar estos costos futuros.

En Perú, Torres (2010) investigó el impacto de las variabilidades climáticas sobre la actividad agrícola en Piura. Eligió esta región porque se encuentra cerca de la línea ecuatorial, con una agricultura de exportación que anualmente experimenta aumentos de temperatura por encima del límite requerido para el desarrollo de plantas y animales. Formuló un modelo con una función de producción cuadrática, pues la temperatura y las precipitaciones pluviales afectan el rendimiento agrícola de manera positiva a niveles bajos, y de manera negativa al pasar el umbral óptimo. Y demostró que las variables climáticas explican el comportamiento de los cultivos en más del $50 \%$, y que, ante cambios en dichas variables, el ingreso de los agricultores es afectado.

De manera similar, Guzmán (2015) mide el impacto de las fluctuaciones climáticas sobre algunos indicadores de la agricultura en la región Cusco. Planteó un modelo ricardiano, en el que el resultado de las estimaciones brindó interpretaciones mixtas (positivas y negativas). Sin embargo, encontró efectos negativos en la agricultura de secano (actividad característica de dicha región), que relaciona con la falta de acceso a otras actividades económicas que puedan mejorar los ingresos, además de con la escasa infraestructura de riego.

Esos hallazgos abren nuevas vetas de investigación para cuantificar el impacto de fluctuaciones climáticas como elevaciones y reducciones en temperaturas y precipitaciones pluviales. Pero todavía se sabe poco sobre los efectos de esas fluctuaciones climáticas en el ingreso de personas dedicadas a la agricultura como actividad de subsistencia o fuente de consumo y ventas a la vez; así como en los ingresos de personas dedicadas a la ganadería. 


\section{Marco analítico y metodología}

\section{a. Marco analítico}

Las primeras ideas modernas sobre la interacción entre desarrollo humano y medio ambiente surgieron en pleno apogeo de la Revolución Industrial (siglos XVIII y XIX, en Europa y Norteamérica), en cuyo contexto la productividad agrícola creció con rapidez, impulsada por nuevas tecnologías (Perman, Ma, McGilvray, \& Common, 2003; Fankhauser \& Stern, 2016). Según Leen (2014), la explicación de Adam Smith acerca de que la eficiencia del mecanismo del mercado supone un buen manejo de los recursos naturales y la economía ambiental, implica que la tierra es un recurso fundamental de ingresos y riqueza.

Pero la tierra es un recurso fijo o limitado que, si es trabajado con retornos decrecientes, conduce a un estado estacionario en el que los estándares de vida (nivel de ingresos, empleo, educación, infraestructura, etc.) se van reduciendo (Harvey, 1974). Con este enfoque, dicho autor rescata lo postulado por Thomas Malthus respecto a que el acelerado crecimiento de la población presiona al límite los medios para proveerla de alimentos, y señala que los países más afectados son los que tienen una alta proporción de su población dedicada a actividades agropecuarias, y que, si estas actividades están orientadas a la subsistencia de las familias a cargo, la vulnerabilidad de estas es mayor ante shocks de desastres naturales, como huaicos o heladas que afectan la actividad productiva (Harvey, 1974).

Con otro enfoque, Perman et al. (2003) se basan en lo analizado por David Ricardo, sobre que la escasez de recursos naturales no se debe a tierras limitadas sino a la falta de una gestión óptima de la tierra que se encuentra disponible en parcelas diferentes de acuerdo con su calidad, de modo que la ventaja económica de un lugar surge de atributos resultantes de factores climáticos, demográficos, tecnológicos, entre otros. Así, el ingreso de las familias agropecuarias dependería del buen uso de sus ventajas relativas: la eficiencia y resiliencia al cultivar alimentos propios de la zona y el clima (Popescu, 2007). Ejemplos de mala gestión son la práctica desmesurada de desmontes para forraje, el pastoreo excesivo, el uso incorrecto de fertilizantes, entre otros (FAO, 2013; Lorente, 2010).

El nexo medio ambiente - desarrollo se ha vuelto mucho más complejo con el transcurrir de los años, debido a la magnitud y fuerza de los riesgos generados por la mala gestión y el cuidado del medio ambiente. Así, el estudio de la contaminación ambiental ha cobrado mayor relevancia. Tyndall des- 
cubrió, en 1859, que el dióxido de carbono altera el balance de la radiación de calor dentro de la atmósfera (Weart, 2008). Arrhenius (1896) argumentó que cambios en la concentración de ese y otros gases intensificaban el efecto invernadero y, con ello, los cambios anormales del clima. Adicionalmente, la extracción intensiva de combustibles fósiles, la degradación de los suelos, la mala gestión en la actividad agropecuaria, entre otros, han incrementado la emisión de GEI, lo que ha provocado mayores variaciones climáticas. (Fankhauser \& Stern, 2016).

Las fluctuaciones climáticas afectan relativamente más a las familias dedicadas a actividades de subsistencia (Hertel, 2010; BID, 2014). Ello se agrava cuando habitan en zonas rurales, donde la actividad predominante es la agricultura y la ganadería, por lo que están expuestas a un fácil deterioro de su infraestructura de riego, uso excesivo de fertilizantes, riesgo por fenómenos climáticos adversos, entre otros (The World Bank, 2010).

El Perú es uno de los países latinoamericanos de ingresos medios donde la actividad agrícola es primordial como fuente de autoconsumo y comercio para muchas familias de zonas rurales (FAO, 2006), y, dentro de la realidad altitudinal de la sierra, se complementa con la actividad pecuaria. Así, los pequeños productores agropecuarios y los minifundistas conforman la mayoría de la población dedicada a la agricultura y ganadería ${ }^{4}$ (Alcántara, 2007), ambas altamente vulnerables al cambio climático. A ello se suma la alta sensibilidad de sus ingresos frente a la volatilidad en los precios de los alimentos (Hertel, 2010).

Entre las metodologías estructurales para estimar el impacto de variaciones climáticas sobre la actividad agropecuaria (véase el anexo 6), utilizaremos aquí la evaluación de impacto económico. Esta brinda cierta holgura para considerar la capacidad de respuesta y adaptación por parte de los agricultores. El modelo más utilizado en las metodologías de evaluación es el ricardiano (De Salvo, Begalli, \& Signorello, 2013), el cual nos sirve de base teórica para esta investigación.

A partir de la teoría ricardiana de la ventaja comparativa, cabe plantear un modelo en el que las familias adecuan sus niveles de producción a las condiciones climáticas ajustando la cantidad óptima de insumos agropecuarios para el cultivo y la cría y explotación eficiente de animales, a fin de maximizar

\footnotetext{
${ }^{4}$ La agricultura y ganadería de minifundio se da en parcelas de menos de 3 hectáreas, trabajadas en economía de subsistencia por familias en condición de pobreza y dependientes de programas de apoyo. La pequeńa agricultura y ganadería comprende parcelas de 3 a 10 hectáreas que producen para autoconsumo y venta.
} 
los beneficios de su actividad. Si bien un modelo así tiene ciertas limitaciones por ser de equilibrio parcial, resulta útil porque plantea una relación no lineal (dada la heterogeneidad de microclimas) y permite remover efectos temporales.

Con base en los especialistas reseñados, desarrollamos el siguiente modelo econométrico para explicar y cuantificar empíricamente el efecto de las fluctuaciones climáticas en los ingresos y condición de pobreza de las familias agropecuarias del Perú.

\section{b. Metodología}

En esta investigación, se evalúan datos de corte transversal y de corto plazo. Se estiman cuatro modelos de manera reducida a nivel distrital sobre la base de Andersen et al. (2009) y con datos anuales. El valor agregado de nuestra investigación está en su enfoque. Por un lado, se analizan los ingresos principales de las familias según la actividad económica que realizan. Las características de tales familias explican que sus decisiones y medidas de respuesta ante variaciones exógenas (climáticas) sean de corto plazo. Ello nos lleva a a utilizar en el estudio una proxy de sus ingresos basados en la producción.

Se analizan tanto la producción total de las familias agropecuarias, como dos variables que la componen: la producción destinada solo al autoconsumo y la producción destinada solo a las ventas. Con ello, se observa si las fluctuaciones climáticas tienen efectos diferenciados por componentes de producción, lo que brindará luces sobre la función de maximización de utilidad (estática o intertemporal) de las familias y su capacidad de resiliencia.

Por otro lado, se analiza el bienestar de esos hogares considerando su capacidad o incapacidad para satisfacer las necesidades de la canasta básica alimenticia y no alimenticia del país (INEI, 2016). La moda estadística de las familias agropecuarias no pobres se concentra cerca del límite del cambio hacia su clasificación como pobres. Por ello, la probabilidad de moverse entre ambas condiciones no es baja. Se observa si las fluctuaciones climáticas impactan en tales condiciones y si existe una relación entre la variación de la producción para el autoconsumo y la condición de pobreza.

Se utilizan dos bases de datos primarias. La primera contiene información mensual de la temperatura y pluviosidad en el Perú. Esta base se desarrolló con la metodología conocida como vectores por coordenadas y se obtuvo del Tyndall Centre for Climate Change Research. La segunda es la Encuesta Nacional de Hogares (Enaho) del Instituto Nacional de Estadística e Informática (INEI) del Perú. Estas bases permiten trabajar con datos de 2004 a 2014. 
La literatura analizada presenta correlaciones entre variables con signos diversos, lo que motiva el uso de modelos cuadráticos (no lineales). Para no forzar la relación, es preferible plantear un modelo de probabilidad lineal (Wooldridge, 2010). De esta manera, la función incluye intervalos de temperatura y precipitaciones pluviales. El modelo permite la inclusión de efectos fijos de distrito y de tiempo, para controlar la heterogeneidad del país debida a su amplia gama de climas y tendencias temporales. Cabe resaltar que las variables exógenas de temperatura (seccionadas en dicotómicas) no están correlacionadas entre sí, lo que brinda un efecto limpio e independiente entre ellas (véase el anexo 7).

A continuación, se presentan tres de los cuatro modelos propuestos centrados en el «ingreso agropecuario»:

(1) ValorTotal $_{i, d, t, a}=\beta_{0}+\beta_{1}$ temp $_{j, t}+\beta_{2} \operatorname{prec}_{l, t}+\mu_{d}+\delta_{m t}+\varepsilon_{i}$

(2) ValConsumo $_{i, d, t, a}=\beta_{0}+\beta_{1}$ temp $_{j, t}+\beta_{2}$ prec $_{l, t}+\mu_{d}+\delta_{m t}+\varepsilon_{i}$

(3) ValVentas $i, d, t, a=\beta_{0}+\beta_{1}$ temp $_{j, t}+\beta_{2}$ prec $_{l, t}+\mu_{d}+\delta_{m t}+\varepsilon_{i}$

$$
\begin{aligned}
& \text { temp }_{j, t}=\mathrm{f}\left(\operatorname{temp}_{1, t,}, \ldots, \text { temp }_{7, t}, \operatorname{temp}_{9, t}, \ldots, \text { temp }_{11, t}, \text { temp }_{12, t}\right) \\
& \operatorname{prec}_{l, t}=f\left(\text { prec }_{2, t}, \operatorname{prec}_{3, t,}, \text { prec }_{4, t}, \operatorname{prec}_{5, t,} \text { prec }_{6, t}, \operatorname{prec}_{7}, \operatorname{prec}_{8, t}\right)
\end{aligned}
$$

Donde el subíndice $i$ denota el hogar correspondiente; $d$, el distrito donde vive el encuestado; $t$, el año de la encuesta; y $a$, la actividad económica estudiada (agricultura o ganadería). Las variables independientes de clima están agrupadas en los vectores temp y prec. Estos contienen $j$ y $l$ dicotómicas del promedio de las temperaturas y las precipitaciones pluviales de los últimos 12 meses en el distrito, por intervalos. Esas dicotómicas son: 1 si se encuentra dentro del intervalo de temperaturas promedio elegido y 0 de otro modo (véase el anexo 8). Los efectos fijos $(\mu+\delta)$ se encuentran a nivel distrital y de tiempo, donde el subíndice $m t$ contiene la suma del mes y ańo del momento de la encuesta. Ambos efectos fijos limpian el sesgo que puede existir por omisión de variables (de características socioeconómicas), debido a que se compara los ingresos y el nivel de pobreza entre familias nacidas en el mismo distrito. Además, controlan los shocks económicos ocurridos en el mes y año en que la familia fue encuestada.

La contribución de utilizar el promedio de los últimos 12 meses de las variables climáticas es eliminar el efecto del comportamiento estacional. Por 
último, se incluye el error de medición del modelo $\varepsilon_{i}$. Las variables dependientes de «Valor Total», «Valor Autoconsumo» y «Valor Ventas» corresponden a la producción total del hogar, producción destinada netamente al autoconsumo y producción destinada netamente a las ventas, respectivamente. Las tres se encuentran bajo la denominación monetaria del sol nominal. Sin embargo, las condiciones de vida pueden variar según región o distrito. Por ello, se aplica una deflactación y estandarización con el uso de la línea de pobreza distrital del país. Para la estandarización, se tomó como insumo principal la línea base máxima del departamento de Lima.

El cuarto modelo, centrado en la condición de pobreza de las familias, es el siguiente:

$$
\begin{gathered}
\text { (4) } \text { Pobreza }_{i, d, t, a}=\beta_{0}+\beta_{1} \text { temp }_{j, t}+\beta_{2} \text { prec }_{l, t}+\mu_{d}+\delta_{m t}+\varepsilon_{i} \\
\text { temp }_{j, t}=\mathrm{f}\left(\text { temp }_{1, t, \cdots,}, \text { temp }_{7, t}, \text { temp }_{9, t}, \ldots, \text { temp }_{11, t}, \text { temp }_{12, t}\right) \\
\text { prec }_{l, t}=f\left(\text { prec }_{2, t}, \text { prec }_{3, t,}, \text { prec }_{4, t}, \text { prec }_{5, t,}, \text { prec }_{6, t}, \text { prec }_{7}, \text { prec }_{8, t}\right)
\end{gathered}
$$

En dicho modelo, la variable dependiente es la única que se altera. La variable «Pobreza» es una dicotómica que toma el valor de 1 cuando la familia es pobre (pobreza extrema o no extrema) y 0 de otro modo.

Para poder sustentar verídicamente los efectos de las fluctuaciones climáticas sin incurrir en relaciones espurias, se plantean los mismos modelos, pero con interacciones. Estas interacciones incluyen a las dicotómicas de temperaturas promedio ya mencionadas y a cuatro niveles de shocks. Estos niveles (medidos en desviaciones estándares de más o menos 2SD, 1,5SD, $1 \mathrm{SD}$ o $0,5 \mathrm{SD}$ ) refuerzan el sustento de vulnerabilidad de dichas familias ante variaciones intensas de clima.

Los modelos con interacciones se plantean de la siguiente manera:

$$
\begin{aligned}
& \text { (5) } \operatorname{ValorX}_{i, d, t, a}=\beta_{0}+\beta_{1} \text { temp }_{j, t}+\beta_{2} \text { prec }_{l, t}+\beta_{3} \text { SHOCK }_{t}+ \\
& \beta_{4} * \operatorname{temp}_{j, t} * \mathrm{SHOCK}_{t}+\mu_{d}+\delta_{m t}+\varepsilon_{i} \\
& \text { temp } p_{j, t}=\mathrm{f}\left(\operatorname{temp}_{1, t, \ldots, \text { temp }_{7, t} \text { temp }} p_{9, t}, \ldots, \text { temp } p_{11, t}, \text { temp } p_{12, t}\right) \\
& \operatorname{prec}_{l, t}=f\left(\operatorname{prec}_{2, t}, \operatorname{prec}_{3, t}, \operatorname{prec}_{4, t}, \operatorname{prec}_{5, t}, \operatorname{prec}_{6, t}, \operatorname{prec}_{7}, \operatorname{prec}_{8, t}\right)
\end{aligned}
$$


Donde $X$ denota las tres variables dependientes de ingresos utilizadas en el modelo original ${ }^{5}$ y $S H O C K$ evalúa cada nivel de desviación con cada una de las variables dependientes ${ }^{6}$. La variable dicotómica $S H O C K$ toma el valor de 1 si el promedio de la temperatura de los últimos 12 meses está por encima / por debajo de la desviación estándar especificada respecto al promedio total del período en estudio ${ }^{7}$, y 0 de otro modo. Los subíndices $i, d, t, a, j, l, m$ y $t$ mantienen la misma nomenclatura.

Cabe resaltar que se planteó un modelo adicional con «lags» (véase el anexo 10) para asegurar la consistencia de los resultados hallados. Como se verá luego, las especificaciones con ambos modelos complementarios mantienen coherencia con los resultados de los modelos originales, lo que refuerza su robustez.

\section{Análisis de resultados}

\section{a. Modelo original: oscilaciones}

Todos los modelos planteados fueron estimados para las variables de producción tanto deflactadas como sin deflactar. La significancia y las interpretaciones de las variables, en ambos casos, se mantuvieron al 95\% de confianza (véanse la tabla 1 y el anexo 9). La misma coherencia se mantuvo al plantear diferentes especificaciones del modelo (incluyendo o excluyendo ciertas variables exógenas). Esto prueba la robustez de los modelos elegidos, así como la consistencia entre la literatura revisada y nuestro marco analítico.

Como se muestra en la tabla 1 , el efecto de las fluctuaciones del promedio de temperaturas en los últimos 12 meses sobre la producción total de las familias agropecuarias es significativo y negativo en zonas geográficas donde la temperatura promedio oscila entre 5 y $17,5^{\circ} \mathrm{C}^{8}$. Estos resultados se interpretan con respecto al rango de temperatura base o de "confort» $(17,5$ a 20 $\left.{ }^{\circ} \mathrm{C}\right)^{9}$; es decir: «condicionado al rango de temperaturas promedio de 2,5 a 5 ${ }^{\circ} \mathrm{C}$ en los últimos 12 meses, una variación en $1{ }^{\circ} \mathrm{C}$ reduciría la producción total en $\mathrm{S} / 1.807$ por comparación con el rango base. En el mismo rango de temperaturas, una variación en $1{ }^{\circ} \mathrm{C}$ reduciría en $\mathrm{S} / 188,70$ los ingresos

\footnotetext{
${ }^{5} X$ denota las especificaciones del modelo (1), (2) y (3), con variables dependientes de producción total, valor del autoconsumo y valor de las ventas, respectivamente.

${ }^{6}$ Son 8 (variables dependientes de ingresos) $\times 4$ (niveles de shock) = 32 especificaciones.

${ }^{7}$ Desviaciones estándar de más o menos 2SD, 1,5SD, 1SD o 0,5SD.

${ }^{8}$ Para el sector agrícola, el efecto es negativo y significativo en el intervalo de temperaturas promedio entre 5 y $15^{\circ} \mathrm{C}$.

9 Según Barron, Heft-Neal \& Pérez (2017), la temperatura óptima para el desarrollo humano, o thermal comfort, es de $18^{\circ} \mathrm{C}$ y la precipitación óptima (medida en milímetros) es de $50 \mathrm{ml}$.
} 
de producción destinados al autoconsumo, con respecto al rango base». Al interpretar el modelo por rangos, se encontró que los resultados significativos se encuentran en zonas con climas más fríos.

Tabla 1

Resultados de estimación del modelo de probabilidad lineal de temperatura y precipitaciones sobre las variables de producción (variables de producción deflactadas, en soles reales)

\begin{tabular}{|c|c|c|c|c|c|c|}
\hline \multirow[b]{2}{*}{ Variables } & \multicolumn{3}{|c|}{ Agricultura } & \multicolumn{3}{|c|}{ Ganadería } \\
\hline & $\begin{array}{l}\text { Producción } \\
\text { total }\end{array}$ & $\begin{array}{c}\text { Producción } \\
\text { para } \\
\text { autoconsumo }\end{array}$ & $\begin{array}{l}\text { Producción } \\
\text { para venta }\end{array}$ & $\begin{array}{l}\text { Producción } \\
\text { total }\end{array}$ & $\begin{array}{c}\text { Producción } \\
\text { para } \\
\text { autoconsumo }\end{array}$ & $\begin{array}{l}\text { Producción } \\
\text { para venta }\end{array}$ \\
\hline \multicolumn{7}{|c|}{ Temperatura $\left({ }^{\circ} \mathrm{C}\right)$} \\
\hline \multirow[t]{2}{*}{$0-2,5$} & -1.961 & $-188,2$ & -1.409 & 63,92 & 136,7 & $-1,979$ \\
\hline & -4.937 & $-315,6$ & -4.072 & -1.321 & $-145,3$ & $-1,611$ \\
\hline \multirow[t]{2}{*}{$2,5-5$} & $-1.807^{*}$ & $-188,7^{* * *}$ & -1.334 & $-444,4$ & $-79,63^{* *}$ & $-266,6$ \\
\hline & -1.013 & $-64,77$ & $-835,7$ & $-355,7$ & $-39,12$ & $-433,7$ \\
\hline \multirow[t]{2}{*}{$5-7,5$} & $-1.773^{* *}$ & $-215,4^{* * *}$ & $-1.346^{* *}$ & $-383,7$ & $-30,74$ & $-293,6$ \\
\hline & $-693,4$ & $-44,32$ & $-571,8$ & $-259,6$ & $-28,55$ & $-316,5$ \\
\hline \multirow[t]{2}{*}{$7,5-10$} & $-2.129^{* * *}$ & $-142,9^{* * *}$ & $-1.410^{* * *}$ & $-459,8^{*}$ & $-33,95$ & $-366,1$ \\
\hline & $-628,8$ & $-40,19$ & $-518,5$ & $-235,9$ & $-25,95$ & $-287,7$ \\
\hline \multirow[t]{2}{*}{$10-12,5$} & $-1.921^{* * *}$ & $-111,3^{* *}$ & $-1.261^{* *}$ & $-538,1^{* *}$ & $-53,41^{* *}$ & $-399,8$ \\
\hline & $-678,5$ & $-43,37$ & $-559,5$ & $-243,9$ & $-26,82$ & $-297,3$ \\
\hline \multirow[t]{2}{*}{$12,5-15$} & $-1.509^{* *}$ & $-54,34$ & $-543,6$ & $-681,0^{* * *}$ & $-63,12^{* * *}$ & $-674,3^{* * *}$ \\
\hline & $-610,5$ & $-39,02$ & $-503,5$ & $-206,4$ & $-22,7$ & $-251,6$ \\
\hline \multirow[t]{2}{*}{$15-17,5$} & 835,8 & $-59,47^{*}$ & 583,2 & $-590,9^{* * *}$ & $-71,83^{* * *}$ & $-513,4^{* *}$ \\
\hline & $-508,5$ & $-32,5$ & $-419,3$ & $-165,4$ & $-18,2$ & $-201,7$ \\
\hline \multirow[t]{2}{*}{$20-22,5$} & 139 & $106,7^{* * *}$ & 436,6 & $-137,7$ & 6,153 & $-67,92$ \\
\hline & -557 & $-35,6$ & $-459,3$ & $-182,4$ & $-20,06$ & $-222,4$ \\
\hline \multirow[t]{2}{*}{$22,5-25$} & 426,5 & $281,7^{* * *}$ & $-11,8$ & $-175,8$ & 0,386 & -112 \\
\hline & $-624,4$ & $-39,91$ & $-514,9$ & $-206,9$ & $-22,75$ & $-252,3$ \\
\hline \multirow[t]{2}{*}{$25-27,5$} & -990 & $148,8^{* * *}$ & $-1.493^{* *}$ & 219,6 & 4,031 & 323,2 \\
\hline & -754 & $-48,19$ & $-621,8$ & -262 & $-28,81$ & $-319,4$ \\
\hline \multirow[t]{2}{*}{$27,5-30$} & -2.170 & 13,42 & -1.349 & 266,7 & 16,64 & 409 \\
\hline & -1.460 & $-93,31$ & -1.204 & $-471,4$ & $-51,84$ & $-574,7$ \\
\hline
\end{tabular}




\begin{tabular}{|c|c|c|c|c|c|c|}
\hline \multirow[b]{2}{*}{ Variables } & \multicolumn{3}{|c|}{ Agricultura } & \multicolumn{3}{|c|}{ Ganadería } \\
\hline & $\begin{array}{l}\text { Producción } \\
\text { total }\end{array}$ & $\begin{array}{c}\text { Producción } \\
\text { para } \\
\text { autoconsumo }\end{array}$ & $\begin{array}{l}\text { Producción } \\
\text { para venta }\end{array}$ & $\begin{array}{l}\text { Producción } \\
\text { total }\end{array}$ & $\begin{array}{c}\text { Producción } \\
\text { para } \\
\text { autoconsumo }\end{array}$ & $\begin{array}{c}\text { Producción } \\
\text { para venta }\end{array}$ \\
\hline \multicolumn{7}{|c|}{ Precipitaciones (ml) } \\
\hline \multirow[t]{2}{*}{$50-100$} & $-248,2$ & $-20,42^{*}$ & $-412,6^{* * *}$ & 82,6 & $19,42^{* * *}$ & 89,71 \\
\hline & $-178,2$ & $-11,39$ & $-146,9$ & $-53,97$ & $-5,935$ & $-65,8$ \\
\hline \multirow[t]{2}{*}{$100-150$} & $1.651^{* * *}$ & 12,21 & $1.375^{* * *}$ & $-11,32$ & $36,61^{* * *}$ & 42,07 \\
\hline & $-358,4$ & $-22,91$ & $-295,5$ & -113 & $-12,43$ & $-137,8$ \\
\hline \multirow[t]{2}{*}{$150-200$} & $1.947^{* * *}$ & $149,3^{* * *}$ & $1.318^{* * *}$ & $-137,2$ & $41,11^{* *}$ & $-239,6$ \\
\hline & $-523,4$ & $-33,46$ & $-431,7$ & $-169,6$ & $-18,66$ & $-206,8$ \\
\hline \multirow[t]{2}{*}{$200-250$} & 517,8 & $167,6^{* * *}$ & 821,8 & $-287,6$ & 14,7 & $-378,4$ \\
\hline & $-677,9$ & $-43,33$ & -559 & $-221,8$ & $-24,4$ & $-270,5$ \\
\hline \multirow[t]{2}{*}{$250-300$} & 582,3 & 56,03 & $1.995^{* * *}$ & 164,9 & $59,06^{*}$ & 63,59 \\
\hline & $-926,5$ & $-59,21$ & -764 & $-301,7$ & $-33,19$ & $-367,9$ \\
\hline \multirow[t]{2}{*}{$300-350$} & 959 & $-154,2^{* * *}$ & $2.140^{* * *}$ & 95,26 & $70,79^{* *}$ & 40,04 \\
\hline & $-925,6$ & $-59,16$ & $-763,3$ & $-296,3$ & $-32,59$ & $-361,3$ \\
\hline \multirow[t]{2}{*}{$350-400$} & $-40,88$ & $-364,0^{* * *}$ & 1.927 & $-16,87$ & 8,998 & 18,7 \\
\hline & -1.646 & $-105,2$ & -1.357 & $-532,3$ & $-58,55$ & -649 \\
\hline $\begin{array}{c}\text { N. } .^{\circ} \text { obs. } \\
(\mathrm{N})\end{array}$ & 97.134 & 97.134 & 97.134 & 92.586 & 92.586 & 92.586 \\
\hline $\mathrm{R}^{2}$ & 0,134 & 0,154 & 0,15 & 0,054 & 0,104 & 0,051 \\
\hline
\end{tabular}

Notas. Errores estándar robustos entre paréntesis.

${ }^{* * *} \mathrm{p}<0,01,{ }^{* *} \mathrm{p}<0,05,{ }^{*} \mathrm{p}<0,1$.

Para verificar la consistencia de las oscilaciones a lo largo del tiempo, se amplió el estudio considerando el efecto de las fluctuaciones climáticas correspondientes a los 12 meses anteriores al primer modelo planteado (mes -12 al -23). Mediante este modelo complementario de «lags», encontramos coeficientes con la misma tendencia que en el modelo original -es decir, el efecto negativo o positivo perdura- y que son significativos a los mismos niveles que el modelo original; e, incluso, para algunos casos, el nivel de confianza aumenta al 99\%. Ello permite reafirmar que los datos son consistentes.

Ese resultado, de que la tendencia se hace más evidente cuando se amplían los meses de estudio, indica que las oscilaciones climáticas son uno de los principales factores determinantes del ingreso de las respectivas familias agropecuarias. Además, la persistencia de estas oscilaciones estaría condi- 
cionando a una mayor vulnerabilidad de economías agrarias por efectos del cambio climático.

Por otro lado, la forma no lineal traza un efecto de las variaciones de la temperatura que es negativo hasta alcanzar la temperatura óptima para el desarrollo humano, para luego cambiar de signo, pero con reducida significancia. Se demuestra así la concavidad de las variables analizadas, sin necesidad de recurrir a variables cuadráticas.

\section{b. Shocks}

Mediante el modelo de «shocks», se observa la relación entre las variaciones climáticas antes explicadas y las desviaciones estándares -las oscilaciones más intensas (shocks), en particular- con respecto a las variaciones promedio de temperatura de los últimos 12 meses. El propósito es entender por qué algunas desviaciones afectan en mayor magnitud los ingresos y, en especial, la canasta básica de las familias agropecuarias; en cuyo caso, estas serían más vulnerables frente a shocks transitorios o permanentes que afecten a su distrito.

Este análisis debe hacerse según niveles de desviaciones (shocks), porque el resultado debido a un shock de temperatura alta o baja en dos desviaciones estándares (2SD) puede ser diferente al de un shock de temperatura alta o baja en media desviación estándar $(0,5 \mathrm{SD})$. Por ello, se incluyeron varios niveles de shocks (-2SD y +2SD, -1,5SD y +1,5SD, -1SD y +1SD, -0,5SD y +0,5SD).

Los resultados obtenidos mantienen su consistencia. Los más resaltantes y significativos son los shocks de temperatura baja o alta en 0,5SD o 1SD (véanse los anexos 11 y 12) sobre la variable dependiente de la producción destinada al autoconsumo, principalmente en la agricultura. El efecto en ganadería es intenso sobre las variables de producción total y de la producción destinada a la venta neta.

Específicamente, si hay un shock de 0,5SD sobre el rango de temperaturas promedio de 15 a $17,5^{\circ} \mathrm{C}$, los ingresos imputables al autoconsumo de las familias agricultoras disminuirían en $\mathrm{S} / 76,25$ por efectos propios del shock (efecto marginal), respecto al rango de temperatura de «confort». Y los ingresos por venta neta de las familias ganaderas disminuirían en $\mathrm{S} / 735,70$ por efectos propios del shock respecto al mismo rango.

Estos resultados complementarios se interpretan así: el mayor impacto de las oscilaciones sobre los ingresos de las familias ocurre en las zonas con climas más fríos (debajo de la temperatura base o óptima), debido a que los productos agrícolas básicos en la canasta peruana suelen desarrollarse en ese clima. Asmismo, disminuye la productividad de las tierras dedicadas a 
la pastura de animales, lo que afecta - en gran medida- el desarrollo de la actividad pecuaria (pues aumenta la probabilidad de muerte y enfermedad de muchos animales).

De ese modo, serían afectadas la producción total y productividad agropecuarias en climas fríos. Sorprendentemente, el efecto marginal de los shocks de $0,5 \mathrm{SD}$ o $1 \mathrm{SD}$ repercute en la mayoría de los rangos de temperaturas del país. Es decir, hay una complementaridad de efectos entre las oscilaciones y los shocks que profundiza la vulnerabilidad de las familias situadas en zonas frías.

En zonas más cálidas, la sensibilidad de la producción apropecuaria puede ser menor, ya que se encuentran cerca del rango óptimo para su crecimiento sostenido. Así, oscilaciones climáticas normales por encima o debajo del promedio no desencadenarían cambios drásticos en la composición de la atmósfera que perjudiquen el desarrollo de cultivos o animales. Pero sí podrían verse afectados si existieran shocks de temperatura.

Respecto a las lluvias, el impacto de las variaciones promedio en las precipitaciones de los últimos 12 meses sobre la agricultura es significativo y positivo en zonas con precipitaciones de 100 a $200 \mathrm{ml}$. Los resultados hallados indican que, en ciertas zonas frías, como la sierra sur del país (Puno, Apurímac, Cusco, etc.), conviene que haya lluvias en un rango alto o moderado, porque allí la agricultura es sensible a las lluvias por ser de secano (no de riego tecnificado). Así, la producción puede mejorar y aumentar siempre y cuando las precipitaciones estén en dicho rango. En cambio, en la agricultura de los grandes valles de la costa (arriba de la temperatura base u óptima), se cuenta con sistemas productivos tecnificados que otorgan un mayor grado de adaptabilidad.

A nivel de ganadería, se puede decir que las precipitaciones no afectarían la producción total, pues se debe mantener un nivel constante de hidratación para el ganado que no depende de las lluvias. Así, estas no provocarían cambios en la natalidad, mortalidad o venta para la ganancia familiar.

El efecto más resaltante es el de las variaciones climáticas sobre la producción agropecuaria destinada al autoconsumo. En agricultura, el efecto es significativo para casi todos los niveles de temperatura dentro del país. En el sector pecuario, es la única variable impactada significativamente por el nivel de precipitaciones. Para la producción total, la variación en la temperatura es significativa y negativa hasta llegar a la línea base $\left(17,5-20{ }^{\circ} \mathrm{C}\right)$, a partir de la cual el efecto se vuelve positivo. Esto reitera la hipótesis de heterogeneidad de climas y función no lineal. Sin embargo, se evidencia la sensibilidad del autoconsumo ante oscilaciones en la temperatura. Ello indica que los agricultores en el Perú, ante oscilaciones o shocks climatológicos, sacrifican parte 
de su canasta básica de subsistencia para no modificar (o modificar poco) su nivel de venta neta (principal fuente monetaria).

Esa explicación se engarza bien con la teoría de restricción de capital y falta de maximización de la utilidad intertemporal. La capacidad de resiliencia de las familias agropecuarias - de las agrícolas, en especial- es tan baja (por factores tales como falta de crédito, información, educación y formalidad) que no pueden suavizar su consumo para mantenerlo durante épocas tanto buenas como malas. A esto se suma la falta de capacidad de ahorro a lo largo del tiempo.

El efecto de las fluctuaciones climáticas (luego del umbral óptimo) se vuelve negativo sobre el autoconsumo, pero positivo para las ventas netas. Y es que las zonas por encima de la temperatura óptima están ubicadas mayormente en los valles costeros, donde una mejor adaptación para el uso eficiente de la tierra permite que el autoconsumo sea menos afectado (variación no significativa de la producción total).

\section{c. Pobreza}

El efecto de las variaciones de la temperatura sobre la probabilidad de ser pobre (con respecto a no serlo) es significativo y positivo. Esto se aplica para ambos sectores (agricultura y ganadería). Los resultados en la tabla 2 muestran que los agricultores no pobres se encuentran en el límite de la línea de pobreza, por lo que es razonable pensar que, ante variaciones exógenas, su condición cambie. Esto comprueba su vulnerabilidad ante shocks climatológicos, en línea con lo señalado por los especialistas. También encontramos una relación inversa entre los ingresos y la pobreza; relación que, por muy estudiada en la literatura especializada, da mayor confianza en nuestros resultados.

Tabla 2

Resultados de estimación del modelo de probabilidad lineal de temperatura y precipitaciones sobre las variables de pobreza

\begin{tabular}{ccc}
\hline \multirow{2}{*}{ Variables } & Agricultura & Ganadería \\
\cline { 2 - 3 } & Pobreza & Pobreza \\
\hline $0-2,5$ & & 0,105 \\
\hline \multirow{2}{*}{$2,5-5$} & 0,0683 & $-0,118$ \\
& $-0,131$ & $0,0560^{*}$ \\
& 0,0407 & $-0,0318$ \\
\hline
\end{tabular}




\begin{tabular}{|c|c|c|}
\hline \multirow{2}{*}{ Variables } & Agricultura & Ganadería \\
\hline & Pobreza & Pobreza \\
\hline \multirow[t]{2}{*}{$5-7,5$} & 0,0138 & 0,0334 \\
\hline & 0,0183 & $-0,0232$ \\
\hline \multirow[t]{2}{*}{$7,5-10$} & $0,0283^{*}$ & $0,0479^{* *}$ \\
\hline & $-0,0166$ & $-0,0211$ \\
\hline \multirow[t]{2}{*}{$10-12,5$} & $0,0415^{* *}$ & $0,0633^{* * *}$ \\
\hline & $-0,0179$ & $-0,0218$ \\
\hline \multirow[t]{2}{*}{$12,5-15$} & $0,0331^{* *}$ & $0,0328^{*}$ \\
\hline & $-0,0162$ & $-0,0184$ \\
\hline \multirow[t]{2}{*}{$15-17,5$} & $0,0242^{*}$ & $0,0334^{* *}$ \\
\hline & $-0,0135$ & $-0,0148$ \\
\hline \multirow[t]{2}{*}{$20-22,5$} & $-0,00603$ & 0,0153 \\
\hline & $-0,0147$ & $-0,0163$ \\
\hline \multirow[t]{2}{*}{$22,5-25$} & 0,0126 & $0,0358^{*}$ \\
\hline & $-0,0165$ & $-0,0185$ \\
\hline \multirow[t]{2}{*}{$25-27,5$} & 0,0183 & $0,0471^{* *}$ \\
\hline & $-0,0199$ & 0,0234 \\
\hline \multirow[t]{2}{*}{$27,5-30$} & 0,0230 & $0,0753^{*}$ \\
\hline & 0,0386 & $-0,0421$ \\
\hline \multicolumn{3}{|l|}{ Precipitaciones (ml) } \\
\hline \multirow[t]{2}{*}{$50-100$} & $-0,0158^{* * *}$ & $0,0141^{* * *}$ \\
\hline & $-0,00471$ & $-0,00482$ \\
\hline \multirow[t]{2}{*}{$100-150$} & $-0,0336^{* * *}$ & $0,0269^{* * *}$ \\
\hline & $-0,00948$ & $-0,0101$ \\
\hline \multirow[t]{2}{*}{$150-200$} & -00638 & 0,00119 \\
\hline & $-0,0138$ & $-0,0152$ \\
\hline \multirow[t]{2}{*}{$200-250$} & $-0,0149$ & 0,00935 \\
\hline & $-0,0179$ & 0,0198 \\
\hline \multirow[t]{2}{*}{$250-300$} & $-0,0411^{*}$ & $0,0462^{*}$ \\
\hline & $-0,0245$ & 0,0270 \\
\hline \multirow[t]{2}{*}{$300-350$} & $-0,03334$ & $-0,0285$ \\
\hline & $-0,0245$ & $-0,0265$ \\
\hline
\end{tabular}




\begin{tabular}{ccc}
\hline \multirow{2}{*}{ Variables } & Agricultura & Ganadería \\
\cline { 2 - 3 } & Pobreza & Pobreza \\
\hline $350-400$ & $-0,0362$ & 0,0257 \\
& $-0,0435$ & 0,0475 \\
\hline N. obs. $(\mathrm{N})$ & 97.067 & 92.530 \\
R-cuadrado & 0,257 & 0,246 \\
\hline
\end{tabular}

Notas. Errores estándar robustos entre paréntesis.

${ }^{* * *} \mathrm{p}<0,01,{ }^{* *} \mathrm{p}<0,05,{ }^{*} \mathrm{p}<0,1$.

\section{d. Limitaciones}

La primera limitación de nuestra investigación es la homogenización del thermal comfort para todas las familias del país. Se utiliza una única base óptima para comparar los productos en distintos climas y altitudes. El problema radica en el supuesto de que todos los tipos de cosecha y ganado necesitan de un clima estándar para su desarrollo. Puesto que la vulnerabilidad es heterogenéa entre distritos, sería importante hallar el thermal comfort por distrito-producto.

La segunda limitación yace en la discretización de las variables exógenas. $\mathrm{Al}$ convertir los promedios y desviaciones de clima en variables dicotómicas, se crea un problema por no considerar las observaciones situadas al límite del rango entre 1 o 0 . Esto podría causar un sesgo mínimo en los resultados hallados, si es que existiera una concentración de observaciones cerca a dicho límite.

\section{Conclusiones}

Esta investigación muestra que el efecto de las fluctuaciones de temperatura sobre la producción total es negativo solo en regiones frías y ubicadas debajo del umbral óptimo. Por encima de este umbral, el efecto cambia de signo y se diluye (no es significativo). El mismo resultado se observa tanto para las familias agrícolas como para las pecuarias. Por el contrario, el efecto de las precipitaciones pluviales es positivo en las regiones frías cuando las lluvias ocurren en un rango alto o moderado; pero solo es significativo para la producción agrícola.

Los shocks climáticos de 0,5SD y 1SD complementarían dichos efectos, principalmente sobre la variable de ingresos destinados al autoconsumo, en el caso de la agricultura, y sobre la variable de producción total o producción para la venta neta, en el caso de la ganadería.

Para la producción de autoconsumo, la relación es cóncava y significativa tanto para regiones frías como cálidas. Se encontró significancia en la mayoría de 
los intervalos de temperatura y regiones del país. Para la producción destinada a ventas netas, la relación es positiva o negativa de acuerdo con el umbral. Por ello, el efecto en conjunto con el autoconsumo se diluye para muchas regiones.

Esos resultados sustentan las siguientes conclusiones:

- El efecto de las fluctuaciones climáticas en los ingresos de los hogares agropecuarios es significativo y negativo; se comprueba así la hipótesis planteada. Pero esto solo se cumple en regiones frías, con temperaturas por debajo del thermal comfort y con precipitaciones por debajo del umbral óptimo de lluvias. Es decir, el efecto resulta heterogéneo dada la topografía del Perú.

- Las fluctuaciones climáticas son un factor determinante en la condición de pobreza de las familias agropecuarias, en especial en la sierra sur del país.

Y nuestros resultados también sugieren lo siguiente:

- La sensibilidad en la sierra sur del país, donde impera una agricultura de secano y subsistencia, es mayor ante fluctuaciones y shocks de temperatura. Esto se explica por la falta de infraestructura, las restricciones de crédito, entre otros.

- En esas zonas del país, el comportamiento de la mayoría de las familias agropecuarias, de los agricultores sobre todo, no considera la suavización de su consumo para aumentar la resiliencia ante diversos shocks exógenos.

- Falta una reducción en las asimetrías de información por el lado de la oferta de créditos (riesgo moral) y por el lado de la demanda (falta de conocimientos, educación, educación financiera, entre otros).

\section{Recomendaciones}

El análisis territorial aquí realizado, según tipos y niveles de temperatura y precipitaciones pluviales, es necesario para entender la repercusión de las variaciones y shocks climáticos en las heterogéneas regiones del país. También ayuda a entender su implicancia sobre la vulnerabilidad de las familias agricultoras y ganaderas pobres según su condición de pobreza. De ahí, las siguientes recomendaciones de política pública.

La primera es concientizar a las familias, con el apoyo del Estado, en temas de adaptabilidad y gestión de riesgo. Para ello, el Ministerio de Agricultura y Riego (Minagri) está implementando un plan de gestión de riego y adaptación al cambio climático en el sector agrario (Plangracc-A). Este es un instrumento 
de gestión que contiene objetivos, acciones estratégicas y lineamientos de políticas para reducir la vulnerabilidad de la población enfocada en esta actividad. También contribuye con una mejor planificación e inversión estatal en investigación e información sobre reducción de riegos (Minagri, 2012).

La segunda recomendación consiste en contar con mejores categorizaciones de los diferentes niveles de vulnerabilidad por cosechas y ganados, que permitan focalizar de manera eficiente las políticas. Para ello, se requiere de más y mejores investigaciones sobre el sector, las familias afectadas y los tipos de clima.

Por último, es necesario aprovechar las ventajas competitivas de regiones con gran diversidad de flora y fauna (BID, 2017, 2010). Por tanto, la tercera recomendación es reducir los cuellos de botella del mercado de capitales para impulsar la inversión y los seguros ante siniestros que limiten el desarrollo competitivo de tales regiones. El eje de política n. 5 del Estado (Plan de Política Nacional Agraria) se refiere al "Financiamiento y Seguro Agrario", con énfasis en los pequeños y medianos productores a nivel nacional (Gaceta Oficial, 2016). Por ello, proponemos que este eje sea más apoyado, así como la realización de estudios de economía del comportamiento, para entender mejor la respuesta de las familias agropecuarias ante siniestros no previstos.

\section{Referencias}

Ahmed, S. A., Diffenbaugh, N. S., \& Hertel, T. W. (2009). Climate volatility deepens poverty vulnerability in developing countries. Environmental Research Letters, 4(3), 034004 .

Alcántara, A. (2007). Semblanza de la ganadería en el Perú. MV Revista de Ciencias Veterinarias, 23(4).

Andersen, L., Suxo, A., \& Verner, D. (2009). Social impacts of climate change in Peru. $A$ district level analysis of the effects of recent and future climate change on human development and inequiality. Washington: The World Bank.

Aragon, F., Miranda, J. J., \& Oliva, P. (2017). Particulate matter and labor supply: The role of caregiving and non-linearities. Washington: The World Bank.

Arrhenius, S. (1896). On the influence of carbonic acid in the air upon the temperature of the ground. The London, Edinburgh, and Dublin Philosophical Magazine and Journal of Science, 41(251), 237-276.

Barron, M., Heft-Neal, S., \& Pérez, T. (Febrero de 2017). Weather fluctuations during gestation and human. Borrador preliminar.

BID (Banco Interamericano de Desarrollo). (27 de agosto de 2010). La agricultura peruana recibe un impulso importante con proyectos respaldados por el BID. Washinton D. C.: Banco Interamericano de Desarrollo. Recuperado de http://www.iadb.org/ es/noticias/articulos/2010-08-27/agricultura-de-peru-banco-interamericano-dedesarrollo,7688.html 
BID (Banco Interamericano de Desarrollo). (2014). La economía del cambio climático en el Perú. Lima: Banco Interamericano de Desarrollo \& Cepal.

BID (Banco Interamericano de Desarrollo). (2017). Banco Interamericano de Desarrollo - sector agropecuario. Recuperado de http://www.iadb.org/es/acerca-del-bid/ sector-agropecuario, 6211.html

Cárdenas, S., \& Renting, H. (2014). La agricultura de autoconsumo. Madrid: Fundación de Estudios Rurales. Unión de Pequeños Agricultores y Ganaderos.

Cline, W. (2007). Global warming and agricuture: Impact estimates by country. Informe. Washington D. C.: Center for Global Development, Peterson Institute for International Economics.

De Salvo, M., Begalli, D., \& Signorello, G. (2013). Measuring the effect of climate change on agriculture. A literature review of analytical models. Journal of Development and Agricultural Economics, 5(12), 499-509.

Deschenes, O., \& Greenstone, M. (2007). The economic impacts of climate change: Agricultural output and random fluctuation in weather. American Economic Review, 97(1), 354-385.

Escobal, J., Fort, R., \& Zegarra, E. (2015). Agricultura peruana: nuevas miradas desde el censo agropecuario. Lima: Grade (Grupo de Análisis para el Desarrollo), Arteta E. I. R. L.

Fankhauser, S., \& McDermott, T. (2013). Understanding the adaptation deficit: Why are poor countries more vulnerable to climate events than rich countries? Londres: Grantham Research Institute on Climate Change and the Environment.

Fankhauser, S., \& Stern, N. (2016). Climate change, development, poverty and economics. Center for Climate Change and Policy Working Paper, 253. Londres. Recuperado de http://www.lse.ac.uk/GranthamInstitute/wp-content/uploads/2016/10/WorkingPaper-253-Fankhauser-and-Stern.pdf

FAO (Organización de las Naciones Unidas para la Alimentación y la Agricultura). (2006). Perú: nota de análisis sectorial. Agricultura y desarrollo rural. Roma: Food and Agriculture Organization, Corporación Andina de Fomento. Recuperado de http://www.fao.org/3/a-ak169s.pdf

FAO (Organización de las Naciones Unidas para la Alimentación y la Agricultura). (2013). Enfrentando el cambio climático a través de la ganadería. Una evaluación global de las emisiones y oportunidades de mitigación. Roma: Food and Agriculture Organization. Recuperado de http://www.fao.org/3/a-i3437s.pdf

Gaceta Oficial. (2016). Decreto Supremo que Aprueba la Politica Nacional Agraria. Decreto Supremo N. ${ }^{\circ}$ 002-2016-Minagri. Lima: El Peruano.

Gaceta Oficial. (2017). Normas legales. Edición extraordinaria. Lima: El Peruano. Recuperado de https://www.mef.gob.pe/es/por-instrumento/decreto-de-urgencia/15691decreto-de-urgencia-n-004-2017/file

García, C. (2011). El cambio climático: Los aspectos científicos y económicos más relevantes. Nómadas, 32(4), 1-28. 
Guzmán, E. (2015). Impacto económico del cambio climático en la agricultura en la región Cusco, Perú: una aproximación a través del modelo ricardiano. Lima: CIES (Consorcio de Investigación Ecomómica y Social).

Harvey, D. (1974). Population, resources, and the ideology of science. Economic Geography, 50(3), 256-277.

Hertel, T. W. (2010). Climate change, agriculture and poverty. Agricultural \& Applied Economics Association, 32(3), 355-385.

Horowitz, J. (2009). The income-temperature relationship in a cross-section of countries and its implications for global warming. Environmental and Resource Economics, 44(4), 475-493.

INEI (Instituto Nacional de Estadística e Informática). (2011). Perú: determinantes de la pobreza, 2009. Lima: Instituto Nacional de Estadística e Informática. Recuperado de https://www.inei.gob.pe/media/MenuRecursivo/publicaciones_digitales/Est/ Lib0942/libro.pdf

INEI (Instituto Nacional de Estadística e Informática). (2013). Resultados definitivos: IV Censo Nacional Agropecuario 2012. Ministerio de Agricutura y Riego. Lima: Instituto Nacional de Estadística e Informática.

INEI (Instituto Nacional de Estadística e Informática). (2016). Evolución de la pobreza monetaria, 2009-2015. Lima: Instituto Nacional de Estadística e Informática.

Leen, A. R. (2014). Adam Smith's policy of international trade. Archives of Economic History, $X X V(2), 7-16$.

Lorente S., A. (2010). Ganadería y cambio climático: una influencia recíproca. Alicante: Repositorio Institucional de la Universidad de Alicante.

Loyola, R., \& Orihuela, C. (2011). El costo económico del cambio climático en la agricultura peruana: El caso de la región Piura y Lambayeque. Lima: Consorcio de Investigación Económica y Social, Universidad Nacional Agraria La Molina.

Macroconsult. (2017). Primeros impactos de El Niño costero, marzo. Lima: Grupo Macro. Recuperado de: https://sim.macroconsult.pe/articulo-de-la-semana-primerosimpactos-de-el-nino-costero/

Martínez, J., \& Fernández, A. (2004). Cambio climático: una visión desde México. (I. N. Naturales, Ed.). Coyoacán, México: Secretaría del Medio Ambiente y Recursos Naturales.

Minagri (Ministerio de Agricultura y Riego). (2012). Plan de Gestión de Riesgos y Adaptación al Cambio Climático en el Sector Agrario. Periodo 2012-2021 - Plangracc-A. Lima: Ministerio de Agricultura y Riego.

Minagri (Ministerio de Agricultura y Riego). (2013). Estrategia Nacional de Seguridad Alimentaria y Nutricional 2013-2021. Lima: Ministerio de Agricultura y Riego, Comisión Multisectorial de Seguridad Alimentaria y Nutricional.

Minam (Ministerio del Ambiente). (2015). Estrategia Nacional ante el Cambio Climático. Lima: Ministerio del Ambiente. 
Minam (Ministerio del Ambiente). (2016). El Perú y el cambio climático. Tercera Comunicación Nacional del Perú. Lima: Ministerio del Ambiente - Dirección General de Cambio Climático, Desertificación y Recursos Hídricos.

Peñaranda, C. (2017). Mecanismo de Obras por Impuestos: útil para atender coyuntura actual. Lima: Cámara de Comercio de Lima. Recuperado de http://www.camaralima.org. pe/repositorioaps/0/0/par/iedep-revista/revista-iedep-27-03-2017.pdf

Perman, R., Ma, Y., McGilvray, J., \& Common, M. (2003). Natural resources and environmental economics. Edimburgo: Pearson Education.

PNUMA (Programa de las Naciones Unidas para el Medio Ambiente). (Abril de 2015). ¿Qué es el cambio climático? Recuperado http://conexioncop22.com/el-cambio-climatico/

Popescu, D. (2007). David Ricardo, contemporary economist. Romanian Journal of Economic Forecasting, 4, 104-113.

Sánchez, A., Gay, C., \& Estrada, F. (2011). Cambio climático y pobreza en el distrito federal. Investigación Económica, LXX(278), 45-74.

The World Bank. (1993). Perú: Encuesta Nacional de Hogares sobre Medición de Niveles de Vida, (Enniv) 1991. Washington D. C. Recuperado de http://siteresources.worldbank. org/INTLSMS/Resources/3358986-1181743055198/3877319-1181853574791/ pe91_s.pdf

The World Bank. (2010). World development report 2010: Development and climate change. Washington D. C. Recuperado de https://openknowledge.worldbank.org/ handle/10986/4387

The World Bank. (2017). Data. World Bank country and lending groups. Recuperado de https://datahelpdesk.worldbank.org/knowledgebase/articles/906519

Torres, L. (2010). Análisis económico del cambio climático en la agricultura de la región Piura - Perú. Caso: Principales productos agroexportables. Lima: CIES (Consorcio de Investigación Económica y Social).

Weart, S. (2008). The carbon dioxide greenhouse effect. En The Discovery of Global Warming. Recuperado de https://history.aip.org/climate/co2.htm

Wooldridge, J. (2010). Introducción a la econometría. Un enfoque moderno. 4. ${ }^{\mathrm{a}}$ ed. México: Cengage Learning. 


\section{Anexos}

\section{Anexo 1}

Clasificación de países según nivel de ingresos

\begin{tabular}{ccc}
\hline Región & Nivel de ingresos & Dólares \\
\hline África Subsahariana & Economías de ingreso bajo & 1.025 o menos \\
Asia Oriental y el Pacífico & Economías de ingreso bajo & 1.025 o menos \\
$\begin{array}{c}\text { Europa Oriental y } \\
\text { Asia Central }\end{array}$ & $\begin{array}{c}\text { Economías de ingreso } \\
\text { mediano bajo }\end{array}$ & De 1.026 a 4.035 \\
América Latina y el Caribe & $\begin{array}{c}\text { Economías de ingreso } \\
\text { mediano alto }\end{array}$ & De 4.036 a 12.475 \\
Oriente Medio & Economías de ingreso alto & 12.476 o más \\
\hline
\end{tabular}

Fuente: The World Bank (2017).

Anexo 2

Porcentaje del PIB por sectores económicos (millones de soles)

$60,00 \%$

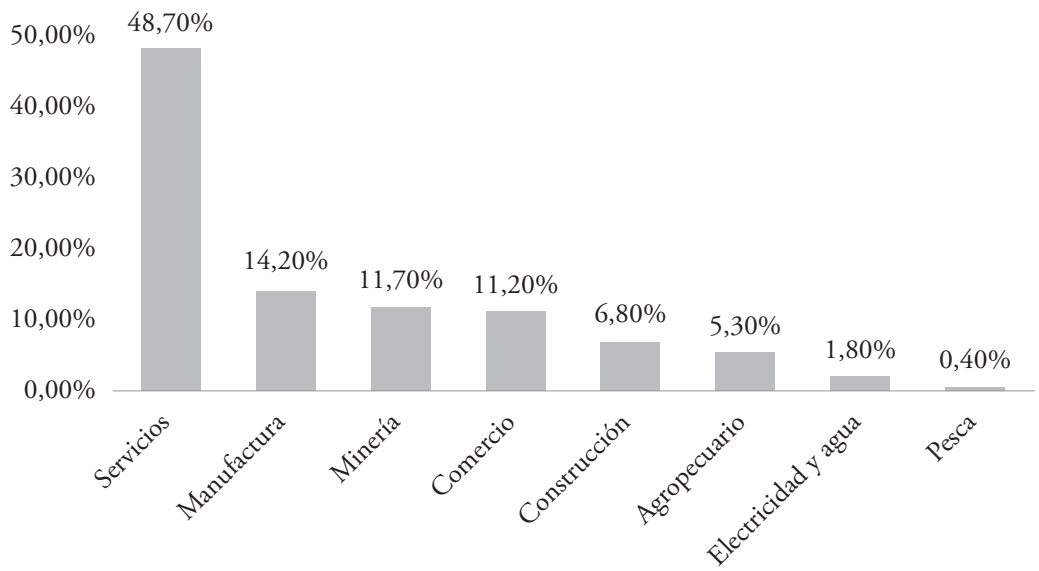

Fuente: Minam (2016). 


\section{Anexo 3}

Población ocupada por sectores, según condición de pobreza

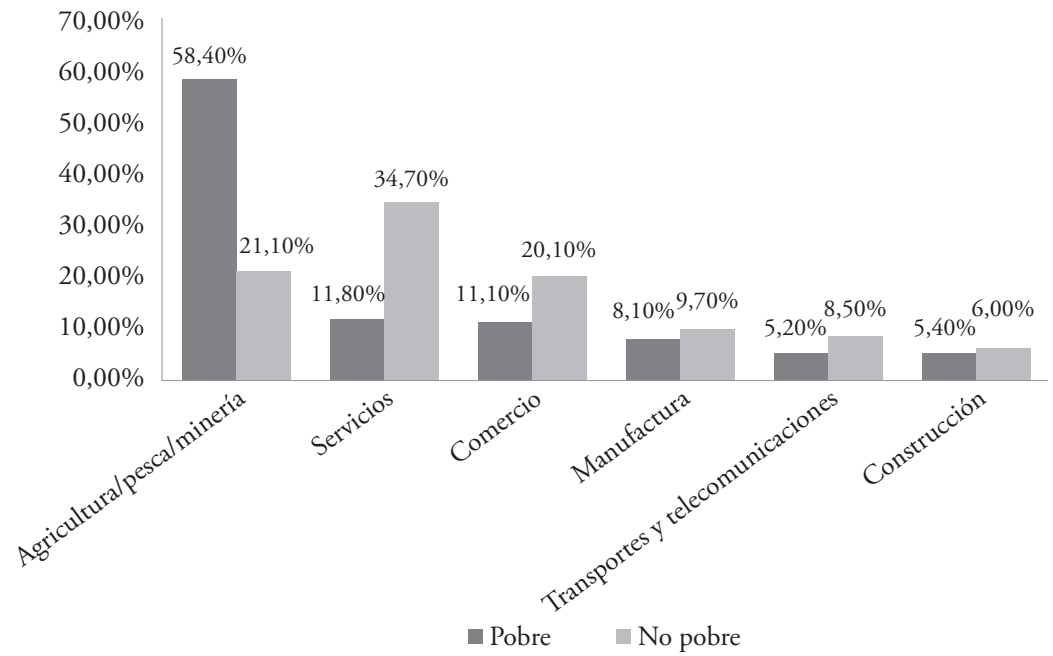

Fuente: INEI (2016).

\section{Anexo 4}

Impacto del fenómeno de El Niño Costero sobre el PIB nacional

\begin{tabular}{lcc}
\hline \multirow{2}{*}{ Sectores } & \multicolumn{2}{c}{ PIB total 2017 } \\
\cline { 2 - 3 } & Sin FEN & Con FEN \\
\hline Agrícola & $1,20 \%$ & $-0,70 \%$ \\
Minería metálica & $6,50 \%$ & $5,00 \%$ \\
Manufactura no primaria & $-0,20 \%$ & $-0,90 \%$ \\
Construcción & $3,70 \%$ & $4,50 \%$ \\
Comercio & $2,30 \%$ & $1,60 \%$ \\
Otros servicios & $4,30 \%$ & $3,80 \%$ \\
PIB global & $3,40 \%$ & $2,90 \%$ \\
\hline
\end{tabular}

Fuente: Macroconsult (2017). 


\section{Anexo 5}

Principales características de los tipos de agricultura identificados

\begin{tabular}{cccccc}
\hline & $\begin{array}{c}\text { Agricultor } \\
\text { familiar de } \\
\text { subsistencia }\end{array}$ & $\begin{array}{c}\text { Agricultor } \\
\text { familiar en } \\
\text { transición I }\end{array}$ & $\begin{array}{c}\text { Agricultor } \\
\text { familiar en } \\
\text { transición II }\end{array}$ & $\begin{array}{c}\text { Agricultor } \\
\text { familiar } \\
\text { consolidado }\end{array}$ & Total \\
\hline $\begin{array}{c}\text { Porcentaje de } \\
\text { productores que } \\
\text { recibieron el crédito } \\
\text { que solicitaron }\end{array}$ & $11 \%$ & $16 \%$ & $21 \%$ & $26 \%$ & $13 \%$ \\
\hline
\end{tabular}

Fuente: INEI (2013). 


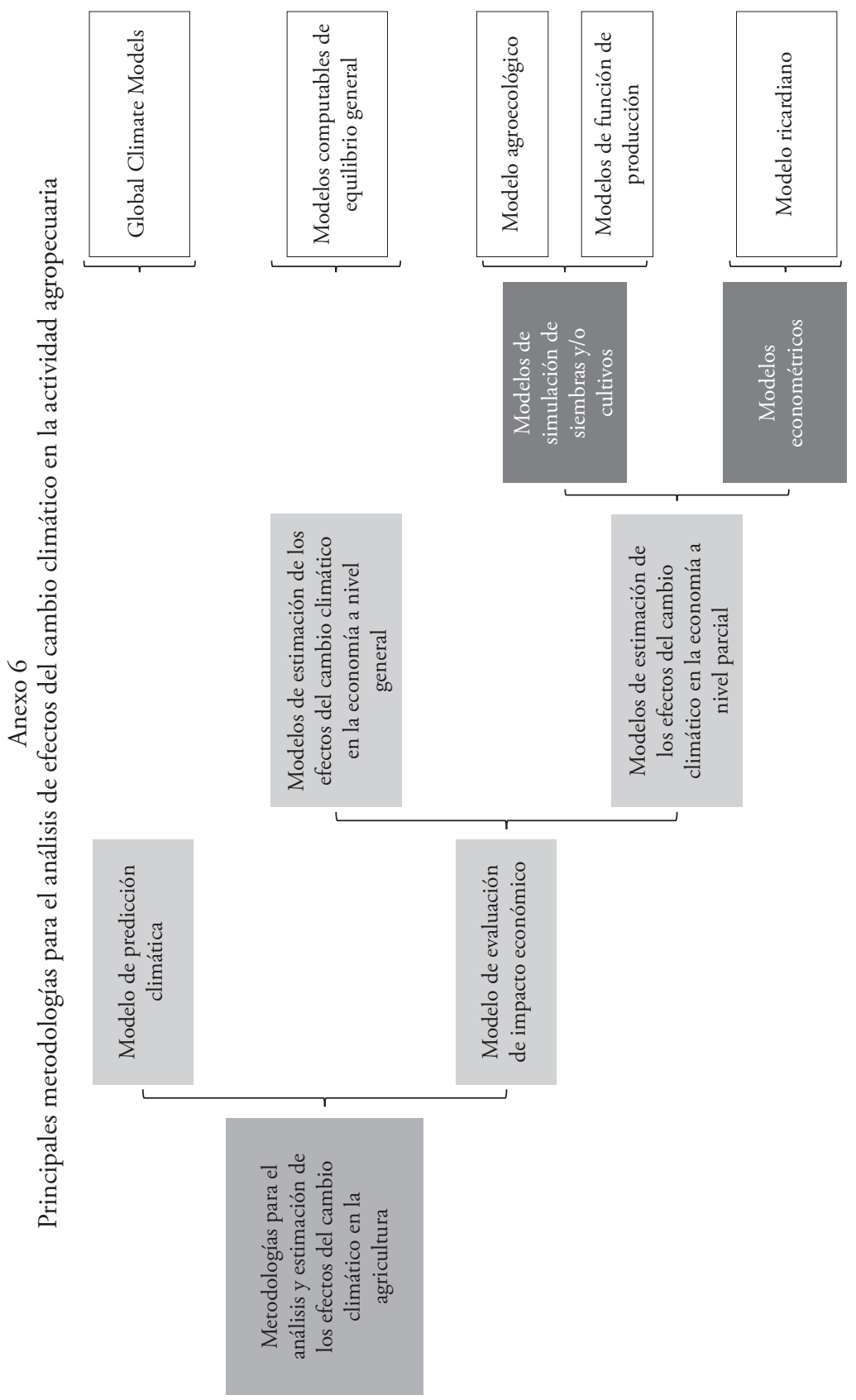

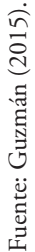




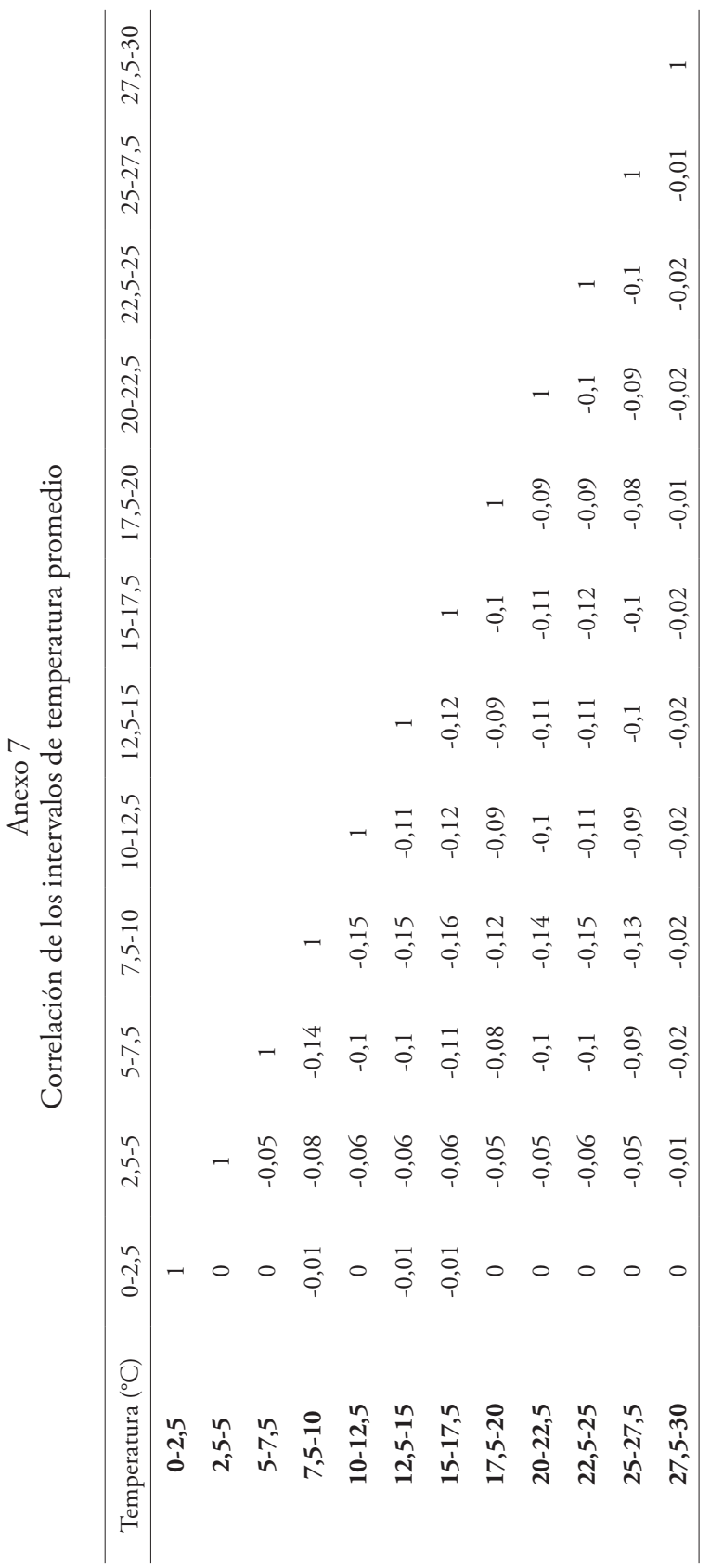


Anexo 8

División de dicotómicas en temperaturas y pluviosidad promedio

\begin{tabular}{|c|c|}
\hline Dicotómicas & Intervalo \\
\hline \multicolumn{2}{|c|}{ Temperatura $\left({ }^{\circ} \mathrm{C}\right)$} \\
\hline temp1 & $0-2,5$ \\
\hline temp2 & $2,5-5$ \\
\hline temp3 & $5-7,5$ \\
\hline temp4 & $7,5-10$ \\
\hline temp5 & $10-12,5$ \\
\hline temp6 & $12,5-15$ \\
\hline temp7 & $15-17,5$ \\
\hline temp8 & $17,5-20$ \\
\hline temp9 & $20-22,5$ \\
\hline temp10 & $22,5-25$ \\
\hline temp11 & $25-27,5$ \\
\hline temp12 & $27,5-30$ \\
\hline \multicolumn{2}{|c|}{ Pluviosidad (ml) } \\
\hline prec1 & $0-50$ \\
\hline prec2 & $50-100$ \\
\hline prec3 & $100-150$ \\
\hline prec4 & $150-200$ \\
\hline prec5 & $200-250$ \\
\hline prec6 & $250-300$ \\
\hline prec7 & $300-350$ \\
\hline prec8 & $350-400$ \\
\hline
\end{tabular}




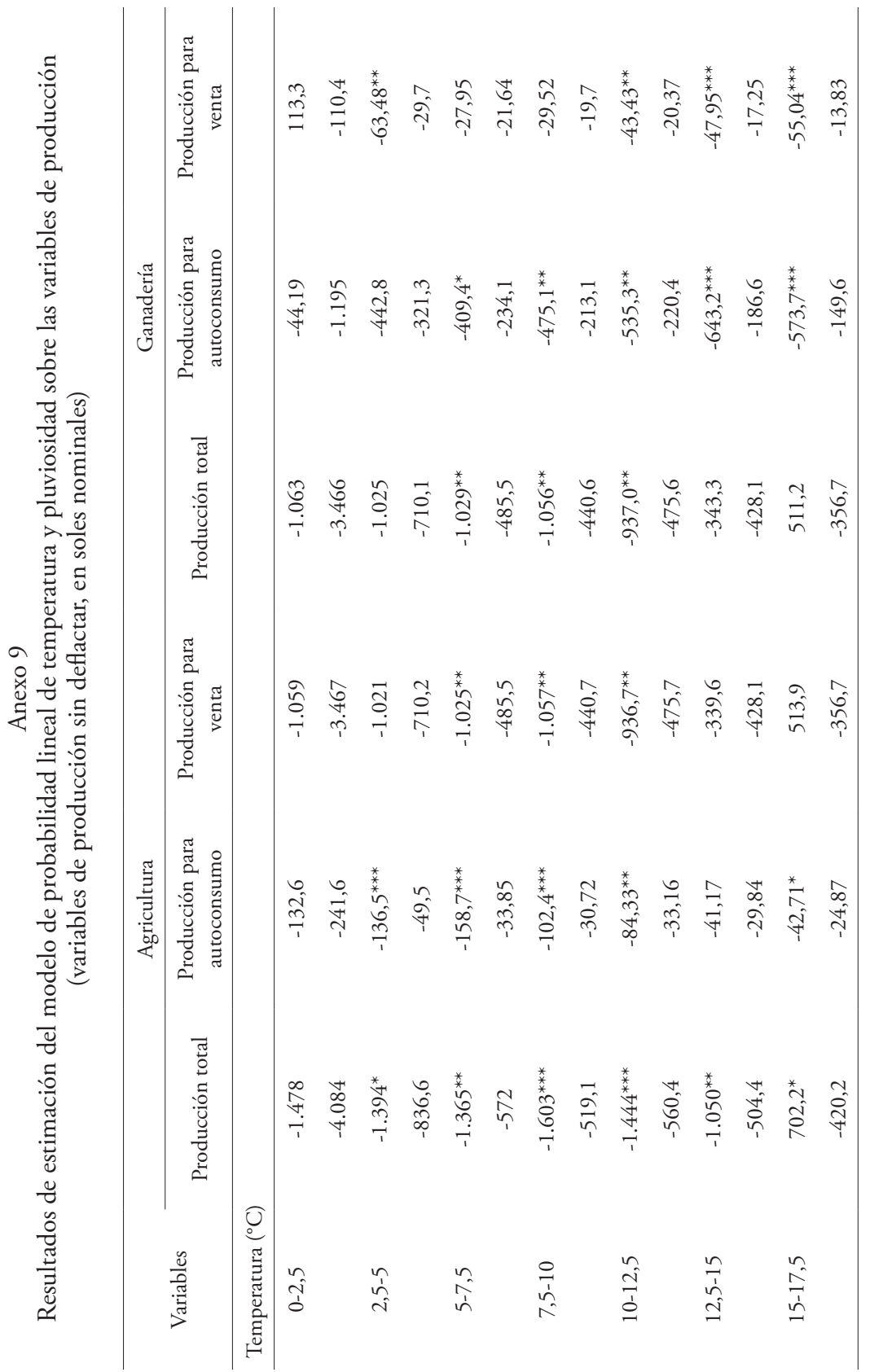




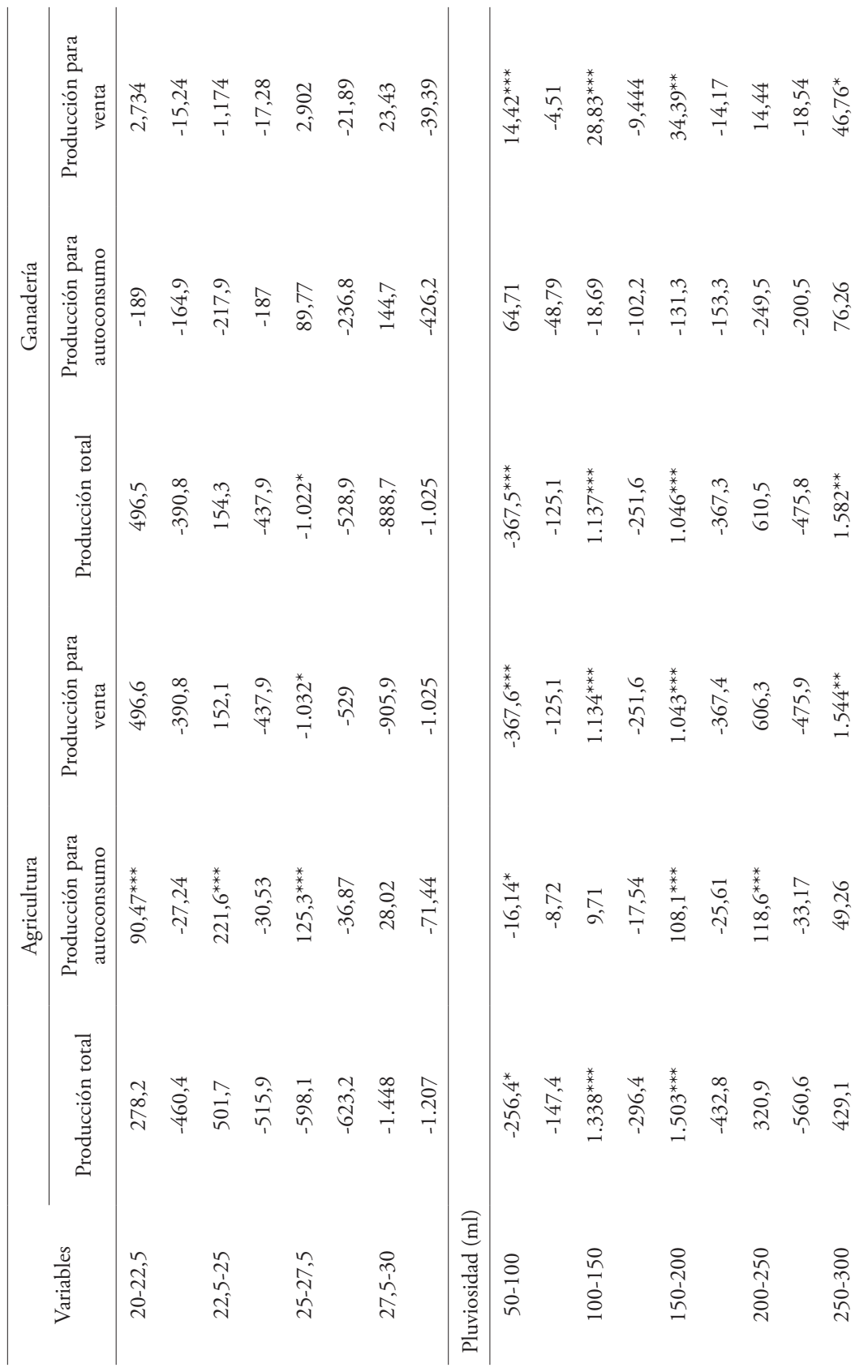




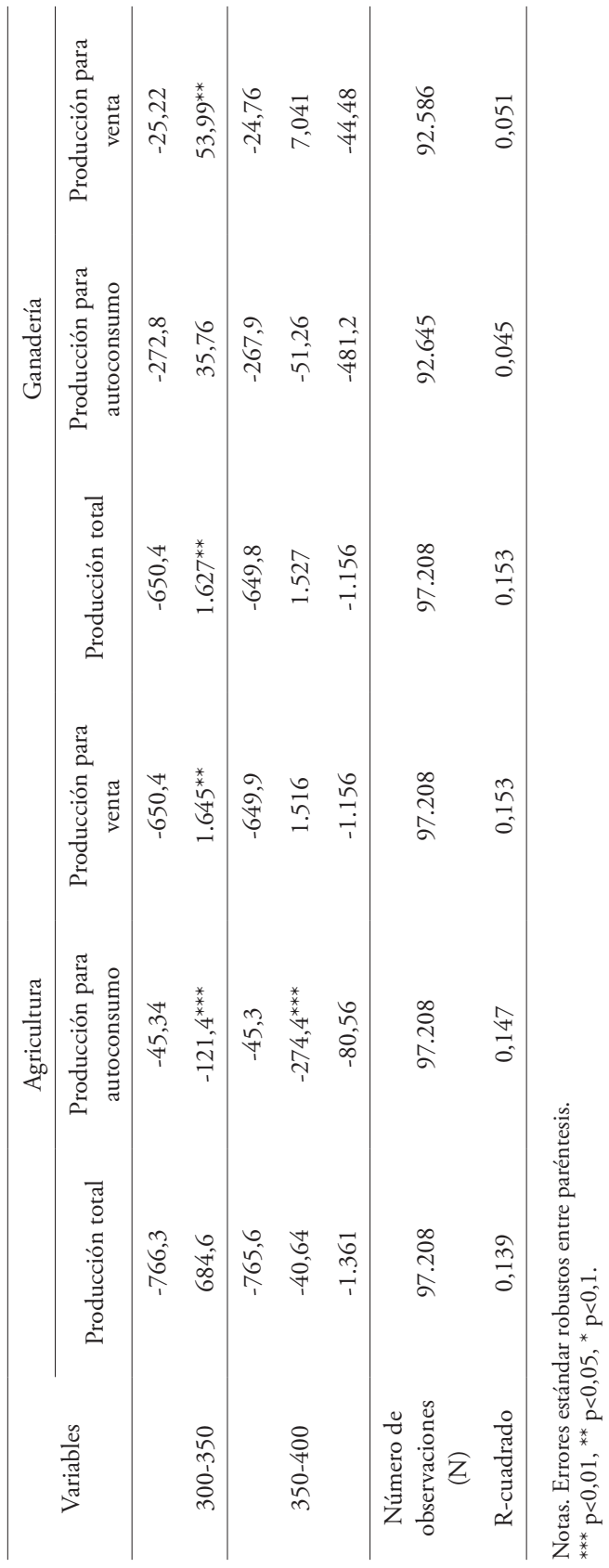




$$
\begin{gathered}
\text { Anexo } 10 \\
\text { Modelo de «lags» } \\
{\text { Valor } X_{i, d, t, a}=\beta_{0}+\beta_{1} \text { temp }}_{j, t-1}+\beta_{2} \text { prec }_{l, t-1}+\mu_{d}+\delta_{m t}+\varepsilon_{i}
\end{gathered}
$$

Donde $X$ es un vector que tomará el valor de las tres variables de ingresos: valor de la producción total, valor del autoconsumo y valor de las ventas. Todos los subíndices que no denotan al año son los mismos que el modelo original $(i, d, t, a, j, l, m) . t$ indica el año de la encuesta y $t-1$, su respectivo rezago. Las variables dicotómicas incorporan el promedio de las temperaturas y las precipitaciones pluviales que corresponden a los 12 meses previos al período estudiado (es decir, $t-1$ o el intervalo de meses entre $m-12$ y $m-23$ ). 


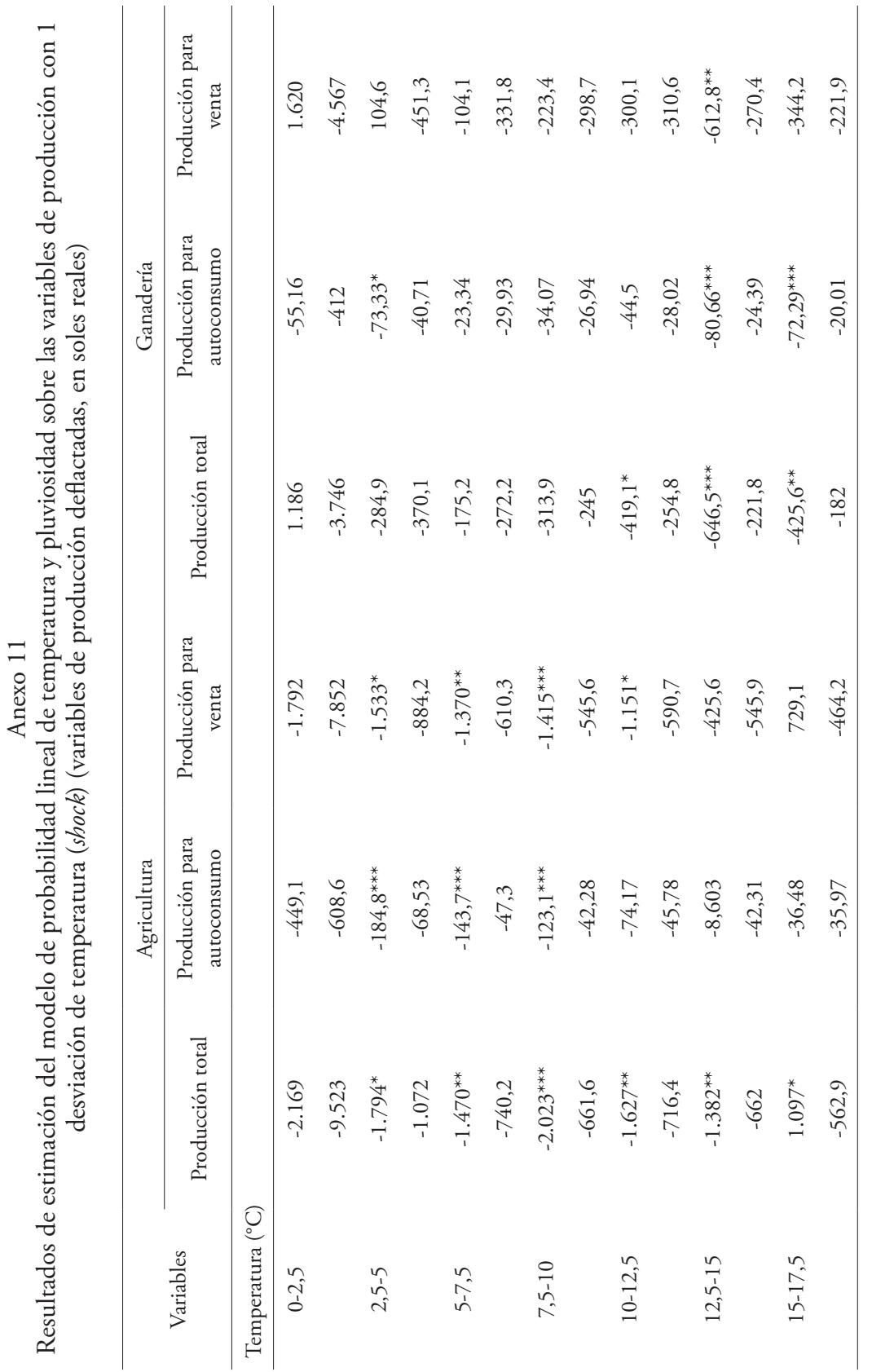




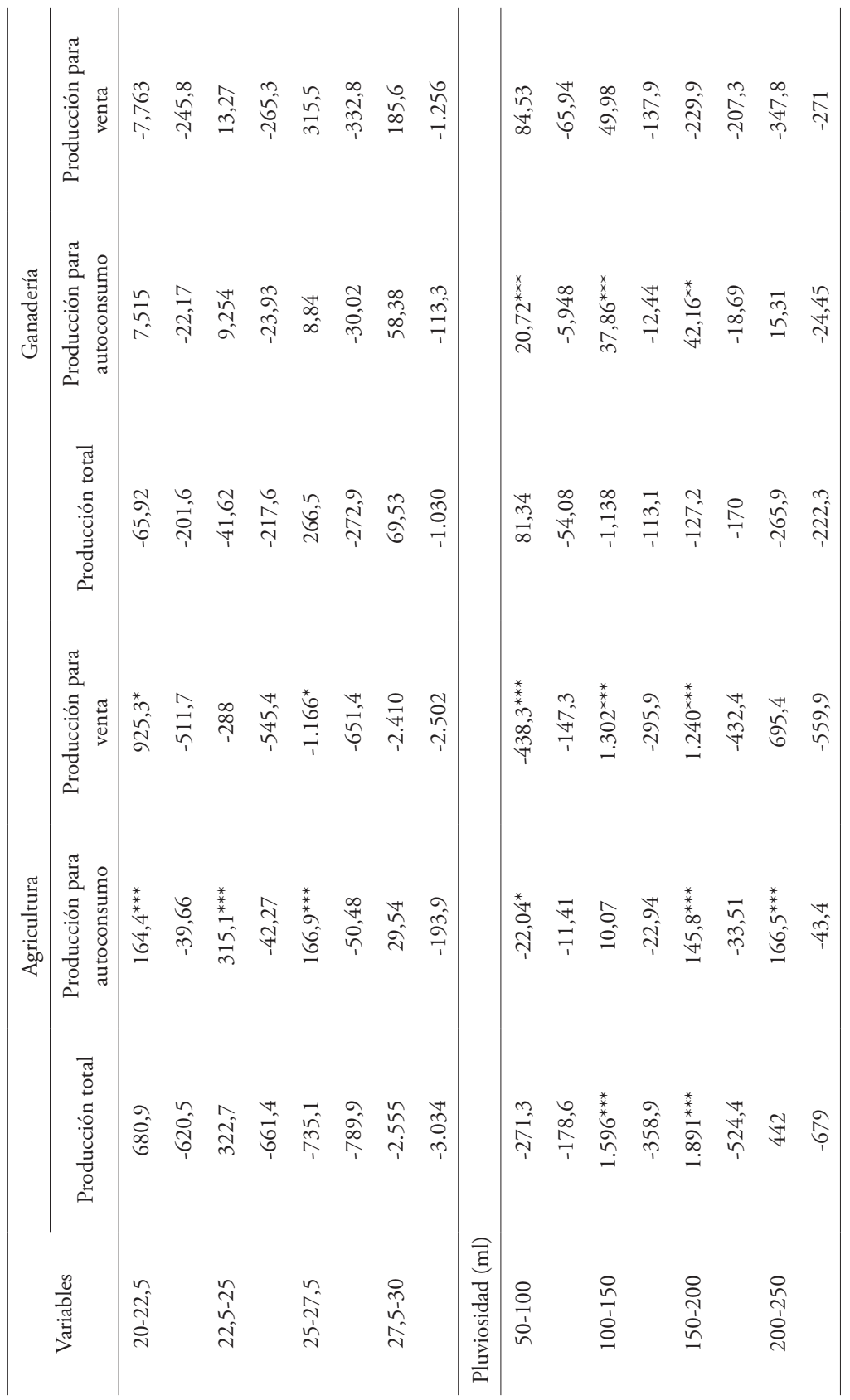




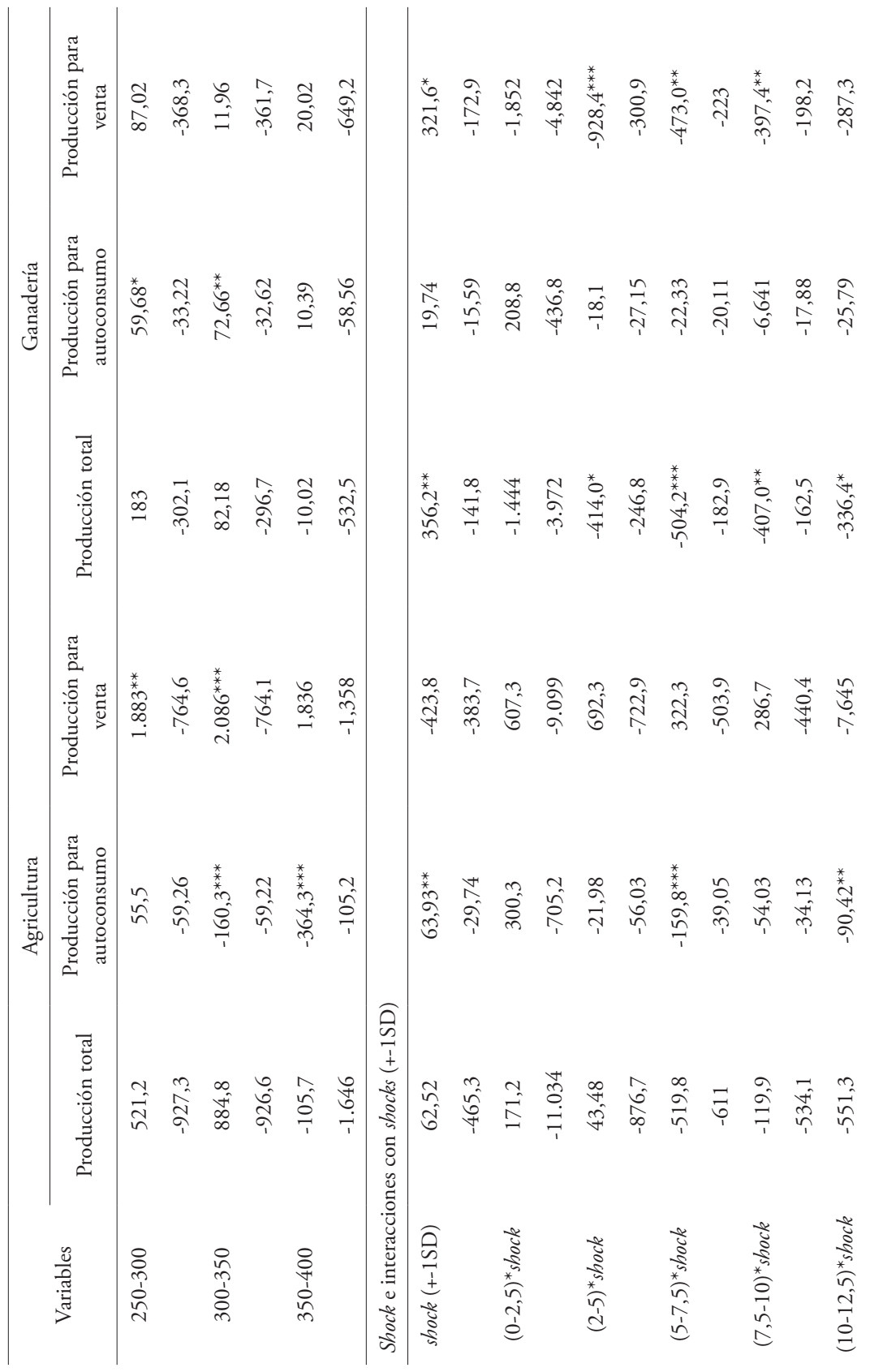




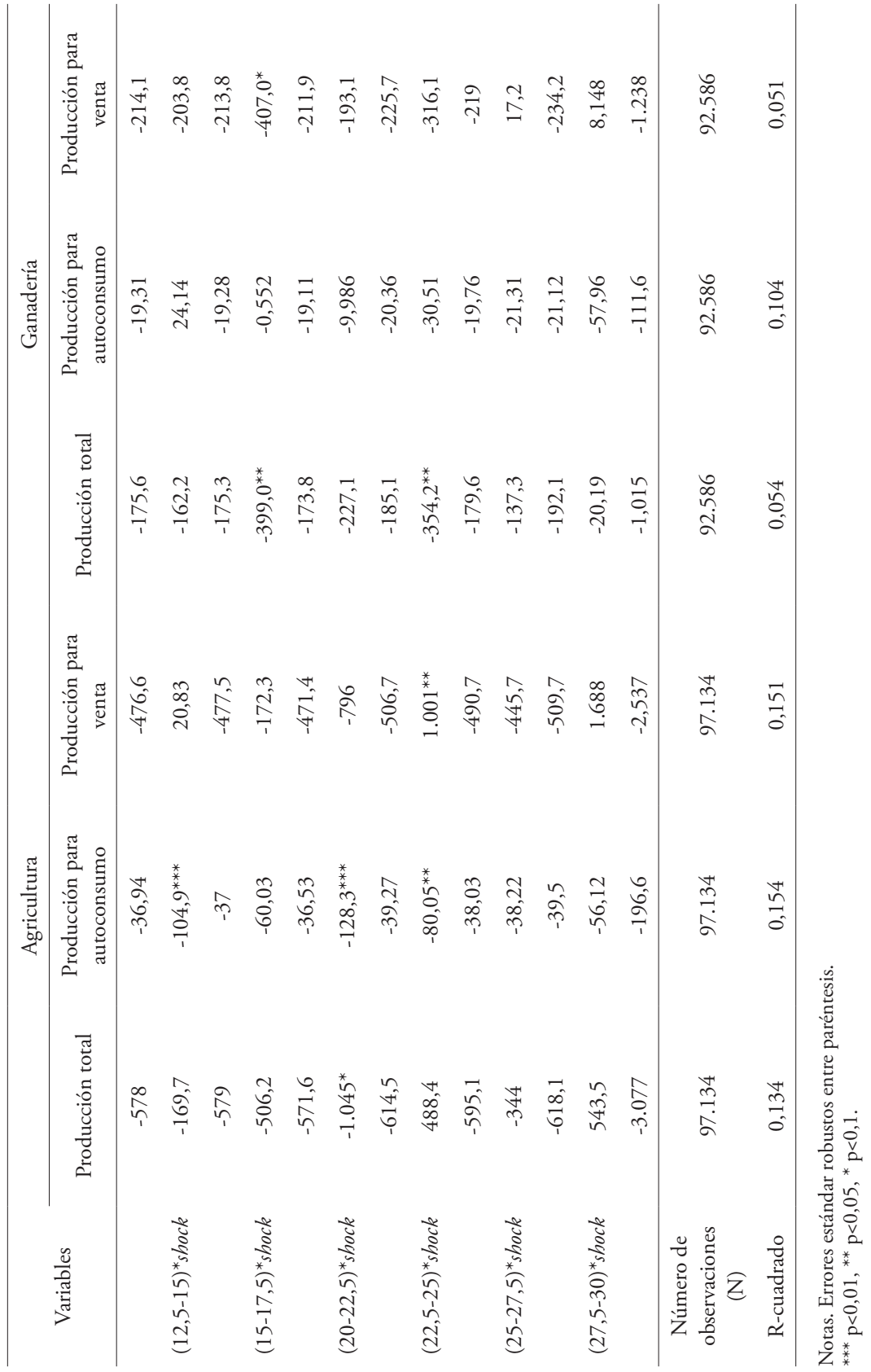




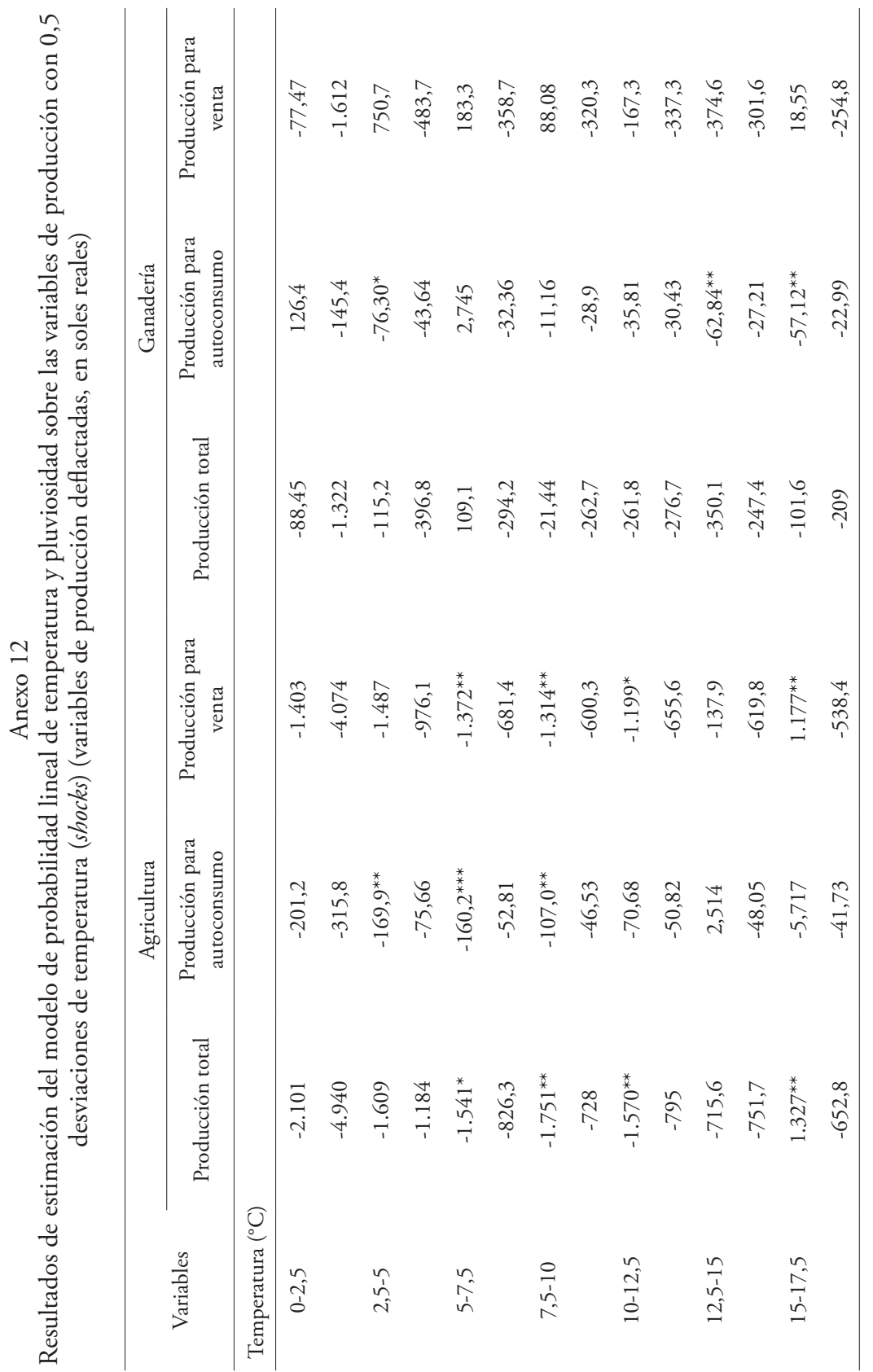




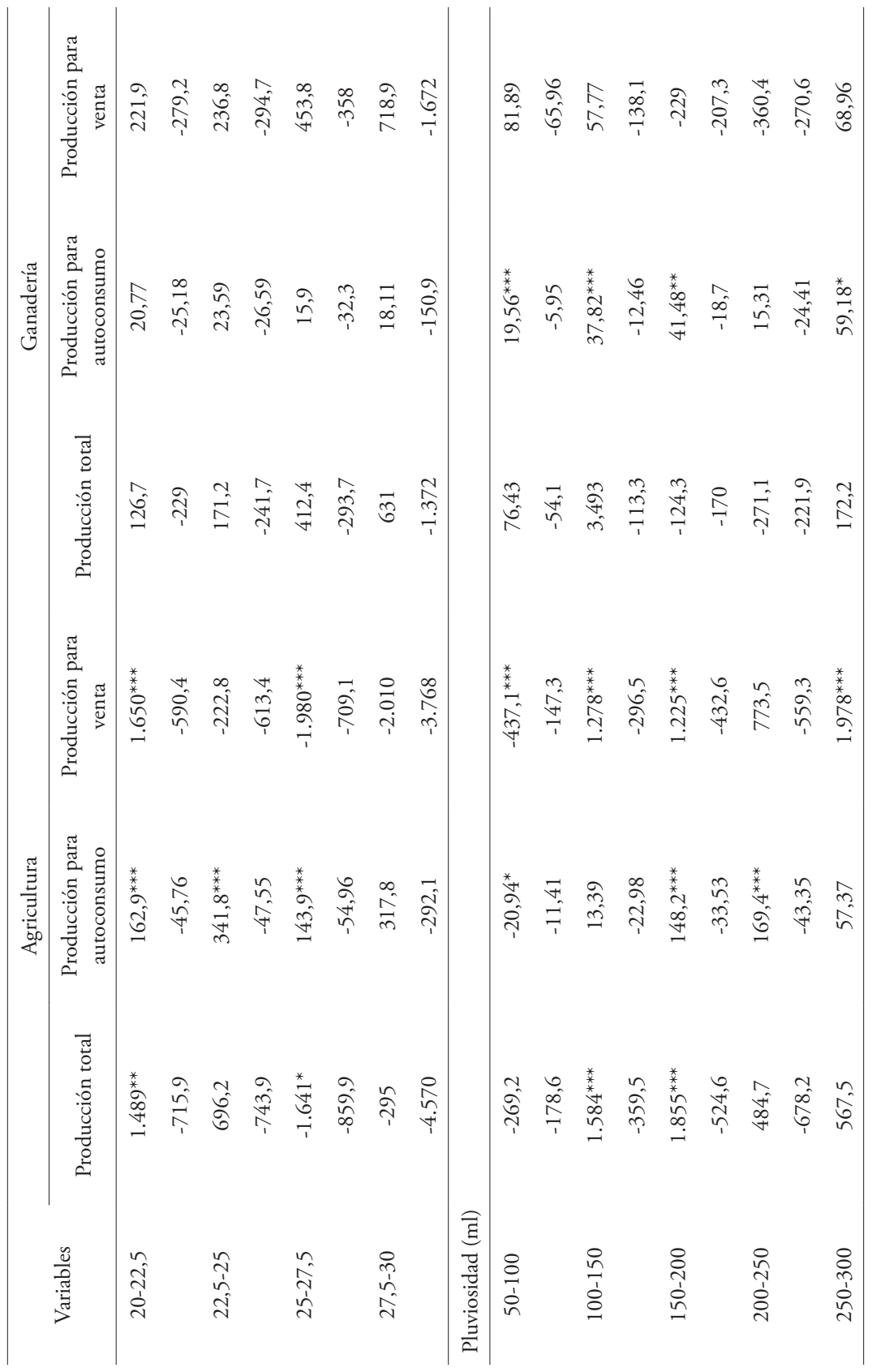




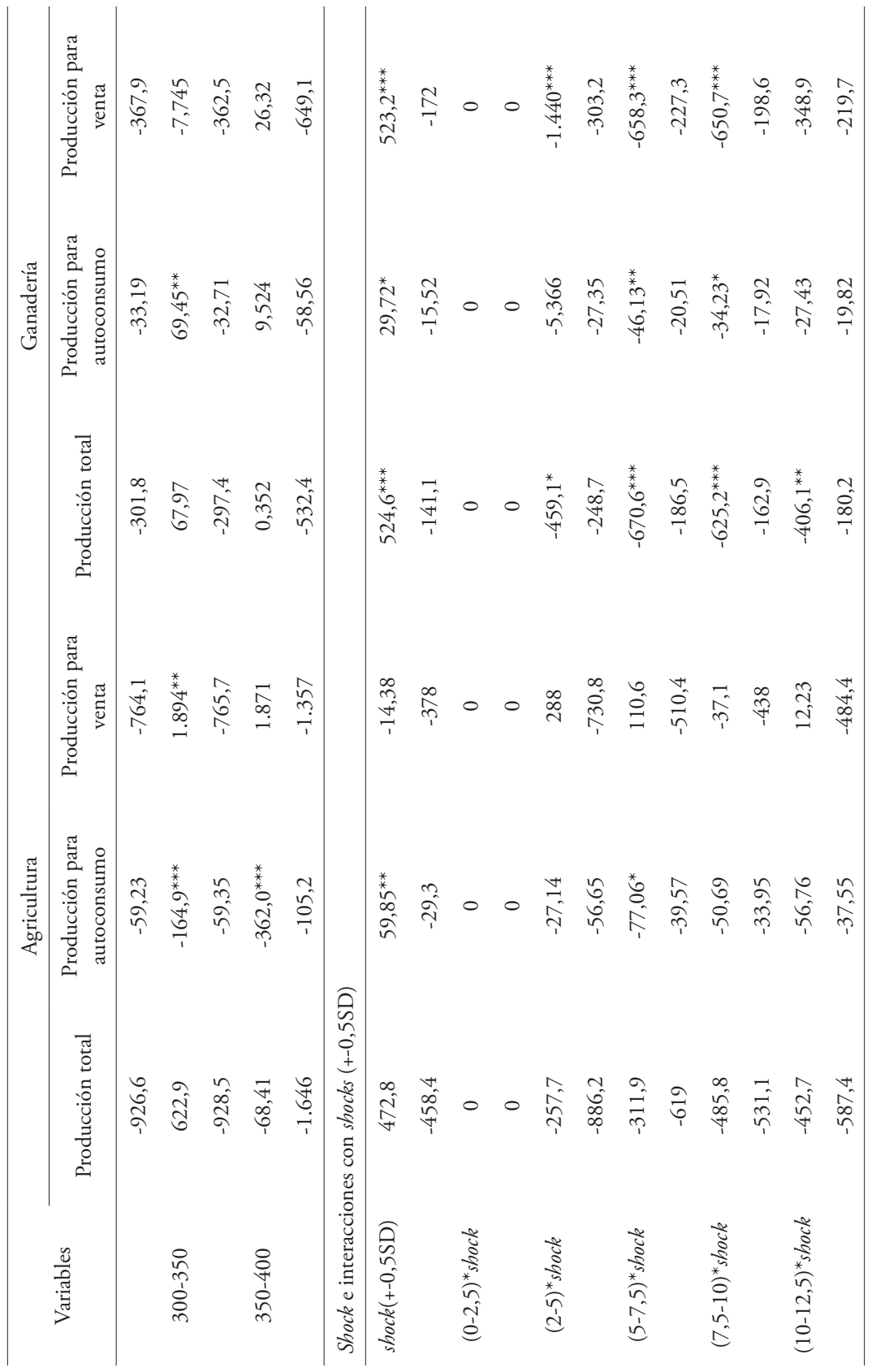




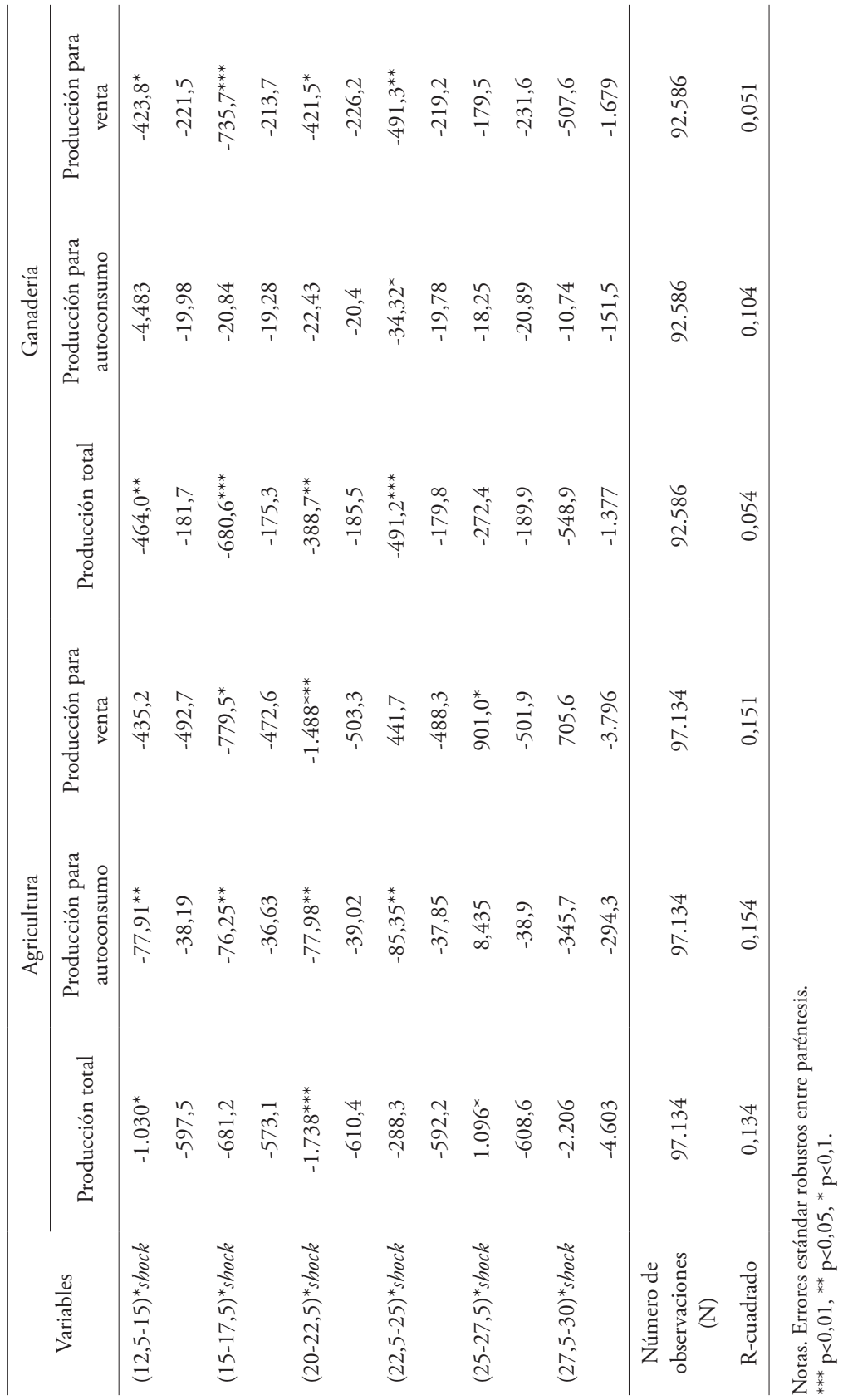




\title{
Asimetría en la transmisión de precios agrícolas: el caso del arroz en el norte del Perú para el 2001-2016
}

\author{
Renzo Muñoz-Nájar Deza \\ Cristina Meykin Wong Tsang
}

\section{Introducción}

La pequeña agricultura todavía predomina en el Perú, y su producción se concentra en la agricultura tradicional como fuente clave de ingresos para esos hogares peruanos (Escobal, Fort, \& Zegarra, 2015). El arroz cáscara es uno de los productos con más participación en el producto bruto agrícola nacional, con un 13,3\% en 2016 (INEI, 2017). Pero el mercado de este producto presenta una oferta atomizada, con 100.000 productores de arroz a nivel nacional al año 2012 (Minagri, 2012), y, en la mayoría de los casos, la producción está condicionada al financiamiento provisto por los acopiadores y molineros (Salcedo \& Stiglich, 2004).

La demanda local de arroz se abastece principalmente con producción local. Las importaciones de arroz procesado o blanqueado no superan el 10\% de la oferta local, y la importación de arroz cáscara es casi nula. Cabe notar que el arroz es un producto sujeto al régimen peruano de franja de precios. Las partidas arancelarias bajo ese régimen incluyen al arroz procesado, pero no incluyen al arroz cáscara (Navarro \& Flores, 2006).

De lo anterior, surge el interés por conocer hasta qué punto los mercados internacionales del arroz están relacionados con el local a través de la transmi-

\footnotetext{
${ }^{1}$ Este ensayo es una versión resumida y editada del Trabajo de Investigación Económica que, con el mismo título, fue concluido en noviembre de 2017. Los autores agradecen al profesor Daniel de la Torre por su valiosa asesoría.
} 
sión de precios. Los objetivos de nuestra investigación son dos. El primero es analizar, mediante datos mensuales por regiones para el período de diciembre de 2001 a marzo de $2016^{2}$, en qué medida los precios internacionales afectan los precios en chacra para los productores de arroz en el norte del Perú (en específico, en las regiones de San Martín, Piura, Lambayeque y La Libertad, principales productoras del arroz cáscara) ${ }^{3}$. El segundo, comprobar la posible existencia de una transmisión asimétrica en precios. Es decir, si los precios en chacra son más sensibles ante caídas de precios internacionales que ante incrementos, dependiendo de las condiciones del mercado.

Nuestra hipótesis de investigación es que hay una transmisión de precios significativa y los precios en chacra reaccionan más ante caídas que ante alzas en los precios internacionales. Esta hipótesis se respalda en la existencia de intermediarios con alto poder de negociación en el mercado del arroz. De modo que los agricultores actúan como tomadores de precios, y los aumentos de precios internacionales se reflejan poco en el precio que reciben.

La relevancia de analizar la asimetría en la transmisión de precios radica en que permite evaluar la necesidad de políticas orientadas a mejorar la competitividad del mercado y asegurar el beneficio de los productores. Según lo propuesto por McLaren (2015), las consecuencias de dicha asimetría pueden ser particularmente perjudiciales en países en vías de desarrollo, donde caídas de precios internacionales agravadas por la asimetría podrían incrementar la vulnerabilidad de pequeńos agricultores a la pobreza.

Estudios especializados previos se han enfocado en comprobar la asimetría en la transmisión de precios de commodities agrícolas en diversos países. Sin embargo, el aporte de nuestra investigación radica en el limitado número de estudios académicos sobre el caso peruano del arroz cáscara. Asimismo, es el primer estudio peruano en aplicar las metodologías modelo de corrección de errores con threshold (TVECM) y modelo de vectores autorregresivos con threshold (TVAR) para evaluar dicha asimetría en el Perú durante el período 2001-2016.

\section{Hechos estilizados}

Para el período de diciembre de 2001 a marzo de 2016, se compara la evolución histórica del precio promedio internacional FOB con los precios en chacra

\footnotetext{
${ }^{2}$ No se pudo escoger un período de análisis más extenso debido a la carencia de datos por regiones peruanas antes de 2001. Y el período, hasta 2016, se explica por el ańo de realización de nuestra investigación (2017). ${ }^{3}$ Durante 2016, según datos del INEI, la región San Martín concentró el 22\% de la producción nacional de arroz cáscara, seguida de Piura (19\%), Lambayeque (13\%) y La Libertad (11\%). En el 90\% de los casos, los productores de esas regiones cultivan en parcelas menores de 5 hectáreas (INEI, 2012).
} 
recibidos por los agricultores en los departamentos de San Martín, Lambayeque, Piura y La Libertad ${ }^{4}$. En la figura 1, se observan similares trayectorias de precios, una correlación significativa y un alto poder explicativo del precio internacional sobre el precio en chacra, caracterizado por un rezago de un mes.

La cotización internacional del arroz tuvo una trayectoria ascendente entre 2005 y 2008, explicada principalmente por factores de oferta: pérdidas de producción por factores climáticos (caída en un $2 \%$ de la producción global de cereales en 2006) y la consecutiva reducción en existencias desde 2005. Esta alza se acentuó en abril de 2008, y acanzó un máximo histórico en el último quinquenio, de S/ 1,34, un 114\% superior al precio en abril de 2006 (Bloomberg, 2017). Algunos países aplicaron políticas para contrarrestar el efecto en los precios locales, como cuotas de exportación en China o eliminación de aranceles en Bolivia. Sin embargo, el Perú no aplicó cambios en política, al parecer porque suponía un bajo impacto de dicho evento en los precios locales del arroz (FAO, 2008). En este sentido, resulta interesante evaluar el impacto del precio internacional sobre el precio en chacra para la zona norte del Perú.

\section{Figura 1}

Evolución de precios de arroz en cáscara en el norte del Perú y del precio internacional, diciembre de 2001 - marzo de 2016 (soles por kilogramo).

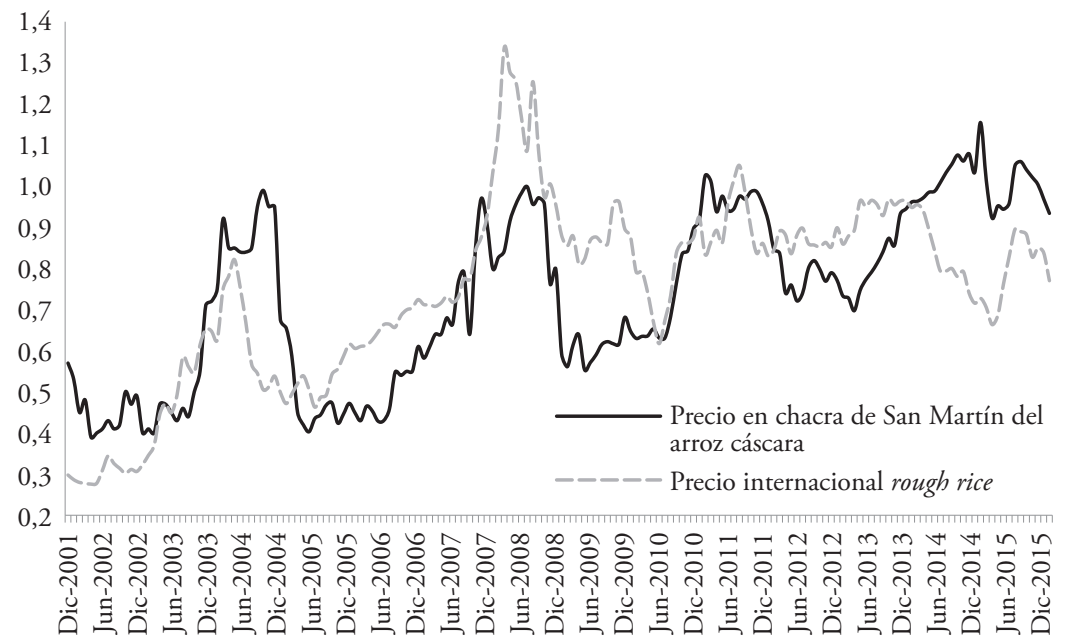

${ }^{4}$ La producción de arroz cáscara en la Costa está determinada por la campaña de siembras, cuyas cosechas se concentran entre abril y julio, mientras que en la Selva se cultiva durante todo el ańo, con picos productivos de mayo a julio y de octubre a noviembre (Minagri, 2012). Por ello, en los meses de marzo y de agosto a noviembre suelen presentarse missing values para el precio en chacra. 

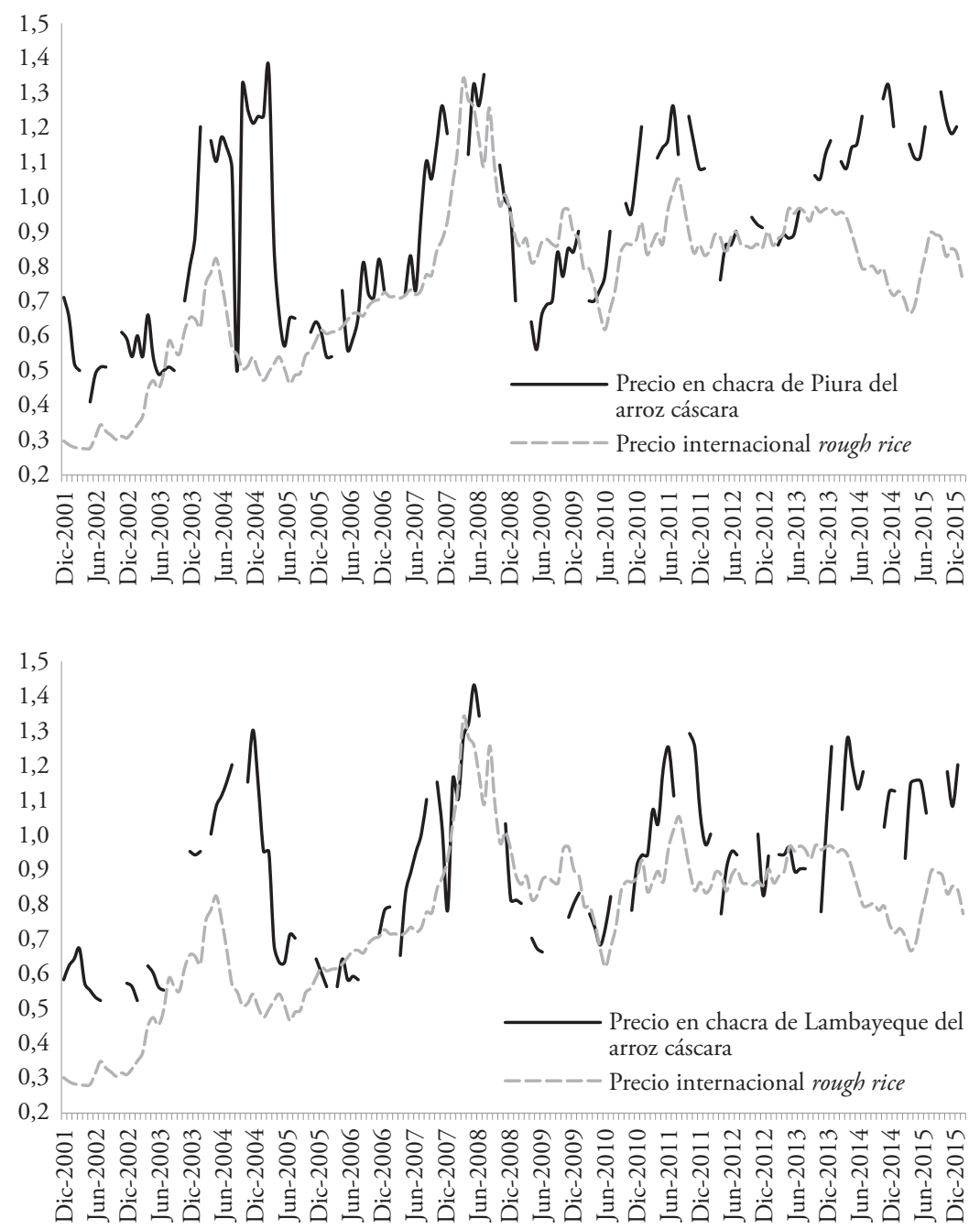


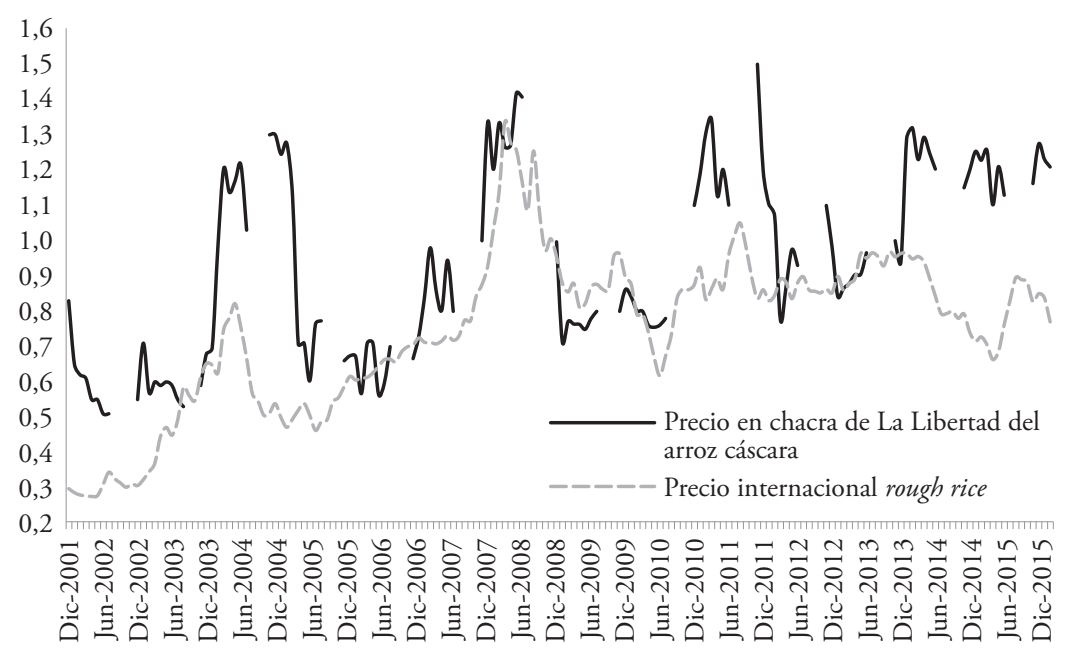

Fuentes: Bloomberg (2017), INEI (2016).

Asimismo, algunas características del mercado local, como el bajo poder de negociación de los agricultores, justifican suponer la existencia de asimetría en la transmisión de precios. Por un lado, la superficie cosechada de arroz por las unidades agropecuarias es pequeña en las regiones estudiadas, lo cual explica en parte el bajo poder de negociación de los agricultores. Según el Censo Agropecuario de 2012, el porcentaje del total de unidades agropecuarias arroceras que tienen una extensión menor de 5 hectáreas es el 96,7\% en Piura, el 92,5\% en Lambayeque, el 86,9\% en La Libertad y el 81,8\% en San Martín. Por otro lado, el modo de financiamiento resulta importante para entender la relación de dependencia de los agricultores de la zona con los intermediarios. Según el censo antes mencionado, el acceso al crédito agrícola formal de las unidades agropecuarias arroceras es del 39\% en Piura, el 25\% en San Martín, el 24\% en Lambayeque y el 20\% en La Libertad (Zavaleta, 2013).

\section{Revisión de literatura especializada}

La transmisión de precios agrícolas ha sido objeto de discusión polarizada en la literatura económica. Investigaciones pioneras de Ardeni (1989) y Asche, Bremnes \& Wessells (1999) asumen la Ley de Un Solo Precio ${ }^{5}$ como síntesis

\footnotetext{
${ }^{5}$ La Ley de Un Solo Precio plantea que, cuando las diferencias entre los diferentes mercados exceden los costos de transacción, las oportunidades de beneficio serían explotadas inmediatamente por los arbitrajes. Así, en un mercado competitivo con información perfecta, el arbitraje garantizará que los diferenciales de
} 
de una perfecta integración del mercado. Pero este modelo ha sido criticado por autores como Frankel, Stein \& Wei (1995), Miljk (1999) y Coleman (2009), quienes argumentan que factores como costos de transporte, barreras arancelarias, fijación de precios, tipo de cambio, factores institucionales y regionalización del comercio pueden impedir que el arbitraje del mercado genere una convergencia perfecta de precios locales hacia los internacionales. Esta idea es compartida por Hernández-Villafuerte (2012), quien indica que una baja transmisión podría conllevar una distorsión de incentivos, una toma de decisiones subóptima y una productividad agrícola limitada.

Morisset (1998) fue uno de los pioneros en investigar empíricamente la existencia de asimetría en la transmisión de precios de commodities en seis países. Sin embargo, este tema cobró mayor relevancia en el sector agrario tras el alza de precios agrícolas durante 2007 y 2008 (Listorti \& Esposti, 2012). Este evento acentuó el interés por conocer si los productores efectivamente se beneficiaban ante un alza de precios por la transmisión, y por comprobar empíricamente la posibilidad de que esta sea distinta cuando los precios se elevan frente a cuando caen.

Mientras que Von Cramon-Taubadel \& Meyer (2004) plantean que la principal causa de la transmisión asimétrica de precios agrícolas es el abuso del poder del mercado, Vavra \& Goodwin (2005) sostienen que una estructura competitiva imperfecta puede ser un factor explicativo principal. De manera similar, McLaren (2015) afirma que el poder de negociación de los intermediarios y acopiadores en el sector agrícola explica la asimetría en la transmisión de precios. Y sostiene que, a medida que disminuya/aumente el precio internacional, los precios locales bajarán/subirán proporcionalmente más/menos. Esto es consistente con Rogers \& Sexton (1994), para quienes la existencia de un monopsonio en el sector agrícola puede darse por tres razones: (1) los altos costos de transporte restringen el acceso de los productores a únicamente consumidores de su entorno, (2) la alta importancia del procesamiento del producto para su consumo final genera dependencia de los productores hacia los intermediarios y (3) la especialización de los agricultores en un solo producto genera barreras a la salida, y su baja elasticidad de oferta aumenta el poder de mercado de los intermediarios.

Los primeros estudios sobre transmisión de precios se basaron en la estimación de mínimos cuadrados ordinarios (MCO), y algunos autores contemporáneos han mantenido el uso de este método de estimación debido a que facilita incorporar controles. McLaren (2015) realizó una estimación en dos

precios reflejen todos los costos de comercialización. 
etapas usando MCO para 117 países y evidenció la existencia de asimetría en la transmisión de precios. Estudios más recientes se han enfocado en el uso de series de tiempo con vectores autorregresivos (VAR). Así, Aguiar \& Santana (2002) comprueban, mediante un VAR, que ni la concentración de mercado ni la capacidad de almacenamiento impiden una transmisión de precios si existen expectativas de precios altos.

No obstante, el TVECM es la metodología que ha tomado mayor relevancia en las investigaciones recientes para modelar el ajuste asimétrico hacia el equilibrio de precios. Abdulai (2000) aplica esta metodología para evaluar el ajuste asimétrico hacia el equilibrio de largo plazo de precios locales en Ghana frente al precio del mercado principal. El autor concluye que estos responden de una manera más sutil ante aumentos que ante reducciones.

Aunque el TVECM permite recoger las diferencias en los niveles de transmisión de precios dependiendo de un determinado umbral, algunos autores recientes reconocen las limitaciones de asumir una cointegración lineal y no permitir que el proceso de transmisión de precios cambie gradualmente. Por ello, Rosales \& Von Cramon-Taubadel (2015) utilizan un nuevo método que combina el modelo de vectores de corrección de errores (VECM) y la cointegración variante en el tiempo para precios de trigo de Ucrania y Francia. Esto con el fin de recoger la transmisión de precios en países donde la relación de largo plazo está sujeta a variaciones en el tiempo por: (1) cambios en políticas, como la introducción de aranceles en el período evaluado; y (2) existencia de un componente estacional que impacta en la calidad y el precio de los productos.

Si bien hay pocos estudios empíricos para el caso peruano ${ }^{6}$, Hernández-Villafuerte (2012) evalúa la transmisión espacial de precios del arroz, el maíz y la soya para distintos países de América Latina. El autor busca comprobar que un mayor comercio entre países como Brasil y Uruguay implica una mayor integración y simetría en la transmisión de precios. En la misma línea, Ceballos, Hernández, Minot \& Robles (2015) evalúan la transmisión de precios en cereales para 27 países de América Latina, África y Asia del Sur. Los autores buscan evidenciar que la transmisión de la volatilidad de los precios se intensifica en los productos con mayor dependencia comercial. No obstante, su principal aporte radica en el hallazgo de un alto nivel de volatilidad y transmisión de precios internacionales al mercado peruano de arroz, donde la participación de las importaciones en la demanda local no superaba el $7 \%$.

\footnotetext{
${ }^{6}$ Salcedo y Stiglich (2004) estudian de manera teórica el poder de mercado de los intermediarios en el arroz cáscara del Perú, pero no realizan una estimación empírica sobre la transmisión de precios.
} 


\section{Marco analítico}

La cadena de valor del arroz cáscara cuenta con tres agentes: agricultores, acopiadores y molineros. Luego de ser cosechado, el arroz puede llegar al molinero directamente o mediante un acopiador. Pero, indiferentemente de eso, los agricultores tienen bajo poder de negociación del precio en chacra. Las principales razones de ello son (1) la restricción financiera para costear la producción y (2) la producción atomizada.

En efecto, los intermediarios actúan como habilitadores que financian la producción de los agricultores a cambio de fijar un precio en su beneficio. Esto genera una continua dependencia de los agricultores hacia los intermediarios: el agricultor no opta por intermediarios alternativos, pues podría arriesgar el financiamiento de sus futuras siembras. El gran número y dispersión de agricultores pequeños impide una producción a gran escala y limita la competitividad del precio del arroz en chacra. Así, esta estructura del mercado de arroz explica la asimetría en la transmisión de precios. Si el precio internacional se encuentra al alza, el precio que reciben los agricultores sube marginalmente. En cambio, cuando el precio internacional está a la baja, el precio en chacra asimila la disminución con mayor intensidad.

El bajo poder de mercado de los productores de arroz puede ser modelado en los términos de Sexton (1990) y McLaren (2015), quienes caracterizan al mercado agrícola como una amplia dispersión de agricultores que actúan como tomadores de precio.

De esta manera, se denota como $\mathcal{P}_{\omega}$ al precio internacional del arroz cáscara, con un comportamiento exógeno al mercado local. Y como $\mathcal{P}_{a}$ al precio que recibe el agricultor, es decir, el precio en chacra. Así, la oferta de un solo agricultor $\left(q^{S}\right)$ se denota como:

$$
q^{S}=q^{S}\left(\mathcal{P}_{a}\right), \operatorname{donde} q^{S}\left(\mathcal{P}_{a}\right)^{\prime}>0 y q^{S}\left(\mathcal{P}_{a}\right)^{\prime \prime} \leq 0
$$

Al sumar la producción del resto de los agricultores, se obtiene la oferta agregada de los agricultores hacia los intermediarios, que depende del precio de chacra y se expresa como:

$$
Q^{S}=Q\left(\mathcal{P}_{a}\right) \text {, donde } Q^{S}\left(\mathcal{P}_{a}\right)^{\prime}>0 \text { y } Q^{S}\left(\mathcal{P}_{a}\right)^{\prime \prime} \leq 0
$$

Con el fin de obtener la función de beneficios de los intermediarios, se despeja el precio de chacra del arroz cáscara de la función de la cantidad. Así, $\mathcal{P}_{a}=\left(Q^{S}\right)^{-1}=C(Q)$. 
Donde $C(Q)^{\prime}>0 y C(Q)^{\prime \prime} \geq 0$. Es decir, el precio en chacra del arroz implica una función que depende de la cantidad ofertada agregada de arroz en el mercado. Y los intermediarios, además de la compra directa de las cosechas a los agricultores y de sus costos fijos $\mathscr{F}$, incurren en gastos asociados al procesamiento, la preparación y el empaquetado del producto agrícola para su distribución en los mercados minoristas. Estos costos variables adicionales se denotan con una función $E$ dependiente de la cantidad producida: $E(Q)$. Así, resulta la siguiente expresión de la función de beneficios que los intermediarios buscan maximizar:

$$
\Pi=\mathcal{P}_{\omega} Q-\mathrm{C}(Q) Q-E(Q)-\mathscr{F}
$$

Donde $\mathcal{P}_{a}=\mathrm{C}(Q)$. De esta manera, a partir de la maximización de beneficios con respecto a $Q$, se obtiene la condición de primer orden, donde $Q$ es una función del precio internacional del arroz, $Q=\left(\mathcal{P}_{\omega}\right)$ :

$$
\frac{d \Pi}{d Q}=\mathfrak{f}\left(Q, \mathcal{P}_{\omega}\right)=\mathcal{P}_{\omega}-C^{\prime}(Q) Q-C(Q)-E^{\prime}(Q)=0
$$

Tomando en cuenta la función $C$ entre el precio de chacra y la cantidad ofertada, es posible encontrar la relación entre el precio de chacra y el del intermediario mayorista, pues $Q$ es una función del precio internacional del arroz. $\mathcal{P}_{a}=\mathrm{C}(Q)=\mathrm{C}\left[Q\left(\mathcal{P}_{\omega}\right)\right]$. Y, así, es posible evaluar el impacto de un shock exógeno en los precios internacionales $\mathcal{P}_{\omega}$ sobre los precios de chacra:

$$
\frac{d \mathcal{P}_{a}}{d \mathcal{P}_{\omega}}=\frac{d \mathrm{C}\left[Q\left(\mathcal{P}_{\omega}\right)\right]}{d Q} * \frac{d Q}{d \mathcal{P}_{\omega}}=\frac{\mathrm{C}^{\prime} Q}{\mathrm{C}^{\prime \prime}(Q)+2 \mathrm{C}^{\prime}(Q)+\mathrm{E}^{\prime \prime}(Q)}>0
$$

De esto, resaltan dos aspectos: (1) el efecto es positivo, tomando en consideración que $C(Q)^{\prime}>0 y C(Q)^{\prime \prime} \geq 0$; y (2) dado que $0<\frac{d \mathcal{P}_{a}}{d \mathcal{P}_{\omega}}<1$, un incremento de precios internacionales del arroz cáscara en un dólar implica un incremento en el precio de chacra en menos de una unidad, lo que evidenciaría la existencia de asimetría en la transmisión de precios. Cabe mencionar que para probar la asimetría es necesario evaluar la segunda derivada. Si su símbolo es negativo, existe asimetría en la transmisión de precios:

$$
\frac{d \mathcal{P}_{a}{ }^{2}}{d \mathcal{P}_{\omega}{ }^{2}}=C^{\prime \prime} *\left(\frac{d Q}{d \mathcal{P}_{\omega}}\right)^{2}+C^{\prime} * \frac{d Q^{2}}{d \mathcal{P}_{\omega}{ }^{2}}
$$


Dado que el primer término es positivo, el resultado dependerá de que $\frac{d Q^{2}}{d \mathcal{P}_{\omega}{ }^{2}}$ sea negativo, lo que es plausible bajo el supuesto de que la curva de costo marginal sea convexa, de modo que, ante un aumento en el precio, la cantidad producida aumente cada vez menos por resultar más costosa la producción adicional. En cuyo caso, la relación entre los precios de chacra y los precios internacionales es positiva, pero cóncava; es decir, ante un incremento en el precio internacional, el precio en chacra aumenta, pero en menor proporción.

\section{Metodología}

La principal metodología planteada para esta investigación consiste en un modelo de corrección de errores con threshold (TVECM). Se eligió esta metodología porque permite modelar asimetrías en la relación de equilibrio de largo plazo de las variables. Ello es posible al establecer umbrales que clasifiquen las variaciones del precio de arroz en chacra según dos criterios: (1) movimientos a la baja del precio internacional del arroz: $E C T_{t-1}>0$; y (2) movimientos al alza: $E C T_{t-1}<0$; donde $E C T_{t-1}$ representa el desequilibrio en la relación de largo plazo. En caso de no evidenciarse cointegración entre las variables, se evalúa la asimetría de transmisión de precios a través de vectores autorregresivos con threshold (TVAR). Este método difiere del TVECM por realizar estimaciones de corto plazo y no de largo plazo.

Para evaluar la asimetría en la transmisión de precios del arroz cáscara en el Perú, se hizo uso de los siguientes datos comprendidos entre los años 2001 y 2016: (1) los precios internacionales del arroz cáscara, según Bloomberg (ISIN: RR1:COM, Rough Rice en US\$/cwt), (2) los precios regionales en chacra (soles/kilogramo), según el Avance económico y social departamental, marzo 2016 del INEI; y (3) el tipo de cambio interbancario promedio del período, según el BCRP.

El uso del precio internacional del arroz cáscara, en vez del precio del arroz procesado o blanqueado, se sustenta, además de en el objetivo de esta investigación (enfocada en el arroz cáscara), en que la transmisión de precios puede ser horizontal (relación espacial) o vertical (a lo largo de una cadena de valor). Por ello, no sería adecuado usar el precio internacional del arroz procesado, porque no se podría distinguir si el efecto del precio internacional se debe a la cadena de valor o al componente espacial. Y, de conformidad con la literatura especializada, se emplean los precios internacionales free on board (FOB), a fin de excluir elementos de logística y comercio internacional para considerar factores propiamente agrícolas. 
Cabe notar la importancia de contar con un número similar de observaciones para ambos regímenes considerados en una estimación con threshold, a fin de evitar una sobreestimación en la asimetría. Por esta razón, se verificó si los datos utilizados sobre precios internacionales del arroz cumplían con dicho criterio, y, en efecto, el $54 \%$ de la muestra corresponde a alzas de precios, mientras que el $46 \%$ restante, a caídas.

A excepción de la región San Martín, cuya campaña de arroz cáscara abarca todos los meses del ańo, la producción en Lambayeque, La Libertad y Piura se concentra entre los meses de abril y julio. El calendario de siembra explica la presencia de missing values durante los meses fuera de la campaña agrícola en la serie regional de precios en chacra del INEI. Con el fin de incorporar dichos meses con datos ausentes, nos basamos en Sendhil, Kar, Mathur \& Jha (2013), quienes, con datos mensuales, evalúan la transmisión de precios de cereales en la India y ajustan los missing values asignándoles el valor de la última cotización disponible. Así, completamos los precios faltantes con el último precio en chacra cotizado a nivel mensual. Cabe mencionar que, si bien otros autores, como Minot (2011), optaron por completar valores ausentes mediante una interpolación lineal, no adoptamos esta opción debido a las desventajas que podría acarrear en la precisión de los datos cuando existen numerosos missing values.

De esta manera, para el caso del TVECM, se analiza la variación del precio en chacra del arroz cáscara $\left(\mathcal{P}_{a_{t}}\right)$ mediante tres variables: $E C T_{t-1}$ : el ajuste de corto plazo en la relación de largo plazo; (2) $\Delta \mathcal{P}_{\omega_{t-i}}:$ rezagos de la variación del precio mundial; y (3) $\Delta \mathcal{P}_{a_{t-i}}:$ rezagos de la variación del precio en chacra.

$$
\Delta \mathcal{P}_{a_{t}}=\left\{\begin{array}{l}
c+\alpha_{1} E C T_{t-1}+\sum_{i=1}^{k} \alpha_{2 i} \Delta \mathcal{P}_{\omega_{t-i}}+\sum_{i=1}^{k} \alpha_{3 i} \Delta \mathcal{P}_{a_{t-i}}+\varepsilon_{t}^{1}, S_{E C T}>0 \\
c+\alpha_{4} E C T_{t-1}+\sum_{i=1}^{k} \alpha_{5 i} \Delta \mathcal{P}_{\omega_{t-i}}+\sum_{i=1}^{k} \alpha_{6 i} \Delta \mathcal{P}_{a_{t-i}}+\varepsilon_{t}^{2}, S i E C T_{t-1}<0
\end{array}\right.
$$

$$
\text { Donde ECT } T_{t-1}=\mathcal{P}_{a_{t-1}}-\beta \mathcal{P}_{\omega_{t-1}}
$$

Y, para el caso del TVAR, se analiza el precio en chacra del arroz cáscara $\left(\mathcal{P}_{a_{t}}\right)$ mediante dos variables: (1) $\mathcal{P}_{a_{t-i}}:$ rezagos del precio en chacra; y $(2) \mathcal{P}_{\omega_{t-i}}$ : rezagos del precio internacional. 


$$
\mathcal{P}_{a_{t}}=\left\{\begin{array}{l}
c+\sum_{i=1}^{k} \beta_{1 i} \mathcal{P}_{\omega_{t-i}}+\sum_{i=1}^{k} \beta_{2 i} \mathcal{P}_{a_{t-i}}+\varepsilon_{t}^{1} \text { Si } \Delta \mathcal{P}_{\omega}<0 \\
c+\sum_{i=1}^{k} \beta_{3 i} \mathcal{P}_{\omega_{t-i}}+\sum_{i=1}^{k} \beta_{4 i} \mathcal{P}_{a_{t-i}}+\varepsilon_{t}^{2}, \text { Si } \Delta \mathcal{P}_{\omega}>0
\end{array}\right.
$$

Es preciso señalar que el período analizado no se caracteriza por la presencia de cambios bruscos de regímenes o inestabilidad en políticas dirigidas al sector agrícola, específicamente al arroz. En caso contrario, podría afectarse la condición de equilibrio a largo plazo entre precios internacionales y de chacra locales, con lo cual el supuesto de linealidad a lo largo del tiempo en la trasmisión de precios podría ser muy restrictivo.

También debemos precisar que el régimen arancelario por franja de precios puede subestimar la relación entre el precio internacional y los precios locales, pues la imposición de precios piso y techo condiciona la dependencia local respecto al precio internacional. Pero no incorporamos ese factor en el análisis porque no dispusimos de información histórica detallada sobre el ajuste arancelario por dicha franja, y la estimación sería imprecisa debido a los diversos factores que influyen en la carga arancelaria. Esto representa una limitación en la estimación realizada.

Por último, debemos explicar que no incluimos variables de control en la estimación por cuatro motivos: (1) falta de información para aproximar controles; (2) carencia de uso de controles en estimaciones similares de especialistas; (3) poca variabilidad de posibles controles: consistencia en el tamańo de la unidad agropecuaria sin variación mensual; y (4) de incluir controles en la ecuación de largo plazo, estos tendrían que interactuar como variables de política para corregir desvíos del equilibrio de largo plazo; pero estas variables podrían en realidad no ser relevantes para guiar el ajuste del precio en chacra.

\section{Análisis de resultados}

Esta sección empieza con el análisis de la relación de largo plazo entre el precio internacional y los precios locales en chacra del arroz cáscara. Luego, se evalúa la relación de corto plazo en aquellas regiones con precios caracterizados por la presencia de quiebres estructurales. 


\section{Metodología 1: Estimación de largo plazo}

\section{Presencia de raíz unitaria}

Primero, se evaluó la estacionariedad en media de las series mediante los tests Augmented-Dicky-Fuller (ADF) y Phillips-Perron (PP). Luego, se aplicó el test de Zivot y Andrews, para evaluar si la no estacionariedad se debe a la presencia de raíz unitaria o quiebre estructural.

Para las series de precios internacionales de San Martín y de Piura, resultó rechazada la estacionariedad en media con un $90 \%$, un $95 \%$ y un $99 \%$ de confianza. Y para las series de precios de La Libertad y de Lambayeque, fue rechazada a un nivel de $95 \%$ y $99 \%$ de confianza, aunque no al de $90 \%$. Así, todas las series de precios estudiadas no son estacionarias en media y presentan una potencial raíz unitaria. De hecho, la no estacionariedad en media en los precios de arroz cáscara es consistente con sus incrementos a lo largo del tiempo como parte de las usuales presiones inflacionarias en los alimentos.

A través del test $\mathrm{F}$ secuencial de Zivot y Andrews, se demostró que solo en las series de precios internacionales y de Lambayeque se rechaza el quiebre estructural al 90\%, 95\% y 99\% de confianza, para cualquier tipo de quiebre. En cambio, para las series de precios de San Martín, Piura y La Libertad, no se rechaza el quiebre estructural en pendiente al $95 \%$ de confianza; mientras que para las de Piura y La Libertad tampoco se rechazan los quiebres estructurales en media y pendiente al $90 \%$ de confianza.

Por consiguiente, si bien las series de precios de San Martín, Piura y La Libertad presentan un quiebre estructural y no cuentan con la presencia de raíz unitaria al 95\% de confianza, sí es posible rechazar la presencia de un quiebre al $99 \%$. Cabe resaltar que los potenciales quiebres tuvieron lugar en 2005, con la caída del precio internacional del arroz en 2004 ante un exceso de producción a nivel mundial. A partir de ese momento, los precios se caracterizaron por un menor ritmo de crecimiento que explica el cambio en pendiente. Esto podría deberse a la decisión de los agricultores de no volver a aumentar drásticamente la producción de arroz para evitar precios desfavorables.

\section{Test de cointegración}

El número de rezagos que asegura la parsimonia en el VECM fue determinado según el Schwartz Bayesian Criterion (SBC), el cual sugiere la incorporación de solo un rezago en la relación de largo plazo para las cuatro regiones estudiadas. El rezago óptimo de un mes podría explicarse por la presencia de información 
imperfecta en los agricultores, que les impide una respuesta inmediata ante movimientos en precios internacionales.

Dado que al 99\% de confianza se puede afirmar la presencia de raíz unitaria, tanto en la serie de precios internacionales del arroz cáscara como en sus precios en chacra para las cuatro regiones estudiadas, se examinó la posible existencia de cointegración. Con este propósito, se aplicó el test de Johansen, por su elevado poder de prueba al respecto.

Los resultados con ese test mostraron la existencia de una relación de largo plazo significativa entre el precio internacional y el precio en chacra de Lambayeque y La Libertad, con un 95\% de confianza. Pero no evidenciaron una relación de largo plazo entre el precio internacional y el precio de chacra en las dos regiones que concentran la mayor producción de arroz nacional: San Martín y Piura, donde el test de Johansen no pudo rechazar la ausencia de vectores de cointegración al $95 \%$ de confianza. Este resultado podría deberse a que, en dichas regiones, una mayor producción permite abastecer la demanda local con una menor dependencia del precio en chacra sobre al precio internacional. En suma, el precio internacional presenta una relación de largo plazo solo con los precios en chacra de Lambayeque y La Libertad.

\section{Test de causalidad}

Para evaluar la dirección de la relación entre las variables, se realizó la prueba de causalidad de Granger en ambos sentidos. Los resultados evidencian que la causalidad se da únicamente en una dirección: el precio internacional causa al precio en chacra en las cuatro regiones. Son resultados lógicos, pues intuitivamente se entiende que el precio internacional sea tomado en cuenta para determinar el precio en chacra; mientras que los precios en chacra de las regiones estudiadas no sean relevantes para la determinación del precio internacional.

\section{Modelo de vectores de corrección de errores}

Dados los resultados previos, se estimó un VECM en el cual el precio en chacra está explicado por el precio internacional para las regiones de Lambayeque y La Libertad. Cabe mencionar que existe la posibilidad de que la cointegración entre el precio internacional y el de La Libertad se vea sesgada por la presencia de un quiebre estructural ${ }^{7}$.

\footnotetext{
${ }^{7} \mathrm{Al}$ respecto, vale recordar lo hallado acerca de que la serie de precios de La Libertad presenta un quiebre estructural y, aunque no presenta raíz unitaria al $95 \%$ de confianza, sí puede presentarla al 99\% de confianza.
} 
La tabla 1 muestra los resultados en la ecuación de cointegración. Estos indican que, ante un movimiento de un sol por kilogramo en el precio internacional, los precios en chacra reaccionan en la misma dirección, pero no capturan completamente la variación del precio internacional. Asimismo, en la tabla 2, se observan los coeficientes de ajuste de corto plazo hacia la relación de equilibrio de largo plazo, los cuales son negativos y significativos al $95 \%$ de confianza.

Cabe notar que el efecto de ajuste para La Libertad $(-0,18)$ es ligeramente mayor que para Lambayeque $(-0,16)$; de modo que, ante un desequilibrio de igual magnitud, el precio en chacra en La Libertad presentaría una mayor variación. Un ajuste de menor magnitud en Lambayeque podría deberse a la presencia de intermediarios con alto poder de negociación. Esto es consistente con Salcedo \& Stiglich (2004), quienes afirman que el mayor desarrollo tecnológico de la industria molinera en Lambayeque respecto a las regiones colindantes, así como la mayor importancia en esa región del crédito informal provisto por los intermediarios que suministran semillas, fertilizantes y dinero en efectivo a cambio de producción de arroz, agrandan el poder de negociación de molineros e intermediarios sobre los agricultores de la región.

Todo ello valida la hipótesis de la existencia de transmisión de precios en las regiones de Lambayeque y La Libertad, porque, ante una variación del precio internacional, el precio en chacra se ajustaría para mantener la relación de largo plazo.

A fin de evaluar la asimetría en la trasmisión de precios, se estimó el TVECM, cuyos resultados se encuentran en la tabla 2. Este modelo se divide en dos regímenes. El primero abarca un desequilibrio de largo plazo negativo ante un aumento de precios internacionales. Dado que los productores no reaccionan inmediatamente a variaciones del precio internacional, un aumento de este implicaría un precio en chacra menor que el esperado según la relación de largo plazo. El desequilibrio tendría que ser mediatizado por un incremento en el precio en chacra. En cambio, el segundo régimen muestra el escenario de una disminución del precio internacional, que implica un desequilibrio de largo plazo positivo. En este escenario, los productores no ajustan su precio inmediatamente y el precio en chacra resulta mayor de lo que se esperaría con la relación de largo plazo. Este desequilibrio debe ser mediatizado luego con una disminución del precio en chacra.

En el régimen 1, ninguno de los coeficientes de ajuste hacia la relación de largo plazo es significativamente distinto de cero para Lambayeque. Sin embargo, en La Libertad, la estimación sugiere que se alcanza el equilibrio 
de largo plazo a través del movimiento del precio internacional, al 95\% de confianza. En el régimen 2, el coeficiente de ajuste hacia la relación de largo plazo es significativo y negativo, al $90 \%$ de confianza, tanto en Lambayeque como en La Libertad, ante caídas del precio internacional.

Ello comprueba la asimetría en la transmisión de precios planteada como hipótesis de estudio. En el régimen 1, caracterizado por un aumento de precios internacionales, el ajuste hacia la relación de largo plazo es significativamente igual a cero; es decir, la transmisión de precios hacia el precio en chacra es baja. Mientras que, en el régimen 2, caracterizado por una disminución de precios internacionales, el ajuste hacia la relación de largo plazo es significativamente distinto de cero, lo cual indica que la transmisión de precios hacia el precio en chacra se da y ocurre en una proporción mayor que en el primer régimen.

Tabla 1

Resultados de estimación de la ecuación de cointegración

\begin{tabular}{ccc}
\hline & \multicolumn{2}{c}{ Ecuación de cointegración } \\
\cline { 2 - 3 } Precio internacional $_{t-1}$ & Precio Lambayeque $_{t}$ & Precio La Libertad $_{t}$ \\
\cline { 2 - 3 } Constante & $-0,866^{* * *}$ & $-0,824^{* * *}$ \\
& $(0,215)$ & $(0,208)$ \\
& $-0,245$ & $-0,308$ \\
\hline
\end{tabular}

Notas. Errores estándar entre paréntesis para los coeficientes estimados. Los asteriscos simples, dobles y triples $(*, * *, * * *)$ indican significancia estadística al $10 \%, 5 \%$ y $1 \%$, respectivamente.

Tabla 2

Resultados de estimación del VECM $\triangle$ Precio departamento $_{\text {it }}$

\begin{tabular}{lccc}
\hline & \multirow{2}{*}{ VECM lineal } & \multicolumn{2}{c}{ Threshold VECM } \\
\cline { 3 - 4 } & & Régimen 1 & Régimen 2 \\
\hline Lambayeque & & & \\
\hline Observaciones (\%) & & 35,3 & 64,7 \\
$E C T_{t-1}$ & $-0,155^{* *}$ & $-0,246$ & $-0,153^{*}$ \\
& $(0,040)$ & $(0,123)$ & $(0,013)$ \\
Constante & 0,004 & $-0,001$ & 0,020 \\
& $(0,007)$ & $(0,966)$ & $(0,190)$ \\
\hline
\end{tabular}




\begin{tabular}{|c|c|c|c|}
\hline & \multirow{2}{*}{ VECM lineal } & \multicolumn{2}{|c|}{ Threshold VECM } \\
\hline & & Régimen 1 & Régimen 2 \\
\hline \multirow[t]{2}{*}{$\Delta$ Precio internacional $l_{t-1}$} & $-0,068$ & 0,213 & $-0,256$ \\
\hline & $(0,152)$ & $(0,374)$ & $(0,204)$ \\
\hline \multirow{2}{*}{$\Delta$ Precio Lambayeque $_{t-1}$} & $-0,029$ & $-0,035$ & $-0,044$ \\
\hline & $(0,076)$ & $(0,803)$ & $(0,634)$ \\
\hline Vector de cointegración & $(1,-0,866)$ & $(1,-1,069)$ & \\
\hline \multicolumn{4}{|l|}{ La Libertad } \\
\hline Observaciones (\%) & - & 48,2 & 51,8 \\
\hline \multirow[t]{2}{*}{$E C T_{t-1}$} & $-0,178^{* * *}$ & $-0,220$ & $-0,175^{*}$ \\
\hline & $(0,042)$ & $(0,130)$ & $(0,017)$ \\
\hline \multirow[t]{2}{*}{ Constante } & 0,004 & $-0,001$ & 0,018 \\
\hline & $(0,008)$ & $(0,956)$ & $(0,353)$ \\
\hline \multirow[t]{2}{*}{$\Delta$ Precio internacional $_{t-1}$} & $-0,107$ & 0,211 & $-0,486$ \\
\hline & $(0,166)$ & $(0,340)$ & $(0,060)$ \\
\hline \multirow[t]{2}{*}{$\Delta$ Precio La Libertad $_{t-1}$} & 0,047 & 0,235 & $-0,027$ \\
\hline & $(0,075)$ & $(0,100)$ & $(0,762)$ \\
\hline Vector de cointegración & $(1,-0,824)$ & $(1,-1,167)$ & \\
\hline
\end{tabular}

Notas. Errores estándar entre paréntesis para los coeficientes estimados. Los asteriscos simples, dobles y triples $\left(*, * *,{ }^{* *}\right)$ indican significancia estadística al $10 \%, 5 \%$ y $1 \%$, respectivamente.

Adicionalmente, se realizó una estimación basada en una elección endógena de umbrales. Sus resultados, mostrados en la tabla 3, mantienen las conclusiones de la estimación previa. No obstante, dado que los umbrales elegidos endógenamente son cercanos a cero, esto indicaría que la asimetría de transmisión de precios no es tan clara ante cambios marginales. 
Tabla 3

Resultados de estimación del TVECM con umbrales endógenos $\Delta$ Precio departamento $_{i t}$

\begin{tabular}{|c|c|c|}
\hline & \multicolumn{2}{|c|}{ TVECM } \\
\hline & Régimen 1 & Régimen 2 \\
\hline \multicolumn{3}{|l|}{ Lambayeque } \\
\hline Observaciones (\%) & 21,8 & 78,2 \\
\hline \multirow[t]{2}{*}{$E C T_{t-1}$} & $-0,018$ & $-0,124^{*}$ \\
\hline & $(0,939)$ & $(0,011)$ \\
\hline \multirow[t]{2}{*}{ Constante } & 0,016 & 0,010 \\
\hline & $(0,689)$ & $(0,390)$ \\
\hline \multirow[t]{2}{*}{$\Delta$ Precio internacional $_{t-1}$} & $0,981^{* *}$ & $-0,248$ \\
\hline & $(0,003)$ & $(0,134)$ \\
\hline \multirow[t]{2}{*}{$\Delta$ Precio Lambayeque $e_{t-1}$} & $-0,728^{* * *}$ & 0,070 \\
\hline & $(0,000)$ & $(0,374)$ \\
\hline Vector de cointegración & $(1,-1,072)$ & \\
\hline Valor del threshold & $-0,090$ & \\
\hline \multicolumn{3}{|l|}{ La Libertad } \\
\hline Observaciones (\%) & 48,2 & 51,8 \\
\hline \multirow[t]{2}{*}{$E C T_{t-1}$} & $-0,225$ & $-0,181^{*}$ \\
\hline & $(0,123)$ & $(0,014)$ \\
\hline \multirow[t]{2}{*}{ Constante } & 0,003 & 0,023 \\
\hline & $(0,878)$ & $(0,274)$ \\
\hline \multirow[t]{2}{*}{$\Delta$ Precio internacional $_{t-1}$} & 0,212 & 0,492 \\
\hline & $(0,338)$ & $(0,057)$ \\
\hline \multirow[t]{2}{*}{$\Delta$ Precio La Libertad $_{t-1}$} & 0,236 & $-0,024$ \\
\hline & $(0,099)$ & $(0,786)$ \\
\hline Vector de cointegración & $(1,-1,141)$ & \\
\hline Valor del threshold & 0,025 & \\
\hline
\end{tabular}

Notas. Errores estándar entre paréntesis para los coeficientes estimados. Los asteriscos simples, dobles y triples $\left(*,{ }^{* *},{ }^{* * *}\right)$ indican significancia estadística al $10 \%, 5 \%$ y $1 \%$, respectivamente. 


\section{Metodología 2: Estimación de corto plazo}

La estimación de corto plazo fue realizada mediante el modelo VAR para San Martín, Piura y La Libertad, debido a los siguientes motivos: (1) ausencia de cointegración entre el precio internacional y precio en chacra para las dos primeras regiones; y (2) existencia de quiebre estructural en la serie de precios en chacra para la tercera región.

\section{Filtro de series con quiebre estructural}

Dada la presencia de quiebre estructural al 95\% de confianza en las series de precios en San Martín, Piura y La Libertad, se filtraron estas series de manera que sean estacionarias en media, modelando los precios de cada región con variables dicotómicas que toman el valor de una unidad desde que ocurre cada tipo de quiebre. En Piura y La Libertad, regiones cuyas series de precios cuentan con quiebre en media y pendiente, ambos tipos de quiebre se dan al mismo tiempo, por lo que resulta suficiente la incorporación de una sola variable dicotómica en el modelo, el cual se plantea de la siguiente manera:

$$
P_{i t}=\mu_{i}+\beta t+\alpha D T_{t}+P_{i t}^{c}
$$

Donde $P_{i t}$ es el precio en chacra en la región $i$ en el período $t, \mu_{i}$ es una constante que refleja el precio base, es una tendencia determinística, $D T_{t}$ es la variable dicotómica que toma el valor de uno después de ocurrido el quiebre estructural y $P_{i t}^{c}$ es el error de la ecuación que captura el componente cíclico del precio en chacra en el período $t$ y que es la nueva serie filtrada. Los resultados del modelo se presentan en la tabla 4 .

Tabla 4

Modelo para filtro por quiebre estructural

\begin{tabular}{lccc}
\hline Precio en chacra & $\begin{array}{c}\text { Precio en chacra en } \\
\text { San Martín }\end{array}$ & $\begin{array}{c}\text { Precio en chacra en } \\
\text { La Libertad }\end{array}$ & $\begin{array}{c}\text { Precio en chacra en } \\
\text { Piura }\end{array}$ \\
\hline Constante & $0,524^{* * *}$ & $0,702^{* * *}$ & $0,707^{* * *}$ \\
Tendencia & $(0,024)$ & $(0,034)$ & $(0,034)$ \\
determinística & $0,004^{* * *}$ & $0,004^{* * *}$ & $0,004^{* * *}$ \\
Dummy ene2005 & $(0,000)$ & $(0,000)$ & $(0,000)$ \\
& $-0,173^{* * *}$ & & \\
Dummy mar2005 & $(0,037)$ & & \\
& & $-0,120^{* *}$ & \\
\hline
\end{tabular}




\begin{tabular}{lccc}
\hline Precio en chacra & $\begin{array}{c}\text { Precio en chacra en } \\
\text { San Martín }\end{array}$ & $\begin{array}{c}\text { Precio en chacra en } \\
\text { La Libertad }\end{array}$ & $\begin{array}{c}\text { Precio en chacra en } \\
\text { Piura }\end{array}$ \\
\hline Dummy abr2005 & & $-0,188^{* * *}$ \\
Observaciones & 172 & 172 & $(0,055)$ \\
\hline
\end{tabular}

Notas. Errores estándar entre paréntesis.

*** $\mathrm{p}<0,01,{ }^{* *} \mathrm{p}<0,05,{ }^{*} \mathrm{p}<0,1$.

La filtración de las series de precios en dichas regiones sirvió para capturar el componente cíclico, eliminando tendencias determinísticas sin alterar las relaciones temporales en estas. Luego, aplicamos los tests Augmented Dicky-Fuller (ADF) y Phillips-Perron (PP) a las series filtradas, para probar su estacionariedad en media y así poder evaluar la efectividad del filtro empleado. Y encontramos que las series filtradas de precios en San Martín, Piura y La Libertad son estacionarias en media al 99\% de confianza para ambas pruebas.

\section{Vectores autorregresivos y vectores autorregresivos con threshold}

Luego de extraer el componente cíclico de las series de precios aplicando el Schwartz Bayesian Criterion (SBC), se obtuvo un número óptimo de rezagos equivalente a 1 para las tres regiones. Debido a la existencia de multicolinealidad entre las variables presentadas (una característica propia de la metodología VAR), no era posible utilizar el test $t$ para probar la significancia del precio internacional. Pero sí resultaba válido evaluar la significancia de las variables a través de la magnitud de los coeficientes.

Los resultados, presentados en la tabla 5, demuestran que, para las tres regiones analizadas, si bien el precio en chacra se ve altamente explicado por su propio rezago, el precio internacional tiene un efecto directo menor. Aunque esto podría interpretarse como que el precio internacional no es significativo para explicar el precio de chacra en las tres regiones, es importante notar que el rezago del precio en chacra incorpora el efecto de rezagos previos del precio internacional. Por esta razón, no se descarta la existencia de transmisión de precios.

El impacto del precio internacional es ligeramente mayor en Piura $(0,039)$, y aún más en La Libertad (0,077), que en San Martín (0,036). Nuevamente, se observa la existencia de una transmisión más débil entre los precios internacionales y de chacra en regiones con mayor producción local de arroz cáscara. De esta manera, es posible concluir que, tanto en las relaciones de corto como de 
largo plazo, el nivel de transmisión de los precios internacionales se intensifica en las regiones con menor producción local.

A fin de evaluar nuestra segunda hipótesis, referida a la asimetría en la transmisión de precios, se estimó el TVAR. De manera similar al TVECM para las relaciones de largo plazo, la metodología TVAR permite evaluar la relación de corto plazo en dos situaciones distintas, sobre la base de un umbral previamente establecido e igual a cero, para distinguir los movimientos al alza o a la baja en los precios internacionales de arroz cáscara. Cabe mencionar que previamente se comprobó la equidad de la muestra, para asegurar una mayor confiabilidad de los resultados. Así, se verificó que el 46\% y el $54 \%$ de la muestra representaban movimientos al alza y caídas del precio internacional, respectivamente.

Tabla 5

Resultados de la estimación de VAR Precio departamento ${ }_{\text {it }}$

\begin{tabular}{|c|c|c|c|}
\hline & \multirow[t]{2}{*}{ VAR lineal } & \multicolumn{2}{|c|}{ Threshold VAR } \\
\hline & & Régimen 1 & Régimen 2 \\
\hline \multicolumn{4}{|l|}{ San Martín } \\
\hline \multirow[t]{2}{*}{ Precio San Martín $_{t-1}$} & 0,899 & 0,954 & 0,849 \\
\hline & $(0,033)$ & $(0,047)$ & $(0,046)$ \\
\hline \multirow[t]{2}{*}{ Precio internacional $_{t-1}$} & 0,036 & 0,004 & 0,065 \\
\hline & $(0,020)$ & $(0,029)$ & $(0,029)$ \\
\hline \multirow[t]{2}{*}{ Constante } & $-0,027$ & $-0,006$ & $-0,048$ \\
\hline & $(0,016)$ & $(0,023)$ & $(0,023)$ \\
\hline Coeficiente de determinación & 0,845 & & \\
\hline \multicolumn{4}{|l|}{ Piura } \\
\hline \multirow[t]{2}{*}{ Precio Piura $_{t-1}$} & 0,891 & 0,930 & 0,852 \\
\hline & $(0,033)$ & $(0,049)$ & $(0,049)$ \\
\hline \multirow[t]{2}{*}{ Precio internacional $_{t-1}$} & 0,039 & 0,013 & 0,061 \\
\hline & $(0,033)$ & $(0,047)$ & $(0,048)$ \\
\hline \multirow[t]{2}{*}{ Constante } & $-0,029$ & $-0,003$ & $-0,052$ \\
\hline & $(0,025)$ & $(0,037)$ & $(0,037)$ \\
\hline Coeficiente de determinación & 0,822 & & \\
\hline
\end{tabular}




\begin{tabular}{lccc}
\hline & \multirow{2}{*}{ VAR lineal } & \multicolumn{2}{c}{ Threshold VAR } \\
\cline { 3 - 4 } & & Régimen 1 & Régimen 2 \\
\hline La Libertad & 0,831 & 0,887 & 0,791 \\
\hline Precio La Libertad $t-1$ & $(0,041)$ & $(0,061)$ & $(0,057)$ \\
& 0,077 & 0,008 & 0,139 \\
Precio internacional & & $(0,056)$ & $(0,055)$ \\
& $(0,039)$ & 0,01 & $-0,109$ \\
Constante & $-0,058$ & $(0,043)$ & $(0,043)$ \\
& $(0,029)$ & & \\
\hline
\end{tabular}

Nota. Errores estándar entre paréntesis para los coeficientes estimados.

Para San Martín, Piura y La Libertad, los resultados (véase la tabla 5) evidencian que los precios en chacra reaccionan más ante caídas que ante alzas del precio internacional, lo cual verifica nuestra hipótesis de asimetría. También es importante notar que la relación asimétrica se acentúa en la región La Libertad, donde se produce menos arroz cáscara entre las tres regiones analizadas. Para dicha región, un alza en un sol en el precio mundial implica una reacción de un alza en 0,008 soles del precio en chacra, mientras que una caída de la misma magnitud implica una caída de 0,139 soles en el precio en chacra.

Los resultados obtenidos resultan interesantes, puesto que evidencian una alta transmisión a pesar del bajo nivel de importaciones. Esto es consistente con lo hallado por Ceballos et al. (2015), quienes, usando la metodología VAR, detectan una alta transmisión para el caso del arroz en el Perú. Además, Hernández-Villafuerte (2012) encuentra que existe una alta transmisión de precios entre países sea con alta o con baja comercialización del producto estudiado, y argumenta que la relación puede ser directa o indirecta. En efecto, la alta transmisión puede deberse a que el arroz es un alimento básico de difícil sustitución en la canasta familiar peruana y, por tanto, los únicos sustitutos del arroz peruano resultan ser arroces importados.

\section{Robustez de la estimación}

Si bien la región San Martín se caracteriza por una producción continua de arroz a lo largo del ańo, en Piura, Lambayeque y La Libertad, la campaña agrícola solo se da en determinados meses del año y, por consiguiente, no existen precios en chacra registrados para los meses restantes. La inexistencia 
de precios en chacra para ciertos meses resulta una limitación debido a dos razones: (1) sí existe un precio internacional en esos meses sin precios de chacra registrados para aquellas regiones y (2) el impacto del precio internacional sobre el precio en chacra tiene un rezago de un mes en nuestra metodología. Por ello, ambas series no pueden restringirse solo a aquellos meses en los que sí se registra el precio en chacra. Por ejemplo, en La Libertad no existe un precio en chacra en diciembre porque todavía no hay cosecha; sin embargo, no se puede excluir este mes del análisis porque el precio internacional de diciembre sí tiene un impacto en el precio en chacra en enero, período de inicio de cosecha.

A fin de lidiar con la ausencia de datos en los meses sin producción, optamos por utilizar el precio inmediato anterior disponible para completar los precios faltantes. La razón de esta elección se basa en el supuesto de que, durante los meses entre el fin y el inicio de una campańa, si los agricultores tuviesen algún remanente, lo ofertarían manteniendo el último precio de la campaña recién finalizada. Asimismo, cabe resaltar que evaluar un potencial mercado de arroz en chacra en dichos meses resulta plausible, porque en algunos años sí se comercializó arroz en chacra en esos meses debido a adelantos o retrasos en la cosecha y por la posibilidad de que los agricultores almacenen parte de la producción.

No obstante, es importante reconocer que la repetición de datos podría restar variabilidad a los datos tomados en consideración y distorsionar la estimación. Por ello, a fin de evaluar la robustez en el manejo de missing values, se emplearon dos metodologías. Primero, se realizaron 10.000 simulaciones de la estimación completando la serie del precio en chacra con la repetición de la última observación, afectada por un ruido aleatorio distribuido normalmente con media 0 y desviación estándar de 0,05. Ello con el objetivo de analizar si el efecto del precio internacional en el precio en chacra se ve afectado ante un cambio de baja magnitud en la serie del precio en chacra (véase la tabla 6). 
Luego, se corroboraron los resultados obtenidos con la repetición inmediata empleando tres métodos de interpolación alternativos: (1) expectation-maximization, (2) splines y (3) media móvil (véanse las tablas 7, 8 y 9).

Con esas cuatro metodologías, las conclusiones se mantienen: existe una transmisión significativa en La Libertad y Lambayeque, mas no para Piura. Sin embargo, al emplear las simulaciones con ruido, splines y media móvil, se observa una ligera sobrestimación de los coeficientes de ajuste de largo plazo en el modelo original. Esto podría deberse a que la repetición del último valor observado para subsanar los valores faltantes resta variabilidad al precio en chacra.

También se comprueba la asimetría en la transmisión de precios para La Libertad y Lambayeque mediante los tres métodos alternativos de interpolación. Pero el análisis de robustez conduce a concluir que, con la metodología del TVAR, no es factible evaluar la relación asimétrica de precios de corto plazo, pues los coeficientes originales se encuentran fuera del rango de los obtenidos mediante las 10.000 simulaciones. 
Tabla 6

Resultados de estimación del VECM - Robustez
$\Delta$ Precio departamento
it

\begin{tabular}{|c|c|c|c|c|}
\hline & \multicolumn{4}{|c|}{ VECM lineal } \\
\hline & Original & $\begin{array}{l}\text { Expectation- } \\
\text { maximization }\end{array}$ & Splines & Media móvil \\
\hline \multicolumn{5}{|l|}{ Lambayeque } \\
\hline \multirow{2}{*}{$E C T_{t-1}$} & $-0,155^{* *}$ & $-0,177^{* * *}$ & $-0,156^{* * *}$ & $-0,136^{* * *}$ \\
\hline & $(0,040)$ & $(0,046)$ & $(0,037)$ & $(0,037)$ \\
\hline \multirow[t]{2}{*}{ Constante } & 0,004 & 0,004 & 0,003 & 0,004 \\
\hline & $(0,007)$ & $(0,008)$ & $(0,007)$ & $(0,006)$ \\
\hline \multirow[t]{2}{*}{$\Delta$ Precio internacional $_{t-1}$} & $-0,068$ & $-0,138$ & $-0,104$ & $-0,107$ \\
\hline & $(0,152)$ & $(0,162)$ & $(0,141)$ & $(0,135)$ \\
\hline \multirow[t]{2}{*}{$\Delta$ Precio Lambayeque $_{t-1}$} & $-0,029$ & $-0,095$ & $0,178^{* * *}$ & 0,057 \\
\hline & $(0,076)$ & $(0,077)$ & $(0,075)$ & $(0,077)$ \\
\hline Vector de cointegración & $(1,-0,866)$ & $(1,-0,804)$ & $(1,-0,798)$ & $(1,-0,832)$ \\
\hline \multicolumn{5}{|l|}{ La Libertad } \\
\hline \multirow[t]{2}{*}{$E C T_{t-1}$} & $-0,178^{* * *}$ & $-0,158^{* * *}$ & $-0,179^{* * *}$ & $-0,137^{* * *}$ \\
\hline & $(0,042)$ & $(0,042)$ & $(0,038)$ & $(0,037)$ \\
\hline \multirow[t]{2}{*}{ Constante } & 0,004 & 0,004 & 0,003 & 0,003 \\
\hline & $(0,008)$ & $(0,008)$ & $(0,007)$ & $(0,007)$ \\
\hline \multirow[t]{2}{*}{$\Delta$ Precio internacional $_{t-1}$} & $-0,107$ & $-0,066$ & 0,001 & 0,051 \\
\hline & $(0,166)$ & $(0,170)$ & $(0,157)$ & $(0,149)$ \\
\hline \multirow[t]{2}{*}{$\Delta$ Precio La Libertad ${ }_{t-1}$} & 0,047 & $-0,037$ & $0,234^{* * *}$ & 0,053 \\
\hline & $(0,075)$ & $(0,076)$ & $(0,073)$ & $(0,075)$ \\
\hline Vector de cointegración & $(1,-0,824)$ & $(1,-0,882)$ & $(1,-0,862)$ & $(1,-0,889)$ \\
\hline
\end{tabular}

Notas. Errores estándar entre paréntesis para los coeficientes estimados. Los asteriscos simples, dobles y triples $\left(*,{ }^{* *},{ }^{* *}\right)$ indican significancia estadística al $10 \%, 5 \%$ y $1 \%$, respectivamente. 


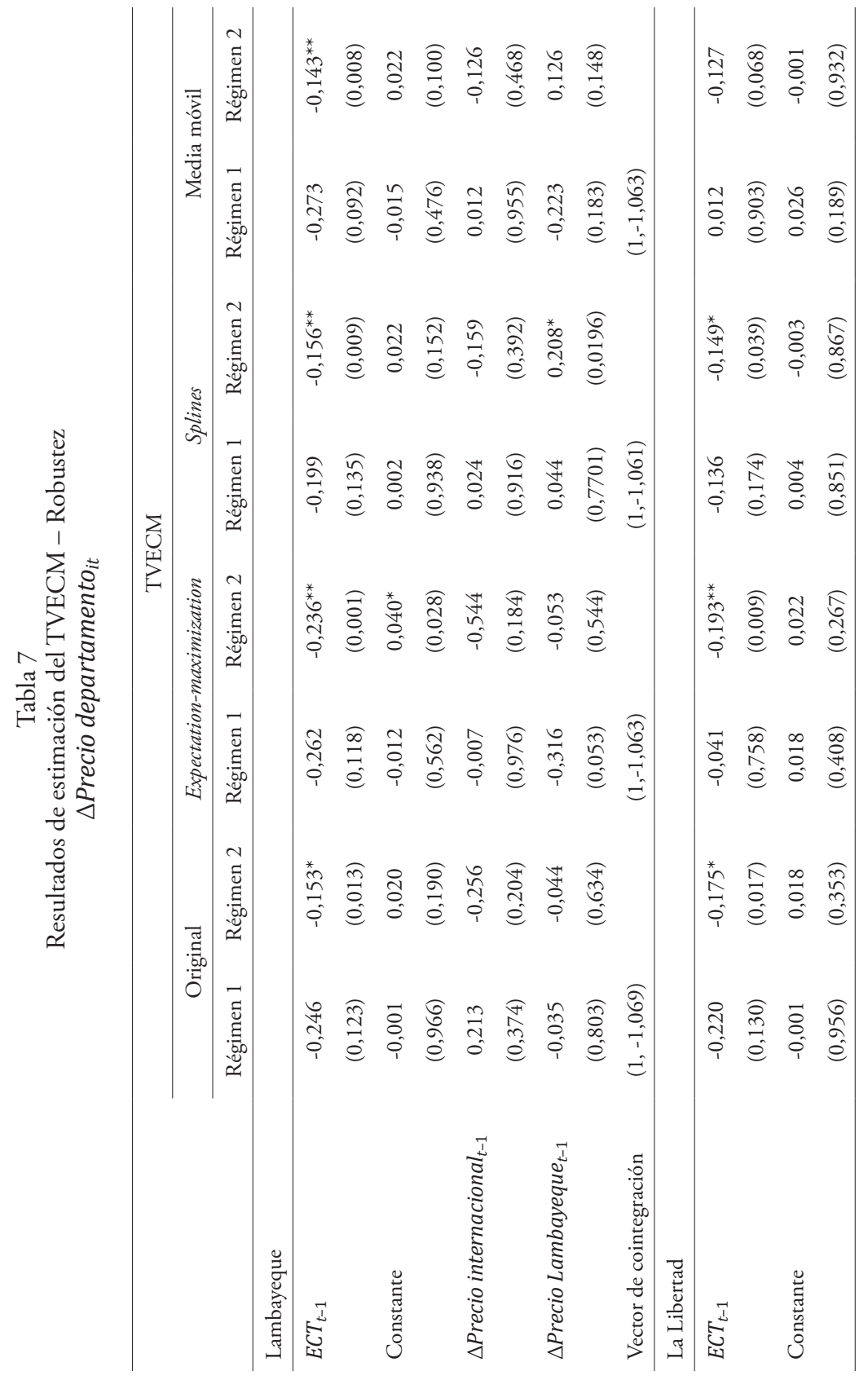




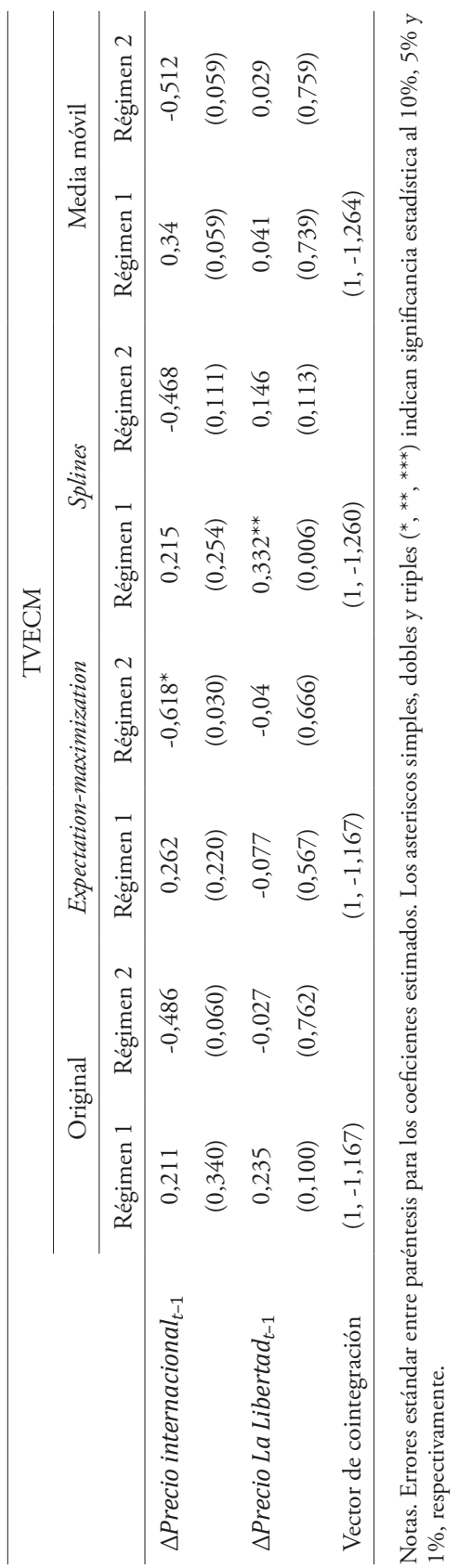


Tabla 8

Resultados de estimación del VAR - Robustez
Precio departamento
it

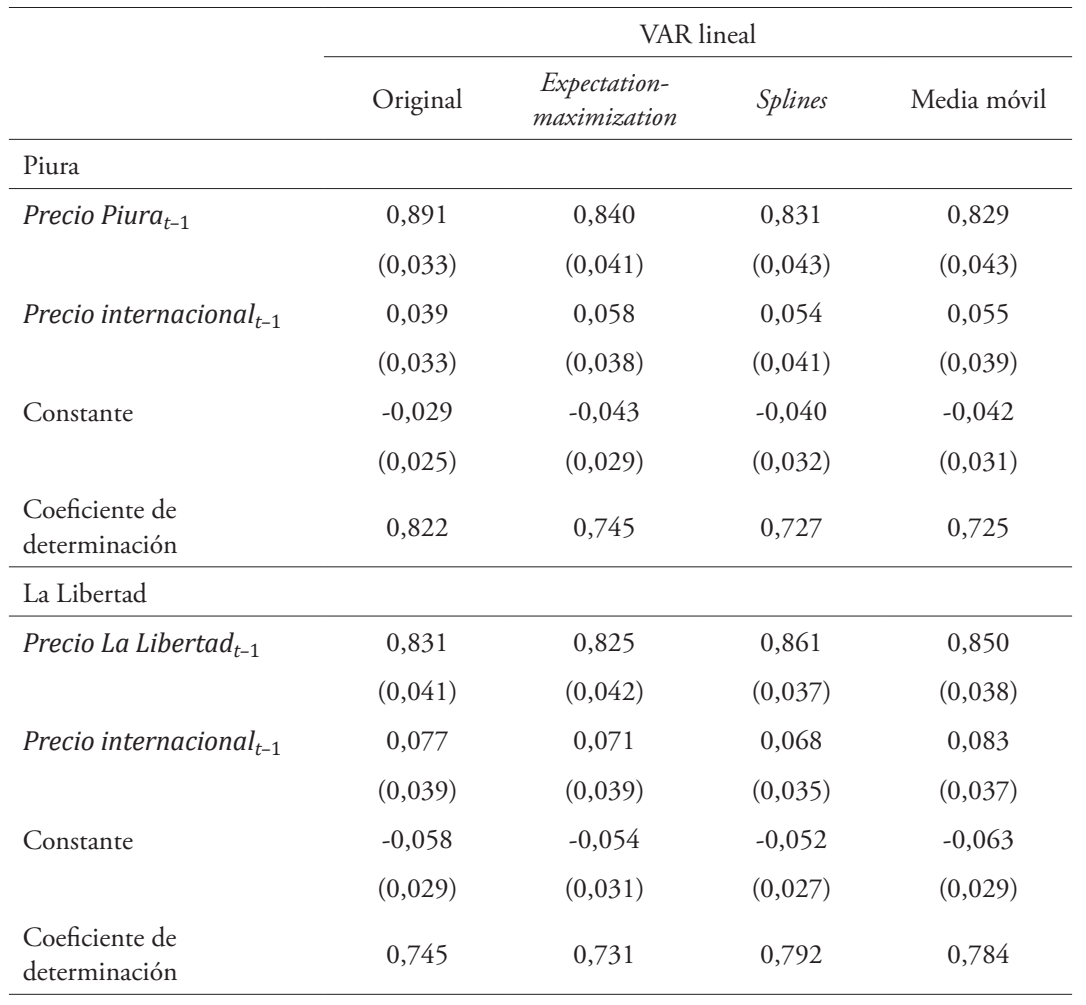

Nota. Errores estándar entre paréntesis para los coeficientes estimados. 


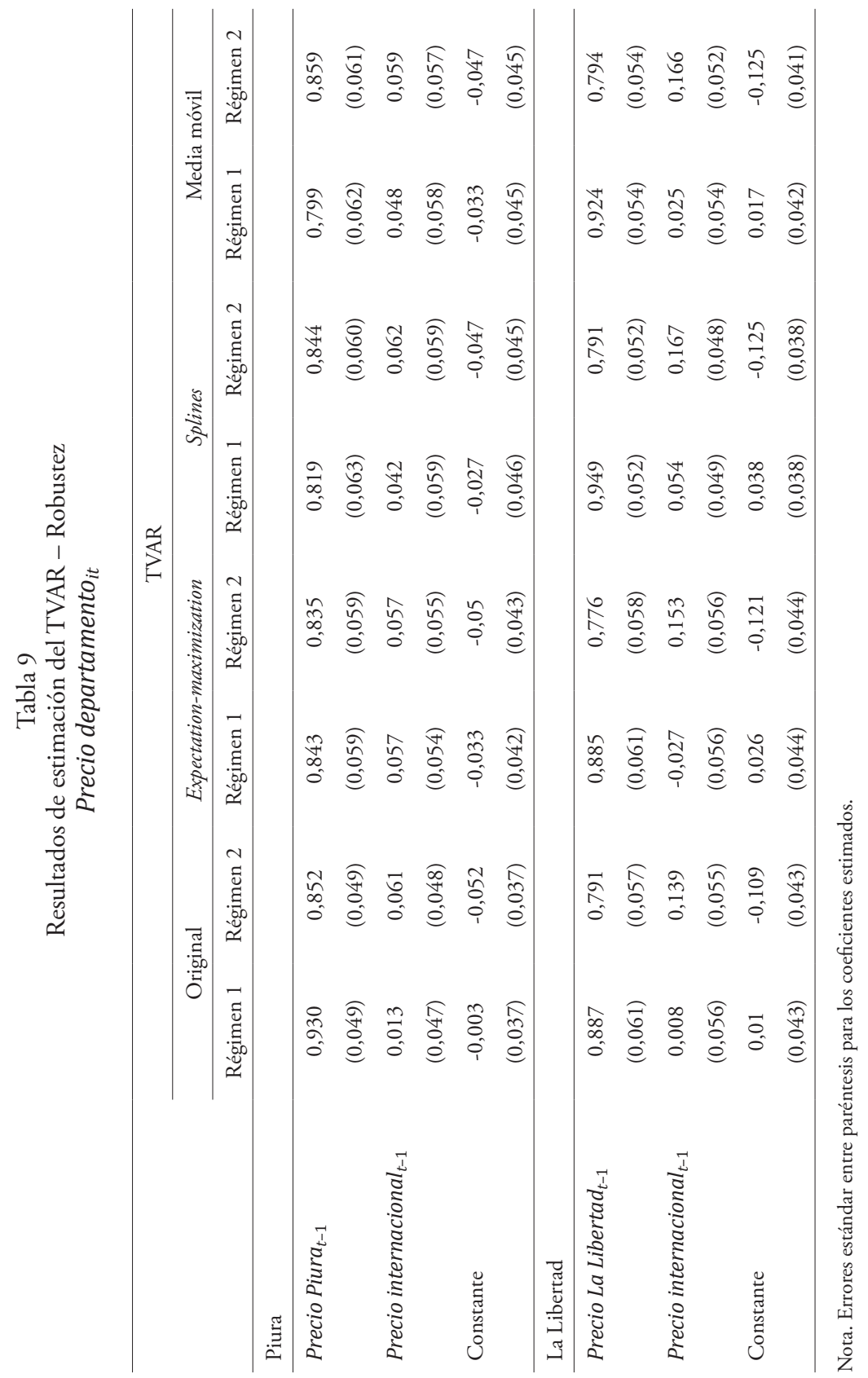




\section{Limitaciones y extensiones para estudios futuros}

Es indudable que nuestra investigación tiene ciertas limitaciones y posibles extensiones que podrían desarrollarse en futuras investigaciones para una mejor comprensión del fenómeno estudiado. Aquí mencionaremos una limitación y dos posibles extensiones importantes.

En primer lugar, la limitación consiste en no haber podido incorporar el efecto del régimen peruano de franja de precios en nuestra estimación de la transmisión de precios, debido a que no se contó con información detallada sobre los ajustes realizados por dicho régimen. Esta carencia de datos puede habernos llevado a subestimar el efecto del precio internacional sobre los precios en chacra locales.

En segundo lugar, la presencia de quiebres estructurales y el uso de filtros en las series de precios en chacra podrían haber sesgado nuestros resultados tanto de las pruebas estadísticas aplicadas como en la estimación del modelo utilizado. Al respecto, algunos autores, como Hernández-Villafuerte (2008), emplean el método planteado por Gregory \& Hansen (1996), que estima una cointegración con quiebres estructurales. Sin embargo, no es posible aplicar ese método con los paquetes estadísticos que hemos utilizado, Eviews y R Studio, por lo que se sugeriría tomarlo en consideración en futuras investigaciones.

En tercer lugar, si bien hemos optado por no incorporar variables de control en la estimación, sería de particular interés considerar como control a una variable relacionada con el poder de negociación de los agricultores. En específico, el índice de Lerner, que evalúa el margen de los agricultores. Dado que la información pública no permite construir ni aproximar dicha variable, la información necesaria podría ser recogida mediante un estudio de campo.

\section{Conclusiones y recomendaciones}

La presente investigación ha evaluado la presencia de una transmisión entre precios internacionales del arroz cáscara y sus precios en chacra a nivel local en las regiones San Martín, Piura, Lambayeque y La Libertad, durante el período de diciembre de 2001 a marzo de 2016. La hipótesis planteada consiste en la existencia no solo de una transmisión de precios sino, además, de una transmisión asimétrica. Es decir, que los precios en chacra reaccionan más ante caídas que ante alzas en los precios internacionales, teniendo en cuenta el alto poder de negociación de los intermediarios en el mercado peruano del arroz.

Se ha verificado una transmisión de precios significativa únicamente en las regiones Lambayeque y La Libertad. San Martín y Piura, ambas principales 
regiones productoras de arroz cáscara peruanas, no presentan una transmisión significativa de precios internacionales, debido a una oferta local autosuficiente. Un hallazgo adicional consiste en que el ajuste de corto plazo con respecto a precios internacionales es mayor en La Libertad que en Lambayeque, lo cual se explicaría por un mayor poder de negociación de los intermediarios en Lambayeque, relacionado con el mayor desarrollo tecnológico de la industria molinera en esa región.

También se comprobó la existencia de una asimetría en la transmisión de precios, en el sentido de que los precios en chacra locales siguen más la tendencia de los precios internacionales cuando estos bajan que cuando suben. Este hallazgo no solo valida nuestra hipótesis al respecto, sino que representa un aporte importante para la elaboración de políticas agrarias, en específico de las destinadas a la producción de arroz. El alto poder de mercado de los intermediarios y su fuerte influencia en el precio que reciben los agricultores pueden perjudicar las políticas aplicadas si estas no fomentan la competencia en la cadena de valor arrocera y su industria molinera en particular. Asimismo, la dependencia de los agricultores de los créditos informales provistos por intermediarios sugiere apuntar a una mayor flexibilidad e inclusión financiera para el sector agrícola. El difícil acceso al crédito formal constituye una de las principales trabas a la competitividad agrícola. La inadecuación de la oferta actual de préstamos bancarios de corto plazo al perfil de pequeños productores agrarios revela un mercado desatendido y favorece el poder de negociación de intermediarios e informales.

Por último, un aporte de nuestra investigación tiene que ver con el limitado número de estudios anteriores para el caso del arroz cáscara en el Perú, así como con el uso de las metodologías TVECM y TVAR para evaluar la transmisión asimétrica de precios durante el período analizado. Pero este trabajo puede ser mejorado por futuras investigaciones que, por ejemplo, superen las limitaciones señaladas respecto a quiebres estructurales y variables de control.

\section{Referencias}

Abdulai, A. (2000). Spatial price transmission and asymmetry in the Ghanaian maize market. Journal of Development Economics, 63(2), 327-349.

Aguiar, D., \& Santana, J. (2002). Asymmetry in farm to retail price transmission: Evidence from Brazil. Agribusiness, 18(1), 37-48.

Ardeni, P. (1989). Does the law of one price really hold for commodity prices? American Journal of Agricultural Economics, 71(3), 661-669. 
Asche, F., Bremnes, H., \& Wessells, C. (1999). Product aggregation, market integration and relationships between prices: An application to world salmon markets. American Journal of Agricultural Economics, 81(3), 568-581.

Bernhard, B., Von Cramon-Taubadel, S., \& Zorya, S. (2006). Vertical price transmission between wheat and flour in Ukraine: A Markov-switching vector error correction approach. En International Association of Agricultural Economists Conference, Gold Coast, Australia.

Bloomberg. (2017). Laboratorio Financiero Bloomberg. Lima: Universidad del Pacífico. https://campusvirtual.up.edu.pe/Biblioteca/laboratorio-financiero-bloomberg.aspx

Ceballos, F., Hernández, M., Minot, N., \& Robles, M. (2015). Grain price and volatility transmission from international to domestic markets in developing countries. Washington D. C.: International Food Policy Research Institute.

Coleman, A. (2009). Storage, slow transport, and the law of one price: Theory with evidence from nineteenth-century U.S. corn markets. The Review of Economics and Statistics, 91(2), 332-350.

Engle, R., \& Granger, C. (1987). Co-integration and error correction: Representation, estimation, and testing. Econometrica, 55(2), 251-276.

Escobal, J., Fort, R., \& Zegarra, E. (2015). Agricultura peruana: nuevas miradas desde el censo agropecuario. Lima: Grupo de Análisis para el Desarrollo (Grade).

FAO (Organización de las Naciones Unidas para la Alimentación y la Agricultura). (2008). Growing demand on agriculture and rising prices of commodities. Roma: Food and Agricultural Organization - Trade and Markets and Agricultural Development Economics Divisions.

Frankel, J., Stein, E., \& Wei, S. (1995). Trading blocs and the Americas: The natural, the unnatural, and the super-natural. Journal of Development Economics, 47(1), 61-95.

Greb, F., Von Cramon-Taubadel, S., Krivobokova, T., \& Munk, A. (2013). The estimation of threshold models in price transmission analysis. American Journal of Agricultural Economics, 95(4), 900-916.

Gregory, A., \& Hansen, B. (1996). Tests for cointegration in models with regime and trend shifts. Oxford Bulletin of Economics and Statistics, 58(3), 555-560.

Hernández, K., Dutoit, L., \& Urrutia, C. (2010). Transmisión de precios en los mercados del maiz y arroz en América Latina. Santiago: Cepal - Unidad de Desarrollo Agrícola División de Desarrollo Productivo y Empresa.

Hernández-Villafuerte, K. (2008). The role of asymmetric price transmission and structural breaks in the relationship between Costa Rican markets of livestock cattle, beef and milk. Gotinga: Georg-August University. Recuperado de https://ageconsearch. umn.edu/record/51697/

Hernández-Villafuerte, K. (2012). Price transmission within selected agricultural markets of Latin America. Gotinga: Georg-August University. Recuperado de https://d-nb. info/1043717366/34

Hylleberg, S., Engle, R., Granger, C., \& Yoo, B. (1990). Seasonal integration and cointegration. Journal of Econometrics, 44(1-2), 215-238. 
INEI (Instituto Nacional de Estadística e Informática). (2012). IV Censo Nacional Agropecuario 2012. Lima: Instituto Nacional de Estadística e Informática.

INEI (Instituto Nacional de Estadística e Informática). (2016). Avance económico y social departamental-Marzo. Lima: Instituto Nacional de Estadística e Informática.

INEI (Instituto Nacional de Estadística e Informática). (2017). Series nacionales. Lima: Instituto Nacional de Estadística e Informática. Recuperado de http://www.inei.gob.pe

Listorti, G. (2009). Testing international price transmission under policy intervention. An application to the soft wheat market. Ancona, Italia: Associazione Alessandro Bartola. Studi e Ricerche di Economia e di Politica Agraria.

Listorti, G., \& Esposti, R. (2012). Horizontal price transmission in agricultural markets: Fundamental concepts and open empirical issues. Bio-Based and Applied Economics, 1(1), 81-96.

McLaren, A. (2015). Asymmetry in price transmission in agricultural markets. Review of Development Economics, 19(2), 415-433.

Miljk, D. (1999). The law of one price in international trade: A critical review. Review of Agricultural Economics, 21(1), 126-139.

Minagri (Ministerio de Agricultura y Riego). (2012). El arroz: principales aspectos de la cadena productiva. Lima: Ministerio de Agricultura y Riego. Recuperado de http:// agroaldia.minagri.gob.pe/biblioteca/download/pdf/agroeconomia/agroecono miaarroz3.pdf

Minot, N. (2011). Transmission of world food price changes to markets in Sub-Saharan Africa. Enero. Washington D. C.: International Food Policy Research Institute.

Morisset, J. (1998). Unfair trade? The increasing gap between world and domestic prices in commodity markets during the past 25 years. The World Bank Economic Review, 12(3), 503-526.

Navarro, H., \& Flores, C. (2006). Impacto de la eliminación del sistema peruano de franja de precios y opciones de politicas para compensar sus efectos en el sector agrario. Lima: Centro Peruano de Estudios Sociales (Cepes).

Rogers, R., \& Sexton, R. (1994). Assessing the importance of oligopsony power in agricultural markets. American Journal of Agricultural Economics, 76(5), 1143-1150.

Rosales, F., \& Von-Cramon, S. (2015). Analysis of price transmission using a nonparametric error correction model with time-varying cointegration. En International Association of Agricultural Economists (IAAE) - 2015 Conference, 9-14 de agosto, Milán, Italia.

Salcedo, R., \& Stiglich, E. (2004). Abuso de poder de compra y determinación de los precios en el mercado de arroz cáscara (el caso de los valles del Bajo Piura y Chancay-Lambayeque). Debate Agrario, 37, 39-73. Lima: Centro Peruano de Estudios Sociales.

Sendhil, R., Kar, A., Mathur, V., \& Jha, G. (2013). Price discovery, transmission and volatility: Evidence from agricultural commodity futures. Agricultural Economics Research Review, 26(1), 41-54.

Serra, T., Goodwin, B., Gil, J., \& Mancuso, A. (2006). Non-parametric modelling of spatial price relationships. Journal of Agricultural Economics, 57(3), 501-522. 
Sexton, R. (1990). Imperfect competition in agricultural markets and the role of cooperatives: A spatial analysis. American Journal of Agricultural Economics, 72(3), 709-720.

Vavra, P., \& Goodwin, B. (2005). Analysis of price transmission along the food chain. OECD Food, Agriculture and Fisheries Working Papers, 3. París: OECD.

Veritrade. (2017). Series - Importaciones de arroz blanqueado Perú. Recuperado de http:// www.veritradecorp.com

Von Cramon-Taubadel, S., \& Meyer, J. (2004). Asymmetric price transmission: A survey. Journal of Agricultural Economics, 5(3), 581-611.

Zavaleta, L. (2013). IV Censo Nacional Agropecuario 2012. En Conferencia del Instituto de Ingenieros de Minas del Perú, noviembre de 2013. Recuperado de http://www. iimp.org.pe/pptjm/jm20131114_conferencia.pdf 


\title{
La infraestructura económica (no urbana) como política win-win en el Perú: hacia el crecimiento económico y la lucha contra la desigualdad
}

\author{
Diana Cáceres Atencio \\ Luis Cruz Cóndor
}

\section{Introducción}

La relación negativa entre crecimiento económico y desigualdad es ampliamente aceptada desde su demostración por Kuznets. El Perú ha mantenido una trayectoria positiva de crecimiento económico (5,7\%) entre 2005 y 2016, superior en algunos años al promedio mundial (INEI, 2017b). Además, la economía peruana se ubica en la mitad del ranking de competitividad mundial 2015-2016 (WEF, 2015). Sin embargo, si bien la desigualdad del gasto se ha reducido en un $17,1 \%$ a nivel nacional durante el período 2005-2015, solo se redujo un $9,4 \%$ en el ámbito rural. Como se observa en la figura 1, dicha reducción fue heterogénea a nivel departamental: en 22 departamentos, la desigualdad del gasto se redujo; en 2, no varió (Amazonas y Junín); y en 1, aumentó (Cajamarca).

Pero hay especialistas que cuestionan la relación negativa entre desigualdad e ingresos. Mientras que López (2003) solo la acepta como poco significativa, otros autores proponen una relación positiva entre ambas variables. Para el caso de la India, Bajar \& Rajeev (2015) encuentran que, si el crecimiento es en el sector industrial, este sería un causante de desigualdad en vez de reducirla. Y en Brasil hubo un impacto positivo del crecimiento sobre la desigualdad durante el período 1976-1996, según un estudio de Paes de Barros (1998, citado por Bourguignon, 2004, p. 15).

\footnotetext{
${ }^{1}$ Este ensayo ha sido elaborado por Diana Cáceres Atencio con base en el Trabajo de Investigación Económica del mismo título que realizó con Luis Cruz Cóndor y concluyó en junio de 2017. Ambos autores agradecen al Mg. Gustavo Guerra-García Picasso, asesor de la investigación.
} 

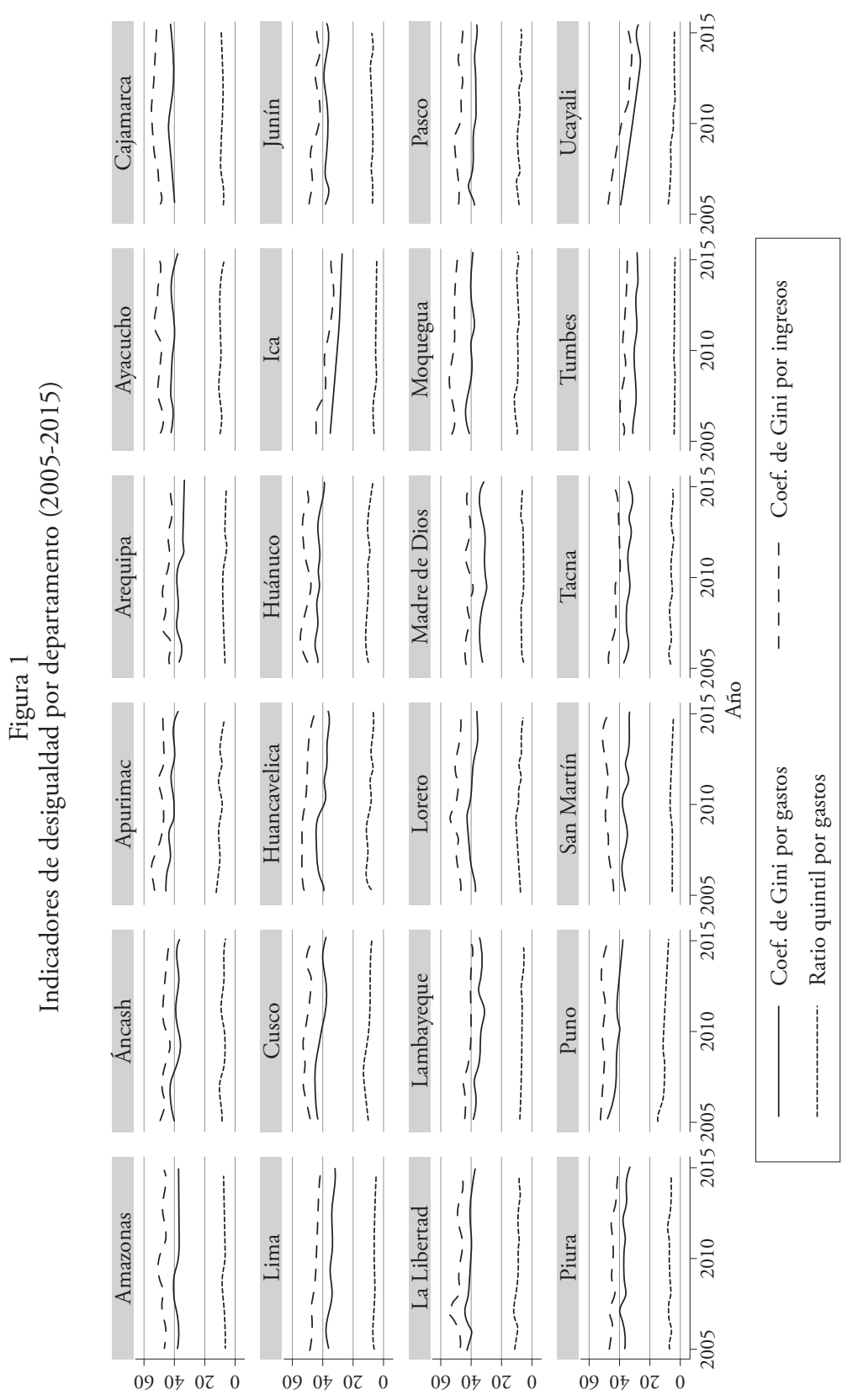

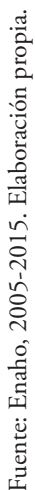


Según Steiner \& Sabogal (2011), el crecimiento económico se siente menos en los sectores menos productivos, dadas las imperfecciones del mercado laboral y la segmentación de mercados. Para el Perú, haciendo referencia a Tello (2013), Arpi (2015) aborda la heterogeneidad a nivel departamental mencionando que el crecimiento y la reducción de la pobreza no lograrán un desarrollo igualitario entre las regiones sin un cambio estructural en la matriz productiva (extractiva) y en el mercado laboral (actividades de baja productividad y alta informalidad).

En la misma línea, Casas (2013) observa que no necesariamente aquellas regiones que perciben canon reducen su desigualdad, sino lo contrario, dado que la actividad extractiva es intensiva en capital físico y no en capital humano, lo que genera concentración del ingreso. Y el sector informal representa el $73,2 \%$ del mercado laboral peruano y se caracteriza por la subutilización de factores productivos y baja productividad (Gestión, 2016). De modo que, en la práctica, no siempre se arriba a la curva de Kuznets tras incorporar las especificidades (fixed-effects) en la ecuación (Deininger \& Squire, 1998).

Este análisis es de vital importancia para diseñar políticas apropiadas, ya que la desigualdad puede intensificar la pobreza y afectar el crecimiento económico, con ocasional causalidad bidireccional. Si los activos económicos de los pobres participan más de la producción, redituarán más ingreso. Así, la pobreza será más sensible al crecimiento mientras más igualitaria sea la distribución. El efecto desigualdad es que, dada la disparidad en los ingresos, el crecimiento económico tendrá una relación positiva con la pobreza en el corto plazo. En el largo plazo, se ajusta por el efecto crecimiento, 20 o 40 años después, según los modelos de crecimiento, lo que genera una persistencia peligrosa para la sociedad (López, 2003). En consecuencia, la vulnerabilidad de la pobreza frente a los ciclos económicos se reduce en una sociedad más igualitaria.

$\mathrm{Al}$ mismo tiempo, la desigualdad puede afectar (negativamente) el crecimiento, por varias vías: a través de créditos a tasas diferenciadas, los pobres enfrentan tasas mayores por falta de colateral (Steiner \& Sabogal, 2011). La teoría del votante medio alude a que en sociedades menos igualitarias se eligen representantes que orientan las políticas hacia la redistribución de recursos (Bourguignon, 2004). La desigualdad gesta crimen, violencia e instituciones débiles que perpetúan la vulnerabilidad de la pobreza (Bourguignon, 2004; Steiner \& Sabogal, 2011). También entorpece la movilidad social, porque la dispersión de ingresos determina la frontera de oportunidades de educación y condiciona la distribución de ingresos de la siguiente generación, lo que perpetúa la pobreza (Steiner \& Sabogal, 2011). Por último, los valores iniciales de 
la desigualdad determinan la trayectoria en la relación crecimiento-pobreza (Steiner \& Sabogal, 2011). Entonces, "para que el crecimiento contribuya de manera efectiva a reducir la pobreza, debe ser incluyente» (Steiner \& Sabogal, 2011, p. 14). De ahí que equilibrar la distribución del ingreso permite un mejor aprovechamiento del crecimiento para reducir la pobreza; en caso contrario, habrá reducciones de pobreza inferiores a las esperadas, y se desaprovecharán años de crecimiento económico.

En razón de ello, existen otras estrategias para combatir la desigualdad, con efectos positivos o negativos en el corto plazo. La asistencia social bien planificada puede contribuir a la reducción de la pobreza, con impactos directos en el corto y largo plazo (por ejemplo: nutrición infantil, control prenatal y primera infancia). Los programas sociales han demostrado que pueden aliviar la desigualdad incrementando el ingreso de las familias pobres (con transferencias, por ejemplo) para mejorar su consumo y alejarlas de la línea de pobreza. Pero esta estrategia es temporal y debe acompañarse, desde la planificación, de políticas que motiven a los beneficiarios a la superación definitiva de la pobreza (Burguignon, 2004). Según Steiner \& Sabogal (2011), ignorar los incentivos perversos a permanecer en el sistema de asistencia resulta en políticas ineficientes de transferencias de ingresos e impuestos. En esta línea, es necesario generar empleo sostenible y evitar políticas comerciales con externalidades negativas para economías más pequeñas.

Otra estrategia es la inversión en infraestructura. Calderón \& Servén (2004) establecen que dicha inversión puede mejorar el ingreso y bienestar de los pobres por encima del promedio. El desarrollo de infraestructura regional genera un círculo virtuoso de oportunidades productivas sostenibles (Guerra-García, 2010; Steiner \& Sabogal, 2011) y se perfila como una política win-win en la relación pobreza - desigualdad - crecimiento a corto y largo plazo. Así, el crecimiento inclusivo surge de políticas que universalizan las oportunidades de acceso a servicios y bienes básicos de calidad. La infraestructura conlleva externalidades de inversión en el mediano plazo y de participación económica sostenible en zonas de pobreza; es decir, un mayor crecimiento potencial regional (López, 2003). Zambrano \& Aguilera-Lizarazu (2011) estiman que invertir en infraestructura podría reducir la desigualdad hasta un $15 \%$ en América Latina. Arpi (2015) muestra que la inversión en infraestructura pública financiada con ingresos fiscales redujo más del 5\% la desigualdad regional en América Latina entre 2003 y 2010.

En concordancia, Vásquez \& Bendezú (2006) encuentran que el stock de infraestructura explica el 63,1\% de la desigualdad en el Perú, donde Lima 
concentra más del $80 \%$ de los activos. A su vez, la cobertura eléctrica, la PEA y la superficie agrícola contribuyen a reducir el impacto de la dotación regional desigual de infraestructura y generan distintos patrones de crecimiento regional; en tanto que el acceso a infraestructura vial y de telecomunicaciones condiciona la desigualdad entre los departamentos. La infraestructura de energía también sería efectiva (Calderón \& Servén, 2004). Adicionalmente, la infraestructura influye en otras variables de interés; por ejemplo, la infraestructura de caminos y energía cuenta para el acceso a educación (Brenneman \& Kerf, 2002), y la infraestructura sanitaria, para el acceso a salud (Fay, Leipziger, \& Yepes, 2003). Según López (2003), el desarrollo de la infraestructura es una de las políticas que impactan positivamente -en el corto y largo plazo- en el crecimiento y la igualdad.

El Perú se ubica en el cuarto quintil del componente infraestructura del ranking de competitividad mundial (WEF, 2015). Entre 2005 y 2015, el acceso a agua potable aumentó del $53 \%$ al $75 \%$, mientras que el acceso a desagüe pasó del 38\% al 51\%. La cobertura de alumbrado aumentó del 67\% al 89\% y la de telefonía móvil se elevó del 14\% al 84\% (INEI, 2016b). Hasta 2013, la extensión de la red de caminos -nacional, departamental y vecinal- era de $25.005,5 \mathrm{~km}$ (16\%), 24.992,3 km (16\%) y $106.794,5 \mathrm{~km}(68 \%)$, respectivamente. De estos, solo están pavimentados el $66 \%$ de la red nacional, el $10 \%$ de la red departamental y menos del $1 \%$ de la red vecinal (AFIN, 2016). Así, la carente articulación entre pueblos dificulta el acceso a servicios básicos y afecta la productividad y calidad de vida; ergo, la infraestructura adecuada aumenta la ventaja comparativa del país y reduce la severidad de la pobreza ${ }^{2}$ y su persistencia.

Por lo expuesto, este estudio tiene como objetivo medir la respuesta de la dispersión del ingreso frente a cambios en la provisión de infraestructura de acceso a servicios básicos, en las cinco macrorregiones del Perú, para el período 2005-2015. Sus objetivos específicos son: estimar las elasticidades para los diferentes tipos de infraestructura, a fin de identificar qué territorios presentan mayor sensibilidad a este tipo de inversión; así como identificar si la heterogeneidad entre las sensibilidades se debe a la existencia de especificidades no observables de las regiones. En función de lo anterior, la hipótesis principal es que la infraestructura de servicios básicos es un instrumento relevante para reducir la desigualdad y aumentar el crecimiento a nivel de departamentos/

\footnotetext{
${ }^{2}$ La severidad de la pobreza es la desigualdad dentro de la población por debajo de la línea de pobreza
} (INEI, 2000). 
regiones. Como hipótesis secundaria, se plantea que las diferencias en el impacto entre los territorios se deben a efectos fijos por región (por ejemplo: acceso al crédito, participación política, idiosincrasia). Se espera que los resultados del estudio contribuyan a una priorización inclusiva y eficiente de las inversiones.

\section{Marco analítico}

El análisis de la sensibilidad de la desigualdad frente a incrementos en la provisión de infraestructura básica gira en torno a dos ejes principales: la desigualdad en los ingresos y el crecimiento económico. Por ello, y a la luz de la literatura especializada, el marco analítico está conformado por dos modelos: los factores determinantes de la desigualdad de oportunidades y la función de producción.

\subsection{Los factores determinantes de la desigualdad de oportunidades}

De conformidad con el enfoque analítico sintetizado por el Banco Mundial (2008) que se presenta en la figura 2, la desigualdad que vemos en los indicadores como el coeficiente de Gini es denominada desigualdad de resultados, observada en los ingresos o gasto per cápita de los hogares. Está compuesta por dos factores: la desigualdad residual, determinada por el azar y decisiones personales en las que solo es responsable el individuo (por ejemplo: relaciones interpersonales, ocupación, esfuerzo); y la desigualdad de oportunidades, determinada por circunstancias que escapan de la responsabilidad personal y configuran las oportunidades abiertas al individuo. Estas circunstancias pueden afectar de manera directa o indirecta los resultados por medio de su implicancia sobre las decisiones de las personas.

Figura 2

Síntesis de los factores determinantes de la desigualdad de oportunidades.

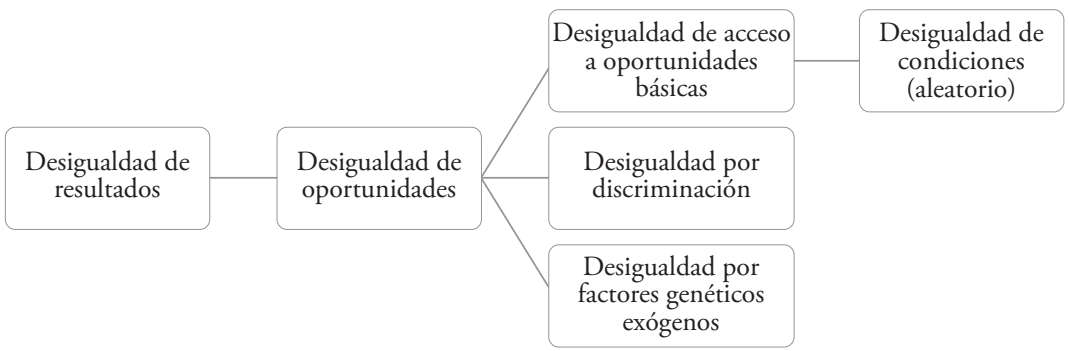

Fuente: Banco Mundial. (2008). Elaboración propia. 
La desigualdad de oportunidades está compuesta por tres factores: la desigualdad por factores genéticos exógenos, determinada por el talento y la motivación individuales; la desigualdad por discriminación, es decir, el trato que uno puede recibir por sus valores iniciales o características intrínsecas (por ejemplo: raza, género, credo); y la desigualdad de oportunidades básicas, determinada por el acceso a servicios básicos en diferentes etapas de la vida (por ejemplo: nutrición, educación, empleo sostenible). Por esta razón, el Estado debe y puede combatir la desigualdad en el Perú reduciendo la desigualdad de oportunidades básicas mediante la provisión universal y adecuada de servicios básicos como política de largo plazo.

$$
\operatorname{Des}_{o p}^{i}=f\left(\operatorname{Des}_{\text {op_ }}^{i}\left(\operatorname{Inf} f_{b}\right), e f_{-} f^{i}\right)
$$

La ecuación (1) plantea la desigualdad de oportunidades para la región $i$ $\left(\operatorname{Des}_{o p}^{i}\right)$ como función de la desigualdad de oportunidades básicas $\left(\operatorname{Des}_{o p_{-} b}^{i}\right)$ y de los efectos fijos de la región $\left(e f_{-} f^{i}\right)$. El primero será una función de la provisión de infraestructura básica $\left(\operatorname{Inf} f_{b}\right)$. El segundo corresponde a especificidades sociales como asistencia social o políticas macroeconómicas estables. Podemos observar que, si bien $\operatorname{Inf}_{b}$ afecta directamente a $D e s_{o p}^{i}$, las especificidades sociales pueden condicionar su efecto.

\subsection{Infraestructura en el crecimiento actual y potencial - función de producción}

Para López (2003), la infraestructura es un instrumento lógico de una política de crecimiento económico inclusivo, ya que el capital ingresa directamente en la función de producción. La inversión en infraestructura tiene un papel importante en el desarrollo de las economías, en especial en su articulación económica y competitividad, lo que genera efectos de escala y amplitud ${ }^{3}$. En este sentido, la Cepal (2004) menciona dos efectos sobre el crecimiento adicionales a su aporte al PIB. Primero, las externalidades de inversión (capitales e innovación) mejoran el crecimiento potencial. Segundo, el efecto indirecto de la provisión (adecuada) de infraestructura sobre la productividad de los factores de producción ${ }^{4}$.

\footnotetext{
${ }^{3}$ Las economías de escala están relacionadas con la reducción de costos medios en función del tamaño de la producción; y las economías de amplitud o ámbito, con la diversificación productiva con base en las mismas instalaciones.

${ }^{4}$ Por ejemplo, un adecuado sistema de caminos y sanidad permite un mejor acceso a los servicios de salud y educación, lo que aumenta el bienestar y la productividad futura del capital humano.
} 
Por un lado, las externalidades de inversión generan zonas de mayor productividad. La geografía económica sustenta que, al ajustar los parámetros de distancia a la densidad poblacional, podemos incluir en la estructura productiva a localidades que, de otro modo, quedarían rezagadas por variables de acceso (Guerra-García, 2010). Por otro lado, la reducción de costos de producción y los aumentos en la productividad de factores resultan en un mayor excedente del productor y amplían la frontera de posibilidades de producción (oportunidades productivas, empleo sostenible). Además, esto aumenta la competitividad de la zona, lo que promueve las exportaciones e importaciones (Guerra-García, 2010), y esta articulación del mercado incrementa las posibilidades de consumo.

Otro efecto importante es que la mayor ejecución de proyectos rentables (TIR ${ }^{5}$ privada positiva más baja) optimiza la capacidad productiva de la economía. La infraestructura pone en valor los activos de los pobres y favorece la acumulación, lo que les brinda un mayor colateral para acceder a préstamos relativamente menos exigentes. Entonces, la articulación económica y los aumentos en la productividad y competitividad permitirán el «arrastre» del crecimiento rural por el urbano (Guerra-García, 2010). El crecimiento económico tendrá así efecto directo y positivo sobre el nivel de vida de los pobres, y modificará su restricción presupuestaria (posibilidades de consumo) y oportunidades (a corto y largo plazo).

$$
\begin{aligned}
& Y=A \cdot f\left(K\left(K_{F}, K_{H}, K_{i}\right), L\right) \quad(2) \\
& \mathrm{K}_{\mathrm{F}}=\mathrm{f}\left(\operatorname{Inf}_{\mathrm{b}}\right) \quad ; \quad \mathrm{K}_{\mathrm{H}}=\mathrm{f}\left(\operatorname{Inf}_{\mathrm{b}}\right) \quad ; \quad \mathrm{K}_{\mathrm{i}}=\mathrm{f}\left(\operatorname{Inf}_{\mathrm{b}}\right) \quad ; \quad \mathrm{L}=\mathrm{f}\left(\operatorname{Inf}_{\mathrm{b}}\right)
\end{aligned}
$$

La ecuación (2) nos muestra los factores determinantes de la función de producción, cuyos insumos son el capital y el trabajo, afectados por la tecnología $(A)$. El capital puede ser físico $\left(K_{F}\right)$, humano $\left(K_{H}\right)$ o financiero $\left(K_{i}\right)$. Considerando el énfasis del modelo en la productividad de los pobres, el trabajo $(L)$ es mano de obra no calificada. Los cuatro factores son afectados por la infraestructura básica $\left(\operatorname{Inf}_{\mathrm{b}}\right)$. Como hemos visto, $\operatorname{Inf}_{\mathrm{b}}$ es primordial en la generación del producto y la infraestructura productiva conexa. En tanto que $K_{H}$ (referido a mano de obra calificada) necesita de $\operatorname{Inf}_{\mathrm{b}}$ para desarrollarse; $K_{i}$ no se verá atraído si no se ofrece rentabilidad ( $P m g K)$; y la oferta de $L$ también se verá afectada, ya que la $\mathrm{Inf}_{\mathrm{b}}$ condiciona el acceso a la salud y la educación de los padres (intertemporal).

$$
\operatorname{Des}_{\text {res }}^{i}=f\left(e f_{-} f^{i}, \operatorname{Des}_{\text {op_b }}^{i}\left(\operatorname{Inf} f_{b}\right), \log Y\left(A \cdot f\left(\operatorname{Inf} f_{b}\right)\right)\right)
$$

\footnotetext{
${ }^{5}$ Tasa interna de retorno. Evalúa la rentabilidad intrínseca de un proyecto.
} 
Por último, la ecuación (3) expresa la propuesta de esta investigación, en la que la desigualdad de resultados para la región $i\left(D e s_{\text {res }}^{i}\right)$ es una función de los efectos fijos, la desigualdad de oportunidades básicas, el crecimiento y un componente no observable. El primer factor se ha explicado con anterioridad. Mediante el segundo y el tercer factor, se puede observar la congruencia entre la política de crecimiento y la de igualdad.

\section{Metodología}

Para estimar la potencial sensibilidad de la desigualdad observada frente a cambios en la provisión de infraestructura de servicios básicos, es necesario obtener primero el efecto impacto correspondiente ${ }^{6}$. Con base en la propuesta de Zambrano \& Aguilera-Lizarazu (2011), para el estudio del impacto de la infraestructura sobre la desigualdad, se planteó la siguiente especificación:

$$
G_{i, t}=\eta^{\prime} X_{i, t}+\beta_{1} I\left(\operatorname{Inf}_{b}\right)_{i, t}+\beta_{2} I(\operatorname{Inf})_{b_{i, t}} * \operatorname{MReg}_{i}+\alpha_{i}+\varepsilon_{i, t}
$$

El lado izquierdo de la ecuación (4) presenta la variable dependiente: la desigualdad observada, definida por el coeficiente de Gini por gasto a nivel de hogares $(G)$. Se propuso $G$ como Des Res en este estudio ${ }^{7}$, ya que no es discrecional, cumple con las propiedades deseables de un indicador de desigualdad y, al ser el indicador más usado en la literatura, facilita la comparabilidad con otros estudios.

El lado derecho de la ecuación (4) presenta las variables explicativas del modelo. El primer término es un vector de variables de control comunes en la literatura $(X)$, como son el ingreso (PIB por cada 1.000 habitantes), el capital humano (tasa de analfabetismo - de 0 a 100) y la ruralidad (proporción de la población rural respecto a la población total - de 0 a 100).

El segundo término hace referencia al stock de infraestructura de acceso a servicios básicos para sus diferentes tipos: telefonía (líneas móviles en servicio por cada 1.000 habitantes, total de líneas en servicio -fijas, móviles y públicas- por cada 1.000 habitantes), electrificación (producción de energía en $\mathrm{kWh}$ por cada 1.000 habitantes, consumo de energía en $\mathrm{kWh}$ por cada 1.000 habitantes), agua (hogares con acceso a agua no contaminada - de 0 a 100) y desagüe (hogares con acceso a una forma adecuada de eliminación

\footnotetext{
${ }^{6}$ La fórmula de la elasticidad es: $\operatorname{Inf_{b}}=E I_{\operatorname{Inf} f_{b}} * \frac{\overline{\operatorname{Inf_{b}}}}{F(\hat{\beta} X)}$.

${ }^{7}$ En el anexo 1, se profundiza sobre las propiedades deseables y la discrecionalidad, y se plantea el análisis con otros dos indicadores de desigualdad observada.
} 
de excretas - de 0 a 100 ${ }^{8}$; a partir de los cuales se construyó el índice de infraestructura básica $(I)$.

Tabla 1

Correlación entre las variables de infraestructura básica

\begin{tabular}{cccccc}
\hline & Telefonía1 & Telefonía2 & Energía1 & Energía2 & Agua \\
\hline Telefonía2 & $98,87 \%$ & 1 & & & \\
Energía1 & $-15,18 \%$ & $-13,72 \%$ & 1 & & \\
Energía2 & $28,83 \%$ & $33,08 \%$ & $32,54 \%$ & 1 & \\
Agua & $67,12 \%$ & $68,34 \%$ & $-17,26 \%$ & $34,48 \%$ & 1 \\
Saneamiento & $46,52 \%$ & $48,9 \%$ & $-26,44 \%$ & $22,61 \%$ & $63,97 \%$ \\
\hline
\end{tabular}

Notas. Telefonía1: líneas móviles en servicio (por cada 1.000 habitantes); Telefonía2: total de líneas en servicio (fijas, móviles y públicas, por cada 1.000 habitantes); Energía1: producción de energía en kWh (por cada 1.000 habitantes); Energía2: consumo de energía en kWh (por cada 1.000 habitantes); Agua: hogares con acceso a agua no contaminada (0-100); Saneamiento: hogares con acceso a una forma adecuada de eliminación de excretas (0-100). Fuentes: Enaho (INEI), Osiptel, DGE (Minem). Elaboración propia.

Como se observa en la tabla 1, existe una importante correlación entre las variables de infraestructura, motivo por el cual en distintas regresiones las incorporaremos agrupadas en un índice $(I)$ y de manera independiente. Planteamos como supuesto que no hay multicolinealidad entre estas variables, de modo que la finalidad de I no sea corregir dicha correlación, sino únicamente la agregación de estas. El índice I fue construido mediante el método de Análisis de Componentes Principales (ACP), como lo proponen Zambrano \& Aguilera-Lizarazu (2011), Casas (2013), y Calderón \& Servén (2004). Este método permite agregar las variables en un índice mediante la combinación lineal del conjunto de variables originales, con el fin de encontrar la mejor agrupación no correlacionada entre sus componentes. El mejor índice es aquel que explica la mayor proporción de la variación de los datos.

El tercer término de la ecuación (4) responde a la interacción entre $I$ y el departamento/región. Se generó una variable (MReg) que permite clasificar los departamentos en las siguientes macrorregiones: Macro-Norte (Tumbes, Piura, Lambayeque, Cajamarca, La Libertad), Macro-Sur (Tacna, Moquegua, Puno, Arequipa, Cusco, Apurímac, Ayacucho), Macro-Centro (Lima, Ica, Huancavelica, Pasco, Huánuco, Ancash, Junín) y Amazonía (Madre de Dios,

\footnotetext{
${ }^{8}$ No fue posible incorporar un indicador de acceso a infraestructura básica de transportes, debido a que no existe dicha información para todo el período evaluado. No obstante, se observa una aproximación en el análisis de robustez.
} 
Ucayali, Loreto, Amazonas y San Martín). Esta agregación se sustenta en la presentada por un informe de la consultora Arellano Marketing, que la propone con base en la proximidad geográfica, las características de la población, los polos de desarrollo y los capitales macrorregionales que concentran inversión privada (El Comercio, 2016).

Por último, el cuarto término denota una de las hipótesis del modelo: la existencia de particularidades atemporales por departamento (efectos fijos). De ser así, excluir los efectos fijos del modelo resultaría en estimaciones sesgadas, ya que dichos efectos podrían estar correlacionados con las variables explicativas. Bajo esta premisa, el panel estático (balanceado) se estimó con el método MCG controlando por efectos fijos. Debido a que el modelo no puede capturar las relaciones de causalidad contemporáneas, se puede entender como una forma reducida (Casas, 2013).

\section{Base de datos}

La base de datos empleada fue construida a partir de la Encuesta Nacional de Hogares (Enaho) 2005-2015 a nivel de hogares e información estadística reportada por el Instituto Nacional de Estadística e Informática (INEI), por el Organismo Supervisor de Inversión Privada en Telecomunicaciones (Osiptel), por la Dirección General de Electricidad (DGE-Minem) en sus Anuarios estadísticos y, respecto a inversión devengada, por el portal SIAF Amigable del Ministerio de Economía y Finanzas (SIAF-MEF). El panel recoge la información para 24 departamentos del Perú, y unifica a Lima Provincias y Lima Metropolitana con el Callao, debido a que gran parte de la estadística nacional reporta información separada para el Callao solo desde 2007. A resultas de ello, la estimación se realizó con una muestra de 264 observaciones y 24 grupos (departamentos).

Las variables dependientes - coeficientes de Gini por gasto e ingreso a nivel de hogares y el ratio quintil (80/20), los indicadores de acceso a agua y saneamiento, y la proporción de población rural- se construyeron a partir de la Enaho. Las variables de cobertura eléctrica -producción y consumo-se obtuvieron de la página web de la DGE; las cantidades de líneas telefónicas -fijas, móviles y públicas- en servicio se obtuvieron de la página web de Osiptel. Otras variables de control, como el PIB, la población económicamente activa (PEA) o la tasa de analfabetismo, se obtuvieron del INEI. La variación de la desigualdad ha sido alta entre cada período de tiempo, por lo que se puede emplear una serie relativamente corta para los propósitos de este trabajo. 


\section{Análisis de resultados}

Como se mencionó anteriormente, una de las principales limitaciones del modelo es la posible autocorrelación de las variables. Tanto la infraestructura provista como el nivel de ingresos, la participación laboral e incluso la desigualdad pueden generarse endógenamente en el sistema económico. Esto impide que los indicadores utilizados sean propiamente exógenos. Ello puede corregirse controlando por rezagos necesarios del panel; no obstante, esto puede desencadenar nuevos problemas si las variables presentan persistencia larga en el tiempo. Una alternativa es el panel dinámico, pero esto excede los objetivos del presente trabajo. Una segunda alternativa es la estimación con variables instrumentales suficientemente exógenas (método IV); sin embargo, actualmente no existen esos datos. Por lo anterior, junto con el supuesto de no multicolinealidad, se opta por construir instrumentos internos a partir de las variables del modelo, como el índice $I$.

\section{Índice de infraestructura de acceso a servicios básicos (I)}

El antes mencionado método ACP consiste en realizar combinaciones lineales (independientes entre sí) de las variables por agregar. Esto da $n$ componentes generados por esas combinaciones lineales, donde $n$ es la cantidad de variables incorporadas, que recuperan parte de la variabilidad explicativa de las variables por las que están compuestos. El índice $I$ se construye idealmente a partir del primer componente principal, que recupera la mayor proporción de la variabilidad explicativa y tiene un valor propio mayor de 1 .

Como muestra la tabla 2, para la construcción de $I$ se plantearon seis posibles combinaciones de indicadores en función de diferentes métricas para cada tipo de infraestructura. Y se obtuvo como primer componente principal, representativo de $I$, al primer componente de la cuarta estimación, pues recupera en mayor proporción la variabilidad explicativa; cumple con la finalidad del índice, que es la agregación de los cuatro tipos de infraestructura citados por la literatura; y es con el cual se consigue un mejor ajuste para las estimaciones finales del modelo. 
Tabla 2

Estimación de I por el método ACP según las alternativas

\begin{tabular}{|c|c|c|c|c|c|}
\hline N. ${ }^{\circ}$ & $\begin{array}{l}\text { Variables } \\
\text { incluidas }\end{array}$ & Valor propio & $\begin{array}{l}\text { Variabilidad } \\
\text { explicada }\end{array}$ & $\begin{array}{l}\text { Coeficientes del } \\
\text { componente }\end{array}$ & $\begin{array}{l}\text { Variabilidad no } \\
\text { explicada }\end{array}$ \\
\hline \multirow{4}{*}{1} & Telefonía1 & \multirow{4}{*}{2,27789} & \multirow{4}{*}{0,5695} & 0,5385 & 0,3395 \\
\hline & Energía1 & & & $-0,2563$ & 0,8504 \\
\hline & Agua & & & 0,59 & 0,2072 \\
\hline & Saneamiento & & & 0,5444 & 0,325 \\
\hline \multirow{4}{*}{2} & Telefonía1 & \multirow{4}{*}{2,3705} & \multirow{4}{*}{0,5926} & 0,531 & 0,3316 \\
\hline & Energía2 & & & 0,3427 & 0,7216 \\
\hline & Agua & & & 0,5841 & 0,1914 \\
\hline & Saneamiento & & & 0,5094 & 0,3849 \\
\hline \multirow{4}{*}{3} & Telefonía2 & \multirow{4}{*}{2,29574} & \multirow{4}{*}{0,5739} & 0,5426 & 0,324 \\
\hline & Energía1 & & & $-0,2473$ & 0,8597 \\
\hline & Agua & & & 0,5886 & 0,2046 \\
\hline & Saneamiento & & & 0,5458 & 0,316 \\
\hline \multirow{4}{*}{4} & Telefonía2 & \multirow{4}{*}{2,40671} & \multirow{4}{*}{0,6017} & 0,5381 & 0,303 \\
\hline & Energía2 & & & 0,3492 & 0,7065 \\
\hline & Agua & & & 0,5769 & 0,1989 \\
\hline & Saneamiento & & & 0,5056 & 0,3848 \\
\hline \multirow{3}{*}{5} & Telefonía1 & \multirow{3}{*}{2,21171} & \multirow{3}{*}{0,7372} & 0,5674 & 0,2879 \\
\hline & Agua & & & 0,6113 & 0,1736 \\
\hline & Saneamiento & & & 0,5517 & 0,3268 \\
\hline \multirow{3}{*}{6} & Energía1 & \multirow{3}{*}{1,83581} & \multirow{3}{*}{0,6119} & 0,4368 & 0,6497 \\
\hline & Agua & & & 0,6534 & 0,2162 \\
\hline & Saneamiento & & & 0,6183 & 0,2982 \\
\hline
\end{tabular}

Notas. Telefonía1: líneas móviles en servicio (por cada 1.000 habitantes); Telefonía2: total de líneas en servicio (fijas, móviles y públicas, por cada 1.000 habitantes); Energía1: producción de energía en $\mathrm{kWh}$ (por cada 1.000 habitantes); Energía2: consumo de energía en kWh (por cada 1.000 habitantes); Agua: hogares con acceso a agua no contaminada (0-100); Saneamiento: hogares con acceso a una forma adecuada de eliminación de excretas (0-100). Fuentes: Enaho (INEI), Osiptel, DGE (Minem). Elaboración propia.

Dicho lo anterior, la ecuación 5 nos muestra la composición de $I$, el cual agrupa el 60,17\% de la variabilidad explicativa de los indicadores de: telefonía (total de líneas en servicio -fijas, móviles y públicas- por cada 1.000 habitantes), electrificación (consumo de energía en kWh por cada 1.000 habitantes), 
agua (hogares con acceso a agua no contaminada - de 0 a 100) y saneamiento (hogares con acceso a una forma adecuada de eliminación de excretas - de 0 a 100). Como es de esperarse, $I$ está altamente correlacionado con sus explicativas. Las otras cinco alternativas de construcción de I son utilizadas para probar la robustez del modelo más adelante.

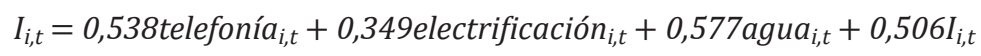

\section{Efectos fijos en la estimación}

El modelo propone la presencia de efectos fijos por departamento/región. Por lo tanto, es necesario realizar dos pruebas de hipótesis: (i) la prueba F, cuya propuesta es que la estimación debe ser por $\mathrm{MCO}$, ya que no considera efectos fijos (pool), y (ii) la prueba Wu-Hausman, cuya propuesta es que la estimación debe ser por MCG controlando efectos aleatorios.

Tabla 3

Resultados de las pruebas F (pool) y Wu-Hausman (efectos aleatorios) para las especificaciones en el modelo

\begin{tabular}{|c|c|c|c|}
\hline Ec. & Variable de interés & F: pool & $\begin{array}{l}\text { Wu-Hausman: efectos } \\
\text { aleatorios }\end{array}$ \\
\hline \multicolumn{4}{|c|}{ Dependiente: coeficiente de Gini por gasto } \\
\hline \multicolumn{4}{|c|}{ Controles: PIB p. c., cuadrado de PIB p. c., analfabetismo (0-100), ruralidad (0-100). } \\
\hline 1 & Índice alternativo 1 & No $(0)$ & Efectos fijos (0) \\
\hline 2 & Índice alternativo 2 & No $(0)$ & Efectos fijos (0) \\
\hline 3 & Índice alternativo 3 & No $(0)$ & Efectos fijos $(0)$ \\
\hline 4 & I & No $(0)$ & Efectos fijos (0) \\
\hline 5 & Índice alternativo 5 & No $(0)$ & Efectos fijos $(0)$ \\
\hline 6 & Índice alternativo 6 & No $(0)$ & Efectos fijos (0) \\
\hline 7 & Líneas móviles en servicio* & No $(0)$ & Efectos fijos (0) \\
\hline 8 & Total de líneas en servicio ${ }^{1 *}$ & No $(0)$ & Efectos fijos $(0,0001)$ \\
\hline 9 & Producción de energía en Kwh* & No $(0)$ & Efectos fijos (0) \\
\hline 10 & Consumo de energía en Kwh* & No $(0)$ & Efectos fijos (0) \\
\hline 11 & Hogares con acceso a agua no contaminada $(0-100)$ & No $(0)$ & Efectos fijos $(0,0034)$ \\
\hline 12 & $\begin{array}{l}\text { Hogares con acceso a una forma adecuada de } \\
\text { eliminación de excretas }(0-100)\end{array}$ & No $(0)$ & Efectos fijos (0) \\
\hline
\end{tabular}

Notas. * Para cada 1.000 habitantes. ${ }^{1}$ Líneas totales: líneas fijas, móviles y públicas. Fuentes: Enaho (INEI), Osiptel, DGE (Minem). Elaboración propia. 
Para la especificación en la ecuación 4, ambas pruebas resultaron no significativas y estadísticamente distintas de cero $(\mathrm{p}<0,05)$, lo que corrobora que el modelo debe estimarse por MCG controlando efectos fijos. Adicionalmente, estos resultados se comprobaron con las alternativas de construcción de $I$ y las infraestructuras de manera independiente.

\section{Resultados del modelo}

Tanto las variables del modelo utilizado como las estimaciones resultantes de él son consistentes con las relaciones establecidas por la literatura especializada. En efecto, como muestra la tabla 4, el índice I está negativamente correlacionado con los tres indicadores de desigualdad. Las infraestructuras están negativamente correlacionadas con el coeficiente de Gini, excepto la producción de energía. Esto puede deberse a que la proporción autoconsumida de energía producida por departamento/región no es muy alta. Es decir, consumen mucho menos de lo que producen, por lo que una mayor cantidad de $\mathrm{kWH}$ por departamento no refleja un mayor acceso por parte de sus habitantes.

Tabla 4

Correlación entre variables dependientes, índice $I$ y variables de infraestructura básica en la literatura especializada

\begin{tabular}{ccccc}
\hline & Gini1 & Gini2 & Ratio & I \\
\hline I & $-37,18 \%$ & $-29,98 \%$ & $-34,25 \%$ & 1 \\
Telefonía1 & $-49,07 \%$ & $-42,05 \%$ & $-41,88 \%$ & $80,91 \%$ \\
Telefonía2 & $-49,76 \%$ & $-42,50 \%$ & $-43,24 \%$ & $83,48 \%$ \\
Energía1 & $11,13 \%$ & $22,33 \%$ & $13,19 \%$ & $-12,47 \%$ \\
Energía2 & $-3,81 \%$ & $8,43 \%$ & $0,62 \%$ & $54,17 \%$ \\
Agua & $-37,79 \%$ & $-34,79 \%$ & $-35,99 \%$ & $89,5 \%$ \\
Saneamiento & $-15,38 \%$ & $-12,88 \%$ & $-18,41 \%$ & $78,43 \%$ \\
\hline
\end{tabular}

Notas. Gini1: coeficiente de Gini por gastos (0-100); Gini2: coeficiente de Gini por ingresos (0-100); Ratio: ratio quintil por gastos; Telefonía 1: líneas móviles en servicio (por cada 1.000 habitantes); Telefonía2: total de líneas en servicio (fijas, móviles y públicas, por cada 1.000 habitantes); Energía1: producción de energía en kWh (por cada 1.000 habitantes); Energía2: consumo de energía en kWh (por cada 1.000 habitantes); Agua: hogares con acceso a agua no contaminada (0-100); Saneamiento: hogares con acceso a una forma adecuada de eliminación de excretas (0-100). Fuentes: Enaho (INEI), Osiptel, DGE (Minem). Elaboración propia. 
Tabla 5

Resultados de las estimaciones para el coeficiente de Gini por gastos

\begin{tabular}{lcc}
\hline \multicolumn{1}{c}{$\begin{array}{c}\text { Coeficiente de Gini por gastos } \\
(0-100)\end{array}$} & $\begin{array}{c}\text { Ec. (4) sin interacción } \\
\text { entre I y macrorregión }\end{array}$ & Ec. (4) completa \\
\hline PIB p. c. & $-0,000000112^{* *}$ & $-0,0000000988^{* *}$ \\
Tasa de analfabetismo (0-100) & 0,0795 & $-0,0172$ \\
Población en zona rural (0-100) & $0,237^{* * *}$ & $0,320^{* * *}$ \\
Índice de infraestructura (I) & $-0,489^{* *}$ & \\
I en Macro-Norte & & 0,0420 \\
I en Macro-Sur & & $-0,691^{* *}$ \\
I en Macro-Centro & & $-0,874^{* * *}$ \\
I en Amazonía & $28,99^{* * *}$ & 0,566 \\
\hline Constante & 264 & $26,93^{* * *}$ \\
N. obs. & 11 & 264 \\
Años & 24 & 11 \\
Grupos & 0,362 & 24 \\
R2 within & 0,442 & 0,390 \\
R2 overall & & 0,446 \\
\hline
\end{tabular}

Notas. ${ }^{*} \mathrm{p}<0,1{ }^{* *} \mathrm{p}<0,05^{* * *} \mathrm{p}<0,01$. Elaboración propia.

Y a la luz de la tabla 5, las estimaciones resultantes del modelo -con y sin distinción por macrorregión- son consistentes con la literatura especializada. Las variables de control PIB p. c. y proporción de población rural resultaron significativas. Si analizamos la ecuación 4 sin considerar las diferencias por macrorregiones, un crecimiento del $5 \%$ en el PIB p. c. promedio (S/ 652,00) reduce la desigualdad solo 0,00007 puntos; y un crecimiento del $1 \%$ en la población rural respecto a la total incrementa la desigualdad en 0,24 puntos. El estimador de $I$ es significativo y negativo; es decir, si I aumenta en una unidad (lo que no implicaría que las infraestructuras que lo componen aumenten en la misma magnitud), la desigualdad medida por el coeficiente de Gini por gasto se reduciría en 0,49 puntos.

Cuando se resuelve la ecuación 4 inalterada (con interacción), incrementos de una unidad en $I$ se traducen en una reducción de la desigualdad de 0,69 puntos en la Macro-Sur y 0,87 puntos en la Macro-Centro; mientras que en la Macro-Norte y en la Amazonía estadísticamente no tienen efecto. Esto último puede deberse a que, en ambos casos, los principales incrementos de 
infraestructura se han dado en los sectores de telecomunicaciones ( $\mathrm{x} 4, \mathrm{x} 7)$ y consumo de energía $(\mathrm{x} 1,8, \mathrm{x} 2)$, donde una mayor inversión no necesariamente se traduce en una expansión del acceso. Por ejemplo, las urbes pueden consumir más energía eléctrica en actividades productivas o recreativas, y lo mismo para las líneas en servicio. Además, para la Amazonía, el decrecimiento (contraintuitivo) en el acceso a saneamiento adecuado puede estar afectando la significancia del índice? .

$\mathrm{Si}$ analizamos el efecto de las infraestructuras por separado, persiste la consistencia de los resultados con los efectos descritos por la literatura. Tal como muestra la tabla 6 , incrementos de una unidad en telefonía, energía y agua reducen la desigualdad y son estadísticamente significativos. Esto significa que si 150 personas de cada 1.000 sin líneas telefónicas las obtienen, la desigualdad se reduce en 0,17 puntos, teniendo en cuenta que 330 personas de cada 1.000 son población rural al año 2015. Si aumenta el consumo de energía en $600.000 \mathrm{kWh}$ por cada 1.000 habitantes, lo que equivale a 20.000 hogares consumiendo el mínimo de $30 \mathrm{kWh}$ (Osinergmin, 2015), la desigualdad se reduce en 0,8 puntos. Y si un $1 \%$ de la población sin acceso a agua no contaminada logra este acceso, la desigualdad se reduce en 0,05 puntos. Por último, los estimadores de las variables de control resultan casi siempre significativos y mantienen el signo. La magnitud del efecto del PIB p. c. y la ruralidad no es muy distinta a la estimación con I; mientras que la tasa de analfabetismo resulta significativa en estos casos: incrementos del $1 \%$ generan un aumento de entre 0,07 y 0,2 puntos en la desigualdad.

Tabla 6

Resultados de las estimaciones para el coeficiente de Gini por gastos según el modelo propuesto e infraestructuras de manera independiente

\begin{tabular}{lcccc}
\hline $\begin{array}{c}\text { Coeficiente de } \\
\begin{array}{c}\text { Gini por gastos } \\
(0-100)\end{array}\end{array}$ & Telefonía & Energía & Agua & Saneamiento \\
\hline PIB p. c. & $-0,000000107^{* *}$ & $-0,0000000861$ & $-0,000000150^{* * *}$ & $-0,000000150^{* * *}$ \\
Analfabetismo & $0,145^{*}$ & $0,156^{* *}$ & 0,0654 & $0,204^{* *}$ \\
Ruralidad & $0,225^{* * *}$ & $0,256^{* * *}$ & $0,190^{* * *}$ & $0,259^{* * *}$ \\
Telefonía2 & $-0,00111^{*}$ & & & \\
\hline
\end{tabular}

\footnotetext{
${ }^{9}$ Después de la elaboración de esta investigación, se identificó que sistemas de saneamiento como letrinas y pozos sépticos no resultan idóneos en la selva rural, ámbito para el cual el BID propone alternativas con pertinencia étnica y eficiencia en el gasto (Vargas, Mendez, \& Altafin, 2018).
} 


\begin{tabular}{lcccc}
\hline $\begin{array}{l}\text { Coeficiente de } \\
\begin{array}{c}\text { Gini por gastos } \\
(0-100)\end{array}\end{array}$ & Telefonía & Energía & Agua & Saneamiento \\
\hline $\begin{array}{l}\text { Energía } 2 \\
\text { Agua }\end{array}$ & & $-0,00000133^{*}$ & & \\
Saneamiento & $29,50^{* * *}$ & $28,89^{* * *}$ & $34,81^{* * *}$ & $26,24^{* * *}$ \\
\hline Constante & 264 & 264 & 264 & 264 \\
N. obs. & 11 & 11 & 11 & 11 \\
Años & 24 & 24 & 24 & 24 \\
Grupos & 0,359 & 0,359 & 0,376 & 0,353 \\
R2 within & 0,475 & 0,335 & 0,424 & 0,475 \\
R2 overall & & & & \\
\hline
\end{tabular}

Notas. Analfabetismo: tasa de analfabetismo (0-100); Ruralidad: población en zona rural (0-100); Telefonía2: total de líneas en servicio (fijas, móviles y públicas, por cada 1.000 habitantes); Energía2: consumo de energía en kWh (por cada 1.000 habitantes); Agua: hogares con acceso a agua no contaminada (0-100); Saneamiento: hogares con acceso a una forma adecuada de eliminación de excretas (0-100). Elaboración propia.

Respecto a los estadísticos de ajuste, los R2 -within y overall- son muy similares entre sí y entre regresiones: estos oscilan alrededor del 37\% para el primero y el $47 \%$ para el segundo. Se puede asumir así que las estimaciones explican de manera similar los resultados observados.

\section{Robustez}

La robustez del modelo fue comprobada realizando estimaciones similares con el mismo enfoque y metodología. Para ello, se emplearon las cinco alternativas propuestas para la construcción del índice $I$, tanto en la regresión que incluye la interacción con las macrorregiones como sin ella, y los seis indicadores de infraestructura considerados de manera independiente; se obtuvieron 16 ecuaciones.

Así, se comprobó que las relaciones entre desigualdad e infraestructura oscilan alrededor de $-0,463(+/-0,08)$ y son en su mayoría significativas, en concordancia con la literatura especializada y los resultados de nuestro modelo. Las discordancias encontradas para las variables Amazonía, producción de energía y acceso a saneamiento se repiten. Para las otras infraestructuras tomadas de manera independiente, el sentido es el esperado (negativo) y significativo. Las variables de control mantienen su consistencia en todos los casos.

Adicionalmente, se comprobó la acuciosidad del modelo estimando todas las formulaciones con el coeficiente de Gini por ingreso y el ratio quintil 
(80/20) como dependientes (anexo 1), así como estimando el modelo inicial con variaciones de uno y tres períodos (anexo 2).

\section{Análisis de elasticidades}

Dado que un objetivo del presente estudio es medir la sensibilidad del coeficiente de Gini ante variaciones en la provisión de infraestructura de acceso a servicios básicos (I), diferenciando por macrorregión, se buscó obtener las 16 elasticidades correspondientes: una por cada tipo de infraestructura (4 tipos) en cada macrorregión ( 4 macrorregiones, sin contar la Amazonía por lo antes explicado). Sin embargo, debido a que solo para las macrorregiones Sur y Centro se obtuvo un efecto estadísticamente significativo de $I$ sobre la desigualdad, nuestro cálculo se redujo a la mitad (8 elasticidades). Es importante mencionar que todas estas elasticidades presentaron el signo negativo esperado, como se observa en la tabla 7.

Tabla 7

Elasticidades de las macrorregiones con efecto estadísticamente significativo de $I$ sobre la desigualdad, por tipo de infraestructura

\begin{tabular}{ccc}
\hline Tipo de infraestructura & Macro-Sur & Macro-Centro \\
\hline Telefonía2 & $-0,0075204$ & $-0,0105094$ \\
Energía & $-0,0136681$ & $-0,019033$ \\
Agua & $-0,0335877$ & $-0,0406223$ \\
Saneamiento & $-0,0030678$ & $-0,0287533$ \\
\hline
\end{tabular}

Notas. Telefonía2: total de líneas en servicio (fijas, móviles y públicas, por cada 1.000 habitantes); Energía2: consumo de energía en kWh (por cada 1.000 habitantes); Agua: hogares con acceso a agua no contaminada (0-100); Saneamiento: hogares con acceso a una forma adecuada de eliminación de excretas (0-100). Elaboración propia.

Las elasticidades - negativas- presentan magnitudes distintas entre regiones. Por ejemplo, un aumento del $1 \%$ en el número de líneas telefónicas reduciría la desigualdad en un $0,010 \%$ en Ica, mientras que solo en un $0,008 \%$ en Tacna. Esta mayor sensibilidad se repite para el acceso a energía, agua y saneamiento. Ello respalda la hipótesis del estudio sobre la existencia de regiones donde inversiones conjuntas en infraestructuras para universalizar el acceso a servicios básicos son más efectivas en reducir la desigualdad que en otras regiones. Esto puede reflejar una función cóncava de acceso con posibles saturaciones según los stocks existentes de infraestructura por región, donde niveles más altos de 
infraestructura implican que la siguiente unidad otorgará menos ganancia marginal que la anterior.

\section{Limitaciones}

Existen limitaciones en los datos, ya que algunas variables -como producción de energía- necesitan de algunos supuestos para reflejar su relevancia en el análisis de acceso a energía por poblaciones deficitarias en este servicio. Además, las variables que recogen el acceso a saneamiento y a agua no contaminada están construidas a partir de una encuesta en la que el autorreporte puede llevarnos a conclusiones imprecisas. Otra limitación referida a los datos es la posible endogeneidad de las variables, tanto dependientes como independientes, las cuales pueden ser débilmente exógenas porque son determinadas por el equilibrio del sistema económico. Convendría reemplazarlas con instrumentos exógenos, pero no existen datos con tales características.

También se pensó en utilizar variables de monto de inversión (devengado) por sector para cada tipo de infraestructura. Sin embargo, esta información no está completa para todos los departamentos en todos los ańos del período y, bajo el supuesto de que el monto haya sido 0 en esos cortes, las variables monetarias presentan otros problemas. Ejemplo de ello son los precios sombra, las licitaciones fantasmas y, por supuesto, la corrupción.

Asimismo, se pensó en utilizar más variables de control, como acceso a educación, acceso al mercado financiero, estabilidad macroeconómica (baja inflación, por ejemplo), regulación fiscal, promedio de ańos de estudio, acceso femenino al mercado laboral y tasa de mortalidad infantil. Pero estas tampoco estaban disponibles para todas las observaciones del panel.

Por último, un horizonte temporal más largo para todas las variables del modelo, incluyendo infraestructura de transportes, hubiera brindado estimadores más sólidos y un mejor insight de la problemática del acceso a servicios básicos.

\section{Conclusiones y recomendaciones}

En primer lugar, el modelo especificado por la ecuación 4 no aceptó ninguna de las hipótesis nulas para las pruebas F y Wu-Hausman. Ello comprueba la hipótesis de que existen efectos fijos atemporales por departamento y, en consecuencia, por macrorregiones, sea por proximidad geográfica u otras características en común. Estos efectos fijos influyen en la sensibilidad que tendrá la desigualdad en ese territorio frente a inversiones en el conjunto de infraestructuras de servicios básicos, medidas mediante el índice $I$. 
Segundo, la estimación de la ecuación 4 y las pruebas de robustez brindan suficiente evidencia para aceptar que la infraestructura de acceso a servicios básicos es una variable relevante como política de disminución de la desigualdad por departamentos. Esto debido a que siempre resultó significativa y con signo negativo. Pero, cuando se evaluó cada infraestructura por separado, surgió una contradicción entre la teoría y la práctica para el caso del saneamiento. Si bien se mencionó que puede deberse a limitaciones de los datos, ello deja sobre la mesa la posibilidad de que, en ciertos contextos geográficos o socioeconómicos, la inversión en cierta infraestructura bajo parámetros institucionales no siempre resulte efectiva. Un ejemplo de ello son los colegios en la Amazonía y la sierra central, donde se ha promovido la educación bilingüe entendiendo las necesidades de la población beneficiaria.

Tercero, la infraestructura también promueve el crecimiento del PIB per cápita. Para una ecuación análoga al modelo ${ }^{10}$ cuya dependiente fue el crecimiento económico, el índice $I$ presenta coeficientes positivos y significativos, con lo que se comprueba que la infraestructura de acceso a servicios básicos favorece el crecimiento económico nacional y macrorregional; mientras que la desigualdad mostró coeficientes negativos y significativos, lo que comprueba que la desigualdad puede afectar negativamente el potencial de crecimiento económico. Esto verifica la afirmación que motivó este estudio: «La infraestructura de acceso a servicios básicos es una política win-win, al ser un instrumento relevante para reducir la desigualdad y para promover el crecimiento del PIB per cápita a nivel de departamentos».

El aporte de este estudio es contribuir a la definición de un modelo que esclarezca la relación infraestructura - crecimiento económico - desigualdad, así como de las técnicas necesarias para mejorar la precisión de los resultados. El análisis por macrorregiones permite enfocar mejor la urgencia por universalizar los niveles de acceso a infraestructura básica, ya que ha quedado comprobado que una inversión poco contextualizada no necesariamente va a traducirse en una reducción de la desigualdad. En ese sentido, «crecimiento económico» no será sinónimo de «desarrollo» si no se hace participar del proceso a toda la población involucrada, respetando sus particularidades. Tomando prestado el rol de policymakers, resultaría más eficiente priorizar la cartera de inversiones

\footnotetext{
${ }^{10} \mathrm{La}$ ecuación $\left.Y_{i, t}=\delta^{\prime} W_{i, t}+\gamma_{1} I(\operatorname{Inf})_{b}\right)_{i, t}+\gamma_{2} I(\operatorname{Inf})_{b_{i t}} * M \operatorname{Meg}_{i}+\varphi_{i}+\mu_{i, t}$ propone como variable dependiente al PIB per cápita $(Y)$, y como explicativas al vector de controles $(W)$, que incorpora la desigualdad de resultados (coeficiente de Gini por gasto - de 0 a 100), el capital humano (tasa de analfabetismo - de 0 a 100) y la ruralidad (proporción de la población rural respecto a la población total - de 0 a 100); al índice de infraestructura de acceso a servicios básicos (I) y a su interacción con el identificador macrorregional (MReg) y los efectos fijos de la región $(\varphi)$. La estimación se realiza bajo la misma metodología que el modelo original.
} 
en aquellas regiones donde la sensibilidad a la desigualdad es más alta frente a cambios en la mencionada infraestructura.

Se recomienda la aplicación de diferentes metodologías de corrección de autocorrelación para la base de datos. A nivel institucional, se recomienda brindar mayor importancia a la evaluación, medición y cuantificación del impacto de los programas de asistencia desarrollados por el Estado o el sector privado. Es muy importante contar con estadística fidedigna para que nuestros gobernantes puedan tomar decisiones acertadas de política y así ejecutar un gasto eficiente de los recursos económicos. En esa línea, se propone realizar el mismo análisis complementándolo con un índice que mida la calidad de la infraestructura y no solo su cantidad. Asimismo, las correlaciones nos muestran que el acceso a energía eléctrica no está tan correlacionado con la desigualdad como los otros tipos de infraestructura. Se recomienda analizar qué infraestructuras son realmente determinantes para nuestro país, considerando que en otros países dicha correlación es muy alta. Esto podría traducirse en efectos fijos por país, como indica la literatura especializada.

\section{Referencias}

Arpi, R. (2015). Perú, 2004-2013: inversión pública en infraestructura, crecimiento y desarrollo regional. Lima: Consorcio de Investigación Económica y Social.

AFIN (Asociación para el Fomento de la Infraestructura Nacional). (2006). El camino para reducir la pobreza. Lima: Asociación para el Fomento de la Infraestructura Nacional. Recuperado de http://www.afin.org.pe/index.php/publicaciones/estudios

AFIN (Asociación para el Fomento de la Infraestructura Nacional). (2016). Un plan para salir de la pobreza: Plan Nacional de Infraestructura 2016-2025. Lima: Asociación para el Fomento de la Infraestructura Nacional. Recuperado de http://www.afin. org.pe/index.php/publicaciones/estudios

Banco Mundial. (2008). Midiendo la desigualdad de oportunidades en América Latina y el Caribe. Recuperado de http://www.dhl.hegoa.ehu.es/recursos/409

Bajar, S., \& Rajeev, M. (2015). The impact of infrastructure provisioning on inequality: Evidence from India. GLU Working Papers, 35. Berlín: Global Labour University. Bourguignon, F. (2004). The poverty-growth-inequality triangle. Working Paper 125. Nueva Delhi: Indian Council for Research on International Economic Relations. Recuperado de https://www.econstor.eu/bitstream/10419/176147/1/icrier-wp-125.pdf Brenneman, A., \& Kerf, M. (2002). Infrastructure \& poverty linkages - A literature review. Documento inédito. Washington D. C.: The World Bank. Recuperado de https:// www.ilo.org/emppolicy/pubs/WCMS_ASIST_8281/lang--en/index.htm

Calderón, C., \& Servén, L. (2004). The effects of infrastructure development on growth and income distribution. Policy Research Working Paper, 3400. Washington D. C.: The World Bank. 
Casas, C. (2013). El impacto de la extracción de recursos naturales en la equidad interpersonal a nivel departamental en el Perú. Lima: Universidad del Pacífico - Centro de Investigación.

Cepal (Comisión Económica para América Latina). (2004). Desarrollo de infraestructura y crecimiento económico: revisión conceptual. Santiago: Comisión Económica para América Latina. Recuperado de http://bit.ly/2gBLb8C

Cowell, F. (2011). Measuring inequality. Oxford University Press. Recuperado de http:// www.siis.net/documentos/ficha/201733.pdf

Deininger, K., \& Squire, L. (1998). New ways of looking at old issues: Inequality and growth. Journal of Development Economics, 57(2), 259-287.

El Comercio. (7 de agosto de 2016). Las nuevas macrorregiones en formación en el país. El Comercio. Recuperado de http://elcomercio.pe/sociedad/peru/cuatro-macrorre giones-formacion-pais-informe-noticia-1922515

Esteban, A., \& Losa, A. (2015). Guia básica para interpretar los indicadores de desigualdad, pobreza y exclusión social. Madrid: European Anti-Poverty Network - España.

Fay, M., Leipziger, D. M., \& Yepes. (2003). Achieving the millennium development goals / the role of infrastructure. Policy Research Working Paper, 3163. Washington D. C.: The World Bank.

García, E., \& Gonzales, J. (2015). El consumo minimo de energía eléctrica y su relación con la selección de beneficiarios del vale de descuento FISE. Lima: Fondo de Inclusión Social Energético.

Gestión. (1 de junio de 2016). Se frena la reducción de la informalidad en Perú: crece a 73.2\% el 2015 alerta la SNI. Gestión. Recuperado de http://bit.ly/24j5h42

Guerra-García, G. (2010). Las demandas de inversión pública y la cohesión social. El caso de Perú. En A. Bárcena \& O. Kacef (Ed.), La política fiscal para el afianzamiento de las democracias en América Latina y el Caribe (pp. 223-237) Santiago: Comisión Económica para América Latina.

INEI (Instituto Nacional de Estadística e Informática). (2000). Metodología para la medición de la pobreza en el Perú. Lima: Instituto Nacional de Estadística e Informática. Recuperado de http://bit.ly/1NnJo16

INEI (Instituto Nacional de Estadística e Informática). (2011). Perfil de la pobreza por departamentos, 2001-2010. Lima: Instituto Nacional de Estadística e Informática. Recuperado de https://www.inei.gob.pe/media/MenuRecursivo/publicaciones_ digitales/Est/Lib0981/Libro.pdf

INEI (Instituto Nacional de Estadística e Informática). (2016a). Evolución de la pobreza monetaria 2009-2015. Lima: Instituto Nacional de Estadística e Informática. Recuperado de http://bit.ly/1rD7awm

INEI (Instituto Nacional de Estadística e Informática). (2016b). Perú: Formas de acceso al agua y saneamiento básico. Síntesis estadística. Lima: Instituto Nacional de Estadística e Informática. Recuperado de https:/www.inei.gob.pe/media/MenuRecursivo/ boletines/boletin_agua.pdf 
INEI (Instituto Nacional de Estadística e Informática). (2017a). Evolución de la pobreza monetaria 2007-2016. Informe técnico. Lima: Instituto Nacional de Estadística e Informática. Recuperado de https:/www.inei.gob.pe/media/MenuRecursivo/ publicaciones_digitales/Est/Lib1425/index.html

INEI (Instituto Nacional de Estadística e Informática). (2017b). Comportamiento de la economía peruana 1950-2016. En Panorama de la economía peruana 1950-2016: año base 2007 (pp. 11-58). Lima: Instituto Nacional de Estadística e Informática. Recuperado de https://www.inei.gob.pe/media/MenuRecursivo/publicaciones_ digitales/Est/Lib1424/libro.pdf

López, H. (2003). Macroeconomics and inequality. Contexts, 9(1), 16-21.

Mancero, X. (2000). Revisión de algunos indicadores para medir la desigualdad. En 6to. Taller Regional - Indicadores sobre el desarrollo social, Buenos Aires (pp. 375-386). Santiago: Comisión Económica para América Latina.

Osinergmin (Organismo Supervisor de la Inversión en Energía y Minería). (2015). Memoria institucional 2015. Lima: Organismo Supervisor de la Inversión en Energía y Minería. Recuperado de https://www.osinergmin.gob.pe/seccion/centro_documental/ Institucional/Institucional/Memoria-Institucional-Osinergmin-2015.pdf

Rehm, P. (2011). Social policy by popular demand. World Politics, 63(2), 271-299.

Steiner, R., \& Sabogal, A. (2011). Reducción de la pobreza y la desigualdad en el hemisferio. VI Cumbre de las Américas. Bogotá: Fedesarrollo (Centro de Investigación Económica y Social).

Vargas, L., Méndez, G., \& Altafin, I. (12 de junio de 2018). Proveer agua y saneamiento en la Amazonía rural: un enfoque integral. Blogs Banco Interamericano de Desarrollo. Recuperado de https://blogs.iadb.org/agua/es/agua-y-saneamiento-en-la-amazoniarural/

Vásquez, A., \& Bendezú, L. (2006). Inversión en infraestructura y desigualdad regional en el Perú: nueva evidencia. Lima: Consorcio de Investigación Económica y Social.

WEF (World Economic Forum). (2015). The global competitiveness report 2015-2016: Full data edition. Ginebra: World Economic Forum. Recuperado de http://www3. weforum.org/docs/gcr/2015-2016/Global_Competitiveness_Report_2015-2016. pdf

Zambrano, O., \& Aguilera-Lizarazu, G. (2011). Brechas de infraestructura, crecimiento y desigualdad en los paises andinos. IDB Working Paper Series, 291. Washington D. C.: Banco Interamericano de Desarrollo. 


\section{Anexos}

\section{Anexo 1 \\ Estimación en niveles con dependientes alternativas}

El siguiente análisis permite comprobar la robustez del modelo a partir de su estimación con otros estadísticos como variable dependiente. Mancero (2000) clasifica los distintos indicadores que permiten estudiar la distribución de ingresos (o gastos) entre individuos en cuatro grupos: los estadísticos tradicionales de dispersión (varianza, rango, desviaciones de la media); el índice de Gini $(G)$, calculado a partir de la curva de Lorenz; medidas basadas en la entropía, como el índice de Theil; $\mathrm{y}$ «medidas normativas» con funciones explícitas de bienestar social, como el índice de Atkinson. Asimismo, estos indicadores de desigualdad deben satisfacer algunas propiedades deseables.

Tabla 8

Indicadores de desigualdad según las propiedades deseables

\begin{tabular}{cccccc}
\hline Indicador & Descripción & $\begin{array}{c}\text { Lorenz } \\
\text { (Gini) }\end{array}$ & $\begin{array}{c}\text { Estadístico } \\
\text { (ratio } \\
\text { quintil) }\end{array}$ & $\begin{array}{c}\text { Bienestar } \\
\text { (Atkinson) }\end{array}$ & $\begin{array}{c}\text { Entropía } \\
\text { (Theil) }\end{array}$ \\
\hline $\begin{array}{c}\text { Principio de } \\
\text { transferencias }\end{array}$ & $\begin{array}{c}\text { Sensibilidad de la } \\
\text { desigualdad frente a } \\
\text { transferencia entre las } \\
\text { colas (rico a pobre) } \\
\text { Se puede obtener } \\
\text { la desigualdad total } \\
\text { sumando la de sus } \\
\text { subgrupos } \\
\text { Descomposición } \\
\text { aditiva }\end{array}$ & No & Débil & Débil & Fuerte \\
$\begin{array}{c}\text { No varía frente a } \\
\text { de escala y } \\
\text { tamaño }\end{array}$ & $\begin{array}{c}\text { cambios proporcionales } \\
\text { en los ingresos o la } \\
\text { distribución }\end{array}$ & Sín & Sí & Sí & Sí \\
Rango del índice & Entre 0 y 1 & Sí & No & Sí & Sí \\
\hline
\end{tabular}

Fuentes: Cowell (2011, p. 72) y Mancero (2000). Elaboración propia.

Una vista rápida de la tabla 8 sugeriría emplear indicadores de bienestar o de entropía. Pero los indicadores de bienestar son estimados a partir de una función de utilidad. Y los indicadores de entropía (o "grado de desorden») aprovechan la mayor información sobre pobreza para enfocarse en la menor probabilidad de su ocurrencia, pero a partir de una fución logarítmica de 
probabilidad en la que preponderan los ingresos más bajos. Dada la arbitrariedad en ambos enfoques, nuestro estudio optó por el coeficiente de Gini $(G)$ y por el ratio quintil.

Si bien $G$ es el indicador más usado por los especialistas, es más sensible a transferencias en el centro que en las colas de la distribución; las transferencias entre individuos no se ponderan por su distancia relativa en la escala de ingresos (transferencia débil). Por ello, Esteban \& Losa (2015) proponen un coeficiente entre los quintiles extremos de la distribución de ingresos, como es el ratio quintil $(\mathrm{S} 80 / \mathrm{S} 20)^{11}$, para estudiar los cambios sobre las colas de la distribución que no modifican la media o mediana.

El modelo original tomó $G$ por gasto como dependiente. Pero se compararon los estadísticos de especificaciones alternativas (tabla 9), a fin de evaluar la pertinencia de un doble o triple análisis. Así, bajo el supuesto de que los hogares no gastan necesariamente todo lo que ganan, una alternativa de dependiente para el modelo es el $\boldsymbol{G}$ por ingreso de hogares. Pero la limitante en este caso es que muchos de los ingresos en la Enaho son imputados, en especial en las colas, por lo que la aproximación puede estar sobreestimada si el reporte es insuficiente en altos ingresos, o subestimada cuando es insuficiente en bajos ingresos. Otra alternativa es el ratio quintil (80/20), que compara el ingreso o gasto promedio del quintil superior (a partir del percentil 80) de la distribución respecto al inferior (hasta el percentil 20).

Tabla 9

Estadísticos de los indicadores de desigualdad para el panel analizado

\begin{tabular}{cccccc}
\hline Estimador & Media (0-100) & Desv. estándar & \multicolumn{2}{c}{ Intervalo de confianza } & Estad. iguales \\
\hline Gini por gasto & 37,08631 & 4,119412 & 36,5871 & 37,58552 & - \\
Gini por ingreso & 45,77889 & 4,979971 & 45,1754 & 46,38239 & No \\
Ratio quintil & 7,60813 & 1,908685 & 7,376826 & 7,839434 & No \\
\hline
\end{tabular}

Fuente: Enaho, 2005-2015. Elaboración propia.

La tabla 9 muestra que la dispersión entre los datos es muy similar en los dos coeficientes de Gini y mucho más concentrada para el ratio quintil. En promedio, el coeficiente de Gini por ingresos tiende a estimaciones de mayor desigualdad que por gastos. El ratio quintil muestra una mayor incidencia de

\footnotetext{
${ }^{11} \mathrm{El}$ «ratio quintil» también puede ser calculado a partir de cuartiles (S75/S25), deciles (S90/S10) u otros tramos, dependiendo del objetivo de la investigación.
} 
la desigualdad que los coeficientes de Gini. Por tanto, el análisis para ambas dependientes alternativas sirve como una verificación adicional de robustez.

Al estimar con Gini por ingreso (tabla 10), los índices resultaron negativos y, en su mayoría, significativos (la región Macro-Centro solo en la interacción). Los controles presentaron los efectos esperados en cada caso, aunque no siempre significativos. Por ejemplo, incrementos en el ingreso llevan a una mayor disparidad, como muestra la literatura especializada.

Para la estimación con ratio quintil, el índice $I$ no resultó significativo de manera individual, aunque sí mantuvo el sentido esperado. En la interacción, se observaron resultados similares a los obtenidos con el modelo inicial (Gini por gasto); Macro-Sur y Macro-Centro resultaron negativos y significativos. Los controles presentaron los efectos esperados en cada caso, aunque no siempre significativos.

Para ambos casos, se comprobó la robustez de las especificaciones con los cinco índices alternativos de infraestructura y con las infraestructuras tomadas independientemente (16 ecuaciones).

\section{Tabla 10}

Resultados de las estimaciones para el coeficiente de Gini por ingreso según el modelo propuesto

\begin{tabular}{lcccc}
\hline & Coef. de Gini por ingreso $(0-100)$ & \multicolumn{2}{c}{ Ratio quintil $(80 / 20)$} \\
\hline Desigualdad & $\begin{array}{c}\text { Ec. }(4) \text { sin } \\
I^{*} \text { MReg }\end{array}$ & $\begin{array}{c}\text { Ec. }(4) \\
\text { completa }\end{array}$ & $\begin{array}{c}\text { Ec. }(4) \text { sin } \\
\text { I*MReg }\end{array}$ & $\begin{array}{c}\text { Ec. }(4) \\
\text { completa }\end{array}$ \\
\hline PIB p. c. & $0,132^{*}$ & $-0,000000032$ & $-0,0000000354$ & $-0,0000000178$ \\
Tasa de analf. (0-100) & $-0,0000000259$ & $-0,0773$ & $0,0710^{*}$ & 0,0140 \\
Pob. en rural (0-100) & 0,0318 & $0,233^{* * *}$ & $0,0943^{* * *}$ & $0,141^{* * *}$ \\
Índice de inf. (I) & $-0,749^{* *}$ & & $-0,182$ & \\
I en Macro-Norte & & $-0,130$ & & 0,180 \\
I en Macro-Sur & & $-0,573$ & & $-0,481^{* * *}$ \\
I en Macro-Centro & & $-1,359^{* * *}$ & & $-0,345^{* *}$ \\
I en Amazonía & & 0,535 & & 0,381 \\
Constante & $3,915^{* * *}$ & $38,58^{* * *}$ & $3,915^{* * *}$ & $2,712^{* *}$ \\
N. obs. & 264 & 264 & 264 & 264 \\
Años & 11 & 11 & 11 & 11 \\
Grupos & 24 & 24 & 24 & 24 \\
\hline
\end{tabular}

Notas. ${ }^{*} \mathrm{p}<0,1,{ }^{* *} \mathrm{p}<0,05,{ }^{* * *} \mathrm{p}<0,01$. Elaboración propia. 


\section{Anexo 2}

\section{Estimación con variaciones de uno y tres períodos}

La literatura especializada enseña que la desigualdad tiene efectos de corto, mediano y largo plazo sobre el ingreso y la pobreza, y viceversa. Estos efectos pueden ser controlados con rezagos de la variable dependiente y de las explicativas. Puesto que el modelo pretende estudiar la relación entre desigualdad e infraestructuras de acceso a servicios básicos, es importante considerar el delay con el que actúan las respectivas políticas de inversión.

En el largo plazo, la infraestructura modifica el crecimiento potencial del territorio económico y el desarrollo de capital humano. En el mediano plazo, la inversión o las externalidades de esta facilitan el empleo sostenible y generan nuevas oportunidades productivas. En el corto plazo, el efecto se observa en dos etapas. Primero, la inversión en infraestructura implica una mayor participación de los activos de los pobres en la producción desde el inicio. La inversión en infraestructura genera empleo temporal para quienes trabajan en su construcción y fomenta el emprendimiento en servicios conexos como consecuencia del mayor dinamismo alrededor de la obra (restaurantes, transporte, etc.), lo que mejora la curva de posibilidades de consumo. Segundo, la infraestructura tiene un efecto considerable después de su implementación, y sujeto al usufructo de la población beneficiada. Finalizada la construcción, la infraestructura se torna en un bien público que incrementa automáticamente las posibilidades de producción de la población, sea por optimización del tiempo, al dirigir el superávit hacia otras actividades productivas, o del gasto, producto del mejor o mayor acceso (pasar de motor a electrificación, de cisterna a tuberías, etc.). El estudio aborda la primera etapa, y este anexo desarrolla la segunda. A continuación, la ecuación por estimar:

$$
\begin{gathered}
{\left[G_{i, t}-G_{i, t-\varepsilon}\right]=\eta^{\prime}\left[X_{i, t}-X_{i, t-\varepsilon}\right]+\beta_{1}\left[I_{i, t}-I_{i, t-\varepsilon}\right]+\beta_{2}\left[I_{i, t}-I_{i, t-\varepsilon}\right] * M \operatorname{Reg}_{i}+} \\
{\left[\varepsilon_{i, t}-\varepsilon_{i, t-\varepsilon}\right]} \\
{\left[\Delta_{\varepsilon} G_{i, t}\right]=\eta^{\prime}\left[\Delta_{\varepsilon} X_{i, t}\right]+\beta_{1}\left[\Delta_{\varepsilon} I\left(\operatorname{Inf}_{b}\right)_{i, t}\right]+\beta_{2}\left[\Delta_{\varepsilon} I\left(\operatorname{Inf}_{b}\right)_{i, t}\right] * M \operatorname{Meg}_{i}+\Delta_{\varepsilon} \varepsilon_{i, t}}
\end{gathered}
$$

En la ecuación (4.1), las variables se encuentran en variaciones de períodos, donde puede tomar el valor de 1 o 3 . Como muestra la tabla $11, \varepsilon=3$ nos presenta, estadísticamente, el peor escenario, donde se cuenta con solo 72 grados de libertad $(g l)^{12}$, producto de tres variaciones trianuales de información

\footnotetext{
${ }^{12}$ Se prefiere contar con alrededor de 60 observaciones para estimar correctamente un panel (apuntes de clase del curso Econometría II, dictado por la profesora Arlette Beltrán, ciclo académico VII, semestre 2016-2).
} 
para 24 departamentos. Pero si se estiman cuatro coeficientes para las macrorregiones en interacción con la infraestructura y cuatro para las variables de control, se cuenta con suficiente capacidad explicativa para las estimaciones. En este modelo ya no se tienen efectos fijos, pues estos se eliminan al restar una observación anterior de la serie.

Tabla 11

Resultados de las estimaciones para el coeficiente de Gini por gasto, según el modelo propuesto y en variaciones de uno y tres períodos

\begin{tabular}{lcccc}
\hline \multicolumn{3}{c}{$\varepsilon=1$} & \multicolumn{2}{c}{$\varepsilon=3$} \\
\hline $\begin{array}{l}\Delta \text { Gini por gasto } \\
(0-100)\end{array}$ & $\begin{array}{c}\text { Ec. }(4) \text { sin } \\
I^{*} \text { MReg }\end{array}$ & $\begin{array}{c}\text { Ec. }(4) \\
\text { completa }\end{array}$ & $\begin{array}{c}\text { Ec. }(4) \text { sin } \\
I^{*} \text { MReg }\end{array}$ & $\begin{array}{c}\text { Ec. }(4) \\
\text { completa }\end{array}$ \\
\hline$\Delta$ PIB p. c. & 0,00000 & 0,0000 & $-0,000000143^{* * *}$ & 0,000000151 \\
$\Delta$ Tasa de analf. $(0-100)$ & $-0,246^{* * *}$ & $-0,219^{* * *}$ & $-0,225^{* *}$ & $-0,341^{* * *}$ \\
$\Delta$ Pob en zona rural (0-100) & $-0,0418$ & $-0,0417$ & $0,388^{* * *}$ & $0,337^{* *}$ \\
$\Delta$ PEA (0-100) & $0,165^{* * *}$ & $0,159^{* * *}$ & $-0,126$ & $-0,232^{* * *}$ \\
$\Delta$ Índice de inf. (I) & $-0,227$ & & $-0,552^{*}$ & \\
$\Delta$ I en Macro-Norte & & 0,364 & & $0,666^{* *}$ \\
$\Delta$ I en Macro-Sur & & 0,0275 & & $-0,516$ \\
$\Delta \mathrm{I}$ en Macro-Centro & & $-0,724^{*}$ & & $-0,293$ \\
$\Delta \mathrm{I}$ en Amazonía & $-0,289$ & & $-0,707$ \\
\hline Constante & $-0,464^{* * *}$ & $-0,432^{* * *}$ & $-0,142$ & $-1,145^{* * *}$ \\
N. obs. & 240 & 240 & 72 & 72 \\
Ańos & 10 & 10 & 3 & 3 \\
Grupos & 24 & 24 & 24 & 24 \\
\hline
\end{tabular}

Notas. ${ }^{*} \mathrm{p}<0,1,{ }^{* *} \mathrm{p}<0,05,{ }^{* * *} \mathrm{p}<0,01$. Elaboración propia.

Los resultados resumidos en la tabla 11 señalan que, para las estimaciones con rezago de un período, el índice $I$ no resultó significativo de manera individual, aunque sí mantuvo el sentido esperado (negativo). En la interacción, solo para la región Macro-Centro resultó significativo y mantuvo el sentido esperado. Respecto a los controles, es interesante observar que el efecto del PIB tiende estadísticamente a 0 en ambas formulaciones (completa y $\sin I^{*} M R e g$ ) cuando la variación es de un período, lo que sugiere un efecto pasajero del crecimiento en la desigualdad. Se observa la permanencia del efecto negativo del analfabetismo y del positivo de la población en el 
mercado laboral, ya que esta última responde a una matriz productiva no necesariamente inclusiva.

Para las estimaciones con rezago de tres períodos, los índices I mantuvieron los sentidos esperados (negativo) en su mayoría, y resultaron significativos de manera independiente y en su interacción para la región Macro-Norte. En esta última, se observa un efecto positivo del incremento de infraestructura de acceso a servicios básicos sobre la desigualdad. Como se abordó en el análisis de elasticidades, ello puede estar relacionado con los stocks actuales de infraestructura y el punto de saturación en la función cóncava de acceso. Podría ser este el caso en que la inversión favorece la canasta de consumo en lo inmediato (primera etapa), pero cuya ganancia marginal se diluye al tercer año, dados los niveles actuales de infraestructura. Respecto a los controles, los resultados son consistentes con la literatura especializada y el modelo utilizado. Se mantienen los sentidos esperados para cada indicador, en especial cuando estos son significativos. Y, nuevamente, se observa que el crecimiento tiene un efecto en la desigualdad que es diluido en el corto plazo.

Se comprobó así la robustez del modelo, a través de la consistencia en el sentido esperado de las variables de infraestructura -índices, interacciones e infraestructuras independientes-, aunque no siempre resultaron significativas, para las 16 ecuaciones del estudio. 


\section{Determinantes del rechazo de ofertas de compensación por expropiación en cinco distritos de Lima Metropolitana}

Alejandra Guardia Muguruza

Nicolle Pegot-Ogier Rodrigo

\section{Introducción}

La existencia de predios donde deben ejecutarse obras públicas retrasa significativamente la inversión en infraestructura. Estas demoras elevan los costos de esas obras y restan dinamismo al crecimiento económico (Prialé, 2015). Por ello, la agilización de procesos expropiatorios es un requisito vital para acelerar la inversión y reducir las brechas de infraestructura que hay en el Perú (AFIN, 2016) (véase el anexo 1).

El objetivo de esta investigación es identificar los factores que explican el rechazo de las ofertas de compensación hechas por el Estado a los habitantes de predios por ser expropiados. La hipótesis principal es que el apego sicológico de las familias hacia sus hogares es el factor más importante en la decisión de aceptar o rechazar la compensación, entre los nueve determinantes analizados.

El análisis se concentra en proyectos de infraestructura vial debido a la alta incidencia de expropiaciones en la construcción de redes viales. Se escogió a Lima Metropolitana como área de estudio por haber participado del 65\% de la inversión en infraestructura de transportes a nivel nacional entre 2012 y 2016 (Apoyo Consultoría, 2016).

\footnotetext{
${ }^{1}$ Este ensayo es una versión resumida y editada del Trabajo de Investigación Económica que, con el mismo título, fue concluido en junio de 2017. Las autoras agradecen de manera especial al profesor Carlos Parodi Trece por su asesoría y acompañamiento durante la elaboración de esta investigación.
} 
Nuestra investigación también permite comprender qué otros factores deberían considerarse para mejorar las recompensas monetarias en materia de expropiaciones. Además, es una primera aproximación cuantitativa al análisis académico de expropiaciones en el Perú, un tema que carecía de estudios empíricos peruanos.

\section{Revisión de literatura especializada}

Varias externalidades positivas son generadas por las inversiones en infraestructura vial (Bonifaz \& Urrunaga, 2008) (véase el anexo 2). Estas promueven la reducción de costos y tiempo de transporte; la mejora de la competitividad y la conectividad; la promoción del comercio, el turismo y la producción; el desarrollo urbano y la generación de nuevos empleos; y, en ciertos casos, la revalorización de inmuebles (Huamaní, 2015).

En vista de esa importancia, resulta relevante evaluar los riesgos que podrían perjudicar la ejecución de proyectos viales. Para Barrionuevo \& Watanabe (2015), los principales motivos que demoran la ejecución de esas obras en el Perú son la identificación y valuación de los predios ${ }^{2}$. Sobre ello, hay dos temas que cobran especial relevancia para el análisis de expropiaciones: la metodología para establecer las compensaciones monetarias y los factores no monetarios que deben considerarse al estimarlas.

Sobre el mecanismo de compensación por expropiaciones, Trembecka (2016) halló poca claridad en los lineamientos establecidos en Polonia. De manera similar, Giammarino \& Nosal (2005) encuentran que, por lo general, no está bien especificada la indemnización que debe pagar el Gobierno. Por ello, reflexionan sobre las reglas de compensación y concluyen que, cuando la probabilidad de expropiación es baja, la compensación óptima del Estado debería ser igual al valor de mercado del inmueble.

Por otro lado, Arumäe \& Kein (2014) evaluaron si la retribución monetaria basada en el precio de mercado podía considerarse justa desde la perspectiva de los dueńos de los predios. Encontraron que el monto no era suficiente para los propietarios de Estonia. Los autores explican que la diferencia entre el precio de mercado y la valoración de los propietarios recaía en variables como costos de transacción, distorsiones y fallas de mercado, inflación, adversidad al riesgo de los individuos, desconocimiento de los valores no comerciales, y la naturaleza heterogénea del bien evaluado.

\footnotetext{
${ }^{2}$ Coincidentemente, Vassallo, Ortega \& Baeza (2002) concluyeron que, entre 1996 y 2004, la agilización de expropiaciones impulsó la inversión en infraestructura en España.
} 
En línea con ello, Ataguba (2014) identificó que el valor de compensación no debía limitarse a un análisis económico restringido, sino que debía incluir los costos sicológicos derivados de la expropiación. Su investigación se enfocó en las expropiaciones realizadas para la construcción de un aeropuerto internacional en Ruanda. Para ello, desarrolló un método de valorización llamado Disturbance-Integrated Method of Assessment, que combina el valor del mercado de la propiedad con su valor contingente.

El valor de mercado se define por el precio de mercado del terreno $(T)$, el precio de la construcción $(C)$ y el valor de las mejoras realizadas al predio $(M)$. El valor contingente, por su parte, toma en cuenta los disturbios generados por la expropiación, tales como los costos de mudanza $(C M)$, los costos adicionales $(A C)$, la pérdida de bienestar $(P B)$ e ingresos $(I)$, los costos sicológicos $(S)$ y otros costos adicionales $(O)$ (véase el anexo 3). Así, la compensación es planteada como sigue:

$$
C_{\text {Total }}=f(T, C, M, C M, A C, P B, I, S, O)
$$

Con base en ello, dicho autor concluyó que el valor al que debían ser compensados los expropiados en Ruanda era significativamente mayor que el valor de mercado.

\section{Marco analítico}

La legislación peruana autoriza las expropiaciones por el Estado cuando se trata de obras de infraestructura declaradas de necesidad pública, interés nacional, seguridad nacional y/o de gran envergadura. En tal caso, el Estado está obligado a realizar el pago de una indemnización justipreciada que compense al expropiado, mientras que los propietarios tienen la obligación de otorgar la propiedad al Estado (Gaceta Oficial, 2016).

En vista de las frecuentes dificultades que enfrenta el Estado peruano para realizar expropiaciones, resulta cada vez más importante determinar si el factor económico es el más relevante en la decisión de los propietarios respecto a entregar o no sus predios. Por ello, sobre la base de las tres variables de valoración no monetaria propuestas por Ataguba $(2014)^{3}$, aquí planteamos un modelo enfocado en el caso de que el predio por expropiar sirva de hogar de alguna familia, y en el cual la variable dependiente es la probabilidad de que la oferta del Estado sea rechazada en el trato directo de negociación ${ }^{4}$; donde

\footnotetext{
${ }^{3}$ Estas son: las características de los propietarios, el apego sicológico y la pérdida de bienestar actual.

${ }^{4} \mathrm{La}$ oferta compensatoria incluye un incentivo del $10 \%$ adicional sobre el valor comercial del inmueble,
} 
$Y=1$ representa la opción de que el propietario rechace la dicha oferta e $Y=0$ indica la aceptación de la compensación ofrecida.

Por su parte, las variables independientes están dadas por nueve determinantes: las características del hogar $(C A)$, el uso económico del predio $(U)$, el bienestar actual $(B A)$, la compensación económica $(C E)$, la comodidad ante la opción de reubicación $(R E)$, la información acerca de los beneficios del proyecto $(B P)$, el apego sicológico de las personas hacia sus hogares $(A S)$, el sentimiento de obediencia a la ley $(L E Y)$ y el riesgo moral $(R M)$. Así, la probabilidad de rechazo a la oferta compensatoria se expresa como:

$$
\operatorname{Prob}_{\text {rechazo }}=\operatorname{Prob}(Y=1)=f(\overrightarrow{C A}, \vec{U}, \overrightarrow{B A}, \overrightarrow{C E}, \overleftarrow{R E}, \overleftarrow{B P}, \overrightarrow{A S}, \overleftarrow{L E Y}, \overrightarrow{R M})
$$

Además, se identifican 17 variables independientes que definen con mayor precisión los componentes de los nueve determinantes anteriores. El primero, características del hogar $(C A)$, es explicado por dos variables discretas: el número de personas que viven en el predio $(\overrightarrow{N P})$ y el nivel de educación del jefe del hogar $(\overrightarrow{E D U})$.

El segundo determinante, uso económico del predio $(U)$, se define por la variable binaria presencia de negocio en la propiedad $(\overrightarrow{U E})$, que identifica si el hogar obtiene una renta adicional por un negocio establecido dentro del predio.

Para el tercer determinante, bienestar actual $(B A)$, se identificaron seis variables relevantes: el nivel de incomodidad por mudanza $(\overrightarrow{M U D})$, el acceso a espacios libres o comunes como parques o losas deportivas $(\overrightarrow{A E L})$, el nivel de tráfico de la zona $(\overleftarrow{N T})$ y la cercanía al resto de la familia $(\overrightarrow{C F})$, al centro educativo de los hijos $(\overrightarrow{C C})$ o al centro de trabajo $(\overrightarrow{C T})$.

El cuarto determinante, compensación económica $(C E)$, se explica por la variable binaria monto de compensación insuficiente $(\overrightarrow{C E})$, que evalúa la percepción de los entrevistados sobre la oferta monetaria planteada por el Estado.

El quinto determinante, reubicación $(R E)$, viene dado por la variable binaria comodidad ante la opción de reubicación $(\overleftarrow{R E})$, la cual detecta si el entrevistado aceptaría la compensación si se le ofrece una opción de reubicación conveniente.

El sexto determinante, beneficio del proyecto $(B P)$, es calculado mediante la variable discreta de información completa acerca de los beneficios del proyecto $(\overleftarrow{B P})$; esta evalúa si los individuos aceptarían la compensación si conocieran los beneficios del proyecto. 
El apego sicológico $(A S)$, por su parte, es medido mediante dos variables: el número de años vividos en la propiedad $(\overrightarrow{A V})$ y si los padres o abuelos vivieron allí $(\overrightarrow{V P})$.

El octavo determinante, obediencia a la ley $(L E Y)$, se mide por dos variables binarias: disposición a entregar la vivienda por respeto a la ley $(\overleftarrow{L E Y})$ y/o por resignación ante la percepción de un alto poder del Estado $(\overleftarrow{P E})$.

Por último, el riesgo moral $(R M)^{5}$ se define mediante una variable binaria $(\overrightarrow{R M})$ que evalúa si el individuo tiene expectativas alcistas sobre el precio del predio que lo motiven a rechazar la oferta para pedir una compensación mayor en el futuro.

Estos vectores y sus respectivas variables se presentan en la tabla 1 y se detallan en el anexo 4.

Tabla 1

Descripción de variables del modelo 1

\begin{tabular}{|c|c|c|c|}
\hline Vector & Nombre del vector & Variable & Nombre de la variable \\
\hline Y & Rechazó la recompensa & Y & Respuesta a la oferta \\
\hline \multirow{2}{*}{$\mathrm{CA}$} & \multirow{2}{*}{ Características del hogar } & NP & Número de personas viviendo en el predio \\
\hline & & EDU & Nivel de educación del jefe de hogar \\
\hline $\mathrm{U}$ & Uso económico del predio & UE & Presencia de negocio en la propiedad \\
\hline \multirow{6}{*}{$\mathrm{BA}$} & \multirow{6}{*}{ Bienestar actual } & MUD & Incomodidad por mudanza \\
\hline & & AEL & Acceso a espacios libres \\
\hline & & NT & Nivel de tráfico \\
\hline & & $\mathrm{CF}$ & Cercanía a la familia \\
\hline & & $\mathrm{CC}$ & Cercanía al centro educativo de los hijos \\
\hline & & $\mathrm{CT}$ & Cercanía al centro de trabajo \\
\hline $\mathrm{CE}$ & Compensación económica & CE & Monto de compensación insuficiente \\
\hline $\mathrm{RE}$ & Reubicación & $\mathrm{RE}$ & Comodidad ante la opción de reubicación \\
\hline $\mathrm{BP}$ & Beneficio del proyecto & $\mathrm{BP}$ & $\begin{array}{l}\text { Tiene conocimiento de los beneficios del } \\
\text { proyecto }\end{array}$ \\
\hline \multirow[b]{2}{*}{ AS } & \multirow[b]{2}{*}{ Apego sicológico } & AV & Ańos vividos en la propiedad \\
\hline & & VP & $\begin{array}{l}\text { Vivencia de padres o abuelos en la } \\
\text { propiedad }\end{array}$ \\
\hline
\end{tabular}
${ }^{5}$ El riesgo moral es el comportamiento oportunista de un agente económico en un contexto en el que no
puede ser monitoreado por existir asimetrías de información (Mankiw, 2012). 


\begin{tabular}{cccl}
\hline Vector & Nombre del vector & Variable & \multicolumn{1}{c}{ Nombre de la variable } \\
\hline \multirow{2}{*}{ LEY } & Obediencia a la ley & Ley & Respeto a la ley \\
& & PE & Resignación ante el poder del Estado \\
\hline RM & Riesgo moral & RM & Riesgo moral \\
\hline
\end{tabular}

Elaboración propia.

Los especialistas han examinado las relaciones entre estas variables, que sustentan los signos esperados en nuestro modelo. Por ejemplo, Contreras, Garay, Santos \& Betancourt (2014), al examinar los componentes de la valoración de predios con riesgo de ser expropiados en Venezuela, encuentran que características como el número de años de la propiedad, el área para estacionamiento, la cercanía a áreas verdes y la proximidad a centros comerciales tienen un impacto positivo en la valoración de las viviendas. Con ello, se esperaría que cuanto mayor sea la cercanía del hogar al centro laboral, centro educativo o espacios recreacionales, mayor será la probabilidad de rechazo.

Asimismo, evidencia empírica relacionada con la valorización de bienes raíces concluye que la presencia de negocios en el interior de los predios incrementa de manera significativa su valor (Tole \& McCord, 2003). Con ello, podría esperarse el rechazo de la oferta por individuos que den uso económico a la vivienda.

Por su parte, Sander \& Polasky (2009) observan, mediante una estimación de precios hedónicos, que existe un impacto significativo y positivo de los espacios al aire libre en el valor de los predios en Minnesota. Así, estas características incrementarían la probabilidad de rechazo de las ofertas de expropiación.

Del mismo modo, Stiefken (2014), en su tesis doctoral sobre el altruismo y la solidaridad, comprobó que existe una relación causal entre el estado de bienestar (definido como aquel en el que se percibe que el Gobierno busca el mayor bienestar de toda la población) y el altruismo. Por ello, si el Estado difunde bien los beneficios del proyecto vial, la población estaría más dispuesta a avenirse al bien común, y la probabilidad de rechazo de la oferta disminuiría.

Por otro lado, Molina, Ruiz, Saura \& García (2010) evalúan el valor emocional que las personas dan a un establecimiento. Respecto a centros comerciales, concluyen que el apego emocional de los clientes eleva de manera significativa su lealtad hacia ellos. Se esperaría, así, que este apego eleve la probabilidad de rechazo a la oferta expropiatoria.

Por último, los economistas George Akerlof, Michael Spence y Joseph Stiglitz recibieron el Premio Nobel de Economía en 2001 por su trabajo sobre 
la Economía de la información, en el que señalan que la asimetría de información genera la presencia de riesgo moral y selección adversa (Zorrilla, 2006). En este caso, el surgimiento de riesgo moral -expresado en el rechazo de la oferta para esperar un aumento de precios en el futuro- podría incrementar la probabilidad de rechazo de la oferta de compensación.

\section{Metodología}

Para analizar los determinantes del rechazo de ofertas de compensación por expropiación, se aplicó un modelo de elección discreta de respuesta dicotómica, apropiado para estimar la probabilidad de que un agente económico elija una alternativa u otra dentro de un conjunto finito de opciones posibles. El modelo se basa en la formulación de una utilidad aleatoria, en la que el jefe del hogar opta, entre dos alternativas, por la que maximiza su utilidad esperada (Medina, 2003). De esta manera, el agente $i$ elegirá la opción 1 solo si la utilidad de rechazar la compensación supera la de aceptarla, de manera que:

$$
Y_{i}=\left\{\begin{array}{l}
1 \text { si } U_{i 1}>U_{i 0} \\
0 \text { si } U_{i 1}<U_{i 0}
\end{array}\right.
$$

Así, el modelo dicotómico es definido como:

$$
\operatorname{Prob}(Y=1)=\operatorname{Prob}\left(U_{i 1}>U_{i 0}\right)=\operatorname{Prob}\left(U_{i 1}-U_{i 0}>0\right)=F\left(X_{i} \beta\right)
$$

Para obtener adecuadas estimaciones de variables dicotómicas, se emplearon los modelos de probabilidad no lineal, probit y logit, que logran un resultado acotado entre 0 y 1 (Medina, 2003); además, se basan en la función de distribución normal acumulada y la función logística, respectivamente.

Por un lado, el modelo probit supone que la variable dependiente $(Y)$ está en función de un índice o variable latente $\left(I^{*}\right)$, explicado por una o varias variables explicativas $(X)$ :

$P_{i}=P(Y=1 \mid X)=P\left(I_{i}^{*} \leq I_{i}\right)=P\left(Z_{i} \leq \alpha+\beta X_{i}\right)$.

\section{Donde:}

$Z$ es una variable normal estándar.

$F$ es una función de distribución normal acumulada.

Así, el modelo probit puede plantearse como sigue:

$$
f(x)=\frac{1}{\sqrt{2 \pi}} e^{-\frac{1}{2} x^{2}}, F(x)=\int_{-\infty}^{x} f(x) d x
$$


Por su parte, el modelo logit expresa la probabilidad de un suceso en función de variables explicativas, empleando la función logística en vez de lineal para realizar la estimación. En particular, el modelo define que: $F(x)=\frac{e^{x}}{1+e^{x}}$.

\subsection{Selección de distritos}

La definición de distritos siguió tres etapas. Primero, se seleccionaron los proyectos de inversión pública (PIP) en infraestructura vial que fueron formulados por la Municipalidad Metropolitana de Lima entre 2005 y 2016. En esta primera etapa, se obtuvo un total de 479 PIP.

Luego, con el objetivo de considerar solo los proyectos con mayor probabilidad de ser ejecutados en el corto plazo, se restringió la muestra a los proyectos que contaban con expediente técnico. El número de proyectos se redujo a 261.

Por último, para obtener los PIP con mayor probabilidad de llevar a cabo procesos de expropiación, se seleccionaron aquellos que involucraban construcciones de intercambios viales, ampliaciones de avenidas, ampliaciones de número de carriles y conceptos similares. Con un total de 240 proyectos relevantes para el estudio, se estableció un ranking de distritos de Lima Metropolitana (anexo 5). El estudio se concentró en los cinco primeros distritos del ranking: San Juan de Lurigancho, Independencia, Villa María del Triunfo, Cercado de Lima y Villa El Salvador.

\subsection{Tamaño de la muestra}

Dada la presencia de 656.700 viviendas en los cinco distritos encuestados (anexo 6), se asumió un universo infinito $(n)$. Considerando que las variables analizadas son cualitativas, se empleó la siguiente fórmula para proporciones:

$$
n_{0}=\frac{\pi(1-\pi) \times Z^{2}\left(1-\frac{\alpha}{2}\right)}{d^{2}}
$$

Donde:

$n_{0}$ : tamańo mínimo de muestra.

$d$ : error máximo de estimación.

$\propto$ : nivel de significancia.

$\pi$ : proporción poblacional de la muestra piloto.

$Z$ : distribución normal.

Debido a restricciones presupuestarias, se definió como tamaño de muestra 200 encuestas, cuyo margen de error estimado fluctuaba entre el $4 \%$ y el $7 \%$ (anexo 7). 


\subsection{Muestreo aleatorio simple sin reemplazo}

Se seleccionaron aleatoriamente 40 viviendas en cada distrito ${ }^{6}$. Para ello, se utilizó el muestreo aleatorio simple y sin reemplazo, según el cual cada hogar tuvo la misma probabilidad de ser escogido para la muestra y solo podía ser encuestado una vez.

\subsection{Cuestionario}

Las encuestas fueron dirigidas a los jefes del hogar. El cuestionario incluye 24 preguntas sobre las características y usos de su vivienda, la comodidad en el entorno actual, la pérdida de bienestar que experimentarían en caso de expropiación, el grado de aprobación de la compensación económica, el nivel de asimetría de información, el apego emocional y la presencia de riesgo moral (anexo 8). Además, con el fin de cuantificar los aspectos sicológicos e intrínsecos, se utilizaron dos métodos psicométricos: las escalas de $\operatorname{Likert}^{7}$ y el método del escalamiento (Meneses et al., 2013).

\section{Análisis de resultados}

\subsection{Descripción de los datos}

La investigación dispuso de observaciones de corte transversal de 200 jefes de hogar en cinco distritos de Lima Metropolitana (anexo 9). En promedio, los encuestados tenían 48 años $^{8}$, y la mayoría eran mujeres (54\% del total). Un 22\% terminó los estudios superiores; un 9\% tenía estudios superiores incompletos; un 53\%, secundaria completa; y un 18\%, secundaria incompleta o menos.

También, en promedio, reportaron haber habitado el predio durante 32 años y vivir con 9 personas en el hogar. Asimismo, el 97\% de los encuestados aseguró contar con un negocio en el predio. Por último, se obtuvo que el $59 \%$ rechazó la oferta compensatoria 9 , lo que indica que la mayoría de las personas encuestadas no estaban de acuerdo con la compensación ofrecida por el Estado.

\footnotetext{
${ }^{6}$ El procedimiento de selección y desarrollo de encuestas fue realizado por la empresa AD-REM S. A., que pertenece a la Asociación Peruana de Empresas de Investigación de Mercados.

${ }^{7}$ Escala psicométrica que especifica el nivel de acuerdo o desacuerdo con una declaración.

${ }^{8}$ La mayoría (33\% del total) tenían entre 30 y 45 años.

${ }^{9}$ Esta compensación incluye un monto adicional del $10 \%$ sobre el valor del predio, como se mencionó antes.
} 


\subsection{Elección del mejor modelo}

Con el fin de garantizar que el resultado de la estimación esté acotado entre 0 y 1 , evitar heterocedasticidad y obtener efectos marginales no constantes, se utilizaron los modelos no lineales probit y logit. Los resultados se presentan en la tabla 2.

\section{Tabla 2}

Modelos de estimación probit y logit

\begin{tabular}{|c|c|c|}
\hline Variable & Modelo probit & Modelo logit \\
\hline Constante & $\begin{array}{c}1,260 \\
(1,243)\end{array}$ & $\begin{array}{c}2,093 \\
(2,170)\end{array}$ \\
\hline Número de personas (NP) & $\begin{array}{c}0,020 \\
(0,034)\end{array}$ & $\begin{array}{c}0,033 \\
(0,061)\end{array}$ \\
\hline Nivel educativo (EDU) & $\begin{array}{c}-0,316^{* * *} \\
(0,119)\end{array}$ & $\begin{array}{c}-0,543^{* * *} \\
(0,206)\end{array}$ \\
\hline Uso económico (UE) & $\begin{array}{c}0,158 \\
(0,340)\end{array}$ & $\begin{array}{c}0,201 \\
(0,600)\end{array}$ \\
\hline Incomodidad por mudanza (MUD) & $\begin{array}{l}0,261^{*} \\
(0,135)\end{array}$ & $\begin{array}{l}0,489^{* *} \\
(0,240)\end{array}$ \\
\hline Acceso a espacios libres (AEL) & $\begin{array}{c}0,625^{* * *} \\
(0,190)\end{array}$ & $\begin{array}{c}1,094^{* * *} \\
(0,339)\end{array}$ \\
\hline Nivel de tráfico (NT) & $\begin{array}{c}-0,339^{* *} \\
(0,167)\end{array}$ & $\begin{array}{c}-0,631^{* *} \\
(0,303)\end{array}$ \\
\hline Cercanía a la familia (CF) & $\begin{array}{l}-0,158 \\
(0,339)\end{array}$ & $\begin{array}{l}-0,345 \\
(0,598)\end{array}$ \\
\hline Cercanía colegio (CC) & $\begin{array}{l}-0,315 \\
(0,379)\end{array}$ & $\begin{array}{l}-0,646 \\
(0,691)\end{array}$ \\
\hline Cercanía trabajo $(\mathrm{CT})$ & $\begin{array}{c}0,033 \\
(0,282)\end{array}$ & $\begin{array}{c}0,123 \\
(0,494)\end{array}$ \\
\hline Inadecuada compensación económica (CE) & $\begin{array}{c}1,424^{* * *} \\
(0,434)\end{array}$ & $\begin{array}{c}2,630^{* * *} \\
(0,794)\end{array}$ \\
\hline Comodidad de reubicación (RE) & $\begin{array}{c}-0,446^{* * *} \\
(0,148)\end{array}$ & $\begin{array}{c}-0,828^{* * *} \\
(0,270)\end{array}$ \\
\hline Información del proyecto (BP) & $\begin{array}{c}-0,492^{* * *} \\
(0,139)\end{array}$ & $\begin{array}{c}-0,807^{* * *} \\
(0,247)\end{array}$ \\
\hline Años vividos en la propiedad (AV) & $\begin{array}{c}0,006 \\
(0,008)\end{array}$ & $\begin{array}{c}0,011 \\
(0,014)\end{array}$ \\
\hline Vivencia de padres (VP) & $\begin{array}{l}-0,144 \\
(0,286)\end{array}$ & $\begin{array}{l}-0,238 \\
(0,496)\end{array}$ \\
\hline
\end{tabular}




\begin{tabular}{lcc}
\hline \multicolumn{1}{c}{ Variable } & Modelo probit & Modelo logit \\
\hline Respeto a la ley (Ley) & $-0,837^{*}$ & $-1,511$ \\
& $(0,483)$ & $(0,931)$ \\
Poder del Estado (PE) & $-0,460$ & $-0,689$ \\
& $(0,443)$ & $(0,747)$ \\
Riesgo moral (RM) & $0,292^{*}$ & $0,534^{*}$ \\
N & $(0,155)$ & $(0,276)$ \\
Pseudo $\mathbf{R}^{2}$ & $\mathbf{1 9 7}$ & $\mathbf{1 9 7}$ \\
\hline
\end{tabular}

Notas. Desviaciones estándar entre paréntesis. ${ }^{* * *} \mathrm{p}<0,01,{ }^{* *} \mathrm{p}<0,05,{ }^{*} \mathrm{p}<0,10$. Elaboración propia.

En vista de que el modelo probit muestra un pseudo $\mathrm{R}^{2}$ mayor que el del logit, se concluyó que tiene una mayor capacidad explicativa o bondad de ajuste. Por ello, se eligió al modelo probit como el mejor para la investigación.

\subsection{Pruebas de robustez}

Para verificar la robustez de los resultados, se analizó la multicolinealidad y robustez de los coeficientes y submuestras de las variables significativas del modelo.

\subsubsection{Multicolinealidad}

Para comprobar que no existe multicolinealidad entre las variables explicativas, se analizó la matriz de correlaciones. Se observó que ninguna variable mantenía una correlación mayor de 0,5 , por lo que se concluyó que no existe multicolinealidad entre ellas (anexo 10$)^{10}$.

\subsubsection{Robustez de los coeficientes}

Para evaluar esta robustez, se estimaron nueve modelos en un proceso que fue extrayendo progresivamente las variables no significativas. Así, el modelo 1 contiene todas las variables, que también son incluidas en el modelo 2, pero sin la variable cercanía al centro de trabajo (CT), y así sucesivamente. Por último, el modelo 9, extrae todas las variables no significativas del modelo y mantiene solo las significativas. En el anexo 11 se presentan los nueve modelos y en la tabla 3 se resumen los resultados.

\footnotetext{
${ }^{10}$ Si bien una alta correlación no sesgaría el resultado de los coeficientes, sí podría haber sobreestimado los niveles de confidencialidad y subestimado los estadísticos.
} 
Tabla 3

Prueba de robustez de los coeficientes

\begin{tabular}{ccccccc}
\hline \multirow{2}{*}{ Variables } & \multicolumn{2}{c}{ Modelo 1 } & \multicolumn{2}{c}{ Modelo 5 } & \multicolumn{2}{c}{ Modelo 9} \\
\cline { 2 - 6 } & Coeficiente & $\mathrm{P}>|\mathrm{z}|$ & Coeficiente & $\mathrm{P}>|\mathrm{z}|$ & Coeficiente & $\mathrm{P}>|\mathrm{z}|$ \\
\hline AEL & 0,624 & 0,001 & 0,630 & 0,001 & 0,593 & 0,001 \\
NT & $-0,339$ & 0,042 & $-0,338$ & 0,035 & $-0,30$ & 0,053 \\
EDU & $-0,316$ & 0,008 & $-0,322$ & 0,005 & $-0,334$ & 0,005 \\
RM & 0,292 & 0,060 & 0,289 & 0,058 & 0,256 & 0,086 \\
BP & $-0,492$ & 0,000 & $-0,506$ & 0,000 & $-0,509$ & 0,000 \\
MUD & 0,261 & 0,054 & 0,257 & 0,056 & 0,235 & 0,067 \\
RE & $-0,441$ & 0,003 & $-0,411$ & 0,003 & $-0,422$ & 0,001 \\
CE & 1,424 & 0,001 & 1,408 & 0,001 & 1,53 & 0,00 \\
LEY & $-0,837$ & 0,083 & $-0,891$ & 0,062 & $-0,725$ & 0,117 \\
\hline
\end{tabular}

Elaboración propia.

Se observa que, pese al cambio en la dimensión de los coeficientes, las variables siguen siendo significativas a un $90 \%$ de confianza, salvo la variable LEY, que es significativa al $85 \%$ de confianza. Así, quedó comprobada la robustez de los coeficientes del modelo.

\subsubsection{Robustez en submuestras}

Para calcular la robustez en submuestras, se emplearon tres modelos. El modelo 1 toma las 197 observaciones obtenidas en el modelo original; el modelo 2, 182 observaciones; y el modelo 3, 172 observaciones (anexo 12). La tabla 4 resume los resultados.

Tabla 4

Prueba de robustez de submuestras

\begin{tabular}{ccccccc}
\hline \multirow{2}{*}{ Variables } & \multicolumn{2}{c}{ Modelo 1 } & \multicolumn{2}{c}{ Modelo 2 } & \multicolumn{2}{c}{ Modelo 3 } \\
\cline { 2 - 7 } & Coeficiente & $P>|z|$ & Coeficiente & $P>|z|$ & Coeficiente & $P>|z|$ \\
\hline AEL & 0,624 & 0,001 & 0,697 & 0,001 & 0,602 & 0,006 \\
NT & $-0,339$ & 0,042 & $-0,517$ & 0,007 & $-0,545$ & 0,005 \\
EDU & $-0,316$ & 0,008 & $-0,329$ & 0,010 & $-0,310$ & 0,016 \\
RM & 0,292 & 0,060 & 0,352 & 0,035 & 0,298 & 0,084 \\
BP & $-0,492$ & 0,000 & $-0,492$ & 0,016 & $-0,372$ & 0,016 \\
\hline
\end{tabular}




\begin{tabular}{ccccccc}
\hline \multirow{2}{*}{ Variables } & \multicolumn{2}{c}{ Modelo 1 } & \multicolumn{2}{c}{ Modelo 2 } & \multicolumn{2}{c}{ Modelo 3 } \\
\cline { 2 - 7 } & Coeficiente & $\mathrm{P}>|\mathrm{z}|$ & Coeficiente & $\mathrm{P}>|\mathrm{z}|$ & Coeficiente & $\mathrm{P}>|\mathrm{z}|$ \\
\hline MUD & 0,261 & 0,054 & 0,345 & 0,020 & 0,322 & 0,033 \\
RE & $-0,441$ & 0,003 & $-0,575$ & 0,001 & $-0,566$ & 0,001 \\
CE & 1,424 & 0,001 & 1,899 & 0,000 & 1,892 & 0,001 \\
LEY & $-0,837$ & 0,083 & $-1,059$ & 0,040 & $-0,852$ & 0,119 \\
\hline
\end{tabular}

Elaboración propia.

Como se puede apreciar, las variables significativas al 90\% de confianza en el modelo original lo siguen siendo en los modelos con submuestras.

\subsection{Discusión de resultados}

La investigación buscó determinar qué factores explican de manera significativa el rechazo de ofertas de compensación por expropiación en cinco distritos de Lima Metropolitana. Los resultados muestran que existen cuatro variables que afectan positivamente la probabilidad de rechazo, mientras que otras cinco la reducen de manera significativa.

En primer lugar, se obtuvo que el factor que eleva en mayor medida la probabilidad de rechazo de las ofertas de compensación es la percepción de una inadecuada compensación monetaria o estimación del justiprecio. Esto podría deberse a asimetrías de información respecto al método de valorización empleado por los tasadores, que generan suspicacias sobre la idoneidad del justiprecio ofrecido.

El segundo factor que eleva la probabilidad de rechazo de expropiación es el acceso a espacios libres o comunes, como áreas verdes y recreacionales. Se encontró que las personas encuestadas cuyos predios se encontraban cerca a estos espacios tendían a rechazar en mayor medida la oferta del Estado.

El tercer factor que eleva la probabilidad de rechazo de la compensación ofrecida es el riesgo moral asociado a la percepción de los propietarios de que sus predios valdrán más en el futuro. Esto se debería a expectativas de apreciación del valor del predio luego de la construcción de la obra, ya sea por mejoras en la infraestructura vial o mejor accesibilidad o temas relacionados.

El cuarto factor que potencia el rechazo de la compensación es la incomodidad por la mudanza, que incorpora el costo y molestias de buscar una nueva vivienda.

Por otro lado, se identificaron cinco determinantes que elevan de manera significativa la probabilidad de aceptación de la oferta compensatoria: 
El primero es el sentimiento de respeto a la Ley experimentado por el expropiado. Con ello, se esperaría que mejoras en la institucionalidad del Estado, que fortalezcan su credibilidad y capacidad de aplicar la ley (enforcement) priorizando el bien común, disminuirían la probabilidad de rechazo de ofertas compensatorias en el futuro.

El segundo factor que reduce de manera significativa el riesgo del rechazo de expropiaciones es la existencia de información completa sobre los beneficios del proyecto. Los resultados muestran que, si el dueño del predio es bien informado sobre esos beneficios y la necesidad de la expropiación, disminuye la probabilidad de rechazo de la compensación ofrecida. Ello podría deberse a que experimenta un sentimiento de responsabilidad social que lo hace actuar en pro del bienestar general.

El tercer factor determinante para aceptar la oferta de compensación es la comodidad ante la reubicación; es decir, la percepción de facilidades otorgadas por el Estado para encontrar una nueva vivienda. Esto tendría relación con el ahorro de costos asociados a la búsqueda de un nuevo domicilio, el deseo de ser recompensado con un activo fijo en vez de dinero en efectivo, así como la posibilidad de mejorar su calidad de vida ${ }^{11}$.

El cuarto factor que aportó de manera significativa y negativa a los resultados del modelo fue la variable nivel de tránsito en la zona del predio. Así, mientras más alto es dicho nivel, menor es la probabilidad de que la expropiación sea rechazada.

Por último, el quinto determinante que eleva la probabilidad de aceptación de la oferta compensatoria es el nivel educativo de los expropiados potenciales. Ello debido a que un mayor nivel educativo incrementa su capacidad de estar bien informados sobre los beneficios del proyecto, de conocer y entender el marco legal peruano y de aproximar mejor el valor de sus predios. Todo lo cual reduce la probabilidad de que rechacen la oferta compensatoria.

Cabe resaltar que el apego sicológico - medido con las variables número de ańos vividos en la propiedad y la presencia de padres o abuelos en la viviendano resultó ser una variable significativa para los dueños de los predios en el momento de decidir si aceptar o rechazar la oferta de compensación por expropiación. De este modo, se rechaza la hipótesis nula planteada por el estudio.

En consecuencia, se puede concluir que el apego sicológico no es un factor determinante para explicar el rechazo de ofertas compensatorias por motivo

\footnotetext{
${ }^{11}$ Dado que podrían tener la opción de mudarse a una vivienda con mejor ubicación, mejores características físicas y accesibilidad a recursos básicos.
} 
de expropiación en Lima Metropolitana. En cambio, el factor monetario resulta trascendental para la decisión de la población. Además, el Estado puede emplear otras herramientas para agilizar los procesos expropiatorios, como mejorar su institucionalidad, la difusión de los beneficios del proyecto y las opciones de reubicación que propone.

\subsection{Limitaciones}

En el trabajo, se presentaron ciertas limitaciones asociadas al proceso de recolección de datos. En primer lugar, el limitado presupuesto económico restringió el número de encuestas y la extensión del cuestionario.

En segundo lugar, no se logró que en todos los casos fueran los dueños de los predios quienes respondan las preguntas de las encuestas, sino solo los jefes del hogar, lo que pudo haber sesgado las respuestas al haber diferencias entre las opiniones de los residentes y los dueños ${ }^{12}$. Pese a ello, es importante resaltar que se observó un alto promedio y mediana -igual a 32 años- de años vividos en el inmueble, por lo que se podría afirmar que las respuestas incorporaron un buen nivel de conocimiento sobre la valoración del predio, lo cual restaría importancia a esta limitación.

De otro lado, es importante precisar que el porcentaje de compensación adicional considerado en las encuestas fue del $10 \%$ y no del $20 \%$, debido a que el cambio normativo al respecto se dio en una fecha posterior a la recolección de datos. Corresponderá a un nuevo trabajo investigar si la nueva tasa del 20\% logra reducir la probabilidad de rechazos de manera significativa.

Por último, debido a que las preguntas realizadas en las encuestas se han dado sobre una situación hipotética de expropiación, pues los individuos encuestados no necesariamente han experimentado un proceso expropiatorio, los resultados obtenidos podrían estar subestimando o sobreestimando la realidad.

\section{Conclusiones}

Los resultados principales muestran que la compensación monetaria es el factor más importante del rechazo a la oferta compensatoria, debido a que es percibida como menor que el valor de mercado del predio. Asimismo, el

\footnotetext{
${ }^{12}$ Cabe mencionar que se realizaron llamadas telefónicas para conseguir esta información. Los resultados mostraron que, de las 35 personas que contestaron las llamadas telefónicas, el $75 \%$ vivía en un predio que pertenecía a sus padres, suegros o algún familiar. Esto evidenciaría que las respuestas otorgadas por los encuestados aportaron información relevante para el estudio.
} 
acceso a espacios libres -como áreas verdes y losas deportivas-cercanos resultó ser el segundo factor más influyente en el momento de rechazar la oferta. El tercer determinante del rechazo es la presencia de riesgo moral, lo cual evidencia que las expectativas de aumentos futuros en el precio del predio aumentan la probabilidad de rechazo de la oferta. Por último, las actividades de búsqueda de una nueva vivienda y mudanza generan incomodidades que incrementan la probabilidad de rechazo de la oferta del Estado.

De otro lado, se encontró que existen cinco determinantes que elevan la probabilidad de aceptación de la oferta compensatoria: un sentimiento de obediencia a la ley, que predispone a entregar el predio; el conocimiento de los beneficios del proyecto, que alienta una conducta altruista en pro del bien común; el nivel educativo del jefe del hogar, que facilita lo anterior; una percepción positiva de la opción de reubicación como modo de compensación; y el nivel de tráfico cerca de la vivienda.

Cabe resaltar que el apego sicológico - medido con las variables número de años vividos en el predio y presencia de padres o abuelos en la vivienda- no resultó ser significativo para los encuestados al decidir si aceptar o rechazar la oferta de compensación, por lo cual se rechazó esta hipótesis del estudio. Tampoco resultó significativo para dicha decisión el nivel de bienestar provisto por algunas características de la vivienda como su cercanía a parientes, al centro educativo de los hijos y al trabajo del jefe del hogar.

Por último, se observó que en Villa María del Triunfo y Villa El Salvador los encuestados aceptaron la oferta compensatoria porque querían mejorar su calidad de vida. De manera coincidente, estos distritos ocuparon, respectivamente, los puestos 2 y 3 en el Índice de Pobreza Distrital a 2013 (INEI, 2015). Es posible, así, que haya una relación positiva entre dicha aceptación y el nivel de pobreza en zonas habitacionales del distrito.

En conclusión, si bien el apego sicológico es relevante para las familias limeñas al decidir si desalojan sus hogares, el factor monetario resulta el dominante cuando toman esa decisión ante una expropiación. Por ello, si se les otorgase una compensación económica que les posibilite adquirir un nuevo predio en condiciones similares, se lograría acelerar el proceso de expropiación. Esto reduciría sobrecostos por retrasos en la ejecución de proyectos y fomentaría la disminución de brechas en infraestructura.

Y también se agilizarían mucho los procesos de expropiación en el Perú si el Estado fortalece su institucionalidad como ente rector y garante del respeto a la ley y mejora su labor con los dueños de los predios, informándoles bien sobre los beneficios del proyecto y las opciones de reubicación, así como 
ofreciéndoles una compensación monetaria que razonablemente considere las expectativas respecto a los futuros precios de los predios.

\section{Recomendaciones de política}

Con el fin de acelerar la puesta en marcha de obras de infraestructura vial y aprovechar sus beneficios socioeconómicos, proponemos las siguientes medidas de política.

\subsection{Medidas de corto plazo}

a. Realizar un pago igual al valor de mercado del predio:

El Estado debe pagar el valor de mercado del predio, de manera que los expropiados puedan adquirir otra vivienda que, cuando menos, mantenga su estándar de vida en condiciones similares. Para asegurar ese valor, los afectados deben tener la posibilidad de cuestionar por vía arbitral -en un plazo corto- la tasación planteada por el Estado. Esto otorgaría a un árbitro especializado en el tema la decisión de determinar si el valor ofrecido es o no un justiprecio a la luz del valor de mercado del predio, y lo facultaría a solucionar las controversias y agilizar el proceso expropiatorio.

Esta propuesta está alineada con el Proyecto de Ley 1117/2016-CR ${ }^{13}$, el cual plantea que, si el sujeto expropiado no está conforme con el valor de la tasación, pueda cuestionarlo por vía arbitral, y especifica que tal arbitraje sea ad hoc, cuente con cinco meses como máximo para determinar la indemnización justipreciada y su decisión tenga "peso de cosa juzgada" o fallo de última instancia no apelable por vía judicial; todo lo cual reduciría los retrasos en expropiaciones. Cabe resaltar que debe evaluarse detenidamente si el valor comercial debe o no incorporar el componente especulativo de incremento futuro de precios (riesgo moral), dado que, en muchos casos, al comprar otro predio del mismo valor comercial podría esperarse que este también se aprecie tanto como el anterior.

b. Informar sobre los beneficios del proyecto:

Nuestros resultados muestran que un buen conocimiento de los beneficios del proyecto favorece la aceptación de la oferta compensatoria. Pero ese conocimiento suele ser limitado en distritos pobres o alejados. Por ello, se sugiere

\footnotetext{
${ }^{13}$ Proyecto de Ley que realiza modificaciones al Decreto Legislativo 1192.
} 
que el Estado mejore la organización de charlas informativas en el distrito repartiendo buenos materiales sobre el proyecto y contando con la presencia de un experto a cargo de este y con el apoyo de autoridades locales y representantes de la comunidad para explicar los beneficios, ya que las personas suelen confiar más en sus propios líderes. También conviene que den información las empresas privadas involucradas en el proyecto, organizando sus propias charlas informativas y/o participando en las convocadas por las autoridades.

c. Informar sobre el verdadero valor del predio:

Dado que una razón para rechazar la oferta compensatoria del Estado es la percepción de que esta es inferior al valor del mercado, conviene informar a los dueños de los predios sobre los factores tomados en cuenta para la tasación, tales como la ubicación, la orientación, el ruido ambiental, la posibilidad de ventilación natural, el área del terreno y la antigüedad y calidad de la construcción. Ello evitaría problemas de información asimétrica, causantes de percepciones erróneas sobre la idoneidad del monto ofrecido.

\section{d. Informar sobre el nuevo incentivo:}

En el estudio se observó que, cuando hay un incentivo de compensación adicional ofrecido por el Estado que es percibido de manera positiva por los jefes de hogar, estos cambian de opinión a favor de aceptar la oferta compensatoria. Esto podría explicarse por los llamados «sesgos cognitivos», que llevan al ser humano a cometer errores de análisis en su toma de decisiones cuando enfrenta condiciones de incertidumbre e información incompleta (Serrano, Batanero, Ortiz, \& Cañizares, 1998).

Un ejemplo particular de este tipo de respuestas instintivas e irracionales es el sesgo de anclaje, según el cual los individuos tienden a sobreestimar el valor de un elemento cuando lo comparan con respecto a un punto ancla. Este es el sesgo que se observó en el estudio, al percibirse que el 23\% de los encuestados que finalmente aceptaron la oferta lo hicieron solo luego de que se les ofreciera un monto de compensación adicional por su predio. Ello indica que los individuos valoraron de manera significativa la oferta del $10 \%$ adicional sobre la base del monto inicial ofrecido (punto de ancla).

En tal sentido, la sugerencia de política consiste en empezar por informar bien sobre la propuesta, detallando los factores tomados en cuenta en la valorización del predio, a fin de hacer atractivo el punto de ancla; y, posterior- 
mente, presentar el monto adicional de compensación. Así podría aumentar la probabilidad de aceptación de la oferta.

\subsection{Medidas de mediano plazo}

a. Brindar mayores opciones de reubicación:

A la luz de los resultados obtenidos, las personas valoran la opción de ser reubicadas; es decir, de recibir una nueva vivienda a manera de compensación. Recomendamos, entonces, que el Estado cree un Plan Anual de Reubicación en el que anticipe la construcción de complejos habitacionales, para tener una rápida capacidad de ofrecer opciones de reubicación que aumenten la aceptación de ofertas de compensación por expropiación.

\subsection{Medidas de largo plazo}

a. Incrementar el nivel educativo:

Nuestro modelo ha mostrado que la variable nivel educativo mantiene una correlación positiva con la decisión de aceptar la oferta compensatoria. Ello debido a que, cuanto mayor sea dicho nivel, mayor es la posibilidad de informar bien sobre los beneficios del proyecto, la valoración de predios y el marco legal peruano; todo lo cual disminuye la probabilidad de rechazo de la oferta compensatoria. Surge así una razón adicional para fortalecer el sistema educativo y el acceso a la enseñanza.

b. Fortalecer la institucionalidad del Estado:

Nuestra investigación también ha comprobado que la variable respeto a la ley explica de manera significativa la aceptación de la compensación por parte de los jefes de hogar. Surge entonces una razón adicional para que el Estado fortalezca su institucionalidad, de manera que pueda dar señales de seriedad y convencer de que toma decisiones oportunas y eficaces para mejorar la calidad de vida de la población.

\section{Referencias}

AFIN (Asociación para el Fomento de la Infraestructura Nacional). (2016). Agilizando la ruta del crecimiento: II parte del Plan Nacional de Infraestructura. Lima: Asociación para el Fomento de la Infraestructura Nacional.

Apoyo Consultoría. (2016). Inversión en infraestructura de transporte por regiones, 2001 2020. Lima. 
Arumäe, U., \& Kein, A. (2014). Is just compensation for property subject to expropriation equal to its market value? Journal of Management and Change, 32/33, 12-25.

Ataguba, J. (2014). Toward a disturbance-integrated method for land expropriation (tesis de maestría). Universidad de Twente, Enschede, Países Bajos.

Barrionuevo, A. C., \& Watanabe, A. J. (2015). Demora en la entrega de predios necesarios para la ejecución de proyectos viales concesionados. Lima: Universidad del Pacífico.

Bonifaz, J. L., \& Urrunaga, R. (2008). Beneficios económicos de la carretera Interoceánica. Lima: Universidad del Pacífico - Centro de Investigación.

Contreras, V., Garay, U., Santos, M. A., \& Betancourt, C. (Mayo de 2014). Expropriation risk and housing prices: Evidence from an emerging market. Journal of Business Research, 67, 935-942.

CPI (Compañía Peruana de Estudios de Mercado y Opinión Pública). (2015). Perú: Población 2015. Lima: Compañía Peruana de Estudios de Mercados y Opinión Pública.

Gaceta Oficial. (2016). Decreto Legislativo 1330, Decreto Legislativo que modifica el Decreto Legislativo 1192. Lima: El Peruano. Recuperado de https://www.gob.pe/institucion/ $\mathrm{mtc} /$ normas-legales/9878-1330

Giammarino, R., \& Nosal, E. (2005). Compensation for the taking of property rights. Journal of Law, Economics \& Organization, 21(1), 136-152.

Huamaní, S. (2015). Una estimación del costo de capital para concesiones en carreteras del Perú. Lima: Ministerio de Transportes y Comunicaciones.

INEI (Instituto Nacional de Estadística e Informática). (Septiembre de 2015). Mapa de pobreza provincial y distrital 2013. Lima: Instituto Nacional de Estadística e Informática. Recuperado de https:/www.inei.gob.pe/media/MenuRecursivo/ publicaciones_digitales/Est/Lib1261/Libro.pdf

Mankiw, G. (2012). Principios de Economía. (6. ${ }^{a}$ ed.). México: Cengage Learning.

Medina, E. (2003). Modelos de elección discreta. Madrid: Universidad Autónoma de Madrid.

Meneses, J., Barrios, M., Bonillo, A., Cosculluela, A., Lozano, L., Turbany, J., \& Valero, S. (2013). Psicometría. Barcelona: Universitat Oberta de Catalunya.

Molina, M., Ruiz, E., Saura, I., \& García, H. (Junio de 2010). El efecto moderador de la edad en la relación entre el valor percibido, las TIC del minorista y la lealtad del cliente. Cuadernos de Economía y Dirección de la Empresa (CEDE), 43, 65-91.

Prialé, G. (25 de marzo de 2015). Expropiaciones: la supertraba. Gestión. Recuperado de https://archivo.gestion.pe/opinion/expropiaciones-supertraba-2127069

Sander, H., \& Polasky, S. (Julio de 2009). The value of views and open space: Estimates from a hedonic pricing model for Ramsey County, Minnesota, USA. Land Use Policy, 26(3), 837-845.

Serrano, L., Batanero, C., Ortiz, J., \& Cañizares, J. (1998). Heurísticas y sesgos en el razonamiento probabilistico de los estudiantes de secundaria. Granada: Universidad de Granada.

Sistema Nacional de Inversión Pública. (2017). Lima: Ministerio de Economía y Finanzas. Recuperado de Consulta de Proyectos de Inversión Pública: http://ofi5.mef.gob. pe/wp/busquedaavanzada.aspx 
Stiefken, J. P. (2014). Altruismo y la solidaridad en el estado de bienestar. Barcelona: Universitat Autònoma de Barcelona.

Tole, T., \& McCord, S. (2003). How much is the business worth? Real Estate Review, 23(2), 39-43.

Trembecka, A. (21 de marzo de 2016). Analysis of surveying and legal problems in granting right-of-way and expropriation for the purpose of locating technical infrastructure. Geodesy and Cartography, 65(1), 95-109.

Vassallo, J. M., Ortega, A., \& Baeza, M. (2002). Impact of the economic recession on toll highway concessions in Spain. Virginia: American Society of Civil Engineers.

Wooldrige, J. (2010). Econometric analysis of cross section and panel data. (2. $\left.{ }^{\mathrm{a}} \mathrm{ed}.\right)$. Cambridge, MA: The MIT Press.

Zorrilla, J. P. (2006). La economía de la información: una revisión a la teoría económica sobre la información asimétrica. En Contribuciones a la Economía, 2006-10. Málaga: Servicios Académicos Intercontinentales S. I. 


\section{Anexos}

\section{Anexo 1}

Figura 1

Brecha en infraestructura según sectores (\%)

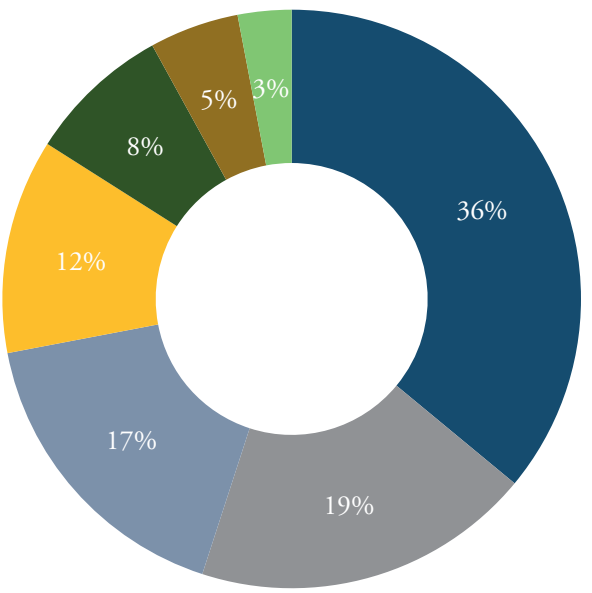

- Transporte

- Energía

— Telecomunicaciones

- Salud

- Agua y saneamiento

• Hidráulico

Educación

Fuente: AFIN (2016). Elaboración propia.

Figura 2

Ratio entre proyectos actuales y brecha de infraestructura estimada

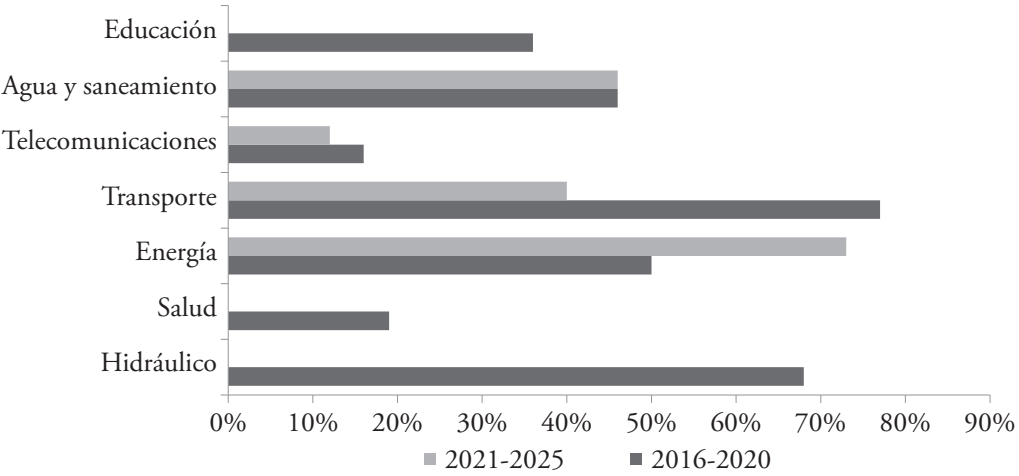

Fuente: AFIN (2016). Elaboración propia. 


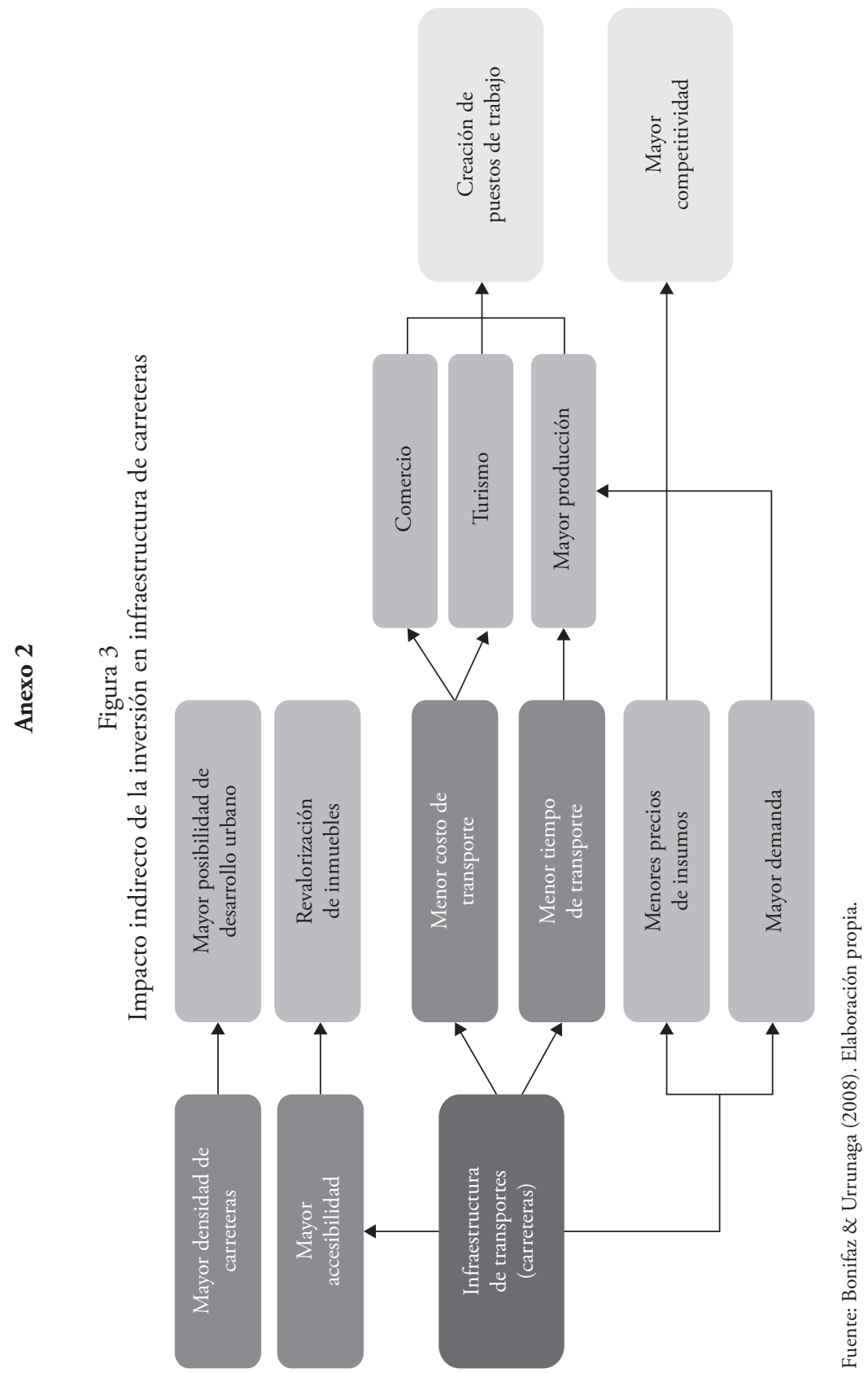




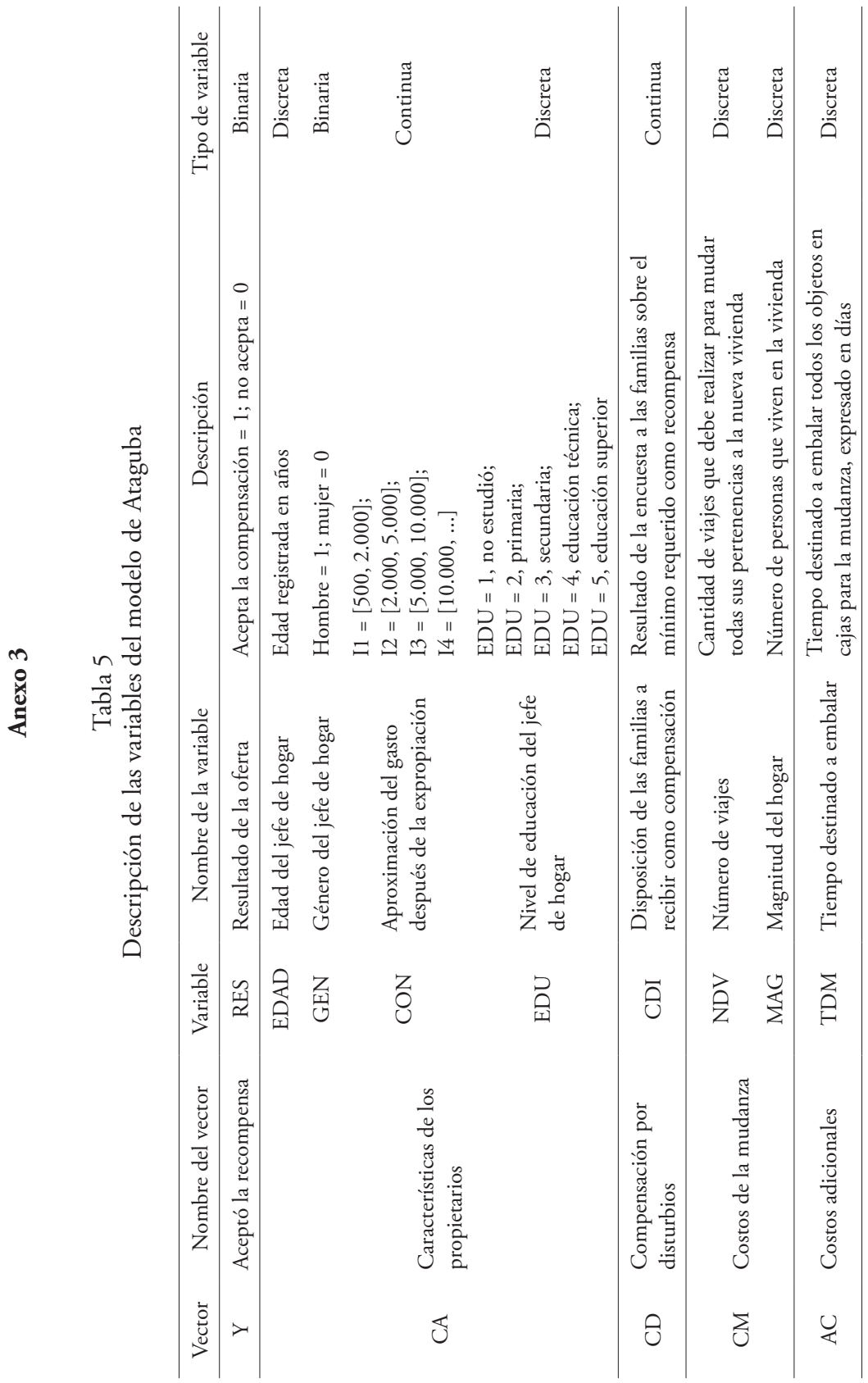




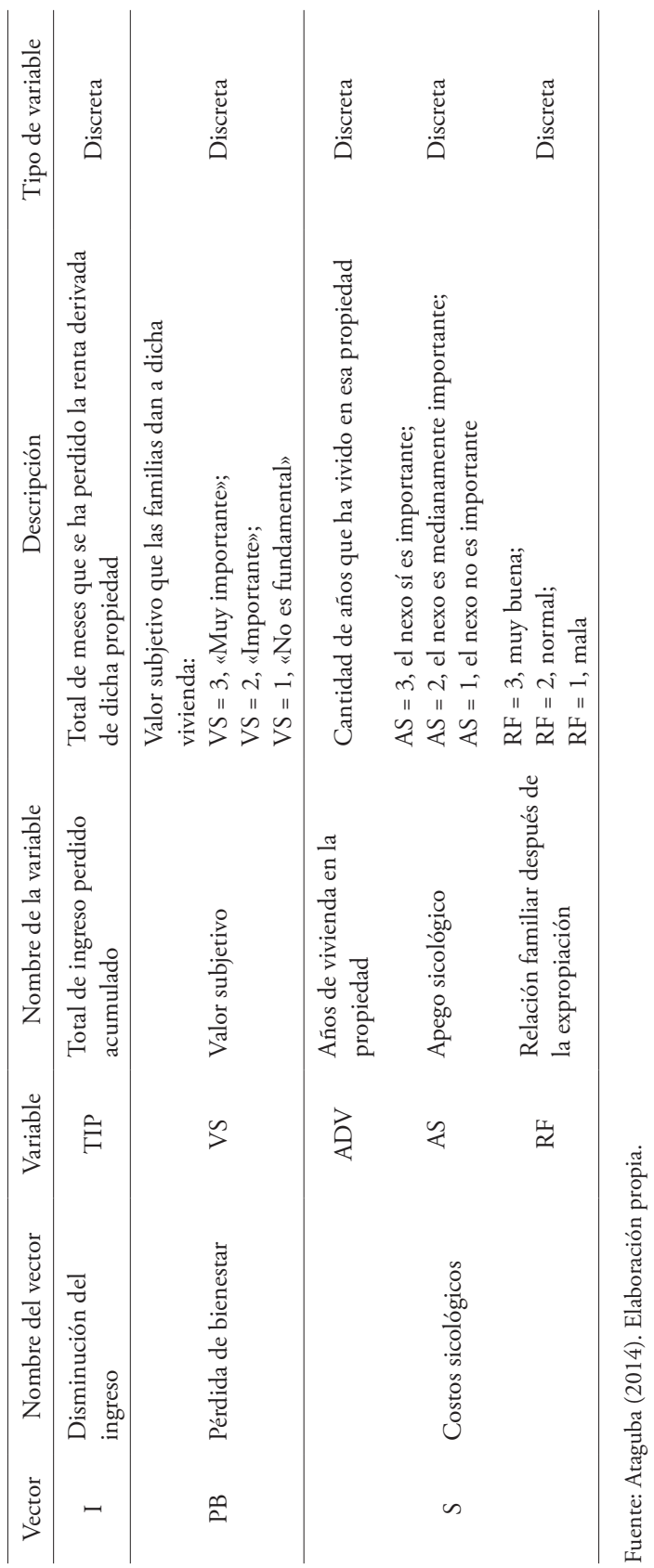




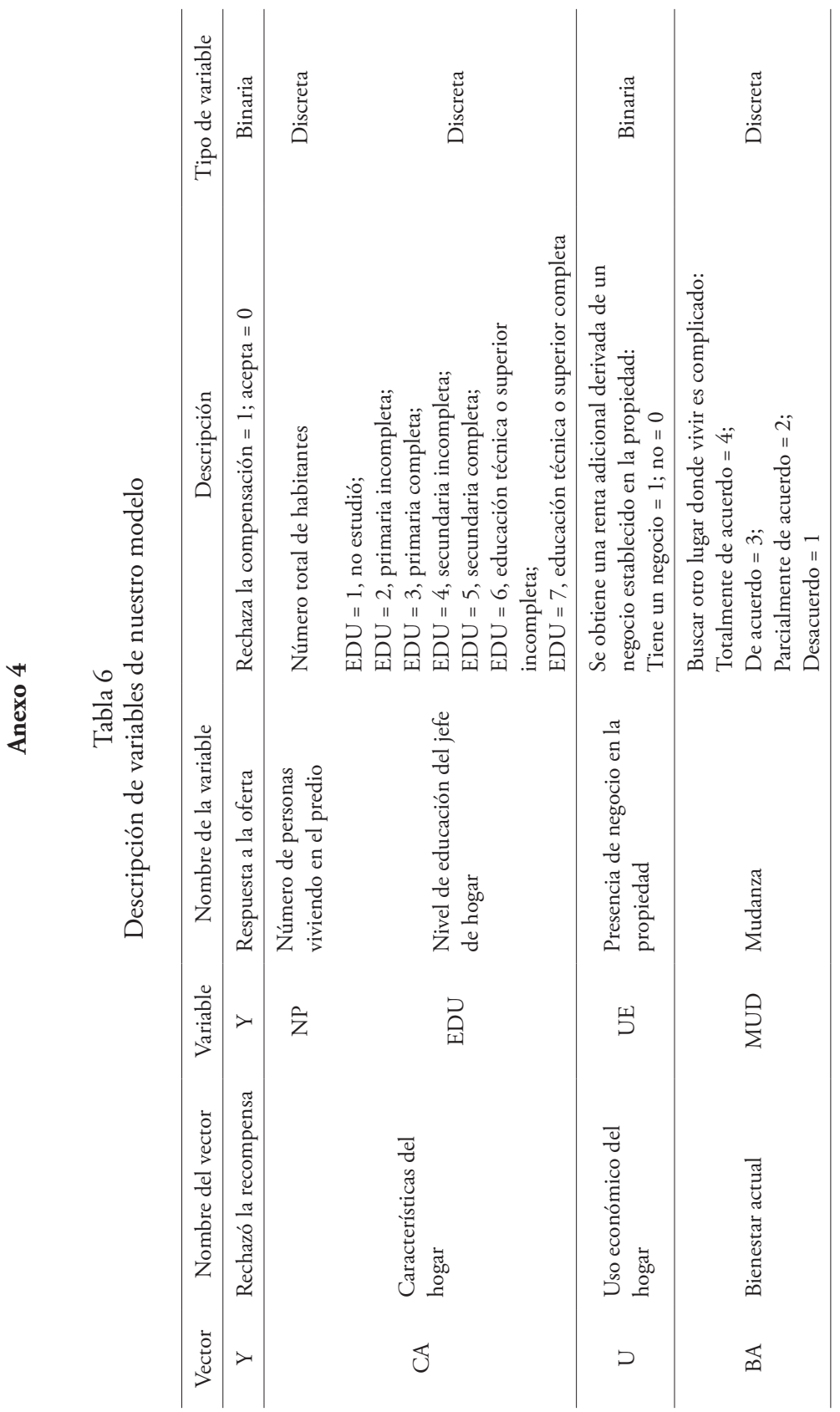




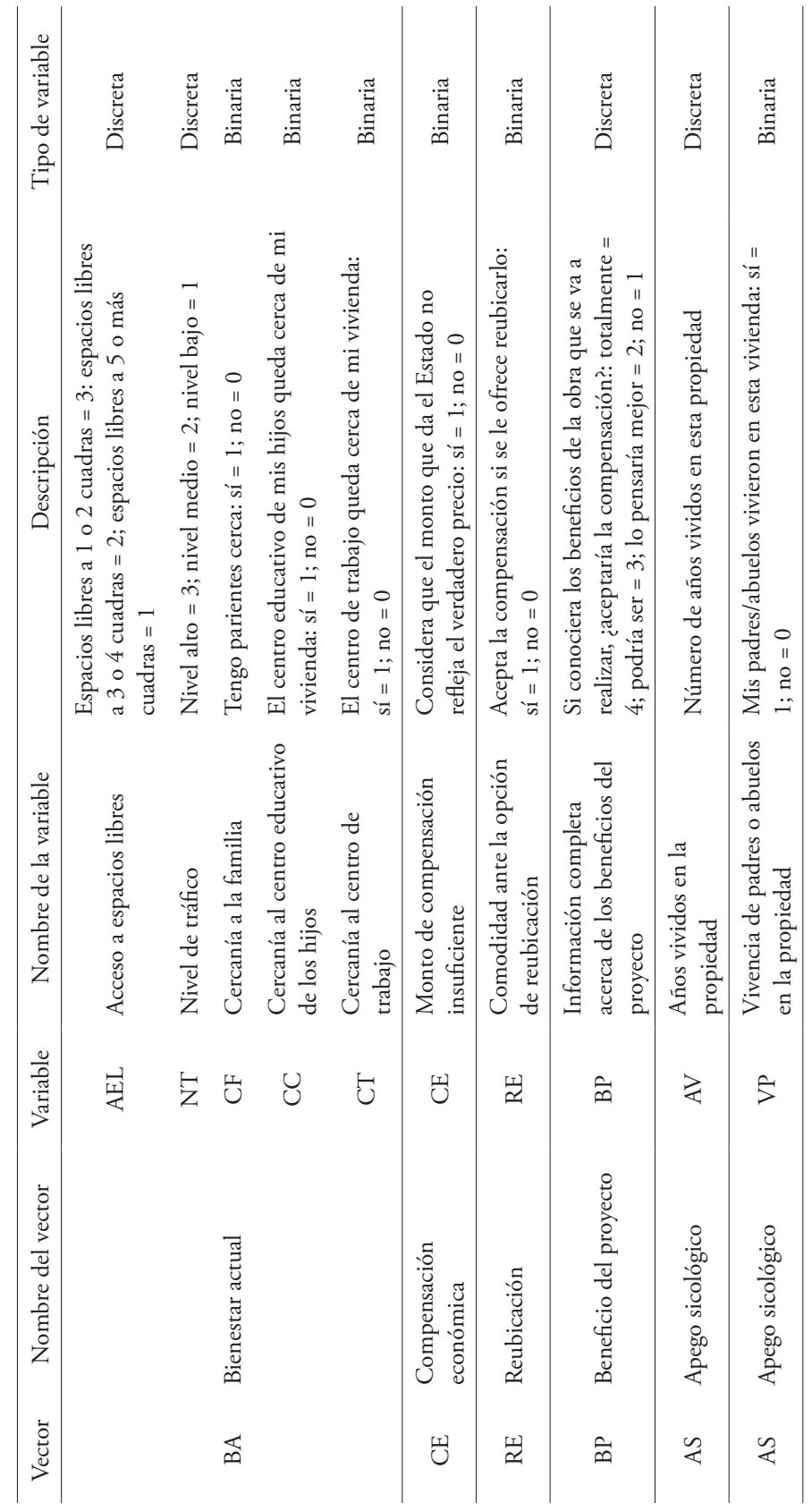




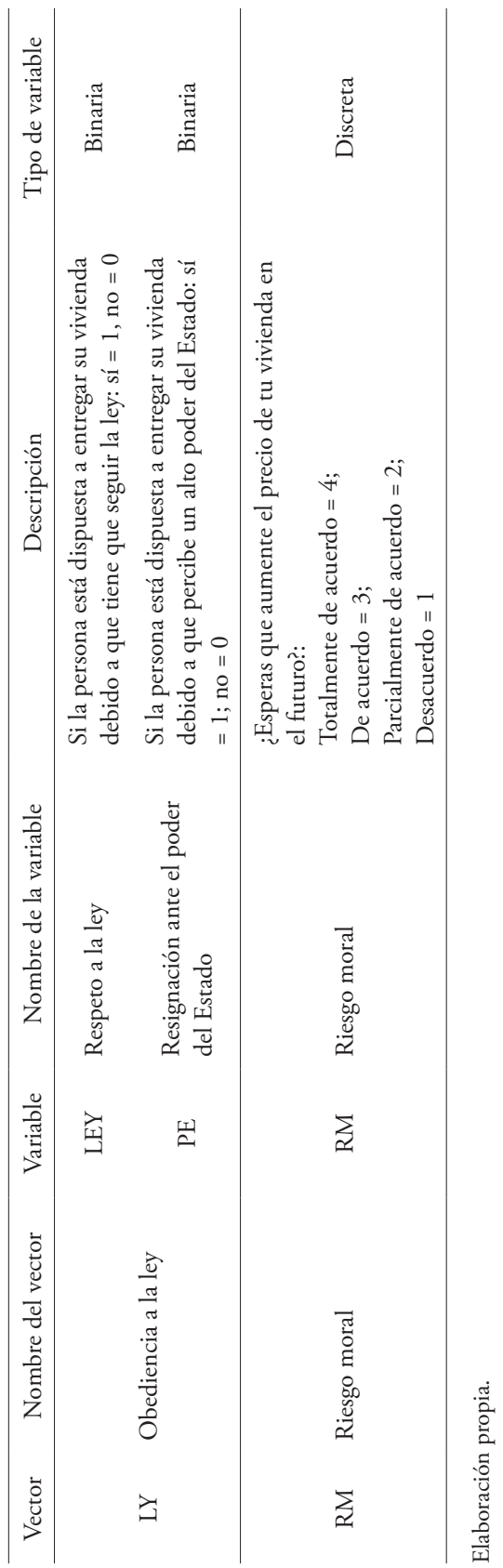




\section{Anexo 5}

\section{Figura 4}

Número de proyectos de inversión pública de infraestructura vial con probabilidad de enfrentar procesos de expropiación en Lima Metropolitana, según distritos

(2005-2016)

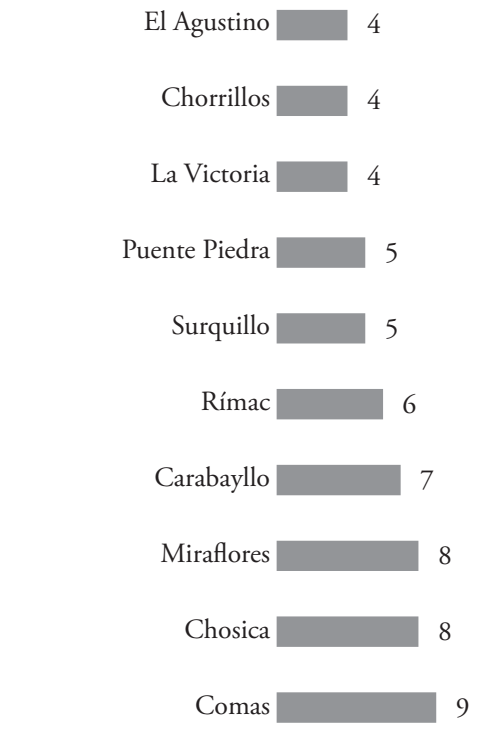

San Juan de Miraflores

10

San Martín de Porres

Ate

Villa El Salvador

Cercado de Lima

Villa María del Triunfo

San Juan de Lurigancho

Fuente: Sistema Nacional de Inversión Pública (2017). Elaboración propia. 


\section{Anexo 6}

Tabla 7

Número de hogares en Lima Metropolitana, según distrito

\begin{tabular}{|c|c|c|}
\hline N. ${ }^{\circ}$ & Distrito & Hogares \\
\hline 1 & San Juan de Lurigancho & 272,0 \\
\hline 2 & San Martín de Porres & 172,5 \\
\hline 3 & Ate & 156,5 \\
\hline 4 & Comas & 136,9 \\
\hline 5 & Villa El Salvador & 114,1 \\
\hline 6 & Villa María del Triunfo & 113,2 \\
\hline 7 & Santiago de Surco & 105,9 \\
\hline 8 & San Juan de Miraflores & 105,8 \\
\hline 9 & Los Olivos & 105,8 \\
\hline 10 & Lima & 90,6 \\
\hline 11 & Chorrillos & 88,0 \\
\hline 12 & Puente Piedra & 87,2 \\
\hline 13 & Carabayllo & 74,2 \\
\hline 14 & Independencia & 66,8 \\
\hline 15 & Santa Anita & 59,0 \\
\hline 16 & La Victoria & 55,5 \\
\hline 17 & Lurigancho & 55,2 \\
\hline 18 & El Agustino & 51,3 \\
\hline 19 & Rímac & 49,7 \\
\hline 20 & La Molina & 47,2 \\
\hline 21 & San Miguel & 44,0 \\
\hline 22 & San Borja & 37,0 \\
\hline 23 & Miraflores & 33,0 \\
\hline 24 & Pachacamac & 32,0 \\
\hline 25 & Surquillo & 32,4 \\
\hline 26 & Pueblo Libre & 27,1 \\
\hline 27 & Breña & 25,9 \\
\hline 28 & Jesús María & 23,4 \\
\hline
\end{tabular}




\begin{tabular}{ccc}
\hline N. ${ }^{\circ}$ & Distrito & Hogares \\
\hline 29 & San Isidro & 22,7 \\
30 & Lurín & 21,2 \\
31 & San Luis & 19,1 \\
32 & Magdalena del Mar & 18,6 \\
33 & Lince & 18,5 \\
34 & Chaclacayo & 13,0 \\
35 & Ancón & 11,9 \\
36 & Cieneguilla & 11,6 \\
37 & Barranco & 10,7 \\
38 & Santa Rosa & 4,6 \\
39 & Pucusana & 4,2 \\
40 & Punta Negra & 2,2 \\
41 & San Bartolo & 2,2 \\
42 & Punta Hermosa & 2,2 \\
43 & Santa María del Mar & 0,4 \\
Total & & $2.425,4$ \\
\hline
\end{tabular}

Fuente: CPI (2015). Elaboración propia. 


\section{Anexo 7}

Tabla 8

Tamaño mínimo de muestra

\begin{tabular}{|c|c|c|c|c|c|}
\hline Distrito & Código & Y & $\begin{array}{c}\text { Bienestar } \\
\text { actual }\end{array}$ & $\begin{array}{c}\text { Poder del } \\
\text { Estado }\end{array}$ & $\begin{array}{l}\text { Beneficios } \\
\text { del proyecto }\end{array}$ \\
\hline \multirow{3}{*}{$\begin{array}{l}\text { Villa María del } \\
\text { Triunfo }\end{array}$} & VMT1 & 0 & 0 & 1 & 0 \\
\hline & VMT2 & 0 & 0 & 1 & 0 \\
\hline & VMT3 & 0 & 0 & 1 & 0 \\
\hline \multirow{3}{*}{ Villa El Salvador } & VES1 & 0 & 0 & 0 & 0 \\
\hline & VES 2 & 1 & 1 & 0 & 0 \\
\hline & VES 3 & 1 & 1 & 0 & 0 \\
\hline \multirow{3}{*}{ Independencia } & INDEP1 & 1 & 0 & 0 & 0 \\
\hline & INDEP2 & 0 & 0 & 0 & 0 \\
\hline & INDEP3 & 0 & 0 & 0 & 1 \\
\hline \multirow{3}{*}{ Cercado de Lima } & LIMACER1 & 1 & 0 & 0 & 0 \\
\hline & LIMACER2 & 0 & 0 & 1 & 0 \\
\hline & LIMACER3 & 1 & 0 & 0 & 1 \\
\hline \multirow{3}{*}{$\begin{array}{l}\text { San Juan de } \\
\text { Lurigancho }\end{array}$} & SJL1 & 0 & 0 & 0 & 0 \\
\hline & SJL2 & 1 & 0 & 0 & 1 \\
\hline & SJL3 & 0 & 0 & 0 & 0 \\
\hline \multicolumn{2}{|c|}{ CONTEO 1} & 6 & 2 & 4 & 3 \\
\hline \multicolumn{2}{|c|}{ CONTEO 2} & 9 & 13 & 11 & 12 \\
\hline \multicolumn{2}{|c|}{ PROPORCIÓN DE 1} & 0,40 & 0,13 & 0,27 & 0,2 \\
\hline \multicolumn{2}{|c|}{ Error máximo de estimación } & $6,79 \%$ & $4,71 \%$ & $6,13 \%$ & $5,54 \%$ \\
\hline \multicolumn{2}{|c|}{ Tamaño mínimo de muestra } & 200,00 & 200,00 & 200,00 & 200,00 \\
\hline
\end{tabular}

Elaboración propia. 


\section{Anexo 8}

Modelo de encuesta de proceso de expropiación

\section{UNIVERSIDAD DEL PACÍFICO - DEPARTAMENTO ACADÉMICO DE ECONOMÍA}

\section{Entrevista para trabajo de investigación sobre el proceso de expropiación en Lima Metropolitana}

Esta entrevista tiene como objetivo recolectar información para la investigación económica realizada por alumnas de 9. ${ }^{\circ}$ ciclo de la Universidad del Pacífico sobre el proceso de expropiación en Lima Metropolitana.

Nombre: Fecha: Distrito: Predio.$^{\circ}$ :

Teléfono: $\square$ No tiene $\square$ No quiere dar

\section{Características del entrevistado}

Edad: años Género: $\square$ Masculino $\square$ Femenino

Nivel educativo:

$\square$ No estudió

$\square$ Primaria incompleta $\square$ Primaria completa

$\square$ Secundaria incompleta $\square$ Secundaria completa

$\square$ Educación técnica o superior incompleta

$\square$ Educación técnica o superior completa

\section{Características de la vivienda y familia}

Número de años vividos en la vivienda: años

Número de personas que viven en la vivienda: personas

Uso del predio como vivienda: $\square$ Sí $\square$ No

¿Le doy algún uso económico a la vivienda? $\square$ Sí $\square$ No

Especificar

¿Consideras que las características de tu casa podría mejorar? $\square$ Sí $\square$ No

$\mathrm{Si}$ te ofrecieran un monto compensatorio igual al precio de mercado actual de la vivienda, ¿aceptarías la oferta de compensación?

$\square$ Sí $\square$ No

¿Por qué?

¿Conoces la nueva Ley de Expropiaciones?

$\square$ Sí $\quad \square$ No

La nueva Ley General de Expropiaciones estipula que los encargados de realizar dicho proceso deben acudir a los predios de interés público y ofrecerles 
un monto de compensación -el cual es fijado por la Dirección Nacional de Construcción del Ministerio de Vivienda, Construcción y Saneamiento-, además de un $10 \%$ adicional a dicho monto por aceptar vender el predio de manera directa.

$\mathrm{Si}$, además, te ofrecieron el incentivo del $10 \%$ adicional, ¿̨aceptarías la oferta de compensación?

$\square$ Sí $\square$ No

Considerando que la oferta anterior es la última que el Estado tiene para ofrecer, ¿cambiarías de opinión?

$\square$ Sí $\quad \square$ No

De ser la respuesta anterior «no», no aceptaría la compensación porque:

1. ¿Tus padres y/o abuelos vivieron en esta propiedad?

$\square$ Sí

$\square$ No

2. ¿El centro educativo de tus hijos queda cerca de tu vivienda?

$\square$ Sí

$\square$ No

3. ¿Tu centro de trabajo queda cerca de tu vivienda?

$\square$ Sí

$\square$ No

4. ¿Usas esta vivienda para algún otro fin económico (como bodega, peluquería, entre otros)?

$\square$ Sí

$\square$ No

5. ¿Tienes parientes que vivan cerca de tu casa?

$\square$ Sí

$\square$ No

6. Si por algún motivo tuvieras que mudarte, ¿el no saber a dónde te mudarías haría que te sientas inseguro(a)?

$\square$ Totalmente de acuerdo

$\square$ De acuerdo

$\square$ Parcialmente de acuerdo

$\square$ No estoy de acuerdo 
7. ¿Crees que el precio de mi vivienda podría aumentar?

Totalmente de acuerdo

$\square$ De acuerdo

$\square$ Parcialmente de acuerdo

No estoy de acuerdo

8. Si conocieras los beneficios del proyecto por el cual te van a expropiar, ¿aceptarías la compensación?

$\square$ Totalmente

$\square$ Podría ser

$\square$ Lo pensaría mejor

$\square$ No

9. ¿Consideras que buscar otro lugar en dónde vivir es complicado?

$\square$ Totalmente de acuerdo

$\square$ De acuerdo

$\square$ Parcialmente de acuerdo

$\square$ No estoy de acuerdo

10. Si se te ofreciera un nuevo espacio de reubicación y no tuvieras que preocuparte por la búsqueda de la vivienda, ¿cambiarías de opinión?

$\square$ Sí $\quad \square$ No

Si tu última respuesta fue «no», indica la importancia que darías a las siguientes razones para no reubicarte:

11. Me importa decidir la ubicación de mi vivienda:

$\square$ Muy importante

$\square$ Importante

Poco importante

$\square$ No es importante en absoluto

12. Me incomoda compartir espacios comunales con personas que no conozco, ya que podrían tener un estilo de vida distinto al mío, que involucre ruido, consumo de alcohol, entre otros.

$\square$ Muy importante

$\square$ Importante

$\square$ Poco importante

$\square$ No es importante en absoluto

Muchas gracias 


\section{Anexo 9}

\section{Figura 5}

Encuestados según género (\%)

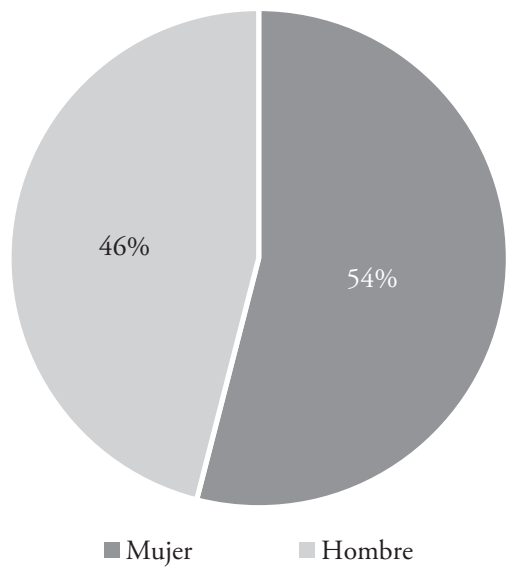

Fuente: encuesta de proceso de expropiación. Elaboración propia.

\section{Figura 6}

Número de personas encuestadas según intervalos de edades

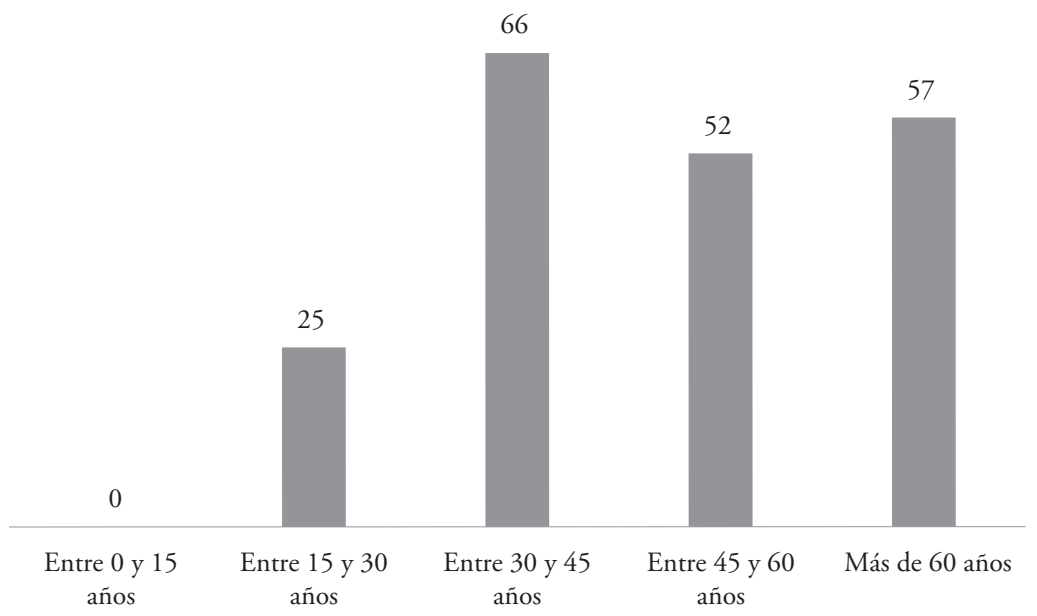

Fuente: encuesta de proceso de expropiación. Elaboración propia. 


\section{Figura 7}

Número de encuestados según nivel educativo

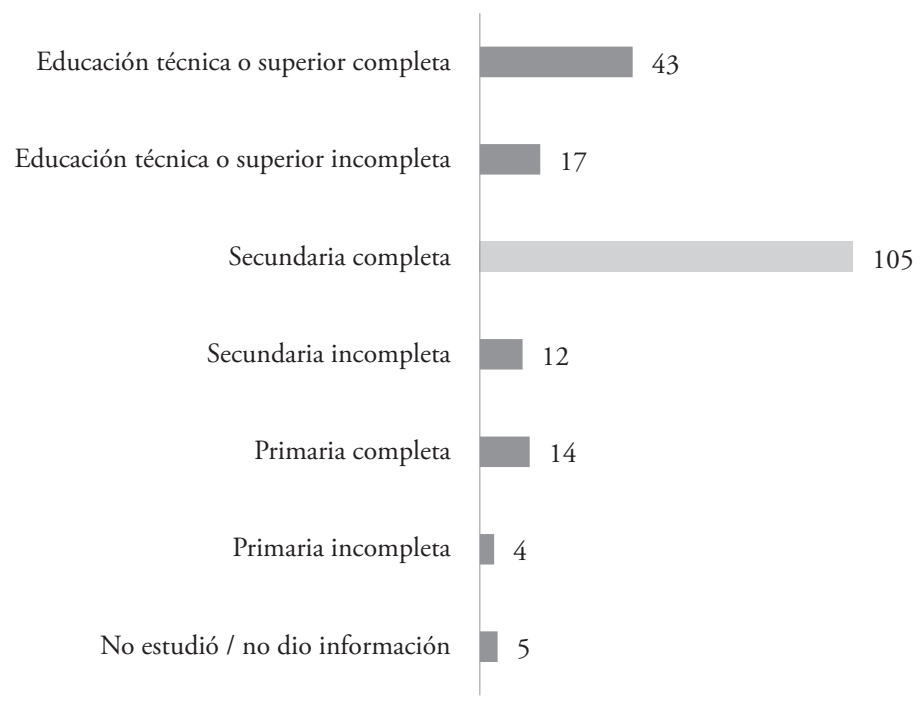

Fuente: encuesta de proceso de expropiación. Elaboración propia.

\section{Figura 8}

Promedio de años vividos en el predio según distritos

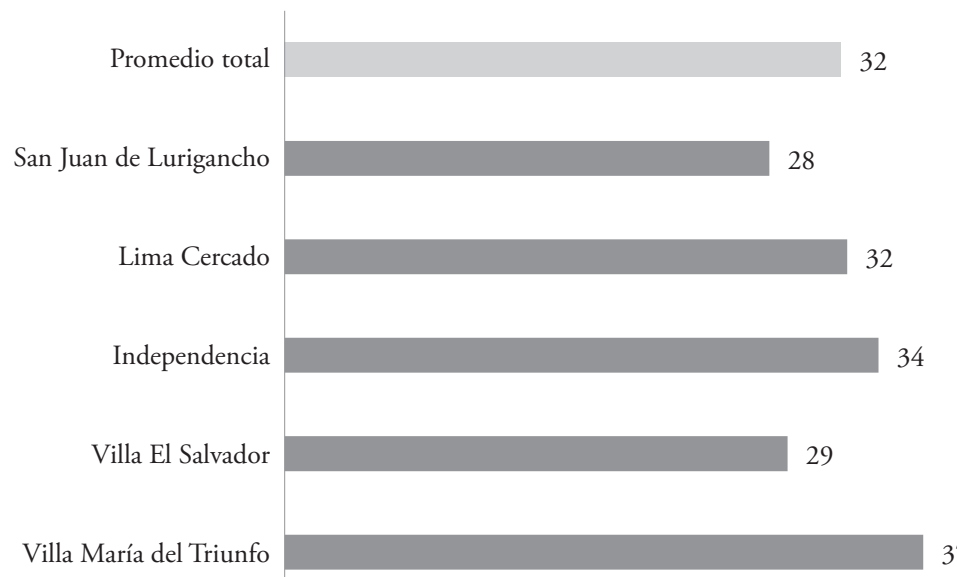

Fuente: encuesta de proceso de expropiación. Elaboración propia. 


\section{Figura 9}

Promedio de número de personas que habitan el predio según distritos

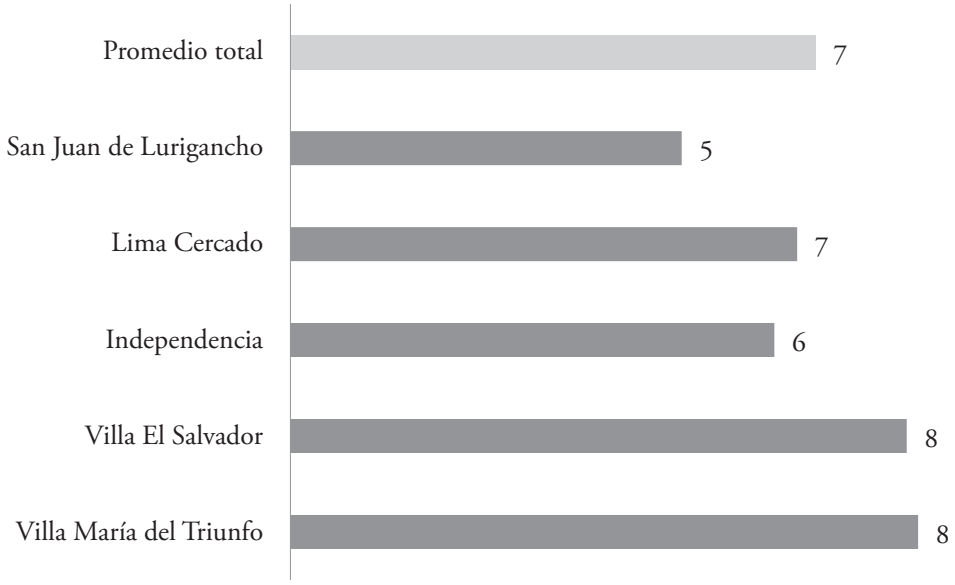

Fuente: encuesta de proceso de expropiación. Elaboración propia.

Figura 10

Uso económico del predio en los distritos encuestados (\%)

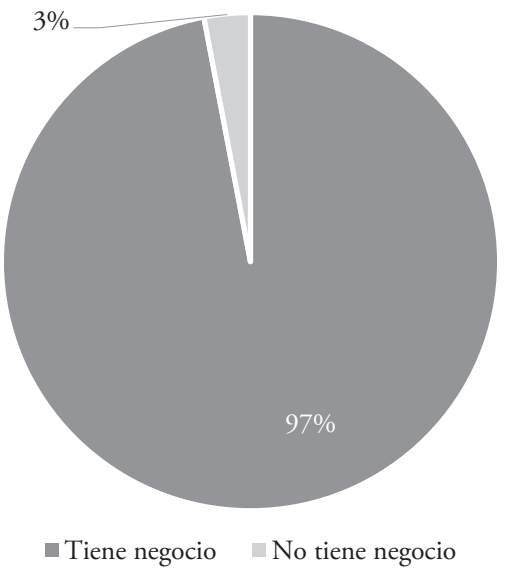

Fuente: encuesta de proceso de expropiación. Elaboración propia. 
Figura 11

Respuesta a la oferta de compensación ofrecida por el Estado (\%)

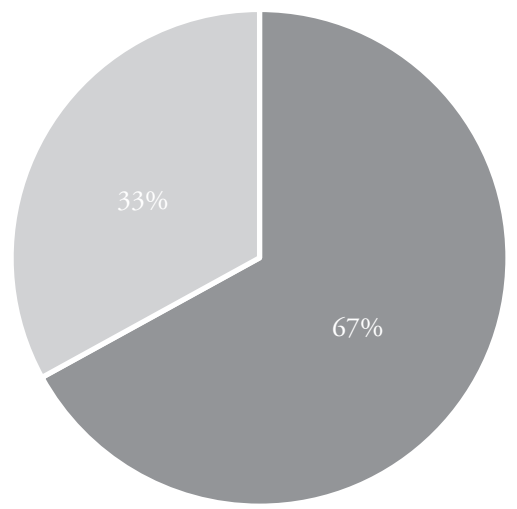

Rechazó la oferta de compensación $\square$ Aceptó la oferta de compensación

Fuente: encuesta de proceso de expropiación. Elaboración propia.

Figura 12

Respuesta a la oferta de compensación ofrecida por el Estado según distritos (número de personas)

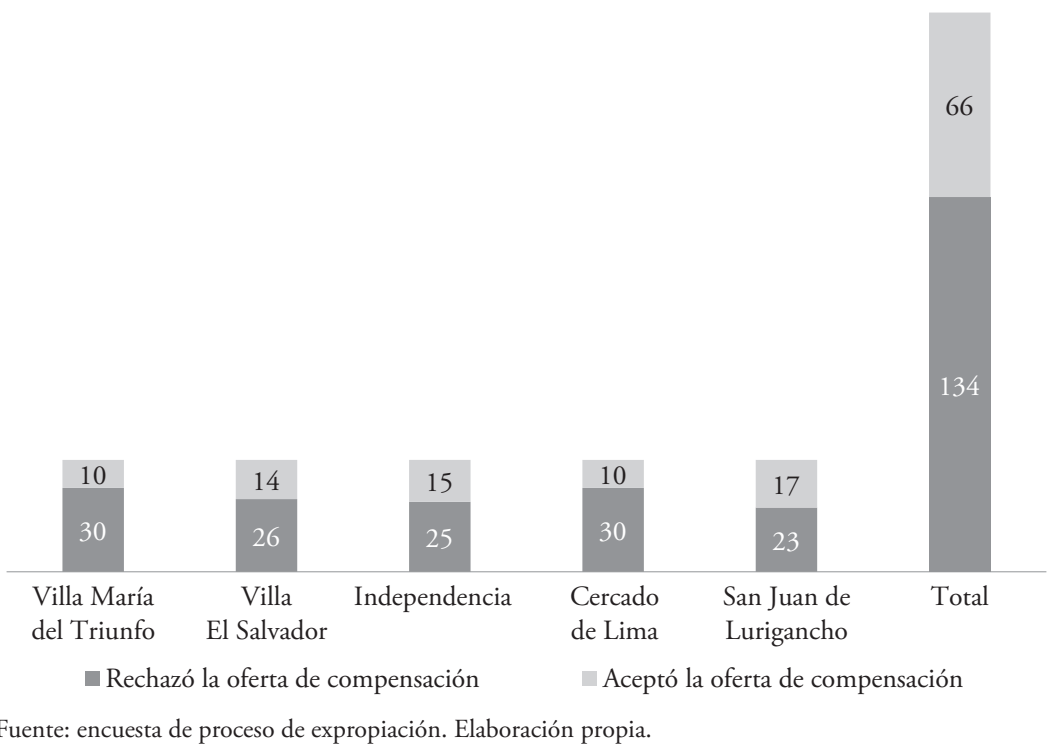




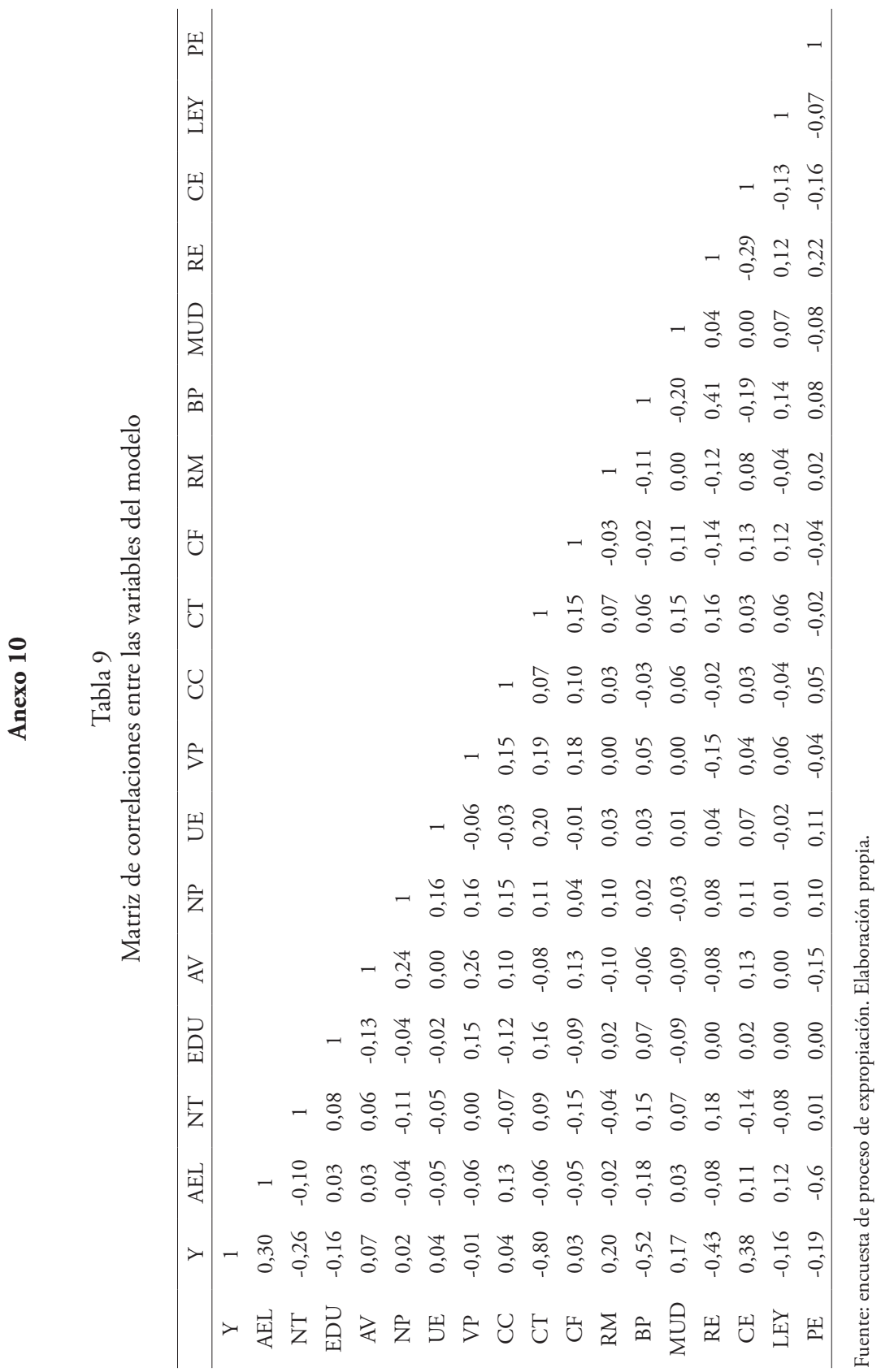




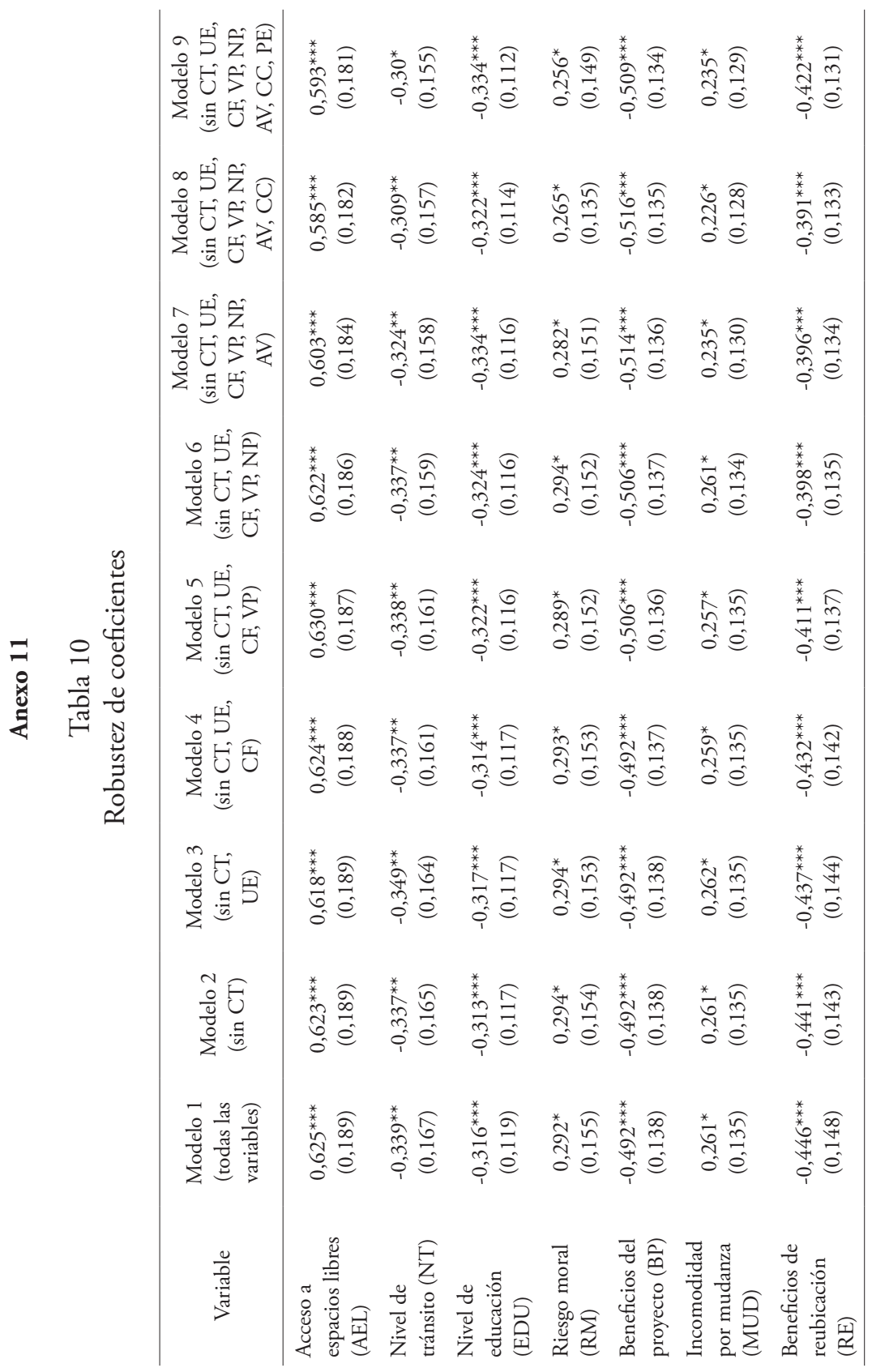




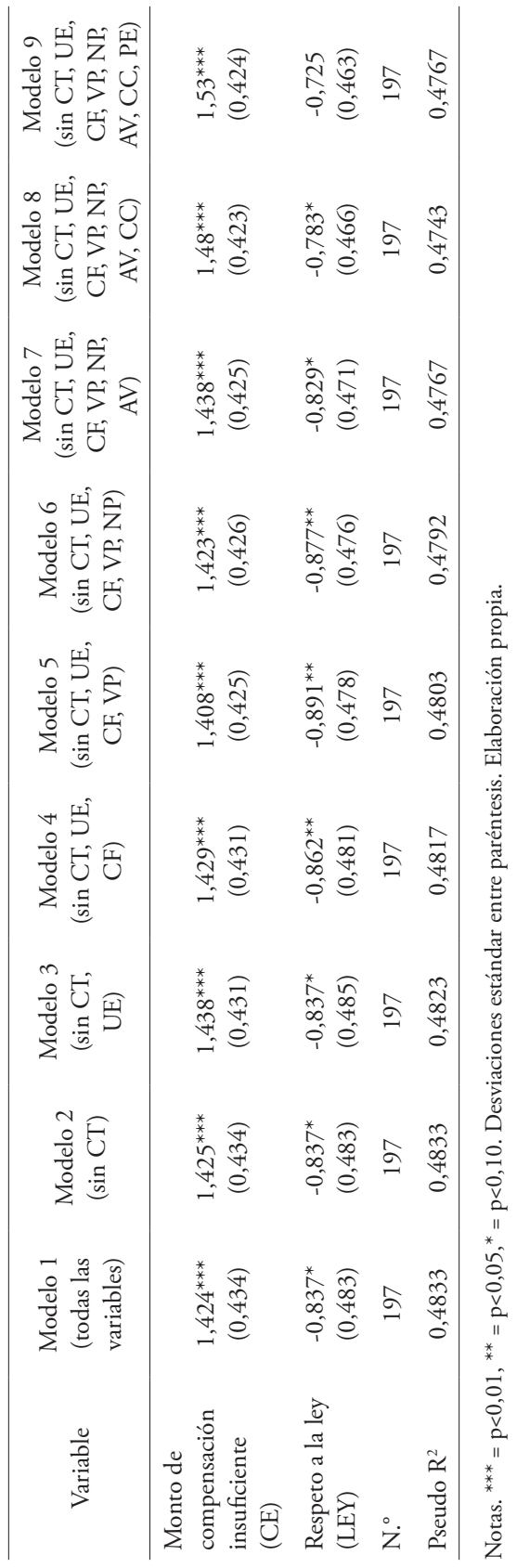




\section{Anexo 12}

Tabla 11

Robustez de submuestras

\begin{tabular}{lccc}
\hline \multicolumn{1}{c}{ Variable } & $\begin{array}{c}\text { Modelo 1 } \\
\text { (todas las } \\
\text { observaciones) }\end{array}$ & $\begin{array}{c}\text { Modelo 2 } \\
(182 \text { observaciones) }\end{array}$ & $\begin{array}{c}\text { Modelo 3 } \\
(172 \text { observaciones })\end{array}$ \\
\hline Acceso a espacios & $0,624^{* * *}$ & $0,697^{* * *}$ & $0,602^{* * *}$ \\
libres (AEL) & $(0,189)$ & $(0,208)$ & $(0,218)$ \\
Nivel de tránsito & $-0,339^{* *}$ & $-0,517^{* *}$ & $-0,545^{* *}$ \\
(NT) & $(0,167)$ & $(0,1914)$ & $(0,194)$ \\
Nivel de educación & $-0,316^{* * *}$ & $-0,329^{* * *}$ & $-0,310^{* * *}$ \\
(EDU) & $(0,119)$ & $(0,1271)$ & $(0,009)$ \\
& $0,292^{*}$ & $0,352^{*}$ & $0,298^{*}$ \\
Riesgo moral (RM) & $(0,155)$ & $(0,1667)$ & $(0,172)$ \\
Beneficios del & $-0,492^{* * *}$ & $-0,492^{* * *}$ & $-0,372^{* * *}$ \\
proyecto (BP) & $(0,138)$ & $(0,0,149)$ & $(0,155)$ \\
Incomodidad por & $0,261^{*}$ & $0,345^{*}$ & $0,322^{*}$ \\
mudanza (MUD) & $(0,135)$ & $(0,1481)$ & $(0,155)$ \\
Beneficios de & $-0,441^{* * *}$ & $-0,575^{* * *}$ & $-0,566^{* * *}$ \\
reubicación (RE) & $(0,147)$ & $(0,544)$ & $(0,175)$ \\
Monto de & $1,424^{* * *}$ & $1,899^{* * *}$ & $1,892^{* * *}$ \\
compensación & $(0,433)$ & $(0,5161)$ & $(0,545)$ \\
insuficiente (CE) & & $-1,059^{*}$ & $-0,852^{*}$ \\
Respeto a la ley (LEY) & $-0,837^{*}$ & $(0,516)$ & $(0,546)$ \\
N. ${ }^{*}$ & $(0,482)$ & 182 & 172 \\
Pseudo R ${ }^{2}$ & 197 & 0,5077 & 0,4983 \\
\hline
\end{tabular}

Notas. ${ }^{* *}=\mathrm{p}<0,01,{ }^{* *}=\mathrm{p}<0,05,{ }^{*}=\mathrm{p}<0,10$. Desviaciones estándar entre paréntesis. Elaboración propia. 



\title{
Análisis experimental sobre sobornos e informalidad en la pequeña y mediana empresa: eficiencia de políticas antisoborno ${ }^{1}$
}

\author{
Renzo Gabriele Arfinengo Roda
}

\section{Introducción}

La corrupción y sus consecuencias son temas que han interesado a economistas y otros académicos durante muchos años. En términos generales, la corrupción se define como "el abuso del poder para beneficio propio» (Transparency International, 2016). Y el soborno gubernamental -una de las manifestaciones más comunes de la corrupción- se define como «el uso inapropiado del servicio público para obtener beneficios materiales personales o privados» (Del Castillo, 2001). En adelante, soborno gubernamental y soborno serán utilizados como sinónimos.

La presente investigación está enfocada en la pequeña corrupción (o corrupción administrativa); es decir, aquella que: (1) involucra a funcionarios de mediano/bajo mando que tienen contacto con ciudadanos y pymes; (2) involucra, por lo general, montos pequeños; y (3) al ser extensa y constante, genera pérdidas considerables (Presidencia del Consejo de Ministros, 2012).

La literatura especializada distingue varias categorías de sobornos, aunque no sigue una clasificación única. Esta investigación categoriza a los sobornos tomando como principal referencia a Basu (2011) y utiliza dos categorías: (1) los sobornos de acoso, aquellos que exigen funcionarios públicos a un ciudadano -el ciudadano también podría ser el promotor- para proveerle un bien

\footnotetext{
${ }^{1}$ Este ensayo es una versión resumida y editada del Trabajo de Investigación Económica que, con el mismo título, fue concluido en junio de 2017. Su autor agradece al profesor Álvaro Cano por su asesoría durante la investigación, así como a los alumnos, profesores, profesionales y familiares que lo apoyaron para materializarla.
} 
o servicio (o acelerar su proceso) que tiene derecho a recibir; lo cual se da, por ejemplo, cuando un agente de aduanas pide un soborno a un empresario para entregarle inmediatamente su mercadería; en caso contrario, deberá esperar a que se lleven a cabo las «inspecciones»; y (2) los sobornos distorsionadores, aquellos que se desembolsan para cambiar por completo una decisión; por ejemplo, un soborno relacionado con la evasión de impuestos (Basu, 2011).

Los fenómenos de corrupción están presentes en todas las sociedades y son motivo de controversias. Como mencionan Méon \& Sekkat (2005), algunos autores -entre ellos Leff (1964) y Huntington (1968)- proponían que la corrupción mediante sobornos era necesaria en países donde el mal funcionamiento de las instituciones había generado grandes distorsiones. Esta hipótesis se basa en la lógica de que los sobornos "aceitan» las transacciones (Méon \& Sekkat, 2005). Sin embargo, un número importante de investigaciones recientes han encontrado evidencia contundente de que la corrupción tiene fuertes impactos negativos sobre el crecimiento económico y la inversión de un país (Mauro, 1995; Méon \& Sekkat, 2005). De acuerdo con $\operatorname{Vogl}^{2}$ (2015), la corrupción tiene un costo de aproximadamente un 5\% del PIB mundial. Según un informe difundido por el diario El Comercio, Proética -la socia/filial peruana de Transparency International- estima que el Perú pierde hasta S/ 33.800 millones anualmente (Vega, 2016). La reciente ola de escándalos de corrupción (caso Lava Jato y otros) que comprometen a los últimos Gobiernos del Perú, ha confirmado la gravedad de la corrupción y sus consecuencias.

Los países en desarrollo también se enfrentan a altos niveles de informalidad, entendida como aquella actividad económica que no es gravada ni monitoreada por el Gobierno (Mishra \& Ray, 2013). Se estima que el 47,7\% de los trabajadores de Latinoamérica trabajan en la informalidad (Organización Internacional del Trabajo, 2015) y que en el Perú esta cifra asciende al 75\% de la población económicamente activa ocupada.

En muchos casos, la corrupción y los sobornos determinan los costos y beneficios del sector formal e informal (Mishra \& Ray, 2013). Un ejemplo de ello es el de una empresa que opera en el sector informal y sabe que puede utilizar sobornos para mantenerse así. De hecho, Friedman, Johnson, Kaufmann \& Zoido-Lobatón (2000) proveen evidencia de que la corrupción y la informalidad son fenómenos complementarios, y plantean que en muchos países los empresarios prefieren el sector informal no porque no quieran pagar impuestos, sino por las constantes trabas burocráticas cimentadas en

\footnotetext{
${ }^{2}$ Frank Vogl es cofundador de Transparency International.
} 
la corrupción. De acuerdo con la Enterprise survey 2010 del Banco Mundial, un $21,4 \%$ de las empresas peruanas hacen pagos informales para que las cosas se hagan, y a un $12,4 \%$ se les ha exigido pagar un soborno para obtener un permiso de operación (Banco Mundial, 2010).

A pesar de grandes esfuerzos, uno de los principales problemas del estudio de la corrupción con sobornos y los métodos para combatirlos es la limitada evidencia empírica existente. Dada su naturaleza de anonimato, es complicado conseguir datos que no se encuentren sesgados. En respuesta a estas limitaciones, en años recientes se ha comenzado a utilizar el método experimental para construir datos no sesgados -en forma de frecuencia de hechos de corrupción- que puedan ser utilizados para análisis estadísticos y/o econométricos.

La presente investigación sigue la línea experimental. Su objetivo es analizar y medir los efectos de ciertos métodos disuasivos (antisoborno) en un contexto empresarial en el que hay informalidad. De manera específica, se utilizan tres métodos como variables independientes: probabilidad de detección del soborno, grado de responsabilidad imputada a las partes involucradas en un soborno (tipo de sistema legal) y salario del funcionario público. Mientras que las variables dependientes son las siguientes: porcentaje de sobornos concretados, porcentaje de agentes económicos formales y, en menor medida, monto de los sobornos.

Del objetivo planteado se desprenden las siguientes preguntas de investigación: (1) ¿cuál es el método antisoborno más eficiente para reducir los sobornos?; (2) ¿podría alguno de estos métodos incrementar la probabilidad de escoger el sector formal?

Las hipótesis de investigación son las siguientes: (1) una mayor probabilidad de detección reducirá los sobornos en ambos sectores (informal y formal) e incrementará el costo relativo de ser informal; (2) un sistema legal que incentive las denuncias y solo castigue a quien recibe el soborno será efectivo en reducir los sobornos de acoso y también la informalidad; (3) un salario alto reducirá los sobornos en ambos sectores, pero no tendrá efecto sobre la elección del sector.

La principal novedad de esta investigación es incorporar la posibilidad de operar en el sector informal. La especificación de esta decisión, basada en experiencias de países en vías desarrollo como el Perú, permitirá encontrar resultados relevantes para los hacedores de política. También representa un aporte la propuesta de comparar diversos métodos antisoborno, aún poco explorada en las investigaciones actuales.

Para responder las preguntas de investigación y comprobar las hipótesis propuestas, a continuación: (1) se hace una revisión de la literatura especia- 
lizada, resumiendo los avances y resultados de investigaciones similares; (2) se presenta un modelo teórico que estiliza el proceso de disyuntivas al que se enfrenta el agente económico; (3) se explica el diseño experimental y sus resultados; y (4) se concluye proponiendo políticas sugeridas por los resultados de la investigación y señalando sus limitaciones.

\section{Investigaciones relacionadas}

Abbink \& Serra (2012) y Bobkova \& Egbert (2012) han elaborado reseñas de un conjunto de experimentos sobre corrupción y sobornos, cuyos hallazgos más relevantes para la presente investigación son los siguientes:

\subsection{Probabilidad de detección}

El primer experimento de corrupción y métodos antisoborno fue realizado por Abbink, Irlenbusch \& Renner (2002). En este, los autores proponen un juego en el que interactúan dos agentes. El primero -rol de CEO que requiere un permiso para llevar a cabo una actividad que impacta al medio ambienteofrece una transferencia monetaria al segundo jugador -rol de funcionario público-, quien decide si acepta o no la transferencia; de hacerlo, las recompensas que reciben ambos jugadores se incrementan considerablemente. Uno de sus principales hallazgos es que si se introduce una probabilidad (de tan solo un $0,3 \%$ en cada ronda) de ser descubierto y descalificado del juego sin obtener ningún payoff, el soborno promedio cae en un 35\%.

Por otro lado, Berninghaus et al. (2013) incorporan una probabilidad endógena determinada en función del número de agentes que decidan ser corruptos: mientras más agentes decidieran ser corruptos, menor era la probabilidad de que los descubrieran. En su grupo de control, los agentes recibieron información completa sobre cuánto sería la probabilidad para cada escenario; es decir, sabían que, si tres personas eran corruptas, entonces la probabilidad de detección era "X». En su grupo de tratamiento, quitaron esta información completa y así, aunque los agentes sabían la lógica detrás de la determinación de esta probabilidad, no sabían su valor exacto. Los autores encuentran que esta incertidumbre redujo la cantidad de agentes que escogieron ser corruptos, de un $81,1 \%$ del total de participantes a un $58,1 \%$.

\subsection{Salario}

Boly (2009) realizó un experimento de laboratorio posteriormente repetido en un experimento de campo. Los participantes tenían que corregir un con- 
junto de exámenes, y por ello recibían un salario base. Sin embargo, uno de los exámenes incluía un soborno y una nota que pedía al calificador encontrar menos errores. Los conductores del experimento descubrieron que, cuando pagaron un mejor salario ( $40 \%$ mayor que el salario base), la probabilidad de que los calificadores aceptaran el soborno se redujo del 48,7\% al 37,5\%.

Anteriormente, Rijckeghem \& Weder (2001) habían formulado una regresión con datos de diversos países y mostraron que los salarios de los funcionarios tienen una correlación significativa con la reducción de la corrupción. Pero no en gran medida, pues hallaron que un incremento del $100 \%$ produce una reducción de tan solo un 8,3\% en el índice de corrupción.

\subsection{Sistema legal}

En lo que respecta a la responsabilidad imputada por ley a los participantes en un soborno, la literatura ha aumentado de manera considerable. La lógica es la siguiente: si se exonera al ciudadano -emisor del soborno- del castigo, entonces hay fuertes incentivos para que este acuse al funcionario público que aceptó el soborno. En consecuencia, el funcionario va a pensarlo dos veces antes de solicitarlo. Evidentemente, tienen que existir mecanismos institucionales que garanticen la protección al ciudadano y el reembolso del soborno una vez consumado un proceso judicial (Basu, 2011). Una de las críticas más importantes a esta medida es que puede volver socialmente aceptado el acto de soborno (Abbink, Dasgupta, Gangadharan, \& Jain, 2013).

Un experimento realizado por Engel, Goerg \& Yu (2012) pone a prueba esta idea. Dichos autores encuentran que los ciudadanos son más propensos a denunciar al funcionario cuando este último acepta el soborno, y más aún cuando lo recibe pero no actúa con reciprocidad. Anticipando este comportamiento, los funcionarios son más reacios a aceptar un soborno, pero, cuando lo hacen, responden con reciprocidad. Cabe destacar que en este experimento no se especificó una situación de soborno de acoso per se. En respuesta a esta limitante, Abbink et al. (2013) crearon un experimento específico para los sobornos de acoso y encontraron que los castigos asimétricos aumentan las denuncias del $25 \%$ al $59 \%$ y disminuyen las demandas de sobornos del $38 \%$ al $24 \%$.

\subsection{Nexo entre informalidad y sobornos}

En lo que respecta al vínculo entre informalidad y sobornos, la literatura especializada es relativamente escasa, y no se ha encontrado literatura propiamente experimental que aborde esta relación. 
Mishra \& Ray (2013) proponen que existe complementariedad entre ambas variables, en especial en países en desarrollo. Esto porque los sobornos son necesarios para expandir el sector informal, y, a su vez, esta expansión propicia los sobornos para mantener la actividad como no detectable. Por consiguiente, estimarla con métodos econométricos resulta complicado. En respuesta a esta limitante, los autores plantean un modelo analítico según el cual las microempresas son informales debido a los costos de ser formal, mientras que las empresas medianas con cierta escala prefieren la informalidad por el beneficio de la corrupción. Asimismo, plantean que este beneficio es función de la fortaleza del régimen anticorrupción; de manera específica, de los salarios de los funcionarios públicos. Cabe destacar que en la citada investigación no se contemplaron sobornos para ingresar al sector formal.

\section{Marco analítico}

Imaginemos que alguien quiere iniciar un negocio pequeño/mediano en algún mercado. Este potencial empresario sabe que puede acceder al sector formal de dos maneras: (1) solicitando/tramitando los permisos respectivos de funcionamiento, lo que implica un tiempo de espera, pues existen trabas burocráticas que dificultan su obtención; (2) ofrecer un soborno a algún funcionario para obtener la formalidad/permiso de manera cuasi inmediata.

Y ese agente económico también sabe que puede optar por ser informal (no tramitar los permisos) y producir beneficios de inmediato, con una pequeña probabilidad endógena de que en algún momento lo descubran. Asimismo, sabe que, si lo descubren, cuenta con dos opciones: (1) abandonar la producción, pagar la multa correspondiente y liquidar los activos; (2) ofrecer un soborno al funcionario público para que lo deje seguir produciendo de manera informal.

Para formalizar el razonamiento, proponemos un modelo costo-beneficio fuertemente influenciado por el modelo de Bjørnskov (2011). En primera instancia, asumamos que todas las empresas que maximizan beneficios requieren un permiso para producir, y que los funcionarios ejercen discrecionalmente su monopolio de otorgar o no los permisos. Bajo estos supuestos, la corrupción mediante sobornos puede surgir a resultas de las siguientes condiciones costo-beneficio, aplicables al funcionario, por un lado, y al empresario, por el otro:

\section{Modelo costo-beneficio}

Un funcionario $(\mathrm{O})$ aceptará un soborno «b» si: 


$$
\left(1+\text { premium }_{h}\right)^{h}\left(1+\text { premium }_{f}\right)^{1-f}(\underbrace{(1-p)(b+w-M)-p}_{\begin{array}{c}
\text { Riqueza obtenida si no hay } \\
\text { detección del soborno }
\end{array}}(\underbrace{\left.\left.L_{0}\right)\right)>w}_{\begin{array}{c}
\text { Costo de ser } \\
\text { detectado }
\end{array}}
$$

Donde:

- $h$ : variable binaria. Se activa si el sistema legal incentiva las denuncias, y solo castiga al receptor de un soborno.

- $f$ : variable binaria. Se activa si el empresario decide operar en el sector formal.

- $\quad p$ : probabilidad de detección exógena de que un soborno sea detectado por un supervisor.

- $b$ : soborno.

- $\quad w$ : salario del funcionario.

- $\quad$ : costo moral (estocástico).

- $L$ : costo de ser descubierto otorgando o recibiendo un soborno (multas y cárcel).

La lógica de las primas para «h»y «1 - f» es que un funcionario buscará sacar mayor partido de un empresario informal (pues sabe que este está en falta); y pedirá un mayor monto si es que el sistema legal lo presenta como el único responsable de un soborno.

Un empresario $(E)$ en el sector formal decidirá pagar un soborno si:

$$
\underbrace{(1-p) *\left((1-t) * \pi(.)-C-b_{f}-M_{E}\right)}_{\begin{array}{c}
\text { Riqueza obtenida si no hay } \\
\text { detección del soborno }
\end{array}}-\underbrace{p *\left(L_{E}+b_{f}+M_{E}\right)}_{\begin{array}{c}
\text { Costo de ser } \\
\text { detectado }
\end{array}}>\underbrace{(1-t) * \pi(.)-d \pi-C}_{\begin{array}{c}
\text { Riqueza normal } \\
\text { obtenida sin soborno }
\end{array}}
$$

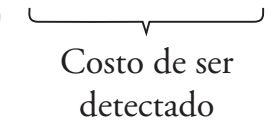

\section{Donde:}

- $t$ : tasa impositiva.

- $\pi($.$) : beneficios generados durante el período.$

- $d \pi$ : costo de oportunidad de esperar por el permiso; depende de la calidad institucional y discrecionalidad de los funcionarios.

- $C$ : costo del permiso requerido para producir.

Un empresario (I) pagará un soborno en el sector informal si ${ }^{3}$ :

\footnotetext{
${ }^{3}$ Resultado obtenido simplificando la siguiente ecuación: $q *\left[(1-p) *\left(\pi()-.i \pi-b_{i}-M_{E}\right)-p *\left(L_{i}+b_{i}+\right.\right.$ $\left.\left.M_{E}\right)\right]+(1-q) *[\pi()-.i \pi]>q *[\Pi-\mathrm{X}]+(1-q) *\lceil\pi()-.i \pi]$, donde «q" es la probabilidad endógena de ser descubierto en el sector informal. Es función de "p» $y$ del esfuerzo de los funcionarios.
} 


$$
\underbrace{(1-p) *\left(\pi(.)-i \pi-b_{i}-M_{E}\right)}_{\begin{array}{c}
\text { Riqueza obtenida si no hay } \\
\text { detección del soborno }
\end{array}}-p *(L_{i}+\underbrace{\left.b_{i}+M_{E}\right)>\Pi-\mathrm{X}}_{\begin{array}{c}
\text { Costo de ser } \\
\text { detectado }
\end{array}}
$$

\section{Donde:}

- $i \pi$ : costo de oportunidad de ser informal (no acceso al crédito, no protección legal).

- П: beneficios acumulados hasta el momento de detección de la actividad informal.

- $\mathrm{X}$ : costo de ser descubierto en el sector informal (multa).

Este modelo, así formulado, permite predecir que: (1) la probabilidad de detección en cada sector magnifica el costo del soborno; (2) el soborno relacionado con el sector formal es de tipo acoso y el relacionado con sector informal es de tipo distorsionador; y (3) los salarios son un costo de oportunidad para los funcionarios.

Cabe destacar que, en la vida cotidiana, es común que los negocios inicien sus operaciones de manera informal antes de convertirse en negocios formales. Adicionalmente, en muchos países en vías de desarrollo es común que, si se da una detección en el sector informal, el negocio cierre y, después de unas semanas, vuelva a iniciar sus operaciones de manera clandestina. Para no complicar innecesariamente el análisis, se asume que situaciones como esas estarían compensadas en los pagos netos esperados del modelo analítico.

\section{Metodología}

A fin de comprobar las predicciones del modelo analítico, se realizaron dos experimentos que incorporan la lógica de este: el primero estuvo dirigido a empresarios y el segundo, a funcionarios. Dado que cada experimento involucra un juego entre dos jugadores con distintos roles, uno de los jugadores fue simulado; por ejemplo, en el experimento dirigido a empresarios, los funcionarios fueron simulaciones programadas con anterioridad. El experimento se realizó en la Universidad del Pacífico, por medio de la interfaz virtual «z-tree» presentada por Fischbacher (2007).

Diversos autores plantean que utilizar estudiantes es una limitación que trae problemas de validez externa. Uno de los pioneros de esta crítica fue Sears (1986), quien, en sus investigaciones, observó que los estudiantes suelen ser más propensos a consentir ante las autoridades, tienen relaciones menos estables y tienen formulaciones más rusticas del ser; por ello, los resultados 
obtenidos con ellos en el laboratorio suelen ser sesgados y no extrapolables a comportamientos poblacionales. Sin embargo, como plantean Cooper, McCord \& Socha (2011) y Boly (2009), los resultados de experimentos con estudiantes son muchas veces idénticos a los obtenidos mediante otros métodos empíricos. Para el caso de la presente investigación, utilizar estudiantes fue un camino práctico para trabajar una muestra grande.

Cada sesión experimental tuvo una duración de 20 minutos, en la que se jugaron tres repeticiones (rondas) del experimento. Cada ronda tuvo una duración de cinco minutos y comprendió la aplicación de alguno de los diseños experimentales (combinación de variables independientes) listados en la tabla 1:

Tabla 1

Diseños experimentales

\begin{tabular}{cccc}
\hline Diseńo & $\begin{array}{c}\text { Probabilidad } \\
(\mathrm{p})\end{array}$ & $\begin{array}{c}\text { Salario } \\
(\mathrm{w})\end{array}$ & $\begin{array}{c}\text { Sistema legal / castigo } \\
(\mathrm{h})\end{array}$ \\
\hline 1 & $5 \%$ & Bajo & Simétrico \\
2 & $20 \%$ & Alto & Simétrico \\
3 & $40 \%$ & Bajo & Simétrico \\
4 & $60 \%$ & Alto & Simétrico \\
5 & $5 \%$ & Alto & Asimétrico \\
6 & $20 \%$ & Bajo & Asimétrico \\
7 & $40 \%$ & Alto & Asimétrico \\
8 & $60 \%$ & Bajo & Asimétrico \\
\hline
\end{tabular}

Para garantizar un muestreo aleatorio que asegurara la validez interna del experimento, cada individuo fue sometido a tres de esos diseños de manera aleatoria (sin reemplazo). Se reclutó a 88 estudiantes por experimento, con lo que se obtuvo 264 observaciones (33 observaciones por diseño).

Respecto a las variables en la tabla 1 , se plantearon grandes cambios bruscos en la probabilidad de detección $(p)$, debido a que las personas en promedio no responden a cambios pequeños en esta variable y suelen subestimar las probabilidades de detección (Abbink et al., 2002). Y, con base en la investigación de Boly (2009), se planteó que el salario alto fuera un 40\% mayor que el salario base. Por otro lado, el castigo imputado en el Perú y en la mayoría de los países es igual para ambas partes de un soborno (simétrico).

Cabe destacar que las instrucciones impartidas a los participantes buscaron ser muy neutras para evitar influir en su comportamiento; aunque, 
como demuestran Abbink \& Henning-Schimdt (2006) en su experimento de sobornos, las instrucciones "cargadas» no tienen un impacto significativo.

Por cada experimento, los participantes recibieron un pago monetario de acuerdo con la riqueza generada (entre 5 y 15 soles), con una tasa de conversión de puntos de 250:1 para el experimento de empresarios y de 700:1 para funcionarios. Al finalizar la sesión, se pidió a los participantes que llenaran una encuesta sociodemográfica con el objetivo de conocer sus características y preferencias, que servirían como variables de control en los modelos econométricos.

\subsection{Experimento en rol de empresarios}

Para el juego esbozado en la figura 1, los participantes en rol de empresarios recibieron información del mercado (variables independientes), una riqueza inicial de 1.500 puntos e instrucciones ${ }^{4}$ para el juego (figura 1).

De cara al sector formal, los empresarios saben que los funcionarios poseen el monopolio de los permisos y fiscalizan el mercado. Tramitar el permiso de funcionamiento tiene un costo de 300 puntos y obtenerlo involucra una espera de 45 segundos. Si deciden ofrecer un soborno y no son detectados, obtendrán el permiso de manera inmediata. Si el régimen legal incentiva las denuncias e imputa responsabilidad solo al receptor del soborno, el empresario tiene la opción de denunciar al funcionario ante su supervisor (y obtiene el permiso de manera inmediata). Una vez que reciben el permiso, responden a un test de preguntas multifacéticas para determinar su matriz de pago. Cada pregunta correcta en el sector formal otorga 200 puntos.

Pero los empresarios pueden optar por operar en el sector informal y producir inmediatamente. Sin embargo, existe la posibilidad de que su actividad sea detectada por un fiscalizador. Se les informa de que esta probabilidad "q" depende de la probabilidad exógena de detectar operaciones fraudulentas "p» (guardan una relación 6 a 1, pues, en promedio, los participantes responden 6 preguntas en cada ronda ${ }^{5}$ ) y de que la probabilidad "q" se renueva y ejecuta al final de cada pregunta contestada. Si su actividad es descubierta, el jugador puede optar por desembolsar un soborno distorsionador para que se haga caso omiso a la detección de su actividad, o por liquidar sus activos. Cada pregunta correcta en este sector otorga 150 puntos.

\footnotetext{
${ }^{4}$ Las instrucciones completas están disponibles en: https://drive.google.com/drive/folders/1d3ODAdgvE k0DIGBwyKK5WygOH_Yed_jT

${ }^{5}$ Conforme a los resultados del experimento piloto.
} 


\section{Figura 1}

Representación gráfica del juego empresarios

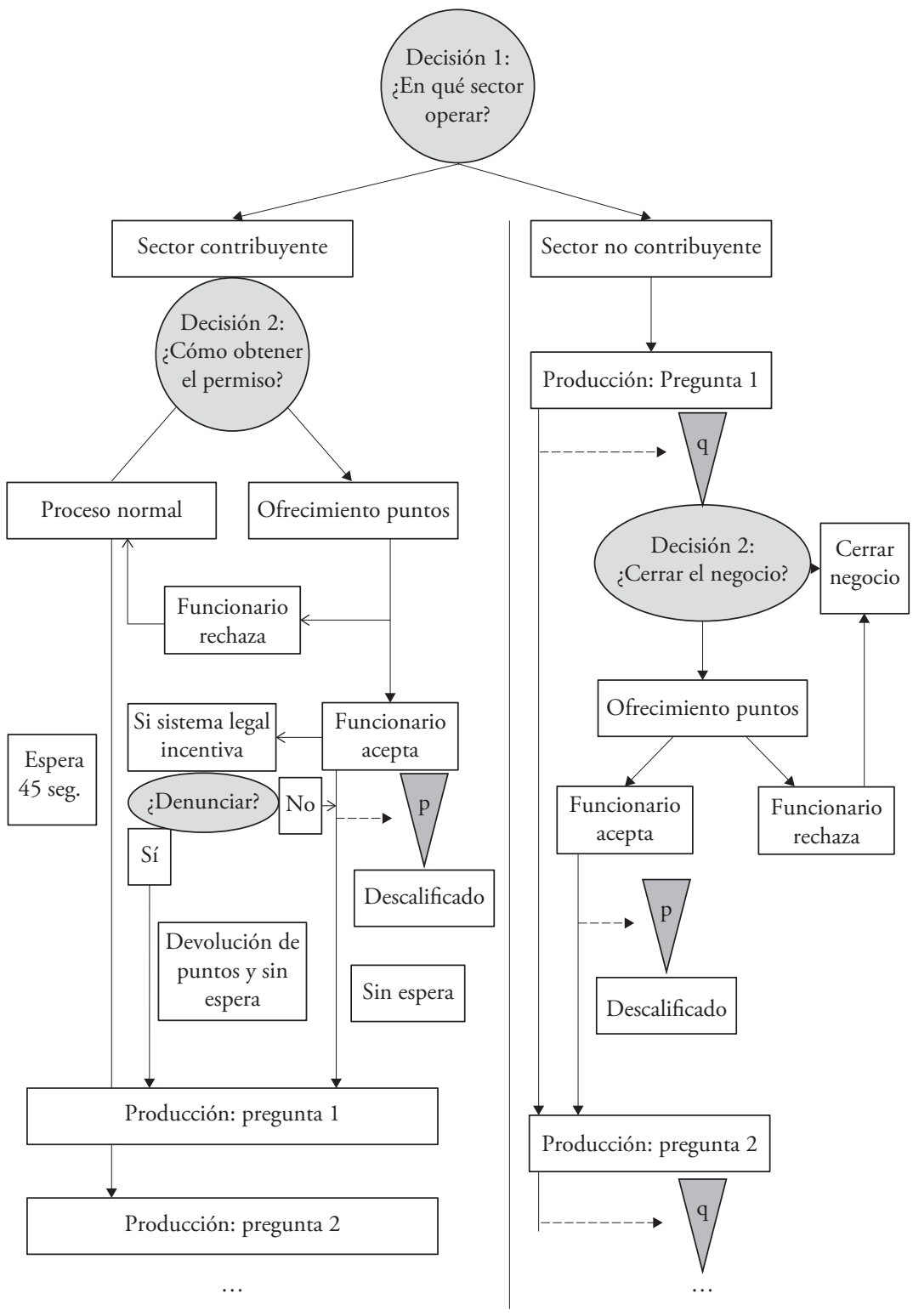




\subsection{Experimento en rol de funcionarios}

Los participantes en rol de funcionarios recibieron un sueldo por su labor, alto (2.110 puntos) o bajo (1.500 puntos); información del mercado (variables independientes); e instrucciones ${ }^{6}$ para un juego en tres fases (figura 2):

Fase 1: reciben cuatro ofrecimientos de empresarios que deseaban obtener su permiso de manera inmediata. El monto ofrecido fue aleatorio en cuanto al orden, pero todos los funcionarios recibieron ofrecimientos de un $4 \%$, un $14 \%$, un $44 \%$ y un $88 \%$ del salario bajo.

Fase 2: reciben las solicitudes normales de los empresarios (trámite formal). Se les indicó que otorguen permisos solo a aquellos que tenga una estructura de costos menor que un cierto umbral. En esta fase hubo cinco empresarios, dos de los cuales tenían una estructura de costo superior al umbral. El funcionario podía optar por «acercarse» a los empresarios que no cumplían con los requisitos y ofrecerles su "ayuda», en cuyo caso también tenía que indicar el monto que quería recibir a cambio (soborno).

Fase 3: reciben cuatro ofrecimientos de empresarios informales que desean seguir operando en este sector. El orden fue aleatorio, pero recibieron ofrecimientos de un $4 \%$, un $14 \%$, un $44 \%$ y un $88 \%$ del salario alto (se escogió el salario alto para representar la prima relacionada con «1-f»).

\footnotetext{
${ }^{6}$ Las instrucciones completas están disponibles en: https://drive.google.com/drive/folders/1d3ODAdgvE k0DIGBwyKK5WygOH_Yed_jT
} 


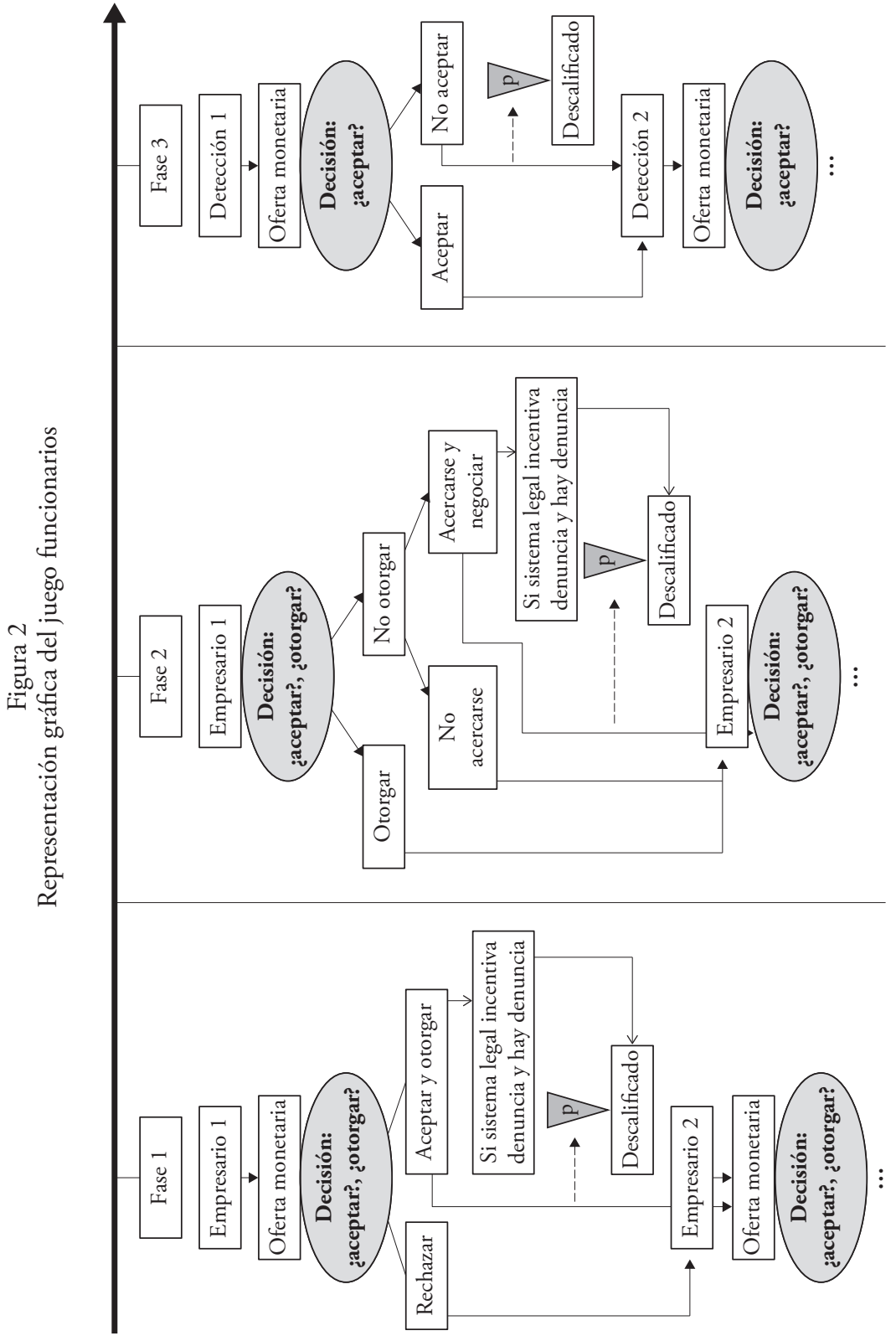




\section{Análisis y resultados}

Para analizar la probabilidad de escoger cada uno de los eventos propuestos en los juegos, se utilizaron los modelos conditional logit y nested logit (empresarios) y logit (empresarios y funcionarios). Cabe destacar que se realizó el análisis econométrico para cada base por separado, para evitar sesgos y errores de proporcionalidad. Además, cuando fue pertinente y posible, se realizó un ajuste por clusters considerando que cada individuo juega tres veces.

En adelante:

- «p»: probabilidad de detección exógena (enteros).

- «W»: salario («1» alto y «0» bajo).

- «h»: sistema legal («1» sistema incentiva las denuncias y la responsabilidad recae en el receptor; «0» ambas partes tienen responsabilidad).

- «X»: variables de control.

\subsection{Análisis de empresarios}

En la base de datos de empresarios, las decisiones se toman de manera secuencial y enfrentan cuatro alternativas (figura 3):

Figura 3

Alternativas de los empresarios
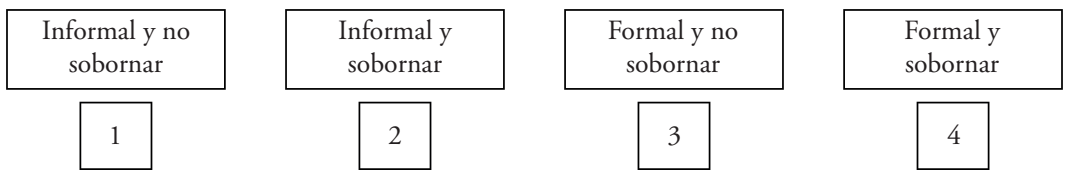

En este caso, si se cumple el supuesto de independencia de alternativas relevantes (IIA), cabría utilizar un modelo logit condicional. Sin embargo, dicho supuesto podría ser muy restrictivo. Por este motivo, y dada la naturaleza de las decisiones, resultaba lógico agrupar las alternativas de acuerdo a cómo se recomponen las probabilidades cuando una alternativa es eliminada. El principal supuesto de un modelo nested logit es que la IIA se cumple dentro del nido de decisión, pero no para alternativas en diferentes nidos de decisión (Greene, 2012; Train, 2002).

La primera agrupación (A) posible es juntar las alternativas 1 y 2 (nido \#1) y las alternativas 3 y 4 (nido \#2). Esto sugeriría que, si eliminamos la alternativa 4, la alternativa 3 absorbería una mayor proporción del efecto en comparación con las alternativas 1 y/o 2. La segunda agrupación posible (B) es juntar las alternativas 1 y 3 (nido \#1) y las alternativas 2 y 4 (nido \#2). 
Sin embargo, no es sencillo seleccionar una de esas agrupaciones. Escoger A sugiere que la elección del sector es la decisión más importante; conjetura plausible en sociedades donde la corrupción dentro de las instituciones es generalizada. Escoger B implica que la elección de sobornar es la más importante; supuesto posible considerando que la acción de sobornar conlleva un proceso mental intenso que incluye un componente ético. Sin embargo, el problema de ambas agrupaciones - pero especialmente de la B- es que, en la práctica (y en nuestro juego), quienes escogen el sector informal no necesariamente llegan a tener la opción de sobornar. En consecuencia, la decisión de sobornar se encuentra limitada.

Lo anterior implica que "p» puede sufrir de endogenidad cuando se evalúa el sector informal porque, para que exista la opción de sobornar, primero tiene que haber una detección de la actividad informal. Dado que «q" depende de "p», los informales detectados por los funcionarios fueron aquellos que estaban asociados a una mayor probabilidad "p». Por tanto, puede haber distorsiones cuando se analiza toda la información en modelos conjuntos como el logit condicional o el nested logit.

A continuación, se muestran las principales medidas de tendencia central:

Tabla 2

Sector formal $(184 / 264)$

\begin{tabular}{ccclll}
\hline$\underline{h=0}$ & $\begin{array}{c}\text { Número de } \\
\text { observaciones }\end{array}$ & $\begin{array}{c}\text { Monto } \\
\text { (promedio) }\end{array}$ & $\underline{\underline{h=1}}$ & $\begin{array}{c}\text { Número de } \\
\text { observaciones }\end{array}$ & $\begin{array}{c}\text { Monto } \\
\text { (promedio) }\end{array}$ \\
\hline Sobornó & 31 & 209 & Sobornó & 40 & 166 \\
& & & Acusó & 23 & 236 \\
& & & Soborno rechazado & 15 & 139 \\
No sobornó & 53 & & No acusó & 2 & 175 \\
\hline
\end{tabular}

Tabla 3

Sector informal $(80 / 264)$

\begin{tabular}{lcc}
\hline & Número de observaciones & Monto (promedio) \\
\hline Sobornó & 20 & 269 \\
No sobornó & 60 & - \\
\hline
\end{tabular}




\subsubsection{Modelo logit condicional}

Este modelo compara las cuatro alternativas a las que se enfrenta el empresario (figura 3). Para ello, se asume que la IIA se cumple y que la toma de decisiones está influida tanto por variables especificas a las alternativas («p»y «h») como por características individuales; de manera que «p» $\mathrm{y}$ «h» pueden cambiar para los individuos (Greene, 2012). Adicionalmente, las variables de control recolectadas mediante la encuesta sociodemográfica sirven como características individuales constantes a lo largo de las alternativas:

$$
\text { choice }=\delta_{0}+\delta_{1} * \text { prob }_{\text {final }}+\delta 2 * h_{\text {real }}+\delta_{3 j} * \text { correctas }+\delta_{4 j} * w+\varphi j X+u
$$

Donde:

- choice: alternativa seleccionada.

- $\quad \operatorname{prob}_{\text {final: }}$ probabilidad de llegar al final del juego (específica a las alternativas). Se encuentra basada en "p» y nos da un efecto más limpio dado el potencial problema de endogeneidad.

- correctas: proporción de preguntas correctas. Proxy de capacidad/ esfuerzo.

A continuación, se muestran los resultados de la regresión bajo este modelo (tabla 4) y los respectivos efectos marginales (tabla 5): 


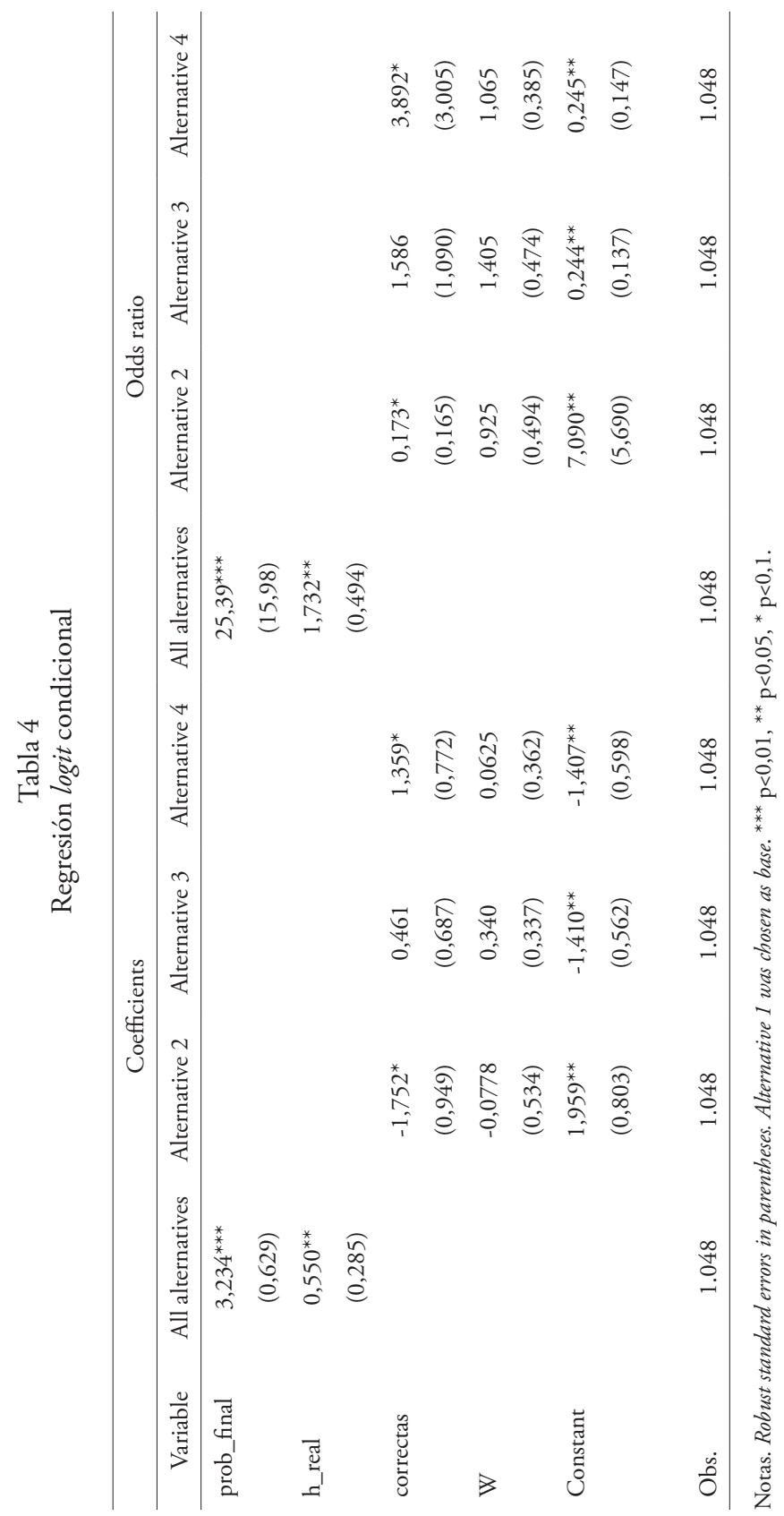


Tabla 5

Efectos marginales logit condicional

\begin{tabular}{|c|c|c|c|c|}
\hline $\begin{array}{l}\text { Variable marginal } \\
\text { effects }(\mathrm{dy} / \mathrm{dx})\end{array}$ & $\begin{array}{c}\text { Prob (Alternative } \\
1 \text { is selected) }\end{array}$ & $\begin{array}{l}\text { Prob (Alternative } \\
2 \text { is selected) }\end{array}$ & $\begin{array}{c}\text { Prob (Alternative } \\
3 \text { is selected) }\end{array}$ & $\begin{array}{l}\text { Prob (Alternative } \\
4 \text { is selected) }\end{array}$ \\
\hline \multicolumn{5}{|l|}{ prob_final } \\
\hline \multirow[t]{2}{*}{ Alternative 1} & $0,545^{* * *}$ & $-0,0488^{* * *}$ & $-0,3217^{* * *}$ & $-0,1944^{* * *}$ \\
\hline & $(0,1183)$ & $(0,0156)$ & $(0,0699)$ & $(0,045)$ \\
\hline \multirow[t]{2}{*}{ Alternative 2} & $-0,048^{* * *}$ & $0,2022^{* * *}$ & $-0,0955^{* * *}$ & $-0,0577^{* * *}$ \\
\hline & $(0,0155)$ & $(0,0604)$ & $(0,0295)$ & $(0,0183)$ \\
\hline \multirow[t]{2}{*}{ Alternative 3} & $-0,3168^{* * *}$ & $-0,0955^{* * *}$ & $0,7973^{* * *}$ & $-0,3911^{* * *}$ \\
\hline & $(0,699)$ & $(0,0295)$ & $(0,1557)$ & $(0,0857)$ \\
\hline \multirow[t]{2}{*}{ Alternative 4} & $-0,1943^{* * *}$ & $-0,0577^{* * *}$ & $-0,3801^{* * *}$ & $0,6325^{* * *}$ \\
\hline & $(0,0458)$ & $(0,0183)$ & $(0,083)$ & $(0,1322)$ \\
\hline \multicolumn{5}{|l|}{ h_real } \\
\hline \multirow[t]{2}{*}{ Alternative 1} & $0,1098^{*}$ & $-0,0095$ & $-0,0625^{*}$ & $-0,0377^{*}$ \\
\hline & $(0,634)$ & $(0,0058)$ & $(0,0364)$ & $(0,0222)$ \\
\hline \multirow[t]{2}{*}{ Alternative 2} & $-0,0106$ & 0,0435 & $-0,0207$ & $-0,0125$ \\
\hline & $(0,0071)$ & $(0,0291)$ & $(0,0139)$ & $(0,0085)$ \\
\hline \multirow[t]{2}{*}{ Alternative 3} & $-0,0544^{*}$ & $-0,0161^{*}$ & $0,1347^{* *}$ & $-0,0642^{* *}$ \\
\hline & $(0,0282)$ & $(0,0090)$ & $(0,0692)$ & $(0,0339)$ \\
\hline \multirow[t]{2}{*}{ Alternative 4} & $-0,0330^{*}$ & $-0,0098^{*}$ & $-0,0645^{* *}$ & $0,1073^{* *}$ \\
\hline & $(0,0175)$ & $(0,0055)$ & $(0,0343)$ & $(0,056)$ \\
\hline
\end{tabular}

Según esta especificación, tener mayores oportunidades de acabar el juego dentro de una alternativa incrementa de manera significativa la probabilidad de escoger esa alternativa (odds ratio de 25,39). Esto indica que, al incrementarse "p», las alternativas menos impactadas por esta probabilidad (alternativas 3 y 4) serían las preferidas.

Un análisis de efectos marginales confirma esta suposición, al indicar que un incremento en "p»: (1) tiene un impacto significativo en la selección del sector (formal o informal) y (2) incrementa la probabilidad de escoger las alternativas más seguras (como la 3). Los resultados asociados a «p» guardan coherencia lógica: ante un mayor "p», los empresarios evitan el sector informal porque: (a) «q» depende de «p»; y (b) si su informalidad es detectada, sobornar se vuelve mucho más caro y riesgoso conforme se incrementa "p». Y es natural evitar alternativas riesgosas, pues una detección expone a castigos importantes. 
Por otro lado, se observa que el sistema legal «h» también tiene un impacto significativo (odds ratio de 1,732). Un sistema legal que incentive las denuncias sin responsabilizar al denunciante hará más factible escoger las alternativas bajo este sistema (sector formal). Sin embargo, este efecto es mucho menor que aquel asociado a "p». Así, los efectos marginales confirman que: (1) dicho efecto es débil, (2) las alternativas 1 y 4 absorben casi el mismo efecto, y (3) la alternativa 3 absorbe la mayor proporción. Estos resultados sugieren que los beneficios de escoger el sector formal se incrementan cuando hay la posibilidad de denunciar sin tener responsabilidad. Pero también indican que ese tipo de sistema legal no tiene impacto en la decisión de sobornar como tal.

Cabe mencionar que varios participantes expresaron su temor a sobornar aun cuando $h=1$, pues pensaban que "p» también aplicaba en este caso. Es decir, que, una vez concretado el soborno (detectado por un proceso de inspección en el que se aplica "p»), era posible denunciar al empresario. Esta lógica tiene mucho sentido y probablemente se da en la práctica. En cuyo caso, aunque es más atractivo el sector formal (pues potencialmente se puede obtener el permiso de inmediato sin costo), el acto de sobornar sigue siendo riesgoso. Puede ser necesario ahondar en este punto y especificar mejor las instrucciones del juego en futuras investigaciones. Por último, «W» parece no tener ningún impacto en la decisión de los empresarios.

A continuación, se presenta un test de Hausman para evaluar el cumplimiento de la IIA:

Tabla 6

Test de Hausman

\begin{tabular}{ccc}
\hline Category ommited vs. full model & chi2 & p >chi2 \\
\hline 1 & 10,431 & 0,236 \\
2 & 10,601 & 0,225 \\
3 & 5,856 & 0,663 \\
4 & 3,324 & 0,912 \\
\hline
\end{tabular}

Los resultados en la tabla 6 sugieren que, en todos los casos, la condición IIA se cumple, pues la hipótesis nula no puede ser rechazada. Sin embargo, como mencionan Chong \& Long (2007), el test de Hausman para probar la IIA suele tener problemas en muestras pequeñas e incluso en modelos bien especificados. En vista de que la condición IIA puede verse violada, a manera de complemento, se elaboró el siguiente modelo nested logit. 


\subsubsection{Modelo nested logit}

Mediante este modelo, se comparan las dos agrupaciones (A y B) propuestas anteriormente.

\section{Agrupación A:}

$$
\begin{aligned}
\text { choice }= & \delta_{0}+\delta_{1} * \text { prob }_{\text {final }}+\delta_{2} * h_{\text {real }} \\
& \text { sector }=\beta_{0}+\beta_{1} * \text { correctas } \\
& \text { alternativa }=\gamma_{0}+\gamma_{1} * w
\end{aligned}
$$

En la tabla 7, se observa que los resultados del modelo anterior se mantienen; solo cambia la magnitud del efecto de cada variable. En este caso, «prob_final» tiene un odds ratio de 17,33 vs. 25,39. Mientras que el sistema legal presenta un odds ratio casi idéntico al del caso anterior: 1,717 vs. 1,732; $y$, nuevamente, el salario parece no tener ningún impacto significativo.

En este caso, la variable "correctas" parece ser una determinante importante en la elección del sector. Así, los resultados sugieren que las personas más capaces son más propensas a escoger el sector formal. Lo cual debe motivar futuras investigaciones.

\section{Agrupación B:}

Se analizaron distintas especificaciones, pero en ningún caso se pudo rechazar la hipótesis nula de la prueba de Wald. Ello puede deberse a la potencial endogenidad de "p», dado que, en esta agrupación, la acción de sobornar es la más importante. Adicionalmente, como menciona Greene (2012), un problema al usar el modelo nested logit es que no hay ningún test para discriminar entre distintas agrupaciones/especificaciones del modelo.

Dadas las limitaciones de los modelos anteriores, a manera de complemento, se elaboraron las siguientes regresiones logit: 


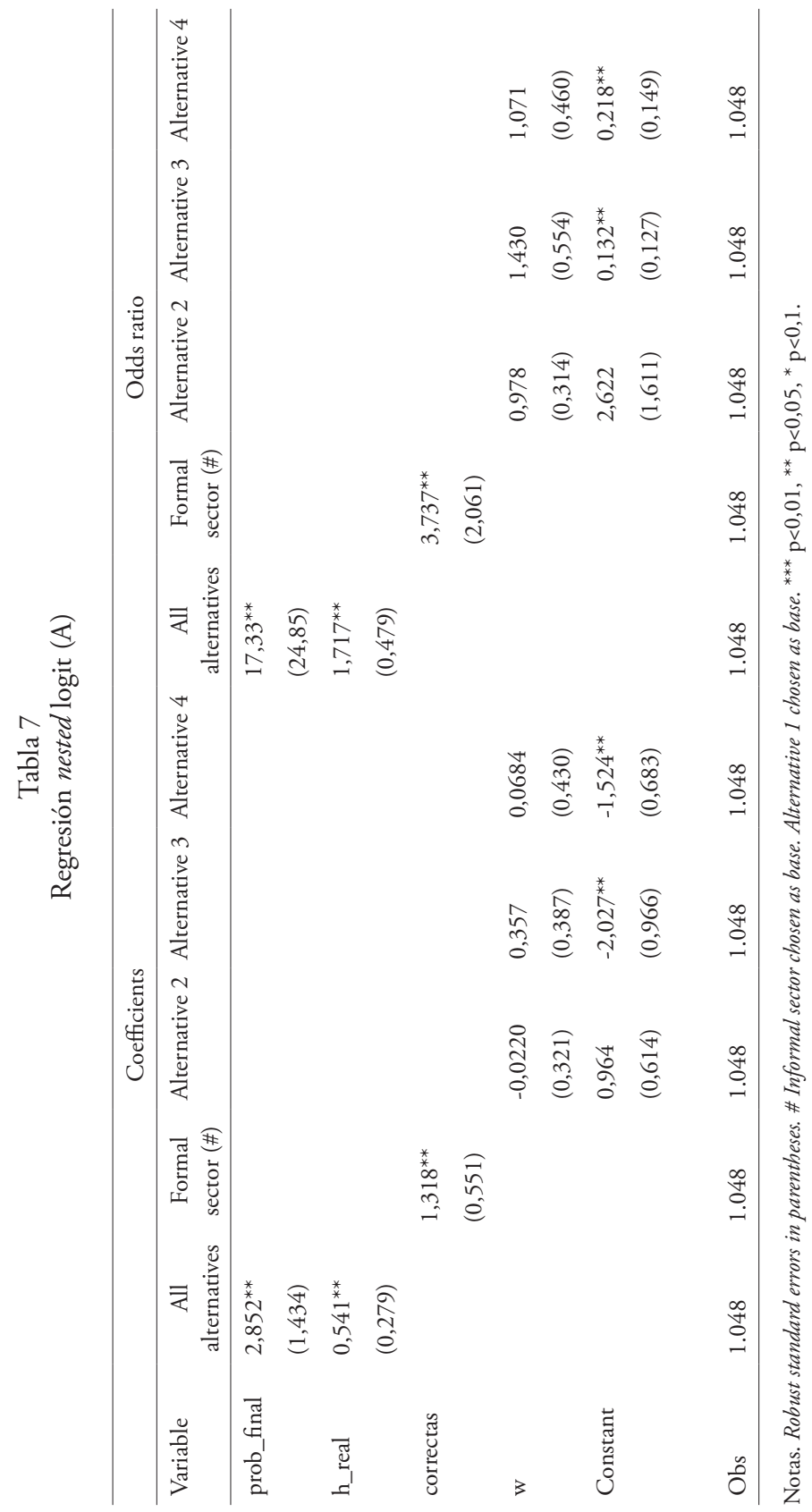




\subsubsection{Modelos logit}

\subsubsection{Selección del sector}

Dado que esta variable corresponde a la primera decisión que toman los empresarios, es factible analizar todas las variables independientes dentro de una misma ecuación sin restricciones:

$$
\begin{gathered}
\operatorname{Pr} .(\text { Formal })=\delta_{0}+\delta_{1} * p+\delta_{2} * h+\delta_{3} * p * h+\delta_{4} * w+\delta_{4} * \\
\text { correctas }+\varphi X+u_{i}
\end{gathered}
$$

Tabla 8

Logit - Probabilidad de ser formal

\begin{tabular}{lllll}
\hline Variables & \multicolumn{1}{c}{ Coefficient } & \multicolumn{1}{r}{ Mean } & Marginal effects & Odds ratio \\
\hline $\mathrm{p}$ & $0,0244^{* *}$ & 31,24 & $0,00506^{* *}$ & $1,025^{* *}$ \\
& $(0,0102)$ & $(20,71)$ & $(0,00210)$ & $(0,0105)$ \\
$\mathrm{h}$ & $1,384^{* *}$ & 0,496 & $0,281^{* *}$ & $3,989^{* *}$ \\
& $(0,606)$ & $(0,501)$ & $(0,116)$ & $(2,420)$ \\
$\mathrm{p}{ }^{* h}$ & $-0,0283$ & 15,65 & $-0,00587$ & 0,972 \\
& $(0,0174)$ & $(21,53)$ & $(0,00357)$ & $(0,0169)$ \\
$\mathrm{w}$ & 0,0271 & 0,500 & 0,00561 & 1,027 \\
& $(0,334)$ & $(0,501)$ & $(0,0692)$ & $(0,343)$ \\
correctas & $1,204^{* *}$ & 0,715 & $0,249^{* *}$ & $3,332^{* *}$ \\
& $(0,581)$ & $(0,248)$ & $(0,119)$ & $(1,936)$ \\
Constant & $-1,000^{* *}$ & & & $0,368^{* *}$ \\
& $(0,454)$ & & & $(0,167)$ \\
Observations & 262 & & & \\
Pseudo R2 & 0,0611 & & 0,707 & \\
Prob. (Formal) & & & & \\
\hline
\end{tabular}

Notas. Robust standard errors in parentheses. ${ }^{* * *} \mathrm{p}<0,01,{ }^{* *} \mathrm{p}<0,05,{ }^{*} \mathrm{p}<0,1$.

Con este modelo, se obtiene (tabla 8) que la probabilidad de escoger el sector formal es del 70,67\%; y que «p» incrementa la probabilidad de escoger este sector en un $0,51 \%$ por cada punto adicional al valor promedio de "p". Estos resultados confirman lo mencionado anteriormente, acerca de que la elección del sector es la decisión más importante y puede restar significancia a otras decisiones (como la de sobornar, en especial en el sector informal). 
Por otro lado, el sistema legal tiene potencialmente un importante efecto del $28,05 \%$, pues pasa del $54,82 \%$ cuando $h=0$ al $82,87 \%$ cuando $h=1$. Y la variable «correctas» tuvo un impacto significativo, lo que refuerza lo antes dicho.

\subsubsection{Probabilidad de sobornar}

Para analizar esta variable adecuadamente, hay que diferenciar entre la probabilidad de sobornar en el sector formal y tal probabilidad en el sector informal; considerando que, por ejemplo, los beneficios del sistema legal «h» solo aplican para el empresario formal.

$\operatorname{Pr} .($ Sobornar $\mid$ Formal $=1)=\beta_{f 0}+\beta_{f 1} * p+\beta_{f 2} * h+\beta_{f 3} * p * h+\beta_{f 4} * w$ $+\varphi X+e$

$\operatorname{Pr} .($ Sobornar $\mid$ Informal $=0)=\beta_{i 0}+\beta_{i 1} * p+\beta_{i 4} * w+\varphi X+e$

Tabla 9

Logit - Probabilidad de sobornar (sector formal)

\begin{tabular}{|c|c|c|c|c|}
\hline Variables & Coefficient & Mean & Marginal effects & Odds ratio \\
\hline \multirow[t]{2}{*}{$\mathrm{p}$} & $-0,0246^{* * *}$ & 32,91 & $-0,00575^{* * *}$ & $0,976^{* * *}$ \\
\hline & $(0,00757)$ & & $(0,00180)$ & $(0,00739)$ \\
\hline \multirow[t]{2}{*}{ hombre } & 0,657 & 0,522 & 0,152 & 1,928 \\
\hline & $(0,480)$ & & $(0,110)$ & $(0,925)$ \\
\hline \multirow[t]{2}{*}{ religioso } & 0,546 & 0,402 & 0,128 & 1,727 \\
\hline & $(0,467)$ & & $(0,111)$ & $(0,806)$ \\
\hline \multirow[t]{2}{*}{ economia } & 0,544 & 0,386 & 0,128 & 1,723 \\
\hline & $(0,528)$ & & $(0,125)$ & $(0,910)$ \\
\hline \multirow[t]{2}{*}{ admin } & $1,446^{* *}$ & 0,207 & $0,346^{* *}$ & $4,248^{* *}$ \\
\hline & $(0,622)$ & & $(0,140)$ & $(2,642)$ \\
\hline \multirow[t]{2}{*}{ negocios } & 1,143 & 0,0815 & $0,278^{*}$ & 3,135 \\
\hline & $(0,708)$ & & $(0,165)$ & $(2,220)$ \\
\hline \multirow[t]{2}{*}{ Constant } & $-0,883$ & & & 0,413 \\
\hline & $(0,546)$ & & & $(0,226)$ \\
\hline Observations & 184 & & & \\
\hline Pseudo R2 & 0,101 & & & \\
\hline $\begin{array}{l}\text { Prob. (Sobornar | } \\
\text { formal) }\end{array}$ & & & 0,370 & \\
\hline
\end{tabular}

Notas. Robust standard errors in parentheses. ${ }^{* * *} \mathrm{p}<0,01,{ }^{* *} \mathrm{p}<0,05,{ }^{*} \mathrm{p}<0,1$. 
Respecto a la probabilidad de sobornar en el sector formal, se observa (tabla 9) que la única variable de interés significativa es "p». Esta reduciría dicha probabilidad de sobornar en un $0,58 \%$ por cada punto adicional a la probabilidad promedio. Sobre las otras variables, resulta interesante que los estudiantes de administración parezcan más propensos a sobornar. Ahondar sobre ello escapa a los objetivos de esta investigación y puede ser materia de futuras investigaciones.

Por otro lado, se observa que las variables «h» $\mathrm{y}$ «w», la interacción «p.h» y «correctas» no aparecen en el modelo. Esto se debe a que, además de ser no significativas, prácticamente no incrementan el (pseudo) $\mathrm{R}^{2}$. Ello parece confirmar lo visto con los otros modelos, salvo para «correctas».

Tabla 10

Logit - Probabilidad de sobornar (sector informal)

\begin{tabular}{lllll}
\hline \multicolumn{1}{c}{ Variables } & \multicolumn{1}{c}{ Coefficent } & \multicolumn{1}{c}{ Mean } & Marginal effects & \multicolumn{1}{c}{ Odds ratio } \\
\hline $\mathrm{p}$ & $0,0478^{* * *}$ & 27,44 & $0,00792^{* * *}$ & $1,049^{* * *}$ \\
& $(0,0112)$ & & $(0,00194)$ & $(0,0118)$ \\
\multirow{2}{*}{ Constant } & $-2,638^{* * *}$ & & & $0,0715^{* * *}$ \\
& $(0,483)$ & & & $(0,0345)$
\end{tabular}

Observations $\quad 80$

Pseudo R2 $\quad 0,148$

Prob. (Sobornar |

Informal)

0,210

Notas. Robust standard errors in parentheses. ${ }^{* * *} \mathrm{p}<0,01,{ }^{* *} \mathrm{p}<0,05,{ }^{*} \mathrm{p}<0,1$.

Respecto a la probabilidad de sobornar en el sector informal, se obtienen resultados (tabla 10) extraños a primera vista: «p» sería la única variable significativa, pero su signo y efecto son contraintuitivos. Esto parece indicar lo antes mencionado respecto a la posible existencia de doble causalidad entre la variable independiente "p" y la probabilidad de sobornar.

Por otro lado, en este caso parece cobrar importancia la vida útil del proyecto. No es lo mismo que la actividad informal sea detectada al finalizar la primera pregunta (cuando la riqueza aún es pequeña) que al finalizar la sexta pregunta (cuando la riqueza es mayor). Se llevó a cabo una regresión incorporando «riqueza» y excluyendo "p», pero no se obtuvieron resultados robustos. 


\subsection{Análisis funcionarios}

Para el juego en rol de funcionario, no sorprende que las medidas de tendencia central indiquen que la aceptación de sobornos se incremente a mayores montos (tabla 11); y que la solicitud de sobornos aumente cuando el salario es bajo (tabla 12), como se verá luego:

Tabla 11

Aceptación de sobornos por tipo (fases 1 y 2)

\begin{tabular}{lcccc}
\hline $\begin{array}{c}\text { Número de } \\
\text { observaciones }\end{array}$ & $\begin{array}{c}\text { Monto bajo (4\% } \\
\text { salario) }\end{array}$ & $\begin{array}{c}\text { Monto medio } \\
(14 \% \text { salario })\end{array}$ & $\begin{array}{c}\text { Monto alto } \\
(44 \% \text { salario })\end{array}$ & $\begin{array}{c}\text { Monto muy alto } \\
\text { (88\% salario) }\end{array}$ \\
\hline Aceptó & 52 & 77 & 102 & 138 \\
Rechazó & 315 & 292 & 263 & 228 \\
\hline
\end{tabular}

Tabla 12

Acercamiento para solicitar un soborno (fase 2)

\begin{tabular}{lcc}
\hline & Número de observaciones & Monto promedio solicitado (\% salario) \\
\hline Se acercó & 107 & $58 \%$ \\
No se acercó & 234 & \\
\hline
\end{tabular}

\subsubsection{Probabilidad de aceptar un soborno}

$$
\begin{gathered}
\operatorname{Pr} .(\text { Aceptar })=\delta_{0}+\delta_{1} * \text { monto }+\delta_{2} * p+\delta_{3} * p * h+\delta_{4} * h+\delta_{5} * w \\
+\varphi X+u
\end{gathered}
$$

Tabla 13

Logit - Probabilidad de aceptar un soborno

\begin{tabular}{lllll}
\hline Variables & \multicolumn{1}{c}{ Coefficient } & \multicolumn{1}{c}{ Mean } & Marginal effects & \multicolumn{1}{c}{ Odds ratio } \\
\hline monto & $0,495^{* * *}$ & 5,921 & $0,0807^{* * *}$ & $1,640^{* * *}$ \\
& $(0,0946)$ & $(1,179)$ & $(0,0148)$ & $(0,155)$ \\
$\mathrm{p}$ & $-0,0333^{* * *}$ & 28,93 & $-0,00544^{* * *}$ & $0,967^{* * *}$ \\
& $(0,00489)$ & $(20,41)$ & $(0,000861)$ & $(0,00473)$ \\
$\mathrm{h}$ & $-2,443^{* * *}$ & 0,223 & $-0,271^{* * *}$ & $0,0869^{* * *}$ \\
& $(0,383)$ & $(0,416)$ & $(0,0369)$ & $(0,0332)$ \\
$\mathrm{p}^{* \mathrm{~h}}$ & $0,0267^{* *}$ & 6,619 & $0,00435^{* *}$ & $1,027^{* *}$ \\
\hline
\end{tabular}




\begin{tabular}{|c|c|c|c|c|}
\hline Variables & Coefficient & Mean & Marginal effects & Odds ratio \\
\hline & $(0,0104)$ & $(15,78)$ & $(0,00178)$ & $(0,0107)$ \\
\hline \multirow[t]{2}{*}{$\mathrm{w}$} & 0,246 & 0,498 & 0,0402 & 1,279 \\
\hline & $(0,173)$ & $(0,500)$ & $(0,0284)$ & $(0,221)$ \\
\hline \multirow[t]{2}{*}{ Ln (num_soborno) } & $-0,333^{* *}$ & 1,255 & $-0,0544^{* *}$ & $0,717^{* *}$ \\
\hline & $(0,138)$ & $(0,795)$ & $(0,0237)$ & $(0,0991)$ \\
\hline \multirow[t]{2}{*}{ percepcion } & $-0,159^{*}$ & 8,458 & $-0,0259^{*}$ & $0,853^{*}$ \\
\hline & $(0,0949)$ & $(1,159)$ & $(0,0152)$ & $(0,0810)$ \\
\hline \multirow[t]{2}{*}{ formal } & 0,247 & 0,628 & 0,0395 & 1,280 \\
\hline & $(0,253)$ & $(0,484)$ & $(0,0395)$ & $(0,324)$ \\
\hline \multirow[t]{2}{*}{ Constant } & $-1,466$ & & & 0,231 \\
\hline & $(0,983)$ & & & $(0,227)$ \\
\hline Observations & 1.445 & & & \\
\hline Pseudo R2 & 0,142 & & & \\
\hline Prob. (Aceptar) & & & 0,205 & \\
\hline
\end{tabular}

Notas. Robust standard errors in parentheses. ${ }^{* * *} \mathrm{p}<0,01,{ }^{* *} \mathrm{p}<0,05,{ }^{*} \mathrm{p}<0,1$.

Los resultados para este caso (tabla 13) indican que la probabilidad de aceptar un soborno es del 20,5\%. También confirman lo encontrado en el juego empresarios, respecto a que "p» es significativa y reduce la probabilidad de aceptar un soborno en un $0,55 \%$ por cada punto adicional al valor promedio de «p». E indican que el sistema legal reduce dicha probabilidad en un $28,75 \%{ }^{7}$, pues pasa de un $32,82 \%$ cuando $h=0$ a un $4,07 \%$ cuando $h=1$. En este caso, como se muestra en la figura 4, la interacción entre "p" $y$ «h» no tiene un impacto significativo. Esto resulta lógico, pues, para el funcionario, ambas variables lo perjudican, y sugiere que se pueden aplicar las dos medidas en simultáneo sin perder eficiencia.

Adicionalmente, se observa que en este caso "W» tampoco tiene un efecto significativo para los funcionarios. Por otro lado, observamos que, conforme el juego va avanzando (número de soborno), se va reduciendo la probabilidad de aceptar un soborno. Probablemente porque los funcionarios van acumulando riqueza y tienen miedo de perderla (aversión al riesgo).

\footnotetext{
${ }^{7}$ Para este caso, se controló por si el soborno vino del sector formal o informal, pues el sistema legal solo impacta cuando se trata del sector formal.
} 
Figura 4

Interacción «p.h».

z-statistics of interaction Effects after Logit

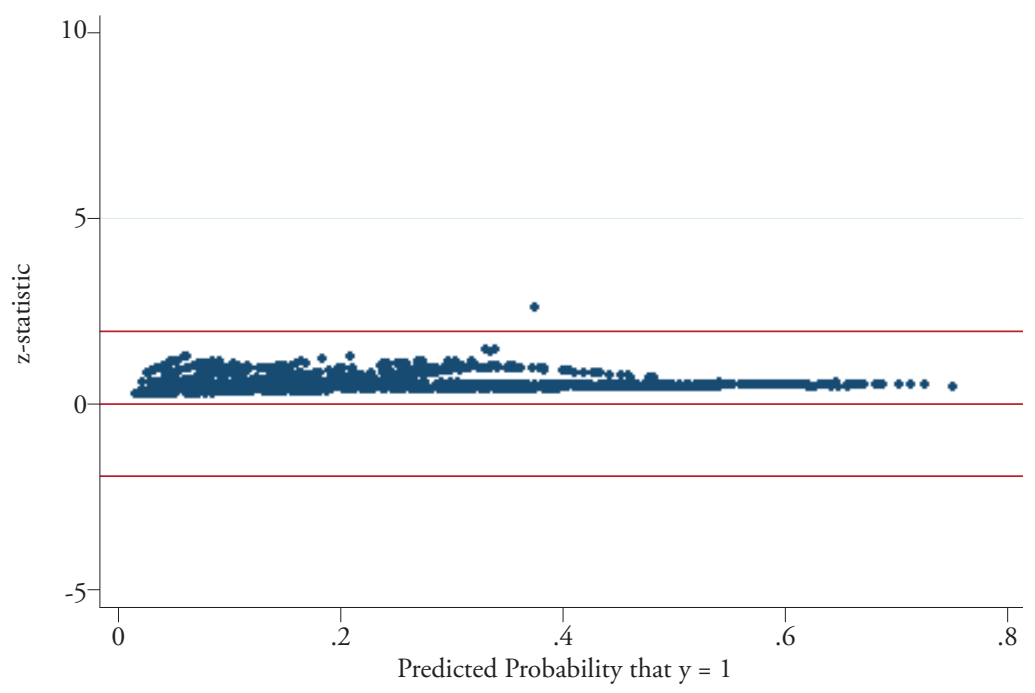

\subsubsection{Probabilidad de solicitar un soborno}

$\operatorname{Pr} .($ solicitar $)=\delta_{0}+\delta_{1} * p+\delta_{2} * p * h+\delta_{3} * h+\delta_{4} * w+\varphi X+u$

Tabla 14

Logit - Probabilidad de solicitar un soborno

\begin{tabular}{lllll}
\hline Variables & \multicolumn{1}{c}{ Coefficient } & \multicolumn{1}{c}{ Mean } & Marginal effects & \multicolumn{1}{c}{ Odds ratio } \\
\hline $\mathrm{p}$ & $-0,0233^{* * *}$ & 28,85 & $-0,00473^{* * *}$ & $0,977^{* * *}$ \\
& $(0,00809)$ & $(20,26)$ & $(0,00168)$ & $(0,00791)$ \\
$\mathrm{h}$ & $-0,955$ & 0,224 & $-0,170^{*}$ & 0,385 \\
& $(0,607)$ & $(0,417)$ & $(0,0953)$ & $(0,234)$ \\
$\mathrm{f}$ & $-0,0126$ & 6,284 & $-0,00255 \#$ & 0,988 \\
& $(0,0200)$ & $(15,01)$ & $(0,00404)$ & $(0,0198)$ \\
$\mathrm{w}$ & $-0,668^{* *}$ & 0,478 & $-0,134^{* *}$ & $0,513^{* *}$ \\
& $(0,275)$ & $(0,500)$ & $(0,0535)$ & $(0,141)$ \\
\hline
\end{tabular}




\begin{tabular}{lllll}
\hline Variables & \multicolumn{1}{c}{ Coefficient } & \multicolumn{1}{c}{ Mean } & Marginal effects & \multicolumn{1}{c}{ Odds ratio } \\
\hline Ln (num_soborno) & $-5,097^{* * *}$ & 1,694 & $-1,034^{* * *}$ & $0,00612^{* * *}$ \\
& $(1,227)$ & $(0,0911)$ & $(0,250)$ & $(0,00751)$ \\
percepcion & $-0,299^{* *}$ & 8,493 & $-0,0606^{* *}$ & $0,742^{* *}$ \\
& $(0,141)$ & $(1,129)$ & $(0,0283)$ & $(0,105)$ \\
Constant & $11,53^{* * *}$ & & & $101,372^{* * *}$ \\
& $(2,431)$ & & & $(246,441)$ \\
& & & & \\
Observations & 335 & & & \\
Pseudo R2 & 0,124 & & & \\
Prob. (solicitar) & & & & \\
\hline
\end{tabular}

Notas. Robust standard errors in parentheses. ${ }^{* * *} \mathrm{p}<0,01,{ }^{* *} \mathrm{p}<0,05,{ }^{*} \mathrm{p}<0,1$.

Los resultados (tabla 14) indican que la probabilidad de solicitar un soborno es del 28,3\%; que "p» es significativa y reduce dicha probabilidad en un $0,47 \%$ por cada punto adicional al valor promedio de "p»; y que el sistema legal resulta significativo con un nivel de confianza del $90 \%$ y su efecto es del $17,01 \%$, pues pasa de un $32,84 \%$ cuando $h=0$ a un $15,83 \%$ cuando $h=1$. Los efectos algo pequeńos de ambas variables pueden deberse a que los participantes están compensando ambos efectos con el monto solicitado por ellos.

Además, «W» sí parece tener un impacto en la probabilidad de solicitar un soborno: cuando el salario era bajo, los participantes estaban más dispuestos a solicitarlo, pues su costo de oportunidad era menor. El efecto es del 13,42\%, pues pasa de un $35,20 \%$ cuando $w=0$ a un $21,78 \%$ cuando $w=1$. Por último, se observa que solicitar un segundo soborno es menos probable. Quizás por aversión al riesgo o porque en varios casos el primer intento fue rechazado por los empresarios ${ }^{8}$.

\section{Recomendaciones}

Al proponer políticas públicas hay que considerar que el Estado tiene recursos limitados y, por ende, hay que aplicar las estrategias más eficientes. En términos generales, las políticas de lucha anticorrupción suelen enfocarse en

\footnotetext{
${ }^{8}$ Se debe recordar que la simulación del empresario hace un análisis costo-beneficio (inducción hacia atrás) para determinar si acepta el monto solicitado; si el monto es muy alto, hay rechazo.
} 
la gran corrupción y dejan de lado la pequeña corrupción, pues la primera (1) involucra a altos mandos y (2) involucra montos considerables que suelen dejar rastro (Presidencia del Consejo de Ministros, 2012).

Según su enfoque, las estrategias anticorrupción pueden ser de dos tipos: (1) estrategias con enfoque preventivo: buscan evitar que los actos de corrupción sean cometidos (ex ante); y/o (2) estrategias con enfoque combativo: buscan castigar a los actores de la corrupción (ex post). Para luchar eficientemente contra la corrupción, se requiere de un conjunto de estrategias con enfoques diferentes. Sin embargo, la pequeña corrupción suele combatirse con estrategias preventivas, porque es una práctica extendida en diversas instituciones y no siempre deja rastros identificables (Presidencia del Consejo de Ministros, 2012; Mujica \& Arbizu, 2015).

Teniendo en cuenta que los resultados econométricos de esta investigación indican que la probabilidad de detección y el tipo de sistema legal tienen un impacto importante en la mayoría de las variables dependientes analizadas, a continuación proponemos dos políticas focalizadas y dos políticas generales; pues, como se mencionará más adelante, las medidas focalizadas suelen tener diversas falencias.

La primera propuesta focalizada es realizar un cambio en el sistema legal para que no se impute responsabilidad al emisor de un soborno de acoso. El actual sistema legal peruano tipifica los sobornos como delitos en las secciones II y IV del Código Penal, y específicamente en los delitos de cohecho pasivo, cohecho activo y de concusión. El cohecho pasivo y la concusión se aplican a funcionarios públicos (receptor) y el cohecho activo, a cualquier ciudadano (emisor). Adicionalmente, de acuerdo con el Código Penal, todos estos delitos tienen como consecuencia dos sanciones: pena privativa de la libertad y multas monetarias; ambas partes de la transacción son castigadas (Minjus, 2016).

Ante ello, debería formularse un proyecto de ley que modifique los artículos relacionados con el cohecho activo (que alude al emisor), para que este no tenga responsabilidad penal ni multas monetarias cuando se trata de un soborno de acoso (relacionado principalmente con el delito de concusión). Esto debería ser complementado con un reglamento que regule el debido proceso, a fin de que el ciudadano tenga incentivos para denunciar, obtenga protección ex post y pueda recibir el reembolso del soborno emitido. Sin embargo, se requiere de análisis más detallados para resolver las disyuntivas que plantea la implementación de una medida así. 
Una primera disyuntiva surge al preguntarse si es eficiente llevar a cabo una investigación detallada, emitir una sentencia y utilizar el erario público por un soborno de 1.000 soles que pagó un microempresario para acelerar la obtención de un permiso. Pero también hay que considerar que un sistema legal de esta envergadura podría ser una amenaza creíble por parte del Estado contra este tipo de sobornos, lo que generaría un efecto preventivo (beneficio adicional intangible). Adicionalmente, se puede proponer que el funcionario sentenciado pague una indemnización (adicional a la multa) para cubrir los gastos de esta medida.

Por otro lado, se enfrenta el costo de crear y efectuar el cambio en el Código Penal. Emitir una ley requiere de estudios técnicos y de cumplir con los procesos congresales. Sin embargo, como menciona Privat (2017), estos costos ya se encuentran pagados mediante los gastos y salarios de las instituciones competentes, cuyos presupuestos incluyen el fondeo de un numero "X» de leyes, que pueden incluir la creación de una ley como la propuesta aquí, la cual podría ser priorizada sin poner en riesgo la creación o el cumplimiento de otras leyes relevantes.

Sin embargo, hay otro tipo de efectos que pueden incrementar los costos o mitigar los potenciales beneficios de la propuesta. En primera instancia, como mencionan Abbink et al. (2013), si bien la modificación legal propuesta busca cortar la relación de complicidad entre ambas partes, cuando el funcionario y el empresario deben interactuar varias veces - porque hay varios pasos dentro del trámite o hay renovaciones-, los incentivos para denunciar disminuyen de manera significativa, pues los funcionarios, o sus conocidos, tienen la posibilidad de tomar represalias. Otros riesgos incluyen: que la nueva ley no se ejecute correctamente; que el sistema de denuncias sea deficiente; entre otros.

La segunda propuesta focalizada se refiere a mejorar la probabilidad de detectar un soborno. Actualmente, la fiscalización y detección de transacciones de soborno es relativamente pobre, y es sabido que el Estado no tiene capacidad para revisar todas las transacciones (Mujica, 2017). Para revertir esto, se propone incrementar el presupuesto público de las entidades encargadas de la fiscalización. Este presupuesto puede ser utilizado para contratar a especialistas con mayor experiencia y pericia técnica. Esta medida, sin embargo, puede ser costosa. Adicionalmente, se pueden fortalecer los mecanismos de supervisión y control de las instituciones competentes. Para esto, se puede profundizar la transparencia y la publicación constante de indicadores, lo que incrementaría la rendición de cuentas y, por ende, la detección de transacciones fraudulentas por parte de esas instituciones (OECD, 2016). Por último, se deben establecer 
incentivos para que haya motivación a la hora de fiscalizar; es decir, se deben otorgar «dientes» a las áreas encargadas de la fiscalización. Obviamente, estas áreas deben estar reguladas por competencias y roles explícitos para evitar denuncias sin sustento (Bustamante, 2016).

Una pregunta que nos debemos hacer es si al atacar los sobornos en funcionarios de bajo mando no se estarán incrementando otro tipo de delitos como el tráfico de influencias, el chantaje, entre otros (efecto globo). Dentro del fenómeno de la corrupción existen nodos y conexiones en red que pueden modificar la composición del fenómeno y, por ende, reducir la eficacia de medidas focalizadas. En consecuencia, las políticas públicas más adecuadas para reducir el espectro de la pequeña corrupción serán aquellas que incentiven el desarrollo y la estabilidad de las instituciones; de manera específica, aquellas que aumenten la eficacia de los servicios públicos (Mujica, 2017).

En este sentido, y como primera medida general, se proponen estrategias que permitan mejorar los servicios brindados y reducir las ventanas para la corrupción. En primera instancia, se debería profundizar la simplificación administrativa en todas las instituciones del país que ofrecen servicios a las empresas y ciudadanos. Como mencionan Yamada \& Montero (2011), la teoría económica nos dice que, a mayor número de fases dentro de un procedimiento institucional (y mientras más discrecionalidad exista en ellas), mayores serán los riesgos y fuentes de la corrupción. Dichos autores también recomiendan incentivar el uso de mecanismos virtuales -como pagos e información en línea- para reducir el contacto directo entre funcionarios y ciudadanos.

Como segunda medida general, se recomienda incentivar a las empresas privadas e instituciones públicas (incluyendo municipalidades, ministerios, comisarías y empresas de servicios públicos) a que incorporen un estándar internacional como el ISO 37001. Este estándar, publicado en octubre de 2016, es la primera certificación global que establece una serie de requerimientos y procesos para implementar, mantener y mejorar un sistema de gestión antisoborno. Es específico para los sobornos, pero aplicable a cualquier tipo de organización, independientemente de su naturaleza, funcionamiento, tamaño, rubro, entre otros. Además, la organización puede optar por extender el alcance del sistema de gestión para incluir actividades relacionadas como el fraude, el tráfico de influencias, entre otras; lo que reduce el potencial efecto globo (International Organization for Standardization, 2016). Los costos asociados a esta medida serían relativamente bajos y su adopción sería relativamente sencilla, ya que existen requisitos claros y asesoramiento continuo. 


\section{Conclusiones}

Aunque la corrupción es un fenómeno sumamente amplio y multifacético, la investigación explicada en este ensayo logró implementar una metodología experimental capaz de dar luces sobre el fenómeno y cómo combatirlo. En particular, se comprobó que tanto la probabilidad de detección como el tipo de sistema legal son variables importantes para reducir la probabilidad de aceptar, ofrecer o solicitar un soborno. Ambas variables también parecen reducir la probabilidad de escoger el sector informal.

A la luz de estos resultados, se han planteado medidas de políticas focalizadas para su aplicación en la realidad peruana, junto con los principales costos y trabas que podrían mitigar los beneficios de las medidas. Adicionalmente, se han propuesto medidas más generales que busquen mejoras continuas en los procesos y competencias institucionales.

Sorpresivamente, la investigación indica que, al parecer, el salario del funcionario público solo tiene un impacto significativo en la probabilidad de que solicite un soborno, por lo que aplicar medidas al respecto sería muy adecuado en procesos institucionales que den cabida a que el funcionario público sea el principal motivador de una transacción de soborno.

Por otro lado, los resultados sugieren algunos temas que ameritan más investigación: (1) la interacción o efecto cruzado que podrían presentar la probabilidad de detección con el tipo de sistema legal; (2) los mecanismos de transmisión que incrementen el impacto de los métodos antisoborno en el comportamiento de los individuos. Una hipótesis al respecto es que la aversión al riesgo puede ser el mecanismo que motive a un individuo a tomar la decisión de sector y de soborno. Como se pudo observar para el caso de los empresarios, la probabilidad de llegar al final del juego evidenciaba esta aversión al riesgo; y algo similar ocurre con los funcionarios, que eran más reacios a aceptar un soborno a medida que el juego avanzaba; y (3) la relación entre las capacidades del empresario con la elección del sector. Los resultados de la variable «correctas» sugieren que las ineficiencias del sector informal no responden exclusivamente a variables internas del sector, sino también a las características de quienes escogen el sector.

Como es natural, la investigación adolece de algunas limitaciones. En primer lugar, al tratarse de un diseño experimental en el que los roles fueron asumidos por estudiantes, la validez externa de la investigación es discutible. Se requeriría que esta investigación fuera continuada y probada en un experimento de campo. Adicionalmente, la base de datos asociada a los empresarios es relativamente pequeńa, lo que responde a limitaciones de presupuesto. De 
hecho, un procedimiento aplicado para obtener un mayor número de observaciones fue que cada individuo jugara tres veces, con la consiguiente desventaja de que los participantes puedan avezarse y condicionen su comportamiento. Aun así, se obtuvieron resultados robustos.

Por último, no está de más recordar que los cambios de políticas dependen de la voluntad política de políticos y gobernantes de turno. La lucha contra la corrupción ha sido deficiente porque la corrupción está arraigada en el sistema y es utilizada por los mismos hacedores de políticas (Bustamante, 2016). Durante las últimas décadas, han existido planes de lucha contra la corrupción con propuestas técnicas y completas, pero poco o nada aplicadas. Sin embargo, la coyuntura actual, convulsionada por escándalos como el de Odebrecht, ha servido para centrar el debate nuevamente en la lucha anticorrupción. En este sentido, es clave que las propuestas de política busquen fortalecer el entorno institucional, pues, como menciona Tanaka (2005), la conducta corrupta está moldeada por incentivos corregibles mediante políticas públicas.

\section{Referencias}

Abbink, K., Dasgupta, U., Gangadharan, L., \& Jain, T. (2013). Letting the briber go free: An experiment on mitigating harassment bribes. Journal of Public Economics, $111(\mathrm{C}), 17-28$.

Abbink, K., \& Henning-Schimdt, H. (2006). Neutral versus loaded instructions. Experimental Economics, 9(2), 103-121.

Abbink, K., Irlenbusch, B., \& Renner, E. (2002). An experimental bribery game. Journal of Law, Economics, \& Organization, 18(2), 428-454.

Abbink, K., \& Serra, D. (2012). Anti-corruption policies: Lessons from the lab. En D. Serra \& L. Wantchekon (Eds.), New advances in experimental research on corruption - Research in experimental economics (volume 15) (pp. 77-115).

Banco Mundial. (2010). Enterprise surveys. Recuperado de http://espanol.enterprisesurveys. org/data/exploreeconomies/2010/peru

Basu, K. (2011). Why, for a class of bribes, the act of giving a bribe should be treated as legal. Ministry of Finance Government of India Working Paper 1/2011.

Berninghaus, S., Haller, S., Kruger, T., Neumann, T., Schosser, S., \& Vogt, B. (2013). Risk attitude, beliefs, and information in a corruption game - An experimental analysis. Journal of Economic Psychology, 34(C), 46-60.

Bjørnskov, C. (2011). Combating corruption: On the interplay between institutional quality and social trust. The Journal of Law \& Economics, 54(1), 135-159.

Bobkova, N., \& Egbert, H. (2012). Corruption investigated in the lab: A survey of the experimental literature. International Journal of Latest Trends in Finance, Economics and Science, 2(4), 337-349. 
Boly, A. (2009). On the external validity of laboratory experiments. Montreal: Université de Montréal.

Bustamante, R. (Mayo de 2016). Abogado y profesor de la Universidad del Pacífico. (R. Arfinengo, entrevistador).

Chong, S., \& Long, J. S. (2007). Testing for IIA in the multinomial logit. Sociological Methods \& Research, 35(4), 583-600.

Cooper, C., McCord, D., \& Socha, A. (2011). Evaluating the sophomore college problem: The case of personality and politics. The Journal of Psychology, 145(1), 23-37.

Del Castillo, A. (2001). El soborno: un marco conceptual para su análisis. Gestión y Politica Pública, X(2), 275-307. México D. F.: Centro de Investigación y Docencia Económica. Recuperado de http://www.gestionypoliticapublica.cide.edu/num_anteriores/ Vol.X_No.II_2dosem/EL\%20SOBORNO.pdf

Engel, C., Goerg, S. J., \& Yu, G. (2012). Symmetric vs. asymmetric punishment regimes for bribery. Max PIanck Institute for Research on Collective Goods Preprint, 2012/1, 37.

Fischbacher, U. (2007). z-Tree: Zurich toolbox for ready-made economic experiments. Experimental Economics, 10(2), 171-178.

Friedman, E., Johnson, S., Kaufmann, D., \& Zoido-Lobaton, P. (2000). Dodging the grabbing hand: The determinants of unofficial activity in 69 countries. Journal of Public Economics, 76(3), 459-493.

Greene, W. H. (2012). Econometric analysis (7. a ed.). Nueva Jersey: Pearson Education. Huntington, S. (1968). Political order in changing societies. Londres: Yale University Press. International Organization for Standardization. (2016). ISO 37001 - Anti bribery management systems. Ginebra. Recuperado de https:/www.iso.org/standard/65034.html

Leff, N. (1964). Economic development through bureaucratic corruption. American Behavioral Scientist, 8(3), 8-14.

Mauro, P. (1995). Corruption and growth. The Quarterly Journal of Economics, 110(3), 681-712.

Méon, P.-G., \& Sekkat, K. (2005). Does corruption grease or sand the wheels of growth? Public Choice, 122(1), 69-97.

Minjus (Ministerio de Justicia y Derechos Humanos). (2016). Código penal peruano (12. ${ }^{\mathrm{a}}$ ed). Lima: Ministerio de Justicia y Derechos Humanos.

Mishra, A., \& Ray, R. (2013). Informality and corruption. Bath Papers in International Development and Wellbeing, 21. Reino Unido: University of Bath - Centre for Development.

Mujica, J. (Junio de 2017). Investigador del Laboratorio de Criminología Social de la PUCP. (R. Arfinengo, entrevistador).

Mujica, J., \& Arbizu, J. (2015). Iniciativas anticorrupción en espacios regionales del Perú: diagnóstico y recomendaciones generales. Lima: Consorcio de Investigación Económica y Social.

OECD (Organisation for Economic Co-operation and Development). (2016). Preventing corruption in public procurement. Ginebra: OECD. 
OIT (Organización Internacional del Trabajo). (2015). Economía informal en América Latina y el Caribe. Lima. Recuperado de http://www.ilo.org/americas/temas/ econom\%C3\%ADa-informal/lang--es/index.htm

PCM (Presidencia del Consejo de Ministros). (2012). Plan Nacional de Lucha contra la Corrupcion 2012-2016. Lima: PCM.

Privat, M. (Mayo de 2017). Asesor legal en Sumopp. (R. Arfinengo, entrevistador).

Rijckeghem, C. V., \& Weder, B. (2001). Bureaucratic corruption and the rate of temptation: Do wages in the civil service affect corruption, and by how much? Journal of Development Economics, 65(2), 307-331.

Sears, D. (1986). College sophomores in the laboratory: Influences of a narrow data base on social psychology's view of human nature. Journal of Personality and Social Psychology, 53(3), 515-530.

Tanaka, M. (2005). La estructura de oportunidad política de la corrupción en el Perú: algunas hipótesis de trabajo. En F. Portocarrero (Ed.), El pacto infame (pp. $355-$ 375). Lima: Universidad del Pacífico.

Train, K. (2002). Discrete choice methods with simulations. University of California at Berkeley, Cambridge University Press.

Tramontana, R. (6 de febrero de 2015). INEI: Informalidad afecta al 75\% de la PEA. Perú 21. Recuperado de http://peru21.pe/economia/inei-informalidad-afectaal-75-pea-2211258

Transparency International. (2016). What is corruption? Recuperado de https://www. transparency.org/what-is-corruption/

Vega, E. (6 de junio de 2016). Corrupcion hace perder al Perú unos 33,800 millones al año. El Comercio. Recuperado de http://elcomercio.pe/economia/dia-1/corrupcionhace-perder-al-peru-s33800-millones-al-ano-noticia-1907067

Vogl, F. (14 de octubre de 2015). Anti-corruption advocate, Frank Vogl, urges bank leaders to initiate cultural changes. En Felaban Annual Assembly. Recuperado de http:// asambleaanual.net/anti-corruption-advocate-frank-vogl-urges-bank-leaders-toinitiate-cultural-changes/

Yamada, G., \& Montero, R. (2011). Corrupción e inequidad en los servicios públicos en el Perú. Lima: Universidad del Pacífico \& Consorcio de Investigación Económica y Social. 



\section{Interpolación del área distorsionada por el cambio de impuesto marginal entre el Régimen General y el Régimen Especial en la distribución de conjunta de contribuyentes}

Mariano Fuster de Bracamonte

Alonso Takamure Guibu

\section{Introducción}

El objetivo de esta investigación es brindar información cuantitativa a la Sunat y al Ministerio de Economía y Finanzas sobre la eficiencia del sistema tributario en incentivar la transición de empresas desde el Régimen Especial hacia el Régimen General. En específico, busca sustentar la necesidad de una reestructuración tributaria aplicando la metodología de bunching propuesta por Chetty, Friedman, Olsen \& Pistaferri (2011) a datos provistos por la Sunat. Para ello, nuestra metodología consiste en modelar la función contrafactual, que describe cómo sería el comportamiento de las empresas si no hubiese un cambio de impuesto en determinado nivel de ingreso, y luego, por diferencia entre esta y la función empírica, estimar la distorsión que genera el esquema tributario.

La literatura especializada enseña que la presencia de umbrales y otras no linealidades en los esquemas impositivos afecta el comportamiento de los agentes, causa distorsiones en el mercado y disminuye la recaudación potencial. Pero la evidencia al respecto se concentra en países desarrollados, donde el incentivo para evadir es menor, dado que la probabilidad de ser atrapado

\footnotetext{
${ }^{1}$ Este ensayo es una versión resumida y editada del Trabajo de Investigación Económica que, con el mismo título, fue concluido en noviembre de 2017. Sus autores agradecen al profesor Diego Bohórquez Morote por su asesoría, así como a Carlos Gallardo Torres por su apoyo y al equipo de la Sunat que proporcionó los datos.
} 
evadiendo impuestos es mayor y las consecuencias penales son más drásticas. Incluso en esos países, la fiscalización tributaria enfrenta desafíos cuando trata con grupos específicos de contribuyentes, como los trabajadores independientes ${ }^{2}$. No sorprende, entonces, que la situación en países en desarrollo sea aún más compleja.

La recaudación tributaria peruana no ha progresado significativamente. A diferencia del Perú, Ecuador y Bolivia han logrado resultados importantes en materia tributaria: han alcanzado niveles de presión tributaria del $21 \%$ y el $24,7 \%$ respectivamente (véase el anexo 1). Según cifras de la OCDE (OECD, 2017), en el año 2015, el Perú estaba en el puesto 21 en nivel de presión tributaria ${ }^{3}$, con un $17,1 \%$, muy por debajo del promedio de Latinoamérica y el Caribe $(22,8 \%)$ y de los países de la OCDE (34,3\%) (véase el anexo 2).

\section{Revisión de literatura especializada}

Sáez (2010) introdujo la metodología de bunching en un estudio sobre la función de distribución de ingresos en los Estados Unidos sujetos al régimen Earned Income Tax Credit (EITC), un impuesto escalonado en función del ingreso familiar y el número de hijos. El autor halló una acumulación significativa de contribuyentes en el nivel de ingreso límite del primer tramo para el régimen, durante el período comprendido entre 1995 y 2004. Por esta razón, desarrolló un modelo en el que estima el tamaño de la distorsión que genera el impuesto por tramos, en el cual espera que los contribuyentes con ingresos mayores, pero cercanos al umbral de ingresos, a quienes llama marginal bunchers, declaren un ingreso menor que el real para acogerse al beneficio tributario. Su investigación calcula la función de densidad con ausencia de bunching mediante una interpolación lineal. Luego, por diferencia de áreas con la función de densidad empírica, encuentra la distorsión generada por el impuesto. Además, estima la elasticidad-ingreso a partir de ambas funciones de densidad. Sáez encontró que las elasticidades eran significativas en el primer umbral para los autoempleados y no significantes (aunque cercanas a cero) para asalariados. Pero no dejó claro si los asalariados no se acumulan porque no reaccionan ante los incentivos marginales del EITC, o no son capaces de manipular su declaración de ingresos porque las horas trabajadas son determinadas por el empleador.

$\mathrm{Al}$ año siguiente, Chetty et al. (2011) utilizaron una muestra de empleados y empleadores en Dinamarca entre 1994 y 2001. El estudio argumenta

\footnotetext{
${ }^{2}$ Los trabajadores independientes pueden manipular sus ingresos con mayor facilidad.

${ }^{3}$ Porcentaje del PIB recaudado por el Estado en impuestos.
} 
que la distorsión del modelo de Sáez está sobredimensionada porque utiliza una extrapolación lineal. Por ello, proponen una nueva metodología con dos cambios fundamentales. El primero es estimar la función sin bunching con un polinomio de grado flexible, que estima una elasticidad menor que la del modelo de Sáez. El segundo es ajustar la estimación para que el área interpolada tenga la misma cantidad de contribuyentes que la función empírica.

Motivados por esos resultados, otros autores han aplicado la metodología a países europeos. Por ejemplo, Devereux, Liu \& Loretz (2012) calcularon la elasticidad y la distorsión del mercado para impuestos corporativos del Reino Unido entre 2001 y 2008. Encontraron que la elasticidad en el primer umbral de ingresos, entre 0,54 y 0,57, es la mayor de todas. Esta evidencia es similar a la hallada por Sáez (2010), en la que el bunching se da en el primer tramo del EITC para los regímenes de un hijo y más de un hijo. Bastani \& Selin (2014) aplicaron el modelo a registros suecos entre 1991 y 2002 para estimar la elasticidad-ingreso y, al igual que Sáez, hallan evidencia empírica de elasticidades significativas para autoempleados y no significativas para asalariados.

Para el caso peruano, y con información a 2011, Al-Karablieh \& Gallardo (2014) aplicaron bunching por histogramas a personas naturales, pero no encontraron evidencia gráfica clara de bunching. Más aún, cuando distinguieron los grupos de empleados y autoempleados, tampoco encontraron evidencia significativa de bunching. Sin embargo, su estudio observó que la distribución luego del segundo punto de quiebre es inusualmente plana, y que el número de contribuyentes se reduce drásticamente en el nivel de 7 UIT $^{4}$.

\section{Marco analítico}

El Perú enfrenta serios problemas de evasión tributaria. Según el INEI (2017), la participación del sector informal en el PIB total es del 19\%, pero es mucho mayor en los sectores agropecuario (89\%), restaurantes y alojamiento (47\%), transporte (37\%) y comercio (32\%); y, al año 2012, el 74,3\% de la PEA estaba en condiciones de empleo informal, un $57 \%$ de ella estaba trabajando para empresas informales y el restante $17,3 \%$ trabajaba para empresas formales (véanse los anexos 3 y 4). Y los avances en materia de formalización son incipientes. Si bien la Sunat constata que está aumentando el número de mypes formales (anexo 5), también se constata, con base en datos de la Enaho, que la participación del empleo informal en el año 2015 (73,2\%) era solo levemente menor que la de 2012 .

\footnotetext{
${ }^{4}$ UIT: unidad impositiva tributaria, equivalente a S/ 3.600 en 2011.
} 
En términos del modelo de Alingham \& Sandmo (1972), los agentes deciden la evasión de impuestos en función de las consecuencias penales y la probabilidad de ser descubiertos. En el Perú, al año 2010, el número de contribuyentes auditados mediante la fiscalización parcial ${ }^{5}$ fue de 5.218 $(0,1 \%$ del total de contribuyentes), mientras que la fiscalización parcial electrónica ${ }^{6}$ auditó a 102.194 (2,0\% del total) y la fiscalización definitiva ${ }^{7}$, a solo 1.738 contribuyentes $(0,0 \%$ del total) (anexo 6). Asimismo, el número de multas administrativas se ubicó en 311.201 y tan solo hubo tres condenas por defraudación tributaria (Díaz et al., 2013) (anexo 7). Evidentemente, probabilidades tan bajas de ser auditados, multados o condenados incentivan la evasión tributaria.

Además, en el Perú, no hay una cultura tributaria que fomente la recaudación. Frey (1997) desarrolla un modelo en el que, además de considerar las variables de Alingham \& Sandmo (1972), añade motivaciones intrínsecas que influyen en la decisión de evadir, como son su efecto en la conciencia y reputación. En una encuesta realizada por Datum (2014), el 37\% de los encuestados respondió que no paga impuestos y, del 63\% restante, un 28\% reconoció que buscaba alternativas para pagar menos. El 81\% consideraba que los impuestos no son utilizados adecuadamente y el 60\%, que la labor fiscalizadora de la Sunat era regular o mala. En el Corruption Perceptions Index 2016 elaborado por Transparencia Internacional, el Perú se ubica en el puesto 101 de 176 países analizados y en el puesto 20 de 32 de América. Adicionalmente, en un estudio elaborado por la Cepal (2011), el Perú se ubicó en el último lugar en cuanto a la proporción de la población que confía en la calidad del gasto público, con solo un 13\% (anexo 8).

El sistema tributario peruano tiene un amplio margen de mejora. En una investigación desarrollada en el marco de las elecciones políticas de 2011, se halló que las principales deficiencias de dicho sistema son el bajo nivel de recaudación, los altos niveles de evasión tributaria, las elevadas tasas impositivas en comparación con estándares internacionales, la reducida base tributaria y la complejidad del sistema en su conjunto (Arias, 2011). La complejidad del sistema tributario fomenta la evasión tributaria debido a que incrementa los costos asociados al pago de impuestos. Datum (2014) revela que el 64\% de

\footnotetext{
${ }^{5}$ Auditoría que revisa algún elemento de la declaración tributaria. Puede realizarse de manera electrónica.

${ }^{6}$ Se realiza desde las oficinas de la Sunat, no requiere visitar al contribuyente.

${ }^{7}$ Auditoría exhaustiva a los libros, registros y documentación del contribuyente con la finalidad de determinar de manera definitiva el monto de la obligación tributaria correspondiente a un determinado tributo y período tributario.
} 
los peruanos considera que el esquema tributario es muy complicado y el 51\% considera que la Sunat dificulta el pago de impuestos ${ }^{8}$. En un estudio al año 2010, el Banco Mundial y PwC hallaron que Latinoamérica y el Caribe son las regiones donde el pago de impuestos requiere la mayor cantidad de horas a los contribuyentes, con un promedio de 385 al año. El Perú se ubicó en el puesto 153 de 183 países, con 380 horas al año (World Bank, 2010). En un estudio similar para 2016, el Perú disminuyo ese tiempo a 260 horas. Una mejora importante, sin duda, aunque no reflejada en un aumento significativo de la recaudación fiscal (World Bank, 2016).

Los dos regímenes tributarios que analizamos en esta investigación son el Régimen Especial de Impuesto a la Renta (RER) y el Régimen General (RG) para dicho impuesto. El RER sujeta a tributo el 1,5\% sobre las ventas netas cuando estas no superan los S/ 525.000, mientras que en el RG no hay umbrales de ventas y la tasa impositiva es del 29,5\% de la utilidad imponible (Sunat, 2017).

\section{Análisis de los datos}

El análisis se realizó utilizando el set de datos provisto por la Sunat, acotado de S/ 253.650 a S/ 795.000 por intervalos de S/ 1.350 para los ańos 2014, 2015 y 2016. En la tabla 1, referida al RG elegible al RER, se observa que los estadísticos descriptivos, aunque distintos, son similares en los tres años; ello sugiere que las estimaciones de bunching serían comparables entre sí.

Tabla 1

Estadísticos - Régimen General elegible al RER 2014, 2015 y 2016

(S/ 253.650-795.000)

\begin{tabular}{lrrr}
\hline Ańo & 2014 & 2015 & 2016 \\
\hline Ingreso promedio & 360.808 & 361.686 & 361.275 \\
Coeficiente de variación & $21,10 \%$ & $21,08 \%$ & $21,12 \%$ \\
Intervalos en la muestra & 401 & 401 & 401 \\
Tamaño de intervalo & $\mathrm{S} / 1.350$ & $\mathrm{~S} / 1.350$ & $\mathrm{~S} / 1.350$ \\
Asimetría & 0,44 & 0,42 & 0,43 \\
Curtosis & 2,03 & 2,02 & 2,03 \\
Número de empresas & 34.737 & 35.289 & 38.259 \\
\hline
\end{tabular}

Fuente: Sunat. Elaboración propia.

${ }^{8}$ La complejidad del sistema tributario proviene no solo de los múltiples esquemas tributarios, sino también de las variadas deducciones y excepciones. 
En el Régimen General así restringido y acotado, el ingreso promedio se encuentra en el octogésimo primer, el octogésimo y el octogésimo primer intervalo de la muestra para los ańos 2014, 2015 y 2016, respectivamente. Los coeficientes de variación, los tres muy cercanos entre sí, muestran una baja dispersión en los datos, pues la desviación estándar es menor que la media de la distribución. Por otro lado, el coeficiente de asimetría es positivo, por lo que la cola derecha contiene valores más separados de la media. Por último, la curtosis sugiere una distribución platicúrtica con una baja concentración de datos cerca de la media.

En la tabla 2 para el Régimen Especial acotado, vemos que el ingreso promedio se encuentra en el cuadragésimo sexto, el cuadragésimo séptimo y el cuadragésimo séptimo intervalo de la muestra para los años 2014, 2015 y 2016, respectivamente. Los coeficientes de variación también son cercanos entre sí, pero menos que en el Régimen General. Por otro lado, el coeficiente de asimetría es positivo al igual que para el Régimen General, aunque notablemente mayor, debido a la presencia del umbral impositivo. Por último, a diferencia del Régimen General, la curtosis sugiere una distribución leptocúrtica con una alta concentración cerca de la media, lo cual es consistente con la hipótesis de bunching.

Tabla 2

Estadísticos - Régimen Especial 2014, 2015 y 2016 (S/ 253.650-795.000)

\begin{tabular}{lrrr}
\hline Año & 2014 & 2015 & 2016 \\
\hline Ingreso promedio & 314.892 & 316.086 & 316.149 \\
Coeficiente de variación & $15,75 \%$ & $16,11 \%$ & $16,08 \%$ \\
Intervalos en la muestra & 401 & 401 & 401 \\
Tamaño de intervalo & $\mathrm{S} / 1.350$ & $\mathrm{~S} / 1.350$ & $\mathrm{~S} / 1.350$ \\
Asimetría & 1,08 & 1,05 & 1,06 \\
Curtosis & 4,11 & 3,96 & 3,97 \\
Número de empresas & 18.009 & 21.223 & 23.286 \\
\hline
\end{tabular}

Fuente: Sunat. Elaboración propia.

Para la estimación de la función contrafactual, se parte de la distribución empírica construida con base en los datos de contribuyentes del Régimen General elegible al RER y en los datos del Régimen Especial. Dicha distribución es el resultado de la suma de los contribuyentes por intervalos de ingreso de ambos regímenes para los tres ańos. 


\section{Metodología}

La función contrafactual es estimada siguiendo la metodología de Chetty et al. (2011). Pero es importante sustentarla con el fundamento microeconómico del bunching desarrollado por Sáez (2010). Si, a partir del nivel de ingresos $z^{*}$, la tasa impositiva aumenta a $t+d t$ para ingresos mayores de $z^{*}$, se producirá la acumulación en el umbral de contribuyentes cuyo ingreso este comprendido en el segmento $\left[z^{*}, z^{*}+d z\right]$. Los individuos con ingresos $z^{*}$ antes del impuesto no se ven afectados, dado que su curva de indiferencia permanece tangente a la restricción presupuestaria con pendiente $1-t$. Sin embargo, no sucede lo mismo con los individuos cuyo ingreso está comprendido en el segmento mencionado. La curva de indiferencia del individuo con ingresos $z^{*}+d z$ ahora es tangente a la restricción presupuestaria con pendiente $1-t-d t$. Cuando el cambio en el impuesto es pequeño, la elasticidad compensada del ingreso se define como:

$$
\frac{d z^{*}}{z^{*}}=e \frac{d t}{1-t^{\prime}}
$$

Entonces, el número total de contribuyentes que se acumulan en el nivel $z^{*}$ es $h\left(z^{*}\right) d z^{*}$, donde $h\left(z^{*}\right)$ es la función de densidad para el nivel de ingreso $z^{*}$ cuando el impuesto es constante. De esta manera, la magnitud del bunching es una función de la elasticidad compensada $e$ y del ratio neto de impuestos $d t /(1-t)$ (figura 1$)$.

Si bien el modelo estima resultados consistentes, implementarlo requiere asumir que el cambio en el impuesto marginal afecta a todos los agentes por igual, así como que estos cuentan con información perfecta del esquema tributario y maximizan utilidad en el punto donde su curva de utilidad es tangente a su restricción presupuestaria.

Por ello, la metodología empleada es la desarrollada por Chetty et al. (2011). En el análisis de bunching, es fundamental conocer el comportamiento en ausencia de cambio marginal en la tasa impositiva. Ello exige determinar $a$ priori los supuestos sobre el nuevo esquema tributario y cómo se comportan los agentes en él. Denotemos como $t_{0}{ }^{9}$ la tasa impositiva en el Régimen Especial de Impuesto a la Renta y como $t_{1}{ }^{10}$ la tasa impositiva del Régimen General. La función empírica analiza a las empresas en dos escenarios distintos: aquellas ubicadas en un rango de ingresos de $[0,525.000]$ que tributan a una tasa de $t_{0}$ y se comportan de acuerdo con esa tasa; y aquellas en el rango de ingresos

\footnotetext{
${ }^{9} t_{0}=1,5 \%$ de las ventas.

${ }^{10} t_{1}=30 \%$ (2014) y $t_{1}=28 \%(2015,2016)$.
} 
de $[525.001, \infty]$ que tributan a una tasa de $t_{1}$. La función contrafactual se construye a partir del supuesto de que la totalidad de empresas tributan a la misma tasa de $t$, por ende, no hay cambio en su comportamiento.

Figura 1

Curvas de indiferencia y bunching

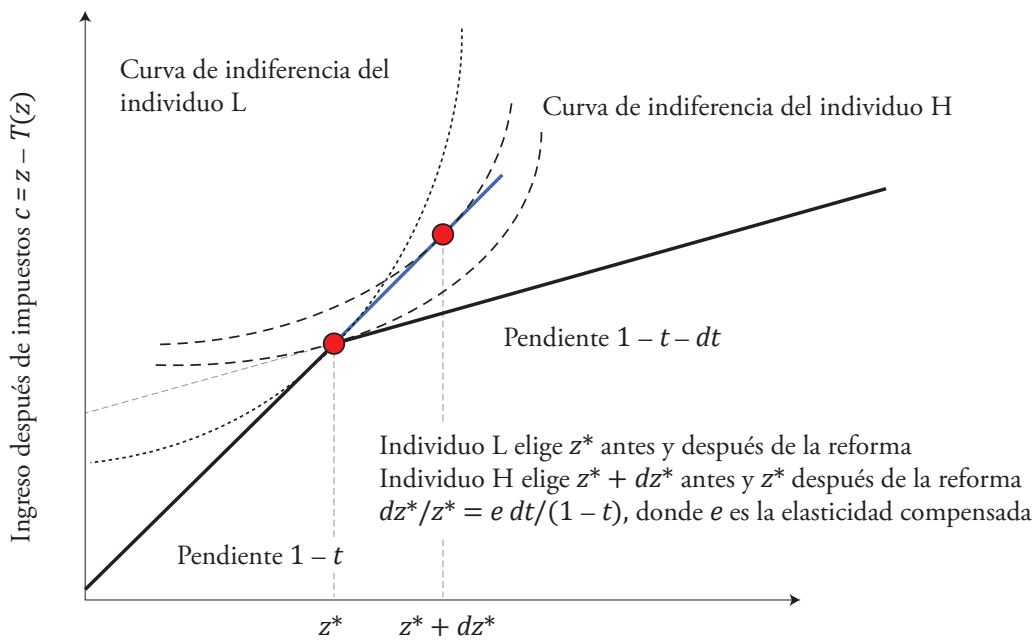

Ingreso antes de impuestos $Z$

Fuente: Sáez (2010).

Para hallar la magnitud del bunching, primero se debe estimar cómo sería la función de distribución sin distorsiones tributarias. Para ello, se ajusta un polinomio flexible a la distribución empírica, exluyendo la información en la vecindad del umbral y extrapolando dicho segmento. La información de contribuyentes se agrupa en $j$ rangos y se estima la distribución contrafactual mediante la siguiente ecuación:

$$
y_{j}=\sum_{i=0}^{q} \beta_{i}\left(z_{j}\right)^{i}+\sum_{k=-W}^{W} \gamma_{k}^{0} \cdot 1[j=k]+\varepsilon_{j}^{0},
$$

Donde $y_{j}$ refiere al número de contribuyentes en el rango $j$; $z_{j}$ refiere al nivel de ingresos del rango $j ; W$ refiere al número de rangos en la vecindad del 
punto de acumulación por excluir; $q$ es el grado de la función polinómica; y $\varepsilon_{j}^{0}$ es el residuo ${ }^{11}$.

La estimación de la función contrafactual, tras la omisión de la región por excluir, queda de la siguiente forma:

$$
\hat{y}_{j}=\sum_{i=0}^{q} \beta_{i}\left(z_{j}\right)^{i},
$$

Por lo tanto, el exceso de empresas en el rango excluido es:

$$
\hat{B}=\sum_{-W}^{W} y_{j}-\hat{y}_{j}=\sum_{-W}^{W} \gamma_{k^{\prime}}^{0}
$$

El parámetro $\gamma_{k}^{0}$ recoge la cantidad de contribuyentes en la vecindad del punto de acumulación que no es explicada por el polinomio $\sum_{i=0}^{q} \beta_{i}\left(z_{j}\right)^{i}$ o, lo que es lo mismo, mide la acumulación adicional de la función empírica en relación con la contrafactual.

Por último, se estima la acumulación de empresas relativa a la densidad promedio de la función contrafactual en el rango seleccionado, de la siguiente manera:

$$
b=\frac{\hat{B}}{\left(\sum_{k=-W}^{W} \widehat{y}_{j} /(2 W+1)\right.},
$$

El estimador $\hat{B}$ se encuentra sobreestimado, dado que no toma en cuenta que el exceso de empresas alrededor del punto de acumulación proviene del lado derecho de la distribución. En otras palabras, el área bajo la curva de la función empírica y la función contrafactual no son iguales. Para corregir este problema, se desplaza la contrafactual hacia la derecha del umbral impositivo hasta cumplir la restricción de que el área por debajo de ambas funciones sea igual.

Sin embargo, asumir que en el Perú la introducción de un umbral impositivo no afecta el número de empresas es un supuesto fuerte, ante la evidencia de atomización de empresas para eludir tributos. En el Perú, es posible la creación de múltiples razones sociales para operar un solo negocio, de manera que una empresa con ingresos de S/ 800.000 imponibles bajo el Régimen General opere bajo dos razones sociales, cada una con un ingreso imponible de S/ 400.000 sujeto al Régimen Especial. De modo que el exceso de empresas proviene, en parte, del lado derecho de la distribución y, en parte, de nuevas

\footnotetext{
${ }^{11}$ La metodología propuesta en Chetty et al. (2011) utiliza una única distribución para el cálculo de la función contrafactual. Por su parte, Mortenson \& Whitten (2016) consideran que la distribución al lado derecho del umbral impositivo es distinta a la distribución del lado izquierdo. Los individuos se comportan de manera diferente dado que tributan a una tasa distinta.
} 
razones sociales empresariales, por lo que es razonable cuestionar el supuesto de igualdad entre la función empírica y la contrafactual.

\section{Selección del modelo}

La especificación del modelo comprende la elección de cuatro parámetros: la región por extrapolar, la región contrafactual, el grado del polinomio y el ancho de los intervalos. La amplitud de la región por excluir y la región contrafactual son determinadas mediante una inspección visual. El polinomio característico se determina modelando la función contrafactual desde un polinomio de grado 10 hacia abajo, en un proceso recursivo hasta encontrar el mejor modelo explicativo según el criterio de información de Akaike. Pero se encontró que, ante polinomios de grado muy alto, la resultante función contrafactual con frecuencia sobreajustaba los datos y, por ende, no reflejaba la realidad, como muestran la figura $2^{12}$ para el año 2014 y la figura 3 para el año 2015.

La región excluida determina el área donde se encuentra el número total de marginal bunchers. Se asume que en cualquier área fuera de esta región no hay acumulación de empresas. Por último, la región contrafactual determina el intervalo, por fuera de la región excluida, que es utilizado para construir la función contrafactual.

Figura 2

Distribución empírica y contrafactual, 2014

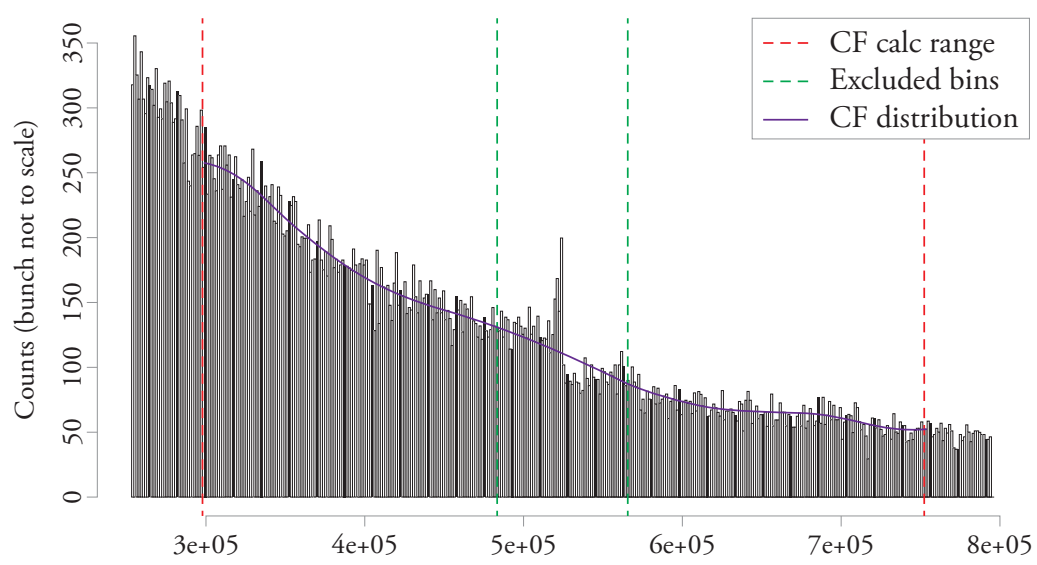

\footnotetext{
${ }^{12}$ Esta figura muestra 400 rangos de $\delta=S / 1.350$ en la vecindad del umbral impositivo de $S / 525.000$. Se observa que, con un polinomio de grado 9 , la distribución contrafactual sobreajusta los datos.
} 
Figura 3

Distribución empírica, 2015

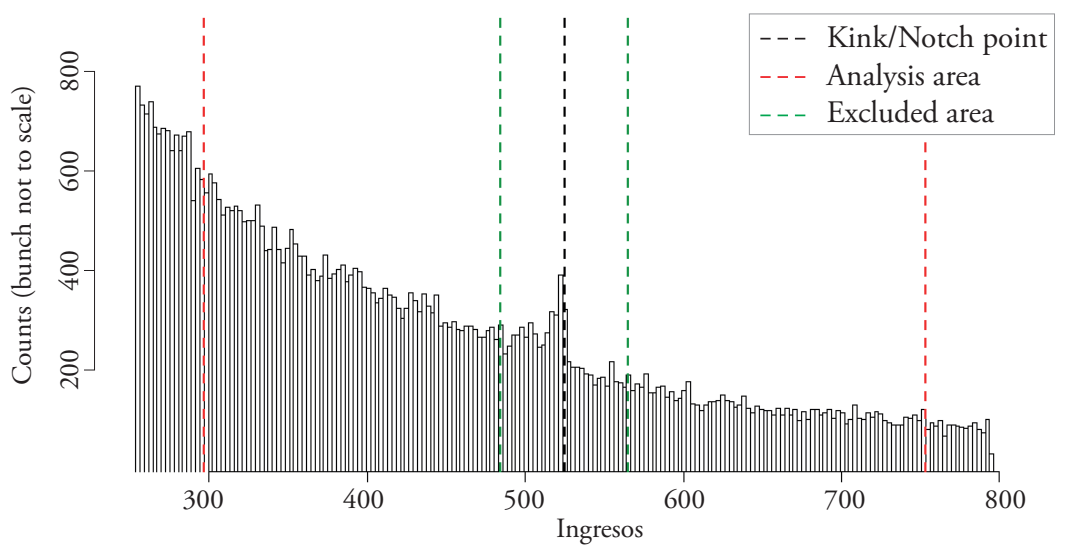

Se determinó el ancho del intervalo $\delta=S / 2.700$. La región excluida se determinó, mediante inspección visual siguiendo la metodología aplicada por Mortenson \& Whitten (2016), como $W=15$ intervalos hacia ambos lados del umbral impositivo ${ }^{13}$. Esto supone que solo el comportamiento de las empresas con ventas de $W * \delta= \pm S / 40.500$ del umbral es influenciado por la presencia del cambio impositivo. Asimismo, se utilizó la distribución empírica entre S/ 40.500 y S/ 226.800 a cada lado para construir la función contrafactual; es decir, una región de $J=84$ hacia ambos lados del umbral. El polinomio óptimo para dicha especificación resultó ser de grado 3. La ecuación 6 muestra la especificación seleccionada.

$$
y_{j}=\sum_{i=0}^{3} \beta_{i}\left(z_{j}\right)^{i}+\sum_{k=-15}^{15} \gamma_{k}^{0} \cdot 1[j=k]+\varepsilon_{j}^{0},
$$

\section{Resultados}

Como se observa en la figura 4, la función contrafactual es un polinomio de grado 3 que utilizó la región contrafactual para extrapolar la ventana excluida y estimar cómo se comportarían las empresas en la vecindad del umbral si no existiese un cambio marginal en el impuesto. Ello permitió el siguiente análisis para los años 2014, 2015 y 2016.

\footnotetext{
${ }^{13}$ Una inflexión en el comportamiento de las empresas (acumulación) es observable 15 rangos a la izquierda del umbral impositivo.
} 
Interpolación del área distorsionada por el cambio de impuesto marginal entre el Régimen General y el Régimen Especial en la distribución de conjunta de contribuyentes

Figura 4

Distribución empírica y contrafactual estimada

Bunching visualization

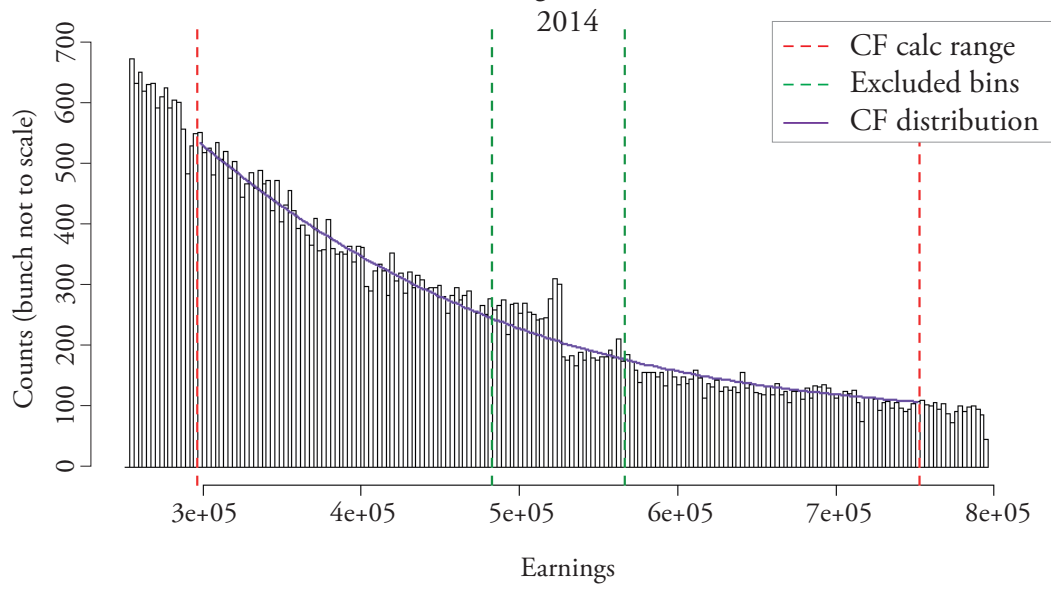

Bunching visualization

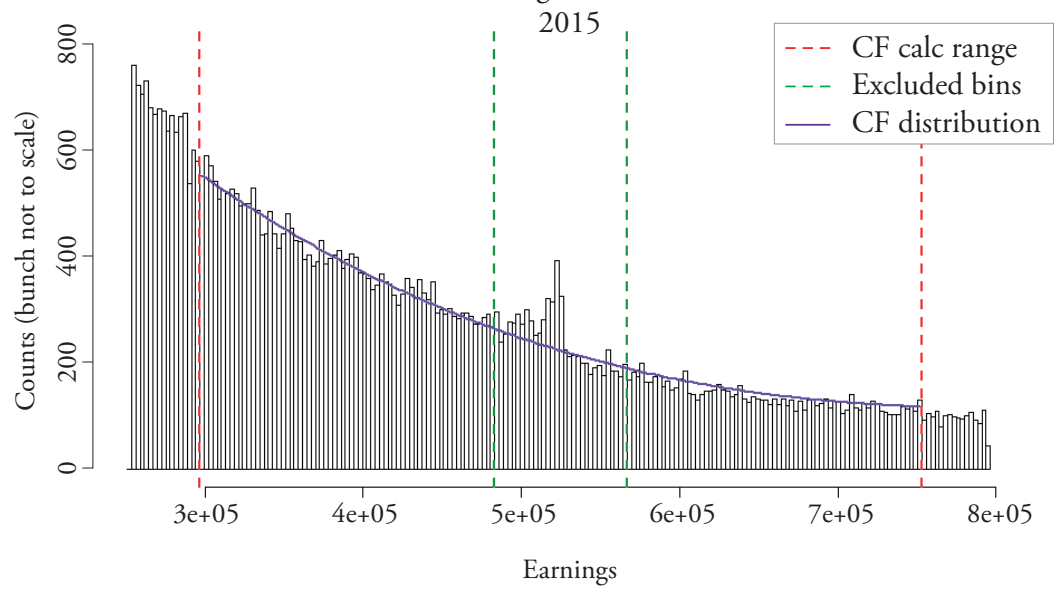




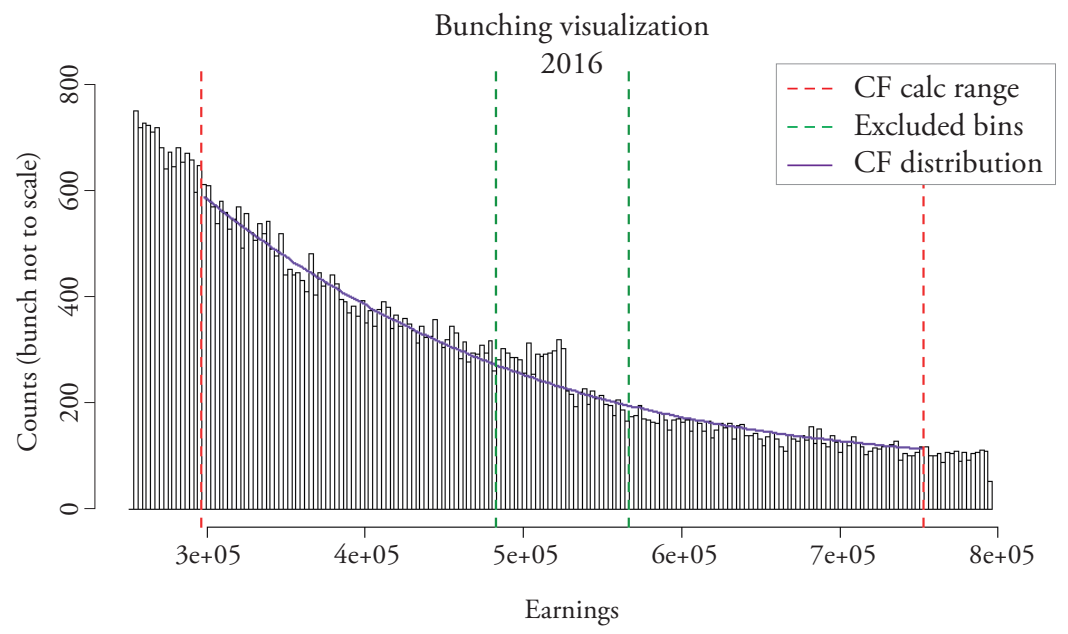

Según las estimaciones, significativas al 99\%, la función empírica presenta 505 empresas más de las que se observan en la ventana de bunching de la función contrafactual para el año 2014, 649 empresas más para el año 2015 y 568 empresas más para el ańo 2016 (véase la tabla 3). Si bien el resultado es bajo en comparación con la totalidad de empresas en el Perú, al tomar en cuenta el rango en el que se encuentran estas empresas, la acumulación producto del cambio marginal en el impuesto representa el 7,47\% de las 6.763 empresas comprendidas en la ventana excluida de la función empírica en el año 2014, el 8,78\% en 2015 y el 7,21\% en 2016. Esto confirma la hipótesis de que existe acumulación en el umbral impositivo de S/ 525.000 que separa el Régimen Especial del Régimen General.

Tabla 3

Resultados

\begin{tabular}{cccccc}
\hline Año & $\begin{array}{c}\text { Marginal } \\
\text { bunchers }\end{array}$ & $\begin{array}{c}\text { Ancho del } \\
\text { intervalo }\end{array}$ & $\begin{array}{c}\text { Región } \\
\text { contrafactual }\end{array}$ & $\begin{array}{c}\text { Ventana de } \\
\text { bunching }\end{array}$ & $\begin{array}{c}\text { Grado del } \\
\text { polinomio }\end{array}$ \\
\hline \multirow{2}{*}{2014} & $\begin{array}{c}505,39 \\
(82,11)\end{array}$ & S/ 2.700 & +- S/ 226.800 & +- S/ 40.500 & 3 \\
& $\begin{array}{l}649,05 \\
2015\end{array}$ & & & & 3 \\
& $(91,90)$ & S/ 2.700 & $+-S / 226.800$ & $+-S / 40.500$ & 3 \\
\hline
\end{tabular}

Nota. Nivel de confianza del 99\% para las tres estimaciones. Fuente: Sunat. Elaboración propia. 
El error estándar es estimado, siguiendo a Devereux et al. (2012), mediante un proceso iterativo de remuestreo de los residuos. Se obtienen los residuos estimados $\hat{\varepsilon}$ mediante la diferencia de las observaciones empíricas y las predichas por el modelo de regresión. Luego, se genera una nueva serie de errores eligiendo $\hat{\varepsilon}$ aleatoriamente y sumándolos a los contribuyentes de la distribución empírica. Por último, se procede a calcular el exceso de masa mediante el procedimiento de bunching. El error estándar se calcula como la desviación estándar del exceso de masa de las 500 simulaciones.

Las implicancias económicas de estos resultados son importantes, puesto que, dado el nivel de ingresos de las empresas, la recaudación potencial es significativa. Más aún, el análisis de los tres ańos revela un comportamiento distorsionador persistente en el esquema tributario y muestra que las empresas tienen pocos incentivos para migrar de un régimen a otro.

Sin embargo, la precisión de la estimación depende de qué tan bien los parámetros elegidos representan la realidad. Además, para confirmar la hipótesis de investigación, se debe garantizar que las estimaciones sean robustas y que las conclusiones cualitativas de los resultados no varíen ante cambios en los parámetros.

\section{Análisis de robustez}

En esta sección, se analiza qué tan sensibles son las estimaciones a cambios en los parámetros elegidos. Tomando en cuenta la especificación predeterminada de $W=15$, $J=84$, el grado del polinomio igual a 3 y el ancho del intervalo $\delta=S / 2.700$, se procede a fijar tres de estos parámetros y dejar libre el cuarto.

En primer lugar, se evaluó cómo varían las estimaciones cuando se fijan los parámetros de la ventana de bunching $( \pm$ S/ 40.500) y el grado del polinomio (3), mientras se deja libre la región contrafactual, que toma valores desde \pm S/ 170.100 hasta \pm S/ 226.800 (véanse los anexos 9, 16-17, 24-26 y 33-35). En este caso, se observa que las estimaciones oscilan desde 450 hasta 650 en los ańos 2014, 2015 y 2016 ${ }^{14}$; por lo que se concluyó que, si bien las estimaciones varían, el modelo es poco sensible a cambios en el tamaño de la región contrafactual.

En segundo lugar, se evaluó la sensibilidad del modelo cuando se fijan los parámetros de la región contrafactual $( \pm$ S/ 226.800) y la ventana de bunching $( \pm S / 40.500)$, mientras se deja libre el grado del polinomio, que toma valores desde 2 hasta 6 (véanse los anexos 13-15, 19-21 y 25-27). En este caso, los

\footnotetext{
${ }^{14}$ Donde todos los resultados son significativos al 99\%.
} 
marginal bunchers toman valores desde 226 hasta $567^{15}$; se concluye así que las estimaciones no son muy sensibles ante cambios en el grado del polinomio, a excepción de polinomios de grado muy alto. La función contrafactual construida con polinomios de grado 6 o más pierde significancia y sobreajusta los datos, lo que da una función poco realista.

En tercer lugar, se evaluó la sensibilidad del modelo cuando se fijan los parámetros de la región contrafactual $( \pm$ S/ 226.800) y el grado del polinomio (3), mientras se deja libre la ventana de bunching, que toma valores desde \pm S/ 8.100 hasta \pm S/ 64.800 (véanse los anexos 10-12, 16-18 y 22-24). En este caso, los marginal bunchers toman valores desde 177 hasta $674^{16}$, lo que indica que la estimación es más sensible ante cambios en el área excluida que en cualquiera de los otros dos parámetros. Ello es lógico, ya que el exceso de contribuyentes se calcula mediante la diferencia de observaciones entre la distribución empírica y contrafactual en el rango excluido. Aun así, se sigue encontrando evidencia de acumulación en el umbral impositivo ante cambios en la ventana de bunching.

Por último, los resultados son similares cuando se trabajó con intervalos de S/ 1.350, S/ 2.700 y S/ 4.050. De esta manera, se puede concluir que el modelo es invariante ante cambios en la elección de este parámetro.

En general, el análisis nos muestra que los resultados obtenidos son robustos ante la elección de los parámetros. Y que son poco sensibles ante cambios en esos parámetros, salvo el caso de la ventana por excluir, que sí influye de manera significativa en los resultados.

\section{Elasticidad}

Debido a que el impuesto del Régimen Especial se aplica sobre las ventas y el impuesto del Régimen General se aplica a la utilidad tributaria, se utilizó la información de ingresos y utilidad tributaria en las empresas del Régimen General para estimar una tasa comparable al Régimen Especial, tal como muestra la tabla 4 .

\footnotetext{
${ }^{15}$ Donde todos los resultados son significativos al 99\%, a excepción de cuando se construye la función contrafactual con un grado del polinomio mayor de 6 .

${ }^{16}$ Donde todos los resultados son significativos al 99\%.
} 
Interpolación del área distorsionada por el cambio de impuesto marginal entre el Régimen General y el Régimen Especial en

Tabla 4

Impuesto efectivo según margen de utilidad ${ }^{17}$

\begin{tabular}{cccc}
\hline Año & Utilidad tributaria & $\begin{array}{c}\text { Impuesto del } \\
\text { Régimen General }\end{array}$ & Impuesto efectivo \\
\hline 2014 & $6,35 \%$ & $30,00 \%$ & $1,91 \%$ \\
2015 & $7,10 \%$ & $28,00 \%$ & $1,99 \%$ \\
2016 & $7,29 \%$ & $28,00 \%$ & $2,04 \%$ \\
\hline
\end{tabular}

Fuente: Sunat. Elaboración propia.

Las elasticidades fueron calculadas utilizando la especificación planteada anteriormente. La tabla 5 muestra las elasticidades halladas, que oscilan desde 2,01 en el ańo 2016 hasta 2,98 en 2014, con un nivel de confianza al 99\%. Y también muestra que, pese a la disminución de la tasa impositiva en el Régimen General, del 30\% en 2014 al 28\% en 2015 y 2016, el aumento en el margen de utilidad tributaria da como resultado un impuesto efectivo mayor cada año.

Tabla 5

Elasticidades

\begin{tabular}{cccccc}
\hline Año & Elasticidad & $\begin{array}{c}\text { Utilidad } \\
\text { tributaria }\end{array}$ & $\begin{array}{c}\text { Impuesto } \\
\text { del Régimen } \\
\text { General }\end{array}$ & $\begin{array}{c}\text { Impuesto } \\
\text { efectivo }\end{array}$ & $\begin{array}{c}\text { Ancho del } \\
\text { intervalo }\end{array}$ \\
\hline 2014 & $\begin{array}{c}2,98 \\
(0,55)\end{array}$ & $6,35 \%$ & $30 \%$ & $1,91 \%$ & S/ 2.700 \\
2015 & $\begin{array}{c}2,97 \\
(0,44)\end{array}$ & $7,10 \%$ & $28 \%$ & $1,99 \%$ & S/ 2.700 \\
2016 & $(0,35)$ & $7,29 \%$ & $28 \%$ & $2,04 \%$ & S/ 2.700 \\
\hline
\end{tabular}

Fuente: Sunat. Elaboración propia.

Como se mencionó en la metodología, la elasticidad mide la sensibilidad de la conducta de los marginal bunchers ante cambios en el impuesto efectivo. Por ejemplo, en 2015, un incremento marginal de un $1 \%$ en la tasa de impuesto efectivo hubiera generado que la cantidad de empresas acumuladas en el umbral se incremente entre un $2,80 \%$ y un $2,97 \%$.

\footnotetext{
${ }^{17} \mathrm{El}$ impuesto fue calculado utilizando la formula Impuesto $R G *$ Margen de Utilidad = Impuesto Efectivo.
} 


\section{Conclusiones y recomendaciones de política}

En los últimos 20 años, en Latinoamérica y el Caribe ha sucedido que, aunque las tasas de impuesto a la renta para empresas han disminuido paulatinamente, la recaudación tributaria ha aumentado. Entre 1990 y 2010, la recaudación tributaria en la mencionada región se incrementó en un $85 \%$, mientras que las tasas de impuesto a la renta pasaron en promedio del 34\% al 28\% (Banco Interamericano de Desarrollo, 2012). Dichas tasas son una herramienta utilizada por los países para retener el ahorro local y atraer inversión, pero no es la única. En particular, en la misma región y durante aquel período, se han creado varios incentivos tributarios y regímenes especiales para nuevas inversiones.

Sin embargo, cuando se generan muchos incentivos, se corre el riesgo de ayudar permanentemente a una actividad ineficiente, si el costo político de eliminar el estímulo es muy elevado. Más aún, independientemente de la naturaleza del incentivo, una subvención directa o indirecta supone un mayor costo fiscal, que debe ser financiado con un aumento en la recaudación.

En el Perú, durante los años 2014-2016, estuvieron sujetos al Régimen Especial del Impuesto a la Renta (RER) y al Régimen Único Simplificado (RUS) entre el 66,67\% y el 70,69\% de las empresas formales (Sunat, 2017). Es inaceptable que, cuando el objetivo de los regímenes simplificados es atender a pequeñas empresas nacientes, porcentajes tan altos de empresas reciban tratamientos tributarios simplificados en perjuicio de la base tributaria. En esta línea, Arias (2009) propone que el límite máximo de ingresos para los regímenes simplificados sea igual al nivel promedio de Latinoamérica, que es de 16 veces el PIB per cápita (equivalente a un monto cercano a S/ 350.000), en vez de 25 veces, como es el caso del RER peruano.

$\mathrm{Al}$ analizar la región latinoamericana, el mismo autor encuentra que la baja probabilidad de ser fiscalizadas incentiva a las empresas a subvaluar ingresos para tributar con un régimen simplificado. También halla evidencia de que las empresas se atomizan ${ }^{18}$ para minimizar aún más la probabilidad de ser fiscalizadas. Adicionalmente, menciona que dicho comportamiento se acentúa cuando el límite de ventas y el beneficio tributario en relación con el Régimen General son altos; como en el caso peruano, donde los tributos efectivos del Régimen General son al menos tres veces la carga del RUS.

Al ser una práctica desleal, la evasión deteriora la equidad y deforma la estructura de competencia. Según el Banco Interamericano de Desarrollo

\footnotetext{
${ }^{18}$ Atomizar: segmentar las actividades de una empresa para fraccionarla en varias de tamaño pequeño.
} 
(2012), en Latinoamérica la evasión representa un 52\% de la recaudación potencial del impuesto a la renta. En el Perú, el año 2006, la recaudación potencial como porcentaje del PIB fue del $10,2 \%$ y la efectiva, de tan solo el $4,9 \%$; mientras que en Chile, el año 2003, la recaudación potencial fue del $7,3 \%$ del PIB y la efectiva, del 5,1\%; y, en República Dominicana, el año 2008, la recaudación potencial fue del 4\% del PIB y la efectiva, del 2,8\%. En la misma línea, Arias (2009) estimó que la evasión de las empresas en 2006 representó un $51 \%$ de la recaudación potencial.

Según el esquema tributario peruano actual, en el RUS se tributa una suma fija; en el RER, un porcentaje de ingresos; y en el Régimen General, un porcentaje de la utilidad tributaria. Que el impuesto esté en función de tres bases distintas, además de las diferenciaciones según número de trabajadores y por actividades económicas, incrementa el costo de transición entre distintos régimenes, tal como lo demuestra la estimación de marginal bunchers realizada por nuestra investigación.

Como menciona Pagés (2010), el impuesto al crecimiento ${ }^{19}$ toma en cuenta tanto costos tributarios como no tributarios. Este, en el Perú, es del $12 \%$ cuando se pasa de la informalidad al RUS, del 31\% cuando se pasa del RUS al RER y del 53\% cuando se pasa del RER al Régimen General. Como puede observarse en la figura 5 , el diferencial de tasas entre un régimen tributario y otro no es el único factor que toman en cuenta las empresas conforme van creciendo.

Peor aún, el Régimen Especial en esencia no incentiva a solicitar comprobantes, ya que el pago del impuesto a la renta está en función de las ventas y no de la utilidad imponible; lo cual también erosiona la base tributaria del IGV (Impuesto General a las Ventas). Tampoco motiva a las empresas a contratar empleados formalmente, ya que los gastos de planilla y honorarios no pueden ser descontados.

En verdad, es imperativa la restructuración del esquema tributario peruano hacia uno en el que todos los regímenes tributen sobre la misma base y el cambio en el impuesto sea marginal (como es el caso para las Rentas de Trabajo comprendidas en la quinta categoría del Impuesto a la Renta). Ello no solo porque la tributación es la herramienta para financiar el gasto público, sino también porque una política tributaria eficiente incrementa la equidad social y aumenta la competitividad de las empresas al incentivarlas a mejorar sus prácticas empresariales.

\footnotetext{
${ }^{19}$ Variación porcentual en las utilidades netas producto del cambio de régimen tributario.
} 
Figura 5

Impuesto al crecimiento: regímenes simplificados

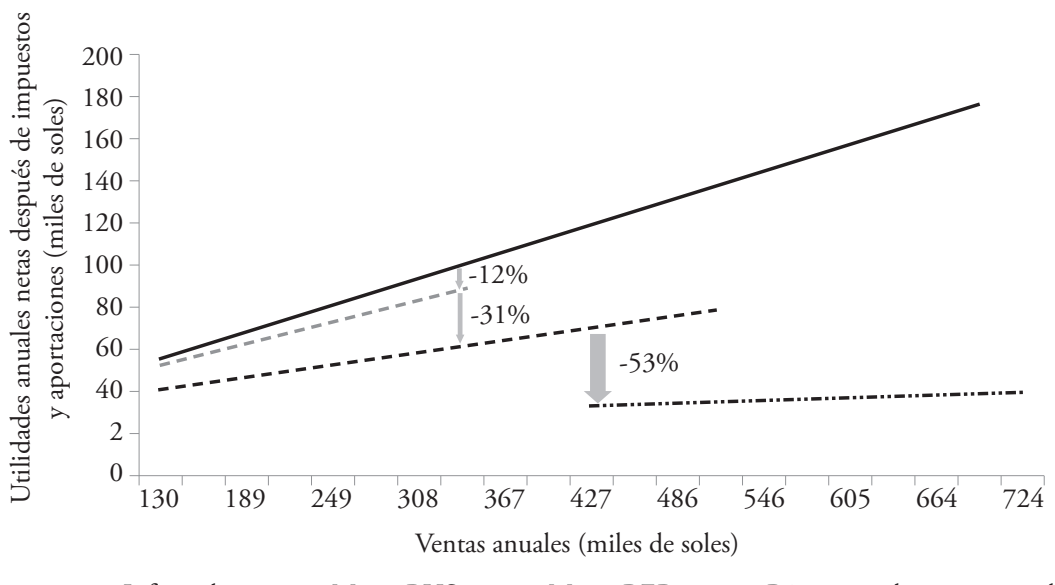

— Informales ----Micro-RUS ---Micro-RER '.-.--Régimen tributario general

Fuente: Pagés (2010).

\section{Referencias}

Alingham, M., \& Sandmo, A. (1972). Income tax evasion: A theoretical analysis. Journal of Public Economics, 1, 323-338.

Al-Karablieh, Y., \& Gallardo, C. (2014). Reducing the earned income gap in Peru. Cambridge: Harvard University - John F. Kennedy School of Government.

Arias, L. (2011). Politica tributaria para el 2011-2016. Lima: Consorcio de Investigación Económica y Social.

Arias, L. A. (2009). La tributacion directa en América Latina: equidady desafíos. El caso de Perú. Santiago: Cepal.

Artana, D., \& Templado, I. (2012). Incentivos tributarios a la inversión: ¿qué nos dice la teoria y la evidencia empirica sobre su efectividad? Washington D. C.: Banco Interamericano de Desarrollo.

Banco Interamericano de Desarrollo. (2012). Recaudar no basta: los impuestos como instrumento de desarrollo. Nueva York: Portico Bookstore.

Bastani, S., \& Selin, H. (2014). Bunching and non-bunching at kink points of the Swedish tax schedule. Journal of Public Economics, 109(C), 36-49.

Carrillo, P., Emran, S., \& Rivadeneira, A. (2012). Do cheaters bunch together? Profit taxes, withholding rates and tax evasion. Quito: Centro de Estudios Fiscales.

Cepal (Comisión Económica para América Latina y el Caribe). (2011). Cepalstat. https:// estadisticas.cepal.org/cepalstat/Portada.html 
Chetty, R., Friedman, J., Olsen, T., \& Pistaferri, L. (2011). Adjustment costs, firm responses and micro vs. macro labor supply elasticities: Evidence from Danish tax records. Quarterly Journal of Economics, 126, 749-804.

Datum. (2014). Encuesta de opinión pública a nivel nacional. Lima: Pulso Perú.

Devereux, M., Liu, L., \& Loretz, S. (2012). The elasticity of corporate taxable income: New evidence from UK tax records. American Economic Journal: Economic Policy, 6(2), 19-53.

Díaz, F., Pecho, M., Cremades, L., Vásquez, O., Velayos, F., \& Barreix, A. (2013). State of the tax administration in Latin America. Washington D. C.: Inter-American Development Bank.

Feldsetin, M. (1995). Effect of marginal tax rates on taxable income: A panel study of the 1986 Tax Reform Act. Journal of Political Economy, 103(3), 551-572.

Frey, B. (1997). A constitution for knaves crows out civic virtues. The Economic Journal, 107(443), 1043-1053.

Gómez, J., \& Jiménez, J. (2012). Tax structure and tax evasion in Latin America. Santiago: Eclac.

INEI (Instituto Nacional de Estadística e Informática). (14 de junio de 2016). Empleo informal en el Perú disminuyó en 3.9 puntos porcentuales. Nota de prensa. Lima: Instituto Nacional de Estadística e Informática.

INEI (Instituto Nacional de Estadística e Informática). (2017). Producción y empleo informal en el Perú. Lima: Cuenta Satélite de la Economía Informal 2007-2016.

Jaramillo, M., \& Saavedra, J. (2010). Inequality in post-structural reform Peru: The role of market forces and public policy. En N. López-Calva \& N. Lustig (Eds.), Declining inequality in Latin America: A decade of progress? (pp. 218-243). Washington D. C.: Brookings Institution Press.

Kleven, H. (2016). Bunching. Annual Review of Economics, 8, 435-464.

Mortenson, J. A., \& Whitten, A. (2016). Bunching to maximize tax credits: Evidence from kinks in the U.S. tax schedule. Washington D. C.: Berkeley Education.

OECD (Organisation for Economic Co-operation and Development). (1 de mayo de 2017). Comparative Tables - Latin American and Caribbean Countries. En OECD Stats. http://stats.oecd.org/index.aspx?DataSetCode=RSLACT

Pagés, C. (2010). La era de la productividad: cómo transformar las economías desde sus cimientos. Washington D. C.: Banco Interamericano de Desarrollo.

Sáez, E. (2010). Do taxpayers bunch at kink points? American Economic Journal: Economic Policy, 2, 180-212.

Sunat (Superintendencia Nacional de Administración Tributaria). (2015). Registro Único del Contribuyente. Lima: Superintendencia Nacional de Admnistración Tributaria.

Sunat (Superintendencia Nacional de Administración Tributaria). (27 de octubre de 2017a). Amazonía. Recuperado de https:/www.sunat.gob.pe/ol-ti-itmoddatruc/ RTAAMA.html 
Sunat (Superintendencia Nacional de Administración Tributaria). (2017b). Contribuyentes inscritos según regimen tributario y cantidad de afiliados a Essalud, 1997-2017 (miles de contribuyentes). Nota Tributaria 48. Lima.

Sunat (Superintendencia Nacional de Administración Tributaria). (27 de abril de 2017c). Régimen Especial del Impuesto a la Renta. Recuperado de http://orientacion.sunat. gob.pe/index.php/empresas-menu/impuesto-a-la-renta-empresas/regimen-especialdel-impuesto-a-la-renta-empresas/2932-concepto-del-regimen-especial

Sunat (Superintendencia Nacional de Administración Tributaria). (27 de octubre de 2017d). Zofratacna. Recuperado de http://www.sunat.gob.pe/legislacion/oficios/2008/ oficios/i0532008.htm

World Bank. (2010). Paying taxes 2010 - The global picture. Washington D. C.: International Finance Corporation \& PriceWaterhouseCoopers.

World Bank. (2016). Paying taxes 2016 - The global picture. Washington D. C.: The World Bank Group \& PriceWaterhouseCoopers. 
Interpolación del área distorsionada por el cambio de impuesto marginal entre el Régimen General y el Régimen Especial en la distribución de conjunta de contribuyentes

\section{Anexos}

\section{Anexo 1}

Presión tributaria (\%), 1990-2015

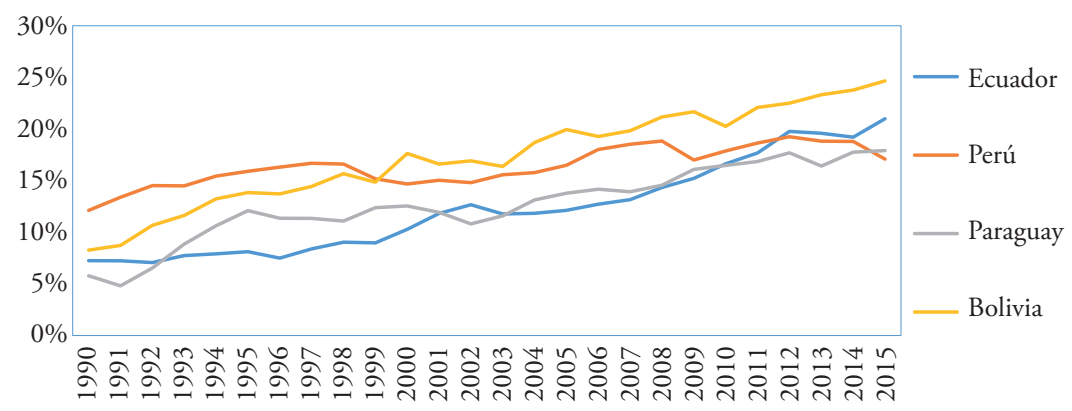

Fuente: OECD (2017). Elaboración propia.

Anexo 2

Presión tributaria (\%), 1990-2015

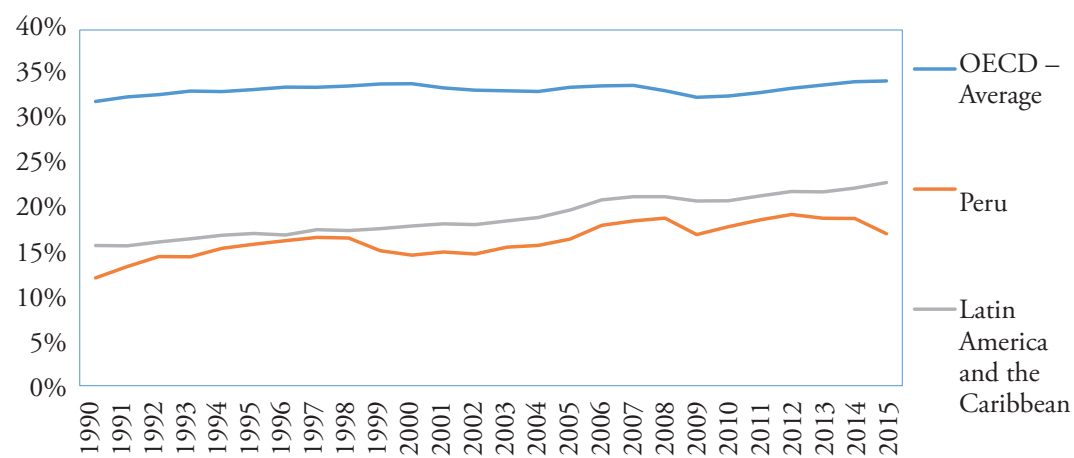

Fuente: OECD (2017). Elaboración propia 
Anexo 3

Participación del sector informal en el PIB por actividad económica

\begin{tabular}{ll}
\hline Sector & Participación \\
\hline Agropecuario & $89 \%$ \\
Restaurantes y alojamiento & $47 \%$ \\
Transporte & $37 \%$ \\
Comercio & $32 \%$ \\
Construcción & $25 \%$ \\
Manufactura & $13 \%$ \\
Otros servicios & $8 \%$ \\
Minería & $2 \%$ \\
\hline
\end{tabular}

Fuente: INEI (2017). Elaboración propia.

Anexo 4

Empleo informal según sector

\begin{tabular}{cccc}
\hline Año & Empleo informal & $\begin{array}{c}\text { Empleo informal } \\
\text { Sector informal }\end{array}$ & $\begin{array}{c}\text { Empleo informal } \\
\text { Sector formal }\end{array}$ \\
\hline 2007 & $79,9 \%$ & $61,5 \%$ & $18,3 \%$ \\
2008 & $79,1 \%$ & $60,6 \%$ & $18,5 \%$ \\
2009 & $77,2 \%$ & $59,5 \%$ & $17,7 \%$ \\
2010 & $77,1 \%$ & $59,4 \%$ & $17,7 \%$ \\
2011 & $75,0 \%$ & $58,3 \%$ & $16,7 \%$ \\
2012 & $74,3 \%$ & $57,0 \%$ & $17,3 \%$ \\
\hline
\end{tabular}

Fuente: INEI (2017). Elaboración propia. 
Interpolación del área distorsionada por el cambio de impuesto marginal entre el Régimen General y el Régimen Especial en la distribución de conjunta de contribuyentes

\section{Anexo 5}

\section{Evolución de las mypes, 2007-2015}

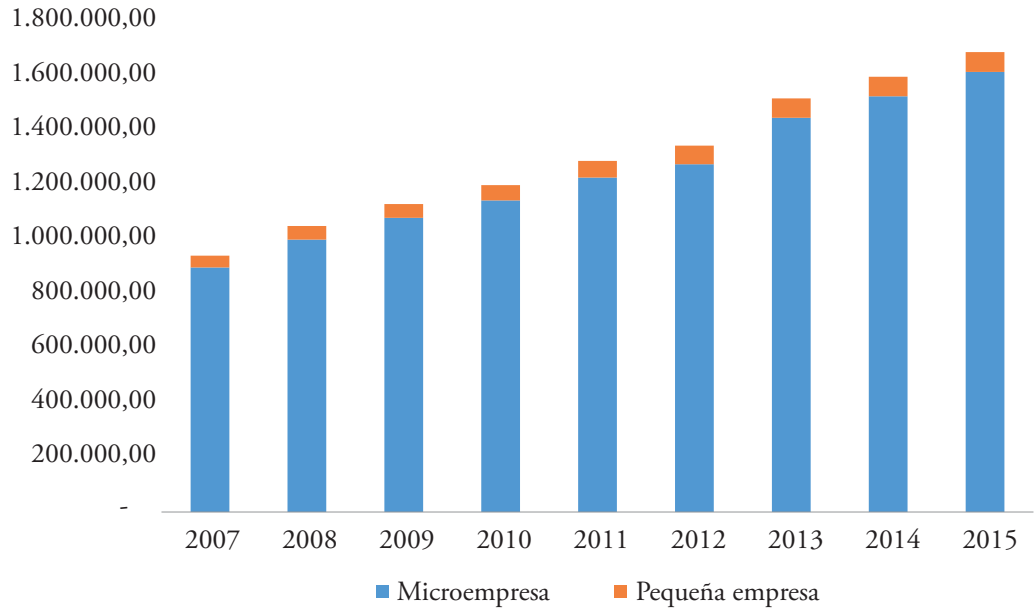

Fuente: Sunat (2017). Elaboración propia. 


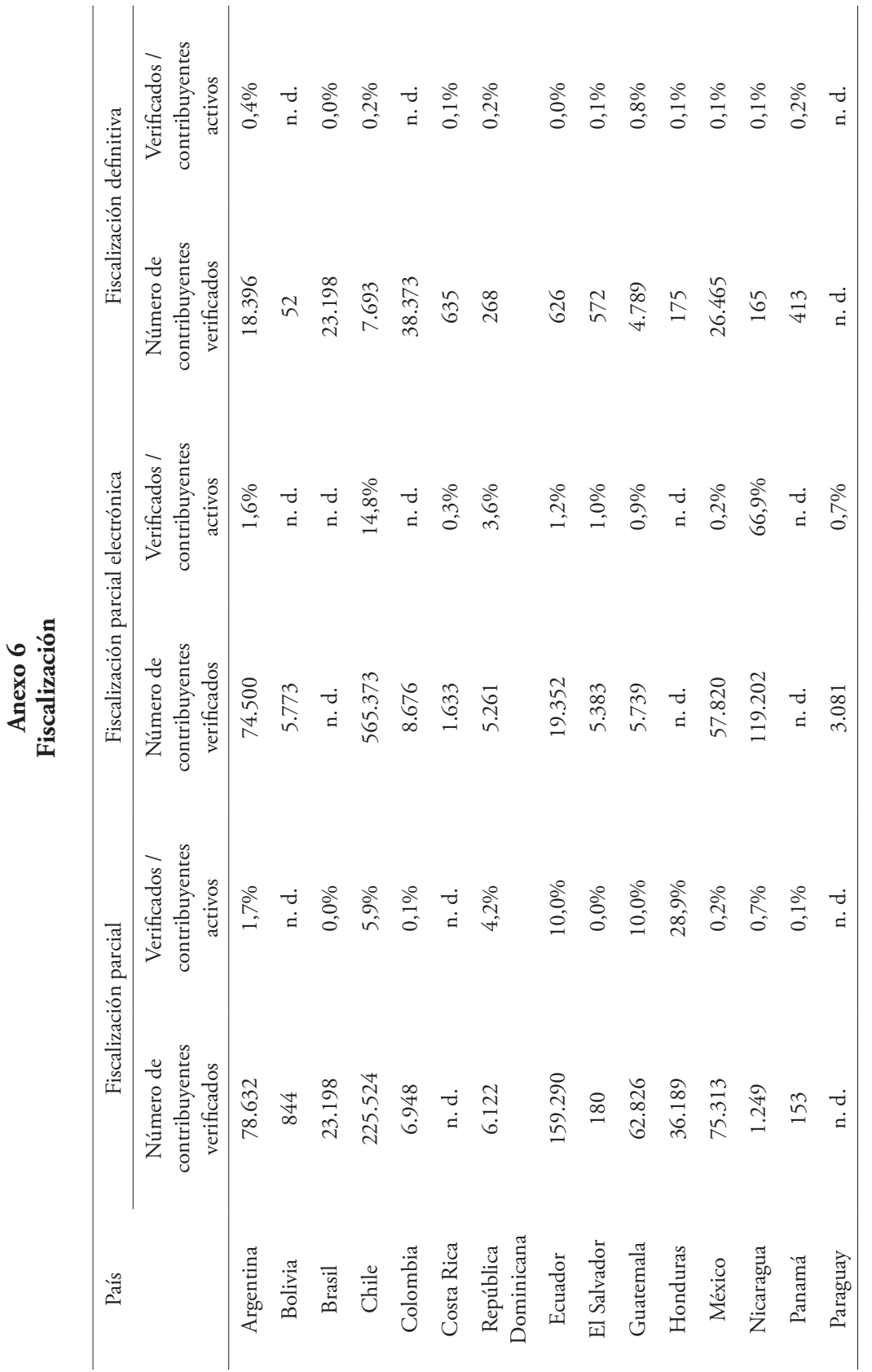


Interpolación del área distorsionada por el cambio de impuesto marginal entre el Régimen General y el Régimen Especial en la distribución de conjunta de contribuyentes

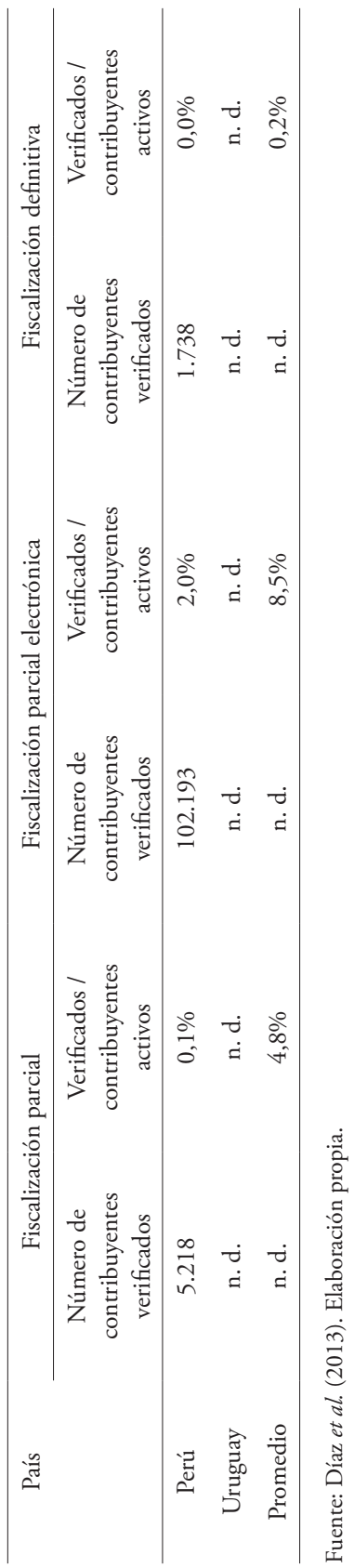


Anexo 7

Número de condenas relacionadas con crímenes de defraudación tributaria

\begin{tabular}{lccccc}
\hline País & 2006 & 2007 & 2008 & 2009 & 2010 \\
\hline Argentina & 36 & 39 & 38 & 7 & 12 \\
Bolivia & n. d. & n. d. & n. d. & n. d. & n. d. \\
Brasil & n. d. & n. d. & n. d. & n. d. & n. d. \\
Chile & 20 & 33 & 79 & 240 & 113 \\
Colombia & 388 & 353 & 389 & 316 & 310 \\
Costa Rica & n. d. & n. d. & n. d. & n. d. & n. d. \\
Ecuador & n. d. & n. d. & n. d. & n. d. & n. d. \\
El Salvador & n. d. & n. d. & n. d. & n. d. & n. d. \\
Guatemala & n. d. & 4 & 8 & 7 & 12 \\
Honduras & n. d. & n. d. & n. d. & n. d. & n. d. \\
México & 448 & 423 & 338 & 414 & 310 \\
Nicaragua & n. d. & n. d. & n. d. & n. d. & n. d. \\
Panamá & n. d. & n. d. & n. d. & n. d. & n. d. \\
Paraguay & n. d. & n. d. & n. d. & n. d. & n. d. \\
Perú & 10 & 19 & 37 & 5 & 3 \\
República Dominicana & n. d. & n. d. & n. d. & n. d. & n. d. \\
Uruguay & n. d. & n. d. & n. d. & 9 & 9 \\
\hline
\end{tabular}

Fuente: Díaz et al. (2013). Elaboración propia.

Anexo 8

Porcentaje de la población que confía en el gasto público

\begin{tabular}{llll}
\hline País & 2003 & 2005 & 2011 \\
\hline Argentina & $18 \%$ & $24 \%$ & $29 \%$ \\
Bolivia & $13 \%$ & $15 \%$ & $24 \%$ \\
Brasil & $19 \%$ & $13 \%$ & $14 \%$ \\
Chile & $31 \%$ & $41 \%$ & $33 \%$ \\
Colombia & $12 \%$ & $22 \%$ & $15 \%$ \\
Costa Rica & $17 \%$ & $12 \%$ & $16 \%$ \\
Ecuador & $7 \%$ & $12 \%$ & $38 \%$ \\
El Salvador & $26 \%$ & $32 \%$ & $22 \%$ \\
\hline
\end{tabular}


Interpolación del área distorsionada por el cambio de impuesto marginal entre el Régimen General y el Régimen Especial en la distribución de conjunta de contribuyentes

\begin{tabular}{lccc}
\hline País & 2003 & 2005 & 2011 \\
\hline Guatemala & $11 \%$ & $15 \%$ & $16 \%$ \\
Honduras & $29 \%$ & $21 \%$ & $18 \%$ \\
México & $9 \%$ & $15 \%$ & $16 \%$ \\
Nicaragua & $21 \%$ & $16 \%$ & $50 \%$ \\
Panamá & $15 \%$ & $14 \%$ & $43 \%$ \\
Paraguay & $4 \%$ & $18 \%$ & $21 \%$ \\
Perú & $10 \%$ & $11 \%$ & $13 \%$ \\
República Dominicana & n. d. & $25 \%$ & $16 \%$ \\
Uruguay & $15 \%$ & $56 \%$ & $51 \%$ \\
Venezuela & $20 \%$ & $43 \%$ & $41 \%$ \\
\hline
\end{tabular}

Fuente: Cepal (2011). Elaboración propia.

Anexo 9

Sensibilidad según región contrafactual $(2014)^{20}$

\begin{tabular}{ccccc}
\hline $\begin{array}{c}\text { Marginal } \\
\text { bunchers }\end{array}$ & $\begin{array}{c}\text { Ancho del } \\
\text { intervalo }\end{array}$ & $\begin{array}{c}\text { Región } \\
\text { contrafactual }\end{array}$ & $\begin{array}{c}\text { Ventana de } \\
\text { bunching }\end{array}$ & $\begin{array}{c}\text { Grado del } \\
\text { polinomio }\end{array}$ \\
\hline $\begin{array}{c}450,54 \\
(93,82)\end{array}$ & S/ 1.350 & S/ 170.100 & S/ 40.500 & 3 \\
470,61 & S/ 1.350 & S/ 178.200 & S/ 40.500 & 3 \\
$(96,99)$ & S/ 1.350 & S/ 186.300 & S/ 40.500 & 3 \\
506,64 & & & & 3 \\
$(89,91)$ & S/ 1.350 & S/ 194.400 & S/ 40.500 & 3 \\
501,84 & & & & 3 \\
$(90,63)$ & S/ 1.350 & S/ 202.500 & S/ 40.500 & 3 \\
496,21 & & & & 3 \\
$(88,94)$ & S/ 1.350 & S/ 210.600 & S/ 40.500 & 3 \\
496,74 & & & & 3 \\
$(86,58)$ & S/ 1.350 & S/ 218.700 & S/ 40.500 & 3 \\
492,14 & S/ 1.350 & S/ 226.800 & S/ 40.500 & 3 \\
$(90,25)$ & &
\end{tabular}

Elaboración propia.

${ }^{20} \delta=\mathrm{S} / 1.350$. 


\section{Anexo 10}

Sensibilidad según región excluida $(2014)^{21}$

\begin{tabular}{|c|c|c|c|c|}
\hline $\begin{array}{l}\text { Marginal } \\
\text { bunchers }\end{array}$ & $\begin{array}{c}\text { Ancho del } \\
\text { intervalo }\end{array}$ & $\begin{array}{c}\text { Región } \\
\text { contrafactual }\end{array}$ & $\begin{array}{c}\text { Ventana de } \\
\text { bunching }\end{array}$ & $\begin{array}{l}\text { Grado del } \\
\text { polinomio }\end{array}$ \\
\hline $\begin{array}{l}177,17 \\
(39,05)\end{array}$ & S/ 1.350 & S/ 226.800 & S/ 8.100 & 3 \\
\hline $\begin{array}{l}217,55 \\
(53,75)\end{array}$ & S/ 1.350 & S/ 226.800 & S/ 16.200 & 3 \\
\hline $\begin{array}{l}284,00 \\
(66,74)\end{array}$ & S/ 1.350 & S/ 226.800 & S/ 24.300 & 3 \\
\hline $\begin{array}{l}364,42 \\
(68,24)\end{array}$ & S/ 1.350 & S/ 226.800 & S/ 32.400 & 3 \\
\hline $\begin{array}{l}482,87 \\
(88,82)\end{array}$ & $S / 1.350$ & S/ 226.800 & S/ 40.500 & 3 \\
\hline $\begin{array}{l}555,15 \\
(94,10)\end{array}$ & $S / 1.350$ & S/ 226.800 & S/ 48.600 & 3 \\
\hline $\begin{array}{c}509,23 \\
(113,55)\end{array}$ & S/ 1.350 & S/ 226.800 & S/ 56.700 & 3 \\
\hline $\begin{array}{c}588,48 \\
(124,81)\end{array}$ & S/ 1.350 & S/ 226.800 & S/ 64.800 & 3 \\
\hline
\end{tabular}

Elaboración propia.

\section{Anexo 11}

Sensibilidad según región excluida $(2014)^{22}$

\begin{tabular}{ccccc}
\hline $\begin{array}{c}\text { Marginal } \\
\text { bunchers }\end{array}$ & $\begin{array}{c}\text { Ancho del } \\
\text { intervalo }\end{array}$ & $\begin{array}{c}\text { Región } \\
\text { contrafactual }\end{array}$ & $\begin{array}{c}\text { Ventana de } \\
\text { bunching }\end{array}$ & $\begin{array}{c}\text { Grado del } \\
\text { polinomio }\end{array}$ \\
\hline $\begin{array}{c}207,30 \\
(39,55)\end{array}$ & S/ 2.700 & S/ 226.800 & S/ 8.100 & 3 \\
220,61 & S/ 2.700 & S/ 226.800 & S/ 16.200 & 3 \\
$(57,63)$ & S/ 2.700 & S/ 226.800 & $S / 24.300$ & 3 \\
300,25 & & & & 3 \\
$(68,60)$ & S/ 2.700 & S/ 226.800 & $S / 32.400$ & 3 \\
365,48 & & & \\
\hline
\end{tabular}

${ }^{21} \delta=\mathrm{S} / 1.350$.

${ }^{22} \delta=\mathrm{S} / 2.700$. 
Interpolación del área distorsionada por el cambio de impuesto marginal entre el Régimen General y el Régimen Especial en la distribución de conjunta de contribuyentes

\begin{tabular}{ccccc}
\hline $\begin{array}{c}\text { Marginal } \\
\text { bunchers }\end{array}$ & $\begin{array}{c}\text { Ancho del } \\
\text { intervalo }\end{array}$ & $\begin{array}{c}\text { Región } \\
\text { contrafactual }\end{array}$ & $\begin{array}{c}\text { Ventana de } \\
\text { bunching }\end{array}$ & $\begin{array}{c}\text { Grado del } \\
\text { polinomio }\end{array}$ \\
\hline $\begin{array}{c}505,39 \\
(86,64)\end{array}$ & S/ 2.700 & S/ 226.800 & S/ 40.500 & 3 \\
585,97 & S/ 2.700 & S/ 226.800 & S/ 48.600 & 3 \\
$(97,87)$ & S/ 2.700 & S/ 226.800 & $S / 56.700$ & 3 \\
562,17 & & & & 3 \\
$(112,30)$ & S/ 2.700 & S/ 226.800 & $S / 64.800$ & 3 \\
623,06 & & & \\
\hline
\end{tabular}

Elaboración propia.

Anexo 12

Sensibilidad según región excluida $(2014)^{23}$

\begin{tabular}{|c|c|c|c|c|}
\hline $\begin{array}{c}\text { Marginal } \\
\text { bunchers }\end{array}$ & $\begin{array}{l}\text { Ancho del } \\
\text { intervalo }\end{array}$ & $\begin{array}{c}\text { Región } \\
\text { contrafactual }\end{array}$ & $\begin{array}{c}\text { Ventana de } \\
\text { bunching }\end{array}$ & $\begin{array}{l}\text { Grado del } \\
\text { polinomio }\end{array}$ \\
\hline $\begin{array}{l}141,79 \\
(41,32)\end{array}$ & S/ 4.050 & S/ 226.800 & S/ 8.100 & 3 \\
\hline $\begin{array}{l}217,48 \\
(55,66)\end{array}$ & S/ 4.050 & S/ 226.800 & S/ 16.200 & 3 \\
\hline $\begin{array}{l}279,38 \\
(65,78)\end{array}$ & S/ 4.050 & S/ 226.800 & S/ 24.300 & 3 \\
\hline $\begin{array}{l}365,75 \\
(78,58)\end{array}$ & S/ 4.050 & S/ 226.800 & S/ 32.400 & 3 \\
\hline $\begin{array}{c}502,12 \\
(105,14)\end{array}$ & S/ 4.050 & S/ 226.800 & S/ 40.500 & 3 \\
\hline $\begin{array}{l}518,04 \\
(88,76)\end{array}$ & S/ 4.050 & S/ 226.800 & S/ 48.600 & 3 \\
\hline $\begin{array}{c}500,64 \\
(109,99)\end{array}$ & S/ 4.050 & S/ 226.800 & S/ 56.700 & 3 \\
\hline $\begin{array}{c}552,73 \\
(117,10)\end{array}$ & S/ 4.050 & S/ 226.800 & S/ 64.800 & 3 \\
\hline
\end{tabular}

Elaboración propia.

${ }^{23} \delta=\mathrm{S} / 4.050$. 
Anexo 13

Sensibilidad según grado del polinomio $(2014)^{24}$

\begin{tabular}{|c|c|c|c|c|}
\hline $\begin{array}{l}\text { Marginal } \\
\text { bunchers }\end{array}$ & $\begin{array}{c}\text { Ancho del } \\
\text { intervalo }\end{array}$ & $\begin{array}{c}\text { Región } \\
\text { contrafactual }\end{array}$ & $\begin{array}{l}\text { Ventana de } \\
\text { bunching }\end{array}$ & $\begin{array}{l}\text { Grado del } \\
\text { polinomio }\end{array}$ \\
\hline $\begin{array}{l}482,86 \\
(96,85)\end{array}$ & S/ 1.350 & S/ 226.800 & S/ 40.500 & 2 \\
\hline $\begin{array}{l}482,86 \\
(77,86)\end{array}$ & S/ 1.350 & S/ 226.800 & S/ 40.500 & 3 \\
\hline $\begin{array}{c}450,22 \\
(104,56)\end{array}$ & S/ 1.350 & S/ 226.800 & S/ 40.500 & 4 \\
\hline $\begin{array}{c}450,22 \\
(104,10)\end{array}$ & S/ 1.350 & S/ 226.800 & S/ 40.500 & 5 \\
\hline $\begin{array}{c}226,65 \\
(136,02)\end{array}$ & $S / 1.350$ & S/ 226.800 & S/ 40.500 & 6 \\
\hline
\end{tabular}

Elaboración propia.

Anexo 14

Sensibilidad según grado del polinomio (2014)

\begin{tabular}{|c|c|c|c|c|}
\hline $\begin{array}{c}\text { Marginal } \\
\text { bunchers }\end{array}$ & $\begin{array}{c}\text { Ancho del } \\
\text { intervalo }\end{array}$ & $\begin{array}{c}\text { Región } \\
\text { contrafactual }\end{array}$ & $\begin{array}{l}\text { Ventana de } \\
\text { bunching }\end{array}$ & $\begin{array}{l}\text { Grado del } \\
\text { polinomio }\end{array}$ \\
\hline $\begin{array}{l}505,39 \\
(89,15)\end{array}$ & S/ 2.700 & S/ 226.800 & S/ 40.500 & 2 \\
\hline $\begin{array}{l}505,39 \\
(82,11)\end{array}$ & S/ 2.700 & S/ 226.800 & S/ 40.500 & 3 \\
\hline $\begin{array}{c}451,38 \\
(108,46)\end{array}$ & S/ 2.700 & S/ 226.800 & S/ 40.500 & 4 \\
\hline $\begin{array}{c}451,38 \\
(102,47)\end{array}$ & S/ 2.700 & S/ 226.800 & S/ 40.500 & 5 \\
\hline $\begin{array}{c}261,23 \\
(119,82)\end{array}$ & S/ 2.700 & S/ 226.800 & S/ 40.500 & 6 \\
\hline
\end{tabular}

Elaboración propia.

${ }^{24} \delta=\mathrm{S} / 1.350$.

${ }^{25} \delta=\mathrm{S} / 2.700$. 
Interpolación del área distorsionada por el cambio de impuesto marginal entre el Régimen General y el Régimen Especial en la distribución de conjunta de contribuyentes

Anexo 15

Sensibilidad según grado del polinomio $(2014)^{26}$

\begin{tabular}{ccccc}
\hline $\begin{array}{c}\text { Marginal } \\
\text { bunchers }\end{array}$ & $\begin{array}{c}\text { Ancho del } \\
\text { intervalo }\end{array}$ & $\begin{array}{c}\text { Región } \\
\text { contrafactual }\end{array}$ & $\begin{array}{c}\text { Ventana de } \\
\text { bunching }\end{array}$ & $\begin{array}{c}\text { Grado del } \\
\text { polinomio }\end{array}$ \\
\hline $\begin{array}{c}502,12 \\
(86,07)\end{array}$ & S/ 4.050 & S/ 226.800 & S/ 40.500 & 2 \\
502,12 & S/ 4.050 & S/ 226.800 & S/ 40.500 & 3 \\
$(90,82)$ & S/ 4.050 & S/ 226.800 & S/ 40.500 & 4 \\
471,13 & S/ 4.050 & S/ 226.800 & S/ 40.500 & 5 \\
$(107,18)$ & & & & 6 \\
471,13 & S/ 4.050 & S/ 226.800 & S/ 40.500 & 6 \\
$(111,42)$ & & & & 6 \\
276,59 & & & & \\
$(129,58)$ & & & & \\
\hline
\end{tabular}

Elaboración propia.

Anexo 16

Sensibilidad según región excluida $(2015)^{27}$

\begin{tabular}{|c|c|c|c|c|}
\hline $\begin{array}{c}\text { Marginal } \\
\text { bunchers }\end{array}$ & $\begin{array}{c}\text { Ancho del } \\
\text { intervalo }\end{array}$ & $\begin{array}{c}\text { Región } \\
\text { contrafactual }\end{array}$ & $\begin{array}{l}\text { Ventana de } \\
\text { bunching }\end{array}$ & $\begin{array}{l}\text { Grado del } \\
\text { polinomio }\end{array}$ \\
\hline $\begin{array}{l}394,59 \\
(43,33)\end{array}$ & S/ 1.350 & S/ 226.800 & S/ 8.100 & 3 \\
\hline $\begin{array}{l}466,34 \\
(61,45)\end{array}$ & S/ 1.350 & S/ 226.800 & S/ 16.200 & 3 \\
\hline $\begin{array}{l}536,84 \\
(63,46)\end{array}$ & S/ 1.350 & S/ 226.800 & S/ 24.300 & 3 \\
\hline $\begin{array}{l}642,04 \\
(83,58)\end{array}$ & S/ 1.350 & S/ 226.800 & S/ 32.400 & 3 \\
\hline $\begin{array}{l}641,18 \\
(96,51)\end{array}$ & S/ 1.350 & S/ 226.800 & S/ 40.500 & 3 \\
\hline $\begin{array}{l}654,46 \\
(96,81)\end{array}$ & S/ 1.350 & S/ 226.800 & S/ 48.600 & 3 \\
\hline $\begin{array}{c}660,12 \\
(114,76)\end{array}$ & S/ 1.350 & S/ 226.800 & $S / 56.700$ & 3 \\
\hline
\end{tabular}

${ }^{26} \delta=\mathrm{S} / 4.050$.

${ }^{27} \delta=S / 1.350$. 


\begin{tabular}{ccccc}
\hline $\begin{array}{c}\text { Marginal } \\
\text { bunchers }\end{array}$ & $\begin{array}{c}\text { Ancho del } \\
\text { intervalo }\end{array}$ & $\begin{array}{c}\text { Región } \\
\text { contrafactual }\end{array}$ & $\begin{array}{c}\text { Ventana de } \\
\text { bunching }\end{array}$ & $\begin{array}{c}\text { Grado del } \\
\text { polinomio }\end{array}$ \\
\hline $\begin{array}{c}674,39 \\
(112,46)\end{array}$ & S/ 1.350 & S/ 226.800 & S/ 64.800 & 3 \\
\hline
\end{tabular}

Elaboración propia.

Anexo 17

Sensibilidad según región excluida $(2015)^{28}$

\begin{tabular}{|c|c|c|c|c|}
\hline $\begin{array}{c}\text { Marginal } \\
\text { bunchers }\end{array}$ & $\begin{array}{c}\text { Ancho del } \\
\text { intervalo }\end{array}$ & $\begin{array}{c}\text { Región } \\
\text { contrafactual }\end{array}$ & $\begin{array}{l}\text { Ventana de } \\
\text { bunching }\end{array}$ & $\begin{array}{l}\text { Grado del } \\
\text { polinomio }\end{array}$ \\
\hline $\begin{array}{l}428,26 \\
(46,50)\end{array}$ & S/ 2.700 & S/ 226.800 & S/ 8.100 & 3 \\
\hline $\begin{array}{l}480,65 \\
(56,76)\end{array}$ & S/ 2.700 & S/ 226.800 & S/ 16.200 & 3 \\
\hline $\begin{array}{l}555,24 \\
(71,51)\end{array}$ & S/ 2.700 & S/ 226.800 & S/ 24.300 & 3 \\
\hline $\begin{array}{l}652,67 \\
(75,77)\end{array}$ & S/ 2.700 & S/ 226.800 & S/ 32.400 & 3 \\
\hline $\begin{array}{l}649,05 \\
(91,90)\end{array}$ & $S / 2.700$ & S/ 226.800 & S/ 40.500 & 3 \\
\hline $\begin{array}{c}666,21 \\
(103,40)\end{array}$ & $S / 2.700$ & S/ 226.800 & S/ 48.600 & 3 \\
\hline $\begin{array}{c}655,72 \\
(104,71)\end{array}$ & S/ 2.700 & S/ 226.800 & $S / 56.700$ & 3 \\
\hline $\begin{array}{c}664,62 \\
(125,88)\end{array}$ & S/ 2.700 & S/ 226.800 & S/ 64.800 & 3 \\
\hline
\end{tabular}

Elaboración propia.

${ }^{28} \delta=\mathrm{S} / 2.700$. 
Interpolación del área distorsionada por el cambio de impuesto marginal entre el Régimen General y el Régimen Especial en la distribución de conjunta de contribuyentes

\section{Anexo 18}

Sensibilidad según región excluida $(2015)^{29}$

\begin{tabular}{|c|c|c|c|c|}
\hline $\begin{array}{l}\text { Marginal } \\
\text { bunchers }\end{array}$ & $\begin{array}{c}\text { Ancho del } \\
\text { intervalo }\end{array}$ & $\begin{array}{c}\text { Región } \\
\text { contrafactual }\end{array}$ & $\begin{array}{c}\text { Ventana de } \\
\text { bunching }\end{array}$ & $\begin{array}{l}\text { Grado del } \\
\text { polinomio }\end{array}$ \\
\hline $\begin{array}{l}388,15 \\
(44,63)\end{array}$ & S/ 4.050 & S/ 226.800 & S/ 8.100 & 3 \\
\hline $\begin{array}{l}431,42 \\
(60,12)\end{array}$ & $S / 4.050$ & S/ 226.800 & S/ 16.200 & 3 \\
\hline $\begin{array}{l}503,81 \\
(74,18)\end{array}$ & $S / 4.050$ & S/ 226.800 & S/ 24.300 & 3 \\
\hline $\begin{array}{l}624,93 \\
(81,57)\end{array}$ & $S / 4.050$ & S/ 226.800 & S/ 32.400 & 3 \\
\hline $\begin{array}{l}608,79 \\
(95,97)\end{array}$ & S/ 4.050 & S/ 226.800 & S/ 40.500 & 3 \\
\hline $\begin{array}{c}674,16 \\
(105,48)\end{array}$ & S/ 4.050 & S/ 226.800 & S/ 48.600 & 3 \\
\hline $\begin{array}{c}649,45 \\
(114,96)\end{array}$ & S/ 4.050 & S/ 226.800 & S/ 56.700 & 3 \\
\hline $\begin{array}{c}654,16 \\
(135,10)\end{array}$ & S/ 4.050 & S/ 226.800 & S/ 64.800 & 3 \\
\hline
\end{tabular}

Elaboración propia.

Anexo 19

Sensibilidad según grado del polinomio $(2015)^{30}$

\begin{tabular}{ccccc}
\hline $\begin{array}{c}\text { Marginal } \\
\text { bunchers }\end{array}$ & $\begin{array}{c}\text { Ancho del } \\
\text { intervalo }\end{array}$ & $\begin{array}{c}\text { Región } \\
\text { contrafactual }\end{array}$ & $\begin{array}{c}\text { Ventana de } \\
\text { bunching }\end{array}$ & $\begin{array}{c}\text { Grado del } \\
\text { polinomio }\end{array}$ \\
\hline $\begin{array}{c}641,18 \\
(88,03)\end{array}$ & S/ 1.350 & S/ 226.800 & S/ 40.500 & 2 \\
641,18 & S/ 1.350 & S/ 226.800 & S/ 40.500 & 3 \\
$(86,53)$ & S/ 1.350 & S/ 226.800 & $S / 40.500$ & 4 \\
466,68 & & & \\
$(107,80)$ & S/ 1.350 & S/ 226.800 & $S / 40.500$ & 5 \\
466,68 & & & \\
$(106,52)$ & &
\end{tabular}

${ }^{29} \delta=\mathrm{S} / 4.050$.

${ }^{30} \delta=S / 1.350$. 


\begin{tabular}{ccccc}
\hline $\begin{array}{c}\text { Marginal } \\
\text { bunchers }\end{array}$ & $\begin{array}{c}\text { Ancho del } \\
\text { intervalo }\end{array}$ & $\begin{array}{c}\text { Región } \\
\text { contrafactual }\end{array}$ & $\begin{array}{c}\text { Ventana de } \\
\text { bunching }\end{array}$ & $\begin{array}{c}\text { Grado del } \\
\text { polinomio }\end{array}$ \\
\hline $\begin{array}{c}522,20 \\
(144,16)\end{array}$ & S/ 1.350 & S/ 226.800 & S/ 40.500 & 6 \\
\hline
\end{tabular}

Elaboración propia.

Anexo 20

Sensibilidad según grado del polinomio $(2015)^{31}$

\begin{tabular}{ccccc}
\hline $\begin{array}{c}\text { Marginal } \\
\text { bunchers }\end{array}$ & $\begin{array}{c}\text { Ancho del } \\
\text { intervalo }\end{array}$ & $\begin{array}{c}\text { Región } \\
\text { contrafactual }\end{array}$ & $\begin{array}{c}\text { Ventana de } \\
\text { bunching }\end{array}$ & $\begin{array}{c}\text { Grado del } \\
\text { polinomio }\end{array}$ \\
\hline $\begin{array}{c}649,05 \\
(91,82)\end{array}$ & S/ 2.700 & S/ 226.800 & S/ 40.500 & 2 \\
649,05 & S/ 2.700 & S/ 226.800 & S/ 40.500 & 3 \\
$(95,69)$ & S/ 2.700 & S/ 226.800 & S/ 40.500 & 4 \\
488,65 & & & & 5 \\
$(102,24)$ & S/ 2.700 & S/ 226.800 & $S / 40.500$ & 5 \\
488,65 & & & & 6 \\
$(107,30)$ & S/ 2.700 & S/ 226.800 & $S / 40.500$ & 6 \\
550,23 & & & & \\
$(129,03)$ & & & & \\
\hline
\end{tabular}

Elaboración propia.

Anexo 21

Sensibilidad según grado del polinomio $(2015)^{32}$

\begin{tabular}{ccccc}
\hline $\begin{array}{c}\text { Marginal } \\
\text { bunchers }\end{array}$ & $\begin{array}{c}\text { Ancho del } \\
\text { intervalo }\end{array}$ & $\begin{array}{c}\text { Región } \\
\text { contrafactual }\end{array}$ & $\begin{array}{c}\text { Ventana de } \\
\text { bunching }\end{array}$ & $\begin{array}{c}\text { Grado del } \\
\text { polinomio }\end{array}$ \\
\hline $\begin{array}{c}608,79 \\
(93,49)\end{array}$ & S/ 4.050 & S/ 226.800 & S/ 40.500 & 2 \\
608,79 & S/ 4.050 & S/ 226.800 & S/ 40.500 & 3 \\
$(94,87)$ & & & & \\
438,09 & S/ 4.050 & S/ 226.800 & S/ 40.500 & 4 \\
$(101,01)$ & & & \\
\hline
\end{tabular}

${ }^{31} \delta=S / 2.700$.

${ }^{32} \delta=S / 4.050$. 
Interpolación del área distorsionada por el cambio de impuesto marginal entre el Régimen General y el Régimen Especial en la distribución de conjunta de contribuyentes

\begin{tabular}{ccccc}
\hline $\begin{array}{c}\text { Marginal } \\
\text { bunchers }\end{array}$ & $\begin{array}{c}\text { Ancho del } \\
\text { intervalo }\end{array}$ & $\begin{array}{c}\text { Región } \\
\text { contrafactual }\end{array}$ & $\begin{array}{c}\text { Ventana de } \\
\text { bunching }\end{array}$ & $\begin{array}{c}\text { Grado del } \\
\text { polinomio }\end{array}$ \\
\hline $\begin{array}{c}438,09 \\
(118,81)\end{array}$ & S/ 4.050 & S/ 226.800 & S/ 40.500 & 5 \\
494,87 & S/ 4.050 & S/ 226.800 & S/ 40.500 & 6 \\
$(137,52)$ & & & \\
\hline
\end{tabular}

Elaboración propia.

Anexo 22

Sensibilidad según región excluida $(2016)^{33}$

\begin{tabular}{|c|c|c|c|c|}
\hline $\begin{array}{c}\text { Marginal } \\
\text { bunchers }\end{array}$ & $\begin{array}{c}\text { Ancho del } \\
\text { intervalo }\end{array}$ & $\begin{array}{c}\text { Región } \\
\text { contrafactual }\end{array}$ & $\begin{array}{l}\text { Ventana de } \\
\text { bunching }\end{array}$ & $\begin{array}{l}\text { Grado del } \\
\text { polinomio }\end{array}$ \\
\hline $\begin{array}{l}196,75 \\
(38,77)\end{array}$ & $S / 1.350$ & S/ 226.800 & S/ 8.100 & 3 \\
\hline $\begin{array}{l}346,42 \\
(57,92)\end{array}$ & $S / 1.350$ & S/ 226.800 & S/ 16.200 & 3 \\
\hline $\begin{array}{l}463,28 \\
(76,65)\end{array}$ & $S / 1.350$ & S/ 226.800 & S/ 24.300 & 3 \\
\hline $\begin{array}{l}485,68 \\
(82,86)\end{array}$ & S/ 1.350 & S/ 226.800 & S/ 32.400 & 3 \\
\hline $\begin{array}{l}542,52 \\
(86,18)\end{array}$ & $S / 1.350$ & S/ 226.800 & S/ 40.500 & 3 \\
\hline $\begin{array}{c}598,67 \\
(112,32)\end{array}$ & $S / 1.350$ & S/ 226.800 & S/ 48.600 & 3 \\
\hline $\begin{array}{c}600,82 \\
(108,59)\end{array}$ & S/ 1.350 & S/ 226.800 & S/ 56.700 & 3 \\
\hline $\begin{array}{c}534,68 \\
(135,48)\end{array}$ & $\mathrm{S} / 1.350$ & S/ 226.800 & S/ 64.800 & 3 \\
\hline
\end{tabular}

Elaboración propia.

${ }^{33} \delta=\mathrm{S} / 1.350$. 
Anexo 23

Sensibilidad según región excluida $(2016)^{34}$

\begin{tabular}{|c|c|c|c|c|}
\hline $\begin{array}{l}\text { Marginal } \\
\text { bunchers }\end{array}$ & $\begin{array}{c}\text { Ancho del } \\
\text { intervalo }\end{array}$ & $\begin{array}{c}\text { Región } \\
\text { contrafactual }\end{array}$ & $\begin{array}{c}\text { Ventana de } \\
\text { bunching }\end{array}$ & $\begin{array}{l}\text { Grado del } \\
\text { polinomio }\end{array}$ \\
\hline $\begin{array}{l}428,26 \\
(46,50)\end{array}$ & S/ 2.700 & S/ 226.800 & S/ 8.100 & 3 \\
\hline $\begin{array}{l}480,65 \\
(56,76)\end{array}$ & S/ 2.700 & S/ 226.800 & S/ 16.200 & 3 \\
\hline $\begin{array}{l}555,24 \\
(71,51)\end{array}$ & S/ 2.700 & S/ 226.800 & S/ 24.300 & 3 \\
\hline $\begin{array}{l}652,67 \\
(75,77)\end{array}$ & S/ 2.700 & S/ 226.800 & S/ 32.400 & 3 \\
\hline $\begin{array}{l}649,05 \\
(91,90)\end{array}$ & S/ 2.700 & S/ 226.800 & S/ 40.500 & 3 \\
\hline $\begin{array}{c}666,21 \\
(103,40)\end{array}$ & S/ 2.700 & S/ 226.800 & S/ 48.600 & 3 \\
\hline $\begin{array}{c}655,72 \\
(104,71)\end{array}$ & S/ 2.700 & S/ 226.800 & S/ 56.700 & 3 \\
\hline $\begin{array}{c}664,62 \\
(125,88)\end{array}$ & S/ 2.700 & S/ 226.800 & S/ 64.800 & 3 \\
\hline
\end{tabular}

Elaboración propia.

Anexo 24

Sensibilidad según región excluida (2016) ${ }^{35}$

\begin{tabular}{ccccc}
\hline $\begin{array}{c}\text { Marginal } \\
\text { bunchers }\end{array}$ & $\begin{array}{c}\text { Ancho del } \\
\text { intervalo }\end{array}$ & $\begin{array}{c}\text { Región } \\
\text { contrafactual }\end{array}$ & $\begin{array}{c}\text { Ventana de } \\
\text { bunching }\end{array}$ & $\begin{array}{c}\text { Grado del } \\
\text { polinomio }\end{array}$ \\
\hline $\begin{array}{l}195,34 \\
(46,91)\end{array}$ & S/ 4.050 & S/ 226.800 & S/ 8.100 & 3 \\
358,89 & S/ 4.050 & S/ 226.800 & S/ 16.200 & 3 \\
$(55,01)$ & S/ 4.050 & S/ 226.800 & $S / 24.300$ & 3 \\
454,96 & & & & 3 \\
$(77,35)$ & $S / 4.050$ & $S / 226.800$ & $S / 32.400$ & 3 \\
498,01 & & & & 3 \\
\hline
\end{tabular}

${ }^{34} \delta=\mathrm{S} / 2.700$.

${ }^{35} \delta=\mathrm{S} / 4.050$. 
Interpolación del área distorsionada por el cambio de impuesto marginal entre el Régimen General y el Régimen Especial en la distribución de conjunta de contribuyentes

\begin{tabular}{ccccc}
\hline $\begin{array}{c}\text { Marginal } \\
\text { bunchers }\end{array}$ & $\begin{array}{c}\text { Ancho del } \\
\text { intervalo }\end{array}$ & $\begin{array}{c}\text { Región } \\
\text { contrafactual }\end{array}$ & $\begin{array}{c}\text { Ventana de } \\
\text { bunching }\end{array}$ & $\begin{array}{c}\text { Grado del } \\
\text { polinomio }\end{array}$ \\
\hline $\begin{array}{c}521,63 \\
(94,22)\end{array}$ & S/ 4.050 & S/ 226.800 & S/ 40.500 & 3 \\
579,45 & S/ 4.050 & S/ 226.800 & S/ 48.600 & 3 \\
$(109,87)$ & S/ 4.050 & S/ 226.800 & $S / 56.700$ & 3 \\
577,44 & & & & 3 \\
$(114,74)$ & $S / 4.050$ & S/ 226.800 & $S / 64.800$ & 3 \\
495,87 & & & \\
$(131,31)$ & &
\end{tabular}

Elaboración propia.

Anexo 25

Sensibilidad según grado del polinomio (2016) ${ }^{36}$

\begin{tabular}{|c|c|c|c|c|}
\hline $\begin{array}{c}\text { Marginal } \\
\text { bunchers }\end{array}$ & $\begin{array}{l}\text { Ancho del } \\
\text { intervalo }\end{array}$ & $\begin{array}{c}\text { Región } \\
\text { contrafactual }\end{array}$ & $\begin{array}{l}\text { Ventana de } \\
\text { bunching }\end{array}$ & $\begin{array}{l}\text { Grado del } \\
\text { polinomio }\end{array}$ \\
\hline $\begin{array}{l}542,52 \\
(89,34)\end{array}$ & S/ 1.350 & S/ 226.800 & S/ 40.500 & 2 \\
\hline $\begin{array}{l}542,52 \\
(97,14)\end{array}$ & S/ 1.350 & S/ 226.800 & S/ 40.500 & 3 \\
\hline $\begin{array}{c}416,80 \\
(110,12)\end{array}$ & $S / 1.350$ & S/ 226.800 & S/ 40.500 & 4 \\
\hline $\begin{array}{c}416,80 \\
(115,60)\end{array}$ & $S / 1.350$ & S/ 226.800 & S/ 40.500 & 5 \\
\hline $\begin{array}{c}333,64 \\
(130,56)\end{array}$ & $S / 1.350$ & S/ 226.800 & S/ 40.500 & 6 \\
\hline
\end{tabular}

Elaboración propia.

${ }^{36} \delta=\mathrm{S} / 1.350$. 


\section{Anexo 26}

Sensibilidad según grado del polinomio (2016) ${ }^{37}$

\begin{tabular}{|c|c|c|c|c|}
\hline $\begin{array}{l}\text { Marginal } \\
\text { bunchers }\end{array}$ & $\begin{array}{c}\text { Ancho del } \\
\text { intervalo }\end{array}$ & $\begin{array}{c}\text { Región } \\
\text { contrafactual }\end{array}$ & $\begin{array}{l}\text { Ventana de } \\
\text { bunching }\end{array}$ & $\begin{array}{l}\text { Grado del } \\
\text { polinomio }\end{array}$ \\
\hline $\begin{array}{l}567,74 \\
(94,81)\end{array}$ & S/ 2.700 & S/ 226.800 & S/ 40.500 & 2 \\
\hline $\begin{array}{l}567,74 \\
(86,51)\end{array}$ & $S / 2.700$ & S/ 226.800 & S/ 40.500 & 3 \\
\hline $\begin{array}{c}450,86 \\
(107,04)\end{array}$ & S/ 2.700 & S/ 226.800 & S/ 40.500 & 4 \\
\hline $\begin{array}{c}450,86 \\
(110,11)\end{array}$ & S/ 2.700 & S/ 226.800 & S/ 40.500 & 5 \\
\hline $\begin{array}{c}365,66 \\
(138,60)\end{array}$ & S/ 2.700 & S/ 226.800 & S/ 40.500 & 6 \\
\hline
\end{tabular}

Elaboración propia.

Anexo 27

Sensibilidad según grado del polinomio (2016) ${ }^{38}$

\begin{tabular}{|c|c|c|c|c|}
\hline $\begin{array}{c}\text { Marginal } \\
\text { bunchers }\end{array}$ & $\begin{array}{c}\text { Ancho del } \\
\text { intervalo }\end{array}$ & $\begin{array}{c}\text { Región } \\
\text { contrafactual }\end{array}$ & $\begin{array}{l}\text { Ventana de } \\
\text { bunching }\end{array}$ & $\begin{array}{l}\text { Grado del } \\
\text { polinomio }\end{array}$ \\
\hline $\begin{array}{l}521,63 \\
(84,87)\end{array}$ & S/ 4.050 & S/ 226.800 & S/ 40.500 & 2 \\
\hline $\begin{array}{c}521,63 \\
(101,31)\end{array}$ & S/ 4.050 & S/ 226.800 & S/ 40.500 & 3 \\
\hline $\begin{array}{c}376,74 \\
(120,96)\end{array}$ & S/ 4.050 & S/ 226.800 & S/ 40.500 & 4 \\
\hline $\begin{array}{c}376,74 \\
(112,58)\end{array}$ & S/ 4.050 & S/ 226.800 & S/ 40.500 & 5 \\
\hline $\begin{array}{c}309,03 \\
(137,31)\end{array}$ & S/ 4.050 & S/ 226.800 & S/ 40.500 & 6 \\
\hline
\end{tabular}

Elaboración propia.

${ }^{37} \delta=\mathrm{S} / 2.700$.

${ }^{38} \delta=\mathrm{S} / 4.050$. 



\section{Determinantes del retiro de fondos del Sistema Privado de Pensiones: un análisis de los destinatarios}

Rodrigo Ojeda del Arco Bautista

\section{Introducción}

Es debido a una relación positiva entre el ahorro y el crecimiento económico que diversas instituciones internacionales recomiendan el aumento de la tasa de ahorro para combatir el bajo crecimiento económico experimentado por varios países (Xala i Martin, 2000). En este contexto, la seguridad social cobra relevancia.

La Organización Internacional del Trabajo define la seguridad social como «la protección que una sociedad proporciona a los individuos y los hogares para asegurar el acceso a la asistencia médica y garantizar la seguridad del ingreso, en particular en caso de vejez, desempleo, enfermedad, invalidez, accidentes del trabajo, maternidad o pérdida del sostén de familia» (OIT, 2004, p. 1) y la presenta como un reto universal en un mundo globalizado. Según información censal, casi la mitad de todas las personas no reciben una pensión cuando se jubilan. Se infiere, entonces, que la mayoría de las mujeres y los hombres en edad de jubilarse deberán seguir trabajando, muchas veces mal pagados o en condiciones precarias, para asegurarse el sustento. Por ello, Prado \& Sojo (2010, p. 16) sostienen que «es crucial innovar en la protección de adultos mayores, prevenir o encarar la pobreza de personas en edad avanzada y labrar y ampliar instrumentos de la seguridad social que permitan consolidar una protección social integral, universal y solidaria en la vejez».

\footnotetext{
${ }^{1}$ Este ensayo es una versión resumida y editada del Trabajo de Investigación Económica que, con el mismo título, fue concluido en noviembre de 2017. El autor agradece a su asesor, Elio Sánchez, profesor de la Universidad del Pacífico y funcionario de la Superintendencia de Banca, Seguros y AFP, cuya orientación y enseñanzas fueron vitales para la elaboración de esta investigación.
} 
Teniendo en cuenta que la gestión pública suele desempeñarse en escenarios de recursos escasos, los esfuerzos gubernamentales para cubrir las necesidades sociales de la población, en cuanto a pensiones para el retiro, deberían apuntar a proveer un marco normativo adecuado e incentivar la competencia para que este mercado funcione correctamente. En tal contexto, tanto el Estado como el sector privado podrían establecer acuerdos útiles para satisfacer las expectativas de los jubilados (Butare, 1998).

Revisando experiencias de reforma fuera de Latinoamérica, tenemos que, en el Reino Unido, un individuo que ha aportado al sistema de pensiones tiene diversas opciones respecto a su fondo de retiro. En un primer momento de la reforma, el aportante podía retirar hasta el $25 \%$ de sus activos ahorrados libres de impuestos y utilizar el resto para comprar una anualidad de una compañía de seguros. Actualmente, el porcentaje de retiro posible ha aumentado hasta casi la totalidad del fondo. Aquí, el análisis para entender el comportamiento y la decisión del aportante se centra en dos factores: el nivel de riesgo que está dispuesto a asumir y el monto de impuestos por pagar. Australia tiene un sistema privado de pensiones obligatorio que fomenta planes de contribución definida, y que también ofrece la opción de retiro del fondo de pensiones. Pero, al igual que en el Reino Unido, se asegura una pensión que garantiza un mínimo nivel de vida a los jubilados. De ahí la importancia de un estudio del caso australiano realizado por Gordon \& Jung-Wha (2009), que incluye información sobre la cultura financiera de esa población y diversos aspectos sociales que son de interés para los formuladores de políticas. Varios de esos aspectos sociales son tomados en cuenta por el presente estudio.

Villagómez (2014) constata que, desde hace algún tiempo, existe preocupación entre académicos y autoridades en muchos países sobre si los individuos están realizando el ahorro necesario para mantener un nivel de consumo y bienestar adecuado durante su jubilación. En el Perú, aproximadamente 2 millones de personas son mayores de 65 ańos. De estas, cerca de la mitad (43\%) no cuentan con una pensión mensual para su vejez, un $27 \%$ recibe una pensión del sistema nacional contributivo (SNP), un 23\% recibe una pensión del sistema nacional no contributivo (Pensión 65) y solo un $7 \%$ recibe una pensión del Sistema Privado de Pensiones (SPP). Esto último significa que alrededor de 140.000 personas mayores de 65 años reciben una pensión resultante de su afiliación a una administradora de fondos de pensiones (AFP).

Luego de sucesivas modificaciones a la Ley de Pensiones, en abril de 2016 el Congreso aprobó por insistencia las Leyes 30425 y 30478, que facultan a los afiliados a las AFP a retirar, a partir de los 65 años o cuando completaran el 
requisito para la jubilación, hasta el $95,5 \%$ sus fondos. En la presente investigación, se analizan las características de los destinatarios de estos montos a suma alzada, para así identificar el segmento de la población que se está acogiendo a dichas leyes y, con ello, entender el porqué de su decisión y la medida en que sus características personales explican esta decisión financiera tan trascendental.

La importancia del ahorro en la economía surge por el impacto de la elección intertemporal entre consumo presente y consumo futuro en el bienestar de las personas, así como por la estrecha relación entre ahorro e inversión a nivel macro. Dicha importancia radica, así, en la íntima relación del ahorro con el bienestar de los individuos y el crecimiento económico. La tasa de dependencia es el índice demográfico que expresa, en forma de porcentaje, la relación existente entre la población dependiente y la población productiva, de la que aquella depende. Como se aprecia en el anexo 1, la tasa de dependencia peruana ha aumentado en las últimas décadas: en 1990 fue de alrededor de un $7 \%$; en el año 2015, subió a alrededor de un $10 \%$; y se espera que para el año 2050 esté por encima del 20\% (INEI, 2018) ${ }^{2}$. Además, Sharpe, Goldstein \& Johnson (2008) enfatizan que invertir para la jubilación es una de las decisiones más trascendentales e intimidantes que enfrentan las personas.

Por ende, el bienestar del adulto mayor jubilado es de interés no solo por razones humanitarias, sino también por la implicancia económica que tiene para la sociedad en su conjunto y en particular por la presión sobre las futuras generaciones. Pero no existen trabajos de investigación anteriores al presente que analicen los destinatarios de las pensiones de jubilación para el caso peruano, cuyas características lo diferencian de casos de economías desarrolladas con sistemas pensionarios avanzados y sistemas de seguridad social de mayor madurez.

Lo anterior justifica los objetivos de la presente investigación, centrados en identificar y analizar los factores por los cuales un sector de la población decidió hacer efectivo el retiro de su dinero del Sistema Privado de Pensiones; además de hallar en qué medida esos factores determinaron dicha decisión y, por contraste, la de aquellos jubilados que mantuvieron sus fondos de pensiones acumulados en una AFP (véanse los anexos 3 y 4 ).

La hipótesis principal plantea que el factor determinante para que una persona retire su dinero es el monto de su cuenta individual de capitalización (o tamaño del fondo), y la consiguiente pensión futura esperada. Esta pensión, a su vez, depende de lo ahorrado; por lo que se propone que son principalmente

\footnotetext{
${ }^{2}$ Véanse los anexos 1 y 2.
} 
personas de bajos ingresos, o que no han realizado suficientes aportes a su AFP, las que en su mayoría tomarían la decisión de retirar sus fondos de la AFP. El individuo, ante una pensión de jubilación muy baja, podría tener una clara preferencia por disponer de «un gran monto» de una sola vez.

De la hipótesis principal se desprenden algunas hipótesis secundarias. Estas postulan que, además del tamaño del fondo, existen otros factores que pueden estimular a una persona a preferir tener todo el dinero en mano en vez de recibirlo por partes en futuros pagos mensuales. Para comprobar esto, aquí también se analiza la incidencia de variables sociodemográficas como el sexo, la edad y la actitud de cada persona frente al riesgo.

Este documento tiene seis secciones, incluyendo esta introducción. En la segunda sección, se revisan trabajos de investigación que han buscado analizar el impacto, los beneficios y/o los potenciales riesgos de políticas pensionarias similares a la peruana actual. En la tercera sección, se explica el marco analítico de esta investigación; en la cuarta, su metodología; y en las últimas dos secciones, se analizan los resultados para, con base en ellos, extraer las conclusiones del trabajo.

\section{Revisión de literatura especializada}

A raíz de la creciente preocupación por el ahorro para la vejez y las pensiones para la jubilación, los estudios -académicos incluso- de este tema se han incrementado en los últimos ańos. Pero buena parte de la literatura revisada versa sobre países con sistemas de pensiones más desarrollados que el peruano, con coyunturas distintas y un perfil del pensionista diferente. Sin embargo, al revisarla, se encontraron algunas similitudes en cuanto a metodología y resultados, que inspiran la presente investigación, cuyo enfoque (antes mencionado) es novedoso de cara a los estudios sobre el caso peruano.

\subsection{Seguridad social}

Las pensiones de jubilación son esenciales para garantizar los derechos, la dignidad y la seguridad de ingresos para las personas mayores. El derecho a la seguridad de los ingresos en la vejez, como se basa en preceptos de derechos humanos y normas internacionales del trabajo, incluye el derecho a una pensión adecuada. Y vale recalcar que la protección social no se basa solo en derechos humanos sino también en sólidos argumentos de política económica (OIT, 2004).

La inseguridad económica en la vejez es un problema mundial, pero cada región y país experimenta y afronta el problema de manera distinta. El Banco 
Mundial (1994) justifica la intervención estatal en la materia, pues advierte que confiar en las acciones voluntarias de las personas puede traer consigo problemas como el desinterés de algunas personas en ahorrar para su vejez, poca o mala información por parte del Estado y la empresa privada, opciones de ahorro poco adecuadas y fallas en el mercado de fondos de pensiones debido a selección adversa y riesgo moral. Por ello, dicho organismo recomienda la existencia de un sistema obligatorio de cobertura amplia. En tal sentido, Bosch, Melguizo \& Pages (2013) señalan como factores determinantes de la cobertura universal el funcionamiento del mercado laboral y la compleja interacción entre trabajadores y empresas.

Para el Perú, los investigadores Mendoza, Seminario \& Cruz Saco (2014) concuerdan con el Banco Mundial en la importancia que debe tener la reforma previsional en un programa de gobierno, pero proponen implementar una pensión no contributiva para todas las personas mayores de 65 años y eliminar el aporte obligatorio a las AFP. Así, el debate en el Perú ha girado entre seguir las pautas del Banco Mundial o apoyar reformas como las planteadas por Mendoza et al. (2014). Sin embargo, hay consenso en que se debe asegurar el bienestar de las personas mayores con pensiones que cubran sus necesidades.

\subsection{Determinantes del ahorro y motivación del ahorro para la jubilación}

Entre las investigaciones aplicadas a países con economías en desarrollo, Esmail \& Abdelaty (2014) analizan los factores macroeconómicos determinantes de ahorros en Egipto usando regresión múltiple corriente. Sus hallazgos sugieren que la tasa de ahorro nacional está relacionada positivamente con la tasa de crecimiento del PIB, y relacionada negativamente con el crecimiento de deuda federal e inflación.

Doker, Turkmen \& Emsen (2015) también analizaron el caso egipcio, pero eligieron como determinantes comunes del ahorro la tasa de dependencia (en total, de jóvenes y según edad), la participación del sexo femenino en la fuerza laboral, la urbanización y la densidad poblacional. Encontraron que los efectos de esas variables concuerdan con las expectativas teóricas, en el sentido de que están correlacionadas positivamente con el ahorro, mientras que la tasa de desempleo, la dependencia en la vejez y la densidad de poblacional lo están negativamente.

Según Finke \& Houston (2013), el ahorro temprano para la jubilación es motivado por el deseo de aumentar o mantener el consumo en un tiempo futuro. Este intercambio intertemporal sugiere una relación teórica entre la 
construcción económica de la preferencia por el tiempo o período y el deseo de ahorrar para la jubilación. A partir de un universo de 6.812 estudiantes de pregrado, posgrado y profesionales, dichos autores construyeron un cuadro de preferencias en cuanto a salud, detectaron que la población era adversa al riesgo y encontraron que más de la mitad de los encuestados creían que el ahorro para la jubilación es muy importante $(30,9 \%)$ o importante $(28,6 \%)$, mientras que pocos pensaban que no es importante para nada $(1,4 \%)$ o que es poco importante $(12,7 \%)$.

Fernández, Vivel \& Otero (2012) evidencian que existe una amplia variabilidad en el porcentaje de individuos que ahorran o ahorrarían para su jubilación, en función del país donde viven. Así, por ejemplo, en Suecia, casi el $70 \%$ de la población menciona la jubilación como una razón importante para su ahorro, frente a aproximadamente el 30\% registrado entre franceses e italianos. Dichos autores identifican que la cultura financiera ejerce una influencia directa y significativa sobre la decisión de ahorrar para la jubilación, por lo cual resaltan la importancia del desarrollo de programas de educación financiera, en especial para la población en peores condiciones económicas. Los resultados de sus estudios muestran que cuanto mayor sea el nivel de ingresos o estatus laboral del individuo, mayor es la probabilidad de ahorrar para la jubilación.

Una investigación de Portocarrero (2013) acerca de la acumulación de riqueza por la élite peruana a inicios del siglo XX nos deja dos hallazgos importantes. En primer lugar, acerca de la aversión al riesgo, comenta que, si bien hubo hacendados cuya acumulación de riqueza se basó en criterios capitalistas, existieron otros, ubicados por lo general en la Sierra, que nunca realizaron inversiones significativas. Según el autor, esta manera de pensar existe hasta hoy y se ha propagado por todo el país. En segundo lugar, ya más específicamente acerca de mecanismos de conservación de las fortunas y maneras de asegurar una vejez sin problemas, señala que estos consistían en realizar gastos en un monto menor que su renta, para así asegurarse una holgura durante la ancianidad o tras el fallecimiento de la cabeza de familia.

\subsection{Modalidad de retiro del fondo de pensiones}

Fatas, Lacomba, Lagos \& Moro-Egido (2013) condujeron un experimento en España con el objetivo de examinar los riesgos potenciales sobre el consumo del pago a suma alzada por retiro del fondo de pensiones. Como se pensaba que el dinero recibido sería gastado rápidamente y ello aumentaría los índices de pobreza, investigaron experimentalmente el consumo en un entorno de 
toma de decisiones intertemporales. Sus resultados demostraron que, en lugar de consumir demasiado al recibir todo el monto para su jubilación, los sujetos mostraban un persistente comportamiento de ahorro por precaución, el cual se explicaría principalmente por su aversión al riesgo.

Moore \& Muller (2002) analizaron los destinatarios de la modalidad de pago a suma alzada en los Estados Unidos. Encontraron que la mayoría de estos destinaron sus fondos a una cuenta en la que ganaran algún tipo de interés, y los que gastaron su dinero lo hicieron para pagar deudas o comprar distintos productos. También analizaron variables demográficas de las personas que ahorraron su pensión, y encontraron que el estado civil, la raza, los ingresos y el total de riqueza de la familia son significativos. El modelo aplicado fue el siguiente:

$$
Y_{j}^{*}=b_{0 j}+b_{j} x+e_{j}
$$

Donde la variable dependiente $\left(Y_{j}\right)$ mide la utilidad del individuo por ahorrar el pago recibido, $x$ es un vector de características financieras y demográficas que afecta el uso del pago a suma alzada recibido y que incluye las variables antes mencionadas, el término $b_{0 j}$ es una constante y $e_{j}$ representa el error.

Butler \& Teppa (2007) comentan que, a pesar de la relevancia mundial adquirida por el tema de la modalidad del pago de pensiones, no hay muchos estudios al respecto. Uno de los primeros fue el de Hurd \& McGarry (1993), quienes utilizaron datos de la Encuesta de Retiro Salud (HRS) en los Estados Unidos. En ambos estudios, la preferencia por las pensiones a suma alzada es mayor que la de una pensión fraccionada tradicional. Asimismo, Beshears, Choi, Laibson, Madrian \& Zeldes (2013) realizaron una investigación de las preferencias sobre modalidades de pensiones en los Estados Unidos. Encontraron que el 60\% de los individuos prefieren tener un bono en un mes de su elección, además de sus pagos mensuales; es decir, bajo esta modalidad, las personas reciben una cantidad $x$ de manera mensual, pero en un mes de su elección recibirían $x+$ una cantidad $b$.

De manera similar, Flaherty (2010) diseñó un modelo para analizar la preferencia individual por planes de pensiones, guiado por un marco analítico que considera los siguientes factores: $g$ (movilidad laboral, alcance de la carrera, aversión al riesgo, conocimientos financieros, activos en el sistema pensionario, edad) $+\mu$. Como algunos de estos factores no son observables, recurre al género como proxy de la aversión al riesgo, y al nivel de educación como proxy del alcance de la carrera. Así, estima la siguiente ecuación: 


$$
\begin{gathered}
Y_{i}=\beta_{0}+\beta_{1}{ }^{*} \text { posición }+\beta_{2}{ }^{*} \text { educación }+\beta_{3}{ }^{*} \text { conoc.financiero }+ \\
\beta_{4}{ }^{*} \text { cobertura }+\beta_{5} \text { Edad }+\mu
\end{gathered}
$$

Sus hallazgos indican que los individuos con preferencias por carreras cortas y una menor aversión al riesgo, entre otros factores, eligen un plan de pensión en el que tengan titularidad de la cuenta y la responsabilidad de su uso, y la otra opción es un plan de pensión que incluye un pago mensual; pero no vinculan al individuo con los fondos totales en ningún sentido. A su vez, Gerrans \& Clark (2013) analizaron la elección entre dos modalidades - defined benefit y defined contributions- similares a las de Flaherty, utilizando datos de los más grandes fondos de Australia. Corrieron un modelo logit multinomial para las distintas opciones entre dichas modalidades y tuvieron como variables explicativas las contribuciones del individuo al sistema, su edad y grado académico, entre otros factores. Encontraron que los individuos jóvenes y con mayores ingresos eran los que preferían cambiarse de modalidad a la más riesgosa (defined contributions) y que, en consecuencia, existe una diferencia considerable en comportamiento frente al riesgo entre los que eligen un plan y el otro.

Otro experimento, realizado por Gunderson \& Luchak (2001) aplicando una encuesta a 517 empleados, tuvo como marco la hipotética situación en la cual cada individuo poseía una cantidad de dinero para asignarla a distintas opciones, como pensiones para el retiro, usar el efectivo, entre otras. Su variable dependiente está representada por las opciones abiertas al individuo respecto al dinero recibido, y las variables independientes son los determinantes de la preferencia por planes de pensión, los cuales, según dichos autores, son características demográficas y personales del individuo e incluyen algunas características del mercado. Los resultados de su experimento (para el cual contaron con mayor cantidad de datos, y más exactos, sobre la población analizada) indican que: la edad es un factor decisivo al elegir un plan de jubilación; las mujeres tienen una fuerte preferencia por la jubilación anticipada; la salud del individuo (posiblemente relacionada con su edad) determina la elección entre un plan de jubilación o utilizar el dinero en efectivo; mientras que las personas con ingresos más altos tienden a asignar su dinero a mecanismos ajustados por la inflación para asegurar la estabilidad de sus pensiones.

En el Perú, no existen estudios sobre ese tipo de preferencias, pero sí encontramos uno acerca de qué prefieren las personas a la hora de cambiarse de una AFP a otra. Méndez (2007) señala que, para los afiliados a una AFP pertenecientes a los NSE A y B, las variables que aumentan la probabilidad de traspaso son: la rentabilidad, la comisión, los regalos, la solidez, la confianza y 
los años en el sistema. Este estudio, si bien se centra en una población específica y en la opción de traspaso, constituye un paso inicial hacia al análisis de las preferencias de individuos por productos pensionarios en el Perú.

\section{Marco analítico}

El sistema previsional peruano está dividido en tres regímenes principales, además de los regímenes pensionarios para militares y la Policía Nacional: el Sistema Nacional de Pensiones (SNP), el denominado Cédula Viva y el Sistema Privado de Pensiones (SPP). Esta investigación se centra solo en el SPP. Actualmente hay cuatro AFP en el mercado peruano: AFP Integra, del grupo Sura; AFP Prima, del grupo Credicorp, liderado por el BCP; AFP Profuturo, del grupo Scotiabank; y AFP Habitat, de Prudential Financial y la chilena Inversiones La Construcción (ILC). Estas AFP compiten en el mercado de traspasos y con el tiempo volverán a licitar para ver cuál capta a los nuevos clientes, derecho otorgado de manera exclusiva a AFP Habitat en la actualidad.

La demanda por el servicio pensionario nace del deseo de tener una calidad de vida similar a la lograda cuando se está laboralmente activo. Pero Friedman (1973) considera al ahorro como un «residuo", porque define a la renta como la cantidad de unidades de consumo que permite consumir, de modo que su análisis considera al consumo como función del ingreso (renta) y supone que la función de utilidad no solo es simétrica sino además homogénea en el consumo durante el período 1 y el período 2 . El respectivo efecto sustitución depende de la proporción entre los consumos de ambos períodos y no del nivel absoluto del consumo.

Mientras tanto, el modelo tradicional del ciclo vital del ahorro explica cómo las personas asignan sus recursos para asegurarse un continuo nivel de consumo durante toda su vida (Modigliani \& Brumberg, 1954). El individuo que es financieramente responsable no consume toda su renta, sino que ahorra una parte para recibirla cuando se jubile en la forma de una pensión que le permita mantener dicho nivel de consumo. Estos individuos eligen así trayectorias óptimas de riqueza y consumo lo largo de toda su vida, y también eligen la edad de su pase al retiro. Para ello, según Eguía (1997), maximizan el valor presente descontado de su utilidad futura esperada sujeto a una restricción presupuestaria. Las correspondientes decisiones del individuo vienen dadas por la siguiente función logarítmica, donde $p$ es la tasa de descuento intertemporal:

$$
M A X_{\{\mathrm{c}(\mathrm{t}), \mathrm{R}\}} \int_{0}^{\infty} e^{-p t} p(t) \operatorname{Lnc}(t) d t-G \int_{0}^{R} e^{-p} p(t) d t
$$


Lo anterior implica que el individuo separa su vida en dos fases: su vida activa, durante la cual ahorra; y su vida como jubilado, durante la cual comienza a gastar el dinero que ahorró en la fase anterior.

Pero una gran pregunta analítica y real preocupación práctica es cómo saber si, cuando un individuo llega a la edad de jubilarse, ha ahorrado lo suficiente o no. Matemáticamente, ello puede ilustrarse de esta manera: $\sum x(n)=n \mu+$ $\operatorname{tq} \sigma^{\wedge}(1 / 2)$; donde $n$ es la esperanza de vida, $\mu$ son los flujos de ingresos anuales medios y se suma un componente relacionado con la incertidumbre propia del mercado. Si se representan los ahorros totales como: $S(n)=\alpha \mu n-\sum x(n)$ (ecuación *), derivando con respecto a $n$ e igualando a 0 , se halla $n^{*}, \mathrm{y}$, al sustituir ese valor en la ecuación *, finalmente se obtiene el monto óptimo de ahorro (Elnekave, 2007).

Este marco analítico sirve para abordar la modalidad de pensión a suma alzada, prevista no solo por la ley peruana actual sino también por las de otros países y tan generadora de polémica alrededor del mundo. Se trata de un único pago, y en algunos casos existe la posibilidad de decidir el porcentaje del fondo por retirar. En el pensionista recaen las decisiones de retirar o no su dinero, de retirar todo o una parte de este. Para tomar estas decisiones, el individuo considera distintos factores, como, por ejemplo, si lo ahorrado es suficiente, destinar su dinero a opciones financieros más rentables, etc. Gracias a la teoría económica, se sabe que el individuo racional toma sus decisiones basándose en la información disponible y así maximiza su utilidad esperada.

\section{Metodología}

\subsection{Base de datos y estadística descriptiva}

Para esta investigación, se contó con una base de datos (despersonalizada) proporcionada por AFP Integra del Grupo Sura, de aproximadamente 35.000 individuos que decidieron retirar o no su dinero de la AFP. Este número de observaciones representa más de un tercio del total de personas jubiladas afiliadas al Sistema Privado de Pensiones. A fin de acotar mejor la población objetivo para esta investigación, se filtró la base de datos para así trabajar finalmente con personas de 65 años o más que viven en el Perú, con lo que se obtuvo una muestra de 13.454 individuos. Es pertinente mencionar que en corridas preliminares se obtuvieron resultados similares con toda la base y la muestra, los cuales serán expuestos y comentados más adelante.

Los datos analizados contienen las siguientes variables: edad, fondo al que pertenece la persona, sexo, si el retiro fue parcial o total, si era pensionista 
en el momento de hacer su solicitud de retiro, monto del retiro, número de beneficiarios, y departamento y provincia donde viven. Se trata, así, de datos únicos por ser muy completos, además de inéditos, de mucha utilidad para un análisis bien sustentado que contribuya a esclarecer uno de los debates socioeconómicos más importantes de los últimos años.

Aquí, empezamos dando una idea de cómo están distribuidos los datos en la base analizada, con la ayuda de cuadros estadísticos que se muestran en los anexos de este ensayo. Aproximadamente un $91 \%$ de dichos afiliados decidieron hacer efectivo el retiro de sus fondos (véase el anexo 4). De ellos, el $66 \%$ son hombres y el $34 \%$ son mujeres, y, del total de montos retirados, un $76 \%$ corresponde a los hombres (anexo 3). Siguiendo a Desmond \& Osorio (2013), estas proporciones se explicarían por el hecho de que los hombres tienden a ser más propensos a tomar riesgos que las mujeres. Y, como era de esperarse, tanto en número de individuos como en valor de los montos existe una alta concentración en Lima y, a su vez, en zonas urbanas (anexo 5).

Además, puesto que una variable clave en la literatura especializada es el nivel de ingreso del afiliado, reflejado en el tamaño de su fondo de pensiones, se elaboró el histograma de la distribución por tamaño del fondo en escala logarítmica que se muestra en el anexo 6. Este confirma que el mayor número de retiros fueron hechos por individuos cuyos fondos eran de tamaño reducido.

Por último, dado que la muestra analizada solo incluye a individuos de 65 años de edad o más, para contribuir a la descripción del contexto se elaboró un histograma de la distribución por edades (anexo 7). Es importante notar que hay personas que hicieron efectivo el retiro de su fondo de pensiones a una edad mucho menor que la de jubilación. Esto se explica porque la ley contempla diversas excepciones que dan pie a una jubilación anticipada (anexo 8).

\subsection{Modelo empírico}

A fin de verificar las hipótesis de esta investigación, se plantea encontrar una relación entre retirar o no los fondos pensionarios en una AFP y variables identificadoras de factores sociodemográficos y/o características del individuo. El análisis de la influencia de esos factores sobre la decisión de retirar los fondos de jubilación de una AFP se basa en la probabilidad de ocurrencia de cualquiera de dos posibles eventos: (i) acogerse a la ley y retirar el dinero; (ii) no acogerse a la ley y no retirar el dinero. Es decir:

Decisión financiera de retiro de fondos de la $A F P=f$ (caracteristicas especificas y sociodemográficas del individuo) 
Para el correspondiente análisis empírico, se definió el siguiente modelo binomial logit:

$$
\begin{gathered}
Y_{i}=\beta_{0}+\beta_{1}{ }^{*} \text { TF } 1+\beta_{2}{ }^{*} \text { TF } 2+\beta_{3}{ }^{*} \text { Sexo }+\beta_{4}{ }^{*} \text { Domicilio }+\beta_{5}{ }^{*} \text { ARiesgo }+\beta_{6} \text { Edad } \\
+\beta_{7}{ }^{*} \text { Beneficiarios }+\beta_{8}{ }^{*} \text { Sector }+\mu
\end{gathered}
$$

Su variable dependiente es un dummy que puede tomar el valor de 0 si no se hace efectivo el retiro de los fondos para jubilación, o 1 si el individuo decide retirar sus fondos. Y sus variables explicativas miden (con base en los tan completos e idóneos datos utilizados) factores sociodemográficos y características específicas a los individuos, como el tamaño de su fondo en la AFP (reflejo de su nivel de ingresos), su edad, su sexo, el lugar donde vive y el número de beneficiarios. Aunque para el caso de una característica muy relevante, pero no medible directamente, como es la actitud frente al riesgo del individuo, se recurrió a una variable proxy, como es usual entre los especialistas.

Las estimaciones del modelo empírico así construido permitirán encontrar respuestas a la pregunta de en qué medida esas variables explicativas determinan la probabilidad de ocurrencia de uno de los dos eventos antes mencionados: la decisión de los titulares de fondos de pensiones en una AFP de retirar o no retirar su dinero.

En la siguiente sección, se presentan seis corridas del modelo. La única diferencia entre cada una de ellas es la manera en que fueron especificadas las variables. Para el modelo 1, que es el presentado líneas arriba, se decidió tomar las variables tamaño del fondo (TF1 y TF2) por intervalos según su magnitud. Si bien esta investigación está enfocada en el SPP, se tomaron como referencia cálculos del SNP para definir valores bajos o medianos o altos en cuanto a las cuentas individuales de capitalización. Los principales criterios utilizados para el tratamiento de esta variable fueron la pensión mínima y máxima del SNP, y además el capital requerido unitario de los individuos. Siguiendo la regla de por cada $n$ categorías incluir $n-1$ variables dummy, la variable TF1 es una variable dummy igual a 0 si el monto pertenece al primer intervalo, y a 1 si pertenece al segundo intervalo; y TF2 es 1 si pertenece al tercer intervalo y 0 de otro modo.

La variable Sexo es una variable dummy que toma el valor de 1 si el individuo es hombre y 0 si es mujer. Para la variable Domicilio, se procesó la base de datos para poder indicar si el individuo vive en un área urbana o rural. La variable ARiesgo es un proxy de la actitud frente al riesgo del individuo según el fondo al que pertenece; es una variable dummy que toma el valor de 1 si el individuo es adverso al riesgo y 0 de otro modo. La variable Edad es una variable continua referida a la edad del individuo. Y la variable Beneficiarios 
es una variable continua que expresa el número de beneficiarios que tiene cada individuo.

Dentro del término de error se incorporan variables no incluidas en el modelo, referidas a distintas características del individuo y de su familia. Sin duda, algunas de ellas son importantes, como si el individuo respeta la ley o no, si está o no bien informado sobre cómo funciona el SPP, sobre sus opciones pensionarias y sobre las rentabilidades que podría ofrecerle otro tipo de producto o activo financiero o real. Es lógico predecir que, si un determinado individuo tiene desconfianza en el sistema, o prevé que recibirá una pensión baja, o puede manejar información sobre opciones que le ofrezcan una mayor rentabilidad y está dispuesto a arriesgarse intentándolas, estará más propenso a retirar su dinero por cualquiera de estos motivos.

\section{Análisis de resultados}

\subsection{Análisis descriptivo}

En primer lugar, se presentan algunas tablas estadísticas que ilustran sobre la dirección que pueden tomar los hallazgos con el modelo empírico para esta investigación.

Tabla 1

Elección de retiro por sexo

\begin{tabular}{ccc}
\hline Elección & Mujer & Hombre \\
\hline No retiro & 242.882 & 308.388 \\
Retiro & 68.521 & 89.724 \\
\hline
\end{tabular}

En la tabla 1, se aprecia claramente que, independientemente del sexo, el monto promedio del fondo de los hombres y mujeres que realizaron el retiro es inferior al de los hombres y mujeres que decidieron no hacerlo.

La tabla 2, por su parte, muestra que el porcentaje de las personas que retiraron sus fondos del SPP es mayor en el sector rural que en el urbano.

Tabla 2

Porcentaje de retiro por sector rural y urbano

\begin{tabular}{lccc}
\hline \multicolumn{1}{c}{ Sector } & No retiro & Retiro & Total \\
\hline Rural & $2,63 \%$ & $97,37 \%$ & $100 \%$ \\
Urbano & $8,47 \%$ & $91,53 \%$ & $100 \%$ \\
\hline
\end{tabular}


En la medida en que el lugar de residencia refleje el nivel de ingreso de los individuos, cabe esperar una relación entre dicho lugar y la probabilidad de efectuar el retiro. Esta relación es sugerida por la tabla 3, donde se distingue entre las personas que viven en la región más próspera del país, la Costa, y las que viven en otras regiones. Es claro que estas últimas han retirado sus fondos de pensiones en mayor proporción. Esto guarda coherencia con lo antes observado en la tabla 2.

Tabla 3

Porcentaje de retiro por región

\begin{tabular}{lccc}
\hline \multicolumn{1}{c}{ Región } & No retiro & Retiro & Total \\
\hline Costa & $9,31 \%$ & $90,69 \%$ & $100 \%$ \\
Otros & $5,35 \%$ & $94,65 \%$ & $100 \%$ \\
\hline
\end{tabular}

La tabla 4, en tanto, ilustra sobre la dirección en que actúa la influencia de la aversión al riesgo en la población analizada, pues indica que el porcentaje de no retiro entre los individuos más adversos al riesgo es mayor que entre los individuos menos adversos.

Tabla 4

Actitud frente al riesgo

\begin{tabular}{lcc}
\hline \multicolumn{1}{c}{ Actitud frente al riesgo } & No retiro & Retiro \\
\hline Adverso & $9,14 \%$ & $90,86 \%$ \\
No adverso & $8,04 \%$ & $91,96 \%$ \\
\hline
\end{tabular}

Las estadísticas presentadas arriba presagian la dirección en que la elección de retiro puede ser influida por algunas de las características sociodemográficas e individuales consideradas en el modelo empírico, cuya estimación econométrica proporciona resultados más concluyentes, los cuales se presentan y analizan a continuación.

\subsection{Resultados del modelo econométrico}

Primero, se presentan y analizan los resultados generales (tabla 5), indicativos de la dirección del efecto de cada variable y también de qué efecto es mayor o menor, considerando los respectivos niveles de significancia. Luego se presentarán los resultados sobre los efectos marginales (tabla 6). 


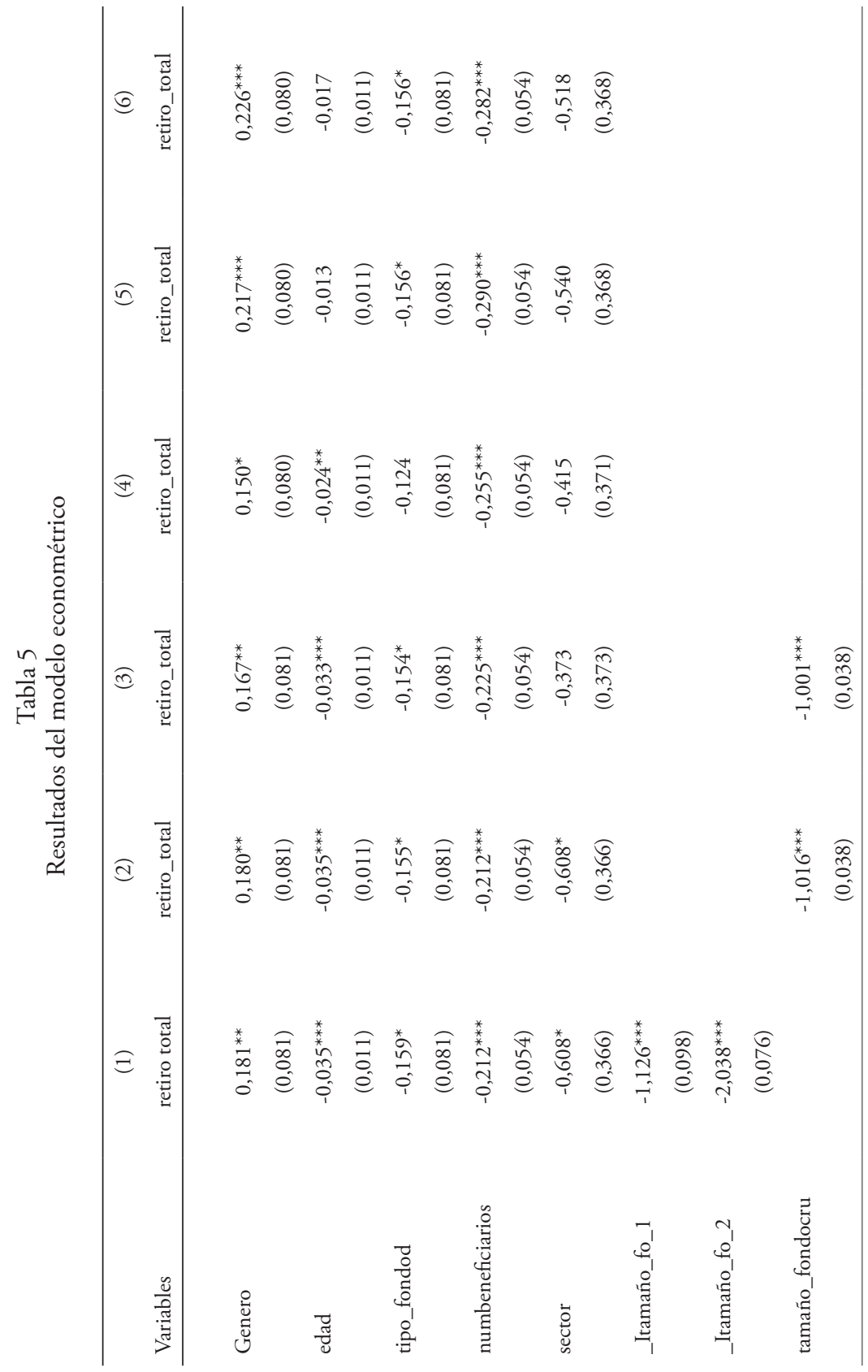




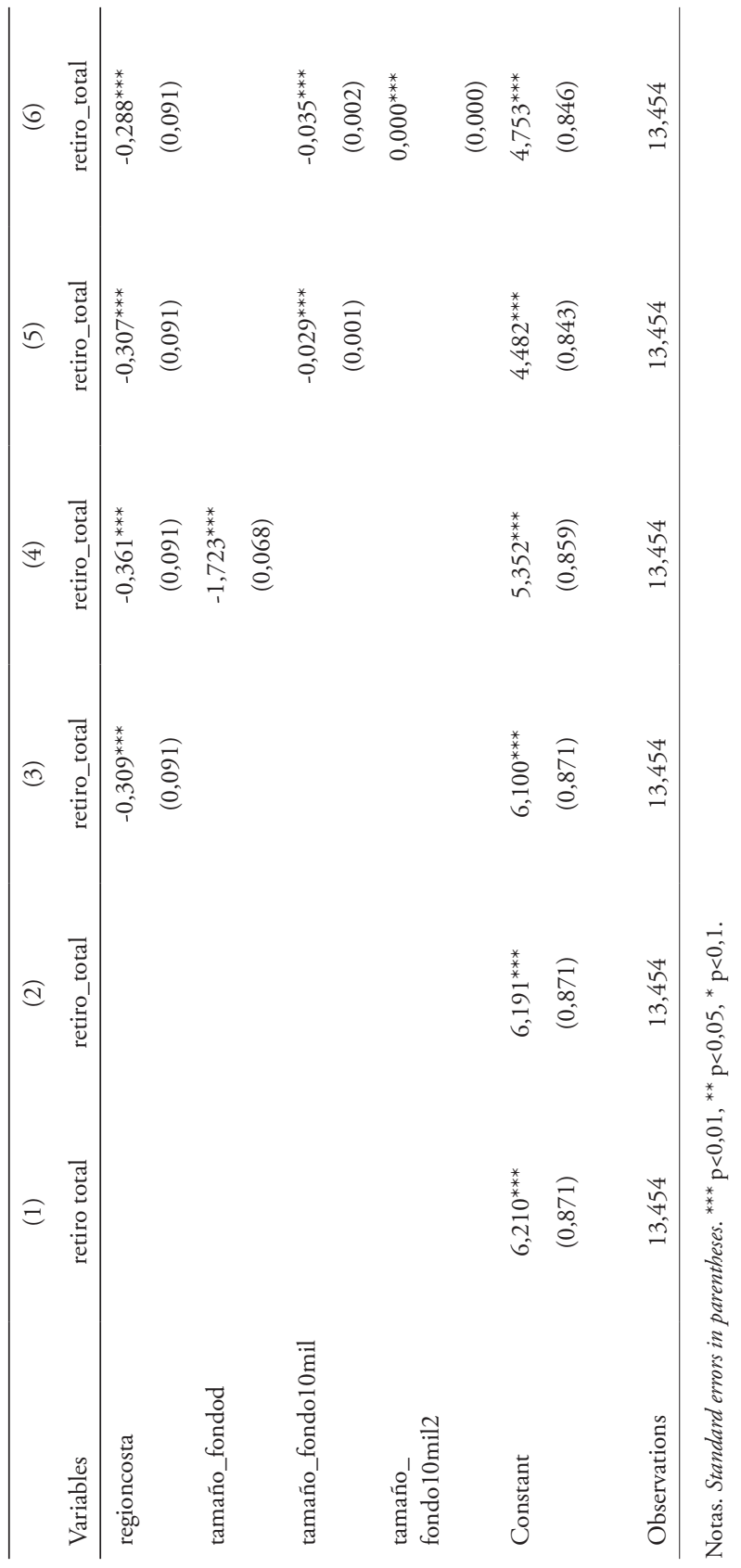


La tabla 5 informa, en primer lugar, que la variable género del individuo tiene un efecto significativo en la probabilidad de retirar fondos de la AFP. Este resultado es coherente con estudios previos mencionados en la revisión de la literatura, pues indica que los hombres suelen tener una menor aversión al riesgo que las mujeres $\mathrm{y}$, por ende, son más propensos a realizar el retiro de sus fondos. Lo mismo sucede con la variable de edad, que también es significativa e indica que, a mayor edad, menor es el interés en retirar los fondos, dado que también es menor el interés por opciones financieras riesgosas.

La variable tamańo del fondo -y, por ende, el tamaño de la pensión futuratiene una relación significativa y positiva con la probabilidad de permanecer en el SPP. Es decir, a mayor tamaño del fondo, hay más probabilidad de que el individuo no retire sus fondos de la AFP. Al respecto, los tres intervalos para el modelo 1 (anunciados cuando se presentó el modelo empírico) fueron especificados así: se tuvo en cuenta un CRU (capital requerido unitario) igual a $165 \mathrm{y}$, utilizando variables dummy (en la tabla,_Itamaño_fo_l significa que el tamaño del fondo está entre $[68.475,145.055]$ y_Itamaño_fo_2 significa que el tamańo del fondo está entre [145.055, a más]), se halló que, si el tamaño del fondo está entre [68.475, 145.055], la probabilidad de un retiro total es menor que cuando el tamańo del fondo es inferior a 68.475, e incluso esa probabilidad es aún menor cuando el tamaño del fondo es mayor de 145.055.

La variable departamento tiene una relación significativa con la variable dependiente. Se calculó el nivel socioeconómico promedio de cada zona y se halló una diferencia entre personas de niveles socioeconómicos altos, y las de niveles socioeconómicos bajos, respecto a la probabilidad de hacer efectivo el retiro de fondos. Un individuo de nivel socioeconómico más bajo tiene más probabilidad de retirar sus fondos.

Para la variable aversión al riesgo, se utilizó como proxy el tipo de fondo de cada persona. Las personas con un fondo del tipo 1 (o "fondo conservador», según las AFP) son las más adversas al riesgo, las titulares de un fondo del tipo 2 son menos adversas y las titulares de un fondo del tipo 3 son las más arriesgadas. Así, se halló que, entre menos aversión al riesgo tiene la persona, más probable es que se incline por retirar su dinero.

La variable beneficiarios resulta muy ilustrativa por lo que implica, pues describe a un titular que tiene personas dependientes de él o ella. Una característica interesante es que el número de beneficiarios corresponde al cónyuge e hijos menores de edad o dependientes del titular, estos últimos evidentemente beneficiarios que no pueden mantenerse por sí solos. Si a ello se agrega que dentro del SPP los beneficiarios son herederos legales del fondo de jubilación, 
mientras que ese derecho se extingue si se efectúa el retiro, puede entenderse fácilmente el siguiente resultado: que la probabilidad de retiro es menor en los fondos con mayor número de beneficiarios.

En el modelo 2, la diferencia es que la variable tamaño del fondo se trató como una variable categórica, que toma el valor de 0,1 y 2 según en qué intervalo de montos se sitúa el fondo. Específicamente, 0 cuando [0, 68.475], 1 cuando [68.475, 145.055] y 2 cuando [145.055, o más]). En este caso, también se encuentra un efecto negativo con respecto a la probabilidad de retiro a medida que crece el tamaño. Pero no se recoge el efecto cuando se va de un intervalo a otro, porque se trata de una variable categórica en vez de continua. En el modelo 4, se hace otra variante con la variable tamańo del fondo: se decide tomar solo 2 intervalos en vez de 3, lo que arroja resultados parecidos a los del modelo 2 , pero que no precisan el efecto cuando se trata de montos pequeños, lo que no puede dejarse desatendido dadas las características de la población analizada.

En vista de lo anterior, se introdujo la variante de considerar al tamaño del fondo como una variable continua. Primero, midiendo el efecto de su variación en unidades de 10.000 soles cada una (modelo 5), pues el efecto de variaciones sol por sol sería demasiado pequeño. En este caso, el efecto encontrado también es negativo, como se esperaba, pero es menor debido a la mencionada medición de la variable. Por ello, en el modelo 6, el tamańo del fondo es medido con la variable cuadrática 10mil2. En este caso, el efecto resultante es muy pequeńo, pero positivo. Ello revela algo muy interesante: que si bien un monto más grande significa menor posibilidad de retiro, se llega a un punto en el cual individuos con montos muy grandes también deciden retirar su dinero.

Pero esa relación positiva que emerge en una situación extrema es la excepción que confirma la regla. A saber, que los resultados obtenidos con el modelo 1 y las distintas variantes hechas a este para recoger todo tipo de efecto pertinente verifican de manera concluyente la hipótesis principal de esta investigación, porque muestran inequívocamente que, cuanto menor es el tamańo del fondo ( $y$, por ende, la pensión que permitiría), mayor es la probabilidad de que sea retirado por su titular.

Respecto a los efectos marginales, en la tabla 6 se observa la variación porcentual en la probabilidad de retiro imputable a cada variable explicativa. A diferencia de la tabla 5, esta vez se aprecia no solo si el efecto es positivo o negativo, sino en cuánto aumenta o disminuye dicha probabilidad por efecto de la variable en cuestión. 
Tabla 6

Efectos marginales

Marginal effects after logit: $\mathrm{y}=\operatorname{Pr}($ retiro_total) $($ predict $)=0,93953688$

\begin{tabular}{rccccccc}
\hline Variable & $\mathrm{dy} / \mathrm{dx}$ & Std. Err. & $\mathrm{Z}$ & $\mathrm{P}>|\mathrm{z}|$ & {$[$ 95\% C. I. ] } & $\mathrm{X}$ \\
\hline genero* & 0,0112973 & 0,00502 & 2,25 & 0,024 & 0,001466 & 0,021129 & 0,782147 \\
edad & $-0,0019422$ & 0,00064 & $-3,02$ & 0,002 & $-0,003201$ & $-0,000684$ & 67,9925 \\
tipo_f $\mathrm{d}^{*}$ & $-0,0093347$ & 0,00499 & $-1,87$ & 0,061 & $-0,019109$ & 0,00044 & 0,205411 \\
Numben+s & $-0,0125656$ & 0,00306 & $-4,11$ & 0,000 & $-0,018599$ & $-0,006572$ & 0,465363 \\
Sector* $^{*}$ & $-0,0322569$ & 0,01001 & $-3,22$ & 0,001 & $-0,51877$ & $-0,012636$ & 0,97458 \\
_Itama $^{*}$ & $-0,0962584$ & 0,01085 & $-8,87$ & 0,000 & $-0,117518$ & $-0,074999$ & 0,12316 \\
_Itama 2* $^{*}$ & $-0,2108423$ & 0,01 & $-21,08$ & 0,000 & $-0,230449$ & $-0,191235$ & 0,195407 \\
\hline
\end{tabular}

Nota. ${ }^{*}$ dy/dx id for discreet change of dummy variable from 0 to 1.

Los porcentajes para cada variable se calculan manteniendo constantes las demás (ceteris paribus). Ya que la probabilidad promedio de retiro es del 93\% (como se anota en la tabla), cada porcentaje significa una variación sobre esa probabilidad. Y cabe recalcar que los porcentajes podrían cambiar mucho según cada individuo específico. Es decir, el modelo utilizado es capaz de calcular la probabilidad de retiro del fondo para un determinado pensionista de contarse con información sobre sus datos y características.

La variable tamaño del fondo 2 es la que conlleva la variación porcentual más grande sobre la probabilidad promedio de retiro, en el sentido de que la probabilidad de retiro disminuye en mayor magnitud cuando el fondo es grande. La variable tamaño del fondo 1 también conlleva una disminución de tal probabilidad, pero, según lo hallado anteriormente, este efecto crece a medida que crece el tamaño del fondo. De modo que los efectos marginales con ambas variables corroboran que la probabilidad de retiro se reduce cada vez más conforme va aumentando el tamaño del fondo. Ello confirma que fue acertada la elección del modelo 1 como el más apropiado.

El efecto marginal de la variable edad es por cada año que pasa; es decir, el porcentaje indicado en la tabla 6 se hace más negativo a medida que la persona se va haciendo más anciana. Lo mismo sucede con la variable número de beneficiarios: el efecto negativo en la probabilidad de retiro crece conforme el fondo tiene más beneficiarios.

Respecto a género, sector (urbano/rural) y tipo de fondo, los respectivos efectos promedio porcentuales confirman la dirección de los efectos de estas variables. 
A continuación, se ilustran dos ejemplos de evolución de la probabilidad de retiro, distinguiendo entre hombres y mujeres, según monto del retiro y edad respectivamente.

\section{Figura 1}

Simulación de la probabilidad de retiro por monto

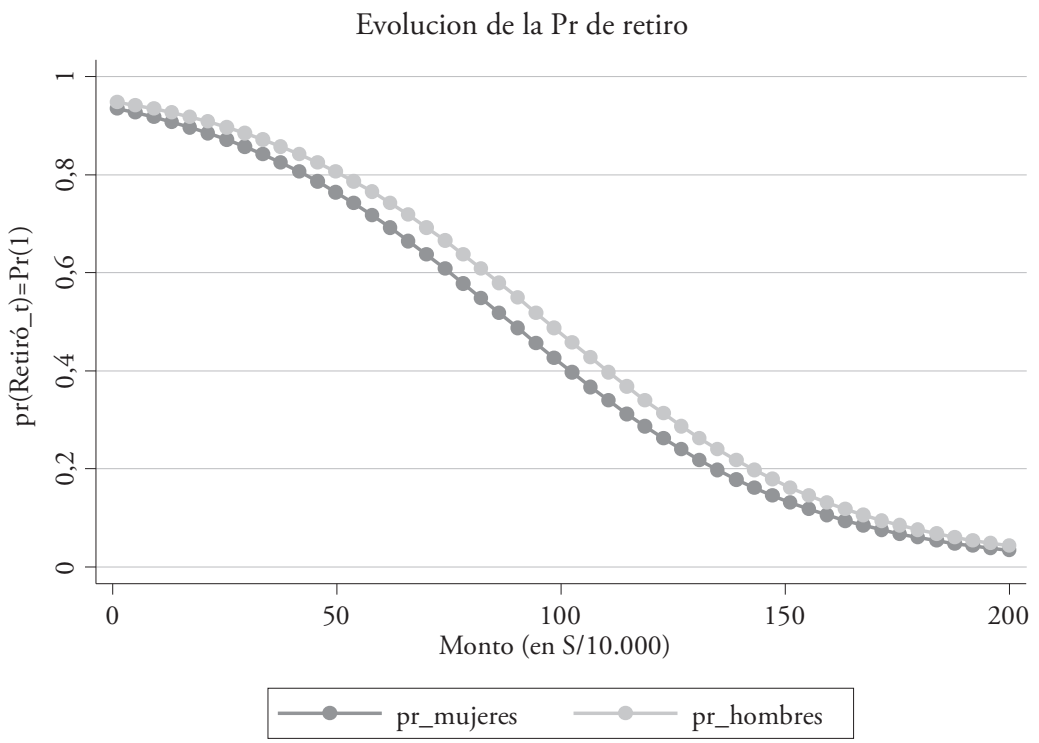


Figura 2

Simulación de la probabilidad de retiro por edad

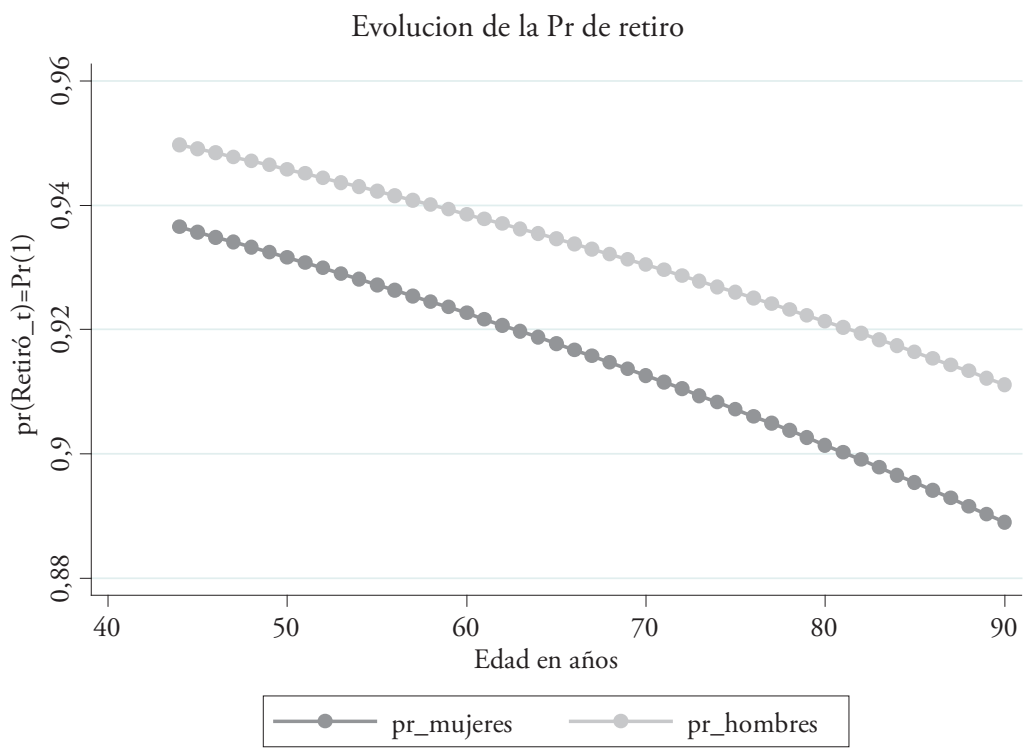

En ambas simulaciones, dicha probabilidad se reduce a medida que el individuo envejece, así como cuando el monto de jubilación es mayor. También se aprecia que la variable género produce diferencias entre las curvas de probabilidad, por edad en particular.

\section{Conclusiones y recomendaciones}

Es necesario resaltar que el sistema de pensiones para la jubilación, tanto en el sector público como en el privado, está pasando por un período de cambios y ajustes, no solo en el Perú sino en el mundo entero. En un inicio, eran ocho las AFP que competían en el mercado peruano, el cual ha experimentado reconfiguraciones hasta llegar a las cuatro que coexisten hoy. Este mercado también ha experimentado cambios en el aspecto legislativo y de reformas regulatorias, aspecto que motivó la investigación presentada en este ensayo. Existen experiencias similares en otros países de las que se puede aprender, pero el caso peruano es especial, no solo por sus sorpresivas leyes y reformas sino también por las características de su población. 
La tendencia mundial en sistemas de pensiones de jubilación es que se innove y creen nuevas modalidades y formas de pensión. La presente investigación es un primer acercamiento al análisis, aplicado al caso peruano, de los factores sociodemográficos y características individuales de la población objetivo que influyen en sus decisiones entre distintas modalidades pensionarias. Se espera que los resultados obtenidos, además de motivar otras investigaciones de este tipo, alienten al Estado y al sector privado a redoblar sus esfuerzos de recolección de información y datos más específicos que ayuden a explicar mejor por qué una persona podría preferir una modalidad de pensión a otra; para que, así, puedan mejorar tanto la gestión del sistema previsional peruano como los modelos empíricos que orienten investigaciones futuras sobre la materia.

Uno de los principales aprendizajes logrados al realizar esta investigación es la importancia de apoyarse en literatura especializada de primer nivel. Ello nos ha servido para identificar que nuestros resultados, si bien reflejan las particularidades de un caso único, como es el peruano, mantienen similitudes reveladoras con los de investigaciones realizadas sobre otros países, lo que da confianza y faculta comparaciones.

Otro aprendizaje importante es que se confirman tanto la relevancia de las variables sociodemográficas e individuales analizadas, como que estas variables influyen en la decisión del titular de un fondo privado de pensiones peruano acerca de si acogerse o no a la ley que le permite retirar el dinero que tiene en una AFP.

Esta investigación respalda la intuición de que un individuo cuenta con un fondo de jubilación para no sufrir una disminución considerable de su calidad de vida cuando pasa al retiro. En efecto, hemos comprobado que el principal factor explicativo de la decisión de mantener o no dicho fondo es su tamańo, que determina la cantidad de dinero disponible durante la jubilación. Si esa cantidad esperada está muy por debajo de la necesaria, habrá una clara preferencia por usar el dinero del fondo en otra cosa. Además, esta investigación arroja indicios de que dicha decisión también es determinada por características sociodemográficas del titular del fondo, como su edad, género, lugar de residencia, número de beneficiarios; así como por su aversión al riesgo, pues cambiar de una modalidad pensionaria a otra o a otro activo financiero siempre conlleva un riesgo.

Es importante promover la reflexión sobre el aporte real de las pensiones -en sus distintas modalidades- para asegurar el bienestar y una vida digna a personas que han trabajado en algunos casos más de 45 años. También es importante enfatizar la obligación por parte del Estado de establecer los 
cambios y reformas necesarios para aumentar la rentabilidad de los fondos en las AFP y, por ende, el monto de las pensiones para los jubilados. En un país como el Perú, donde la mayor parte de los trabajadores están en el sector informal, es clara la urgencia de diseńar mecanismos y productos orientados a promover el ahorro en fondos para la jubilación.

El Estado debe asumir el compromiso de regular bien el mercado de las AFP, favoreciendo a los usuarios, pero tratando de asegurar una jubilación digna. Y también le corresponde sumar esfuerzos con las AFP para crear conciencia entre los afiliados sobre los diversos instrumentos existentes para hacer uso de sus fondos, brindándoles información relevante para estas decisiones.

En tal sentido, debe tenerse en cuenta que una persona que realiza el retiro de su fondo de pensiones pierde el tratamiento tributario preferencial que obtiene como jubilado. Su dinero que estaba en un fondo de pensiones deja de estar protegido frente a deudas, pues pasa a ser embargable e incluso, al morir el titular, su familia queda desafiliada del seguro de salud. Estas son algunas de las consecuencias de hacer efectivo el retiro. Si bien es cierto que un individuo puede preferir administrar su propio dinero, el problema surge cuando la mayor parte de la población no está bien enterada de todo lo que trae consigo, para bien o para mal, el acogerse al retiro permitido por la ley. Si se dicta esta ley y solo se informa de manera parcial de algunos beneficios, se actúa irresponsablemente y no se vela cabalmente por el bienestar de la población.

De ahí que resulte de vital importancia entender el comportamiento de las variables analizadas en esta investigación, cuyos efectos sobre las personas deben orientar la formulación de nuevas políticas que configuren un sistema previsional que realmente maximice los beneficios para peruanos y peruanas durante su vejez. El tener claridad sobre los factores que explican las preferencias de las personas en materia de pensiones, y determinan así sus decisiones al respecto, facilitaría grandemente la labor del Estado y del sector privado para prever mejor el alcance y los efectos de las reformas.

Por ello, se propone que se realicen investigaciones más detalladas sobre las preferencias respecto a todas las modalidades del SPP, así como sobre las de los pensionistas y jubilados del SNP, para así extender los resultantes hallazgos y recomendaciones de políticas, a fin de velar bien por la vejez no solo de un sector de la población sino de todas las personas afiliadas a algún tipo de sistema pensionario. Tengamos en cuenta que, para combatir la inequidad en las pensiones, se requieren cambios estructurales, y es responsabilidad de todos tratar de mejorar la calidad de vida, sobre todo de las poblaciones más vulnerables. 


\section{Referencias}

Banco Mundial. (1994). Envejecimiento sin crisis. Washington D. C.

Beltrán, A. (2007). Econometría de corte trasversal. Notas de clase. Lima: Universidad del Pacífico.

Bernheim, D. (1993). Is the baby boom generation preparing adequately for retirement? Nueva York: Merrill Lynch.

Beshears, J., Choi, J., Laibson, D., Madrian, B., \& Zeldes, S. (2013). What makes annuitization more appealing? Journal of Public Economics, 116, 2-16.

Bookman, A., \& Kimbrel, D. (2011). Families and elder care in the twenty-first century. The Future of Children, 21(2), 117-140.

Bosch, M., Melguizo, A., \& Pages, C. (2013). Mejores pensiones, mejores trabajos: hacia la cobertura universal en América Latina y el Caribe. Washington D. C.: Banco Interamericano de Desarrollo.

Butare, T. (1998). Social needs and the roles of governments and markets: The case of retirement pensions. International Social Security Review, 51(3), 37-62.

Butler, M., \& Teppa, F. (2007). The choice between an annuity and a lump sum: Results from Swiss pension funds. Journal of Public Economics, 91, 1944-1966.

Chernev, A., Bockenholt, U., \& Goodman, J. (2015). Choice overload: A conceptual review and meta-analysis. Journal of Consumer Psychology, 25(2), 333-358.

Desmond, L., \& Osorio, B. (2013). The effect of prior outcomes on gender risk taking differences. Journal of Risk Research, 16(7), 791-802.

Doker, C., Turkmen, A., \& Emsen, S. (2015). What are the demographic determinants of savings? An analysis on transition economies (1993-2013). Procedia Economics and Finance, 39, 275-283.

Eguía, B. (1997). Seguridad social y estructura demográfica en un modelo de ciclo vital con edad de retiro endógena. Revista de Economía Aplicada, V(13), 5-38.

Elnekave, R. (2007). The mathematics of savings and retirement planning. Chicago: Investment Management Institute, LLC.

Esmail, H., \& Abdelaty, H. (2014). Macroeconomic determinants of savings in Egypt «statistical model». International Journal of Business \& Economic Development, 2(2), 26-33(8).

Fatas, E., Lacomba, J., Lagos, F., \& Moro-Egido, A. (2013). An experimental test on dynamic consumption and lump-sum. Granada: Springerlink.

Fernández, S., Vivel, M., \& Otero, L. (2012). El ahorro para la jubilación en la UE: un análisis de sus determinantes. Revista de Economía Mundial, 31, 111-135.

Finke, M., \& Houston, S. (2013). Time preference and the importance of saving for retirement. Journal of Economic Behavior \& Organization, 89(C), 23-34.

Flaherty, C. (2010). The effect of pension plan type on retirement age: Distinguishing plan incentives from career length preferences. Southern Economic Journal, 77(1), $104-125$. 
Friedman, M. (1973). Una teoría de la función de consumo. Madrid: Alianza Editorial. Gaceta Oficial. (1992). Decreto Ley 25897 - Creación del Sistema Privado de Fondos de Pensiones (SPP). Lima: El Peruano.

Gerrans, P., \& Clark, G. (2013). Pension plan participant choice: Evidence on defined benefit and defined contribution preferences. Journal of Pension Economics and Finance, 12(28), 351-378.

Gordon, I., \& Jung-Wha, L. (2009). Pensions in Australia and South Korea: A comparative analysis. Pensions: An International Journal, 14(4), 273-281.

Gunderson, M., \& Luchak, A. (2001). Employee preferences for pension plans features. Journal of Labor Research, 22(4), 795-808.

Hurd, M., \& McGarry, K. (1993). Evaluation of subjective probabilities distribution in the HRS. NBER Working Papers, 4560. Cambridge MA: National Bureau of Economic Research.

Hyde, M., \& Shand, R. (2017). Retirement pensions and justice: A philosophical analysis. Reino Unido: Palgrave Mcmillan.

INEI (Instituto Nacional de Estadística e Informática). (2018). Perú: crecimiento y distribución de la población 2017 - Primeros resultados censos 2017. Lima: Instituto Nacional de Estadística e Informática.

Lusardi, A., \& Mitchell, O. (2007). Baby boomer retirement security: The roles of planning, financial literacy and housing wealth. Journal of Monetary Economics, 54(1), 205-224.

Méndez, D. (2007). Competencia perversa o consumidores desinteresados: el caso de las AFP. Documento inédito. Lima.

Mendoza, J., Seminario, B., \& Cruz Saco, M. (2014). El sistema previsional del Perú: diagnóstico 1996-2013, proyecciones 2014-2050 y reforma. Documento de Discusión, DD/14/11. Lima: Universidad del Pacífico - Centro de Investigación.

Mitchell, O., \& Fields, G. (1985). Retirement, pensions, and social security. Cambridge, MA: MIT Press.

Modigliani, F., \& Brumberg, R. (1954). Utility analysis and the consumption function: An interpretation of cross section data. En K. Kurihara (Ed.), Post-Keynesian economics (pp. 388-436). Nuevo Brunswick: Rutgers University Press.

Moore, J., \& Muller, L. (2002). An analysis of lump-sum pension distribution recipients. Monthly Labor Review, 125(5), 29-46.

OIT (Organización Internacional del Trabajo). (2004). Social protection for older persons: Key policy trends and statistics. Ginebra: Organización Internacional del Trabajo.

Portocarrero, F. (2013). Grandes fortunas en el Perú: riqueza y filantropía de la élite económica. Lima: Universidad del Pacifico.

Prado, A., \& Sojo, A. (2010). Envejecimiento en América Latina: sistemas de pensiones y protección social integral. Santiago: Cepal.

Skinner, J. (2007). Are you sure you're saving enough for retirement? Journal of Economics Perspectives, 21(3), 59-80. 
Sharpe, W., Goldstein, D., \& Johnson, E. (2008). Choosing outcomes versus choosing products: Consumer-focused retirement investment advice. Journal of Consumer Research, 35(3), 440-456.

Sweeting, P. (2009). Tax efficient pension choices in the UK. Annals of Actuarial Science, 4(2), 177-197.

Villagómez, A. (2014). El ahorro para el retiro: una reflexión para México. Tlalpan: Fondo de Cultura Económica.

Xala i Martin, X. (2000). Crecimiento económico (2. ${ }^{\mathrm{a}}$ ed.). Barcelona: Antoni Bosch Editor.

Yong, C., \& Yuan, C. (2014). Pension reform in China: Challenges and opportunities. Journal of Economic Surveys, 28(4), 636-651. 


\section{Anexos}

\section{Anexo 1}

\section{Tasa de dependencia}

Proyección de la tasa de dependencia

$30 \%$

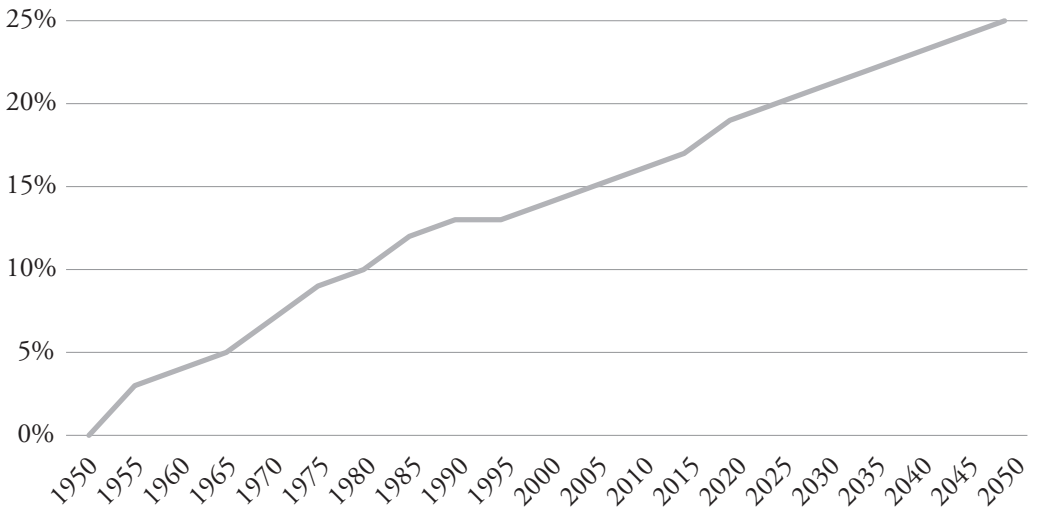

Fuente: INEI (2018). Elaboración propia.

\section{Anexo 2}

\section{Edad media de la población peruana}

Proyección de la edad media

45

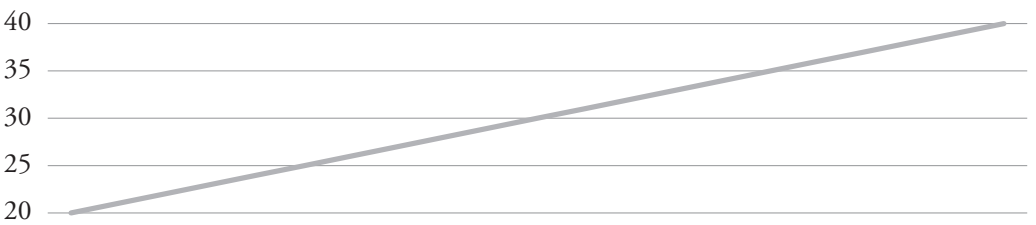

15

10

5

0

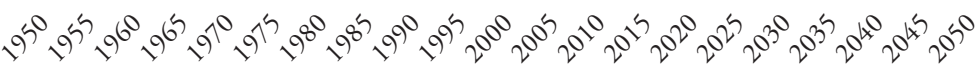

Fuente: INEI (2018). Elaboración propia. 


\section{Anexo 3}

\section{Destinatarios y montos retirados por género}

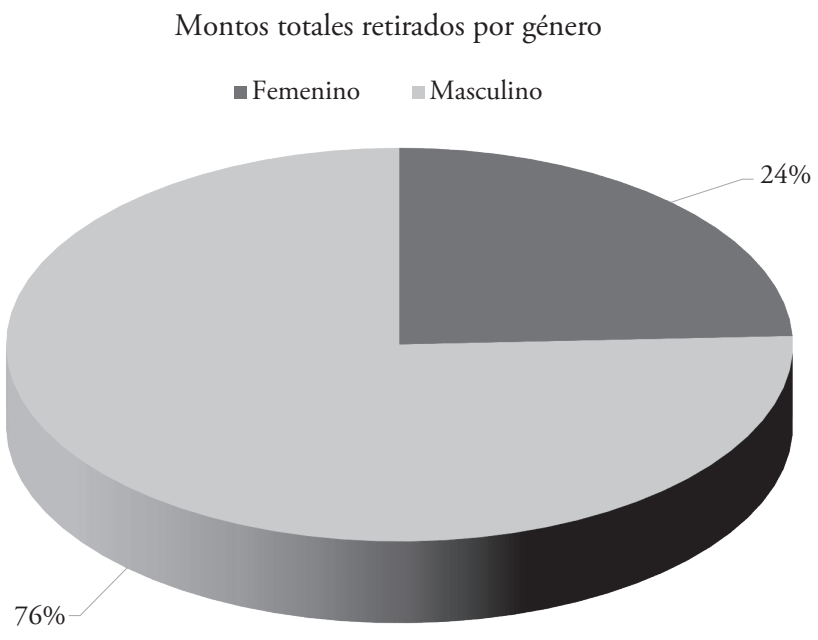

Destinatarios por género

$\square$ Femenino $\quad$ Masculino

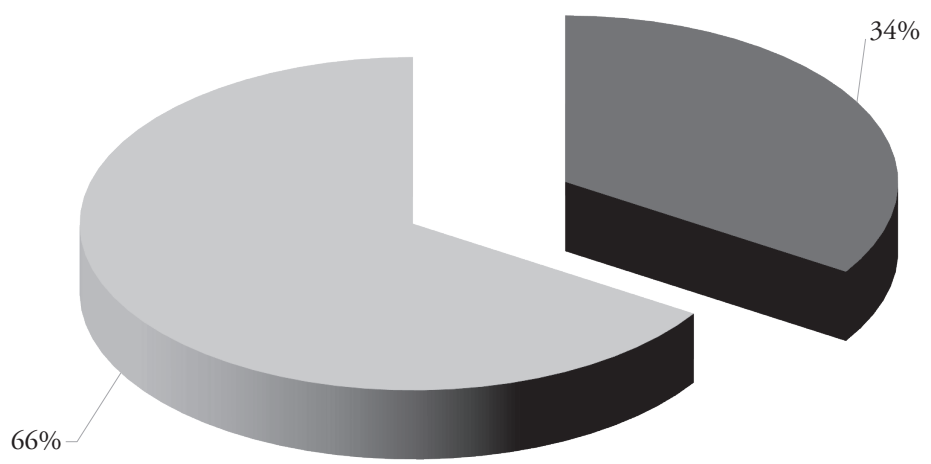

Fuente: elaboración propia con base en datos provistos por una AFP. 


\section{Anexo 4}

\section{Pensionistas por tipo de elección}

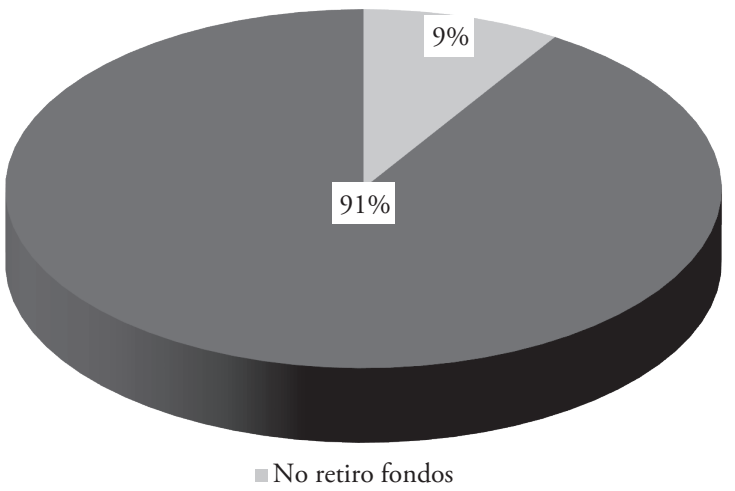

\begin{tabular}{lcc}
\hline Pensionistas por tipo de elección & & \\
\hline Tipo de elección & Número & $\%$ \\
\hline No retiró fondos & 1.120 & $9 \%$ \\
Retiró fondos & 12.334 & $91 \%$ \\
Total & 13.454 & \\
\hline
\end{tabular}

Fuente: elaboración propia, con base en datos provistos por una AFP. 


\section{Anexo 5}

\section{Distribución de pensionistas y montos retirados por provincia}

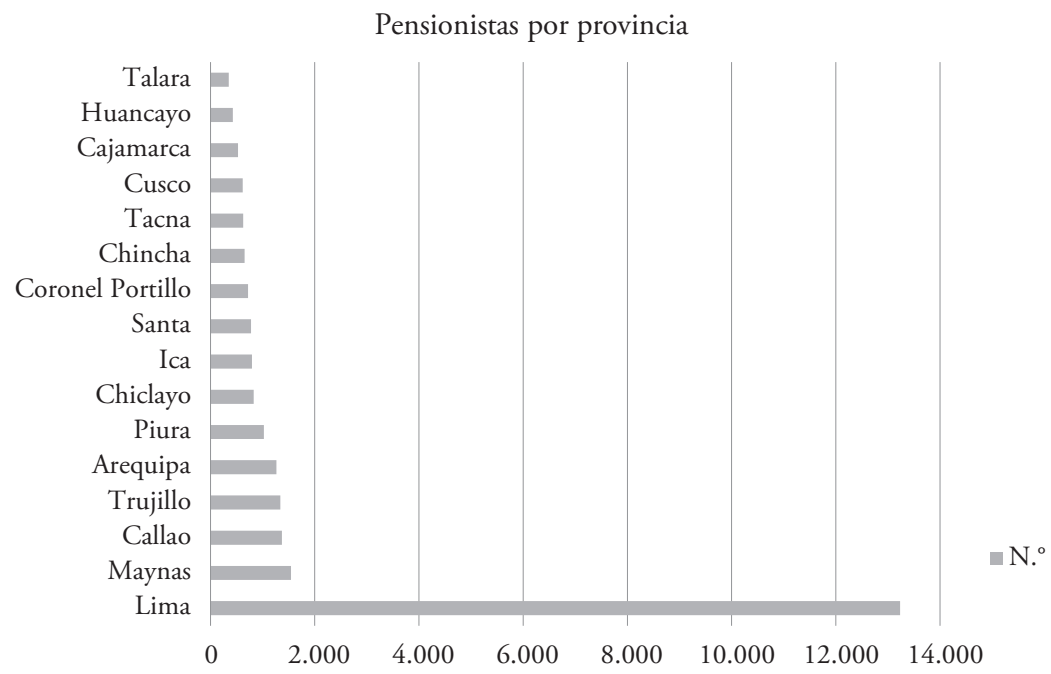

Monto retirado por provincia

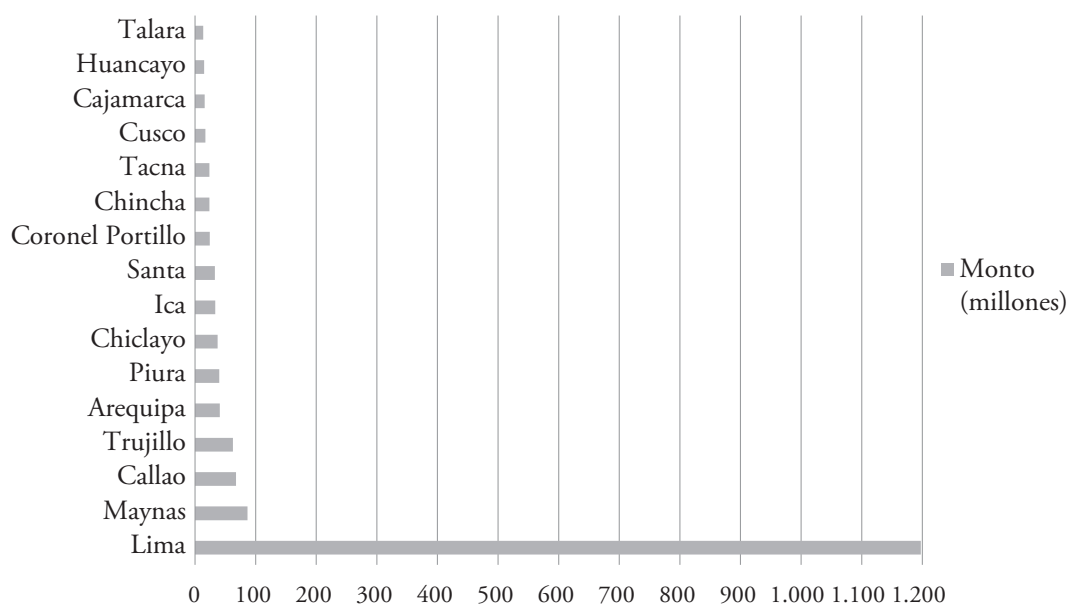

Fuente: elaboración propia con base en datos provistos por una AFP. 


\section{Anexo 6 \\ Tamańo del fondo y frecuencia de retiros}

Frecuencia de montos retirados

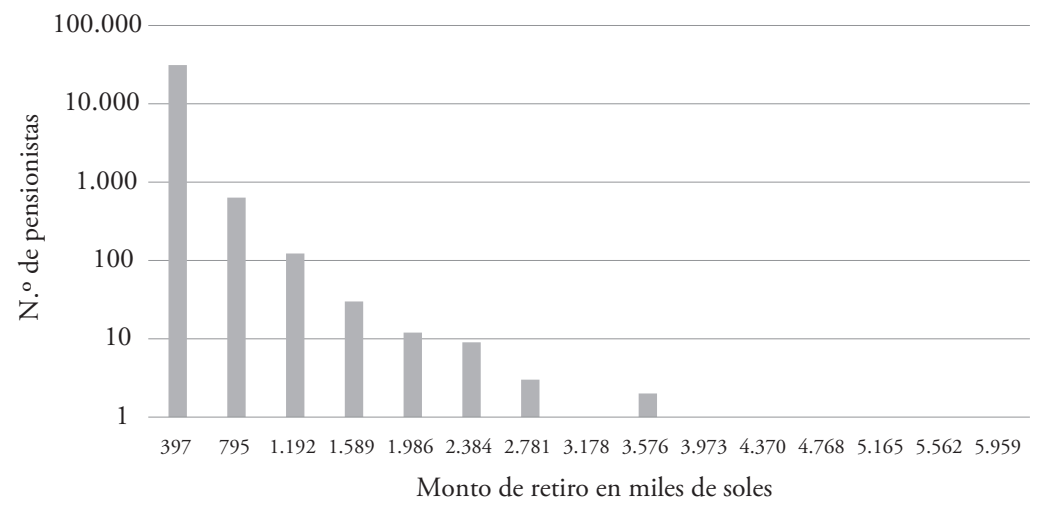

Fuente: elaboración propia con base en datos provistos por una AFP.

\section{Anexo 7}

Histograma de edades

Frecuencia de edades

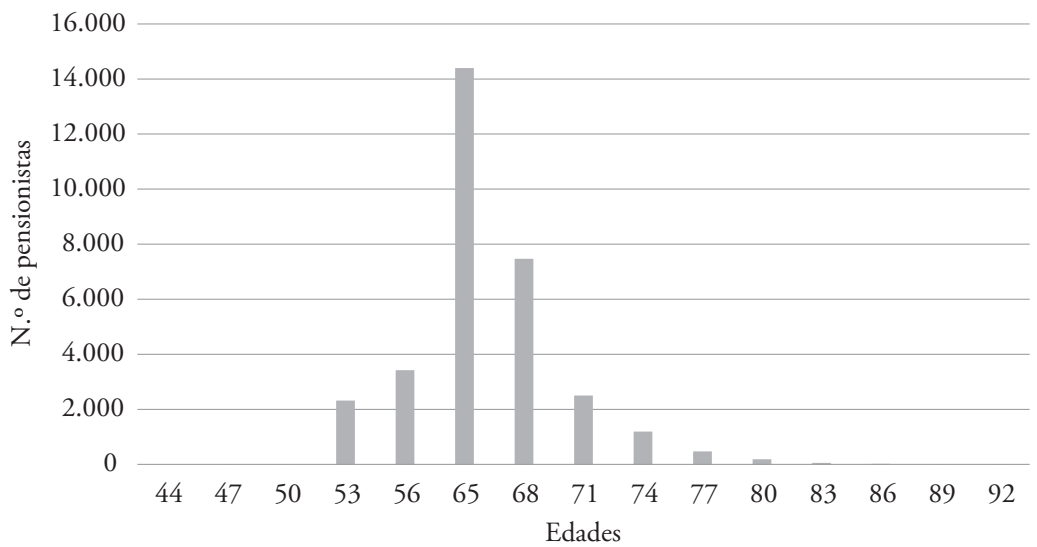

Fuente: elaboración propia con base en datos provistos por una AFP. 


\section{Anexo 8}

\section{Requisitos para jubilación anticipada}

\begin{tabular}{cl}
\hline Tipos de jubilación adelantada & \multicolumn{1}{c}{ Requisitos } \\
\hline Jubilación anticipada regular & $\begin{array}{l}\text { Que la pensión calculada sea equivalente a, por lo menos, el } \\
40 \% \text { de la remuneración mensual. }\end{array}$ \\
$\begin{array}{c}\text { Jubilación anticipada por } \\
\text { desempleo }\end{array}$ & $\begin{array}{l}\text { Encontrarse desempleado por } 12 \text { meses o más. Edad } \\
\text { mínima: hombres, 55 ańos; mujeres, 50 años. }\end{array}$ \\
Jubilación anticipada por riesgo & $\begin{array}{l}\text { Es un régimen especial de jubilación para personas que } \\
\text { hayan realizado trabajos pesados en las actividades de } \\
\text { minería, metalurgia, siderurgia o construcción civil. Las } \\
\text { especificaciones varían según la actividad y el tiempo de } \\
\text { exposición al riesgo. }\end{array}$ \\
Jubilación anticipada por & $\begin{array}{l}\text { Contar con dictamen de enfermedad terminal o cáncer que } \\
\text { no amerite condición de invalidez. }\end{array}$ \\
Jubilación anticipada 19990 & $\begin{array}{l}\text { Haber cumplido con los requisitos de jubilación en el SNP } \\
\text { antes de afiliarse al SPP y haberse incorporado al SPP hasta } \\
\text { el 1/1/2002. }\end{array}$ \\
\hline
\end{tabular}

Fuente: https://www.sbs.gob.pe/usuarios/informacion-de-pensiones/pensiones-y-beneficios/jubilacionanticipada/ 


\title{
El valor de los profesores: un análisis del efecto del conocimiento docente sobre el rendimiento de los estudiantes en el Perú
}

\author{
Diego Camacho Valencia Dongo \\ Naara Cancino Díaz
}

\section{Introducción}

El docente cumple un rol clave en el aprendizaje de los estudiantes. Un reconocido informe de McKinsey (Barber \& Mourshed, 2007, p. 16) concluye que «la calidad docente es el factor decisivo para la calidad de un sistema educativo» y señala que los niños expuestos a docentes sin calificación adecuada tienen pocas probabilidades de recuperarse en sus estudios siguientes.

Lamentablemente, en el Perú los docentes han sido muy subvalorados socialmente y por las políticas públicas. La acción política ha estado mal enfocada, se ha orientado a consolidar un cuerpo reducido de profesores calificados y ha dejado de lado a la masa de profesores menos calificados que están en un mercado privado en aumento (Espinoza, Espezua, \& Choque, 2015, p. 327). Además, como mencionan Díaz \& Saavedra (2000), la carrera docente en el Perú es considerada como proveedora de ingresos seguros y estabilidad laboral, pero que no ofrece estímulos claros para innovar, actualizarse y tener un mejor desempeño. Sin embargo, el problema de los docentes en el Perú es aún más amplio y diverso: bajos salarios, sobreoferta

\footnotetext{
${ }^{1}$ Este ensayo resume el trabajo de investigación del mismo título, concluido en junio de 2017. Sus autores agradecen en especial al asesor de dicho trabajo, profesor Juan Francisco Castro, así como a los profesores César Guadalupe y Gustavo Yamada, por sus valiosos comentarios y sugerencias. También agradecen a los asistentes al Congreso Anual 2017 de la Asociación Peruana de Economía y al Encuentro de Economistas BCRP 2017. Una versión previa y más extensa de este ensayo fue publicada como Working Paper del Banco Central de Reserva del Perú, disponible en http://www.bcrp.gob.pe/docs/Publicaciones/Documentosde-Trabajo/2017/documento-de-trabajo-11-2017.pdf
} 
de profesores, bajo grado de profesionalismo e inadecuada infraestructura (Espinoza et al., 2015).

Revalorar a los docentes requiere conocer su importancia en los logros de aprendizaje de los niños, para así justificar medidas de política que mejoren el desempeńo docente en la escuela. La necesidad de revalorar el rol docente en el Perú motiva el presente estudio, cuyo objetivo es calcular el impacto del conocimiento docente sobre los logros de aprendizaje en niños de primaria. Para medir este efecto, se trabaja con una muestra de nińos de sexto grado de primaria y sus logros de aprendizaje en matemáticas, así como con una medida del conocimiento en matemáticas de los docentes. La variable «conocimiento docente» utilizada incluye tanto el conocimiento de la materia como el conocimiento pedagógico.

A continuación, se presenta la revisión de literatura especializada, que incluye análisis de la calidad docente, el conocimiento docente y la heterogeneidad de sus efectos en la educación. En la tercera sección, se plantea el marco analítico, donde se detallan nuestras hipótesis y los fundamentos teóricos para su validación. Luego, se describen la metodología y bases de datos utilizadas para la estimación empírica. Por último, se presentan los resultados, las conclusiones y las recomendaciones pertinentes.

\section{Revisión de literatura especializada}

\section{a. Logros de aprendizaje}

En economía, el estudio de la calidad educativa se ha concentrado en los insumos que generan mejoras en el aprendizaje de los estudiantes. Se formulan funciones de producción de aprendizajes que expresan relaciones estructurales entre los determinantes del logro educativo. En la función planteada por Glewwe \& Kremer (2006), el aprendizaje depende de los siguientes insumos: (i) ańos de estudio, (ii) características de los alumnos, (iii) características del hogar, (iv) insumos educativos controlados por los padres y (v) características de calidad de la experiencia formativa del colegio. Estas últimas son de particular relevancia para nuestra investigación, porque incluyen la calidad docente.

\section{b. Calidad docente}

La calidad docente ha sido medida con distintas variables, porque es un concepto amplio que incluye dominio del contenido y habilidades interpersonales, en especial pedagógicas y comunicativas (Hightower et al., 2011). Es, entonces, difícil establecer qué determina que un profesor motive el aprendizaje 
durante un proceso de enseñanza que se asemeja a una "caja negra» (Schwerdt \& Wuppermann, 2010; Black, Harrison, Lee, Marshall, \& Wiliam, 2002). Investigaciones iniciales ${ }^{2}$ aproximaron la calidad del maestro con las siguientes variables: (i) si cuenta con certificación o licencia; sus años (ii) de educación y (iii) de experiencia; y su conocimiento (iv) de la materia y (v) pedagógico.

Sin embargo, posteriormente se concluyó que la preparación (nivel de educación y número de cursos tomados) y la experiencia laboral (certificación y ańos de experiencia) eran aproximaciones pobres del desempeño docente en el aula (Hill, Rowan, \& Loewenberg, 2005). Por ello, estudios recientes se han enfocado en evaluar la calidad docente mediante el conocimiento docente, el cual suele medirse por medio de exámenes de certificación o pruebas estandarizadas (Hill et al., 2005). Diversos estudios probaron que esta variable es la de mayor correlación con el desempeño estudiantil (Wayne \& Youngs, 2003; Eide, Goldhaber, \& Brewer, 2004; Hanushek \& Rivkin, 2006). Por ejemplo, Hanushek (1997, p. 144) contabilizó 41 estimaciones del efecto de las puntuaciones de los maestros y encontró que «de todas las medidas explícitas de los maestros y las escuelas que se prestan a la tabulación, los puntajes de pruebas están más asociados con un mayor rendimiento de los estudiantes».

\section{c. Conocimiento docente}

La definición actual de conocimiento docente fue propuesta por Shulman (1987) y sus colegas Wilson, Shulman \& Richert (1987). Ellos manifestaron que, hasta ese momento, no se había dado la importancia suficiente al conocimiento del docente en los estudios académicos educativos (Guadalupe, León, \& Cueto, 2013).

Tomando como base a Shulman (1986), en esta investigación planteamos que el conocimiento docente se divide en dos principales aspectos: subject matter knowledge (SMK) y pedagogical content knowledge (PCK). El SMK es el conocimiento de los conceptos propios de la materia, así como la comprensión de por qué estos conceptos son verdaderos; es decir, la cantidad acumulada y organización del conocimiento de la materia en la mente del docente (Hill et al., 2005). Tal como apunta Shulman (1987), todo docente debe, como mínimo, demostrar conocimiento de la materia que enseña antes de poder ayudar a los alumnos a aprender. Este SMK se consigue mediante programas de formación altamente calificados o a través de la práctica (Shepherd, 2015).

\footnotetext{
${ }^{2}$ Resumido de Jadama (2014), Goldhaber \& Brewer (1999) y Darling-Hammond (2000).
} 
Por su parte, el PCK incluye el conocimiento de las estrategias más adecuadas para representar y transmitir ideas de una manera comprensible, ya sea mediante analogías, ilustraciones, ejemplos, explicaciones, demostraciones, entre otras (Shulman, 1986).

El aporte de Shulman marcó el inicio de una mayor investigación del rol del docente en la educación. Pero la mayoría de los estudios se han concentrado únicamente en el SMK y en economías industrializadas (Guadalupe et al., 2013). Varios estudios evalúan el impacto del SMK sobre el rendimiento estudiantil en los Estados Unidos utilizando los resultados de evaluaciones estandarizadas de rendimiento de docentes y estudiantes. Estos estudios encuentran que existe un rol importante del SMK sobre el rendimiento del alumno (Hanushek, 1971, 1992; Summers \& Wolfe, 1977; Murnane \& Phillips, 1981; Ehrenberg \& Brewer, 1995; Rowan, Chiang, \& Miller, 1997; Hill et al., 2005).

Entre los estudios más recientes, hay algunos referidos a países en desarrollo, pero muy pocos al Perú. Estos utilizan los puntajes de los docentes en pruebas de conocimiento de su materia. Algunos ejemplos son los trabajos de Tan, Lane \& Coustère (1997) en Filipinas; Bedi \& Marshall (2002) en Honduras; Behrman, Ross \& Sabot (2008) en Pakistán; Altinok (2013) y Shepherd (2015) en países de África; y Metzler \& Woessmann (2010) y Guadalupe et al. (2013) en el Perú. Todos encuentran que existe una asociación positiva entre el SMK y el rendimiento del alumno. No obstante, son estudios propensos a distintos problemas econométricos de estimación.

Un problema potencial es la existencia de características no observables del docente, del alumno o de la escuela. Cuando estas características tienen correlación con el conocimiento docente y, a la vez, con el rendimiento estudiantil, se generan sesgos en los estimadores. Uno de los ejemplos más claros es la omisión de la variable «motivación del profesor» (Goldhaber \& Brewer, 1997; Glewwe \& Kremer, 2006; Glewwe \& Miguel, 2008). Profesores más motivados suelen conocer más su materia, $y$, al mismo tiempo, su motivación influye de manera positiva en el rendimiento del alumno.

Sesgos similares ocurren si no se incluye al PCK en la regresión, puesto que está correlacionado con el SMK y, a la vez, con el rendimiento del estudiante. Si el SMK es complementado con el PCK, se mejora la identificación de los efectos del profesor de calidad en el rendimiento estudiantil (Hill et al., 2005). Pero son pocos los estudios que han incluido al PCK, y todos se enfocan en los Estados Unidos (Frome, Lasater, \& Cooney, 2005; Harris \& Sass, 2011; Hill et al., 2005). 
Otro problema potencial es el error de medición del conocimiento docente. Esta variable es difícil de medir y, por ende, las investigaciones suelen utilizar proxies (Metzler \& Woessmann, 2010). Por ejemplo, existen casos en los que se mide el conocimiento docente por medio de un cuestionario con una única pregunta de matemáticas (Rowan et al., 1997). Este tipo de cuestionarios no logran capturar ni el SMK ni el PCK.

En el caso peruano, los estudios que miden el impacto de los docentes sobre el rendimiento estudiantil también muestran problemas econométricos. Guadalupe et al. (2013), utilizando la IV Evaluación Nacional del Rendimiento Estudiantil 2004, encuentran una correlación positiva entre calificaciones de alumnos y las de docentes, pero alertan que su investigación no arroja relaciones causales. Metzler \& Woessmann (2010) también utilizan la misma Evaluación Nacional y encuentran una asociación positiva entre el SMK y el rendimiento de los alumnos. Ellos aplican una metodología within-teacher within-student que pretende resolver el problema de variables omitidas ${ }^{3}$. Pero, con esta metodología, reducen su muestra al 35\% del total de los alumnos, lo que ocasiona pérdida de variabilidad y, por tanto, de representatividad. Específicamente, su muestra considera estudiantes en su mayoría del ámbito rural, por lo que las conclusiones extraídas no son generalizables a todos los estudiantes del país.

\section{d. Equidad y efectos heterogéneos del conocimiento del docente}

Hightower et al. (2011) señalan que los profesores con baja puntuación en pruebas estandarizadas de conocimiento docente suelen ser asignados a los estudiantes de bajos ingresos o pertenecientes a minorías.

La heterogeneidad de efectos del conocimiento del docente en el rendimiento estudiantil ha sido poco estudiada. Hill et al. (2005) encuentran que el efecto del conocimiento del docente de matemáticas se diluye en los quintiles inferiores de la muestra de los docentes. Es decir, los peores profesores no ayudan a que sus alumnos aprendan. Altinok (2013) muestra que un mayor conocimiento del docente es más efectivo en las zonas urbanas que en las rurales en distintos países africanos. Por su parte, Shepherd (2015) encuentra que, en los quintiles de menor nivel socioeconómico de los alumnos, el conocimiento docente pierde significancia para predecir el rendimiento académico.

\footnotetext{
${ }^{3}$ Aunque su metodología combina información generada por pruebas de matemáticas y de comprensión lectora a los docentes. Esto es problemático, puesto que las escalas latentes no son conmensurables, incluso después de la normalización de los datos (Guadalupe et al., 2013).
} 
En el Perú, los resultados de distintas evaluaciones nacionales muestran una fuerte inequidad en el sistema educativo. Los estudiantes con el peor rendimiento se ubican en los departamentos más pobres del país, en el ámbito rural, en las zonas de la Sierra y Selva, y, además, asisten a instituciones públicas (UMC, 2005, 2014, 2015, 2016b). Guadalupe et al. (2013) encontraron que este patrón de brechas en los estudiantes fue similar para el caso de los docentes en 2004; es decir, los alumnos que más apoyo necesitan tienen a los peores docentes. Sin embargo, estos autores no analizan la heterogeneidad del impacto del conocimiento docente.

\section{Marco analítico}

Esta investigación busca probar dos hipótesis. Primera, que existe una relación positiva entre el conocimiento docente y los logros de aprendizaje de los estudiantes en Perú. Segunda, que es heterogéneo el efecto del conocimiento docente sobre los alumnos, debido a una complementariedad entre insumos de la función de producción de aprendizajes. Es posible que, a un mismo nivel de calidad docente, el impacto en un sector de la población (favorecido) sea mayor que en otro sector (desfavorecido), debido a que, en los sectores favorecidos, los nińos tienen un mayor nivel de aprendizaje acumulado en el pasado y existen mejores insumos educativos dentro del hogar.

Para medir el efecto del docente en los alumnos, la variable que utilizamos es el conocimiento docente (CD). Siguiendo a Shulman (1986, 1987), se define al CD como la combinación de SMK y PCK, ambos tipos de conocimiento ya definidos anteriormente. Por sí solo, el SMK es una buena forma de medir el desempeño del docente (Wayne \& Youngs, 2003; Eide et al., 2004; Hanushek \& Rivkin, 2006; Hanushek, Piopunik, \& Wiederhold, 2014), pero la precisión de este estimador aumenta al añadirle el PCK (Frome et al., 2005; Harris \& Sass, 2011; Hill et al., 2005).

Sin embargo, debe recalcarse que el CD no mide directamente el desempeńo del docente en el aula (que es lo que realmente impacta en el aprendizaje de los niños). Ante la dificultad de observar dicho desempeño, el CD representa una buena aproximación, según la literatura especializada.

El modelo teórico que subyace a las hipótesis planteadas es una adaptación de la función de producción de rendimiento académico de Glewwe \& Kremer (2006), a la cual agregamos un componente específico que mide el impacto directo del conocimiento docente sobre el rendimiento de los alumnos. Además, siguiendo a Cunha \& Heckman (2007), se incluye la habilidad anterior del alumno como un componente de valor agregado que captura la historia 
de los insumos familiares y escolares del pasado. Es importante la inclusión de esta variable, ya que el desarrollo educativo del niño es un proceso acumulativo (Todd \& Wolpin, 2003).

Así, la función de producción de aprendizajes es la siguiente:

$$
\mathrm{A}_{t}=\mathrm{a}\left(\mathrm{A}_{t-1}, \mathrm{H}_{t} C D_{t} z_{i}\right)
$$

Donde " $\mathrm{A}_{t}$ " es la habilidad actual del alumno; « $\mathrm{A}_{t-1}$ " es la habilidad del alumno en un período anterior; « $\mathrm{H}_{t}$ " es un índice de insumos educativos del hogar ${ }^{4} ; \mathrm{y}$, «CD$D_{t}$ " es el conocimiento docente. Estas variables son los inputs de la función de producción. Además, son variables de elección que impactan de manera directa en los aprendizajes y, por ende, permiten que se caracterice correctamente el entorno educativo de los niños. Por último, siguiendo a Castro (2015), $z_{i}$ es un vector de controles de perfil socioeconómico que determinan de manera exógena a los insumos 5 .

Según la ecuación (1), para testear nuestra primera hipótesis debemos encontrar el valor de $\frac{\partial_{A t}}{\partial C D_{t}}$. Esperamos que el signo de esta derivada sea positivo y robusto.

La segunda hipótesis está motivada por la realidad de la inequidad en la distribución de la calidad educativa en el Perú. Los resultados de la Evaluación Muestral (EM) 2013 indican que los alumnos con menor rendimiento se encuentran en: (i) zonas rurales y (ii) colegios públicos. Estas brechas se repiten en los docentes; es decir, existe menor calidad docente donde más se necesita. Ante esta inequidad educativa, a la luz de los (antes mencionados) estudios que han encontrado efectos heterogéneos de la calidad docente en escenarios con inequidad educativa similares al del Perú, planteamos que el efecto de los docentes sobre los alumnos no sería el mismo en todo el país. Sustentamos teóricamente esto dividiendo al país en dos sectores: favorecidos y desfavorecidos, y definiendo al sector favorecido como aquel en el que los niños tienen un mayor nivel de aprendizaje acumulado en el pasado y existen mejores insumos educativos en el hogar.

Siguiendo a Cunha \& Heckman (2007), proponemos que la causa subyacente a la heterogeneidad de efectos es la complementariedad entre los insumos de aprendizaje. Dichos autores plantearon un modelo que toma

\footnotetext{
${ }^{4}$ Este índice está conformado por la existencia de un espacio de estudio apropiado para el estudiante, el acceso a internet, el número de libros en la casa y la tenencia o no de los siguientes materiales educativos: enciclopedias, libros especializados, libros de literatura, CD/DVD o software educativo, software de conocimiento general y libros digitales (UMC, 2016a).

${ }^{5}$ Se incluyen estos determinantes exógenos de insumos para controlar por la posibilidad de haber omitido otros insumos de producción relevantes (Castro, 2015); ello permite evaluar la robustez del modelo.
} 
en cuenta la habilidad pasada $\left(\mathrm{A}_{t-1}\right)$ e inversiones pasadas y presentes en educación. Postulan que existe complementariedad cuando los inputs de la función de producción no son sustitutos perfectos. Por ejemplo, existe complementariedad dinámica cuando las habilidades producidas en una etapa de la infancia aumentan la productividad de la inversión en educación en las siguientes etapas. Además, se entiende que un insumo no puede ser sustituido completamente por otro, sino que cada uno es necesario para la formación de habilidades del niño.

Nosotros aplicamos el planteamiento de Cunha \& Heckman (2007) al caso del CD. Así, consideramos que existe complementariedad dinámica entre el CD y la habilidad pasada $\left(\mathrm{A}_{t-1}\right)$. Es decir, es más probable que los niños con mayor habilidad inicial aprovechen más a sus profesores en el presente. Con la misma óptica, también es posible que exista una complementariedad directa entre el CD y los insumos educativos del hogar $\left(\mathrm{H}_{t}\right)$. En este sentido, los sectores más favorecidos son aquellos que tienen mayor habilidad pasada $\mathrm{y}$ mejores insumos educativos del hogar.

Para formalizar el modelo, al igual que Cunha \& Heckman (2007), se asume que la función de producción de aprendizajes (ecuación 1) es estrictamente creciente, cóncava en $\mathrm{CD}_{t}$ y doblemente diferenciable en todos sus elementos. De modo que la complementariedad dinámica surge cuando $\partial^{2} \mathrm{~A}_{t} /\left(\partial \mathrm{CD}_{t} \partial \mathrm{A}_{t-1}\right)>0$. Esto implica que los alumnos de sectores más favorecidos (con mayor nivel de habilidad pasada) aprovechan más a sus profesores actuales ${ }^{6}$. Es decir, la productividad del CD aumenta debido a mayores niveles de aprendizaje acumulados en el pasado. De esta manera, para cada nivel de CD, el impacto marginal de la calidad docente es mayor en los sectores favorecidos que en los desfavorecidos. Esto se observa mejor en la figura 1.

\footnotetext{
${ }^{6}$ Un claro ejemplo de ello es que un niño que aprendió más en años escolares anteriores entenderá más rápido lo que su profesor le enseña en el período actual; asimismo, podría realizar las tareas más rápido y aceptar un mayor nivel de dificultad de enseñanza (si el profesor desea profundizar los contenidos).
} 
Figura 1

Heterogeneidad de efectos debido a brechas de habilidad pasada

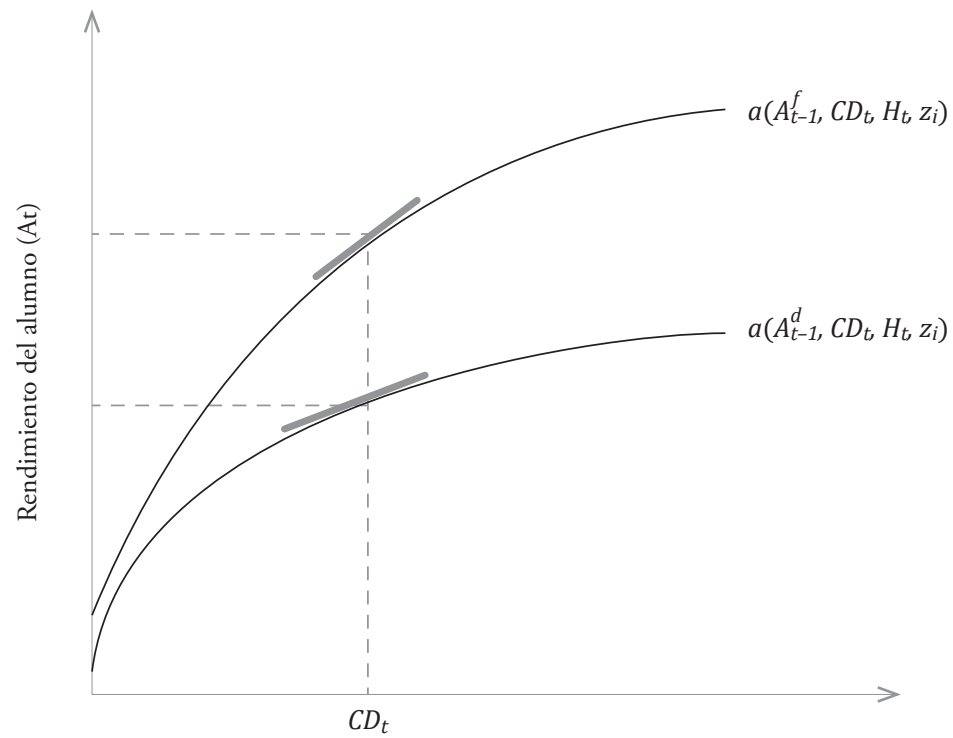

Conocimiento docente (CDt)

Elaboración propia.

Donde $A_{t-1}^{f}$ pertenece al sector favorecido y $A_{t-1}^{d}$, al desfavorecido. Es decir, $A_{t-1}^{f}>A_{t-1}^{d}$. Se cumple, así, que $\frac{\partial A_{t}(\text { Favorecido })}{\partial C D_{t}}>\frac{\partial A_{t}(\text { Desfavorecido })}{\partial C D_{t}}$, para cada nivel de CD.

Por último, la complementariedad directa entre los insumos educativos del hogar y el CD surge cuando $\partial^{2} \mathrm{~A}_{t} /\left(\partial \mathrm{CD}_{t} \partial H_{t}\right)>0$. Esto indica que los alumnos de sectores favorecidos, en cuanto a insumos educativos del hogar $\left(H_{t}\right)$, aprovechan más a los profesores que los de sectores desfavorecidos. Así, la complementariedad directa podría darse cuando el niño aprende más lo que su profesor le enseña, debido a que en su hogar accede a insumos educativos (libros, acceso a internet, discos, espacio para estudiar, etc.) que facilitan su aprendizaje. Ello permite que el niño pueda estudiar más eficazmente lo recomendado por el profesor. Esto se observa mejor en la figura 2. 
Figura 2

Heterogeneidad de efectos debido a brechas de insumos educativos del hogar

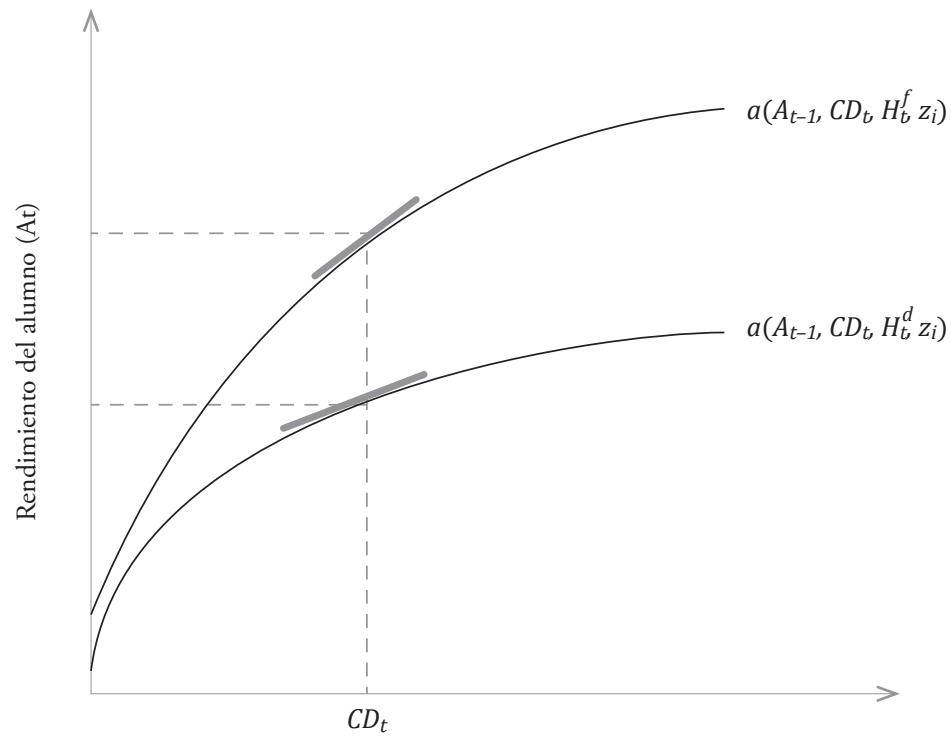

Conocimiento docente $(\mathrm{CDt})$

Elaboración propia.

Donde $H_{t}^{f}$ pertenece al sector favorecido y $H_{t}^{d}$, al desfavorecido. Es decir, $H_{t}^{f}>H_{t}^{d}$. Se cumple, así, que $\frac{\partial A_{t}(\text { Favorecido })}{\partial C D_{t}}>\frac{\partial A_{t}(\text { Desfavorecido })}{\partial C D_{t}}$, para cada nivel de CD.

\section{Metodología}

La metodología elegida para estimar la ecuación (1) es la de valor agregado (value-added). Esta relaciona el logro de aprendizaje del niño $\left(\mathrm{A}_{t}\right)$ con su logro de aprendizaje en el pasado, además de con insumos escolares y familiares contemporáneos. Según Todd \& Wolpin (2003) y Andrabi, Das, Khwaja \& Zajonc (2011), las estimaciones mediante modelos de valor agregado asumen que los resultados de pruebas estandarizadas rezagadas pueden capturar correctamente los inputs educativos que recibió un nińo en el pasado, así como otras dotaciones no observables o shocks del pasado. $\mathrm{Al}$ incluir $\mathrm{A}_{t-1}$ como variable explicativa de $A_{t}$, se incorporan determinantes del logro de aprendizaje del niño que de otra manera serían no observables y generarían sesgo por variable omitida. 
Gracias a esta metodología, se pueden obtener estimados más confiables del efecto del conocimiento docente sobre los logros educativos del nińo, en comparación con lo que se lograría con una especificación basada solo en insumos contemporáneos (Singh, 2015). Algunos estudios muestran que los modelos de valor agregado proveen los mismos resultados que métodos experimentales y cuasiexperimentales usados para identificar los efectos de los docentes (Deming, Hastings, Cane, \& Staiger, 2014; Kane, McCaffrey, Miller, \& Staiger, 2013).

Siguiendo a Todd \& Wolpin (2003), se asume que la ecuación (1) puede escribirse como una función aditiva separable, con lo que se obtiene la siguiente especificación empírica:

$$
A_{i t}=\beta_{0}+\beta_{1} C D_{i t}+\beta_{2} C D_{i t}^{2}+\beta_{3} A_{i t-1}+\beta_{4} H_{i t}+\alpha z_{i t}+\eta_{i t}
$$

Donde $\mathrm{A}_{i t}$ es el logro de aprendizaje en matemáticas del niño «i» en el tiempo «t»; $C D_{i t}$ es el conocimiento docente ${ }^{7}$ asignado al nińo «i» en el tiempo «" $; \mathrm{H}_{i t}$ es el índice de insumos educativos del hogar del niño «i» en el tiempo «t»; $z_{i t}$ es un vector de controles de perfil socioeconómico que determinan exógenamente a los insumos (véase el anexo 1 para mayor detalle) ${ }^{8}$; y $\eta_{i t}$ es un componente de error específico al individuo.

La ecuación (2) es la representación de mínimos cuadrados ordinarios más sencilla de nuestro modelo empírico, y bastaría con encontrar que el efecto marginal $\left(\frac{\partial \mathrm{A}_{\mathrm{it}}}{\partial \mathrm{CD}_{\mathrm{it}}}=\beta_{1}+2 \beta_{2} \overline{\mathrm{CD}}_{i t}\right)$ sea positivo para comprobar la primera hipótesis de esta investigación?

Pero, para poder comprobar nuestra segunda hipótesis, es necesario plantear un modelo que permita medir si el impacto del conocimiento docente es heterogéneo, debido a las complementariedades entre insumos.

Siguiendo a Castro (2017), desarrollamos una alternativa que modifica la ecuación (2) tomando en cuenta las complementariedades. Para ello, se incluyen interacciones entre el conocimiento docente y las variables que capturan la complementariedad (habilidad pasada e insumos educativos del hogar). La ecuación modificada es la siguiente:

\footnotetext{
${ }^{7}$ Se incluye un término cuadrático del CD para capturar los rendimientos decrecientes de la función de producción.

${ }^{8}$ Estas variables permiten controlar por posibles factores causales omitidos. Entre estas, vale destacar la motivación del profesor, la infraestructura escolar y las expectativas de los padres con respecto a la educación de sus hijos; variables que pocas veces han sido incluidas en estudios pasados debido a la dificultad de medirlas.

${ }^{9}$ Dicho efecto marginal debe evaluarse en el promedio de CD.
} 


$$
\begin{gathered}
\mathrm{A}_{\mathrm{it}}=\beta_{0}+\beta_{1} \mathrm{CD}_{\mathrm{it}}+\beta_{2} \mathrm{CD}_{\mathrm{it}}^{2}+\beta_{3} \mathrm{~A}_{\mathrm{it}-1}+\beta_{4} \mathrm{H}_{\mathrm{it}}+\beta_{5} \mathrm{CD}_{\mathrm{it}} \mathrm{A}_{\mathrm{it}-1}+\beta_{6} \mathrm{CD}_{\mathrm{it}} \mathrm{H}_{\mathrm{it}} \\
+\alpha \mathrm{Z}_{\mathrm{it}}+\eta_{\mathrm{it}}
\end{gathered}
$$

Esta ecuación de valor agregado (3) será estimada por una regresión de mínimos cuadrados ordinarios ${ }^{10}$. Y el impacto del CD (efecto marginal evaluado en el promedio) se calcula de la siguiente manera:

$$
\frac{\partial \mathrm{A}_{\mathrm{it}}}{\partial \mathrm{CD}_{\mathrm{it}}}=\beta_{1}+2 \beta_{2} \overline{\mathrm{CD}}_{i t}+\beta_{5} \overline{\mathrm{A}}_{i t-1}+\beta_{6} \overline{\mathrm{H}}_{i t}
$$

Nuestra primera hipótesis seguiría implicando que el efecto marginal sea positivo $\left(\frac{\partial \mathrm{A}_{\mathrm{it}}}{\partial \mathrm{CD}_{\mathrm{it}}}>0\right)$. Para comprobar nuestra segunda hipótesis, es necesario concentrarse en los valores de $\beta_{5}\left(\beta_{5}=\frac{\partial^{2} \mathrm{~A}_{i t}}{\partial \mathrm{CD}_{i t} \partial \mathrm{A}_{i t-1}}\right)$ y $\beta_{6}\left(\beta_{6}=\frac{\partial^{2} \mathrm{~A}_{i t}}{\partial \mathrm{CD}_{i t} \partial H_{i t}}\right)$, esperando que sean positivos. Un $\beta_{5}>0$ indicaría que los nińos de sectores favorecidos por mayor habilidad pasada aprovechan más a sus docentes (complementariedad dinámica). Y un $\beta_{6}>0$ implicaría que nińos favorecidos por mayores insumos educativos del hogar también aprovechan más a sus profesores (complementariedad directa).

\section{Datos}

La principal fuente de datos es la Evaluación Muestral 2013 (EM 2013), la cual contiene evidencia sobre los niveles de logro de aprendizaje en matemáticas de los estudiantes de sexto grado de primaria en instituciones educativas públicas y privadas de todo el país, sobre las características individuales y familiares de los estudiantes evaluados, así como de las condiciones y procesos escolares que se encuentran asociados a su desempeño (UMC, 2014). Y en la EM 2013 también se evaluó algo muy relevante para nuestro estudio: el conocimiento del docente de matemáticas en fracciones.

La EM 2013 evaluó a aproximadamente 66.500 estudiantes de sexto de primaria en 3.120 instituciones educativas de todas las regiones de Perú. Estas fueron seleccionadas de manera aleatoria mediante un diseño muestral bietápico. Primero, se eligieron las escuelas y, para aquellas con más de dos secciones, en una segunda etapa, se seleccionaron solo dos secciones. La selección en la primera etapa fue sistemática simple dentro de cada estrato; y en la segunda etapa, la selección fue aleatoria simple. De esta manera, se obtuvo

\footnotetext{
${ }^{10}$ Todas las variables de esta regresión fueron reescaladas a una misma media (500) y desviación estándar (100). Esto permite que cada coeficiente refleje, más claramente, el impacto del cambio en una desviación estándar de los regresores.
} 
representatividad en los siguientes estratos: (i) nacional; (ii) departamental; (iii) gestión de la IE (pública y privada); y (iv) ámbito (urbano y rural) ${ }^{11}$.

En dicha EM, los alumnos rindieron pruebas estandarizadas de matemáticas, cuyos resultados siguieron un proceso de modelamiento psicométrico de Rasch. Es importante señalar que el Ministerio de Educación (Minedu) transformó linealmente las medidas de habilidad de los estudiantes, de tal manera que la media aritmética fuera 500 y la desviación estándar, 100 (UMC, 2016a).

Asimismo, en dicha EM se examinó el conocimiento de los docentes relacionado con fracciones, uno de los contenidos del currículo escolar de matemáticas ${ }^{12}$. En la encuesta, los docentes respondieron un conjunto de 35 preguntas. El Minedu utilizó 21 de estas preguntas para elaborar un constructo de conocimiento disciplinar (únicamente de SMK). A través de un análisis factorial confirmatorio (CFA) de segundo orden, el Minedu identificó cinco factores latentes subyacentes al constructo de conocimiento disciplinar evaluado: fracción como parte-todo, fracción como operador, operación con fracciones, fracción como medida y fracción como razón.

Sin embargo, esa encuesta a docentes también incluyó preguntas relacionadas con el PCK (véase el anexo 2). Si bien el Minedu no las utilizó al elaborar su constructo, el carácter abierto de tales preguntas dio pie a que el docente explique su estrategia pedagógica, $y$, por ende, da la posibilidad de asignarle un puntaje según la calidad de su estrategia.

Ello nos permitió calcular un nuevo constructo de conocimiento docente (CD) que incluye componentes de SMK y también de PCK, siguiendo un proceso bietápico similar al del Minedu. Como primera etapa, calculamos seis factores latentes subyacentes mediante un análisis de componentes principales categóricos (Catpca) ${ }^{13}$ : (i) fracción como parte-todo, (ii) fracción como operador, (iii) operación con fracciones, (iv) fracción como medida, (v) fracción como razón y (vi) conocimiento pedagógico de fracciones. En la segunda etapa, integramos el análisis de Catpca con los seis factores para obtener el constructo de CD (véase el anexo 3 con información de los resultados de las dos etapas).

\footnotetext{
${ }^{11}$ Estos son los estratos más importantes para esta investigación. Pero vale aclarar que la EM 2013 también es representativa por sexo, lengua materna del estudiante y tipo de escuela.

${ }^{12}$ Las fracciones son un conocimiento básico para el aprendizaje del estudiante, porque median la construcción de representaciones del mundo que lo rodea, le permiten comparar dos cantidades midiéndolas adecuadamente y le sirven para conocimientos más avanzados en matemáticas (UMC, 2016a).

${ }^{13}$ Para los primeros cinco factores latentes, se utilizaron las mismas preguntas que el Minedu había asignado a cada factor. Para el sexto factor, se utilizaron las preguntas del cuestionario que permiten identificar la capacidad pedagógica del docente.
} 
También hemos reescalado linealmente el puntaje del docente siguiendo la metodología del Reporte Técnico de la EM 2013, de manera que la media aritmética fuera 500 y la desviación estándar, 100.

La segunda fuente de información es la Evaluación Censal de Estudiantes (ECE). Esta ofrece un procedimiento estandarizado que permite conocer el logro de aprendizaje alcanzado en matemáticas por todos los estudiantes de segundo grado de primaria del Perú. Utilizamos la ECE 2009 y la EM 2013, a fin de identificar los logros educativos en matemáticas de una muestra común de estudiantes en dos períodos de aprendizaje: segundo ${ }^{14}$ y sexto grado de primaria.

Los estudiantes que coincidieron en ambas evaluaciones (ECE 2009 y EM 2013) fueron aproximadamente 42.000 niños, que representan el 64\% del total de estudiantes evaluados en dicha EM. La explicación de esta coincidencia imperfecta fue brindada por el Minedu por medio de una consulta formal (anexo 4).

Por último, la muestra que trabajamos está compuesta por 24.986 estudiantes, para los cuales se tiene información sobre sus logros educativos en matemáticas en 2009 y 2013, así como el cálculo del conocimiento de su docente de matemáticas en $2013^{15}$.

\section{Resultados}

Los resultados de las estimaciones de nuestras ecuaciones base -(2) y (3)- se muestran en las tablas 1 y 2 . La tabla 1 presenta la especificación más sencilla y permite verificar nuestra primera hipótesis de trabajo. La tabla 2 permite observar si se cumple la complementariedad entre insumos de la función de producción de aprendizajes y, por tanto, comprobar nuestra segunda hipótesis de trabajo, al mismo tiempo que refuerza las conclusiones de la primera especificación ${ }^{16}$.

\section{a. Efecto positivo del conocimiento docente}

La tabla 1 muestra el efecto del CD sobre los logros de aprendizaje de los estudiantes, bajo distintas especificaciones del modelo simple de valor agregado

\footnotetext{
${ }^{14}$ Los alumnos que estuvieron en sexto grado en 2013 cursaron el segundo grado en 2009 . Se solicitó al Minedu la ECE 2008 para poder detectar alumnos repitentes y utilizar una mayor cantidad de datos. Pero no pudimos obtener esa información.

${ }_{15}$ No todos los docentes respondieron por completo el cuestionario. Solo se cuenta con cuestionarios completos de 2.361 docentes.

${ }^{16}$ Todos los regresores fueron reescalados de tal manera que el efecto se mida en desviaciones estándar.
} 
(ecuación 2). Se incluyeron todos los insumos de la función de producción de aprendizaje planteados en el marco analítico y la metodología, que caracterizan el entorno de aprendizaje de los nińos. Asimismo, se incluyó un set de controles de perfil socioeconómico que determinan de manera exógena a los insumos.

Tabla 1

Efecto del conocimiento docente sobre los logros educativos

\begin{tabular}{|c|c|c|}
\hline & \multicolumn{2}{|c|}{ Logro educativo } \\
\hline & (1) & (2) \\
\hline \multirow[t]{2}{*}{ Conocimiento docente } & $0,3321^{* * *}$ & $0,3783^{* * *}$ \\
\hline & $(0,021)$ & $(0,021)$ \\
\hline \multirow[t]{2}{*}{$(\text { Conocimiento docente })^{2}$} & $-0,0002^{* * *}$ & $-0,0003^{* * *}$ \\
\hline & $(0,000)$ & $(0,000)$ \\
\hline \multirow[t]{2}{*}{ Logro educativo pasado } & $0,4116^{* * *}$ & $0,3827^{* * *}$ \\
\hline & $(0,0020)$ & $(0,002)$ \\
\hline \multirow[t]{2}{*}{ Índice de insumos educativos del hogar } & $0,0655^{* * *}$ & $0,0325^{* * *}$ \\
\hline & $(0,0021)$ & $(0,002)$ \\
\hline \multirow[t]{2}{*}{ Expectativas de los padres } & $0,1961^{* * *}$ & $0,1708^{* * *}$ \\
\hline & $(0,0022)$ & $(0,002)$ \\
\hline \multirow[t]{2}{*}{ Satisfacción del docente } & $0,0314^{* * *}$ & $0,0196^{* * *}$ \\
\hline & $(0,0019)$ & $(0,002)$ \\
\hline \multirow[t]{2}{*}{ Infraestructura escolar } & $0,1675^{* * *}$ & $0,1255^{* * *}$ \\
\hline & $(0,0025)$ & $(0,003)$ \\
\hline Control por lengua materna & No & Sí \\
\hline Control por ámbito geográfico & No & Sí \\
\hline Control por gestión del colegio & No & Sí \\
\hline Control por autoeficacia del estudiante & No & Sí \\
\hline Control por liderazgo del director & No & Sí \\
\hline Control por sexo & No & Sí \\
\hline \multirow{2}{*}{ 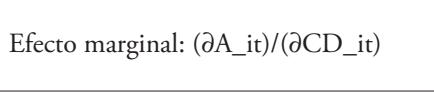 } & $0,1175^{* * *}$ & $0,1030^{* * *}$ \\
\hline & $(0,0021)$ & $(0,0023)$ \\
\hline$N$ & 17.404 & 17.404 \\
\hline
\end{tabular}

Notas. ${ }^{*} p<0,05 ;{ }^{* *} p<0,01 ;{ }^{* * *} p<0,001$. Errores estándar entre paréntesis. El efecto marginal se evalúa en el promedio de las variables de análisis. 
La primera columna muestra una regresión que incluyó como regresores solo los insumos directos de la función de producción $\left(\mathrm{A}_{t-1}, \mathrm{H}_{t}, C D_{t}\right)$, y tres principales controles socioeconómicos: expectativas de los padres, satisfacción docente e infraestructura escolar. Como se observa, un aumento de una desviación estándar en el conocimiento docente incrementa los logros de aprendizaje de los niños en 0,12 desviaciones estándar. Este efecto es significativo al 0,1\%.

La regresión mostrada en la segunda columna incluyó todos los controles de perfil socioeconómico que determinan de manera exógena a los insumos. En este caso, un aumento de una desviación estándar en el conocimiento docente incrementa los logros de aprendizaje de los nińos en 0,10 desviaciones estándar. Por ende, los resultados son robustos ante la inclusión de controles adicionales a los insumos indirectos de la función de producción.

En el anexo 5, se muestran modelos adicionales que incorporan distintas especificaciones de los controles de la regresión. En las nuevas especificaciones, el efecto marginal del conocimiento docente se encontró en un rango de entre 0,09 y 0,12 desviaciones estándar. Esto reafirma la robustez de lo presentado en la tabla 1 .

Por consiguiente, los resultados del modelo utilizado confirman, con un buen nivel de robustez, nuestra primera hipótesis: existe una relación positiva entre el conocimiento docente y los logros de aprendizaje de los estudiantes en el Perú.

Además, es importante percatarse de que, bajo todas las especificaciones mostradas en la tabla 1 , existe evidencia de una productividad marginal decreciente del conocimiento del profesor. Esto se refleja en el coeficiente negativo del término cuadrático del conocimiento docente ${ }^{17}$.

\section{b. Evidencia de complementariedad de insumos}

La tabla 2 muestra los resultados de nuestra ecuación de valor agregado que permite identificar la presencia de complementariedades en la función de producción (ecuación 3). Esto se logra al incluir dos interacciones adicionales: (i) el conocimiento docente multiplicado por el logro educativo del pasado (complementariedad dinámica); y (ii) el conocimiento docente multiplicado por el índice de insumos educativos del hogar (complementariedad directa). La tabla 2 fue elaborada (al igual que la anterior) incluyendo los insumos de la

\footnotetext{
${ }^{17}$ También se hicieron regresiones incluyendo el componente cuadrático de todos los insumos de la función de producción. El efecto marginal del conocimiento docente no se alteró.
} 
función de producción de aprendizajes ${ }^{18}$ y controles de perfil socioeconómico que determinan de manera exógena los insumos.

Tabla 2

Complementariedad de insumos y el conocimiento docente

\begin{tabular}{|c|c|c|}
\hline & \multicolumn{2}{|c|}{ Logro de aprendizaje } \\
\hline & (1) & (2) \\
\hline \multirow[t]{2}{*}{ Conocimiento docente } & $0,1706^{* * *}$ & $0,2472^{* * *}$ \\
\hline & $(0,022)$ & $(0,023)$ \\
\hline \multirow[t]{2}{*}{$(\text { Conocimiento docente })^{2}$} & $-0,0003^{* * *}$ & $-0,0003^{* * *}$ \\
\hline & $(0,000)$ & $(0,000)$ \\
\hline \multirow[t]{2}{*}{ Logro de aprendizaje pasado } & $0,2093^{* * *}$ & $0,2186^{* * *}$ \\
\hline & $(0,0104)$ & $(0,010)$ \\
\hline \multirow[t]{2}{*}{ Índice de insumos educativos de hogar } & $-0,0113$ & $-0,0188$ \\
\hline & $(0,0109)$ & $(0,011)$ \\
\hline \multirow[t]{2}{*}{ (Conocimiento docente) $)^{*}($ Logro educativo pasado) } & $0,0004^{* * *}$ & $0,0003^{* * *}$ \\
\hline & $(0,000)$ & $(0,000)$ \\
\hline \multirow[t]{2}{*}{$($ Conocimiento docente)*(Índice del hogar) } & $0,0001^{* * *}$ & $0,0001^{* * *}$ \\
\hline & $(0,000)$ & $(0,000)$ \\
\hline \multirow[t]{2}{*}{ Expectativas de los padres } & $0,1956^{* * *}$ & $0,1712^{* * *}$ \\
\hline & $(0,0022)$ & $(0,002)$ \\
\hline \multirow[t]{2}{*}{ Satisfacción del docente } & $0,0297^{* * *}$ & $0,0190^{* * *}$ \\
\hline & $(0,0019)$ & $(0,002)$ \\
\hline \multirow[t]{2}{*}{ Infraestructura escolar } & $0,1693^{* * *}$ & $0,1266^{* * *}$ \\
\hline & $(0,0025)$ & $(0,003)$ \\
\hline Control por lengua materna & No & Sí \\
\hline Control por ámbito geográfico & No & Sí \\
\hline Control por gestión del colegio & No & Sí \\
\hline Control por autoeficacia del estudiante & No & Sí \\
\hline Control por liderazgo del director & No & Sí \\
\hline Control por sexo & No & Sí \\
\hline
\end{tabular}

${ }^{18}$ Se realizaron también regresiones incluyendo el componente cuadrático de todos los insumos de la función de producción. El efecto marginal del conocimiento docente no se alteró. 
Logro de aprendizaje

(1)

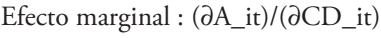

(2)

$0,1035^{* * *}$

$(0,0023)$

$\begin{array}{lrr}N & 17.404 & 17.404\end{array}$

Notas. ${ }^{*} p<0,05 ;{ }^{* *} p<0,01 ;{ }^{* * *} p<0,001$. Errores estándar entre paréntesis. El efecto marginal se evalúa en el promedio de las variables de análisis.

La primera columna muestra la especificación más simple para evaluar la existencia de dichas complementariedades. Como se observa, el coeficiente de la interacción del conocimiento docente con la habilidad pasada es positivo, con lo que se comprueba la existencia de complementariedad dinámica. También se acepta la presencia de complementariedad directa, puesto que el coeficiente de la interacción del conocimiento docente con el índice de insumos educativos del hogar es positivo ${ }^{19}$.

$\mathrm{Y}$ esa columna muestra que aumentar el conocimiento docente en una desviación estándar incrementa los logros de aprendizaje en 0,12 desviaciones estándar. Este efecto marginal tiene la misma magnitud que el observado en la columna 1 de la tabla 1. Ello indica que el cambio de especificación del modelo no altera el resultado principal.

La segunda columna resulta de la especificación que incluye todos los controles de perfil socioeconómico que determinan de manera exógena a los insumos. Como se observa, los coeficientes de las interacciones que evalúan las complementariedades no cambian de magnitud y siguen siendo altamente significativos.

En la figura 3, se muestra la relación entre el efecto marginal del conocimiento docente $\left(\frac{\partial \mathrm{A}_{\text {it }}}{\partial \mathrm{CD}_{\mathrm{it}}}\right)$ y los logros educativos del pasado $\left(\mathrm{A}_{\mathrm{it}-1}\right)$. De manera consistente con los resultados de la tabla 2, la pendiente de esta relación es positiva para todos los niveles de logro educativo del pasado. Es claro, entonces, que la productividad de un profesor aumenta a medida que el capital educativo acumulado en el pasado de un niño es mayor ${ }^{20}$. Esto refuerza la evidencia a favor de la complementariedad dinámica.

\footnotetext{
${ }^{19}$ Los coeficientes de las interacciones premultiplican a variables que fueron reescaladas para tener una misma media (500) y desviación estándar (100). Por tanto, se espera que las magnitudes de los coeficientes sean bajas, pero significativas.

${ }^{20}$ Se corrobora así lo proyectado en la figura 1: $\frac{\partial A_{t}\left(\text { Favorecido por } A_{t-1}\right)}{\partial C D_{t}}>\frac{\partial A_{t}\left(\text { Desfavorecido por } A_{t-1}\right)}{\partial C D_{t}}$.
} 
Figura 3

Relación entre el efecto marginal del conocimiento docente en los logros educativos (eje vertical) y los logros educativos del pasado (eje horizontal)

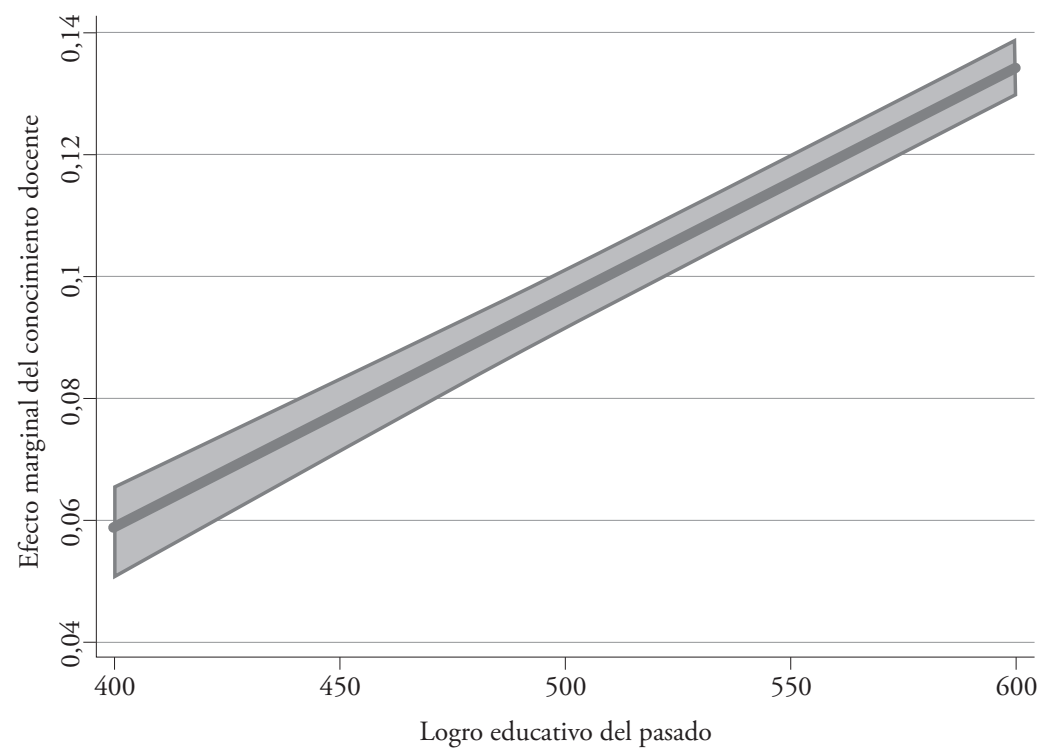

Nota. Intervalos de confianza al 95\%. Elaboración propia.

Y la figura 4 muestra que la relación entre los insumos educativos del hogar $\left(\mathrm{H}_{\mathrm{it}}\right)$ y el efecto marginal del conocimiento docente $\left(\frac{\partial \mathrm{A}_{\mathrm{it}}}{\partial \mathrm{CD}_{\mathrm{it}}}\right)$ es positiva para todos los niveles de insumos educativos del hogar. Esto refuerza la evidencia a favor de la complementariedad directa, puesto que los profesores son más productivos cuando educan a niños favorecidos por insumos educativos del $\operatorname{hogar}^{21}$.

${ }^{21}$ Se corrobora así lo planteado en la figura 2 del marco analítico: $\frac{\partial A_{t}\left(\text { Favorecido por } H_{t}\right)}{\partial C D_{t}}>\frac{\partial A_{t}\left(\text { Desfavorecido por } H_{t}\right)}{\partial C D_{t}}$. 
Figura 4

Relación entre el efecto marginal del conocimiento docente sobre los logros educativos (eje vertical) y los insumos educativos del hogar (eje horizontal)

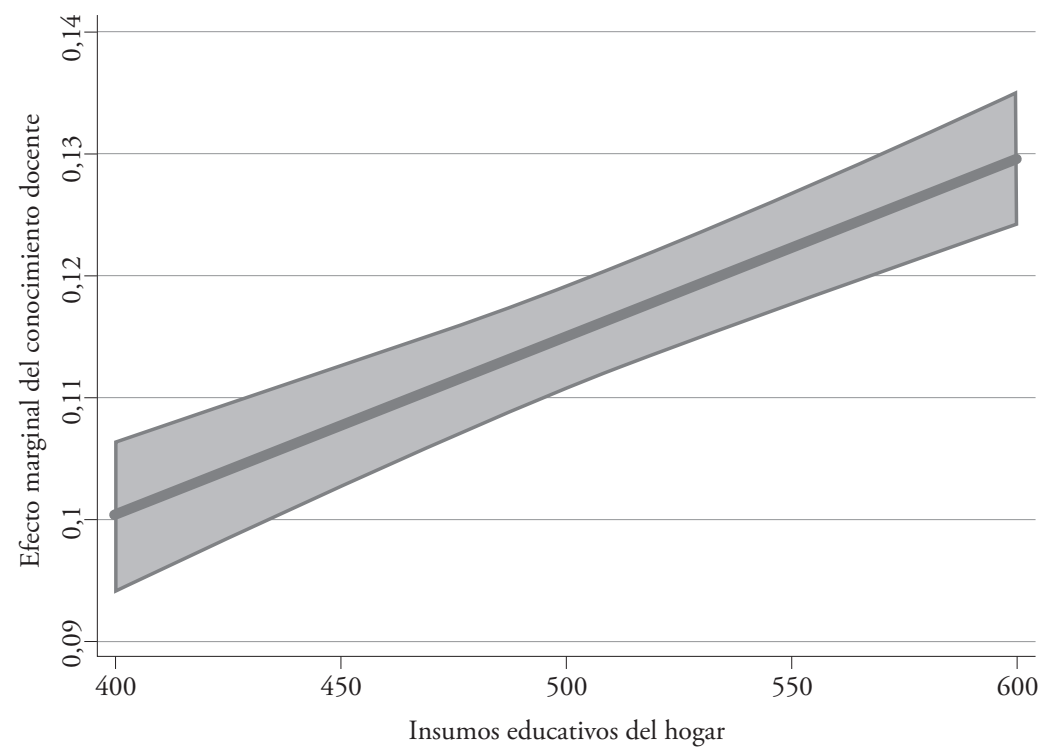

Nota. Intervalos de confianza al 95\%. Elaboración propia.

Para evaluar la robustez de estas complementariedades, se estimaron modelos adicionales que incorporan distintas especificaciones de las variables de control (véase el anexo 6). En todas, se encontró que la presencia de complementariedades sigue siendo significativa. Más aún, las magnitudes de dichas complementariedades son robustas.

Por tanto, el modelo ampliado de valor agregado confirma nuestra segunda hipótesis: existe heterogeneidad del efecto del conocimiento docente sobre los alumnos. Y robustamente valida la existencia de complementariedad tanto dinámica como directa.

\section{c. Enfoque adicional para la discusión educativa}

Los resultados obtenidos respaldan el enfoque analítico de considerar el conocimiento docente como una combinación de SMK y PCK. Pero falta analizar por separado el impacto de cada uno de esos componentes. Esto es importante, pues podría ocurrir que uno solo de los dos componentes sea el que genere 
los mayores incrementos de logros educativos en los niños. De ser así, cabría enfatizar las recomendaciones de políticas para mejorar el componente más importante. Por ello, a continuación, analizaremos el impacto desagregado de cada componente del CD sobre los logros educativos.

Como fue mencionado en la sección de datos, para construir la variable de conocimiento docente (CD) se calcularon seis componentes subyacentes al cuestionario de docentes de la EM 2013 (anexo 3), cinco de los cuales pertenecen al SMK y uno al PCK. Por consiguiente, para el análisis desagregado, se realizó un nuevo Catpca para construir el SMK con sus cinco componentes subyacentes. Y no se tuvo que reelaborar el constructo de PCK porque está basado en un solo componente subyacente ${ }^{22}$ (véase el anexo 7 con los resultados de la elaboración de ambos constructos).

Tabla 3

Efecto del conocimiento docente desagregado

\begin{tabular}{lcc}
\hline & \multicolumn{2}{c}{ Logros de aprendizaje } \\
\hline Subject matter knowledge & $(1)$ & $(2)$ \\
& $0,1586^{* * *}$ & $0,2110^{* * *}$ \\
(Subject matter knowledge $)^{2}$ & $(0,021)$ & $(0,021)$ \\
& $-0,0001^{* * *}$ & $-0,0002^{* * *}$ \\
Pedagogical content knowledge & $(0,000)$ & $(0,000)$ \\
& $0,1912^{* * *}$ & $0,1746^{* * *}$ \\
(Pedagogical content knowledge $)^{2}$ & $(0,018)$ & $(0,018)$ \\
Logro educativo pasado & $-0,0001^{* * *}$ & $-0,0001^{* * *}$ \\
Índice del hogar & $(0,000)$ & $(0,000)$ \\
Expectativas de los padres & $0,4116^{* * *}$ & $0,3821^{* * *}$ \\
& $(0,0020)$ & $(0,0020)$ \\
& $0,0655^{* * *}$ & $0,0322^{* * *}$ \\
& $(0,0021)$ & $(0,0022)$ \\
& $0,1961^{* * *}$ & $0,1703^{* * *}$ \\
\hline
\end{tabular}

${ }^{22}$ Es importante advertir que el constructo de SMK ha sido elaborado a partir de un mayor número de preguntas del cuestionario docente que el constructo de PCK; por lo cual, la fiabilidad del constructo SMK podría ser mayor que la del constructo PCK (esto se aprecia en el anexo 7, donde el alpha de Cronbach del SMK es mayor que el del PCK). 


\begin{tabular}{lcc}
\hline & \multicolumn{2}{c}{ Logros de aprendizaje } \\
\hline Satisfacción del docente & $(1)$ & $(2)$ \\
\hline Infraestructura escolar & $0,0314^{* * *}$ & $0,0197^{* * *}$ \\
& $(0,0019)$ & $(0,0020)$ \\
& $0,1675^{* * *}$ & $0,1272^{* * *}$ \\
Control por lengua materna & $(0,0025)$ & $(0,0032)$ \\
Control por ámbito geográfico & & Sí \\
Control por gestión del colegio & No & Sí \\
Control por autoeficacia del estudiante & No & Sí \\
Control por liderazgo del director & No & Sí \\
Control por sexo & No & Sí \\
\hline Efecto marginal (SMK) & No & $0,0566^{* * *}$ \\
& $0,0704^{* * *}$ & $(0,0027)$ \\
\hline Efecto marginal (PCK) & $(0,0026)$ & $0,0583^{* * *}$ \\
& $0,0591^{* * *}$ & $(0,0026)$ \\
\hline
\end{tabular}

Notas. ${ }^{*} p<0,05 ;{ }^{* *} p<0,01 ;{ }^{* * *} p<0,001$. Errores estándar entre paréntesis. El efecto marginal se evalúa en el promedio de las variables de análisis.

La tabla 3 lista los efectos marginales del SMK y del PCK sobre los logros de aprendizaje de los estudiantes, bajo distintas especificaciones del modelo simple de valor agregado. La primera columna muestra que un aumento de una desviación estándar del SMK incrementa los logros de aprendizaje en 0,070 desviaciones estándar; mientras que un aumento del PCK lo hace en 0,059 desviaciones estándar. En la segunda columna, que incluye los controles de perfil socioeconómico, los efectos de SMK y PCK pasan a ser 0,057 y 0,058 desviaciones estándar, respectivamente.

De estos resultados, se extraen tres conclusiones. En primer lugar, los efectos marginales del SMK y del PCK son ambos positivos, lo cual descarta que sea solo un componente el que determina el impacto del conocimiento docente.

Segundo, los impactos del SMK y PCK sobre el rendimiento educativo son menores que el efecto marginal conjunto que tuvo la variable de conocimiento docente en el modelo simple (tabla 1). Esto indica que el impacto de un docente sobre los logros de aprendizaje de los niños es mayor cuando 
el docente cuenta con SMK y PCK a la vez, que cuando cuenta con solo uno de los dos componentes por separado.

Por último, no se puede afirmar cuál de los efectos marginales -del PCK o del SMK- es mayor, ya que, por un lado, el efecto marginal del SMK resulta mayor que el del PCK (columna 1). Pero, cuando se agregan los controles de perfil socioeconómico (columna 2), el efecto marginal del PCK se vuelve mayor.

Para analizar la robustez, en el anexo 8, se muestran modelos adicionales que incorporan distintas especificaciones de los controles de la regresión. Nuevamente, no queda claro qué componente del conocimiento docente es más importante, puesto que en algunos casos el efecto marginal del SMK es mayor que el del PCK y en otros casos ocurre lo contrario. Así, prudentemente concluimos que los impactos del SMK y del PCK sobre los logros educativos son significativos y muy relacionados entre sí, pero no encontramos una respuesta única a cuál de los componentes impacta más.

\section{d. Limitaciones}

Nuestra investigación adolece de dos limitaciones principales: (i) un posible error de medición al estimar el conocimiento docente; y (ii) una reducción de la muestra de datos de la EM 2013.

Sobre lo primero, cabe recordar que el conocimiento docente no es observable y fue aproximado mediante un conjunto de preguntas que buscaban evaluar la capacidad de un docente respecto a fracciones en matemáticas. Hay así una medición restringida del CD que podría haber generado un sesgo de atenuación (Pischke, 2007). Es decir, el impacto de mejorar el conocimiento docente en el Perú podría ser mayor que el estimado.

La segunda limitación se debe a una reducción de la muestra de la EM 2013. La muestra de 66.500 alumnos y 3.000 profesores se redujo a 25.000 estudiantes y 2.400 docentes para poder obtener el logro educativo en matemáticas de los alumnos tanto en $2 .^{\circ}$ de primaria como en $6 .^{\circ}$ de primaria. Cabe recordar que los datos no se emparejaron perfectamente, por las razones apuntadas en el anexo 4.

\section{Conclusiones y recomendaciones}

Los resultados de nuestras estimaciones son concluyentes e indican que se verifican nuestras dos hipótesis. Respecto a la primera hipótesis, bajo distintas especificaciones se obtuvo que el conocimiento docente (CD) impacta de manera positiva sobre el aprendizaje de estudiantes. Un aumento de una desviación estándar del CD incrementa los logros educativos en 0,12 desvia- 
ciones estándar. Las pruebas validan la robustez de este resultado, tanto en su magnitud como en su nivel de significancia.

También hemos confirmado la relevancia de que los docentes dominen la materia que enseñan $(\mathrm{SMK})$ y cuenten con capacidades pedagógicas para la enseñanza (PCK), al haber mostrado que un profesor con esas dos competencias bien desarrolladas impacta más en el aprendizaje de un niño que un profesor competente en solo una. De hecho, ambas competencias que componen el CD tienen un impacto muy similar sobre los logros educativos, y no se puede colegir qué componente es más importante. En consecuencia, se recomienda que las políticas educativas de acompañamiento pedagógico sean integrales y dirigidas a desarrollar ambas competencias en los profesores.

Respecto a nuestra segunda hipótesis, hemos comprobado que hay evidencia de efectos heterogéneos del CD debido a complementariedades en la función de producción de aprendizajes. Por un lado, los docentes son más productivos cuando educan a niños con mayor stock de aprendizajes acumulados; es decir, existe complementariedad dinámica. Por otro lado, los docentes son más productivos cuando enseñan a nińos con un mejor entorno educativo dentro del hogar; es decir, existe complementariedad directa. Ambos resultados de complementariedades son robustos.

En efecto, el impacto positivo del CD en el aprendizaje de los alumnos es mayor en los niños de sectores favorecidos del país. Un resultado muy relevante, pues indicaría que las brechas educativas ya existentes en el Perú pueden continuar expandiéndose. Por tanto, si bien debe promoverse que todos los docentes del sistema educativo incrementen su conocimiento, el énfasis al respecto debe estar en los que enseñan a sectores desfavorecidos, a fin de reducir las brechas educativas.

Ambas políticas, de mejora docente en las dos competencias (SMK y PCK) y de énfasis en sectores desfavorecidos, encajan en dos áreas de acción del Minedu: revalorización de la carrera docente y mejora de aprendizajes con énfasis en el cierre de brechas. Por ello, nuestra investigación aporta a un tema vigente en la agenda educativa del país, pese a que tuvimos que reducir la muestra en la base de datos principal (EM 2013) para poder contar con información de logros de aprendizaje de los niños en dos períodos de tiempo $y$, por distintos motivos, no se pudo obtener un emparejamiento perfecto. 


\section{Referencias}

Altinok, N. (2013). The impact of teacher knowledge on student achievement in 14 Sub-Saharan African countries. París: Unesco.

Andrabi, T., Das, J., Khwaja, A., \& Zajonc, T. (2011). Do value-added estimates add value? Accounting for learning dynamics. American Economic Journal: Applied Economics, 3(3), 29-54.

Banco Mundial. (1996). India: Primary education achievement and challenges. Washington D. C.: The World Bank.

Barber, M., \& Mourshed, M. (2007). How the world's best-performing school systems come out on top. McKinsey \& Company.

Bedi, A. S., \& Marshall, J. H. (2002). Primary school attendance in Honduras. Journal of Development Economics, 69(1), 129-153.

Behrman, J. R., Ross, D., \& Sabot, R. (2008). Improving quality versus increasing the quantity of schooling: Estimates of rates of return from rural Pakistan. Journal of Development Economics, 85(1-2), 94-104.

Black, P., Harrison, C., Lee, C., Marshall, B., \& Wiliam, D. (2002). Working inside the black box: Assessment for learning in the classroom. Londres: King's College.

Castro, J. F. (2015). Linear decompositions of cognitive achievement gaps: A cautionary note and an illustration using Peruvian data. Working Paper DD1508. Lima: Universidad del Pacífico - Centro de Investigación

Castro, J. F. (2017). Revisiting dynamic complementarity in the production of cognitive skills and its implications for a cognitive achievement gap decomposition. Lima: Universidad del Pacífico.

Cunha, F., \& Heckman, J. (2007). The technology of skill formation. American Economic Review, 97(2),31-47.

Darling-Hammond, L. (2000). Teacher quality and student achievement: A review of state policy evidence. Education Policy Analysis Archives, 8(1), 1-44.

Deming, D., Hastings, J., Cane, T., \& Staiger, D. (2014). School choice, school quality and post secondary attainment. American Economic Review, 104(3), 1-25.

Díaz, H., \& Saavedra, J. (2000). La carrera de maestro: factores institucionales, incentivos económicos y desempeño. Lima: Grupo de Análisis para el Desarrollo.

Ehrenberg, R. G., \& Brewer, D. J. (1995). Did teachers' verbal ability and race matter in the 1960s? Economics of Education Review, 14(1), 1-21.

Eide, E., Goldhaber, D., \& Brewer, D. (2004). The teacher labour market and teacher quality. Oxford Review of Economic Policy, 20(2), 230-244.

Espinoza E., Espezua, L., \& Choque, R. (2015). ¿Qué significa ser profesor en el Perú? Documento de Discusión 11. Lima: Pronabec.

Frome, P., Lasater, B., \& Cooney, S. (2005). Well-qualified teachers and quality teaching: Are they the same? Atlanta: Southern Regional Education Board. 
Glewwe, P., \& Kremer, M. (2006). Schools, teachers, and education outcomes in developing countries. En E. Hanushek \& F. Welch (Eds.), Handbook of the economics of education, Vol. 2 (pp. 945-1017). Elsevier B. V.

Glewwe, P., \& Miguel, E. (2008). The impact of child health and nutrition on education in less developed countries. En T. Schultz \& J. Strauss (Eds.), Handbook of development economics, Vol. 4 (pp. 3561-3606). Elsevier B. V.

Goe, L. (2002). Legislating equity: The distribution of emergency permit teachers in California. Education Policy Analysis Archives, 10(42), 1-50.

Goldhaber, D., \& Brewer, D. (1997). Why don't schools and teachers seem to matter? Assessing the impact of unobservables on educational productivity. Journal of Human Resources, 32(3), 505-523.

Goldhaber, D., \& Brewer, D. (1999). Does teacher certification matter? High school teacher certification status and student achievement. Educational Evaluation and Policy Analysis, 22(2), 129-145.

Guadalupe, C., León, J., \& Cueto, S. (2013). Charting progress in learning outcomes in Peru using national assessments. París y Lima: Unesco.

Hanushek, E. (1971). Teacher characteristics and gains in student achievement: Estimation using micro data. American Economic Review, 61(2), 280-288.

Hanushek, E. (1992). The trade-off between child quantity and quality. Journal of Political Economy, 100(1), 84-117.

Hanushek, E. (1997). Assessing the effects of school resources on student performance: An update. Educational Evaluation and Policy Analysis, 19(2), 141-164.

Hanushek, E., \& Rivkin, S. (2006). Teacher quality. En E. Hanushek \& F. Welch (Eds.), Handbook of the economics of education, Vol. 2 (pp. 1052-1078). Ámsterdam: North-Holland.

Hanushek, E., Piopunik, M., \& Wiederhold, S. (2014). The value of smarter teachers: International evidence on teacher cognitive skills and student performance. NBER Working Papers 20727. Cambridge, MA: National Bureau of Economic Research.

Harbison, R., \& Hanusheck, E. (1992). Educational performance of the poor: Lessons from rural Northeast Brazil. Oxford: Oxford University Press.

Harris, D., \& Sass, T. (2011). Teacher training, teacher quality and student achievement. Journal of Public Economics, 95(7-8), 798-812.

Hightower, A., Delgado, R., Lloyd, S., Wittenstein, R., Sellers, K., \& Swason, C. (2011). Improving student learning by supporting quality teaching: Key issues, effective strategies. Bethesda, MD: Editorial Projects in Education.

Hill, H., Rowan, B., \& Loewenberg Ball, D. (2005). Effects of teacher's mathematical knowledge for teaching on student achievement. American Educational Research Journal, 42(2), 371-406.

Jadama, L. (2014). Impact of subject matter knowledge of a teacher in teaching and learning process. Middle Eastern \& African Journal of Educational Research, 7, 20-29. 
Kane, T., McCaffrey, D., Miller, T., \& Staiger, D. (2013). Have we identified effective teachers? Validating measures of effective teaching using random assignment. MET Project Research Paper. Bill \& Melinda Gates Foundation.

Metzler, J., \& Woessmann, L. (2010). The impact of teacher subject knowledge on student achievement: Evidence from within-teacher within-student variation. IZA Discussion Papers, 4999. Bonn: Institute of Labor Economics.

Murnane, R. J., \& Phillips, B. R. (1981). What do effective teachers of inner-city children have in common? Social Science Research, 10(1), 83-100.

Pischke, S. (2007). Lecture notes on measurement error. London School of Economics.

Rowan, B., Chiang, F., \& Miller, R. J. (1997). Using research on employees' performance to study the effects of teachers on students' achievement. Sociology of Education, $70(4), 256-285$.

Schwerdt, G., \& Wuppermann, A. (2010). Is traditional teaching really all that bad? A within-student between-subject approach . Economics of Education Review, 30(2), 365-379.

Shepherd, D. (2015). Learn to teach, teach to learn: A within-pupil across-subject approach to estimating the impact of teacher subject knowledge on South African grade 6 performance. Stellenbosch Economics Working Papers, 01/15. Sudáfrica: University of Stellenbosch.

Shulman, L. S. (1986). Those who understand: Knowledge growth in teaching. Educational Researcher, 15(2), 4-14.

Shulman, L. S. (1987). Knowledge and teaching: Foundations of the new reform. Harvard Educational Review, 57(1), 1-21.

Singh, A. (2015). Private school effects in urban and rural India: Panel estimates at primary and secondary school ages. Journal of Development Economics, 113(C), 16-32.

Summers, A., \& Wolfe, B. (1977). Do schools make a difference? American Economic Review, 67(4), 630-652.

Tan, J.-P., Lane, J., \& Coustère, P. (1997). Putting inputs to work in elementary schools: What can be done in the Philippines? Economic Development and Cultural Change, 45(4), 857-879.

Todd, P., \& Wolpin, K. (2003). On the specification and estimation of the production function for cognitive achievement. The Economic Journal, 113(485), F3-F33.

UMC (Oficina de Medición de la Calidad de los Aprendizajes). (2005). Evaluación nacional del rendimiento estudiantil 2004. Informe pedagógico de resultados. Lima: Ministerio de Educación - Oficina de Medición de la Calidad de los Aprendizajes.

UMC (Oficina de Medición de la Calidad de los Aprendizajes). (2014). Evaluación censal de estudiantes 2013. Lima: Ministerio de Educación - Oficina de Medición de la Calidad de los Aprendizajes.

UMC (Oficina de Medición de la Calidad de los Aprendizajes). (2015). Evaluación censal de estudiantes 2014. Lima: Ministerio de Educación - Oficina de Medición de la Calidad de los Aprendizajes. 
UMC (Oficina de Medición de la Calidad de los Aprendizajes). (2016a). ¿Cuánto aprenden nuestros estudiantes al término de la educación primaria? Informe de logros de aprendizaje y sus factores asociados en la evaluación muestral 2013. Lima: Ministerio de Educación - Oficina de Medición de la Calidad de los Aprendizajes.

UMC (Oficina de Medición de la Calidad de los Aprendizajes). (2016b). Evaluación censal de estudiantes 2015. Lima: Ministerio de Educación - Oficina de Medición de la Calidad de los Aprendizajes.

Wayne, A. J., \& Youngs, P. (2003). Teacher characteristics and student achievement gains: A review. Review of Educational Research, 73(1), 89-122.

Wilson, S. M., Shulman, L. S., \& Richert, A. E. (1987). 150 different ways of knowing: Representations of knowledge in teaching. En J. Calderhead (Ed.), Exploring teachers' thinking (pp. 104-124). Sussex, Inglaterra: Holt, Rinehart and Winston. 


\section{Anexos}

\section{Anexo 1 \\ Tabla 4 \\ Principales controles incluidos en la regresión}

\begin{tabular}{|c|c|c|}
\hline $\begin{array}{c}\text { Variables de } \\
\text { control }\end{array}$ & Explicación del valor & Justificación de la inclusión \\
\hline \multicolumn{3}{|c|}{ Controles de familia } \\
\hline $\begin{array}{l}\text { Expectativa } \\
\text { educativa del } \\
\text { padre sobre el } \\
\text { hijo }\end{array}$ & $\begin{array}{l}\text { Este índice refleja la percepción } \\
\text { del padre sobre el máximo nivel } \\
\text { educativo que alcanzará su hijo. } \\
\text { Es un índice con valores entre } 0 \text { y } \\
\text { 1. Un valor cercano a } 0 \text { indica que } \\
\text { el padre tiene bajas expectativas } \\
\text { educativas para su hijo, mientras que } \\
\text { un valor cercano a } 1 \text { indica que tales } \\
\text { expectativas son altas. }\end{array}$ & $\begin{array}{l}\text { Cuando estas expectativas educativas } \\
\text { de los padres son altas, pueden elegir } \\
\text { para sus hijos escuelas con profesores } \\
\text { de mayor SMK y PCK, y también } \\
\text { promover su aprendizaje de otras } \\
\text { maneras (Glewwe \& Kremer, 2006; } \\
\text { Altinok, 2013). Este importante } \\
\text { control caracteriza el entorno } \\
\text { educativo del niño. }\end{array}$ \\
\hline \multicolumn{3}{|c|}{ Controles de colegio } \\
\hline $\begin{array}{l}\text { Infraestructura } \\
\text { del colegio y } \\
\text { disponibilidad } \\
\text { de materiales }\end{array}$ & $\begin{array}{l}\text { Este índice se compone de (1) } \\
\text { pistas y veredas; (2) electricidad; } \\
\text { (3) red pública de agua; (4) red de } \\
\text { telefonía; (5) seńal de internet; y } \\
\text { (6) disponibilidad de materiales } \\
\text { (carpetas suficientes, escritorios } \\
\text { suficientes, libros suficientes, } \\
\text { materiales del aula, y plana docente } \\
\text { completa). El índice se encuentra } \\
\text { entre } 0 \text { y } 1 \text {. Un valor de } 0 \text { indica } \\
\text { que no se cuenta con ninguno de } \\
\text { los factores antes mencionados, y } \\
\text { un valor de } 1 \text { indica que se cuenta } \\
\text { con todos. }\end{array}$ & $\begin{array}{l}\text { Una omisión común en los modelos } \\
\text { de value added son los controles } \\
\text { por infraestructura educativa y } \\
\text { materiales disponibles del colegio. } \\
\text { Numerosas investigaciones resaltan } \\
\text { la importancia de estos factores } \\
\text { intraescuela para los logros de } \\
\text { aprendizaje de los alumnos (Banco } \\
\text { Mundial, 1996; Harbison \& } \\
\text { Hanushek, 1992; Goe, 2002). Es } \\
\text { posible que docentes con alto CD no } \\
\text { puedan generar esos logros debido a } \\
\text { carencias en dichos factores. }\end{array}$ \\
\hline
\end{tabular}




\begin{tabular}{|c|c|c|}
\hline \multicolumn{3}{|c|}{ Controles del profesor de matemáticas } \\
\hline $\begin{array}{l}\text { Motivación del } \\
\text { profesor }\end{array}$ & $\begin{array}{l}\text { Índice que va de } 0 \text { a } 1 \text {, donde } 1 \\
\text { indica que el profesor se encuentra } \\
\text { muy satisfecho de su relación con: } \\
\text { (a) los estudiantes evaluados, (b) } \\
\text { los respectivos padres de familia, } \\
\text { (c) el director de la institución } \\
\text { educativa, (d) los otros docentes } \\
\text { de la institución educativa, (e) los } \\
\text { promotores o propietarios de la } \\
\text { institución educativa; así como (f) } \\
\text { la programación curricular de la } \\
\text { institución educativa, (g) las normas } \\
\text { y la disciplina de la institución } \\
\text { educativa, (h) la infraestructura y } \\
\text { recursos educativos de la institución } \\
\text { educativa, e (i) su remuneración. }\end{array}$ & $\begin{array}{l}\text { La literatura económica educativa } \\
\text { ha tenido dificultad de medir la } \\
\text { motivación de los profesores, lo que } \\
\text { ha generado un problema potencial } \\
\text { de sesgo por variable omitida en } \\
\text { la medición causal de la calidad } \\
\text { docente. Esto ya que profesores más } \\
\text { motivados incitan más aprendizaje de } \\
\text { estudiantes, pero también acumulan } \\
\text { más conocimiento de la materia de } \\
\text { su curso e incluso pueden mejorar } \\
\text { su pedagogía (Altinok, 2013). Esto } \\
\text { indica la importancia de incluir este } \\
\text { control en la estimación. }\end{array}$ \\
\hline \multicolumn{3}{|c|}{ Controles adicionales (variables socioeconómicas determinantes de los insumos) } \\
\hline Lengua materna & $\begin{array}{l}\text { Variable dummy con un valor de } 1 \text { si } \\
\text { la lengua materna del estudiante es } \\
\text { castellano y } 0 \text { si no. }\end{array}$ & $\begin{array}{l}\text { Como se menciona en Castro (2015), } \\
\text { la inclusión de estos determinantes } \\
\text { exógenos se realiza para controlar }\end{array}$ \\
\hline $\begin{array}{l}\text { Ámbito } \\
\text { geográfico }\end{array}$ & $\begin{array}{l}\text { Variable dummy que toma el valor } \\
\text { de } 1 \text { si el estudiante estudia en un } \\
\text { colegio que pertenece al ámbito } \\
\text { urbano y } 0 \text { si pertenece al rural. }\end{array}$ & $\begin{array}{l}\text { por la posibilidad de haber omitido } \\
\text { insumos relevantes en la función } \\
\text { de producción de aprendizaje. Su } \\
\text { inclusión ayuda a evaluar la robustez } \\
\text { del modelo. }\end{array}$ \\
\hline $\begin{array}{l}\text { Gestión del } \\
\text { colegio }\end{array}$ & $\begin{array}{l}\text { Variable dummy que toma el valor } \\
\text { de } 1 \text { si el colegio es gestionado de } \\
\text { manera privada y } 0 \text { si es estatal. }\end{array}$ & \\
\hline $\begin{array}{l}\text { Autoeficacia del } \\
\text { estudiante }\end{array}$ & $\begin{array}{l}\text { Este índice refleja la autopercepción } \\
\text { del estudiante sobre su rendimiento, } \\
\text { con valores entre } 0 \text { y } 1 \text {, donde un } \\
\text { valor cercano a } 0 \text { indica que el } \\
\text { estudiante piensa que no podrá } \\
\text { obtener buenas calificaciones. }\end{array}$ & \\
\hline $\begin{array}{l}\text { Liderazgo del } \\
\text { director }\end{array}$ & $\begin{array}{l}\text { Índice con valores entre } 0 \text { y } 1 \text {, } \\
\text { cercano a } 0 \text { cuando el director carece } \\
\text { de liderazgo. }\end{array}$ & \\
\hline Sexo & $\begin{array}{l}\text { Variable dummy que toma el valor } \\
\text { de } 1 \text { si el estudiante es hombre y el } \\
\text { valor de } 0 \text { si es mujer. }\end{array}$ & \\
\hline
\end{tabular}

Elaboración propia. 


\section{Anexo 2}

\section{Figura 5 \\ Ejemplo de pregunta que evalúa el SMK}

3. Al resolver el siguiente problema:

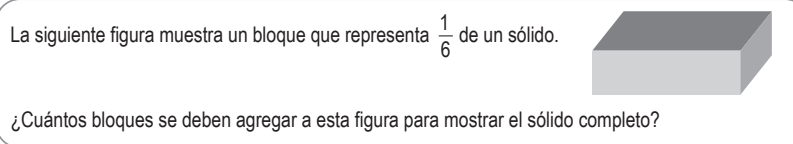

algunos estudiantes respondieron que se deben agregar 6 bloques para mostrar el sólido completo. Una adecuada explicación de por qué responden de ese modo es:

(Marque solo una respuesta)

a comprenden muy bien el concepto de fracción, ya que cumple con tomar 1 de 6 .

b) porque se muestra una parte de otras 6 , siendo entonces una respuesta correcta.

(c) no comprenden que el bloque mostrado también es parte del total.

(d) no comprenden el problema porque lo que debe hacer el estudiante es dividir el bloque mostrado en 6 partes iguales.

Fuente: UMC (2016a).

\section{Figura 6}

Ejemplo de pregunta que evalúa el PCK

16. Formule un problema de contexto cotidiano en el que intervenga la siguiente operación: $2 \frac{3}{4} \div \frac{1}{2}$

Fuente: UMC (2016a). 


\section{Anexo 3}

Figura 7

Construcción del conocimiento docente

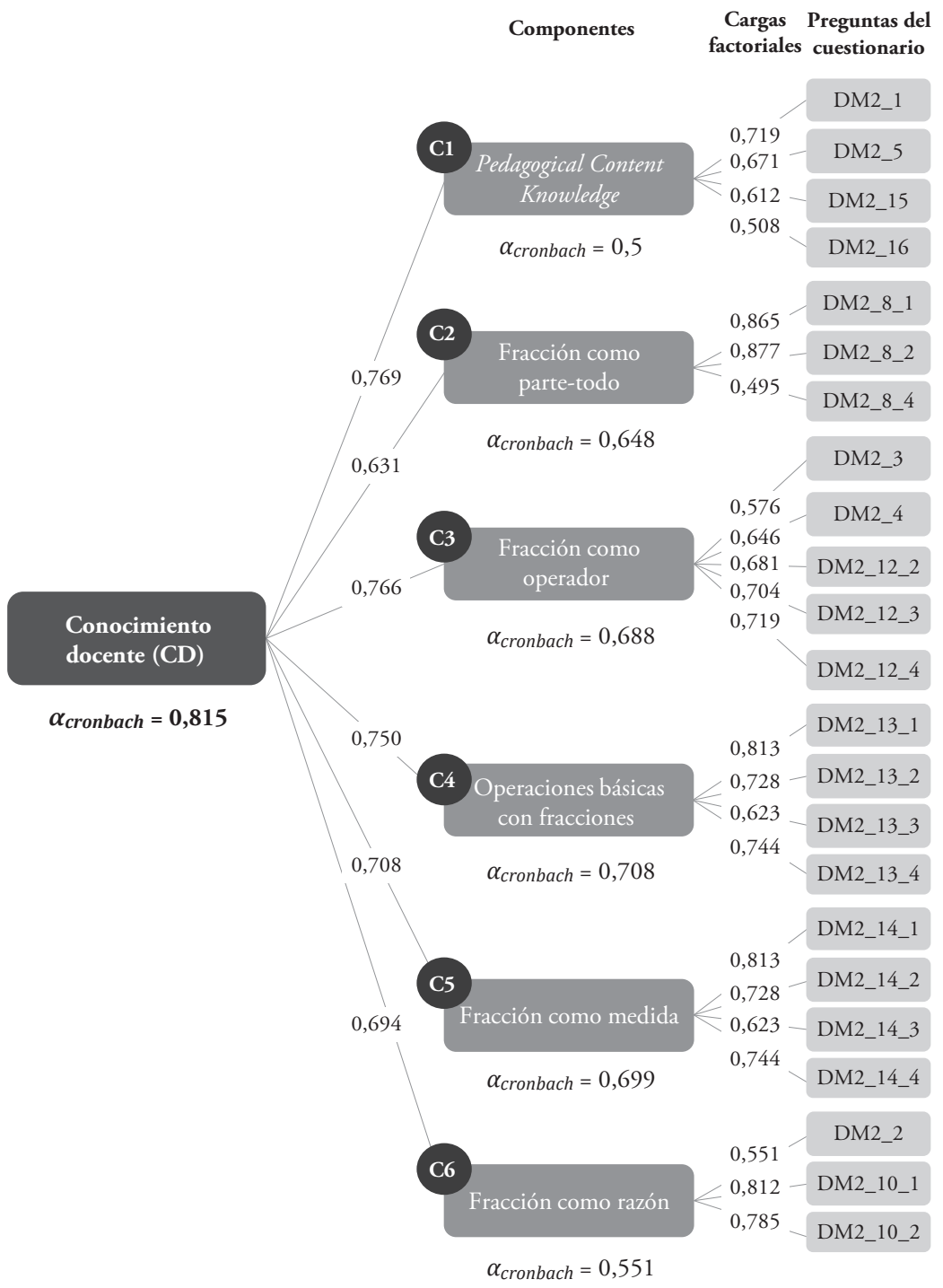

Elaboración propia. 


\section{Anexo 4}

Tabla 5

Razones de la coincidencia imperfecta de los datos

- No todos los estudiantes que rindieron la ECE 2009 rindieron la EM 2013, ya que pueden haber repetido o haberse retirado en alguno de los grados intermedios (también pueden haber migrado al exterior o fallecido).

- Los estudiantes en la ECE 2009 pueden haber sido evaluados en $4 .^{\circ}$ grado (en vez de en el 2..$^{\circ}$ ) de primaria, porque asistían a una escuela que desarrollaba Educación Intercultural Bilingüe.

- Puede existir una gran cantidad de estudiantes que no fueron evaluados en la ECE 2009, debido a la fuerte oposición a rendir la prueba en algunas regiones como Ayacucho, Cajamarca, Cusco, Huancavelica, Puno, entre otras.

- El emparejamiento por nombres y apellidos es un proceso en el que hay un margen de error originado por la manera en que cada aplicador registró dichos datos.

Estas cuatro razones fueron brindadas por el Minedu en respuesta a una consulta formal, luego de solicitar los datos emparejados de la ECE 2009 y la EM 2013. Vale señalar que el Ministerio solo reporta la cantidad total de datos no emparejados, sin desagregarlos por cada una de las razones. 


\section{Anexo 5}

Tabla 6

Pruebas de robustez para el modelo simple

\begin{tabular}{|c|c|c|c|c|c|}
\hline & \multicolumn{5}{|c|}{ Logro de aprendizaje } \\
\hline & (1) & (2) & (3) & $(4)$ & (5) \\
\hline Conocimiento docente & Sí & Sí & Sí & Sí & Sí \\
\hline$(\text { Conocimiento docente })^{2}$ & Sí & Sí & Sí & Sí & Sí \\
\hline Logro de aprendizaje pasado & Sí & Sí & Sí & Sí & Sí \\
\hline $\begin{array}{l}\text { Índice de recursos educativos } \\
\text { del hogar }\end{array}$ & Sí & Sí & Sí & Sí & Sí \\
\hline Infraestructura escolar & Sí & Sí & Sí & Sí & Sí \\
\hline Expectativas de los padres & Sí & Sí & Sí & Sí & Sí \\
\hline Satisfacción del docente & Sí & Sí & Sí & Sí & Sí \\
\hline $\begin{array}{l}\text { Control por satisfacción del } \\
\text { docente }\end{array}$ & Sí & Sí & Sí & Sí & Sí \\
\hline $\begin{array}{l}\text { Control por expectativa de los } \\
\text { padres }\end{array}$ & Sí & Sí & Sí & Sí & Sí \\
\hline Control por lengua materna & Sí & Sí & Sí & Sí & Sí \\
\hline Control por ámbito geográfico & No & Sí & Sí & Sí & Sí \\
\hline Control por gestión del colegio & No & No & Sí & Sí & Sí \\
\hline $\begin{array}{l}\text { Control por autoeficacia del } \\
\text { estudiante }\end{array}$ & No & No & No & Sí & Sí \\
\hline $\begin{array}{l}\text { Control por liderazgo del } \\
\text { director }\end{array}$ & No & No & No & No & Sí \\
\hline Control por sexo & No & No & No & No & No \\
\hline Efecto marginal: $\frac{\partial \mathrm{A}_{i t}}{\partial \mathrm{CD}_{i t}}$ & $\begin{array}{c}0,1179^{* * *} \\
(0,0021)\end{array}$ & $\begin{array}{c}0,1186^{* * *} \\
(0,0021) \\
\end{array}$ & $\begin{array}{c}0,0950^{* * *} \\
(0,0023)\end{array}$ & $\begin{array}{c}0,1003^{* * *} \\
(0,0023)\end{array}$ & $\begin{array}{c}0,1026^{* * *} \\
(0,0023)\end{array}$ \\
\hline$N$ & 17.404 & 17.404 & 17.404 & 17.404 & 17.404 \\
\hline
\end{tabular}

Notas. ${ }^{*} p<0,05 ;{ }^{* *} p<0,01 ;{ }^{* * *} p<0,001$. Errores estándar entre paréntesis. El efecto marginal se evalúa en el promedio de las variables de análisis. 


\section{Anexo 6}

Tabla 7

Pruebas de robustez para el modelo con complementariedades

\begin{tabular}{|c|c|c|c|c|c|}
\hline & \multicolumn{5}{|c|}{ Logro de aprendizaje } \\
\hline & (1) & (2) & (3) & (4) & (5) \\
\hline Conocimiento docente & Sí & Sí & Sí & Sí & Sí \\
\hline (Conocimiento docente) & Sí & Sí & Sí & Sí & Sí \\
\hline Logro de aprendizaje pasado & Sí & Sí & Sí & Sí & Sí \\
\hline $\begin{array}{l}\text { Índice de recursos educativos } \\
\text { del hogar }\end{array}$ & Sí & Sí & Sí & Sí & Sí \\
\hline (Conocimiento docente)* & $0,0004^{* * *}$ & $0,0004^{* * *}$ & $0,0004^{* * *}$ & $0,0003^{* * *}$ & $0,0003^{* * *}$ \\
\hline (Logro educativo pasado) & $(0,000)$ & $(0,000)$ & $(0,000)$ & $(0,000)$ & $(0,000)$ \\
\hline (Conocimiento docente)* & $0,0001^{* * *}$ & $0,0001^{* * *}$ & $0,0001^{* * *}$ & $0,0001^{* * *}$ & $0,0001^{* * *}$ \\
\hline (Índice del hogar) & $(0,000)$ & $(0,000)$ & $(0,000)$ & $(0,000)$ & $(0,000)$ \\
\hline Expectativas de los padres & Sí & Sí & Sí & Sí & Sí \\
\hline Satisfacción del docente & Sí & Sí & Sí & Sí & Sí \\
\hline Infraestructura escolar & Sí & Sí & Sí & Sí & Sí \\
\hline Control por lengua materna & Sí & Sí & Sí & Sí & Sí \\
\hline Control por ámbito geográfico & No & Sí & Sí & Sí & Sí \\
\hline Control por gestión del colegio & No & No & Sí & Sí & Sí \\
\hline $\begin{array}{l}\text { Control por autoeficacia del } \\
\text { estudiante }\end{array}$ & No & No & No & Sí & Sí \\
\hline $\begin{array}{l}\text { Control por liderazgo del } \\
\text { director }\end{array}$ & No & No & No & No & Sí \\
\hline Control por sexo & No & No & No & No & No \\
\hline Efecto marginal: $\frac{\partial \mathrm{A}_{i t}}{\partial \mathrm{CD}_{i t}}$ & $\begin{array}{l}0,1167^{* * *} \\
(0,0021)\end{array}$ & $\begin{array}{l}0,1174^{* * *} \\
(0,0021)\end{array}$ & $\begin{array}{l}0,0956^{* * *} \\
(0,0023)\end{array}$ & $\begin{array}{c}0,1008^{* * *} \\
(0,0023)\end{array}$ & $\begin{array}{l}0,1031^{* * *} \\
(0,0023)\end{array}$ \\
\hline$N$ & 17.404 & 17.404 & 17.404 & 17.404 & 17.404 \\
\hline
\end{tabular}

Notas. ${ }^{*} p<0,05 ;{ }^{* *} p<0,01 ;{ }^{* * *} p<0,001$. Errores estándar entre paréntesis. El efecto marginal se evalúa en el promedio de las variables de análisis. 


\section{Anexo 7}

Figura 9

Construcción desagregada del conocimiento docente

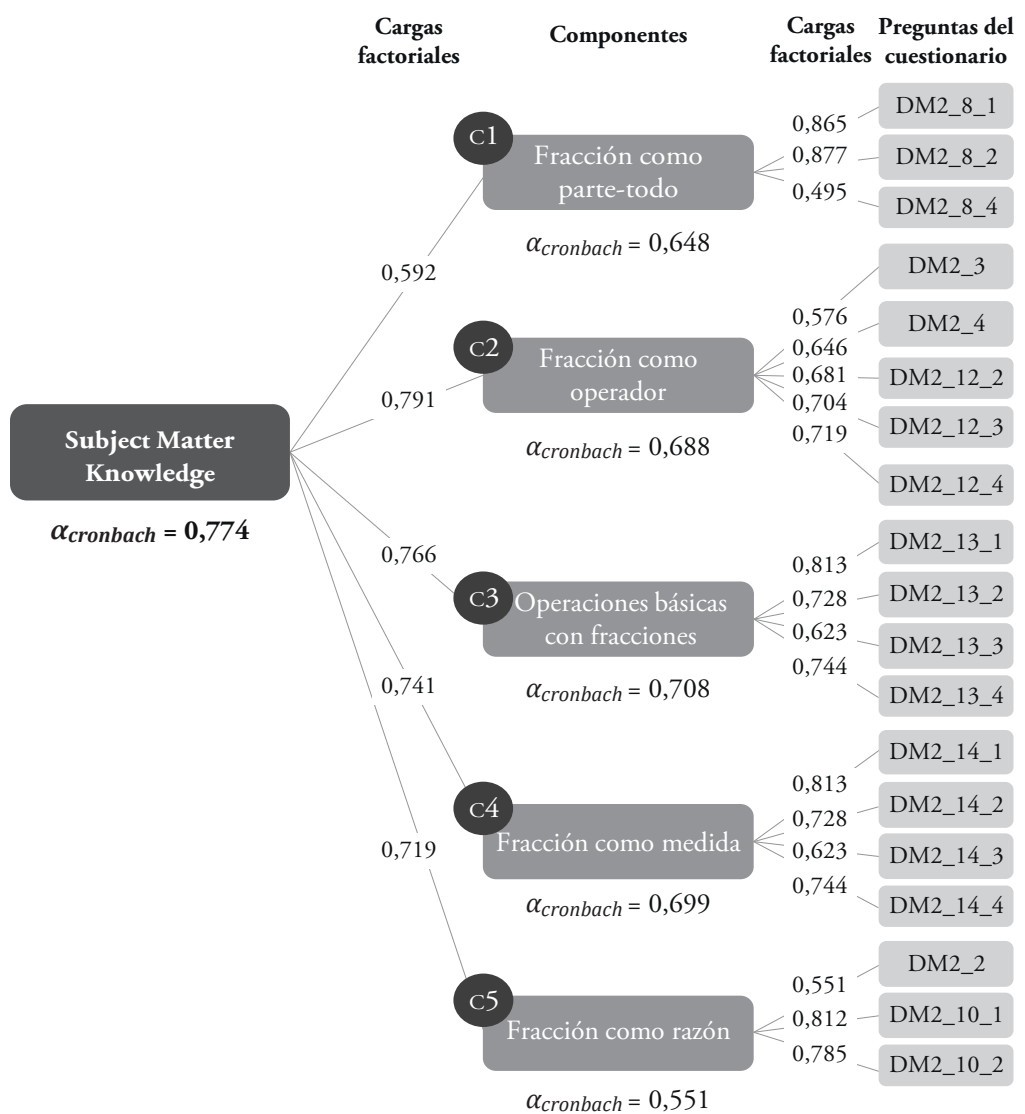

Cargas Preguntas del factoriales cuestionario

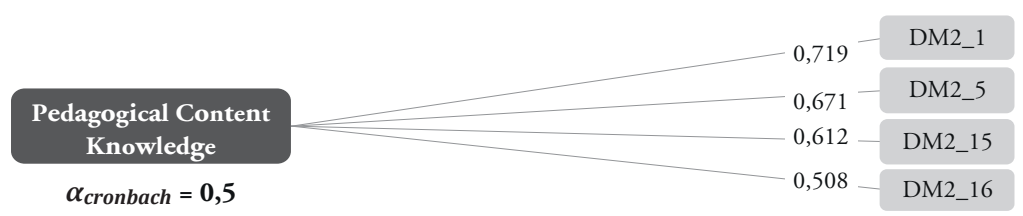

Elaboración propia. 


\section{Anexo 8}

Tabla 8

Pruebas de robustez para el modelo con conocimiento docente desagregado

\begin{tabular}{|c|c|c|c|c|c|}
\hline & \multicolumn{5}{|c|}{ Logro de aprendizaje } \\
\hline & (1) & $(2)$ & (3) & (4) & (5) \\
\hline$S M K$ & Sí & Sí & Sí & Sí & Sí \\
\hline$(S M K)^{2}$ & Sí & Sí & Sí & Sí & Sí \\
\hline PCK & Sí & Sí & Sí & Sí & Sí \\
\hline$(P C K)^{2}$ & Sí & Sí & Sí & Sí & Sí \\
\hline Logro de aprendizaje pasado & Sí & Sí & Sí & Sí & Sí \\
\hline Índice del hogar & Sí & Sí & Sí & Sí & Sí \\
\hline Expectativas de los padres & Sí & Sí & Sí & Sí & Sí \\
\hline Satisfacción del docente & Sí & Sí & Sí & Sí & Sí \\
\hline $\begin{array}{l}\text { Infraestructura y materiales } \\
\text { escolares }\end{array}$ & Sí & Sí & Sí & Sí & Sí \\
\hline Control por lengua materna & Sí & Sí & Sí & Sí & Sí \\
\hline Control por ámbito geográfico & No & Sí & Sí & Sí & Sí \\
\hline Control por gestión del colegio & No & No & Sí & Sí & Sí \\
\hline $\begin{array}{l}\text { Control por autoeficacia del } \\
\text { estudiante }\end{array}$ & No & No & No & Sí & Sí \\
\hline $\begin{array}{l}\text { Control por liderazgo del } \\
\text { director }\end{array}$ & No & No & No & No & Sí \\
\hline Control por sexo & No & No & No & No & No \\
\hline \multirow[t]{2}{*}{ Efecto marginal (SMK) } & $0,0704^{* * *}$ & $0,0726^{* * *}$ & $0,058^{* * *}$ & $0,0536^{* * *}$ & $0,0567^{* * *}$ \\
\hline & $(0,0026)$ & $(0,0026)$ & $(0,0027)$ & $(0,0027)$ & $(0,0027)$ \\
\hline \multirow[t]{2}{*}{ Efecto marginal (PCK) } & $0,0596^{* * *}$ & $0,0577^{* * *}$ & $0,0543^{* * *}$ & $0,0592^{* * *}$ & $0,0576^{* * *}$ \\
\hline & $(0,0026)$ & $(0,0026)$ & $(0,0026)$ & $(0,0026)$ & $(0,0026)$ \\
\hline$N$ & 17.404 & 17.404 & 17.404 & 17.404 & 17.404 \\
\hline
\end{tabular}

Notas. ${ }^{*} p<0,05 ;{ }^{* *} p<0,01 ;{ }^{* * *} p<0,001$. Errores estándar entre paréntesis. El efecto marginal se evalúa en el promedio de las variables de análisis. 
